\title{
Molekulargenetische Verwandtschaftsanalysen am prähistorischen Skelettkollektiv der Lichtensteinhöhle
}

Dissertation zur Erlangung des Doktorgrades der Mathematisch-Naturwissenschaftlichen Fakultäten der Georg-August-Universität zu Göttingen 
D7

Referent : Prof. Dr. B. Herrmann

Korreferent: Prof. Dr. R. Willmann

Termin der mündlichen Prüfung: 02. Mai 2006 
Diese Arbeit wurde angefertigt am Johann Friedrich Blumenbach Institut für Zoologie und Anthropologie, Abteilung Historische Anthropologie und Humanökologie der Georg-August-Universität Göttingen im Rahmen des Projektes:

„Die Lichtensteinhöhle bei Osterode - Menschenopferstätte oder Bestattungsplatz? Anthropologische Untersuchungen zur Biologie der Menschen aus der Höhle“.

Das Projekt wurde gefördert vom Ministerium für Wissenschaft und Kultur (MWK) des Landes Niedersachsen, Kapitel 0608 TG 74.

Projektleiterin: Dr. Susanne Hummel 


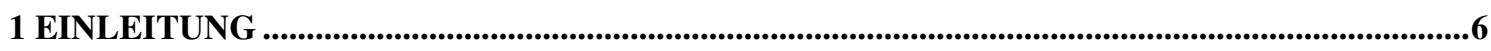

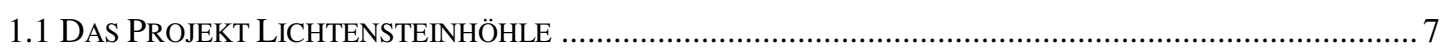

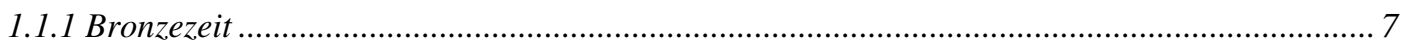

1.1.2 Fundstätte: Die Lichtensteinhöhle im Harz .......................................................................... 10

1.1.3 Menschenopferstätte oder Bestattungsplatz?..................................................................... 14

1.1.4 Verteilungsmuster der Knochenelemente: prähistorischer Eingang der Höhle und Ablagereihenfolge der Verstorbenen in die Lichtensteinhöhle........................................ 15

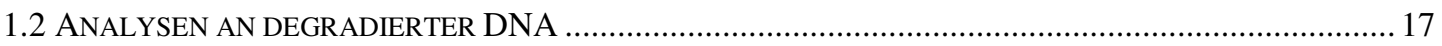

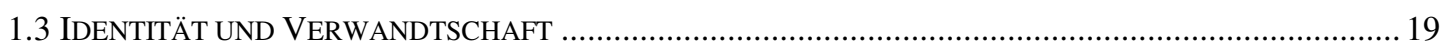

1.4 DNA - TYPISIERUNGSMARKER UND ANWENDUNGSBEISPIELE …................................................ 20

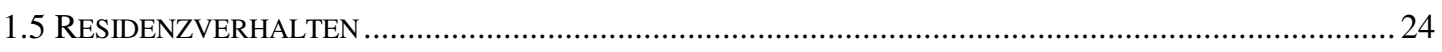

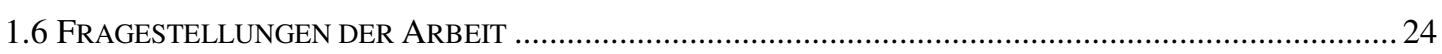

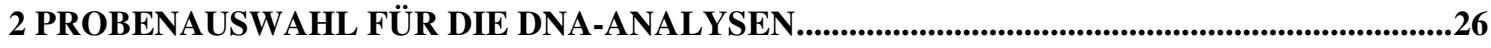

3 MOLEKULARGENETISCHE VERWANDTSCHAFTSANALYSE .............................................30

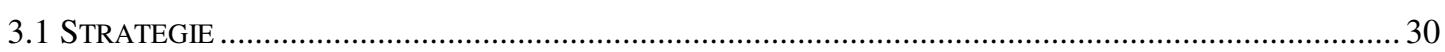

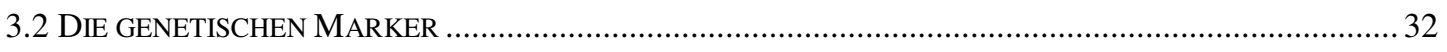

3.2.1 Autosomale STRs und der genetische Fingerabdruck ................................................... 32

3.2.2 Mitochondriale DNA, Haplotypisierung und Haplogruppen.................................................... 35

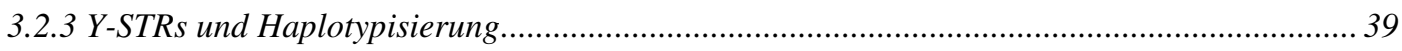

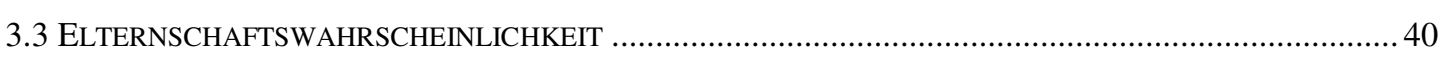

4 METHODEN

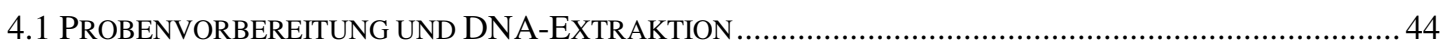

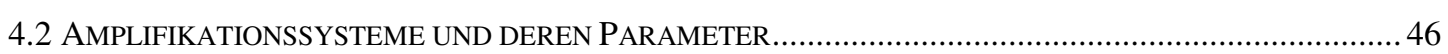

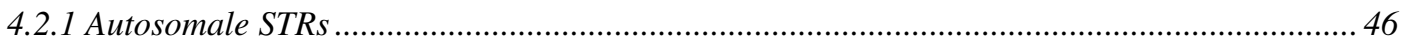

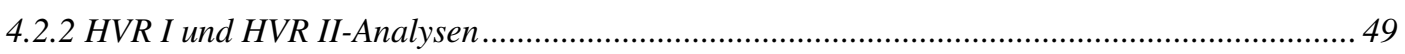

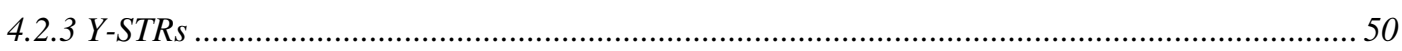

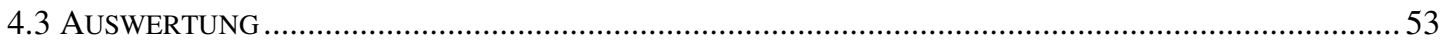

4.3.1 Agarosegelelektrophorese …............................................................................................... 53

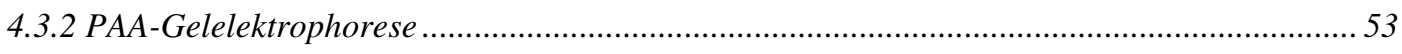

4.3.3 Sequenzierung und Kapillarelektrophorese .................................................................... 54

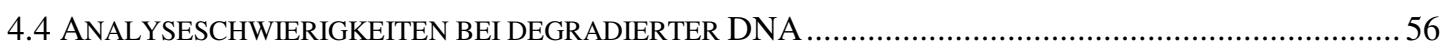

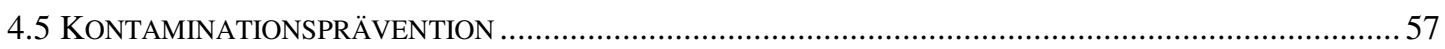

4.6 TYPISIERUNGSSTRATEGIEN ZUR SICHERSTELLUNG VON AUTHENTIZITÄT

UND ZUR AUFKLÄRUNG LIEGEZEITBEDINGTER DNA-DEGRADIERUNGSARTEFAKTE .......................58

5 TYPISIERUNGSERGEBNISSE UND ABLEITUNGEN AUS DEN DATENSÄTZEN ................64

5.1 Autosomale STRs, GeschleChtSBESTIMMUNG UND ZUORDNUNG VON SKELETTELEMENTEN ... 64

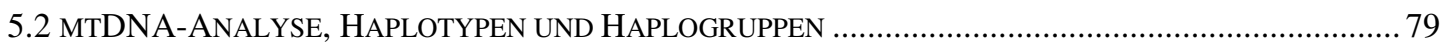

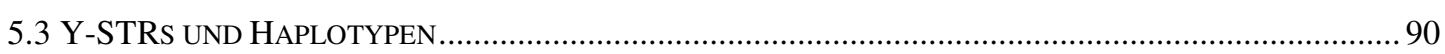




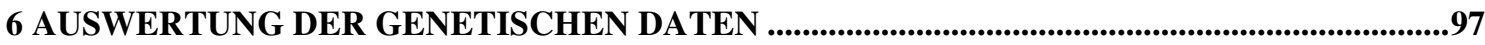

6.1 VERWANDTSCHAFTSREKONSTRUKTION AM SKELETTKOLLEKTIV DER LICHTENSTEINHÖHLE............97

6.1.1 Genealogische Rekonstruktion einzelner Verwandtschaftsbeziehungen................................ 98

6.1.2 Der Familienstammbaum der Lichtensteinhöhle .............................................................. 114

6.1.3 Abschlussbewertung der Verwandtschaftsrekonstruktion................................................. 121

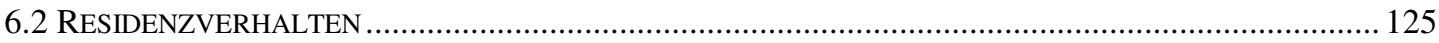

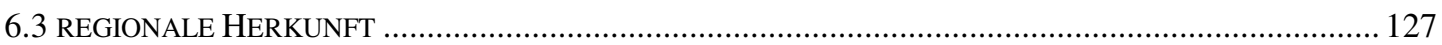

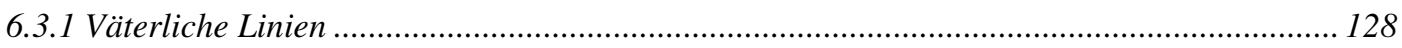

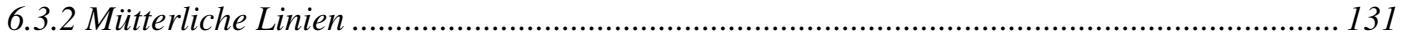

6.4 VERTEILUNGSMUSTER DER KNOCHENELEMENTE: PRÄHISTORISCHER EINGANG UND

ABLAGEREIHENFOLGE DER VERSTORBENEN IN DIE LICHTENSTEINHÖHLE ................................. 138

7 BESTATTUNGSPLATZ ODER MENSCHENOPFERSTÄTTE?...................................................145

7.1 ZUSAMMENFÜHRUNG DER ERGEBNISSE DES ANTHROPOLOGISCHEN BEFUNDES

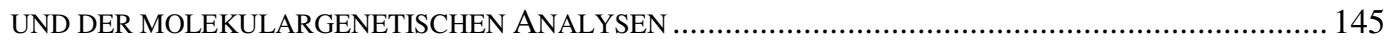

7.2 ERGEBNISINTERPRETATION UND DEREN EINORDNUNG IN DEN ARCHÄOLOGISCHEN KONTEXT ....... 146

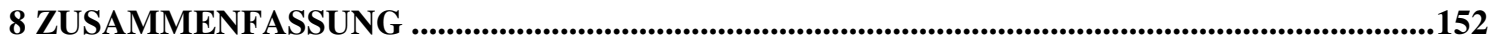

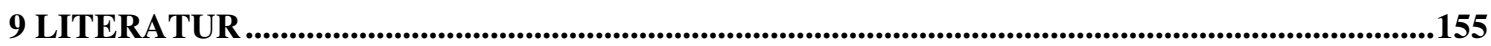

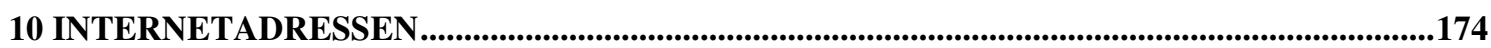

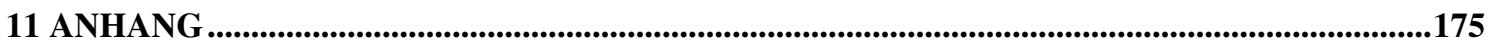

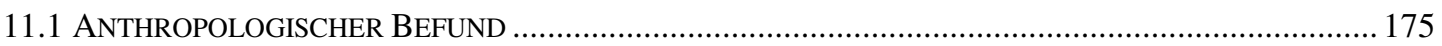

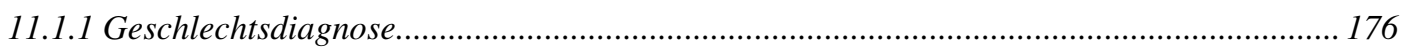

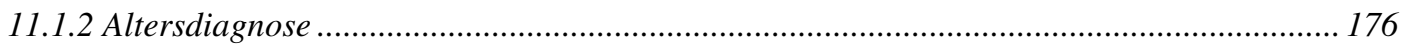

11.1.3 Schätzung der Körperhöhe ........................................................................................... 182

11.1.4 Erhaltungszustand der Knochen, anatomische Varianten und Pathologien....................... 184

11.2 DiE LiCHTENSTEINHÖHLE ALS BIOLOGISCH-GENETISCHES ARCHIV .......................................... 189

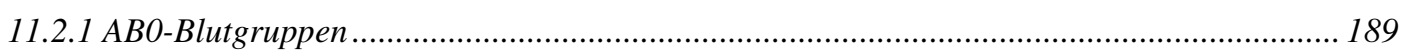

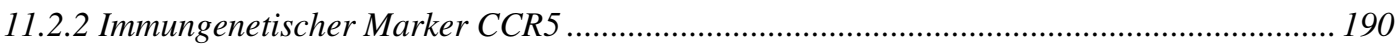

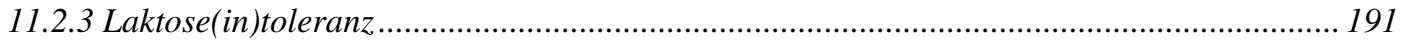

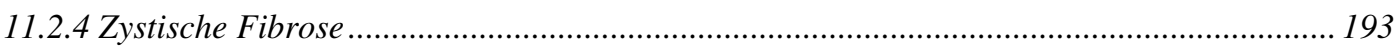

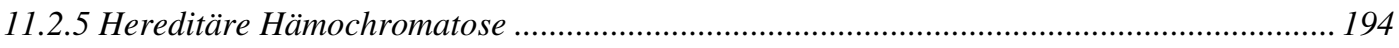

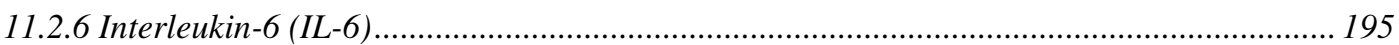

11.2.7 Graphische Darstellung der ergänzenden genetischen Studien an den............................ 197

Knochen aus der Lichtensteinhöhle ............................................................................. 197

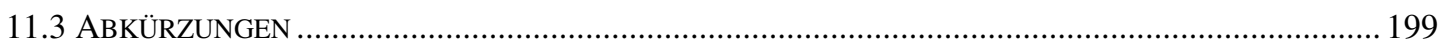

11.4 Verwendete GerÄte, ChEMiKalien, Hilfsmittel und EinweGMaterialien ...................... 202

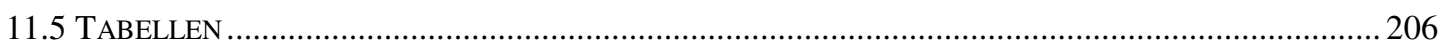

11.5.1 Fundorte und Quadrantenangabe der cranialen Skelettelemente ........................................ 206

11.5.2 Autosomale STR-Typisierungsergebnisse ................................................................. 207

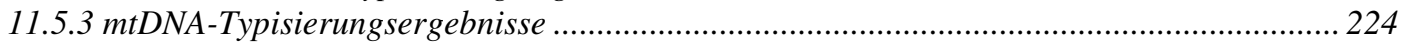

11.5.4 Y-chromosomale Typisierungsergebnisse ..................................................................... 245

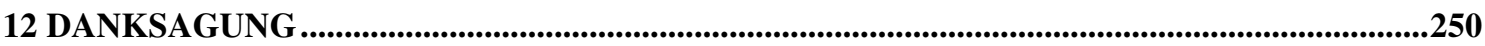




\section{Einleitung}

Molekulargenetische Verwandtschaftsanalysen an den Überresten historischer Skelettkollektive können maßgebliche Hinweise zur Interpretation archäologischer Fundplätze liefern. Dies kann an dem bronzezeitlichen 3000 Jahre alten Skelettkollektiv aus der Lichtensteinhöhle (Landkreis Osterode am Harz/Niedersachsen) gezeigt werden. Archäologen stießen bei den Ausgrabungen auf die menschlichen Überreste von mindestens 40 Individuen. Die Fundsituation der Individuen sowie die Nutzung der Höhle als Kultstätte für rituelle Handlungen werfen dabei unterschiedliche archäologische Fragestellungen auf. Eine der wichtigsten Fragen ist dabei die nach der möglichen Nutzungsart der Höhle. Der archäologische Befund wies anfangs auf eine Opferstätte hin. Anthropologische Arbeiten ließen an dieser Interpretation jedoch Zweifel aufkommen. Insbesondere die seit 1998 durchgeführten molekulargenetischen Untersuchungen lassen die Vermutung auf ein anderes prähistorisches Geschehen zu. Sind die Individuen im Sinne eines Familienclans miteinander verwandt, könnte man von einer Familienbegräbnisstätte ausgehen. Durch günstige Umweltfaktoren wurde die DNA in den menschlichen Skeletten herausragend gut konserviert, sodass chromosomale DNA-Typisierungen und damit Verwandtschaftsanalysen an den prähistorischen Knochen möglich sind. Die Molekulare Anthropologie wendet dabei genetische Marker an, welche durch die Gerichtsmedizin (Forensik) in den letzten Jahren etabliert wurden. In einer ersten Studie (Schultes 2000) konnte mit den molekulargenetischen Methoden, in einem für die Anthropologie und Archäologie bisher einzigartigem Fall, eine Teilgenealogie des bronzezeitlichen Fundkollektivs der Lichtensteinhöhle rekonstruiert werden. Dies deutet darauf hin, dass es sich bei der Nutzung der Höhle sehr wahrscheinlich um einen Bestattungsplatz handelt.

In der vorliegenden Studie soll geklärt werden, ob alle Individuen in einem verwandtschaftlichen Bezug zueinander stehen. Hiermit könnte abschließend die archäologische Fragestellung, die mit der Nutzung der Höhle in Verbindung gebracht wird, beantwortet werden. Darüber hinaus können über die genetischen Analysen weitere Aussagen, beispielsweise zur Herkunft der Individuen und zur sozialen Organisation der Gruppe, getroffen werden. Unterstützt wird diese Studie durch die morphologische Befundung der Knochen. Mithilfe der vielseitigen Arbeitsmethoden der Anthropologie ist ein einzigartiger Einblick in die Lebensbedingungen einer prähistorischen Population möglich. 


\subsection{Das Projekt Lichtensteinhöhle}

In diesem Kapitel wird die Lichtensteinhöhle als archäologische Fundstätte vorgestellt, die archäologischen Fragestellungen zur Nutzung der Höhle erörtert und Lösungsstrategien aufgezeigt. Durch die Archäologie konnte der Fundplatz in die Bronzezeit datiert werden. Einleitend wird die Bronzezeit kurz vorgestellt, um die späteren Ergebnisse in den zeitlichen Kontext einordnen zu können. Im Wesentlichen wird hierbei auf Zeitstellung, Bestattungssitte, Opferung und Lebensumstände der Menschen eingegangen.

\subsubsection{Bronzezeit}

Der Name der Bronzezeit resultiert aus dem zu dieser Zeit vorherrschenden Werkstoff Bronze. Durch das Auftreten dieses neuen Werkstoffes legen die Archäologen eine neue Zeitepoche fest. In Mitteleuropa folgt auf die Jungsteinzeit (Neolithikum) die Bronzezeit. Sie beginnt ca. 2200 Jahre v.Chr. und lässt sich in drei übergeordnete Zeitepochen einteilen. Die Frühbronzezeit reicht bis ins 16 Jhd. v.Chr.. An sie schließt die Mittelbronzezeit an, welche bis etwa ins 13 Jhd. v.Chr. andauert. Der dritte und jüngste Abschnitt wird als Jungbronzezeit bezeichnet und endet mit dem Übergang in die Eisenzeit im 8 Jhd. v.Chr.. Die Untergliederung der Bronzezeit beruht im Wesentlichen auf Bestattungssitten und Grabformen, welche sich im Laufe der Bronzezeit verändert haben. In der Frühen Bronzezeit waren Flachhockergräber verbreitet, d.h. Verstorbene wurden auf der Seite liegend mit angezogenen Beinen und vor den Oberkörper angewinkelten Armen bestattet. In der Mittleren Bronzezeit erfolgte die Beisetzung weitgehend in gestreckter Rückenlage als Körperbestattung unter Grabhügeln, weshalb diese Zeitperiode auch als Hügelgräberkultur bezeichnet wird. In der Jungbronzezeit kommt es vermutlich zu einer Veränderung in den religiösen Vorstellungen. Man rückt von den Körperbestattungen ab und nimmt Brandbestattungen vor, welche heute als Charakteristikum der Jungbronzezeit gelten. Aufgrund dieser Bestattungssitte, der „Brandbestattungen in Urnenfeldergräbern“, wird oftmals der Begriff der Urnenfelderbronzezeit benutzt. Bestimmend für die unterschiedlichen Bestattungssitten waren wahrscheinlich vorherrschende Jenseitsvorstellungen oder das Bestreben, die gesellschaftliche Stellung des Verstorbenen darzustellen (Kuhbach 1994, 48). 
In Deutschland kann diese übergeordnete Einteilung der Epochen in Früh-, Mittel und Jungbronzezeit nicht immer einheitlich angewandt werden. Durch interdisziplinäre Forschungsergebnisse der Archäologie (z.B. Typologie von Fund und Befund) und der Naturwissenschaften (z.B. $\mathrm{C}^{14}$-Datierung) wurde festgestellt, dass der Beginn der Bronzezeit im Süden des heutigen Deutschlands sehr viel früher als im Norden war (ca. 700 Jahre). Des Weiteren lassen sich regional durch den Vergleich der archäologischen Inventare, der Art und Form von Bestattungen sowie Siedlungsüberresten, kulturelle Unterschiede und Entwicklungen feststellen. „So ergibt sich eine Vielzahl von archäologischen Gruppen (»Kulturen«) in einem Recht komplizierten Zeitgefüge [...] (Jockenhövel 1994, 11). "Die Gliederung und Datierung der einzelnen Kulturstufen wiederum basiert auf einer relativen Chronologie, welche im Wesentlichen durch Anwendung der Typologischen Methode zustande kommt. Bei dieser Methode wird die chronologische Einstufung eines archäologischen Objektes durch die Entwicklung seiner verschiedenen Typen bestimmt, d.h. ob ein Objekt im Laufe der Zeit eine Wandlung hinsichtlich Verzierung oder Form durchlaufen hat (Eggert 2001, 182).

Neben einer chronologischen Datierung kann über die Begutachtung des archäologischen Quellenmaterials eine Rekonstruktion der Lebensumstände historischer Bevölkerungen erstellt werden. So sind z.B. Einsichten in ihre soziale Organisation oder in ihre Ernährungsgewohnheiten möglich.

Das Quellenmaterial umfasst dabei deponierte Objekte, Gräber (z.B. menschliche und tierische Skelettüberreste), Grabbeigaben und Siedlungsreste (z.B. Kamine und Aschen von Feuerstellen, Nahrungsmittelrückstände). Typisches Fundinventar der Bronzezeit sind z.B. Keramiken, Kleidungsstücke, Nadeln, Schmuck und Waffen.

Für bronzezeitliche Gesellschaften konnte man herausfinden, dass sie im Gegensatz zu früheren Zeitepochen organisierter waren (Jockenhövel 1994, 7). Es herrschte gemäß Arbeit und Geschlecht eine Arbeitsaufteilung. Männer waren geprägt durch kriegerische Attribute. Frauen erfüllten traditionelle Aufgaben wie Kochen und Kinderaufzucht. Die Größe der bäuerlichen Siedlungen reichte von Einzelhöfen bis hin zu 30 Gebäuden und wies Einwohnerzahlen von 50 - 80 Personen auf.

Die Familie bildete in der Bronzezeit die biologische, soziale und wirtschaftliche Grundeinheit (Jockenhövel 1994, 45). Nach Jockenhövel (1994, 45) bestand sie aus ca. fünf bis zehn Familienmitgliedern und eine Siedlung aus fünf bis acht Familien. Diese Großfamilien bildeten mit benachbarten Siedlungen überörtliche Gemeinschaften. Jedoch blieben in der Regel nur drei bis fünf Generationen am gleichen Ort, da im Lauf 
der Jahre zum einen kein fruchtbarer Boden mehr vorlag und zum anderen die Bauwerke durch Witterungseinflüsse langsam zerstört waren (Jockenhövel 1994, 21). Wegen der geringen Spuren (Gruben, Pfostenlöcher) und der starken Erosion der Böden lassen sich Siedlungen in der heutigen Zeit schlecht nachweisen.

Nicht alle Orte an denen menschliche Überreste gefunden wurden sind auf gewöhnliche Bestattungen zurückzuführen. Angst vor Naturgewalten trieb die Menschen zu rituellen Handlungen, welche neben der Opferung von Gütern (Metallgegenständen, Steinwerkzeugen, Tongefäßen, Scherben) und Lebensmitteln (Pflanzen) auch die von Tieren und ganz gezielt von Menschen mit einschloss (Kubach 1994, 65). Denn „Ebenso leicht, ja leichter als ein flüchtiges Wild aber ist ein Mensch zu töten“ (Burkert 1972, 26-27) und „[...] von der Austauschbarkeit von Mensch und Tier im Opfer sprechen die Mythen nicht nur bei den Griechen immer wieder“" (Burkert 1972, 29). Die Menschen versuchten ihre Götter mit Opferungen gnädig zu stimmen.

Opferungen von Lebewesen sind nicht auf eine Zeitepoche festgelegt, sondern sind nach Burkert $(1972,21)$ die älteste Form religiöser Handlungen. Aus der Bronzezeit sind ebenfalls solche Opferungsrituale bekannt. In der Regel geschahen sie in der freien Natur und an exponierten Plätzen (Kubach 1994, 65). Belege für Opferhandlungen, in denen Menschenopfer eine große Rolle spielten, kennt man u.a. aus dem Südharzgebiet und dem Kyffhäuser. Liegen Opferungen vor, beziehen sie sich in der Regel auf bestimmte Gruppen, wie z.B. Kinder, Jugendliche oder Frauen. Zusätzlich werden oftmals Tierknochen, Pflanzenreste, Sachgüter, Trachten und Schmuck unmittelbar mit den Opfern deponiert. Spezielle Plätze sakraler Deponierungen waren beispielsweise Höhlen, da sie als Zugang zum Erdinneren verstanden wurden, in denen man den Göttern näher kommen konnte. In der Jüngeren Bronzezeit wurden Opfergaben einer weiblichen, erdverbundenen Gottheit dargeboten, welche für die Regelung von „Leben und Tod“" und „Fruchtbarkeit“" zuständig war (Flindt 2001). 


\subsubsection{Fundstätte: Die Lichtensteinhöhle im Harz}

Im Harz bei Osterode/Niedersachsen gelegen, befindet sich in einem Gipskarstgebiet der Lichtenstein (Abb.1). Innerhalb dieses Berges befindet sich einer der herausragenden bronzezeitlichen Fundplätze Deutschlands. Im Februar 1980 konnten Höhlenforscher eine Engstelle, in einem 1972 entdeckten Höhlensystem, künstlich erweitern und tiefer in den Berg vordringen.

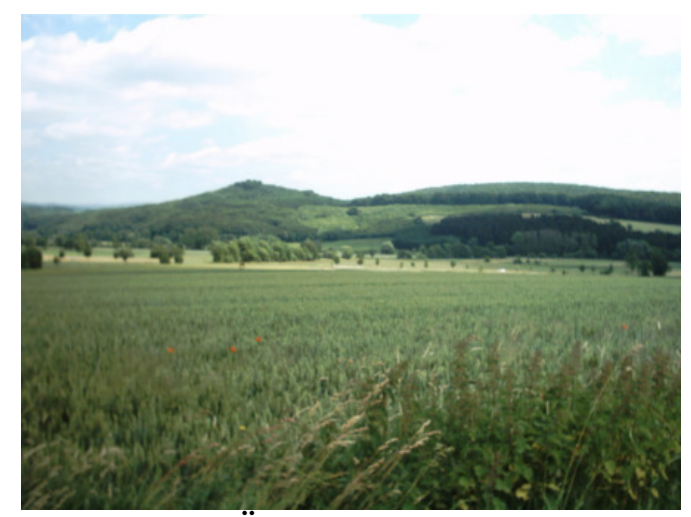

Abbildung 1: Übersichtsaufnahme mit Blick auf den 261m hohen Lichtenstein.

Obwohl sie nicht wussten was sie erwartet, bewegten sich die Forscher durch stellenweise kaum mehr als $30 \mathrm{~cm}$ breite Klüfte und Spalten ca. $100 \mathrm{~m}$ in den Berg

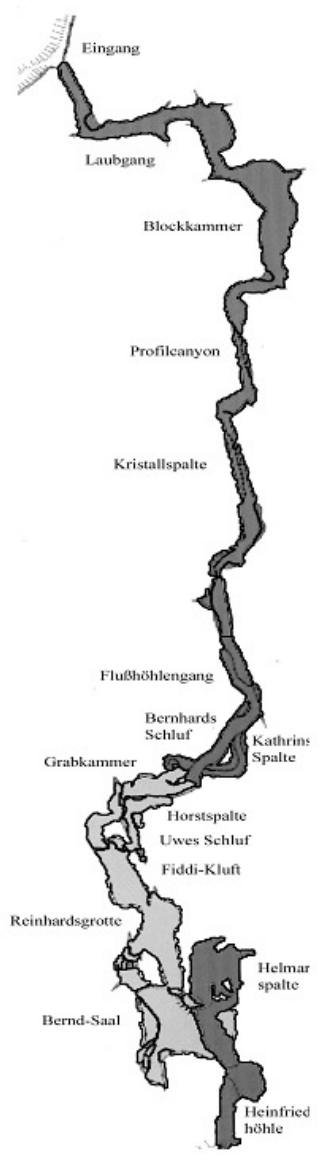

Abbildung 2: Lageplan der Lichtensteinhöhle (nach Flindt \& Leiber 1998, Abb.54). Die fünf fundführenden Höhlenabschnitte sind hellgrau dargestellt. hinein. Am Ende dieses Kluftsystems stießen sie auf fünf, mit Menschenknochen belegte, Höhlenkammern (Abb.2). Anschließende Befahrungen der Höhle brachten erstaunliche Funde zutage. In den fundführenden Höhlenabschnitten (Grabkammer, Horstspalte, Fiddi-Kluft, Reinhardsgrotte und Bernd-Saal) wurden die Skelette von mindestens 40 Individuen gefunden. Mit Ausnahme eines in der Grabkammer liegenden Skelettes war keines mehr in seinem vollständigen anatomischen Verband. Vielmehr lagen die Skelette disloziert, ohne erkennbare Ordnung verlagert und zum Teil an den Seiten der Kammern zusammengeschoben, vor. Die Fundsituation der Skelettelemente in der Lichtensteinhöhle kann mit „sehr stark gestört" beschrieben werden. Zwischen den Knochen wurden umfangreiche Beifunde festgestellt. Sowohl Knochen als auch Fundinventar waren zumeist von einer mehreren Zentimeter dicken Gipssinterschicht überzogen. Die Stärke dieser Schicht deutet darauf hin, dass die Höhle schon seit prähistorischer Zeit nicht mehr benutzt wurde. Des Weiteren konnte festgestellt werden, dass sich unter 
den Knochenlagen keine Gipssinterschicht befand und damit der Sinterprozess erst mit dem Ende der Höhlennutzung einsetzte (Flindt 1996b, 223). In Grabkammer, Horstspalte, Reinhardsgrotte und Fiddi-Kluft wurden über hundert Bronzegegenstände, in der Regel schlichter Körperschmuck wie Ohr-, Arm- und Fingerringe aus dünnem Draht oder Blech, gefunden. Eine sehr viel ausgewogenere archäologische Fundsituation zeigte sich im Bernd-Saal. Er stellt den größten Höhlenabschnitt dar und in ihm wurden die meisten Skelettelemente gefunden (Abb.3).

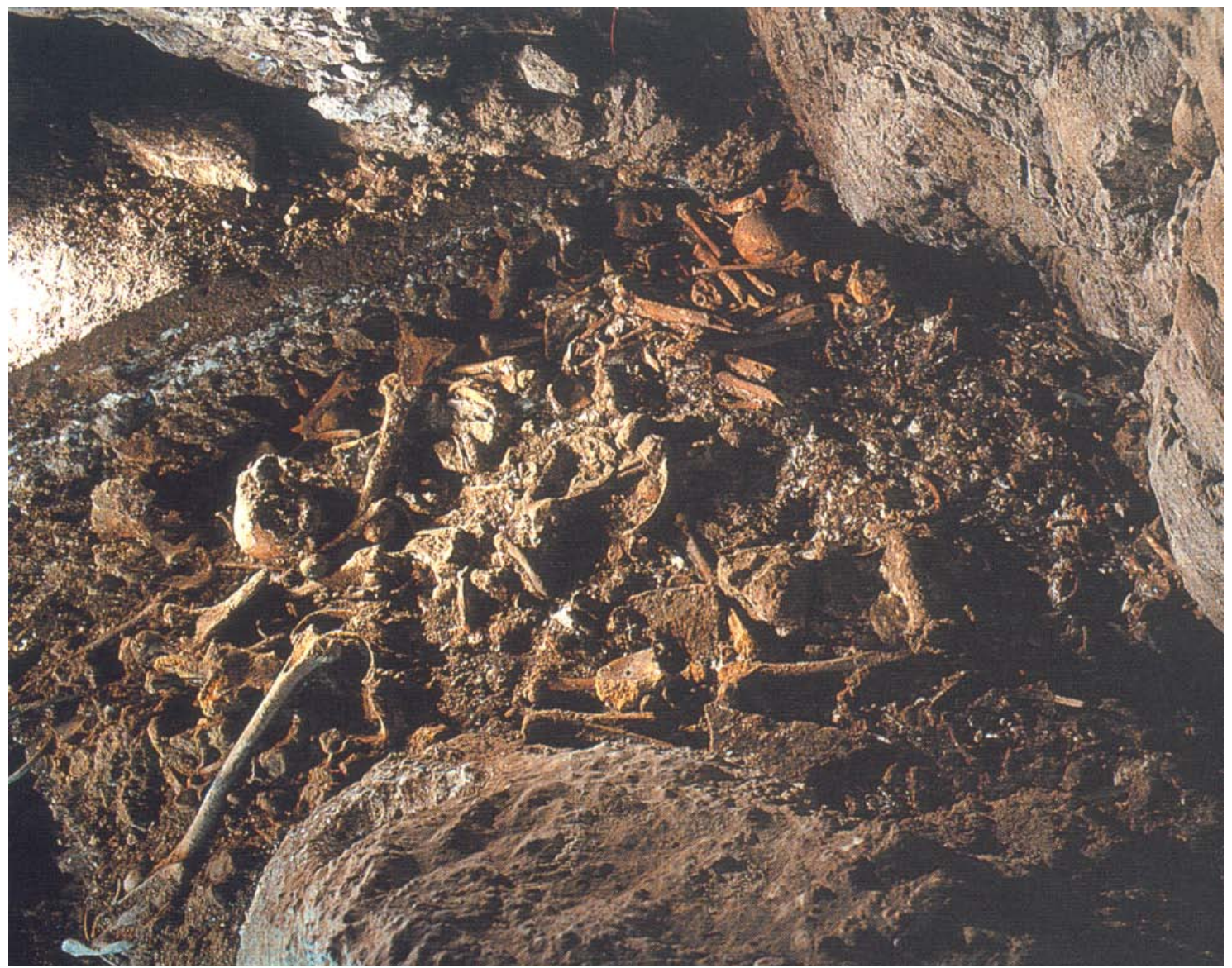

Abbildung 3: Blick in den Bernd-Saal. Menschenknochen in ungestörter dislozierter Fundlage (aus Flindt 2001, Abb.159).

Das Inventar im Bernd-Saal umfasst neben den einfachen Schmuckbronzen z.B. auch Glas- und Bernsteinperlen, durchbohrte Tierzähne, Bronzenadeln, kleinere Beschlagbleche für Ledergürtel und sogar zwei Bronzepfeilspitzen (Abb.4). Diese Gegenstände werden von den Archäologen als Grabbeigaben gedeutet. 

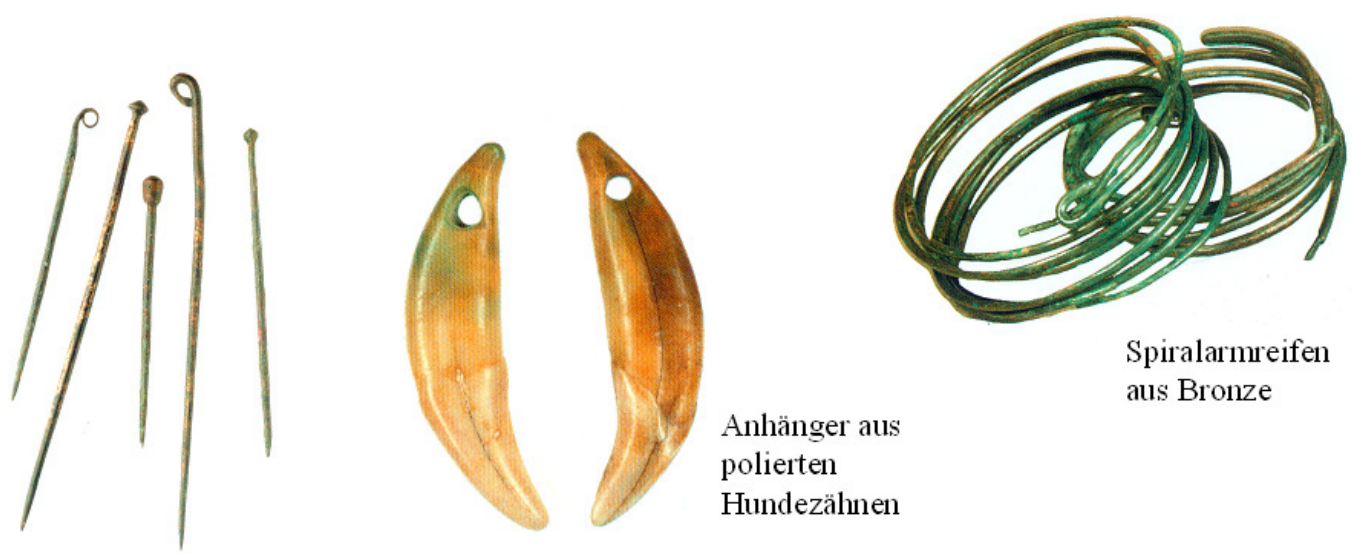

Spiralarmreifen

Anhänger aus

aus Bronze

\section{polierten}

Hundezähnen

Gewandnadeln (Fibeln) aus Bronze

Pfeilspitze aus Bronzeblech
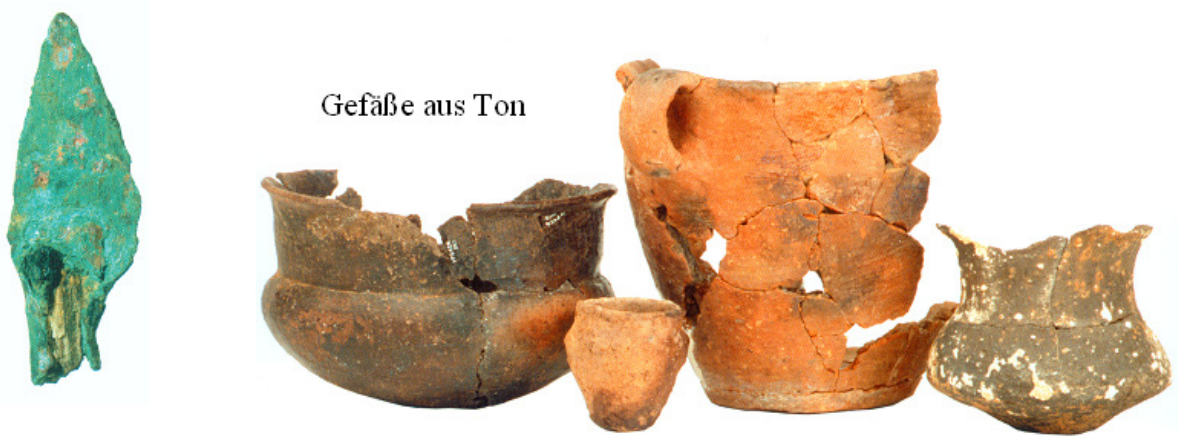

Abbildung 4: Zusammenstellung einiger archäologischer Fundstücke, Gebrauchs- und Schmuckgegenständen (aus Flindt 2001, Abb. 146, 154, 155, 161 und 169).

Zusätzlich entdeckte man hier unter den flächendeckenden Knochenlagen umfangreiche Reste ritueller Handlungen aus einem älteren Nutzungsabschnitt. In einem mehreren Zentimeter dicken Paket aus Erdschichten fanden sich große Mengen Holzkohle (=schwarze Schichten), welche auf ca. 15 übereinander liegende Feuerstellen hindeuten. Neben Bronzen wurden in den Aschen auch angebrannte oder mit Schnittspuren versehene Tierknochen, verkohltes Getreide und Feldfrüchte sowie Keramikgefäße entdeckt. Aufgrund dieser Fundsituation gehen die Archäologen von regelrechten Kultmahlzeiten aus (Flindt 2001, 75). Die Größe dieses Höhlenabschnittes lässt es zudem zu, dass sich hier mehrere Individuen gleichzeitig aufhalten konnten, welches nicht für die anderen Abschnitten angenommen werden kann. Alles in allem bildet der Bernd-Saal offensichtlich den zentralen Kultraum.

Anhand des Fundinventars (Metall- und Keramikfunde) konnten die Archäologen die Fundstätte in die Zeit zwischen ca. 1000 und 700 Jahre v.Chr. in die Urnenfelderbronzezeit eingrenzen (Ha $\mathrm{B}_{2 / 3}$ nach Flindt 1996a, 459). Kulturell gehört sie der vorwiegend in Thüringen verbreiteten Unstrutgruppe an (Flindt 1996a, 456). Diese 
Gruppe findet vom 13 bis 8 Jhd. v. Chr. im Thüringer Becken ihre Verbreitung (Abb.5) und mit dem Verschwinden dieser Kultur endet auch die Nutzung der Lichtensteinhöhle.

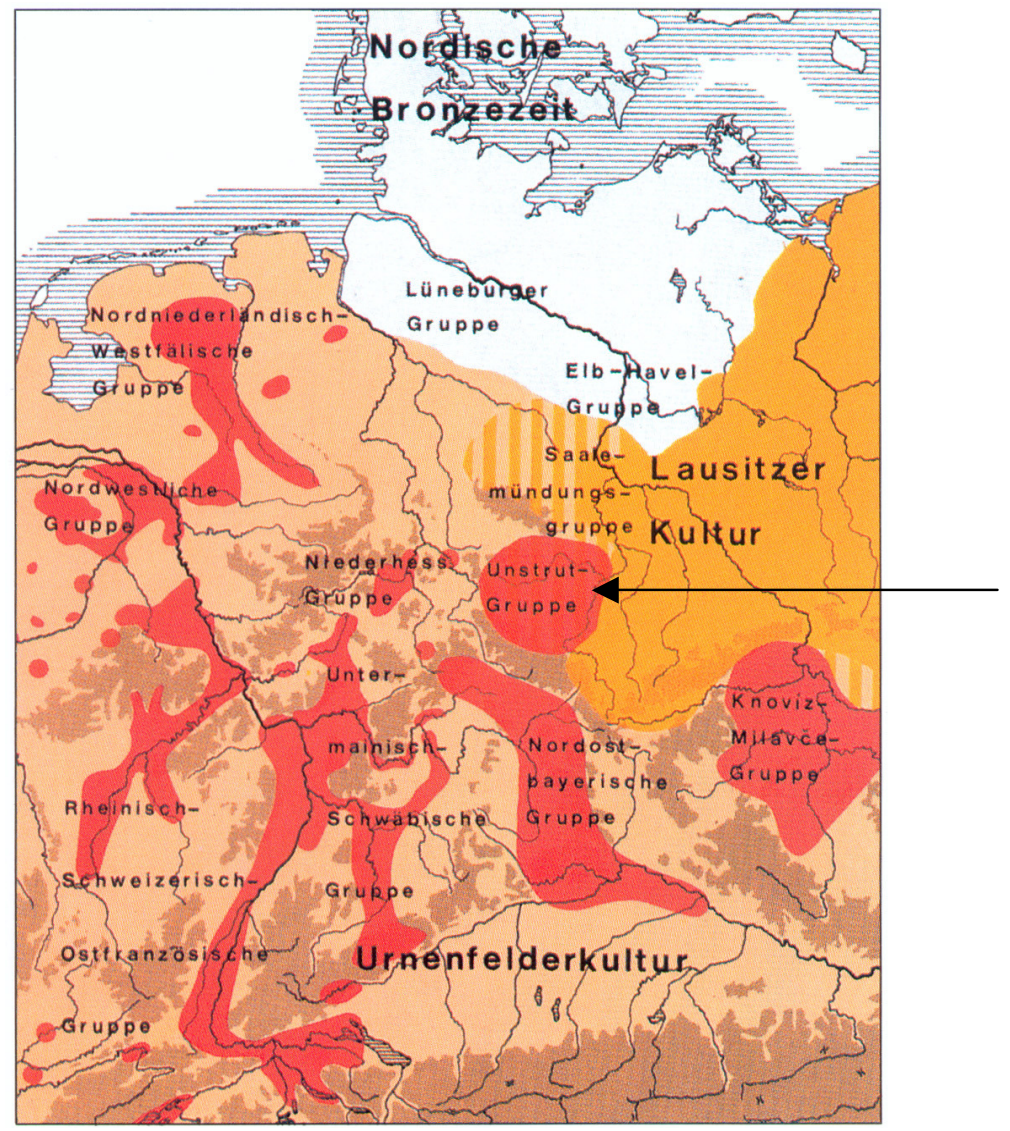

\begin{abstract}
Abbildung 5: Verbreitungskarte jungbronzezeitlicher Kulturgruppen in Deutschland (nach Jockenhövel 1994, 14). Der Pfeil weist auf das Verbreitungsgebiet der Unstrutgruppe hin, welcher die Lichtensteinhöhle kulturell zugeordnet wird.
\end{abstract}

Ungeklärt ist noch das regionale Einzugsgebiet der Menschen aus der Höhle. Ein Bezugspunkt könnte der Bereich der bei Osterode gelegenen heutigen Pipinsburg sein. Bei Ausgrabungen der späteren Burganlage (Eisenzeit, Mittelalter) wurden Reste einer urnenfelderzeitlichen Höhensiedlung gefunden. Es konnte bisher nicht nachgewiesen werden, ob die Höhensiedlung in der Urnenfelderzeit befestigt war und damit den Charakter einer Burganlage hatte. Dies wäre aus archäologischer Sicht jedoch vorstellbar. Der Bau von Burgen stellt eine Neuerung in der Bronzezeit dar. Diese Anlagen waren zum Teil stark befestigt und dienten sicherheitspolitischen Aspekten. Die meisten Burgen stehen im Zusammenhang mit angrenzenden, für die Bronzezeit üblichen, offenen Siedlungen. Ein jungbronzezeitliches Kleinterritorium setzte sich in 
der Regel aus einer befestigten Siedlung und mehreren offenen Siedlungen zusammen (Jockenhövel 1994, S.24). Eine offene Siedlung ist in der Umgebung der Lichtensteinhöhle bisher nicht bekannt (pers. Mitteilung S. Flindt). Daher ist zurzeit die Nutzung der Lichtensteinhöhle mit der zeitgleichen Höhensiedlung zu sehen.

\subsubsection{Menschenopferstätte oder Bestattungsplatz?}

Die Knochen- und Inventarfunde der Lichtensteinhöhle geben den Anthropologen und Archäologen einige Rätsel auf. Insbesondere die Nutzungsart der Höhle konnte bisher nicht hinreichend geklärt werden.

Die Archäologen klassifizierten die Lichtensteinhöhle anfänglich als Opferstätte (Flindt 1996a, 463). Von ganz erheblicher Bedeutung ist dabei die Tatsache, dass alle Toten der Lichtensteinhöhle unverbrannt vorliegen. Von der Unstrutgruppenkultur ist bekannt, dass sie ihre Toten birituell, also sowohl in Brandgräbern als auch in Körpergräbern bestatteten (Flindt 2001, 78). Die abweichende Fundsituation, dass ausschließlich unverbrannte Menschenüberreste in der Lichtensteinhöhle gefunden wurden, ist archäologisch gesehen eine Form der Sonderbestattung. Auffallend ist zusätzlich, dass Metallbeigaben wie Rasiermesser, Schwerter, Lanzenspitzen oder massiverer Bronzeschmuck (=Großbronzen) in der Höhle vollständig fehlen. Beigaben dieser Art sind in der Urnenfelderzeit zwar selten, dürften aber in der Regel nicht gänzlich fehlen. Die sonst häufig anzutreffende Keramik wurde allein in Verbindung mit den schwarzen Schichten in Bernd-Saal, aber nicht im Zusammenhang als Grabbeigabe mit den Skeletten gefunden.

Der kultische Charakter der Höhle ist durch seine zahlreichen Feuerstellen sowie Gefäße und anderer Gegenstände, denen bei rituellen Zeremonien eine zentrale Rolle beigemessen wird, gegeben. Solche rituellen Zeremonien schließen Opferungen mit ein (Flindt 1998). Des Weiteren könnte die dislozierte Lage der menschlichen Knochen ein mögliches Merkmal einer urgeschichtlichen Opferstätte sein (Flindt 2001, 36).

Nach dem ersten Anthropologischen Befund der Knochen kamen daran jedoch Zweifel auf. Es fehlen an den Knochen jegliche Zeichen direkter Gewalteinwirkung, d.h. Schnitt-, Brand- und Tötungsspuren sowie Spuren nachträglicher Leichenbehandlung. Im benachbarten Kyffhäuser sind aus gleicher Zeitstellung Höhlen bekannt, welche durch ihre eindeutige Fundsituation mit deutlichen Tötungs- und Zerlegungsspuren an den Skeletten als Opferstätten benannt werden können (Geschwinde 1988). 
Das Geschlechterverhältnis der Gruppe ist ausgeglichen und ihre Altersstruktur bewegt sich zwischen vier bis zu in einem Fall über sechzig Jahre. Auffallend ist das Fehlen von Kleinkindern unter vier Jahren, dies könnte jedoch andere Gründe haben (s.Kap.11.1.2). Mit den genannten Punkten entfallen wesentliche Kriterien aus dem Klassifikationsmodell von Geschwinde (1988), um eine Einteilung der Lichtensteinhöhle in die Kategorie Opferstätte vorzunehmen. Die Höhle könnte demnach als Bestattungsplatz in Betracht gezogen werden. Es steht dabei nicht in Frage, dass der Nutzung der Höhle weiterhin kultischer Charakter beigemessen wird, da die rituellen Handlungen im Bernd-Saal ebenso Teil eines Bestattungsrituals gewesen sein könnten (Flindt 2001, 81).

Die Funktionalität der Höhle kann demnach mit rein morphologischen und archäologischen Methoden nicht geklärt werden. Eine Lösung könnte in der Klärung der Frage liegen, ob es sich bei den gefundenen Individuen möglicherweise um eine Großfamilie handelt. Sind die Individuen über mehrere Generationen miteinander verwandt, ist die Interpretation als Bestattungsplatz wahrscheinlicher. Sollte sogar ein Individuum älter geworden sein als eines seiner Elternteile, schließt dieses einen Kollektivtod aus. Als letzte Option könnte ein Nutzungswandel in Betracht kommen, d.h. die Höhle wurde beispielsweise in der Anfangsphase als Kult- und Opferstätte und in der Endphase als Bestattungsplatz genutzt.

\subsubsection{Verteilungsmuster der Knochenelemente: prähistorischer Eingang der Höhle und Ablagereihenfolge der Verstorbenen in die Lichtensteinhöhle}

Bislang konnte noch nicht zweifelsfrei nachgewiesen werden, an welcher Stelle sich der prähistorische Eingang zur Höhle befindet.

Der Anthropologische Befund zeigt, dass neben den großen Langknochen und Schädeln auch kleinste Knochenelemente, wie z.B. Handwurzelknochen, in großer Zahl vorhanden sind. Liegt keines der verschiedenen Skelettelemente in Unterzahl vor, d.h. wären für 40 Individuen jeweils alle Knochen repräsentiert, würde es bedeuten, dass die Menschen entweder lebend oder nach ihrem Tod, aber vor der Skelettierung in die Höhle gebracht worden sind.

Der Bernd-Saal als Kultstätte weist neben den menschlichen Knochen zudem die Überreste von tausenden Tierknochen auf (Schoon 2003). Die Archäozoologen konnten 
dabei ganze Rinderextremitäten im anatomischen Verband finden. Es ist nicht vorstellbar, dass die Menschen, welche sich hier regelmäßig in der Höhle zu Kulthandlungen trafen, stets den von den Forschern gegangenen über 100m langen Weg durch die engen Klüfte und Spalten nahmen und dabei zusätzlich große Tierüberreste oder gar regungslose menschliche Körper transportierten (Maier \& Linke 1985, 154). Zusätzlich sollte eine Deponierung von einzelnen Leichenteilen eher unwahrscheinlich sein, da zumindest in einem Fall Skelettelemente in ihrem anatomischen Verband gefunden wurden (z.B. Flindt 2001, Abb.141). Aufgrund dessen gehen die Archäologen davon aus, dass es sich bei dem 1972 gefundenen Eingang nicht um den prähistorischen handeln kann.

Eine Aufklärung dieser Frage könnte mit der topographischen Verteilung der Skelettelemente gelingen. Über die Typologie des Fundinventars konnte belegt werden, dass die Höhle über einen Zeitraum von über 100 Jahren aufgesucht wurde. Die Menschen, welche regelmäßig die Lichtensteinhöhle durchquerten, schafften sich eventuell Platz, um ungestört durch die engen Abschnitte zu gelangen. Sie könnten die Knochen an den Wänden der Kammer zusammengeschoben haben, um nicht auf diese zu treten. In der Reinhardsgrotte wurden Langknochen als deponierte Knochenpakete gefunden (Flindt 2001, Abb.142). Letzteres zeigt, dass die Lichtensteinhöhle auch noch $\mathrm{zu}$ einer Zeit genutzt wurde, als die Individuen schon skelettiert und ohne Zusammenhalt durch Sehnen und Bänder vorlagen.

Die verstreut vorliegenden Knochenelemente können mithilfe genetischer Analysen (=genetischer Fingerabdruck, s.Kap.3.2.1) individualisiert und somit den einzelnen Individuen wieder zugeordnet werden. Damit lässt sich rekonstruieren, wie stark die Skelettelemente der einzelnen Individuen in ihrer jeweiligen anatomischen Ordnung gestört worden sind, bzw. wie hoch ihr Streuungsgrad in der Höhle ist.

Über den Streuungsgrad der zusammengehörenden Knochenelemente wird versucht die Bewegungsrichtung der Höhlennutzer aufzuklären. Der Streuungsgrad könnte in den Abschnitten am höchsten sein, durch die sich die Höhlennutzer vorwiegend bewegt haben. Hier dürfte keines der Skelette mehr in seiner anatomischen Ordnung liegen. Dagegen könnte der Störungsgrad eines zuletzt in der Höhle platzierten Skelettes am geringsten sein. Eine mögliche Hypothese ist, dass dort wo die Skelettelemente der einzelnen Individuen noch am ehesten in ihrer anatomischen Ordnung vorliegen, der prähistorische Eingang der Höhle zu vermuten ist. Die Höhlennutzer könnten die letzten 
Toten im Bereich des Eingangs niedergelegt haben, kurz bevor die Höhle nicht mehr genutzt wurde. In diesem Fall würde der geringere Streuungsgrad aus der Tatsache resultieren, dass die Höhlennutzer nur noch einen kurzen Zeitabschnitt über die Skelette gestiegen sind. Denkbar ist natürlich auch, dass die letzten Toten in die vom Eingang entfernten Bereiche gelegt wurden. Somit könnte sich anhand der Bewegungsrichtung der Höhlennutzer letztendlich ein Hinweis auf den prähistorischen Eingang ergeben.

Aus diesen Ergebnissen könnte auch hervorgehen, in welcher zeitlichen Reihenfolge die Toten in die Höhle gelegt wurden. Es wäre denkbar, dass der Streuungsgrad der Knochenelemente eines später abgelegten Individuums geringer ist, als das von einem aus der Anfangszeit der Höhlennutzung.

Für die repräsentative Analyse wurden verschiedene Knochenelemente ausgewählt, die das Skelett über seine komplette Länge belegen. Neben den in diesem Projekt bearbeiteten cranialen Elementen (s.Kap.2) und den von Schultes (2000) typisierten Femora, konnten in ergänzenden Studien Daten von Calcanei (Klingner 2005), Humeri (Mußlick 2005), Radii (Gärtner 2005) und Tibiae (Croll 2005) gesammelt werden. Die Interpretation der gewonnenen Daten und die Einordnung in den archäologischen Kontext wird in Kapitel 6.4 vorgenommen.

\subsection{Analysen an degradierter DNA}

DNA-Analysen sind an historischem Probenmaterial erst durch die Erfindung der Polymerase Chain Reaction (Polymerase-Kettenreaktion, Abk.: PCR) (Saiki et al. 1985, Mullis \& Faloona 1987) möglich geworden. Das PCR-Verfahren, für welches dem Erfinder Kary Mullis 1985 der Nobelpreis verliehen wurde, ist auch die Schlüsselerfindung für die Analyse von ancientDNA (Abk. aDNA, vgl. Herrmann \& Hummel 1993). Das PCR-Verfahren kann aus sehr geringen DNA-Mengen definierte Sequenzabschnitte bis zur Nachweisgrenze vermehren. DNA aus historischem und forensischem Probenmaterial liegt nur noch im Spurenbereich vor und weist in der Regel sehr stark degradierte DNA auf. Auswirkungen auf die DNA-Erhaltung haben Umwelteinflüsse wie Temperatur, $\mathrm{pH}-$ Wert des Liegemilieus und die Besiedlungsdichte von Mikroorganismen, der Zeitfaktor spielt eher eine geringere Rolle (z.B. Burger et al. 1999). Die degradierenden Prozesse bewirken dabei Strangbrüche der DNA- 
Doppelhelix, sodass in der Regel DNA-Fragmentlängen unter 300 Basenpaaren (bp) vorliegen (z.B. Hummel \& Schultes 2000). Jedoch können aus historischen Probenmaterialien auch sehr viel längere Fragmente, z.B. über $800 \mathrm{bp}$, nachgewiesen werden (Haack et al. 2000). Aufgrund der DNA-Qualität findet die PCR-Technik als Standardverfahren ihre Anwendung in der Paläogenetik.

Umfangreiche Forschungsarbeiten an aDNA konnten bereits in verschiedenen Disziplinen durchgeführt werden. Im Bereich der Paläozoologie konnten z.B. erfolgreiche aDNA-Analysen an Höhlen- und Braunbären (Loreille et al. 2001, Hofreiter et al. 2001a, Barnes et al. 2002, Orlando et al. 2002), historischen Pinguinen (Lambert et al. 2002) und ausgestorbenen Tierarten wie dem Dodo (Shapiro et al. 2002) durchgeführt werden. Anhand dieser Analysen können phylogenetische Studien betrieben sowie evolutive Veränderung innerhalb einer Spezies aufgedeckt werden. Weitere DNA-Studien an historischen Skelettüberresten von Haus- und Nutztieren wurden mit dem Ziel der Aufklärung ihrer regionalen Herkunft und Verbreitung angefertigt, wie z.B. aDNA-Analysen an Pferden (Vilà et al. 2001), Hunden (Leonard et al. 2002) und Rindern (Burger et al. 2002). Aus diesen Studien können zusätzlich Domestikationsbemühungen und Handelsbeziehungen historischer menschlicher Kulturen abgelesen werden. Des Weiteren lassen aDNA-Analysen in der Paläobotanik Rückschlüsse auf Herkunft, Evolution und Verbreitung von Nutzpflanzen in historischen Zeiten zu und geben einen Einblick in das Nahrungsspektrum historischer Bevölkerungen. So wurden zu diesen Themen u.a. Arbeiten an historischen ca. 300 Jahre alten Weizenüberresten (Blatter et al. 2002) sowie an über 4000 Jahre alten archäologischen Maisproben aus Mexiko (Jaenicke-Despres et al. 2003) angefertigt. Ebenfalls gelang es aus historischem Knochenmaterial Erreger-DNA zu extrahieren. Auf diese Weise gelangen u.a. die Nachweise für Lepra (Rafi et al. 1994) und Tuberkulose (z.B. Dixon \& Roberts 2001, Zink et al. 2005). Diese Studien von Infektionskrankheiten zeigen u.a. die Interaktion zwischen Wirtstier und Krankheitserreger, die Ausbreitung von Infektionskrankheiten in historischen Zeiten und die evolutive Anpassung von Krankheitserregern.

Die Ergebnisse aus diesen Forschungsrichtungen helfen bei der Rekonstruktion der Lebensbedingungen historischer Bevölkerungen. In der Prähistorischen Anthropologie werden aDNA-Analysen an historischen menschlichen Skelettüberresten durchgeführt. Zentrale Aspekte sind hier die Identifizierung historischer Personen und die Aufklärung verwandtschaftlicher Beziehungen. 


\subsection{Identität und Verwandtschaft}

Anfänglich wurde versucht, die Identität von historischen Individuen und die verwandtschaftlichen Beziehungen historischer Bevölkerungen mithilfe morphologischer (z.B. Rösing 1986, Hauser \& DeStefano 1989) und metrischer Merkmale herzuleiten (z.B. Ullrich 1969). Die sicherste Methode zur Aufklärung dieser Fragestellungen ist jedoch die DNA-Typisierung. Die Notwendigkeit einer Identitätsüberprüfung bei historischen Skelettfunden ist gegeben, wenn keine historischen Aufzeichnungen zu einer Fundstätte vorliegen oder diese nicht präzise sind. Geschichtliche Überlieferungen zeigten beispielsweise den Werdegang von vier Zwickauer Ratsherren. Sie machten sich 1407 der Veruntreuung von öffentlichen Geldern schuldig und wurden hingerichtet. Skelettfunde im St.Afra-Kloster in Meißen legten den Verdacht nahe, dass es sich hierbei um die vier Ratsherren handelte, jedoch war man sich dessen nicht sicher. DNA-Analysen konnten sie mit einer hohen Wahrscheinlichkeit identifizieren (Bohnhage 2004) und damit die historischen Aufzeichnungen verifizieren.

Ein weiteres wichtiges Thema anthropologischer Forschung ist die Verwandtschaftsanalyse. Sie kann, unter Hinzunahme archäologischer und sozialgeschichtlicher Forschungsergebnisse, zur Aufklärung des Sozialgefüges einer Gruppe führen. Verwandtschaft gibt dabei einen Einblick in die kulturellen Normen und Handlungsmuster unserer Vorfahren.

Verwandtschaft bildet in den meisten Gesellschaften die Grundlage für ihre soziale Organisation (z.B. Parkin \& Stone 2004, 1). Der Begriff Verwandtschaft wird dabei nicht immer einheitlich angewandt, da kulturell und historisch nicht einvernehmlich geklärt ist, wer als verwandt gilt (Schütze \& Wagner 1998, 7). Jede Gesellschaft, ob historisch oder modern, regelt die Zugehörigkeit bei der Verwandtschaft selbst. Sie ist in der Regel eindeutig anerkannt, wenn es sich um direkte biologische Abstammung handelt. Dieses beinhaltet Abstammungsbeziehungen, die über mehrere Generationen gehen (Deszendenz) oder innerhalb von Kernfamilien vorliegen (Filiation). Die Kernbzw. Kleinfamilie hat dabei zumeist eine herausragende Bedeutung. Für das Verwandtschaftskonzept innerhalb einer Sozialgemeinschaft unterscheidet man grundsätzlich zwischen unilinearer Deszendenz, d.h. als verwandt gelten Individuen der mütterlichen oder der väterlichen Linie sowie kognater Deszendenz, d.h. als verwandt gelten die Nachkommen beider Geschlechter (z.B. Herrmann et al. 2001). 
Unter dem Begriff Verwandtschaft können aber auch Formen sozialer Beziehungen zwischen Menschen verstanden werden, wie sie z.B. durch Pflege, Adoption oder Heirat entstehen. Diese nichtbiologischen Beziehungen werden als Affinalität oder Affinalverwandtschaften bezeichnet. Die Heirat verbindet dabei Verwandtschaftsgruppen, indem sie Schwägerschaften bildet.

Heirat ist ein soziales und rechtliches Konstrukt. Durch sie wird einerseits die Geburt von Kindern legitimiert und eine sichere Aufzucht ermöglicht, Sie unterliegt andererseits aber auch klaren Vorgaben, wie z.B. die generelle gesellschaftliche Übereinkunft im Inzestverbot (Schütze \& Wagner 1998, 8). Des Weiteren kann Heirat bestimmten Eignungskriterien, wie ethnischer Zugehörigkeit, Sozialstatus und Besitzstand unterliegen (z.B. Gerstenberger 2002, 3). Bei den wohlhabenden Schichten von Bevölkerungen waren Sicherung und Vermehrung des Eigentums wesentlicher Bestandteil verwandtschaftlicher Beziehungen (Rosenbaum 1998, 22). So gibt es gezielte Heiratsstrategien, um Besitzzersplitterung zu vermeiden, politische Macht zu erhalten oder ein soziales Netzwerk aufzubauen.

\subsection{DNA - Typisierungsmarker und Anwendungsbeispiele}

Die DNA-Qualität und die ähnlichen Fragestellungsziele zeigen den Zusammenhang zwischen der forensischen DNA-Analytik und der molekulargenetischen Anthropologie. Im Fokus beider Zugänge liegen die Fragestellungen zur Identifikation, Verwandtschaftsrekonstruktion und Populationsgenetik. Zur Klärung dieser Fragestellungen bedient man sich im Wesentlichen dreier genetischer Marker, welche durch die forensische DNA-Analytik etabliert wurden: (i) autosomale short tandem repeats (Abk. STRs), (ii) mitochondriale DNA (Abk. mtDNA), und (iii) Ychromosomale STRs. Die außerordentliche Aussagekraft dieser Marker zu den oben genannten Anwendungen soll im Folgenden dargelegt werden. Aufgrund der starken methodischen und fragestellungsbezogenen Verknüpfung von Molekularer Anthropologie und Forensik sind Anwendungsbeispiele nicht strikt trennbar und werden daher zusammen besprochen.

(i) Die eindeutige Identifizierung einer Person ist über seinen genetischen Fingerabdruck möglich. Zum Nachweis dieses „Fingerabdrucks“ werden seit 1991 sog. short tandem repeats (Abk. STRs, Edwards et al. 1991) analysiert. Dabei handelt es sich um kurze DNA-Abschnitte, welche durch unterschiedlich lange 
Wiederholungseinheiten (repeat units) von zwei bis sechs Basenpaaren langer Sequenzmotive gekennzeichnet sind (Litt \& Luty 1989). Der längenpolymorphe Bereich eines STR-Locus ist kurz, sodass Fragmentlängen unter 400bp mithilfe der PCR zu amplifizieren sind. Dadurch eignen sich STR-Typisierungen besonders für Analysen an stark degradierter und fragmentierter DNA aus historischem und forensischem Probenmaterial (Edwards et al. 1991).

Seit Einführung der autosomalen STR-Typisierung konnte diese Technik in vielen Fällen helfen, sowohl Opfer als auch Täter, zu identifizieren. Beispielsweise konnten Skelettüberreste dem KZ-Arzt Josef Mengele zugeordnet werden (Jeffreys et al. 1992) sowie die Opfer der Massenexekution in Waco/Texas (Clayton et al. 1995), die Opfer des Terroranschlages am 11.September in den USA (Holland et al. 2003) und die menschlichen Überreste aus den Massengräbern in Bosnien, Kroatien und Herzegowina (z.B. Alonso et al. 2001, Andelinovic et al. 2005) mittels autosomaler STR-Analyse identifiziert werden.

Neben der Identifikation von Personen weisen sich autosomale STRs auch als wertvolle Marker für die Aufklärung direkter biologischer Verwandtschaft, d.h. Eltern-KindBeziehungen, aus. Sie werden kodominant vererbt, weshalb ein Kind jeweils zur Hälfte die genetischen Eigenschaften seiner Mutter sowie seines Vaters trägt.

Aus anthropologischer Sicht konnten in den letzten Jahren Arbeiten, die sich mit der Rekonstruktion von Genealogien historischer und prähistorischer Bevölkerungen beschäftigen, angefertigt werden. Zum einen ist dies im ersten Projekt der Lichtensteinhöhle gezeigt worden (Schultes 2000), zum anderen auch an den Überresten von 38 Individuen aus einem 1500 Jahre altem Fundkollektiv aus Neresheim/Süddeutschland (Scholz et al. 2001) sowie an ca. 1200-5000 Jahre altem Skelettmaterial aus Kirchheim am Ries und Niederstotzingen (Zeller 2000).

(ii) Mitochondriale DNA weist einen uniparental-maternalen Vererbungsweg auf, d.h. sie wird ausschließlich über die mütterliche Linie an die Kinder beiderlei Geschlechts vererbt. Sie liegt gegenüber chromosomaler DNA in einer tausendfach höheren Kopienzahl pro Zelle vor (s.Kap.3.2.2). Die hohe Kopienzahl ermöglicht eine effektive Analyse von mtDNA auch dann noch, wenn sie stark degradiert vorliegt und genomische DNA nicht mehr $\mathrm{zu}$ analysieren ist (Lutz et al. 1996). So konnten beispielsweise mtDNA-Analysen aus 7000 Jahre alten Hirngewebe (Pääbo et al. 1988) und an ca. 5000 Jahre alten Hart- und mumifizierten Weichgewebe (Handt et al. 1994) 
erfolgen. Im Bereich der paläogenetischen Studien konnte die Abstammungsfrage des Neandertalers (z.B. Krings et al. 1997, Ovchinnikov et al. 2000, Schmitz et al. 2002) durch dessen mtDNA-Sequenzmuster geklärt werden. Populationsgenetische Studien an heute lebenden Bevölkerungen werden ebenfalls mithilfe von mtDNA-Analysen durchgeführt. Über Mutationsstudien konnte gezeigt werden, dass alle heute lebenden Menschen von einer afrikanischen Vorfahrin abstammen, welche vor weniger als 200.000 Jahren in Afrika gelebt hat (Cann et al. 1987), d.h. der Ursprung des anatomisch modernen Menschen ist dort $\mathrm{zu}$ sehen. Damit soll das von einem überwiegenden Teil der Paläoanthropologen bevorzugte Modell des ,out-of-africa“ unterstützt werden (z.B. Cavalli-Sforza 1998). Aufbauend auf diesen Studien ist es mithilfe von mtDNA-Analysen möglich geworden Migrationsbewegungen (z.B. Kaestle \& Smith 2001), oder die Abstammung (z.B. Endicott et al. 2003) von historischen Populationen nachzuweisen. Dabei können sich für die Anthropologie Rückschlüsse auf Beziehungen zwischen Bevölkerungen ergeben. Ebenso sind Aussagen zur regionalen Herkunft von Populationen oder Individuen möglich, wie z.B. die Analysen an Hartgeweben des Heiligen Lukas zeigen (Vernesi et al. 2001). Dieses Forschungsbeispiel verdeutlicht auch die Möglichkeit einer Identifizierung über mtDNA-Analysen. Da in der Regel alle Personen der mütterlichen Linie identische mtDNA aufweisen, besitzt sie eigentlich keinen identifizierenden Charakter. In jedem Fall kann jedoch ein Ausschluss erfolgen, wenn die ermittelte Sequenz von der abweicht, welche aus einer Vergleichsprobe vorliegt. Weist eine ermittelte Sequenz jedoch eine Vielzahl charakteristischer Mutationen (=Sequenzpolymorphismen) auf, welche mit einer Vergleichsprobe hundertprozentig übereinstimmt, dann kann mtDNA mit einer signifikanten Wahrscheinlichkeit einen identifizierenden Charakter bekommen. Eine Vergleichsprobe muss dabei nicht immer identisch mit der zu untersuchenden Person sein, denn auch Verwandte mit gleicher mütterlicher Linie können als Vergleichsprobe herangezogen werden (Sullivan et al. 1992). Diese Strategie wurde beispielsweise bei der Identifizierung von Skelettüberresten eines US-Soldaten aus dem Vietnamkrieg verfolgt (Holland et al. 1993). Durch den Vergleich mit heute lebenden maternalen Verwandten konnte auch die Identifizierung der Skelettüberreste von Jesse James gelingen (Stone et al. 2001).

Der uniparentale Erbgang erlaubt es Verwandtschaft über viele Generationen hinweg zu verfolgen, selbst wenn einzelne Bindeglieder fehlen. Die Identität der Zarenfamilie 
Romanov konnte z.B. über die mütterliche Linie zu Prinz Philip von Großbritannien aufgeklärt werden (Gill et al. 1994).

(iii) Genau wie auf den Autosomen befinden sich auf dem Y-Chromosom STRs, welche sich von autosomalen STRs lediglich in ihrem Erbgang unterscheiden (Roewer et al. 1992). Y-STRs werden gekoppelt, d.h. unverändert, vom Vater an den Sohn vererbt. Auf diese Weise lassen sich väterliche Linien bis weit in die Vergangenheit zurückverfolgen. Die gekoppelte Erbinformation des Y-Chromosoms wird auch YHaplotyp genannt. Aus diesem kann jedoch nicht die Generationsfolge abgeleitet werden, da in der Regel kein Unterschied in der Erbinformation einer väterlichen Linie besteht. Ausnahmen der Regel resultieren aus Mutationen (s.Kap.3.2.3). Durch die Analyse von Y-STRs kann streng genommen nur die Zugehörigkeit zu einer Familienlinie oder der Vaterschaftsausschluss erfolgen. Letzteres liegt dann vor, wenn sich die Y-Haplotypen unterscheiden (Kayser et al. 1997). Allerdings gilt auch hier, wie im Fall der mtDNA-Analysen, dass wenn Probe und Vergleichsprobe das gleiche genetische Muster aufweisen, die Wahrscheinlichkeit einer Identifizierung mit Anzahl der untersuchten Genorte steigt. In der Forensik ist in den letzten Jahren die Analyse von Y-STRs zu einer wichtigen Anwendung, z.B. bei Vaterschaftstests oder bei Aufklärungen von Vergewaltigungen (z.B. Prinz et al. 1997), geworden. Darüber hinaus ergeben sich durch den generationsübergreifenden paternalen Vererbungsmodus des YChromosoms Forschungsmöglichkeiten, die auch für anthropologische Fragestellungen interessant sind. Ein klassischer Fall eines Vaterschaftsnachweises wurde von Foster et al. (1998) durchgeführt. Durch den Vergleich von Y-Haplotypen, heute lebender männlicher Familienmitglieder des Amerikanischen Präsidenten Thomas Jefferson, konnte mit hoher Wahrscheinlichkeit nachgewiesen werden, dass ein von seiner Sklavin Sally Hemings 1808 geborenes Kind, das leibliche des Präsidenten war. Des Weiteren konnte u.a. mithilfe einer Y-STR-Analyse die historische Genealogie der Königsfelder Grafen aus dem niederbayrischen Reichersdorf rekonstruiert werden (Gerstenberger et al. 1999). Methoden der klassischen Genealogie können durch die Analyse von Y-STRs erweitert werden. Sykes \& Irven (2000) konnten die Korrelation zwischen YHaplotypen und Familiennamen nachweisen. Dies konnte in Teilen auch für männliche Personen mit dem Familiennamen Zierdt nachgewiesen werden (Trumme et al. 2004). Weiterhin sind Y-STR-Analysen für populationsgenetische Studien geeignet, welche für Europa immer häufiger werden (z.B. Ploski et al. 2002, Roewer et al. 2005, Kayser et 
al. 2005). Über die geographische Verteilung heute nachweisbarer Y-Haplotypen können Populationsbewegungen in historischen Zeiten nachgewiesen sowie die Unterscheidung verschiedener Populationen ermöglicht werden (z.B. Roewer et al. 2001, Roewer et al. 2005). Damit ergeben sich Forschungsmöglichkeiten mit Y-STRs wie sie bereits für mtDNA nachgewiesen sind. Letztendlich kann so die regionale Herkunft eines männlichen Individuums oder einer Population aufgeklärt werden.

\subsection{Residenzverhalten}

Neben der Verwandtschaft kann auch das Residenzverhalten einer Bevölkerung ermittelt werden. Dabei beeinflusst die soziale Organisation der Menschen die genetische Variabilität stark, sodass genetische Informationen verwendet werden können, um Sozialstrukturen zu studieren (Hamilton et al. 2005). Durch den Vergleich der genetischen Variabilität von väterlichen und mütterlichen Mustern kann eine Aussage zum Residenzverhalten in einer Bevölkerung gemacht werden (z.B. Oota et al. 2001). Dabei wird festgelegt, an welchem Ort die neugegründete Familie lebt (Vivelo 1981). Grundsätzlich unterscheidet man zwei Möglichkeiten. Bei Patrilokalität lebt die neugegründete Familie in der Nähe der Familie des Mannes, bei Matrilokalität in der Nähe der Familie der Frau (vgl. Gerstenberger 2002, 8 und Schmidt 2004, 4). Bei Patrilokalität sollte die Variabilität der männlichen Muster geringer sein als die der weiblichen Individuen, d.h. Frauen migrieren in eine bestehende Gruppe. Arbeitshypothesen liegen für beide Modelle vor und werden exemplarisch im Ergebnisteil behandelt. Praktiziertes Residenzverhalten stellt eine wichtige soziale Kenngröße einer Bevölkerung dar und kann bei der Rekonstruktion gesellschaftlicher Regeln der untersuchten Gruppe helfen.

\subsection{Fragestellungen der Arbeit}

Das hier vorgestellte Projekt versucht über die genetischen Analysen abschließend herauszufinden, wie hoch die Individuenanzahl ist und wie viele dieser Individuen sich letztendlich in einen Familienstammbaum eingliedern lassen. Die sich daraus ergebenen Verwandtschaftsverhältnisse werden hinsichtlich der sozialen Organisation der Gruppe analysiert.

Die ermittelte Genealogie soll unter Einbeziehung des archäologischen Kontextes, eine Klärung der Funktionalität des Fundplatzes als Opferplatz oder Bestattungsplatz ermöglichen oder einen Nutzungswechsel anzeigen. 
Die genetischen Untersuchungen an den Individuen sollen, durch den Abgleich ihrer Erblinien mit publizierten Datensätzen, Hinweise zum überregionalen Einzugsgebiet der Gruppe ergeben. Dafür müssen die mütterlichen Linien in die offizielle internationale Nomenklatur eingeteilt und die Y-Haplotypen der Männer in der nötigen Y-STRAnzahl bestimmt werden. Darüber hinaus soll über den internen Vergleich der Variabilität ihrer mütterlichen und väterlichen Linien Aufschluss über das praktizierte Residenzverhalten ermittelt werden.

Durch die Zuordnung der Skelettelemente $\mathrm{zu}$ einzelnen Individuen soll die topographische Verteilung der Skelettelemente in der Höhle aufgezeigt und damit Hinweise zum prähistorischen Eingang und zur zeitlichen Ablagereihenfolge der Toten gefunden werden.

In separaten wissenschaftlichen Projekten sind an den prähistorischen Knochen der Lichtensteinhöhle weitere genetische Untersuchungen, u.a. AB0Blutgruppenbestimmung und Bestimmung der Status der Laktose(in)toleranz, durchgeführt worden. Diese Ergebnisse werden für die Gesamtübersicht des genetischen Archivs Lichtensteinhöhle in einem eigenem Kapitel (Kap.11.2) zusammengefasst. In einigen Fällen konnten diese Analysen bei der Bestätigung schwer nachzuweisender Verwandtschaftsverhältnisse, z.B. Geschwisterschaften, helfen.

Die weiteren praktischen Arbeiten beinhalten die morphologische, histologische und radiologische Befundung der Skelette mit dem Ziel der Atersdiagnose, Körperhöhenschätzung und Identifizierung möglicher Pathologien. Die Ergebnisse werden im Anthropologischen Befund zusammengefasst (Kap.11.1). Der Befund liefert damit Grunddaten, welche für die Verwandtschaftsrekonstruktion und für die Nutzungsart der Höhle von entscheidendem Interesse sind. In den jeweiligen Kapiteln wird darauf verwiesen. Der Anthropologische Befund steht jedoch nicht im Mittelpunkt dieser Arbeit. Er hat deskriptiven Charakter und erhebt nicht den Anspruch auf Vollständigkeit aller anthropologischen Arbeitsmethoden. 


\section{Probenauswahl für die DNA-Analysen}

Die Skelettelemente der Lichtensteinhöhle weisen trotz ihres Alters eine sehr gute DNA-Erhaltung auf. Dies begründet sich in den günstigen Lagerungsbedingungen in der Höhle. Eine Besonderheit ist eine dicke Gipssinterschicht, die wie ein Überzug in der Höhle auf den Knochen liegt (Abb.6). Aufgrund ihrer chemischen Eigenschaften bewirkt sie, in Verbindung mit einer seit tausenden von Jahren gleichbleibend niedrigen Temperatur von $6-8^{\circ} \mathrm{C}$ in der Höhle, konservierende Bedingungen für die Knochen und somit auch für die DNA (Burger et al. 1999). Um die DNA vor weiterer Degradierung zu schützen, wurde der überwiegende Teil der Knochen, mit Ausnahme der Fundnummern der Erstbegehung (E), nach ihrer Bergung aus der Höhle umgehend bei $-20^{\circ} \mathrm{C}$ tiefgefroren.

Die ersten genetischen Analysen an den Knochen aus der Lichtensteinhöhle wurden vorwiegend an DNA-Extrakten durchgeführt, die aus Knochenproben linker Oberschenkelbeine (Femora) hergestellt wurden (Schultes 2000). Zu diesem Zeitpunkt repräsentierte dieses Skelettelement die vermutete Mindestindividuenzahl $(n=36)$ und zusätzlich schloss man so eine Mehrfachbeprobung einzelner Individuen aus. In dieser Beprobungsserie wurden zusätzlich DNA-Extrakte von Zähnen aus sieben Unter- und drei Oberkiefern angefertigt.

In den von Schultes (2000) durchgeführten DNA-Analysen konnten 21 Individuen unterschieden werden. Insbesondere die Typisierungen an den DNA-Extrakten der Zahnproben zeigten dabei nahezu vollständige genetische Profile. Zähne eignen sich besonders gut für die Analyse von degradierter DNA (z.B. Oota et al. 1995, Burger et al. 1997, Alonso et al. 2001). Sie weisen gegenüber Knochen besondere Vorzüge auf. Dentin stellt das härteste menschliche Hartgewebe dar und hält Abbauprozessen besser stand. Des Weiteren sind die Zähne im Kiefer besser vor der Besiedlung von DNAabbauenden Mikroorganismen (z.B. Hummel \& Schultes 2000) und gegenüber exogenen DNA-Kontaminationen geschützt (Montiel et al. 2001). Es erscheint demnach plausibel, dass eine bessere DNA-Erhaltung in Zähnen, die Typisierungsergebnisse weiter verbessern und somit weitere Individuen bestimmt werden könnten.

Zu Beginn der ersten Studie (1998) stellten craniale Skelettelemente jedoch nicht die vermutete Höchstindividuenzahl dar. Im Gegensatz zu den 36 linken Femora konnten z.B. nur 26 Unterkiefer (Mandibulae) beschrieben werden. Seit dem Jahr 2000 wurden 
von den Archäologen in fortführenden Grabungskampagnen weitere craniale Elemente geborgen. Daher wurde zum Anfang dieses Projektes jeder intakte Unterkiefer sowie alle eindeutig $\mathrm{zu}$ identifizierenden Unterkieferfragmente neu aussortiert (Tab.1). Aus den 37 vorliegenden Fundnummern konnten, über den morphologischen Abgleich, die Unterkiefer von 34 Individuen bestimmt werden.

Aus den Unterkiefern wurden Zähne für die DNA-Analyse entfernt. In zwei Fällen (Do38 und DoE39) konnten keine Zähne beprobt werden, da sie postmortal aus dem Kiefer gefallen waren. In diesen Fällen wurde an den Innenseiten der Kiefer eine Knochenprobe genommen. Für die weitere Arbeit werden vereinfachend die Fundnummern aus Tabelle 1 unabhängig ihres Fragmentierungsgrades als Mandibula angesprochen.

Tabelle 1: Übersicht der Probenauswahl von intakten und fragmentierten Mandibulae.

\begin{tabular}{|c|c|c|c|c|c|c|c|}
\hline $\mathrm{Nr}$. & Fund. & Deskription & Probe & $\mathrm{Nr}$. & Fund. & Deskription & Probe \\
\hline 1 & $4 a$ & Intakt & $\mathrm{Z}$ & 20 & 2133 & intakt & $\mathrm{Z}$ \\
\hline 2 & $4 b$ & Ramus rechts fehlt & $\mathrm{Z}, \mathrm{K}$ & 21 & 2263 & intakt & $\mathrm{Z}$ \\
\hline 3 & 38 & intakt, keine Zähne & $\mathrm{K}$ & 22 & 2388 & intakt & - \\
\hline 4 & $87 \mathrm{a}$ & Bereich $42-48$ & $\mathrm{Z}$ & 23 & 2589 & intakt & $\mathrm{Z}$ \\
\hline 5 & $87 \mathrm{~b}$ & Bereich $37-47$, Rami fehlen & $\mathrm{Z}$ & 24 & 2749 & intakt & $\mathrm{Z}$ \\
\hline 6 & $87 \mathrm{c}$ & Bereich $41-48$ & $\mathrm{Z}$ & 25 & 3190 & intakt & $\mathrm{Z}$ \\
\hline 7 & 159 & Bereich $33-45$ & $\mathrm{Z}, \mathrm{K}$ & 26 & 3380 & li. von 36 nach posterior & $\mathrm{Z}$ \\
\hline 8 & 193 & rechter Ramus fehlt & $\mathrm{Z}$ & 27 & 3644 & intakt & $\mathrm{Z}$ \\
\hline 9 & 302 & intakt & $\mathrm{Z}$ & 28 & 3709 & intakt & $\mathrm{Z}$ \\
\hline 10 & 398 & linker Ramus fehlt & $\mathrm{Z}$ & 29 & 3713 & Rami fehlen & $\mathrm{Z}$ \\
\hline 11 & 480 & rechter Ramus fehlt & $\mathrm{Z}$ & 30 & 3746 & intakt & $\mathrm{Z}$ \\
\hline 12 & 934.02 & Bereich $44-48$ & $\mathrm{Z}$ & 31 & 3889 & Bereich $46-48$ & $\mathrm{Z}$ \\
\hline 13 & 1078 & intakt & $\mathrm{Z}$ & 32 & 4003 & linker Ramus fehlt & $\mathrm{Z}$ \\
\hline 14 & 1172 & Intakt & $\mathrm{Z}$ & 33 & 4078 & Intakt & $\mathrm{Z}$ \\
\hline 15 & 1247 & Intakt & $\mathrm{Z}$ & 34 & 4309 & Intakt & $\mathrm{Z}$ \\
\hline 16 & 1482 & Intakt & $\mathrm{Z}$ & 35 & E33 & Intakt & $\mathrm{Z}$ \\
\hline 17 & 1744-1 & Bereich $75-$ ca. 84 & $\mathrm{~K}$ & 36 & E39 & intakt, keine Zähne & $\mathrm{K}$ \\
\hline 18 & $1745 b$ & Bereich $31-38$ und $41-43$ & $\mathrm{Z}$ & 37 & N969 & Intakt & $\mathrm{Z}$ \\
\hline 19 & 2111 & Intakt & $\mathrm{Z}$ & & & & \\
\hline
\end{tabular}

Legende: Beprobung eines Zahnes (Z) und/oder des Knochens (K), - = nicht beprobt

Darüber hinaus wurden Schädel und Schädelfragmente beprobt (Tab.2). Hier wurden, wenn vorhanden, Zähne aus den Oberkiefern (Os maxillae) gezogen. Neben den Zahnproben wurden auch DNA-Extrakte aus Felsenbeinen (partes petrosae) hergestellt. In einem Forschungsprojekt, deren Ziel die Typisierung von Individuen einer 2000 Jahre alten keltischen Fundstelle in Manching war (Schütt 2005), zeigte sich die 
Tendenz, dass dieses Skelettelement eine sehr gute DNA-Erhaltung aufweist. Es wurden sowohl isoliert vorliegende Felsenbeine, als auch aus dem Schädel herauspräparierte Felsenbeine für die DNA-Analysen bearbeitet. Jede aufgeführte Fundnummer wurde mindestens einmal, in der überwiegenden Zahl jedoch doppelt beprobt. Die Abbildung 6 zeigt exemplarisch den Zustand einiger Funde. In weiteren Analysen wurden zusätzliche genetische Typisierungen an bereits bestehenden DNAExtrakten früherer Arbeiten (Schultes 2000 und Schmidt 2004) durchgeführt.

Tabelle 2: Übersicht der Probenauswahl von cranialen Elementen ohne Mandibulae.

\begin{tabular}{|c|c|c|c|c|c|c|c|}
\hline $\mathrm{Nr}$. & Fund & Deskription & Probe & Nr. & Fund & Deskription & Probe \\
\hline 1 & 3 & Felsenbein li. & $\mathrm{F}$ & 17 & $1745 \mathrm{a}$ & Maxilla mit Os zygomaticum & $\mathrm{Z}$ \\
\hline 2 & 46 & Maxilla, Abschnitt 11-18 & $\mathrm{Z}$ & 18 & 1746 I & $\begin{array}{l}\text { Felsenbein re. mit Os } \\
\text { temporale }\end{array}$ & $\mathrm{F}$ \\
\hline 3 & 58 & $\begin{array}{l}\text { Felsenbein li. mit Os temporale } \\
\text { und Abschnitte des Os parietale }\end{array}$ & $\mathrm{F}$ & 19 & 1746 II & $\begin{array}{c}\text { Felsenbein li. mit Os } \\
\text { temporale }\end{array}$ & $\mathrm{F}$ \\
\hline 4 & 65 & Neurocranium & $\mathrm{F}$ & 20 & 3631 & Calvarium & $\mathrm{Z}, \mathrm{F}$ \\
\hline 5 & 71 & Felsenbein li. & $\mathrm{F}$ & 21 & 3705 & $\begin{array}{c}\text { li. Os zygomaticum u. Arci } \\
\text { zygomatica fehlen }\end{array}$ & $\mathrm{Z}, \mathrm{F}$ \\
\hline 6 & 126 & Felsenbein li. & $\mathrm{F}$ & 22 & 3706 & Calvarium & $\mathrm{Z}$ \\
\hline 7 & 152 & Neurocranium & $\mathrm{F}$ & 23 & 3757 & Calvarium & $\mathrm{Z}, \mathrm{F}$ \\
\hline 8 & 900 & $\begin{array}{c}\text { Neurocranium mit Teilen des } \\
\text { Viscerocranium }\end{array}$ & $\mathrm{F}$ & 24 & 3886 & $\begin{array}{c}\text { Felsenbein li. mit Os } \\
\text { temporale }\end{array}$ & $\mathrm{F}$ \\
\hline 9 & 908 & Calvarium & $\mathrm{F}$ & 25 & 5516 & Calvarium & $\mathrm{Z}$ \\
\hline 10 & 910 & $\begin{array}{c}\text { Neurocranium mit Teilen des } \\
\text { Viscerocranium }\end{array}$ & $\mathrm{F}$ & 26 & 5517 & Calvarium & $\mathrm{Z}, \mathrm{F}$ \\
\hline 11 & 918 & Neurocranium & $\mathrm{F}$ & 27 & 6525 & Calvarium & $\mathrm{Z}$ \\
\hline 12 & 1046 & $\begin{array}{c}\text { Calvarium; Maxilla im Bereich } \\
2 \text { nicht vorhanden }\end{array}$ & $\mathrm{F}$ & 28 & E35 & $\begin{array}{c}\text { Felsenbein re. mit Os } \\
\text { temporale }\end{array}$ & $\mathrm{F}$ \\
\hline 13 & 1075 & Calvarium mit isolierter Maxilla & $\mathrm{Z}, \mathrm{F}$ & 29 & E37 & Viscerocranium & $\mathrm{Z}$ \\
\hline 14 & 1176 & Calvarium & $\mathrm{Z}$ & 30 & $\mathrm{R} 1$ & $\begin{array}{l}\text { Os occipitale und Teile des } \\
\text { li. Os parietale fehlen }\end{array}$ & $\mathrm{Z}$ \\
\hline 15 & 1473 & Calvarium & $\mathrm{Z}$ & 31 & $\mathrm{R} 2$ & $\begin{array}{c}\text { Schädelbasis und Os occipitale } \\
\text { beschädigt }\end{array}$ & $\mathrm{Z}, \mathrm{F}$ \\
\hline 16 & 1485 & Calvarium & $\mathrm{Z}$ & 32 & R3 & $\begin{array}{c}\text { Schädelbasis und Os occipitale } \\
\text { nicht vorhanden }\end{array}$ & $\mathrm{Z}$ \\
\hline
\end{tabular}

Legende: Beprobung eines Zahnes (Z) und/oder des Felsenbeines (F)

Insgesamt wurden 69 craniale Funde bearbeitet, aus denen 177 DNA-Extrakte hergestellt wurden. Dabei handelt es sich um 116 DNA-Extrakte aus Zahnpulver, 55 aus Knochenmehl von Felsenbeinen und sechs aus Knochenmehl von Unterkiefern. Nur in einem Fall wurde für einen Unterkiefer (Do2388) kein DNA-Extrakt angefertigt. Bereits vor der Probenentnahme eines Zahnes konnte über den genetischen Fingerabdruck ein Felsenbein (Do1746I), dem bereits von Schultes (2000) und Schmidt (2004) vollständig typisierten Unterkiefer (Do2388), eindeutig zugeordnet werden (s.Kap.5.1). 

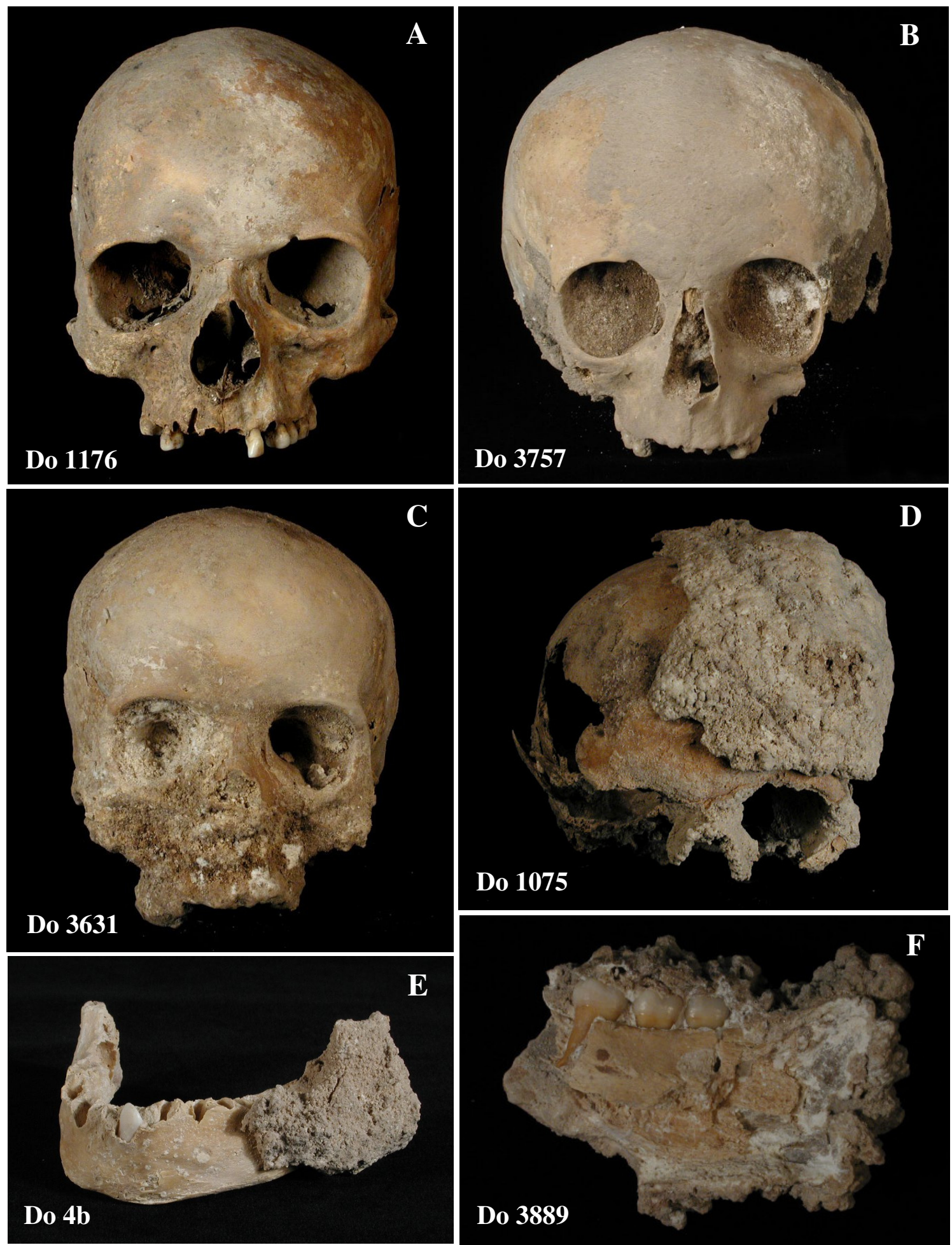

Abbildung 6: Auswahl einiger Funde. Frontalansicht der Schädel (A) einer adulten Frau (Do1176), (B) eines ca. 7 Jahre alten Jungen (Do 3757), (C) einer frühadulten Frau (Do3631) und (D) einer maturen Frau (Do1075). Deutlich ist die beschriebene Gipssinterschicht z.B. auf dem Schädel mit der Fundnummer Do1075 zu sehen. (E) Frontal-lateral-Ansicht des Unterkiefers eines ca. 9-10 jährigen Kindes (Do4b). (F) In Gipssinter eingeschlossenes Mandibularfragment (Do3889) mit Molaren. 


\section{Molekulargenetische Verwandtschaftsanalyse}

\subsection{Strategie}

Vor dem Jahr 1998 gab es keinerlei Hinweise darauf, ob die in der Lichtensteinhöhle gefundenen Individuen in einem verwandtschaftlichen Verhältnis zueinander standen und wenn ja, ob dies für alle, keinen, oder nur für einige Individuen gilt. Schultes (2000) arbeitete eine Strategie aus, mit der innerhalb eines gestörten Fundkollektivs eine molekulargenetische Verwandtschafsrekonstruktion durchführbar ist.

Die Analyse autosomaler STRs dient der Erstellung genetischer Fingerabdrücke, mit welchen der Nachweis direkter biologischer Verwandtschaft, d.h. Mutter-Vater-Kind, erbracht werden kann. Fehlen jedoch Bindeglieder in einem Verwandtschaftsbaum und bilden sich somit Generationslücken, ist mit der Analyse autosomaler STRs die Verwandtschaft einer Großfamilie, mit weiten komplexen Verzweigungen, nicht mehr nachzuweisen.

Wenn innerhalb eines Skelettkollektivs keine Hinweise auf verwandtschaftliche Beziehungen vorliegen, dann ist es erforderlich, nach familientypischen und generationsübergreifenden genetischen Mustern zu suchen, welche variabel genug sind nicht verwandte Individuen abzugrenzen. Dafür bieten sich, wie erwähnt, mütterliche und väterliche Linien an. Die väterlichen Linien sind über die in der Regel unveränderte Vererbung des Y-Chromosoms vom Vater an seine Söhne realisiert. Eine väterliche Erblinie endet somit erst, wenn der Vater ohne biologischen männlichen Nachwuchs bleibt. Mitochondriale DNA weist ebenfalls einen uniparentalen Vererbungsweg auf (z.B. Schwartz \& Vissing 2003). Dieser nicht rekombinante Weg verläuft ausschließlich maternal, d.h. nur über die weibliche Linie. Mütter vererben ihren mtHaplotyp an ihre weiblichen und männlichen Nachkommen (Giles et al. 1980, Jobling et al. 1997), wobei allein die Töchter wiederum ihre mtDNA weitergeben.

Somit lassen sich maternale und paternale Linien bestimmen, welche auch weitläufigere Verwandtschaftsgrade nachweisbar machen. Nach der Zuordnung der Individuen in maternale und paternale Linien kann die genealogische Rekonstruktion anhand der genetischen Fingerabdrücke durchgeführt werden, wodurch nun eine Identifikation der genauen Generationsabfolge möglich wird. Weiterhin ist das biologische Alter der Individuen zu beachten. Vorzugsweise beginnt man bei Kindern, da sie noch nicht im reproduktionsfähigen Alter sind und so Endpunkte eines Stammbaumes bilden. Die 
Angabe der Individualalter der jeweiligen Individuen wird dem Anthropologischen Befund entnommen (Kap.11.1.2).

In Abbildung 7 ist die besprochene Strategie (nach Schultes 2000, Abb.1) dargestellt. Sie konnte von Schultes (2000) innerhalb des ersten Projektes erfolgreich an den Knochen der Lichtensteinhöhle angewendet werden.

\section{Schema für die Verwandtschafts- rekonstruktion}

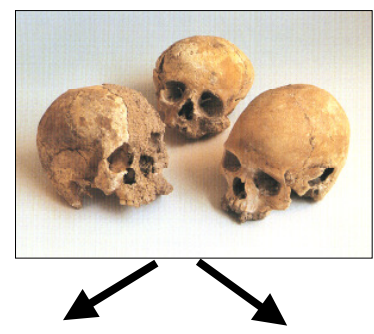

keinen Hinweis auf

Verwandtschaft suchen nach typischen Familienmustern

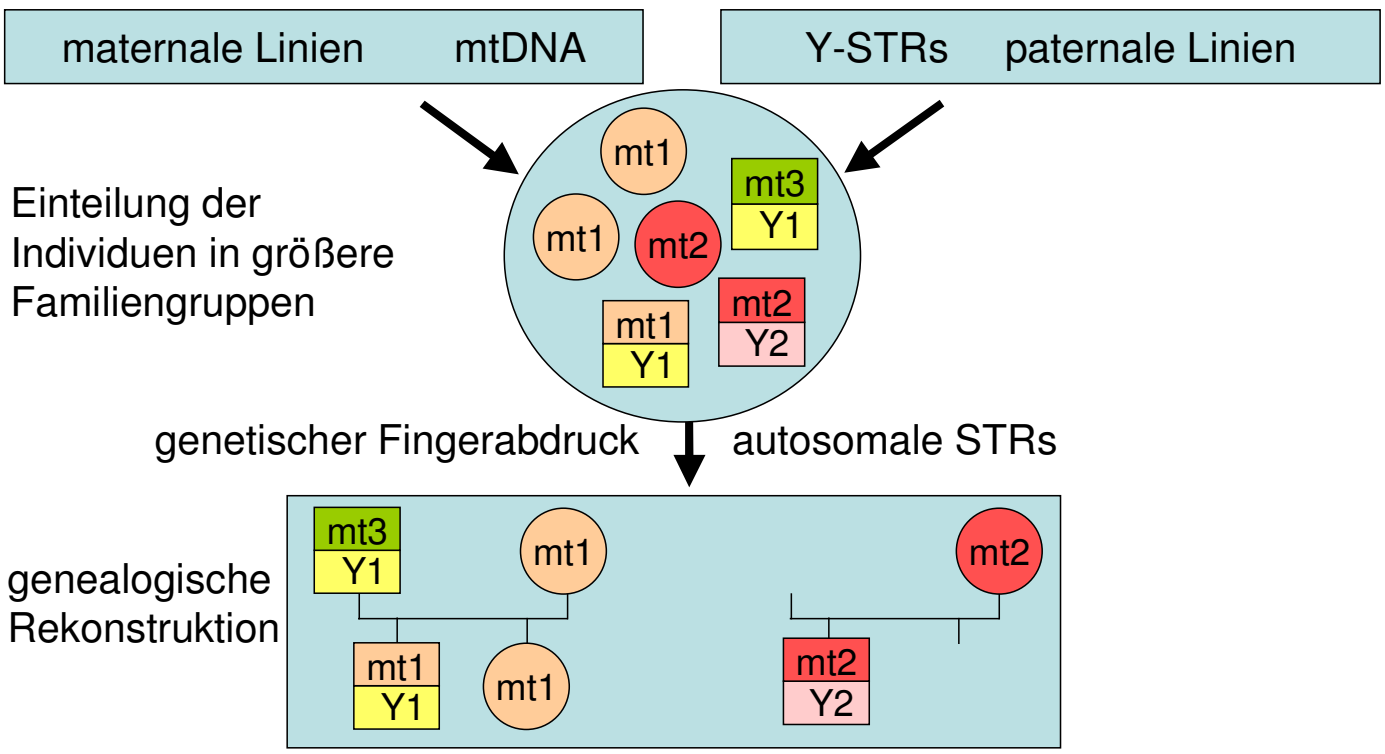

\begin{abstract}
Abbildung 7: Strategie für die Verwandtschaftsrekonstruktion in einem gestörten Kollektivfund (nach Schultes 2000, Abb. 1). Liegt innerhalb eines Skelettkollektivs keine Hypothesen auf konkrete Verwandtschaftsstrukturen vor, empfiehlt es sich alle Individuen nach familientypischen Mustern zu untersuchen. Mithilfe von mtDNA-Analysen (mt1-3) lassen sich maternale (=mütterliche) Linien, mit Y-STR-Analysen (Y1-2) paternale (=väterliche) Linien ermitteln. Beide Verwandtschaftslinien werden in der Regel unverändert vererbt. Dabei wird die mtDNA ausschließlich von den Müttern weitergegeben. Väter hingegen vererben ihr Y-Chromosom an die Söhne. Weisen Individuen die gleiche maternale und/oder paternale Linien auf, liegen Hinweise auf potenzielle Verwandtschaftsverhältnisse vor. Diese Individuen werden in einzelne Gruppen zusammengefasst. Anschließend kann mithilfe autosomaler STR-Analysen (=genetischer Fingerabdruck) eine genealogische Rekonstruktion erfolgen. Über den kodominanten Erbgang der autosomalen STRs lassen sich direkte biologische Verwandtschaften (=Eltern-Kind) nachweisen. Kann keine direkte biologische Verwandtschaft, trotz gleicher Verwandtschaftslinie, bestätigt werden, deutet dies auf weiterführende Verwandtschaftsgrade (z.B. Großelternschaft) hin.
\end{abstract}

Zum Ende der Untersuchungen werden alle männlichen Individuen im reproduktionsfähigen Alter und alle weiblichen Individuen über ihre genetischen 
Fingerabdrücke auf mögliche Vater-Tochter-Relationen überprüft. Diese Verbindungen können über die maternalen bzw. paternalen Linien nicht ersehen werden. Schmidt (2004) typisierte im Rahmen ihrer Arbeit u.a. eine Reihe der Lichtensteiner Individuen mittels X-chromosomaler STRs. Für die Verwandtschaftsanalysen stellen diese ein nicht unerhebliches Potential dar. Ziel war die Überprüfung sog. Vater-Tochter-Dyaden, aber auch möglicher Geschwisterschaften. Der Vater vererbt nur an seine Töchter sein X-Chromosom. Die X-STRs werden bei Männern wie Y-chromosomale STRs gekoppelt, d.h. unverändert an die Nachkommenschaft weitergegeben, weshalb sein XHaplotyp bei den Töchtern vorliegen muss. Für weibliche Geschwister kann daher über die X-STR-Analyse ein möglicher gemeinsamer Vater ermittelt und somit deren Geschwisterschaft weiter gesichert werden. Weitere Details zu diesen Untersuchungen sowie zu X-STRs im Allgemeinen sind bei Schmidt (2004) nachzulesen. Für die weitere Verwandtschaftsanalyse werden diese Daten mit einbezogen.

Für die Verwandtschaftsanalyse wurde unterstützend die Computersoftware „aDNATyping“ (Fa. MoReData, Gießen) verwendet. Diese wurde speziell für eine Arbeit zur Ermittlung von Heiratsmustern konzipiert (Gerstenberger 2002). Mit dieser Software ist es möglich, über den Abgleich eingegebener Datensätze, Übereinstimmungen oder Ähnlichkeiten der Allelprofile sowie mögliche Eltern-Kind-Beziehungen aufzudecken.

\subsection{Die genetischen Marker}

Im Folgenden werden die genetischen Marker, welche für die Verwandtschaftsanalyse verwendet werden, detailliert vorgestellt. Die in diesem Kapitel aufgezeigten Informationen, z.B. Mutationsraten und Haplotypen, sind für die Verwandtschaftsrekonstruktion und für die Analysen zur regionalen Herkunft von großer Bedeutung.

\subsubsection{Autosomale STRs und der genetische Fingerabdruck}

Im Laufe der Jahre wurden über alle Chromosomen verteilt STRs gefunden, welche zur Bestimmung eines genetischen Fingerabdrucks verwendet werden können. Wichtige Grundbedingungen für die Eignung eines STR-Locus ist im Wesentlichen die 
Heterozygotenrate, ein gesicherter Erbgang (d.h. ungekoppelt), ein geringes Vorkommen von Stotterbanden (Urquhart et al. 1994) und eine möglichst geringe Mutationsrate (Schlenk et al. 2004). Die Heterozygotenrate eines STR-Locus ist determiniert durch die Anzahl seiner Allele und deren Frequenzen innerhalb einer Population und die Allele eines STR-Locus nach der Anzahl ihrer Wiederholungseinheiten.

Anfänglich wurde die Bestimmung von STRs in Einzelreaktionen, d.h. im SingleplexVerfahren, durchgeführt (van Oorschot et al. 1994). Durch den technologischen Fortschritt und der besseren Reaktionskomponenten konnten die Analysen bald darauf im sog. Multiplex-Verfahren analysiert werden (Kimpton et al. 1993). Dabei werden mehrere STRs simultan in einer Reaktion amplifiziert. Dies hat den Vorteil, dass sehr viel weniger Probenmaterial benötigt wird (Hummel et al. 1999a) und dass mit steigender STR-Anzahl die Wahrscheinlichkeit verringert wird, dass ein zweites nicht verwandtes Individuum weltweit das gleiche Muster im genetischen Fingerabdruck aufweist. Diese Wahrscheinlichkeit wird auch als sog. matching probability bezeichnet (Abk. $\mathrm{P}_{\mathrm{M}}$, Brenner 1993). Grundlage für die Berechnung der $\mathrm{P}_{\mathrm{M}}$ sind die Allelfrequenzen der STR-Loci. Diese können für verschiedene Populationen beispielsweise der Internet DNA-Datenbank der Universität Düsseldorf (http://www.uni-duesseldorf.de/WWW/MedFak/Serology/dna.html, 20.01.06) entnommen werden. Die Einzelwahrscheinlichkeiten aller untersuchten STR-Loci werden multipliziert, um die $\mathrm{P}_{\mathrm{M}}$ zu berechnen. Bei der simultanen Analyse von sieben STRs beträgt die matching probability bereits $10^{-8}$ (Urquhart et al. 1995).

Die internationale Vergleichbarkeit der Daten wird durch die Verwendung einheitlicher STRs in nationalen STR-Datenbanken gewährleistet. Das Combined DNA Index System (Abk. CODIS; Budowle et al. 1998) ist eine vom FBI geführte DNA-Datenbank, welche eine Identifikation von Straftätern mithilfe von STR-Analysen ermöglicht (Budowle et al. 1999). In Deutschland wurde 1998 die DNA-Analyse-Datei (Abk. DAD) als Verbunddatei beim BKA eingeführt. Die in den Datenbanken geführten STR-Systeme erfüllen eingangs genannte Kriterien und sind Bestandteil vieler handelsüblicher Typisierungskits, wie z.B. der in diesem Projekt u.a. angewendete AmpFlSTR ${ }^{\circledR}$ Profiler Plus $^{\mathrm{TM}}$ PCR Amplification Kit (PE Applied Biosystems). Die deutsche Datenbank DAD umfasst gegenwärtig acht, CODIS 13 STR-Systeme. Werden die 13 Kern-Loci von CODIS zusammen in einer Multiplex-PCR typisiert, ergibt sich eine durchschnittliche $\mathrm{P}_{\mathrm{M}}$ von $1 \times 10^{-12}$ bei nicht miteinander verwandten Personen (Chakraborty et al. 1999). 
Mit dem Profiler Plus ${ }^{\mathrm{TM}}$ Kit wird eine $\mathrm{P}_{\mathrm{M}}$ von ca. $1 \times 10^{-11}$ (Applied Biosystems, Profiler Plus $^{\mathrm{TM}}$ User Manual) erreicht, wodurch eine sichere Individualisierung der Proben gewährleistet ist. Auf diese Weise kann für jedes Individuum, auch für die nah verwandten der Lichtensteinhöhle, jedoch mit Ausnahme eineiiger Zwillinge, weltweit ein einzigartiger genetischer Fingerabdruck ermittelt werden. Aus den genetischen Fingerabdrücken lassen sich die Eltern-Kind-Verwandtschaften deutlich ableiten, da das Kind je die Hälfte des Chromosomensatzes seiner Eltern erbt. Weicht dies in einem Locus ab, könnte dies an einem Mutationsereignis während des Allel-Transfers zwischen Eltern und Kind liegen. Eine Möglichkeit dafür ist ein slippage Ereignis während der Replikation in der Meiose (z.B. Kayser et al. 1997a, Brinkmann et al. 1998a). Die Häufigkeit eines Mutationsereignisses ist abhängig von der repeat Struktur eines Locus und der Anzahl seiner Allele (Brinkmann et al. 1998a). Des Weiteren konnte festgestellt werden, dass von Männern eine höhere Mutationsfrequenz ausgeht als von Frauen (Brinkmann et al. 1998b). In etwa 90\% der Fälle handelt es sich bei einer Mutation um ein single-step Ereignis, d.h. eine Längenvariation um eine Wiederholungseinheit (z.B. Brinkmann et al. 1998a). Vereinzelt kann es aber auch zu Mutationen kommen, welche zwei oder mehr Wiederholungseinheiten umfassen. In der Regel ist eine Zunahme von Wiederholungseinheiten wahrscheinlicher als deren Verlust (z.B. Brinkmann et al. 1998a, Dupuy et al. 2004, Gusmao et al 2005b). Die Mutationsrate autosomaler STRs kann bei $7 \times 10^{-3}$ liegen (Brinkmann et al. 1998a). Beträgt die durchschnittliche Mutationsrate für ein STR ca. 0,1\%, sollten mindestens 1000 Allelübertragungen zwischen Eltern-Nachwuchs-Konstellationen beobachtet werden, bis ein Mutationsereignis auftritt (vgl. Butler 2001, 94).

Auf STR spezifische Hintergrundinformationen soll in dieser Arbeit nicht weiter eingegangen werden. Zur Übersicht werden hier Referenzen angegeben um ein Nachschlagen bestimmter Sachverhalte, z.B. der Nomenklatur, zu ermöglichen.

Die wichtigsten Daten (fact sheets) für autosomale STR-Loci können der Short Tandem Repeat DNA Internet DataBase (Abk. STRbase; http://www.cstl.nist.gov/div831/strbase/; Ruitberg et al. 2001) entnommen werden. Hierbei handelt es sich u.a. um Literatur, Erstbeschreiber, Lage auf dem Chromosom, Referenzallele und Repeatmotiv nach Vorgabe der DNA Commission of the International Society for Forensic Genetics (Abk. ISFG; Bär et al. 1997). Die systematische Nomenklatur der STRs ist detailliert beschrieben u.a. in Butler 2001, die 
Definition und Nomenklatur der Sequenzmotive der repeat units z.B. in Urquhart et al. (1994) und Gill et al. (1995).

\subsubsection{Mitochondriale DNA, Haplotypisierung und Haplogruppen}

Die Menge an Mitochondrien in einer tierischen Zelle ist abhängig von deren Energiebedarf. Je mehr Energie eine Zelle benötigt, desto höher ist deren Anzahl und kann so mehrere Tausend pro Zelle betragen (z.B. Herzmuskelzelle). Des Weiteren kann ein Mitochondrium in seinem Matrixraum mehrere DNA-Moleküle (bis in den zweistelligen Bereich) enthalten. Während es nur einen Zellkern pro Zelle gibt, d.h. zwei Kopien für jeden nuklearen Locus, liegen hier bis zu mehrere tausend Kopien mtDNA vor (Robin et al. 1988). Durch die Menge der Mitochondrien und deren Lage frei im Zytoplasma ist eine erfolgreiche DNA-Extraktion meist noch effektiv, wenn chromosomale DNA nicht mehr nachzuweisen ist. Das bedeutet jedoch nicht, dass mtDNA Degradierungsphänomenen schwächer ausgesetzt ist. Vielmehr ist chromosomale DNA durch die Kernmembran sowie durch DNA schützende Histone, vor degradierenden Einflüssen besser geschützt.

Anderson et al. (1981) gelang es das mitochondriale Genom vollständig zu sequenzieren. Innerhalb der 16569bp konnte ein 1122bp Bereich ausgemacht werden, der nicht codierend und sich als hoch polymorphe Region, d.h. schnell evolvierend, auswies. Dieser Bereich wird als D-Loop oder auch als Kontrollregion bezeichnet. Die größte Sequenzvariabilität weisen dabei zwei etwa 400bp lange Bereiche auf, welche als hypervariable Region I und II bezeichnet werden (Abk. HVR I \& HVR II; Stoneking et al. 1991). Die Variabilität entsteht durch Sequenzpolymorphismen (=Punktmutationen) die in der mtDNA zehnmal schneller fixiert werden als bei den entsprechenden Sequenzen im Kerngenom (Brown et al. 1979). Die genaue Mutationsrate für die HVRBereiche ist nicht einvernehmlich geklärt (Pakendorf und Stoneking 2005). Sie ist jedoch höher als im restlichen mitochondrialen Genom und wird, in Abhängigkeit der Arbeitsgruppe, mit 0,075 bis $0,165 \times 10^{-6}$ Substitutionen/Stelle/Jahr angegeben (in Pakendorf und Stoneking 2005, 168).

Von der ISFG wurden, für die Labore, zu deren Standardverfahren die Analyse von mtDNA gehört, Empfehlungen zur Nomenklatur dieser Polymorphismen ausgesprochen (Bär et al. 2000). Ziel dieser Empfehlungen ist es Variationen im mitochondrialen Genom darstellen zu können und vergleichbar zu machen. Der Empfehlungskatalog beinhaltet, neben der Qualitätssicherung und -kontrolle, u.a. die Nomenklatur. Dabei 
wird als Referenzsequenz die von Anderson (1981) ermittelte Sequenz (= Cambridge Reference Sequence; Abk. CRS) als Vergleich herangezogen.

Abweichungen, die im Bezug auf CRS bestehen, können so, nach international standardisierten Vorgaben, benannt werden. Eine Abweichung wird durch deren Nukleotidposition (Abk. np) und ihrer Base angegeben, d.h. tritt beispielsweise an $n p$ 16304 ein Cytosin, anstatt der in CRS realisierten Base Thymidin, auf, wird sie als 16304C angegeben. Eine Deletion wird durch Angabe der np und einem D (z.B. 71D), die Insertion einer Base wird mit einem Punkt nach der Position der regulären Base plus der Angabe um welche und wie viele Insertionen es sich handelt (z.B. 315.1C) beschrieben. Weitere Empfehlungen können u.a. bei Bär et al. 2000 nachgeschlagen werden.

Familienlinienspezifische Sequenzpolymorphismen im mt-Genom werden als mtHaplotypen bezeichnet und wie ein Locus behandelt. Eine definierte Anzahl stabiler Sequenzpolymorphismen in der Kontrollregion humaner mitochondrialer DNA werden als mt-Haplogruppen bezeichnet.

\section{Haplogruppen}

Neben den Analysen zur Identifikation und Verwandtschaftsrekonstruktion sind Untersuchungen an mtDNA für populationsgenetische Untersuchungen vom hohen Interesse. Solche Studien versuchen die Historie von Populationen in Hinblick auf ihr Migrationsverhalten (z.B. „Woher stammt die Bevölkerung Europas?“) und ihre Ausbreitung (,Besiedlungszeitpunkt?“) aufzuklären. Diese Fragestellungen können durch den Vergleich der weltweit vorkommenden mt-Haplogruppen aufgeklärt werden. Der Ursprung des Menschen liegt in Afrika, von wo aus er sich über die Welt ausbreitete. Mit der Zeit kam es innerhalb der HVR zu Mutationsereignissen, die zu hoher Diversität der mtDNA führte. Dabei können ganz charakteristische Sequenzpolymorphismen bestimmt werden, die spezifisch für eine Haplogruppe sind. Richards et al. (1998) und Macaulay et al. (1999) schlagen für diese Haplogruppen eine kladistische hierarchische Notierung mit Gruppen und Untergruppen vor. Diese bezieht sich neben RFLP-Schnittstellen im gesamten mtDNA-Genom, auch auf die Sequenzabschnitte der HVR I \& II. Da zum gegenwärtigen Zeitpunkt weltweit nicht genügend Datensätze vorhanden sind, die sich auf das gesamte mt-Genom beziehen, werden die Haplogruppen hauptsächlich über die Sequenzvariabilität von HVR I \& II eingeteilt. Dennoch gilt der Abgleich des gesamten Genoms aufgrund der höheren 
Aussagekraft als längerfristiges Ziel (Richards et al. 1998). Eine Amplifikation des gesamten mt-Genoms der „Lichtensteiner Individuen“ ist schon aufgrund der zu erwartenden starken DNA-Degradierung und der nötigen Probenmenge nicht möglich. Aus diesem Grund erfolgte die Zuordnung von den Haplogruppen ebenfalls auf Grundlage der HVR I \& II Daten. Die Mehrzahl der Haplogruppen sind kontinentspezifisch (Torroni et al. 1996). In Afrika weisen beispielsweise über 70\% der Bevölkerung die Haplogruppe L auf (z.B. Chen et al. 1995), während für Ost-Eurasien die Haplogruppen M und N ihre Hauptverbreitung haben (z.B. Derenko et al. 2003) und bei den amerikanischen Ureinwohnern ausschließlich A,B,C und D vorkommen (z.B. Mulligan et al. 2004). Innerhalb Westeuropas konnten sieben übergeordnete Haplogruppen identifiziert werden, die mit H, U, J, X, K, T und V bezeichnet werden (z.B. Macaulay et al. 1999) und in welche sich ca. 95\% aller endemischen Europäer einordnen lassen. Abbildung 8 gibt eine Übersicht über die mtDNAMigrationsbewegungen und die kontinentspezifischen Haplogruppen. Diese Abbildung entstammt der mtDNA-Datenbank mitomap.

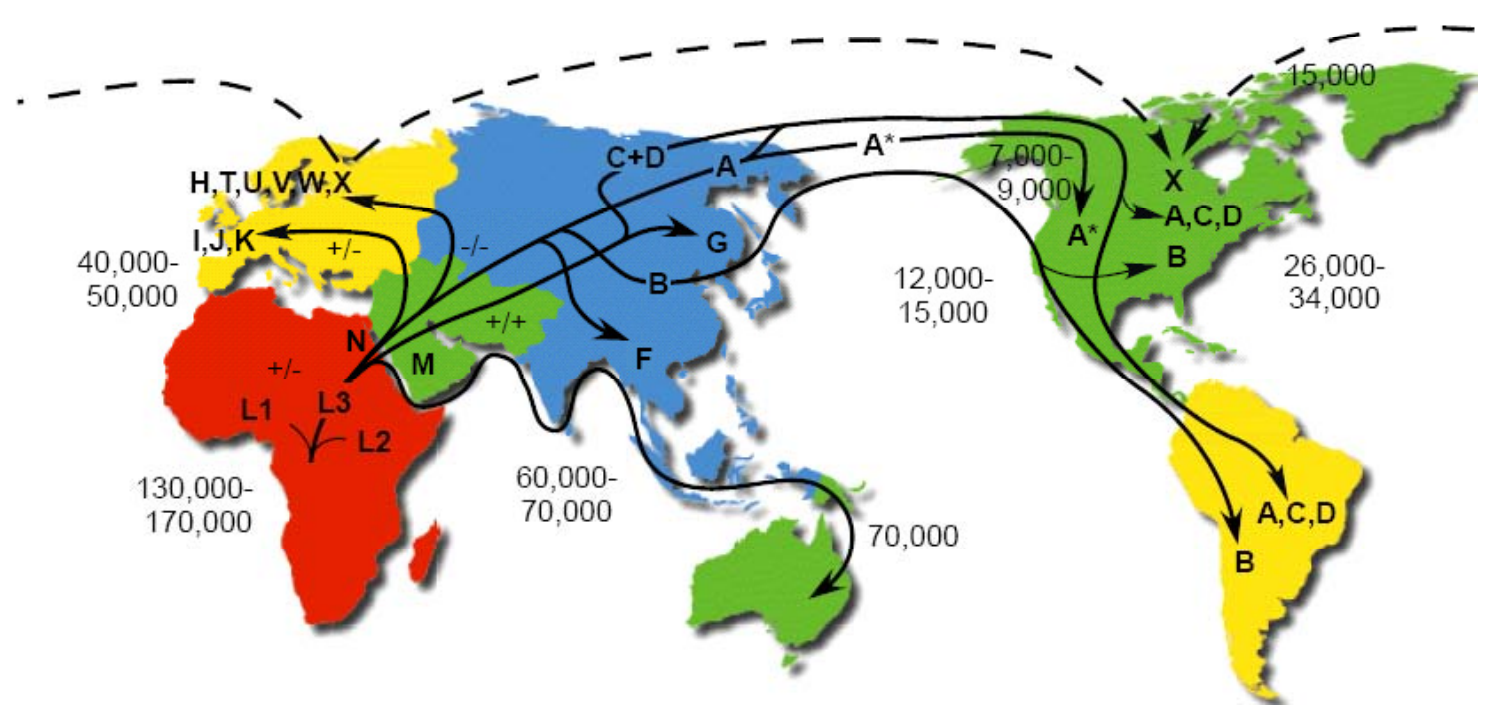

Abbildung 8: mtDNA-Migrationsbewegungen (aus http://www.mitomap.org/mitomap/ WorldMigrations.pdf, 20.01.06). Der Ursprung des anatomisch modernen Menschen liegt in Afrika. Die Wanderungsbewegungen können anhand der mtDNA nachgewiesen werden. Die Zahlen geben an zu welchen Zeiträumen die Regionen besiedelt wurden. Die Buchstaben bezeichnen die mtHaplogruppen, +/- sowie * beschreiben definierte Enzymschnittstellen im mt-Genom.

Die älteste für Europa spezifische Haplogruppe ist U5 (Richards et al. 1998). Mit einem Alter von ca. 50.000 Jahren lässt sie sich dem Frühen Oberen Paläolithikum zuordnen und ist damit die einzige Haplogruppe, welche Europa mit den ersten Siedlern aus dem Nahen Osten erreichte. Im letzten glazialen Maximum vor 20.000 Jahren gab es einen sog. ,founder effect“ oder ,bottleneck“ aus welcher die größte noch vorkommende 
Fraktion der Haplogruppen herrührt (Richards et al. 2000). Diese Haplogruppen (H, X, K, T, V) sind altersdatiert auf 14-11.000 v.Chr. und gehören somit in das Späte Obere Paläolithikum. Haplogruppe $\mathrm{J}$ ist datiert auf $8.500 \mathrm{Jahre} \mathrm{v.Chr.} \mathrm{und} \mathrm{ist} \mathrm{damit} \mathrm{die} \mathrm{Jüngste}$ der sieben und die einzige Haplogruppe die im Neolithikum entstand (Sykes 1999). Ihre Verbreitungsroute, an der mediterranen und atlantischen Küste und durch die Flusstäler Europas, könnte ein Hinweis auf die neolithischen Farmer sein (Sykes 1999). Jedoch kommen durch neuere mtDNA-Analysen an Skeletten neolithischer Fundorte Zweifel daran auf, ob Vorfahren der heute lebenden Menschen tatsächlich Abkömmlinge der frühen neolithischen Farmer sein können (Haak et al. 2005).

Die Alter der Haplogruppen sollen mithilfe einer kalibrierten Mutationsrate, der sog. molecular clock, datiert werden können. Bei diesen Altersschätzungen werden Neumutationen, die man in der Sequenzabfolge finden kann, untersucht. Die Rate der Neumutation soll dabei konstant sein. Die molecular clock benennt somit den Zeitraum, in dem sich, ausgehend von einer einzigen Ur-Sequenz, Mutationen angesammelt haben. Das Verfahren der molecular clock wird jedoch kontrovers diskutiert. Kritiker warnen davor, z.B. aufgrund der Komplexität der DNA-Substitutionen, eine streng metronomische Uhr anzunehmen. Die Kontroverse soll jedoch nicht weiter Gegenstand dieser Arbeit sein. Für genauere Informationen zur molecular clock vgl. Lowe et al. (2004, 176-177). Ist die Sequenzvielfalt innerhalb einer Haplogruppe groß und weist sie eine große Zahl von Untergruppen auf, ist die Population älter als eine, deren Anzahl an Untergruppen klein ist.

Eine Übersicht über die europäischen Haplogruppen und ihre charakteristischen Punktmutationen gibt Tabelle 3. Nicht zweckdienlich ist es hier eine Liste der jeweiligen Untergruppen zu erstellen, da diese zu umfangreich wäre. Die Untergruppen können in der jeweiligen Literatur nachgeschlagen werden (z.B. Richards et al. 2000). Untergruppen werden im Ergebnisteil vorgestellt, wenn sie bei Individuen der Lichtensteinhöhle analysiert werden.

Tabelle 3: Mitochondriale Haupthaplogruppen in Europa und deren charakteristische Sequenzpolymorphismen in Bezug auf die CRS (nach Richards et al. 1998, 247).

\begin{tabular}{|c|l|c|c|}
\hline mt-Haplogruppen & Punktmutation [np] & mt-Haplogruppen & Punktmutation [np] \\
\hline $\mathbf{H}$ & - & $\mathbf{J}$ & $73,16069,16126$ \\
\hline $\mathbf{V}$ & 16298 & $\mathbf{T}$ & $73,16126,16294$ \\
\hline $\mathbf{U}$ & 73 & $\mathbf{X}$ & $73,16223,16278$ \\
\hline $\mathbf{K}$ & $73,16224,16311$ & & \\
\hline
\end{tabular}


Für die Haplogruppe $\mathrm{H}$ wird in Europa eine generelle Häufigkeit von ca. 50\% angegeben (z.B. Richards et al. 1998, Richards et al. 2002). Die Angaben über die Häufigkeiten der anderen Haplogruppen variieren in Abhängigkeit von der Untersuchungsregion. Für einen Überblick werden hier prozentuale Häufigkeiten von Richards et al. (1998) genannt. Demnach weisen 4\% der Europäer die Haplogruppe V auf, die Frequenz der Haplogruppe J beträgt ca. $11 \%$ und die von $\mathrm{K}$ ca. $7 \%$. Haplogruppe X kommt dagegen in Europa seltener vor, ihre Häufigkeit wird mit ca. 2\% angegeben. Die Haplogruppe U setzt sich aus vielen Untergruppen zusammen, deren häufigsten Gruppen U5 mit ca. 7\% (Richards et al. 1998) und U4 mit ca. 3\% (Richards et al. 2000) sind.

\subsubsection{Y-STRs und Haplotypisierung}

Aufgrund der geringen Aussagekraft nur eines Y-STRs sollten zur Bestimmung eines Y-Haplotyps möglichst viele polymorphe Loci simultan untersucht werden (Butler et al. 2002, Bosch et al. 2002). Heute sind auf dem Y-Chromosom über 200 Y-STRs bekannt (Kayser et al. 2004). Die internationale Forschungsgemeinschaft einigte sich auf neun Y-STRs (DYS19, DYS389I, DYS389II, DYS390, DYS391, DYS392, DYS393, DYS385 a und b; das System DYS385 besteht aus zwei unabhängigen Loci), die überwiegend für die Y-Haplotypisierung analysiert werden. Diese neun Y-STRs bilden den sog. „minimal haplotype“ (Abk. minHt, Roewer et al. 2001) und erwiesen sich alle als hoch polymorph (Kayser et al. 1997a). Der minHt ermöglicht in Kombination den Abgleich internationaler Ergebnisse für vergleichende populationsgenetische Analysen (Kayser et al. 1997a) und ist aufgrund seiner forensischen Unterscheidungsmöglichkeit für die europäischen Gerichte zugelassen (Pascali et al. 1999). Die Analyse dieser neun Y-STRs ermöglicht die Differenzierung von ca. 70-90\% der europäischen männlichen Individuen (Kayser et al. 1997b). Für eine höhere Diskriminierungsrate sorgt der „extended haplotype“ (Roewer et al. 2001). Zusätzlich werden hier die Y-STR loci DYS438 und DYS439 untersucht. Der extended haplotype wird von der Scientific Working Group on DNA Analysis Methods (Abk. SWGDAM) vorgeschlagen (Krenke et al. 2005).

Die ISFG empfiehlt einen Katalog für Nomenklatur, Umgang mit Mutationsereignissen und Auswahlkriterien von Y-STRs (Gill et al. 2001 und Gusmão et al. 2005a). Weitere Informationen, wie z.B. Mutationsraten, Repeatstruktur, Allelvorkommen und 
Populationsanalysen, können den international anerkannten und öffentlichen websites der Y Chromosome Haplotype Reference Database (Abk. YHRD, http://www.yhrd.org/index.html, 20.01.06) und, wie im Bezug auf die autosomalen STRs, der STRbase entnommen werden.

Die genaue Interpretation von Mutationsraten bei Y-STRs ist für Vaterschaftsanalysen und für forensische Anwendungen wichtig. Darüber hinaus sind populationsgenetische Studien ebenfalls abhängig von locusspezifischen Mutationsraten (Kayser et al. 2000). Bei Y-STRs konnten keine signifikanten Unterschiede für Mutationsmechanismus und -rate gegenüber autosomalen STRs festgestellt werden (Kayser et al. 2000, Gusmão et al. 2005b). Ihre durchschnittliche Mutationsrate beträgt ca. $2 \times 10^{-3}$ (Kayser et al. 2000, Gusmão et al. 2005b). Dabei kann z.B. ein höheres Individualalter der Männer bei der Reproduktion eine Zunahme der Mutationswahrscheinlichkeit mit sich bringen (Gusmão et al. 2005b). Mutationsereignisse modifizieren die Y-Haplotypen (Kayser et al. 1997) und sind letztendlich für die Entstehung der unterschiedlichen Y-Haplotypen verantwortlich (z.B. Gusmão et al. 2005b).

\subsection{Elternschaftswahrscheinlichkeit}

Die Wahrscheinlichkeitsberechnungen von Elternschaften basieren auf den Allelfrequenzen rezenter, nichtverwandter Individuen und Populationen. Dabei werden die $\mathrm{zu}$ untersuchenden Personen mit ihrer Herkunftspopulation verglichen. Die Verwendung rezenter Allelfrequenzen könnte bei der Berechnung der Elternschaftswahrscheinlichkeiten in der bronzezeitlichen Gruppe zu Abweichungen in den Wahrscheinlichkeitswerten führen. Dies könnte dann vorliegen, wenn die Allelfrequenzen aus der heutigen Zeit stark von denen der Bronzezeit abweichen würden. Die Wahrscheinlichkeitsberechnungen der Elternschaften in der Lichtensteinhöhle sollten demnach mit Allelfrequenzen einer größeren Population aus gleicher Zeitstellung, z.B. aus der Unstrut-Kultur, geschehen. Zurzeit gibt es jedoch keine Erhebungen über Allelfrequenzen zeitstellungsähnlicher Populationen. Theoretisch könnten die Allelfrequenzen aus der zu untersuchenden Population selbst ermittelt werden. Dafür sollten jedoch die Individuen nicht verwandt sein, da sonst nicht sichergestellt werden kann, dass die Ausgangsvoraussetzungen für die Erhebung von Populationsdaten erfüllt sind (z.B. Schultes 2000). Des Weiteren können diese Berechnungen durch aDNA-Degradierungsartefakte, z.B. allelic dropout (s.Kap.4.4), 
beeinflusst werden, da die Nichtamplifikation von Allelen in den STR-Loci zu falschen Frequenzen führen (Bramanti et al. 2000).

An einer Skelettserie aus dem 18 Jhd. (Goslar/Niedersachsen) sowie an einer aus den 5.8. Jhd. (Weingarten/Baden-Württemberg) konnte gezeigt werden, dass die historischen Kollektive gegenüber rezenten Populationen keine signifikanten Abweichungen der Allelfrequenzen aufweisen (Bramanti et al. 2000, Gerstenberger 2002). Damit kann für das bronzezeitliche Skelettkollektiv angenommen werden, dass die Allelfrequenzen der Individuen aus der Lichtensteinhöhle, wenn überhaupt, nur unwesentlich von denen rezenter Bevölkerungen abweichen. Ein Hinweis darauf, dass keine Abweichung vorliegt, ist die ermittelte Allelvariabilität, welche in gleicher Weise bei rezenten Bevölkerungen vorliegen.

Chakraborty et al. (1999) untersuchten in einer Studie mit 13 autosomalen STRs die genetische Variabilität in sieben rezenten Populationen, u.a. auch die einer Population amerikanischer Ureinwohner (Apache). Die Studie zeigt, dass die Allelsegregation für diese Population hoch ist (ca. 8.0-10.1 per Locus) und dass die STR-Loci auch hier hochpolymorph sind. Darüber hinaus unterscheiden sich die Allelmuster zwischen den untersuchten Populationen nicht bezüglich ihrer Häufigkeit bzw. Seltenheit. Festgestellt wurde, dass die Population der amerikanischen Ureinwohner zwar die geringste genetische Variabilität der sieben untersuchten Populationen aufweist, jedoch zeigen die Wahrscheinlichkeitsberechnungen, dass selbst mit einer geringeren Variabilität, die $\mathrm{P}_{\mathrm{M}}$ bei 1 in einer Trillion liegt und dass so für Elternschaftswahrscheinlichkeiten Werte bis $\mathrm{zu} 99,81 \% \mathrm{zu}$ erzielen sind. Aus diesem Grund hat eine geringere genetische Variabilität der Individuen aus der Lichtensteinhöhle keinen entscheidenden Einfluss auf die Wahrscheinlichkeitsberechnungen der Elternschaften.

In der Regel stehen bei Verwandtschaftsanalysen Probenmaterialien der Mutter, des Kindes und eines möglichen Vaters (= Putativvater) zur Verfügung. In der Regel wird ein Ausschluss vorgenommen, wenn ein Putativelternteil eine Abweichung in einem STR-System zum Kind aufweist. Für gerichtsmedizinische Fälle wird dagegen eine Vaterschaft erst dann ausgeschlossen, wenn Abweichungen in mindestens zwei STRLoci vorliegen (Kratzer \& Bär 1997). In den Fällen, in denen ein eindeutiger Ausschluss vorliegt, werden keine Wahrscheinlichkeiten errechnet. Erfüllt beispielsweise der Vater genau 50\% des Profils des Kindes, wird die Vaterschaftswahrscheinlichkeit berechnet. Dies geschieht mithilfe eines Likelihoodquotienten, dem sog. Paternitätsindex (engl. 
paternity index, PI). Nach Brenner (1993) werden dabei zwei Hypothesen miteinander verglichen und zwar, ob der Putativvater der tatsächliche leibliche Vater ist $\left(\mathrm{H}_{1}\right)$, oder ob es ein nichtverwandter, zufällig aus der Population stammender Mann sein könnte $\left(\mathrm{H}_{0}\right)$. Der PI gibt dann an, um wie viel wahrscheinlicher $\mathrm{H}_{1}$ (Verwandtschaft MutterKind-Putativvater) im Gegensatz zur zufälligen Übereinstimmung $\mathrm{H}_{0}$ ist.

Für die Berechnung des PI einer Triade gilt, unter der Annahme eines Hardy-WeinbergGleichgewichts sowie Panmixie und der Voraussetzung der Nachweisbarkeit aller Allele, dass PI $=\mathrm{X} / \mathrm{Y}$ ist (Smouse und Chakraborty 1986). $\mathrm{X}$ ist dabei als die Wahrscheinlichkeit determiniert, mit der ein potenzieller Vater einen Nachkommen mit einem bestimmten Genotypen gezeugt haben kann und Y zeigt die Wahrscheinlichkeit an, mit der ein zufällig aus der Population ausgewähltes männliches Individuum diesen Nachkommen gezeugt haben kann. X hängt von der Segregationswahrscheinlichkeit der Allele und Y von der Häufigkeit der Allele in der Population ab, d.h. je seltener ein Allelmuster in einer Population ist, desto höher ist der Wahrscheinlichkeitswert einer Vaterschaft. Werden mehrere unabhängige Marker untersucht, ergibt sich der kombinierte Index aus dem Produkt der Einzelindizes der autosomalen STRs. Unter der Annahme, dass die Wahrscheinlichkeit einer Vaterschaft vor der Untersuchung 0,5 beträgt, lässt sich die positive Vaterschaftswahrscheinlichkeit aus $\mathrm{W}=\mathrm{X} / \mathrm{X}+\mathrm{Y}=$ PI/1+PI berechnen (Brenner 1993). Die Vaterschaft gilt als „praktisch erwiesen“, wenn eine Wahrscheinlichkeit von 99,8\% (Kratzer \& Bär 1997) erreicht wird.

In Fällen, in denen ein Elternteil nicht für die Analyse zur Verfügung steht, handelt es sich um einen sog. Defizienzfall. Hier basiert die Berechnung der Mutter- bzw. Vaterschaft auf den Genotypen des Kindes und einem Putativelternteil. Die Werte, die hier für einen Paternitäts- bzw. Maternitätsindex (MI) erreicht werden, sind deutlich geringer als die einer Dreierkonstellation (Chakraborty et al. 1994). Das verbale Prädikat „praktisch erwiesen“ wird hier bei einem PI von 399 vergeben. Eine Übersicht über die verbalen Prädikate nach Konrad Hummel ist unter http://www.dnaview.com/hummel.htm (20.01.06) gegeben.

Ist lediglich eines der möglichen Elternteile bekannt und kann dieses aufgrund des Genotyps von der Elternschaft nicht ausgeschlossen werden, ergeben sich zwischen ihm bzw. ihr und dem Kind fünf verschiedene Allelkonstellationen, welche bei der Berechnung des Paternitätsindex berücksichtigt werden müssen (vgl. Brenner 1993). Für jeden STR-Locus wird der PI einzeln errechnet. Das Endergebnis setzt sich auch hier aus dem Produkt zusammen. 
Es wurden 33 Individuen der Lichtensteinhöhle mithilfe des PI gegeneinander auf ein mögliches verwandtschaftliches Verhältnis getestet. Dieses screening wurde freundlicherweise von Charles H. Brenner, Ph.D. (Oakland, Kalifornien) mithilfe der Computersoftware DNA $\bullet$ VIEW durchgeführt. Die Berechnungen basieren auf Allelfrequenzen einer kaukasischen Referenzbevölkerung. Darüber hinaus wurde ein SI-Index (sibling index; http://dna-view.com/sibfmla.htm, 20.01.2006) berechnet, welcher für weitläufigere Verwandtschaften, z.B. Geschwister, Halbgeschwister, Onkel oder Cousins, steht. In der Regel ist dieser Wert hoch, wenn es sich um Geschwister handelt (pers. Mitteilung Brenner).

Geschwisterschaften werden wahrscheinlicher, stimmen ihre maternale Linien (unter der Bedingung der gleichen Mutter) überein bzw. liegen bei Brüdern zusätzlich der gleiche Y-Haplotyp vor. Der genetische Fingerabdruck ist bei Geschwistern in der Regel sehr ähnlich, kann jedoch auch durch Rekombination bei der Vererbung stark voneinander abweichen.

Die PI der Kernfamilien, d.h. Eltern-Kind, wurden durch Verwendung der Formeln der Internetseite http://www.dna-view.com/patform.html (20.01.06) berechnet. Dafür wurden die Allelfrequenzen der DNA-Datenbank der Universität Düsseldorf zugrunde gelegt (s.Kap.3.2.1). Referenz war hierbei jeweils der Datensatz Germany (pooled).

Bei der Berechnung der Elternschaftswahrscheinlichkeiten müssen, wenn erforderlich, die Mutationsraten der einzelnen STR-Systeme, d.h. sowohl für autosomale als auch für Y-chromosomale STRs, berücksichtigt werden. Die Y-STR-Mutationsraten sind z.B. auf der Internetseite der YHRD angegeben. Die Mutationsraten für die autosomalen STRs (CODIS STR-Loci) können bei Butler $(2001,95)$ nachgeschlagen werden. 


\section{Methoden}

\subsection{Probenvorbereitung und DNA-Extraktion}

Eine Schlüsselstellung in der aDNA-Analytik nimmt die DNA-Extraktion aus dem historischen Probenmaterial ein. Der Erfolg oder Misserfolg, sowie die Anwendungsmöglichkeit einer Untersuchung wird von der Qualität der angefertigten DNA-Extrakte bestimmt.

Insbesondere die vorliegende Untersuchung zur Rekonstruktion von Verwandtschaftsverhältnissen benötigt DNA-Extrakte von guter Qualität. Es ist zwingend erforderlich DNA-Extrakte herzustellen, deren Qualität zumindest die Generierung von Teilfingerabdrücken und die Untersuchungen von väterlichen Linien zulässt.

Für eine erfolgreiche DNA-Extraktion aus Knochen- und Zahnmehl gilt eine Menge von 100 bis 300mg Pulver (z.B. Hummel \& Herrmann 1996).

Die für eine DNA-Extraktion aus Zähnen wichtigen Zellen liegen im Wesentlichen in deren Wurzeln. Um möglichst viel Zahnpulver für eine DNA-Extraktion zu gewinnen, wurden überwiegend die mehrwurzeligen Backenzähne ausgewählt. Nach der Zahnentnahme wurde die Wurzel mit einer Dentalbohrmaschine (Typ K10, KaVo) mit Diamantsägeblatt von deren Krone separiert. Anschließend wurde die Wurzeloberfläche mit dem Diamantsägeblatt mechanisch abgetragen. Damit lassen sich Verunreinigungen sowie eventuell anhaftende Kontaminationen entfernen. Die Krone kann anschließend wieder an ihre Position im Kiefer platziert werden. Somit ist in der Regel rein äußerlich ohne Röntgentechnik kein Eingriff zu erkennen und das Fundstück auch weiterhin für archäologische Ausstellungen zu verwenden.

Die Felsenbeine wurden dem Schädel mithilfe des Diamantsägeblatts und einem kleinen Bohrer entnommen. Zur Beprobung der Unterkiefer wurde ein Knochenstück an der Innenseite des Kiefers im Bereich der Molaren herausgesägt. Anschließend erfolgte auch für die Felsenbeine und Unterkieferknochenproben eine gründliche Oberflächenabtragung. Die Weiterverarbeitung der Probenmaterialien bis zum Zahnbzw. Knochenmehl erfolgte, wie bei Hummel (2003) beschrieben.

Das Verhältnis Probenpulver zu Inkubationspuffer wurde so gewählt, dass das Pulver ausreichend in Flüssigkeit gelöst werden kann, aber trotzdem, im Hinblick auf die 
letztendliche Extraktion bei welcher der Flüssigkeitseinsatz limitiert ist (s.u), nicht zu hoch ist. Somit wurde das Verhältnis auf 1:6 festgelegt. Standardmäßig wurde mit einer

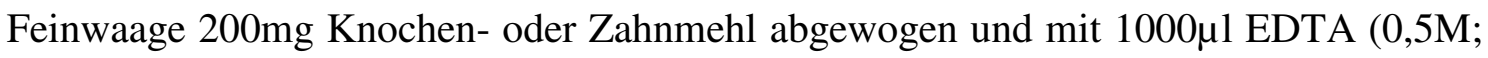
pH8) versetzt. Erwies sich die DNA-Qualität in einem ersten Extrakt als nicht ausreichend, wurden 300mg Pulver mit 1500 $\mu$ l EDTA inkubiert. War weniger als 200mg Probenmaterial vorhanden, wurde im oben genannten Verhältnis mit EDTA inkubiert. Die Inkubation erfolgte für 72Std. in einem Über-Kopf-Rotator bei RT mit anschließender Zugabe von $20 \mu$ l Proteinase K $(20 \mathrm{mg} / \mathrm{ml}$, Qiagen) zur Zelllyse. Die Lyse erfolgte für $2 \mathrm{Std}$ bei $56^{\circ} \mathrm{C}$ im Rotator. Danach wurden die Proben für $4 \mathrm{~min}$ bei

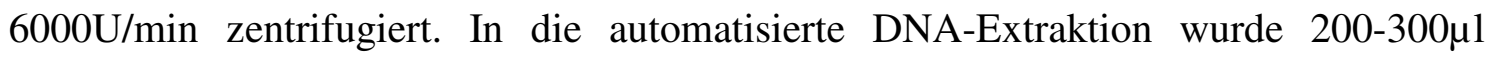
Probenflüssigkeit eingesetzt.

Während im Zeitraum von 1998-2000 die DNA-Extrakte mithilfe eines automatisierten Phenol-Chloroformextraktionsgerätes (Typ 341 PE Applied Biosystems) angefertigt wurden, ist in dieser Arbeit ein in der Forensik neu etabliertes Extraktionsgerät (Montpetit et al. 2005), der EZ1 Biorobot (Qiagen), eingesetzt worden. Dieser konnte bereits von Schmidt (2004) an Proben der Lichtensteinhöhle erfolgreich verwendet werden. Hier scheint die DNA-Ausbeute zwar nicht an die deutlich aggressivere Phenol-Chloroform-Extraktion heranzureichen (Schmidt 2004), dennoch ist der EZ1DNA-Extraktor durch seinen hohen Probendurchsatz in geringer Zeit (sechs Proben in ca. 20min), seiner durch Automatisierung verminderten Möglichkeit zur Einschleppung von Fremd-Kontaminationen sowie der hohen Reinheit der DNA-Extrakte, in denen PCR-Inhibitoren keine Rolle spielen sollen (Montpetit et al. 2005), für aDNA-Analysen höchst geeignet. Das Prinzip der EZ1-DNA-Extraktion basiert auf einer Guanidiumthiocyanat/Guanidiumhydrochlorid-Extraktion, in der die DNA an silikatbeschichtete Magnetpartikel (magnetic beads) gebunden wird (Fa. Qiagen). Weitere Details zur Extraktion sind u.a. bei Schmidt (2004) oder Montpetit et al. (2005) aufgeführt. Die DNA wurde mit dem forensic Protokoll für trace samples extrahiert. Das Elutionsvolumen betrug in der Regel $50 \mu 1$, selten $100 \mu 1$.

Neben den historischen Proben wurden Kontrollproben, u.a. des Bearbeiters, angefertigt. Es wurden Mundschleimhautabstriche genommen und die DNA mithilfe der Chelex ${ }^{\circledR}$ 100-Methode (Biorad) extrahiert (Walsh et al. 1991). 


\subsection{Amplifikationssysteme und deren Parameter}

Der Mengeneinsatz an DNA-Extrakt in die PCR sowie die Anzahl der zu durchlaufenden Zyklen orientierte sich an der jeweiligen Qualität einer Probe. Die PCR wurde je nach Probenanzahl entweder in einem Thermocycler des Typs Mastercycler ${ }^{\circledR}$ gradient oder personal (Eppendorf) durchgeführt.

\subsubsection{Autosomale STRs}

Die Analyse der autosomalen STRs wurde mithilfe einer eigens etablierten OktaplexPCR sowie dem kommerziellen Amplifikationssystem AmpFlSTR ${ }^{\circledR}$ Profiler Plus $^{\mathrm{TM}}$ (PE Applied Biosystems) durchgeführt. Teils überschneidend werden so simultan zehn autosomale STRs und der geschlechtsspezifische Marker Amelogenin untersucht. Damit ist eine sichere Individualisierung der zu analysierenden Proben gewährleistet. Darüber hinaus weist der größte STR-Locus (FGA) der Oktaplex mit seinem längsten berücksichtigten Allel 30 eine Fragmentlänge unter 300bp auf (Schilz et al. 2004). Wegen der geringen Fragmentlängen ist die Oktaplex-PCR höchst geeignet für die Analyse von aDNA. Der Profiler Plus ${ }^{\mathrm{TM}}$ Amplifikationskit konnte bereits in zahlreichen forensischen (z.B. Alonso et al. 2001, Holland et al. 2003) und anthropologischen Studien (z.B. Hummel et al. 1999a, Schultes 2000, Bramanti et al. 2000) erfolgreich angewendet werden. Die STR-Systeme der beiden Analyse-Kits liegen in unterschiedlichen Fragmentlängenbereichen. Dies ist in vielerlei Hinsicht von Vorteil. Sind für Proben aufgrund starker Degradierung der DNA ausschließlich kurze Fragmentlängen zu amplifizieren, ist es mit den zwei Systemen möglich, eine größere Anzahl an STR-Loci zu bestimmen. Beispielsweise liegt im Profiler Plus ${ }^{\mathrm{TM}}$ Kit der Locus D13S317 im Fragmentlängenbereich zwischen 206 und 234bp, bei der OktaplexPCR zwischen 103 und 131bp. Ein zweiter wesentlicher Punkt ist, dass bei den beiden Amplifikationskits die Primersequenzen der einzelnen Loci mit sehr hoher Wahrscheinlichkeit unterschiedlich sind. Da die Sequenzen der Primer des Profiler Plus $^{\mathrm{TM}}$ Kit nicht öffentlich zugänglich sind, lässt sich dies jedoch lediglich vermuten. Wenn andere Primerpaare für denselben Locus verwendet werden, dann kann dies zur Verifizierung von Nullallelen (s.Kap. 4.4) führen (Budowle et al. 2001).

Die wichtigsten Daten der beiden Amplifikationssysteme sind in Tabelle 4 aufgeführt. Die beiden Multiplex-PCRs werden mit Dreifarb-Fluoreszenztechnik analysiert, hierbei ist je STR-System einer der Primer mit einem Fluoreszenzfarbstoff markiert. 
Tabelle 4: Übersicht der Amplifikationskits für die Analyse autosomaler STRs.

\begin{tabular}{|c|c|c|c|c|c|c|c|c|}
\hline & \multicolumn{4}{|c|}{ Oktaplex-PCR } & \multicolumn{4}{|c|}{ AmpFISTR $^{\circledR}$ Profiler Plus ${ }^{\mathrm{TM}}$} \\
\hline STR-Locus & $\begin{array}{c}\text { in } \\
\text { Multiplex }\end{array}$ & Allele & $\begin{array}{c}\text { Länge } \\
\text { [bp] }\end{array}$ & Label & $\begin{array}{c}\text { in } \\
\text { Multiplex }\end{array}$ & Allele & $\begin{array}{c}\text { Länge } \\
\text { [bp] }\end{array}$ & Label \\
\hline D3S1358 & $a$ & $14-19$ & $173-193$ & $\mathrm{NED}^{\mathrm{TM}}$ & $a$ & $12-19$ & $114-142$ & 5-FAM \\
\hline D5S818 & $a$ & 7-16 & 109-145 & $\mathrm{NED}^{\mathrm{TM}}$ & $a$ & $7-16$ & $135-171$ & $\mathrm{NED}^{\mathrm{TM}}$ \\
\hline D7S820 & & & & & $\mathfrak{a}$ & $6-15$ & $258-294$ & $\mathrm{NED}^{\mathrm{TM}}$ \\
\hline D8S1179 & & & & & a & $8-19$ & $128-168$ & JOE \\
\hline D13S317 & $a$ & $8-15$ & 103-131 & 6-FAM & $a$ & $8-15$ & $206-234$ & $\mathrm{NED}^{\mathrm{TM}}$ \\
\hline D18S51 & & & & & $a$ & $9-26$ & $273-341$ & JOE \\
\hline D21S11 & $a$ & $27-33.2$ & $204-230$ & $\mathrm{NED}^{\mathrm{T} M}$ & $\mathbf{a}$ & $24.2-36,38$ & $189-243$ & JOE \\
\hline CSF1PO & $a$ & $9-14$ & 161-181 & 6-FAM & & & & \\
\hline FGA & 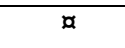 & $18-30$ & $215-263$ & 6-FAM & $a$ & $18-30$ & $219-267$ & 5-FAM \\
\hline VWA & $a$ & $11-21$ & $127-171$ & HEX & $a$ & $11-21$ & 157-197 & 5-FAM \\
\hline Amelogenin & $a$ & $\mathrm{X}, \mathrm{Y}$ & 107,113 & HEX & 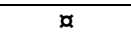 & $\mathrm{X}, \mathrm{Y}$ & 107,113 & JOE \\
\hline
\end{tabular}

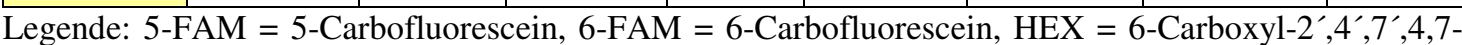
Hexachlorofluorescein, JOE = 6-carboxy-4',5'-dichloro-2',7'-dimethoxy-fluorescein, NED = n.b.. Die Längen sind jeweils inklusive +A (Adenylation; Butler 2001) berechnet. Die Angaben der Fragmentlängen des Profiler Plus ${ }^{\mathrm{TM}}$ Kits stammen aus dessen User Manual (PE Applied Biosystems).

In der folgenden Abbildung wird der Aufbau der Oktaplex-PCR schematisch dargestellt. Die Balken repräsentieren die in Tabelle 4 aufgeführten Allelspannweiten der STR-Loci und deren Fragmentlängen.

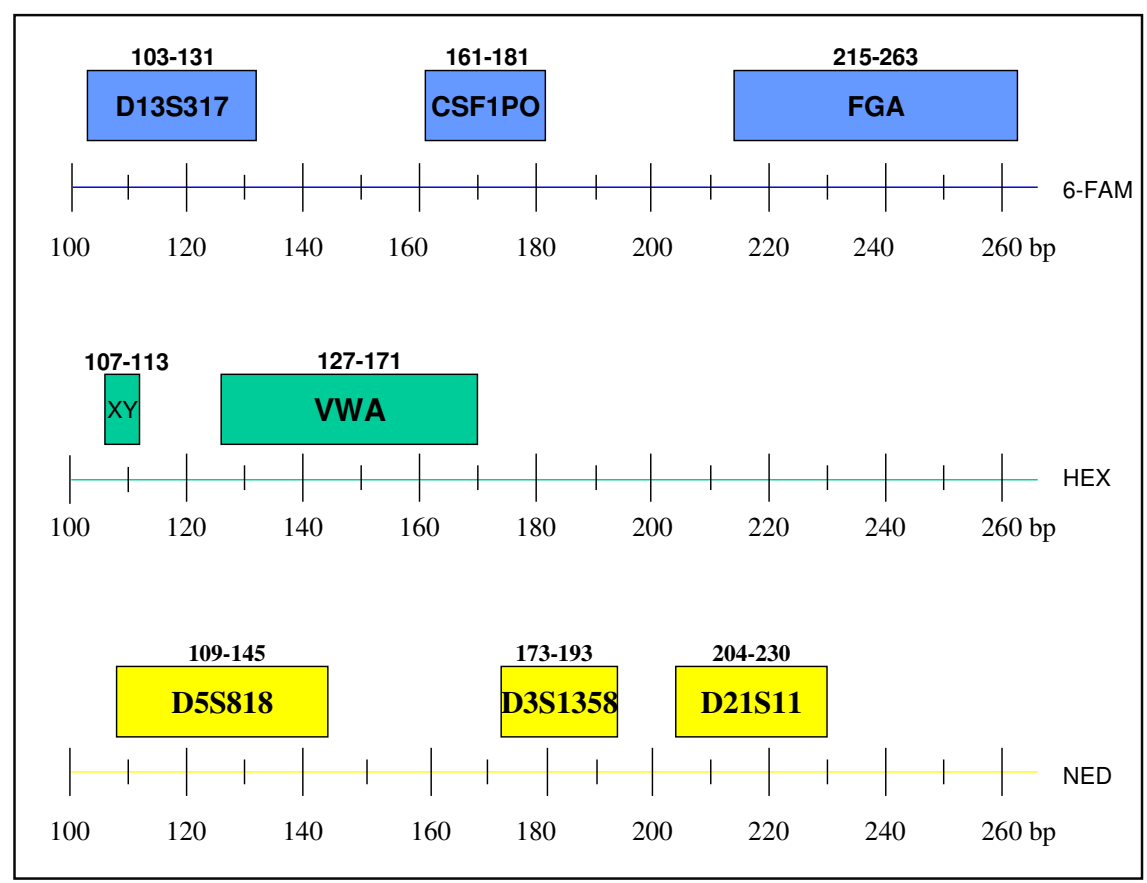

Abbildung 9: Dargestellt sind die Fragmentlängenbereiche der STR-Loci der Oktaplex-PCR in Basenpaaren (bp). Die sieben STRs und der geschlechtsdiskriminante Marker Amelogenin (XY) sind mit einem der drei Fluoreszenzfarbstoffen 6-FAM, HEX und NED markiert und können so einer Farbspur zugeordnet werden. 


\section{PCR-Parameter der Oktaplex-PCR}

Das Reaktionsvolumen beträgt $25 \mu 1$ und beinhaltet: $12,5 \mu 1$ Qiagen ${ }^{\circledR}$ Multiplex PCR Kit (Qiagen), 3,3 $\mu$ l PrimerSet (für Primersequenzen und -konzentrationen siehe Tab. 5) und 1-9,2 $\mu$ l DNA-Extrakt. Das Volumen wurde mit DNA freien Wasser (Qiagen) ausgeglichen. Die Cycle-Parameter lauten: $15 \min 95^{\circ} \mathrm{C} ; 1 \min 94^{\circ} \mathrm{C}, 1 \mathrm{~min} 58^{\circ} \mathrm{C}, 1 \mathrm{~min}$ $72^{\circ} \mathrm{C}\left(35-40\right.$ Zyklen); $30 \mathrm{~min} 60^{\circ} \mathrm{C} ; 10 \mathrm{~min} 10^{\circ} \mathrm{C}$.

Tabelle 5: Oktaplex-PrimerSet

\begin{tabular}{|c|c|c|c|c|}
\hline System & Primer & $\begin{array}{l}\text { Primersequenz }\left(5^{\prime} \rightarrow 3^{\prime}\right) \\
\text { und Fluoreszenzfarbstoff (=6-FAM, HEX, NED) }\end{array}$ & $\begin{array}{c}\text { AK } \\
{[p m o l]}\end{array}$ & $\begin{array}{l}\text { PrimerSet } \\
\quad[\mu \mathrm{M}]\end{array}$ \\
\hline \multirow[t]{2}{*}{ D3S1358 } & Upper & NED- AGGAGTTTGAGGCTGTAGTGAG & 20 & 0,3 \\
\hline & Lower & САТСТСТTАТАСТСАТGАAАТСААСА & 20 & 0,3 \\
\hline \multirow[t]{2}{*}{ D5S818 } & Upper & NED- GGTATCCTTATGTAATATTTTGAAGAT & 50 & 0,15 \\
\hline & Lower & ATCATAGCCACAGTTTACAACATT & 50 & 0,15 \\
\hline \multirow[t]{2}{*}{ D13S317 } & Upper & 6-FAM- CTAACGCCTATCTGTATTTACAAATA & 50 & 0,2 \\
\hline & Lower & AGCCCAAAAAGACAGACAGA & 50 & 0,2 \\
\hline \multirow[t]{2}{*}{ D21S11 } & Upper & NED- ACTTTTCTCAGTCTCCATAAATATGT & 20 & 0,25 \\
\hline & Lower & GGAGGTAGATAGACTGGATAGATAGAC & 20 & 0,25 \\
\hline \multirow[t]{2}{*}{ CSF1PO } & Upper & 6-FAM- TAACCACCCTGTGTCTCAGTT & 50 & 0,15 \\
\hline & Lower & ACAGCATTTCCTGTGTCAGAC & 50 & 0,15 \\
\hline \multirow[t]{2}{*}{ FGA } & Upper & 6-FAM- CATAGGTTTTGAACTCACAGATTAA & 20 & 0,25 \\
\hline & Lower & CTGAAATCGAAAATATGGTTATTG & 20 & 0,25 \\
\hline \multirow[t]{2}{*}{ VWA } & Upper & HEX- CCCTAGTGGATGATAAGAATAATCAGTATG & 50 & 0,3 \\
\hline & Lower & GGACAGATGATAAATACATAGGATGGATGG & 50 & 0,3 \\
\hline \multirow{2}{*}{$\begin{array}{l}\text { Amelo- } \\
\text { genin }\end{array}$} & Upper & HEX- CCCTGGGCTCTGTAAAGAATAGTG & 20 & 0,2 \\
\hline & Lower & ATCAGAGCTTACACTGGGAAGCTG & 20 & 0,2 \\
\hline
\end{tabular}

Legende: $\mathrm{AK}=$ Arbeitskonzentration

Die Primer der Systeme D3S1358, D5S818, D13S317, D21S11, CSF1PO und FGA entstammen einer zuvor designten Multiplex-PCR (Schilz et al. 2004). Das Primerpaar des STR-Locus VWA wurde aufgrund guter Amplifikationsergebnisse von einer Multiplex-PCR zur Bestimmung des immungenetischen Markers $\triangle 32$ CCR5 übernommen (Hummel et al. 2005). Die Primersequenzen des geschlechtsspezifischen Markers Amelogenin wurden ebenfalls übernommen (Sullivan et al. 1993). In der Sequenz des lower-Primers von Amelogenin ist eine Basen-Fehlpaarung eingebaut (Hummel 2003). 
PCR-Parameter des AmpFlSTR ${ }^{\circledR}$ Profiler Plus ${ }^{T M}$ Kit

Das Reaktionsvolumen beträgt $25 \mu 1$ und beinhaltet: 10 $\mu 1$ AmpFISTR PCR Reaction $\operatorname{Mix}^{\mathrm{TM}}, 5 \mu \mathrm{l}$ AmpFlSTR ProfilerPlus PrimerSet ${ }^{\mathrm{TM}}$ (PE Applied Biosystems), 0,5 $\mu 1$ (=2,5U) AmpliTaqGold $^{\text {TM }}$ DNA polymerase (Perkin Elmer Cetus) und 1-9,5 $\mu$ l DNA-Extrakt. Das Volumen wurde mit DNA freien Wasser (Qiagen) ausgeglichen.

Die Cycle-Parameter sind: $11 \min 94^{\circ} \mathrm{C}$; $1 \min 94^{\circ} \mathrm{C}, 1 \min 59^{\circ} \mathrm{C}, 1 \min 72^{\circ} \mathrm{C}(35-40$ Zyklen); $45 \min 60^{\circ} \mathrm{C} ; 10 \min 10^{\circ} \mathrm{C}$.

Die Primersequenzen und -konzentrationen des Kits sind nicht öffentlich zugänglich und somit nicht bekannt.

\subsubsection{HVR I und HVR II-Analysen}

Weite Bereiche der HVR müssen untersucht werden, um die mt-Haplotypen der Individuen aus der Lichtensteinhöhle der offiziellen Nomenklatur zu zuordnen. Aus diesem Grund wurden für diese Arbeit neue Amplifikationssysteme erstellt. Das Primerdesign wurde speziell an die Bedingungen von aDNA angepasst. Die Vorgehensweise für die Generierung eines optimalen Primers ist bei Hummel (2003) beschrieben. Es wurden innerhalb dieser Arbeit jeweils vier Primer erstellt, welche überlappende Bereiche der HVR I bzw. HVR II amplifizieren (s.Tab.6). Für die Analyse der HVR entstehen durch Kombination der einzelnen Primer mehrere Amplifikationsmöglichkeiten. Abbildung 10 verdeutlicht das am Beispiel der HVR IIAnalyse.

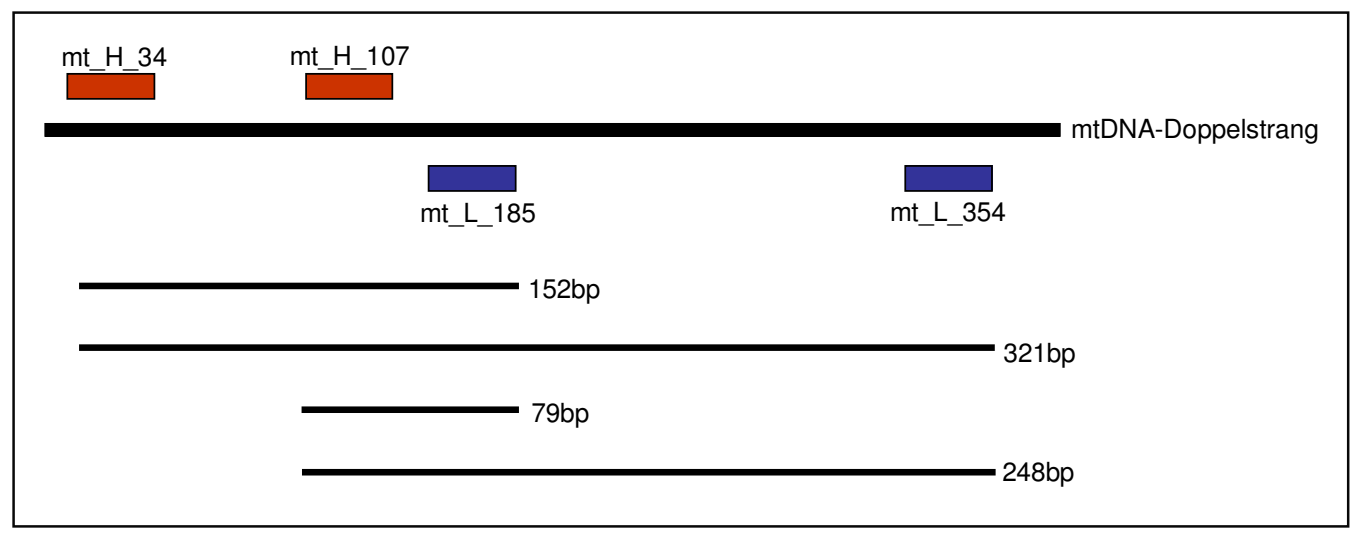

Abbildung 10: Amplifikationsmöglichkeiten für die HVR II-Analyse. Durch Kombination der vier Primer entstehen vier Amplifikationsprodukte mit unterschiedlichen Fragmentlängen. 
Für die HVR I-Analyse sind durch die Kombination der Primer die Fragmentlängen 69bp, 173bp, 235bp und 339bp generierbar. Überwiegend wurde hierbei das 339bp umfassende Fragment (mt_H_16026 und mt_L_16364) und für HVR II das 321bp lange Fragment (mt_H_34 und mt_L_354) amplifiziert (Kap.5.2). Die Amplifikationen erfolgten in Singleplex-Analysen.

Tabelle 6: Primer der HVR I- und HVR II-Analysesysteme

\begin{tabular}{|l|l|l|}
\hline Primername & Primersequenz $\left(5^{\prime} \rightarrow 3^{\prime}\right)$ & Region \\
\hline mt_H_16026 & CTTTCATGGGGAAGCAGATTTGG & HVR I \\
\hline mt_H_16192 & CCATGCTTACAAGCAAGTACAGCAAT & HVR I \\
\hline mt_L_16260 & GGTGGCTTTGGAGTTGCAGTTG & HVR I \\
\hline mt_L_16364 & GGACGAGAAGGGATTTGACTGTAATG & HVR I \\
\hline mt_H_34 & GGGAGCTCTCCATGCATTTGG & HVR II \\
\hline mt_H_107 & GAGCACCCTATGTCGCAGTATCTGT & HVR II \\
\hline mt_L_185 & CCTGTAATATTGAACGTAGGTGCGATAA & HVR II \\
\hline mt_L_354 & GGTTTGGCAGAGATGTGTTTAAGTGC & HVR II \\
\hline
\end{tabular}

Legende: Der Name der Primer setzt sich folgendermaßen zusammen: $\mathrm{mt}=$ mitochondrial, $\mathrm{H}=$ heavy chain, L = lower chain, und einer Zahl, die das jeweilige 5'-Ende des Primers nach der Nomenklatur von Anderson (1981) angibt.

\section{PCR-Parameter der HVR-Analysen}

Die Amplifikationen wurden in einem Volumen von $50 \mu 1$ mit folgenden Komponenten und Konzentrationen durchgeführt: $50 \mathrm{mM} \mathrm{KCl}, 10 \mathrm{mM}$ Tris- $\mathrm{HCl}$ (10x Buffer II, PE Applied Biosystems), $2 \mathrm{mM} \mathrm{MgCl}$ (PE Applied Biosystems), $175 \mu \mathrm{M}$ dNTPs (Sigma), 1,5U AmpliTaqGold ${ }^{\mathrm{TM}} \mathrm{DNA}$ polymerase (Perkin Elmer Cetus), 0,125 $\mu \mathrm{M}$ upper Primer und $0,125 \mu \mathrm{M}$ lower Primer. Bei rezenten Speichelproben wurden $1 \mu \mathrm{l}$ DNA-Extrakt in die PCR eingesetzt. Für die historischen Proben wurde je nach Qualität des Extraktes 1$15 \mu 1$ verwendet. Der Ansatz wurde anschließend mit DNA freien Wasser (Qiagen) auf das Endvolumen aufgefüllt. Die PCR-Parameter sind: Aktivierung der hitzeinduzierten Taq Polymerase bei $94^{\circ} \mathrm{C}$ für $11 \mathrm{~min} ; 94^{\circ} \mathrm{C} 1 \mathrm{~min}, 56^{\circ} \mathrm{C} \quad 1 \mathrm{~min}, 72^{\circ} \mathrm{C} 1 \mathrm{~min}(35-40$ Zyklen); $10^{\circ} \mathrm{C}$ für $10 \mathrm{~min}$.

\subsubsection{Y-STRs}

Die Analyse der Y-Haplotypen wurde mit zwei Y-STR-Analysesystemen durchgeführt, die ebenfalls mit Dreifarb-Fluoreszenztechnik analysiert werden. Zum einen wurde eine Y-Nonaplex (Müller 2002, Hummel 2003) und zum anderen der kommerzielle 
PowerPlex ${ }^{\circledR}$ Y System Kit (Promega, Madison, WI, USA) verwendet. Mithilfe der YNonaplex ist der minHt, mit dem PowerPlex $^{\circledR} \mathrm{Y}$ Kit der extended haplotype bestimmbar. Der PowerPlex ${ }^{\circledR}$ Y System Kit wurde für die Anwendungsgebiete Forensik, Vaterschaftsnachweise und für anthropologische Studien entwickelt (Krenke et al. 2005). Die Y-Nonaplex wurde speziell für die Anforderungen von aDNAAnalysen etabliert (Hummel 2003), d.h. kurze Fragmentlängen und optimiertes Primerdesign. Die wichtigsten Daten der beiden Amplifikationssysteme sind in Tabelle 7 dargestellt.

Tabelle 7: Übersicht der Amplifikationskits für die Analyse Y-chromosomaler STRs.

\begin{tabular}{|c|c|c|c|c|c|c|c|c|}
\hline & \multicolumn{4}{|c|}{ Y-Nonaplex } & \multicolumn{4}{|c|}{ PowerPlex ${ }^{\circledR}$ Y System Kit } \\
\hline System & $\begin{array}{c}\text { in } \\
\text { Multiplex }\end{array}$ & Allele & $\begin{array}{c}\text { Länge } \\
\text { [bp] }\end{array}$ & Label & $\begin{array}{c}\text { in } \\
\text { Multiplex }\end{array}$ & Allele & $\begin{array}{c}\text { Länge } \\
\text { [bp] }\end{array}$ & Label \\
\hline DYS19 & $a$ & $10-19$ & $174-210$ & 6-FAM & $a$ & $10-19$ & $232-268$ & JOE \\
\hline $\begin{array}{l}\text { DYS385 } \\
\mathrm{a} / \mathrm{b}\end{array}$ & $a$ & $7-23$ & $146-210$ & $\mathrm{NED}^{\mathrm{TM}}$ & $\mathfrak{a}$ & $7-25$ & $243-315$ & TMR \\
\hline $\begin{array}{l}\text { DYS389 I } \\
\text { DYS389 II }\end{array}$ & a & $\begin{array}{c}9-16 \\
26-33 \\
\end{array}$ & $\begin{array}{l}103-131 \\
223-251\end{array}$ & HEX & $a$ & $\begin{array}{l}10-15 \\
24-34\end{array}$ & $\begin{array}{l}148-168 \\
256-296\end{array}$ & $\mathrm{FL}$ \\
\hline DYS390 & $a$ & $18-27$ & $150-186$ & HEX & $a$ & $18-27$ & $191-227$ & TMR \\
\hline DYS391 & $a$ & $7-14$ & $138-166$ & 6-FAM & 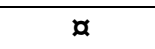 & $6,8-13$ & $90-118$ & $\mathrm{FL}$ \\
\hline DYS392 & $a$ & $6-16$ & $91-121$ & 6-FAM & 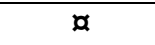 & $7-18$ & $294-327$ & JOE \\
\hline DYS393 & $a$ & $9-16$ & $107-135$ & $\mathrm{NED}^{\mathrm{TM}}$ & $a$ & $8-16$ & $104-136$ & TMR \\
\hline DYS437 & & & & & $a$ & 13-17 & 183-199 & JOE \\
\hline DYS438 & & & & & $a$ & $8-12$ & $101-121$ & JOE \\
\hline DYS439 & & & & & $a$ & $8-15$ & 203-231 & $\mathrm{FL}$ \\
\hline
\end{tabular}

Legende: 6 -FAM $=$ 6-Carbofluorescein, $\mathrm{FL}=$ fluorescein, $\mathrm{HEX}=6$-Carboxyl-2', 4',7 , 4,7Hexachlorofluorescein, JOE $=6$-carboxy-4', $5^{\prime}$-dichloro-2', $7^{\prime}$-dimethoxyfluorescein, NED = n.b., TMR $=$ carboxy-tetramethylrhodamine. Die Fragmentlängen sind jeweils inklusive +A (Adenylation; Butler 2001) berechnet. Die Angaben der Fragmentlängen des PowerPlex ${ }^{\circledR}$ Y System Kits stammen aus dessen User Manual (Promega).

\section{PCR-Parameter der Y-Nonaplex}

Die PCR-Reaktion erfolgte in einem $25 \mu 1$ Ansatz mit 12,5 $\mu$ l Qiagen ${ }^{\circledR}$ Multiplex PCR Kit (Qiagen), $6 \mu 1$ Y-PrimerSet (für Primerkonzentrationen s. Tab.8) und 1-9,5 $\mu 1$ DNAExtrakt. Das Reaktionsvolumen wurde mit DNA freien Wasser (Qiagen) ausgeglichen. Die Cycle-Parameter waren: $15 \min$ bei $95^{\circ} \mathrm{C} ; 1 \min 94^{\circ} \mathrm{C}, 1 \min 53^{\circ} \mathrm{C}, 1 \min 72^{\circ} \mathrm{C}$ (35-40 Zyklen) und abschließende $30 \mathrm{~min}$ bei $60^{\circ} \mathrm{C}$. Die Primersequenzen der Y-STRMultiplex sind bei Hummel (2003, 249) aufgeführt. 
Tabelle 8: Primerkonzentrationen der Y-Nonaplex

\begin{tabular}{|l|c|c|}
\hline Y - SYSTEM & $\begin{array}{c}\text { Arbeitskonzentration } \\
{[\mathrm{pmol}]}\end{array}$ & $\begin{array}{c}\text { PrimerSet } \\
{[\mu \mathrm{M}]}\end{array}$ \\
\hline DYS19 a & 50 & 0,6 \\
\hline DYS19 b & 50 & 0,6 \\
\hline DYS385 a & 50 & 2,4 \\
\hline DYS385 b & 50 & 2,4 \\
\hline DYS389 a & 50 & 0,3 \\
\hline DYS389 b & 50 & 0,3 \\
\hline DYS390 a & 50 & 0,6 \\
\hline DYS390 b & 50 & 0,6 \\
\hline DYS391 a & 50 & 0,28 \\
\hline DYS391 b & 50 & 0,28 \\
\hline DYS392 a & 50 & 0,8 \\
\hline DYS392 b & 50 & 0,8 \\
\hline DYS393 a & 20 & 0,4 \\
\hline DYS393 b & 20 & 0,4 \\
\hline
\end{tabular}

PCR-Parameter des PowerPlex ${ }^{\circledR} Y$ System Kit

Die Amplifikation des PowerPlex ${ }^{\circledR}$ Y Systems wurde in einem $25 \mu 1$ PCR-Volumen durchgeführt. Die Komponenten und deren Konzentration/Menge lauten wie folgt: $2,5 \mu 1$ 10X GoldStar Puffer (Promega), 2,5 $\mu 1$ 10X PrimerPair Mix (Promega), 0,55 $\mu 1$ (=2,8U)

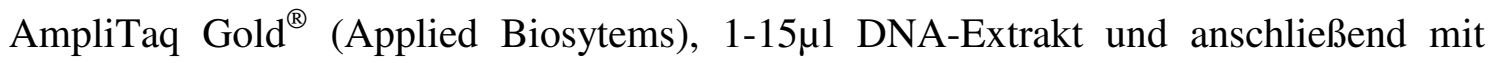
Ampuwa $^{\circledR}$ (Fresenius) auf das Endvolumen auffüllen. Die Cycle-Parameter lauten: 11 $\min 95^{\circ} \mathrm{C} ; 1 \min 96^{\circ} \mathrm{C} ; 10$ Zyklen bei $1 \min 94^{\circ} \mathrm{C}, 1 \min 60^{\circ} \mathrm{C}, 1.5 \min 70^{\circ} \mathrm{C} ; 25-30$ Zyklen bei $1 \min 90^{\circ} \mathrm{C}, 1 \min 58^{\circ} \mathrm{C}, 1,5 \min 70^{\circ} \mathrm{C}$; anschließend $30 \mathrm{~min} 60^{\circ} \mathrm{C}$; $10 \mathrm{~min}$ $10^{\circ} \mathrm{C}$.

Die Primersequenzen und -konzentrationen des Kits sind nicht öffentlich zugänglich. 


\subsection{Auswertung}

\subsubsection{Agarosegelelektrophorese}

Der Amplifikationserfolg der PCR-Systeme wurde mit einem 2,5\%-Agarosegel überprüft. Dafür wurde standardmäßig 10 101 Amplifikationsprodukt aufgetragen. Die Zusammensetzung und das Verfahren der Agarose-Gelelektrophorese ist z.B. in Hummel (2003) beschrieben.

\subsubsection{PAA-Gelelektrophorese}

Die Auftrennung der Amplifikationsprodukte, sowohl der Y-STRs als auch der autosomalen STRs, erfolgte mittels der hochauflösenden PolyacrylamidGelelektrophorese, welche durch eine bessere Trennschärfe eine Bestimmung der exakten Produktlängen ermöglicht. Die Zusammensetzung eines 6\%-igen denaturierenden Polyacrylamid-Gels ist z.B. in Schultes (2000) beschrieben.

Die Probenvorbereitung für die PCR-Produkte der Oktaplex-PCR, des ProfilerPlus ${ }^{\mathrm{TM}}$ Kit (PE Applied Biosystems) und der Y-Nonaplex wurde wie folgt vorgenommen: $0,25 \mu 1$ spurinterner Standard GS500 ${ }^{\mathrm{TM}}$ Rox (6-Carboxylrhodamin, PE Applied Biosystems), 0,5 $\mu$ l Loading Buffer (PE Applied Biosystems), $2 \mu 1$ Formamid (Fluka) und je nach Signalintensität auf dem Agarosegel 0,1-2 $\mu$ l PCR-Produkt.

Die Probenvorbereitung für den PowerPlex ${ }^{\circledR}$ Y System Kit (Promega) wurde wie folgt vorgenommen: 0,5 $\mu 1$ spurinterner Standard ILS600 (carboxy-X-rhodamine Abk. CXR, Promega), 1,5 $\mu$ l Dextran Blau Loading Buffer (Promega) und je nach Signalintensität auf dem Agarosegel 0,1-2 $\mu 1$ PCR-Produkt.

Die elektrophoretische Auftrennung der Proben erfolgte mit einem DNA-Sequencer (373A stretch, PE Applied Biosystems). Die ermittelten Daten wurden mithilfe der GeneScan ${ }^{\mathrm{TM}}$-Collection und GeneScan ${ }^{\mathrm{TM}}$-Analysis Software (PE Applied Biosystems) weiterverarbeitet. Die Fragmentlängenbestimmung wurde mithilfe des spurinternen Längenstandards unter Verwendung der Local Southern Methode durchgeführt (Elder \& Souther 1987). Die Fragmente stellen sich als Peaks in einem Elektropherogramm dar, deren Höhe in relativen Fluoreszenzeinheiten (=rfu) angegeben wird. Die Allele wurden im Fall der Oktaplex-PCR und Y-Nonaplex mit selbst generierten, im Fall des Profiler Plus $^{\mathrm{TM}}$ und des PowerPlex ${ }^{\circledR}$ Y System Kits mit mitgelieferten, Allelleitern bestimmt. 


\subsubsection{Sequenzierung und Kapillarelektrophorese}

Für die Analyse der HVR I und II muss die jeweilige mtDNA-Sequenzabfolge der Proben bestimmt werden. Dafür wurden die Amplifikationsprodukte nach dem Prinzip der Cycle Sequencing Reaktion (Sanger et al. 1977) direktsequenziert. Es wurden sowohl forward- (H-Strang) als auch reverse-Sequenzierungen (L-Strang) durchgeführt. Vor der Sequenzierreaktion wurden die PCR-Produkte mithilfe des MinElute ${ }^{T M}$ PCRPurification Kit (Qiagen) aufgereinigt. Hierbei werden überschüssige dNTPs, Polymerase, Primer, Primerdimere und Puffersalze entfernt. Das Verfahren arbeitet mit Zentrifugationssäulen, in denen sich eine silikatbeschichtete Membran befindet. Doppelsträngige DNA, ab einer Länge von 70bp, bindet daran (Qiagen Handbuch). Kleinere DNA-Moleküle, wie z.B. Primerdimere, werden von der Membran nicht zurückgehalten. Es wurden $40 \mu \mathrm{l}$ PCR Produkt nach Vorgabe des Herstellers

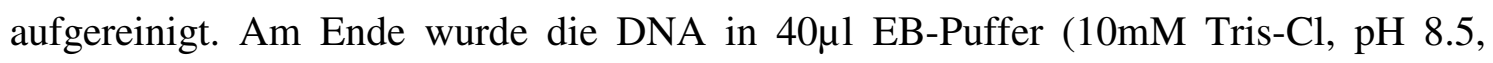
Qiagen) eluiert. Das Eluat ist danach bereit für die Taq-Cycle-Sequencing Reaktion. Der optimale DNA-Mengeneinsatz für eine Sequenzier-PCR liegt zwischen 3 - 100 ng. Zum Abschätzen diese Menge, wird das aufgereinigte PCR-Produkt noch einmal auf ein 2,5\% Agarosegel aufgetragen (10 $\mu$ l Auftragmenge) und anschließend die DNA-Menge im Vergleich mit der 1KB-Leiter (Invitrogen), deren Konzentration bekannt ist $(1 \mu \mathrm{g} / \mu 1$ Stammkonzentration, Herstellerangabe), abgeschätzt.

Das Volumen der Taq Cycle-Sequencing Reaktion beträgt $20 \mu 1$ und beinhaltet: $2 \mu 1$ BigDye Terminator V1.1 (PE Applied Biosystems), 3 $\mu 1$ 5XSequencing Buffer (PE Applied Biosystems), 0,6 $\mu 1$ Primer (AK $5 \mathrm{pmol} / \mu \mathrm{l}=3,2 \mathrm{pmol}$ ) und 1- $6 \mu$ l aufgereinigtes PCR-Produkt. Das Volumen wurde mit HPLC- $\mathrm{H}_{2} \mathrm{O}$ (Merck) ausgeglichen. Die Sequenzierreaktion erfolgte in einem DNA Thermal Cycler Typ TC1 (Perkin Elmer Cetus). Jede Probe wurde mit einem Tropfen Mineralöl (NUJOL, Perkin Elmer Cetus) überschichtet. Die Cycle-Parameter lauten: $1 \mathrm{~min} 96^{\circ} \mathrm{C} ; 10 \mathrm{sec} 96^{\circ} \mathrm{C}, 5 \mathrm{sec} 50^{\circ} \mathrm{C}, 4 \mathrm{~min}$ $60^{\circ} \mathrm{C}$ (25-30 Zyklen).

Das Sequenzierprodukt wird anschließend ebenfalls aufgereinigt. Dabei werden freie Primer, Polymerase sowie die überschüssigen fluoreszenzmarkierten ddNTPS entfernt. Auf diese Weise werden eine hohe Leseweite und ein geringes Hintergrundrauschen gewährleistet. Zum Erreichen dieser Idealbedingungen wird die Methode der Gelfiltration eingesetzt. Das NucleoSeq Kit (Macherey-Nagel) hat eine mit trockener 
Trennmatrix vorgefüllte Zentrifugationssäule, welche nach Angaben des Herstellers eingesetzt wurde.

Der gesamte Überstand aus der Aufreinigung wird in ein sample tube überführt und direkt in den DNA-Sequenzer Modell 310 (PE Applied Biosystems) gebracht. Die elektrophoretische Auftrennung erfolgte unter Verwendung des Polymer POP-6 ${ }^{\mathrm{TM}}$ (PE Applied Biosystems). Am Ende eines Sequenzierlaufes wurden die ermittelten Signale mithilfe der Analyse-Software ABI Prism ${ }^{\mathrm{TM}}$ Sequencing Analysis (PE Applied Biosystems) ausgewertet. Die Daten werden wie bei der Fragmentlängenanalyse in Form eines Elektropherogrammes dargestellt. $\mathrm{Zu}$ sehen ist eine Aneinaderreihung von Peaks, welche je eine von vier Farben aufweisen. Jeder Peak entspricht einer Base. Die Farben werden den Basen durch die Software wie folgt zugeordnet: $\mathrm{A}=$ grün, $\mathrm{C}=$ blau, $\mathrm{G}=$ schwarz und $\mathrm{T}=$ rot. Die so ermittelte Abfolge der Basen entspricht der DNASequenz. Die anschließende Auswertung der Sequenzen und der Abgleich mit der CRS erfolgte mit den Programmen SeqMan und MegAlign des DNAStar Software Pakets (Lasergene). 


\subsection{Analyseschwierigkeiten bei degradierter DNA}

Die Typisierungen an degradierter DNA unterliegen Schwierigkeiten, die sowohl durch die DNA-Qualität als auch -Quantität einer Probe bedingt sein können.

Bei der Typisierung von Mikrosatelitten kann es zur Bildung sog. „Stotterbanden“ kommen (engl. „stutter bands“, Kimpton et al. 1993). Dieses betrifft vor allem die Dinucleotide, weniger anfällig sind die in diesem Projekt verwendeten Tetranucleotide (z.B. Urquhart et al. 1995). Der am meisten favorisierte Mechanismus, der dieses Phänomen erklären soll, wird als ,slippage event" bezeichnet und liegt in der sich tandemartig wiederholenden Sequenz eines STRs begründet. Während der Elongation kommt es zu einer ständigen Re- und Denaturierung zwischen dem Matrizenstrang und dem in der Neusynthese befindlichen Strang. Die beiden DNA-Stränge können bei der Renaturierung um eine Repeatunit verrutschen. Tritt dieser Fall ein, dann generiert die Polymerase Amplifikationsprodukte mit abweichender Größe (z.B. Hummel 2003). In der Regel sind die Produkte eine Wiederholungseinheit kürzer, selten länger als das richtige Allel (Hite et al. 1996). Proben mit ausreichend intakter Target-DNA leiden weniger als aDNA unter diesem Phänomen. Kommt bei aDNA-Analysen ein slippage in den ersten Zyklen der PCR vor, kann es zu einer bevorzugten Amplifikation dieses Produktes kommen und ein falsches Allel entsteht.

Eine weitere Schwierigkeit stellt das Phänomen des allelic dropout dar (z.B. Schmerer et al. 2000). Dabei wird bei der Amplifikation eines heterozygoten STR-Locus nur eines der beiden Allele amplifiziert oder eines erreicht nicht die Nachweisgrenze. Dies führt zur Generierung falsch-homozygoter Ergebnisse. Dieses Phänomen korreliert eng mit der Anzahl intakter Target-DNA (Kimpton et al. 1994). Aus diesem Grund sind auch STR-Loci mit großen Fragmentlängen stärker von allelic dropout betroffen.

Eine weitere Möglichkeit eines falsch-homozygoten Ergebnisses ist ein Phänomen, das als Nullallel bezeichnet wird (z.B. Butler 2001). Jedoch ist dieses kein spezifisches Problem degradierter DNA. Nullallele kommen zustande, wenn Primer aufgrund von Sequenzpolymorphismen in den flankierenden Bereichen eines STRs nicht hybridisieren können oder die Verlängerung des Primers ausbleibt. Das bedeutet, obwohl für die Ausgangs-DNA ein STR-Allel vorliegt, findet die Amplifikation nicht statt. Nullallele sollten in dieser Arbeit durch die Verwendung von jeweils zwei verschiedenen Amplifikationssystemen erkannt werden. 
Analysen an Y-chromosomalen STRs unterliegen in gleicher Weise dem Phänomen der Stotterbanden. Nullallele und allelic dropout würden dagegen bei Y-STRs zum Ausfall eines Locus führen, da diese hemizygot sind.

Eine bekannte DNA-Mutationsform ist die hydrolytische Desaminierung. Sie ist ebenfalls im Zusammenhang mit postmortalen DNA-Schäden identifiziert worden (Hofreiter et al. 2001) und soll chromosomale DNA in gleicher Weise wie mtDNA betreffen (Binladen et al. 2005). Insbesondere die Desaminierung von Cytosin zu Uracil soll hierbei die häufigste Form der Desaminierung sein (z.B. Binladen et al. 2005). Das eigentlich nur in RNA vorkommende Uracil bildet, wie Thymidin, mit Adenin ein Basenpaar aus. Wenn DNA eine solche Basensubstitution aufweist und als Matrize in der PCR verwendet wird, dann baut die Polymerase inkorrekte Basen ein, d.h. ein dATP an die Stelle, an der normalerweise ein dGTP eingebaut werden müsste. Es kommt zu C

$\rightarrow \mathrm{T}$ und respektive auf dem Gegenstrang $\mathrm{G} \rightarrow$ A Transitionen (Hofreiter et al. 2001, Gilbert et al. 2003a, Gilbert et al. 2003b). Gilbert et al. (2003a) zeigten, dass es durch postmortale hydrolytische Desaminierung in der HVR zu Falschbestimmungen der mtHaplotypen kommen kann. Funktionale Gene sind dagegen weit weniger betroffen, als selektionsneutrale Abschnitte wie die HVR (Gilbert et al. 2003a). Die autosomale STRAnalyse erfolgt über die Fragmentlänge der Produkte und nicht über die Basenabfolge. Eine Desaminierung bleibt damit für die Analyse von STRs ohne Konsequenzen, außer sie würde am 3'-Ende eines Primers auftreten und somit die Amplifikation verhindern.

Ein übergeordnetes Problem jeder PCR-Analyse stellen unspezifische Nebenprodukte, welche durch Primerfehlbindungen entstehen, dar (van Oorschot et al. 1994). Diese Fehlbindungen können, durch ein speziell an die Anforderungen von aDNA-Analysen angepaßtes Primerdesign, verringert werden (Hummel 2003).

\subsection{Kontaminationsprävention}

Ein wichtiger Punkt für die aDNA-Forschung ist die Gewährleistung der Authentizität ermittelter Analyseergebnisse. Das heißt, es muss sichergestellt werden, dass keine falsch-positiven Ergebnisse durch Einschleppung kontaminierender exogener DNA generiert werden. Kontaminationsquellen sind „carry over“-Kontamination (Kwok 1990), Kreuzkontamination (Kitchin et al. 1990), nicht DNA-freie Laborutensilien wie 
z. B. Einwegmaterialien, insbesondere PCR-Cups und Reagenzien (Schmidt et al. 1995) sowie der Eintrag menschlicher DNA durch Körperzellen (Kitchin et al. 1990).

Zur Vermeidung von Kontaminationen sind folgende Laborstandards und Präventionsmaßnahmen eingehalten worden: Es besteht eine strikte Trennung der Laboratorien in Prä- und Postamplifikationsräume (Kwok 1990). Die Bearbeiter im Labor sowie die beteiligten Archäologen trugen stets Einmalhandschuhe aus Latex, Haarhaube, Mundschutz und Brille. Die Oberflächen der Probenmaterialien wurden mit einem Diamantsägeblatt mechanisch abgetragen (s.Kap.4.1). Einwegmaterialien, Pipettenspitzen und PCR-Cups wurden vor der Benutzung mit UV-Licht bestrahlt (Cone \& Fairfax 1993). Arbeitsgeräte mit Probenkontakt wurden zur Verhinderung von Kreuzkontaminationen mit Seife, bidestilierten Wasser und Ethanol gereinigt.

4.6 Typisierungsstrategien zur Sicherstellung von Authentizität und zur Aufklärung liegezeitbedingter DNA-Degradierungsartefakte

Falsche Ergebnisse können durch zwei Möglichkeiten generiert werden. Zum einen kann ein mögliches authentisches Signal aus einer historischen Probe durch eine Kontamination überlagert werden. In diesem Fall muss durch Prävention (Kap.4.5) und gezielten Typisierungsstrategien die Authentizität der Ergebnisse gesichert werden (i).

Ein anderer Sachverhalt ist, dass ein authentisches Signal vorliegt, dieses aber durch Degradierungsartefakte der DNA (Kap.4.4) falsche Ergebnisse produziert. In diesem Fall sollte die Authentizität der Ergebnisse nicht in Frage gestellt werden, sondern es müssen Typisierungsstrategien angewendet, welche diese Artefakte minimieren (ii).

(i) Molekulargenetische Studien zur Evolution, Migration und Phylogenie von menschlichen Bevölkerungen werden im Wesentlichen mithilfe von mtDNA-Analysen durchgeführt. Diese Studien unterliegen dem Problem, dass die Bearbeiter und die zu untersuchende Probe der gleichen Spezies angehören und die PCR-Technik nicht in der Lage ist, gegen Kontaminationen der gleichen Spezies zu diskriminieren. Darüber hinaus sind mtDNA-Sequenzen wenig variabel. Nur in Fällen, in denen ein ermitteltes mtDNA-Sequenzmuster außerhalb heute lebender Populationen liegt, wie z.B. bei den Arbeiten an den Neandertalerskelettfunden, kann eine Aussage mit hoher Wahrscheinlichkeit hinsichtlich der Authentizität eines Analyseergebnisses gemacht werden. Dagegen fordert man von Forschungsarbeiten, die sich mit mtDNA-Analysen 
an Skelettmaterial von modernen Menschen beschäftigen, wie z.B. an den Resten des Cro-Magnon-Menschen (Caramelli et al. 2003), dass sie den Nachweis der Authentizität ihrer Ergebnisse erbringen.

In Fällen, in denen die DNA-Erhaltung des Probenmaterials zusätzlich die Analyse von chromosomaler DNA erlaubt, empfiehlt sich zur Authentizitätssicherung die Analyse von individuellen Mustern, wie sie der genetische Fingerabdruck darstellt (Hummel et al. 1999a). Mit dieser Technik kann die Authentizität eines aDNA-Extraktes mit einer hohen Wahrscheinlichkeit sichergestellt werden. Dies ist insbesondere dann gewährleistet, wenn die genetischen Fingerabdrücke sämtlicher Personen die Probenkontakt hatten, bekannt sind. Für den Abgleich der Ergebnisse der Lichtensteinhöhle wurden die genetischen Fingerabdrücke aller Institutsmitarbeiter und Studenten, sowie der beteiligten Archäologen ermittelt. Durch die Individualisierbarkeit eines genetischen Fingerabdrucks können Kontaminationen direkt einem Bearbeiter und einem Arbeitsschritt zugeschrieben werden (Hummel et al. 2000). Zwar vermag die STR-Typisierung nicht gegen Probenkontaminationen aus historischen Zeiten zudiskriminieren, diese Art von Kontaminationen würden aber auch nicht mit der Involvierung eines zweiten unabhängigen Labors (second lab; Cooper \& Poinar 2000) aufgedeckt werden (Hummel et al. 1999a, Capelli et al. 2003, Hummel 2003). Diese Kontaminationen können in der Regel durch Mehrfachamplifikationen aus unabhängig hergestellten DNA-Extrakten ermittelt werden (Montiel et al. 2001).

Die Typisierungsergebnisse der Lichtensteiner Proben basieren grundsätzlich nicht nur auf Einzelbestimmungen. In der Regel wurden sie aus zwei DNA-Extrakten und mit mehrfachen Amplifikationen abgesichert. Des Weiteren sollte für die Ergebnisse der Lichtensteinhöhle das intraindividuelle Konkordanzkriterium berücksichtigt werden. Das bedeutet, dass übereinstimmende genetische Fingerabdrücke, welche von verschiedenen Proben desselben Individuums ermittelt werden konnten, sich gegenseitig bekräftigen. Ein nicht unerhebliches Kriterium für die Authentizität der Lichtenstein Ergebnisse ist zudem das hohe Verwandtschaftsverhältnis der Individuen. Es ist sehr unwahrscheinlich, dass man von zwei Individuen genetische Fingerabdrücke ermittelt, deren jeweilige Hälfte sich exakt in einem Dritten verwirklicht und es sich bei diesem um eine Kontamination handelt. Bei Proben, die über ihren genetischen Fingerabdruck eindeutig einem bereits erfassten historischen Individuum zugeordnet werden konnten, wurde vereinzelt, für die Bestimmung der autosomalen STRs, der YSTRs und der mtDNA, auf die reproduzierte Analyse aus zwei unabhängigen Extrakten 
verzichtet. Durch die hohe Individualisierbarkeit des genetischen Fingerabdrucks reichte die einfache Reproduktion aus. Konnten aufgrund der DNA-Erhaltung nur Teilfingerabdrücke oder keine chromosomale DNA ermittelt werden, wurden zur Authentifizierung der mtDNA-Ergebnisse in der Regel jeweils zwei Amplifikationen pro Locus aus zwei unabhängig hergestellten DNA-Extrakten angefertigt. Ergab sich aus dem Sequenzmuster ein Hinweis auf die Zugehörigkeit zu einem Individuum, wurde versucht die Probe über die Morphologie, d.h. den visuellen Vergleich und über das Individualalter, zuzuordnen. In regelmäßigen Abständen wurden bei den mtDNAAnalysen zusätzlich Leerkontrollen mitgeführt. Dies gibt einen Hinweis auf die herstellerabhängige Kontaminationsrate der Reaktionsgefäße.

(ii) Die in Kapitel 4.4 beschriebenen Artefaktprodukte können zu Schwierigkeiten bei der Analyse alter DNA führen. Im Folgenden soll dargelegt werden, welche Strategien verfolgt wurden, um deren Einfluss auf die Analysen so gering wie möglich zu halten.

Niedrige Lagerungstemperaturen des archäologischen Probenmaterials, wie im Fall der Lichtensteinhöhle, reduzieren das Problem der postmortalen Desaminierung (Hofreiter et al. 2001). Es empfehlen sich dennoch Mehrfachamplifikationen für die HVRSysteme, um mögliche Desaminierungsartefakte in den Sequenzen der HVR aufzudecken. Punktuelle Abweichungen in den Sequenzen sollten überprüft werden. Ergeben sich aus den Verwandtschaftsanalysen Abweichungen in den Sequenzen zwischen Kind und einer Putativmutter sollte neben dem Mutationsereignis auch die Desaminierung in Betracht gezogen werden. Liegt der Verdacht auf ein Sequenzierartefakt vor, empfiehlt sich, sowohl H- und L-Strang zu sequenzieren (Lutz et al. 1996). Die Bestimmung der mitochondrialen Basenabfolge erfolgte im Wesentlichen nach den Kriterien, welche bei Schultes (2000, 45) beschrieben sind. Um den Einfluss von Stotterartefakten auf die STR-Typisierung von stark degradierter aDNA so gering wie möglich zu halten, empfiehlt sich im Prinzip ein Handlungskatalog wie er von Schultes (1997) beschrieben wurde. In dem Verfahren wird versucht die korrekt amplifizierten Produkte von den Artefakten zu trennen. Dabei werden die in den Einzelbestimmungen auftretenden Amplifikationsprodukte in drei Kategorien eingestuft: Allelsignal, unsicheres Allelsignal (in Klammern aufgenommen) und Artefaktsignal. Für die Entscheidung, um welches dieser drei Signale es sich handelt, werden die Produkte auf ihre relativen Signalintensitäten und ihren Peakabstand zueinander verglichen. 
Als ein sicheres Allelsignal gelten Peaks, die innerhalb der an sie direkt angrenzenden Bereiche von einer Repeatunit die höchste Signalintensität aufweisen.

$>$ Peaks, die ein bereits bestimmtes Allel um eine Repeatunit flankieren, werden als Artefaktsignal gewertet, wenn ihre relative Höhe zum Allelsignal bei einem kleineren Produkt unter 40\%, bei einem größeren Produkt unter 20\% liegt.

$>$ Peaks, die ein bereits bestimmtes Allel um eine Repeatunit flankieren, werden als unsicheres Allelsignal gewertet, wenn ihre relativen Höhen zum Allelsignal zwischen $40 \%$ und $80 \%$ bei kürzeren Produkten, bei längeren Produkten zwischen $20 \%$ und $60 \%$ liegen.

Signale, die mehr als eine repeat unit vom ersten determinierten Allel entfernt sind und die Fragmentlänge eines möglichen Allels aufweisen, werden unabhängig ihrer Produktintensität gewertet. Beispielsweise wird ein Allel 19 auch dann gewertet, wenn es nur 10\% der Stärke eines Allels 26 erreicht. Ein Stotterartefakt ist in diesem Fall nahezu ausgeschlossen. Die Abweichungen in den Produktintensitäten sind in der unterschiedlichen Anzahl intakter DNATargets, die in der PCR für die beiden Allele zur Verfügung standen, begründet.

$>$ Peaks, die eine ungewöhnliche Form aufweisen, d.h. sehr breitbasig sind, werden als Artefaktsignale gewertet.

Der Genotyp einer Probe setzt sich letztendlich aus mehreren Einzelbestimmungen zusammen. Ein Allel sollte dabei nach Schultes (2000) aus zwei unabhängigen DNAExtrakten mindestens einmal reproduziert worden sein, um im Genotyp berücksichtigt zu werden. Wenn ein Allel dagegen lediglich aus einem Extrakt reproduziert wird, sollte es in Klammern aufgenommen werden. Für die Genotypisierung eines homozygoten Zustandes empfiehlt Schultes (2000) die Homozygotie nur dann zu typisieren, wenn ausschließlich ein Allel innerhalb vier PCRs aus zwei unabhängigen Extrakten amplifiziert wurde.

Der Auswertungskatalog für die Einzelbestimmungen und die Genotypisierung ist in Schultes (2000) detailliert zusammengefasst. Anzumerken ist, dass diese strikte Vorgehensweise des Katalogs sich im Grundsatz bei STR-Analysen an degradierter DNA empfiehlt, jedoch sollte darüber hinaus auch ein fragestellungs- und situationsbedingtes Abweichen möglich sein. 
Eine Signalintensitätsgrenze (z.B.100 rfu), ab welcher ein Allel gewertet wird, sollte nicht von vornherein festgelegt werden. Letztendlich spiegelt die Signalintensität nur die nahezu lineare Auftragmenge des PCR-Produktes wieder. Setzt man doppelt so viel PCR-Produkt in die Fragmentlängenanalyse ein, erhöht sich im gleichen Maße auch die Signalintensität. Peaks unter $50 \mathrm{rfu}$ sind schwer $\mathrm{zu}$ beurteilen, sollten aber nicht kategorisch als Artefakt behandelt werden. Für vergleichende Analysen (Schultes 1997) kann eine rfu-Grenze dagegen sinnvoll sein.

Weiterhin sollte bei der Typisierung der Gesamteindruck eines genetischen Fingerabdrucks, dargestellt in einem Elektropherogramm, berücksichtigt werden. Liegen mehr als zwei Allele in einem Locus vor, dann kann dies auf Stotterartefakte oder eine Mischspur hindeuten. Die Mischspur kann durch die Beurteilung der anderen Loci überprüft werden, das Stotterartefakt durch oben genannten Katalog. Liegen aber beispielsweise in einem Locus nur zwei direkt aufeinanderfolgende Allele vor, d.h. ein möglicher heterozygoter Zustand und ein Allel weist weniger als die oben geforderten Prozentsätze des Größeren auf, kann das kleinere Allel als unsicheres Signal gewertet werden. Bei diesem Beispiel sollten die Ausgangszahlen intakter targets berücksichtigt werden. Startet die Amplifikation der beiden Allele mit stark unterschiedlichen Zielsequenzen, führt dies zu unbalancierten Peakhöhen. Im schlimmsten Fall führt dies zum allelic dropout. Ungleiche Peakhöhen sind für aDNA nicht ungewöhnlich (z.B. Schmerer et al. 1997).

Die Fehlerrate für falsch-homozygote Ergebnisse, verursacht durch allelic dropout, kann bei stark degradierter DNA und bei geringen DNA-Mengen $(<0,05 \mathrm{ng} / 10 \mu \mathrm{l})$ sehr hoch sein und bei nur einer durchgeführten Analyse z.B. 31,3\% erreichen (Gagneux et al. 1997). Um die Möglichkeit eines falsch-homozygoten Ergebnisses zu minimieren, sollten die Genorte mehrfach amplifiziert werden (z.B. Schmerer et al. 1997). Gagneux et al. (1997) schlagen beispielsweise die dreifache Amplifikation vor, um dem statistischen Auftreten von allelic dropout bei stark degradierter Spuren-DNA Rechnung zu tragen.

Für die Proben der Lichtensteinhöhle ergeben sich zusätzliche Möglichkeiten eines flexibleren Typisierungsverfahrens. Wenn für zwei Individuen ein klarer Hinweis auf direkte biologische Verwandtschaft vorliegt (z.B. Vater-Sohn) und schließt sich dies nur in einem STR-System aus, weil einer der beiden in diesem Locus scheinbar homozygot ist und hier nicht das Allel des zweiten Individuums aufweist, könnte das Ergebnis auch nachträglich noch auf allelic dropout zurückgeführt werden (Gagneux et al. 1997). 
Weiterhin sind die Peakhöhen in einer Farbspur für homozygote Allele ungefähr doppelt so hoch wie die Peaks eines heterozygoten Locus (Budowle et al. 1999), da die Amplifikationsprodukte gleicher Allele die gleichen Fragmentlängen aufweisen und sich somit akkumulieren. Diese Aussage trifft in erster Linie für rezente nicht degradierte DNA zu. Ist die aDNA-Erhaltung außergewöhnlich gut, wie es in manchen Fällen für die Proben der Lichtensteinhöhle zutrifft, kann eventuell aus dem Gesamteindruck ein homozygoter Status ersehen werden. Hinweise darauf ergeben sich, wenn ein vollständiges Allelprofil erzielt wurde und für alle anderen STR-Loci ausbalancierte Peakhöhen vorliegen. In jedem Fall sollte das Ergebnis aber reproduziert werden.

Lässt sich ein Skelettelement über seinen genetischen Fingerabdruck eindeutig einem anderen zuordnen und ist demnach seine Authentizität gesichert, reicht die einfache Reproduktion aus nur einem DNA-Extrakt aus. Möglich ist auch, dass zwei DNAExtrakte aus einem Skelettelement qualitative Unterschiede aufweisen. Wurde für einen DNA-Extrakt reproduziert ein vollständiger genetischer Fingerabdruck ermittelt und für einen zweiten Extrakt ein Teilabdruck, der aber nicht im Widerspruch zum Ersten steht, sollten die erzielten Ergebnisse des ersten Extraktes nicht kategorisch als unsicher eingestuft werden. 


\section{Typisierungsergebnisse und Ableitungen aus den Datensätzen}

Alle angefertigten DNA-Extrakte wurden der autosomalen STR-Analyse unterzogen. Diese Analyse schließt die Geschlechtsbestimmung mit ein. Wurde eine Probe als männlich determiniert, schlossen sich Y-STR-Typisierungen an. Für die Bestimmung der mt-Haplotypen wurden nahezu alle hergestellten DNA-Extrakte mit den beiden HVR-Systemen untersucht.

Vereinzelt konnten keine cranialen Skelettelemente einem von Schultes (2000) typisierten Femur und damit einem eigenständigen Individuum zugeordnet werden (s.u.). Die Daten der jeweiligen mt- und Y-Haplotypen sind jedoch nötig, um eine Eingliederung in den Stammbaum der Lichtensteinhöhle zu ermöglichen. Aus diesem Grund wurden authentifizierte DNA-Extrakte der jeweiligen Femora für die mtDNAund Y-Marker nachtypisiert.

\subsection{Autosomale STRs, Geschlechtsbestimmung und Zuordnung von Skelettelementen}

Der Amplifikationserfolg der autosomalen STR-Typisierung kann für viele der bearbeiteten Fundstücke mit sehr gut beschrieben werden. Die in diesem Projekt etablierte Oktaplex-PCR zeigte dabei ihre Eignung für die Typisierung stark degradierter DNA. Dies war zu erwarten, da mit Ausnahme des STR-Locus VWA die Primer aus einer bestehenden 17-Plex stammen, welche sich bereits für die Typisierung der bronzezeitlichen Proben als geeignet erwies (Schilz et al. 2004). Im Gegensatz zur 17-Plex werden mit der Oktaplex zwar weniger STR-Loci pro Analyse bestimmt, jedoch brachte die verminderte Anzahl der STR-Loci eine weitere Steigerung der Robustizität der PCR mit sich. Eine erfolgreiche Oktaplex-Amplifizierung ist für eine Auswahl der angefertigten DNA-Extrakte beispielsweise in Abbildung $11 \mathrm{zu}$ sehen. Als Bestätigung der sicheren Allel-Bestimmung mit der Oktaplex-PCR können die Ergebnisse des Profiler Plus ${ }^{\mathrm{TM}}$ Kits gelten. Abweichungen in den Typisierungsergebnissen zwischen den beiden Kits, deren Ursache in einem falschen Design der Oktaplex begründet wäre, konnten nicht festgestellt werden. Jedoch tritt gelegentlich ein unspezifisches PCR-Produkt im Bereich des blau markierten STRLocus FGA im Bereich des Allels 26 auf. Zu erkennen ist ebenso im gelb markierten Analysebereich ein unspezifisches Produkt, dessen Fragmentlänge und 
Peakmorphologie exakt mit dem Produkt in FGA übereinstimmt. Folglich wird ein unspezifisches Produkt, durch Primerfehlbindungen eines gelb markierten und eines blau markierten Primers, im Genom gebildet. In Fällen in denen eine Abgrenzung zwischen einem echten Allel und einem unspezifischen Produkt nicht möglich war, wurde auf die Ergebnisse des ProfilerPlus ${ }^{\mathrm{TM}}$ Kits zurückgegriffen. Dieses in der Forensik und Anthropologie etablierte Analysesystem zeigt wie erwartet hervorragende Amplifikationsergebnisse (Abb.12). Für die Typisierung der Proben wurden die PCRProdukte auf ein PAA-Gel aufgebracht. Die Elektropherogramme (Abb.13 und 14) zeigen exemplarisch die Qualität der generierten genetischen Fingerabdrücke jeweils für eines der beiden Amplifikationssysteme. Alle Typisierungsergebnisse der bearbeiteten Funde sind im Anhang tabellarisch aufgeführt (Kap.11.5.2). 


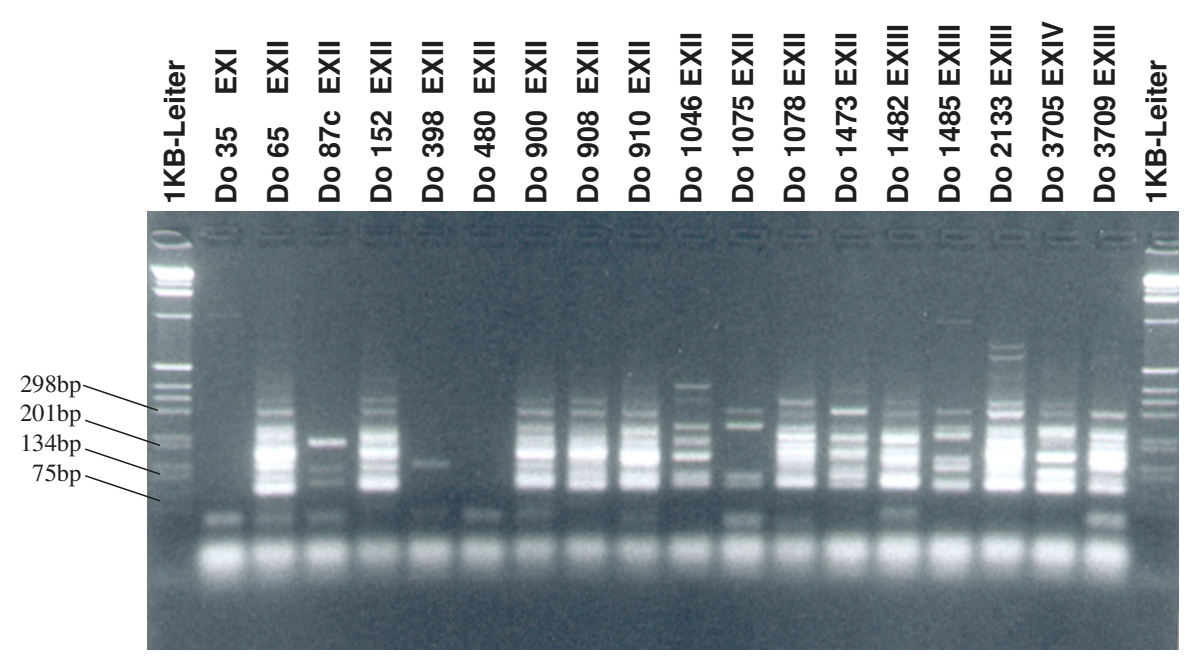

Abbildung 11: Das Agarosebild zeigt den Amplifikationserfolg der Oktaplex-PCR (PCR 45) für die bronzezeitlichen Proben der Lichtensteinhöhle (Do). Die Amplifikationsprodukte liegen zwischen 100-280bp. Unter 75bp befinden sich Primerdimere und freie Primer. Als Längenstandard diente die 1KB-Leiter.

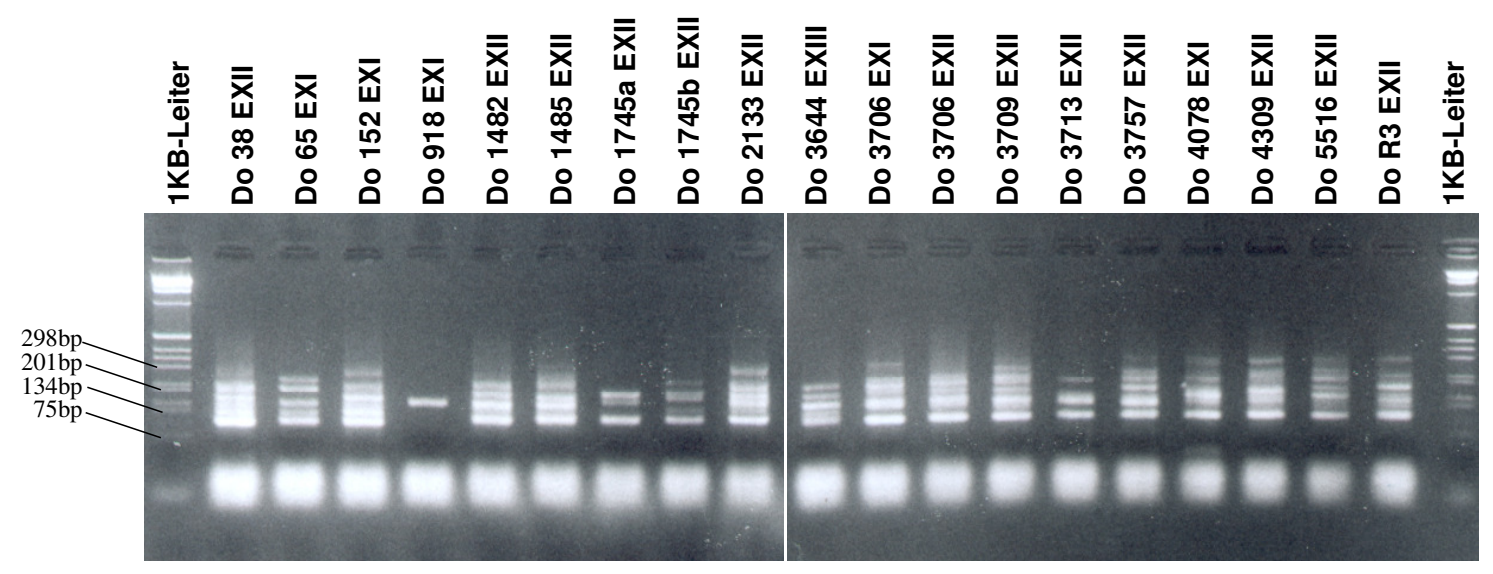

Abbildung 12: Agarosebild. Dargestellt sind Profiler Plus ${ }^{\mathrm{TM}}$ Amplifikationen (PCR 41) mit verschiedenen bronzezeitlichen Proben aus der Lichtensteinhöhle (Do). Die Amplifikationsprodukte liegen zwischen 100 und 360bp. Unter $75 \mathrm{bp}$ befinden sich Primerdimere und freie Primer. Als Längenstandard diente die 1KB-Leiter. 


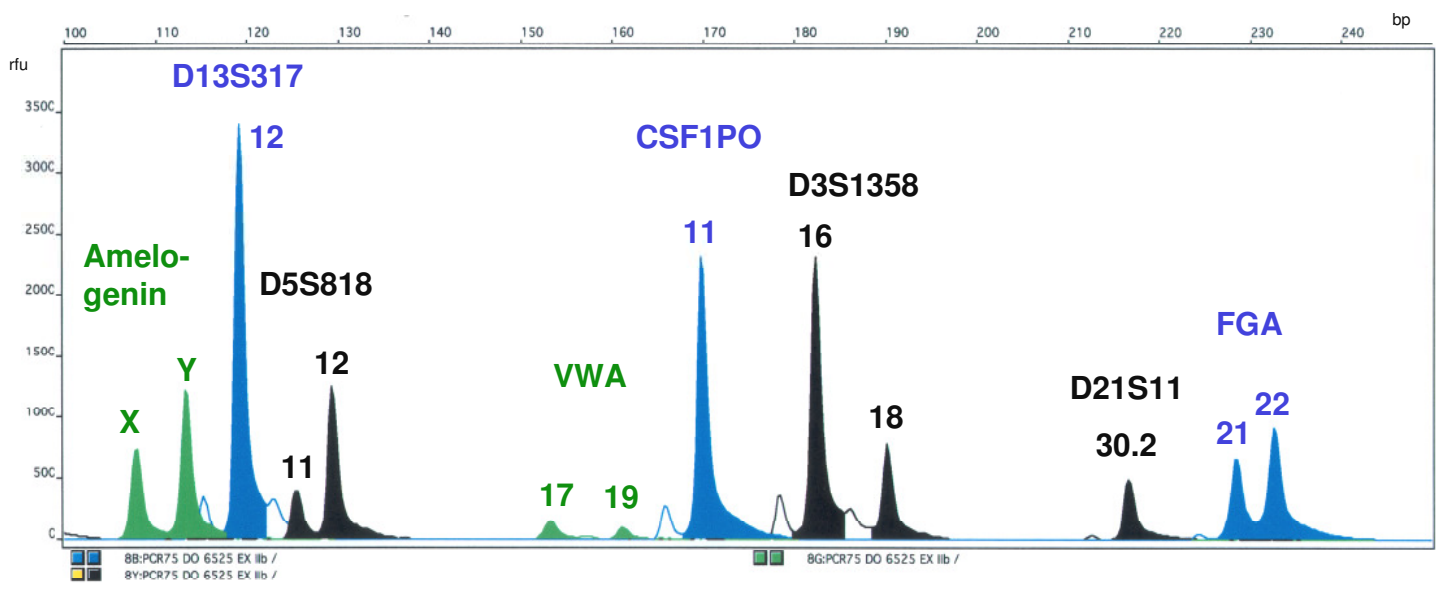

Abbildung 13: Genetischer Fingerabdruck des Fundes mit der Nummer Do6525, amplifiziert mit der Oktaplex-PCR. Auf der x-Achse ist die Fragmentlänge der Produkte in Basenpaaren (bp) dargestellt, die y-Achse gibt die Peakhöhen in relativen Fluoreszenzeinheiten (rfu) wieder.

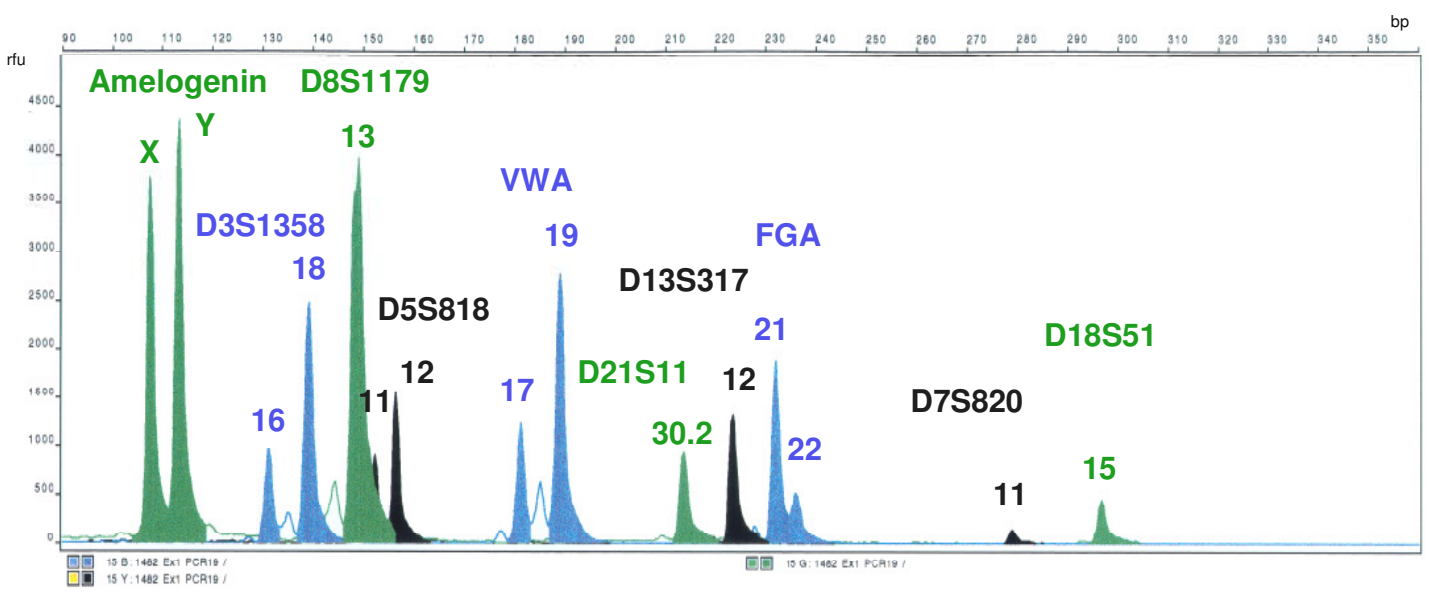

\begin{abstract}
Abbildung 14: Genetischer Fingerabdruck des Fundes mit der Nummer Do1482, amplifiziert mit dem Profiler Plus ${ }^{\mathrm{TM}}$ Kit. Auf der $\mathrm{x}$-Achse ist die Fragmentlänge der Produkte in Basenpaaren (bp) dargestellt, die y-Achse gibt die Peakhöhen in relativen Fluoreszenzeinheiten (rfu) wieder.
\end{abstract}

Neben der Bestimmung des Amplifikationserfolges anhand von Agarosebildern und Elektropherogrammen kann der Erfolg auch rechnerisch gezeigt werden. Bestimmt man für die cranialen Skelettelemente ihre Anzahl sicher typisierter Allele, kann eine Einteilung in verschiedene qualitative Kategorien erfolgen (Abb. 15).

Für zehn autosomale STRs sind 20 Allele zu typisieren. Für jedes untersuchte Skelettelement wurde die Zahl ihrer sicher typisierten Allele zusammengezählt. Unsichere Allele (= in Klammern aufgenommen) wurden bei dieser Auswertung genauso wenig berücksichtigt wie STR-Loci, bei denen mehr als zwei Allele im Genotyp stehen (= Stotterartefakte). 
Es sollte bei dieser Auswertung jedoch berücksichtigt werden, dass nicht für jedes Skelettelement gleich viele DNA-Extrakte angefertigt worden sind. Des Weiteren wurde nicht immer gleich häufig pro Amplifikationskit typisiert. Zusätzlich basieren die Gesamtgenotypen von neun cranialen Skelettelementen (die Unterkiefer Do 1172, 1247, 2111, 2263, 2589, 2749 und die Schädel R1, R2, R3) auch auf den Typisierungsergebnissen von Schultes (2000). Diese wurden jeweils als unabhängiges Ergebnis gewertet und mit in die eigene Genotypisierung einbezogen. Dabei haben diese Ergebnisse eine ebenfalls hohe Aussagekraft, da hinter diesen Ergebnissen immer zwei unabhängige DNA-Extrakte und mehre Amplifikationen mit dem ProfilerPlus ${ }^{\mathrm{TM}}$ Kit stehen. Konnte in dieser Studie für einen STR-Locus kein Genotyp ermittelt werden, dagegen aber in 2000, wurde letzteres Ergebnis mit in den Genotyp des Individuums übernommen (Tab.9). Standen die Ergebnisse im Widerspruch mit den eigenen Datensätzen, d.h. unsichere und/oder abweichende Typisierungen, wurden die Einzeltypisierungen von Schultes (2000) überprüft und gegebenenfalls durch weitere Amplifikationen bestätigt oder korrigiert.

Tabelle 9: Beispiel für eine Berücksichtigung der Typisierungsdaten von Schultes (2000). In den unterlegten Feldern (STR-Loci D8S1179 und D7S820) sind die Allele 13/13 bzw. 11/12 von Schultes (2000) sicher typisiert worden und werden in den Genotyp übernommen.

\begin{tabular}{|c|c|c|c|c|c|c|c|c|c|c|c|c|}
\hline \multirow{2}{*}{$\begin{array}{l}\text { F12 } \\
\text { PCR }\end{array}$} & \multicolumn{12}{|c|}{ R1 [Calvarium] } \\
\hline & $\mathrm{EX}$ & Amelo & D3S1358 & VWA & FGA & D8S1179 & D21S11 & D18S51 & D5S818 & D13S317 & D7S820 & CSF1PO \\
\hline \multicolumn{2}{|c|}{$\begin{array}{c}\text { Schultes } \\
2000\end{array}$} & $\mathrm{XX}$ & $16 / 16$ & $14 / 17$ & $21 / 21$ & $13 / 13$ & $29 / 33.2$ & $16 / 17$ & $9 / 12$ & $11 / 12$ & $11 / 12$ & \\
\hline 7 & I & $\mathrm{X}$ & 16 & 17 & 21 & $3<$ & $29 / 33.2$ & $3<$ & $9 / 12$ & $11 / 12$ & 3 & 10 \\
\hline 8 & I & $\mathrm{X}$ & 16 & $14 / 17$ & 21 & 13 & $29 / 33.2$ & $16 / 17$ & $9 / 12$ & $11 / 12$ & 12 & $3<$ \\
\hline 9 & I & $\mathrm{X}$ & 16 & 17 & 21 & $3<$ & $28 / 29 / 33.2$ & 3 & $9 / 12$ & $11 / 12$ & $3<$ & $10 / 11$ \\
\hline 69 & II & $\mathrm{X}$ & 16 & $14 / 17 / 19$ & 21 & $3<$ & 33.2 & $3<$ & $9 / 12$ & $11 / 12$ & $3<$ & $10 / 11$ \\
\hline 75 & $\mathrm{IIb}$ & $\mathrm{X}$ & 16 & $14 / 17$ & $(21)$ & 3 & $29 / 33.2$ & 3 & $9 / 12$ & $11 / 12$ & 3 & $10 / 11$ \\
\hline \multicolumn{2}{|c|}{ Genotyp } & $\mathrm{XX}$ & $16 / 16$ & $14 / 17$ & $21 / 21$ & $13 / 13$ & $29 / 33.2$ & $16 / 17$ & $9 / 12$ & $11 / 12$ & $11 / 12$ & $10 / 11$ \\
\hline
\end{tabular}

Legende: $\mathrm{F}=$ male, - = Allel nicht bestimmbar, ( ) = unsicheres Allel

Für die Auswertung wurden die Typisierungsdaten in fünf verschiedene Kategorien eingeteilt: sehr guter Amplifikationserfolg (20 - 16 Allele typisiert), guter (15 - 11), mittlerer $(10-6)$, schlechter Erfolg (5 - 1) sowie kein Ergebnis (0).

Die graphische Darstellung (Abb. 15) zeigt, dass für 21 von 68 Proben nahezu vollständige genetische Fingerabdrücke und für weitere 14 Elemente mindestens 11 Allele typisiert werden konnten. Elf Allele entsprechen ca. fünf STR-Loci, deren Bestimmungssicherheit immer noch ausreichend ist um eine Individualisierung oder einen Ausschluss zu gewährleisten. Zusammen stellen diese beiden Kategorien $51 \%$ der Proben dar (Abb.16). Nur in $21 \%$ der Fälle konnte aufgrund der schlechten 
chromosomalen DNA-Erhaltung keine sicheren Allele im Genotyp der Proben festgestellt werden.

\section{Amplifikationserfolg autosomaler STRs}

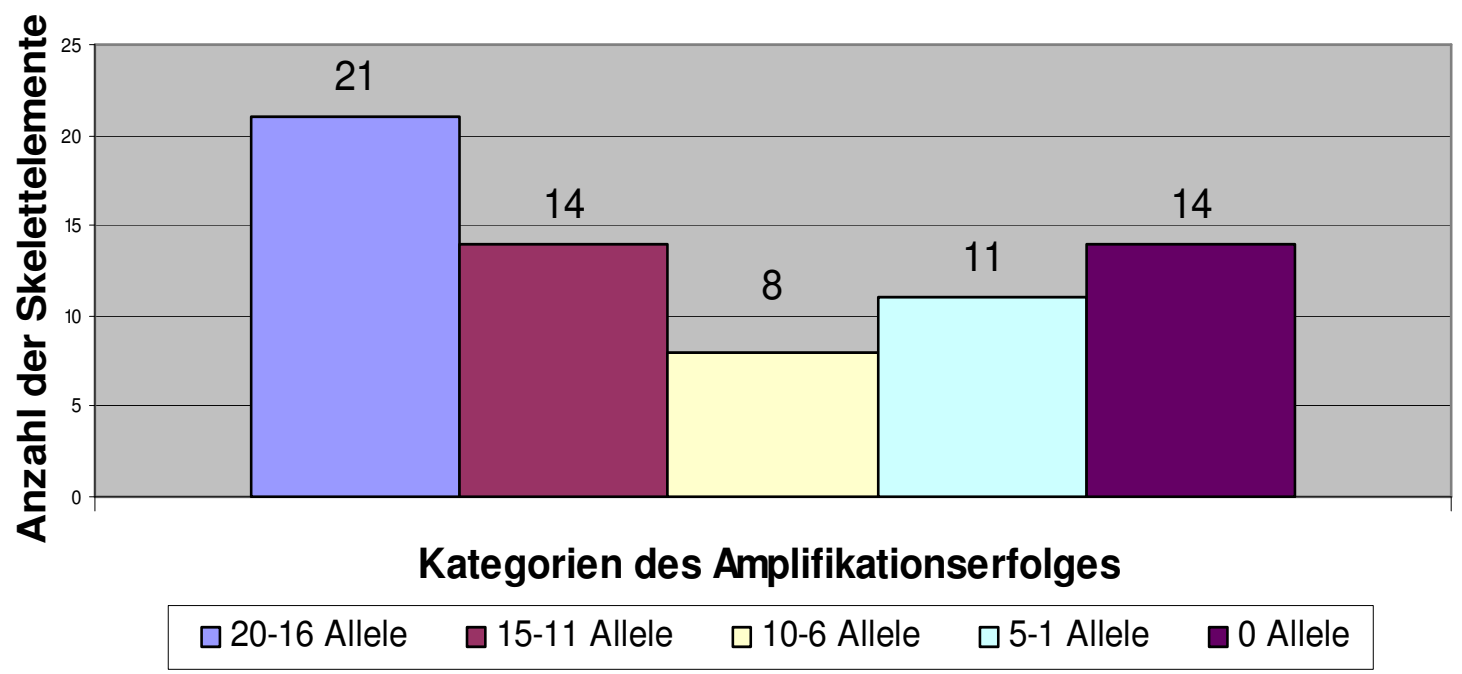

Abbildung 15: Autosomaler STR-Amplifikationserfolg für die 68 bearbeiteten cranialen Skelettelemente. Die Anzahl der sicher typisierten Allele im Gesamtgenotyp der Proben legen die Zugehörigkeit zu einer der fünf Kategorien fest. Für 21 craniale Skelettelemente konnten zwischen 20 und 16 sicher typisierte Allele bestimmt werden und stellen damit einen nahezu vollständigen genetischen Fingerabdruck dar.

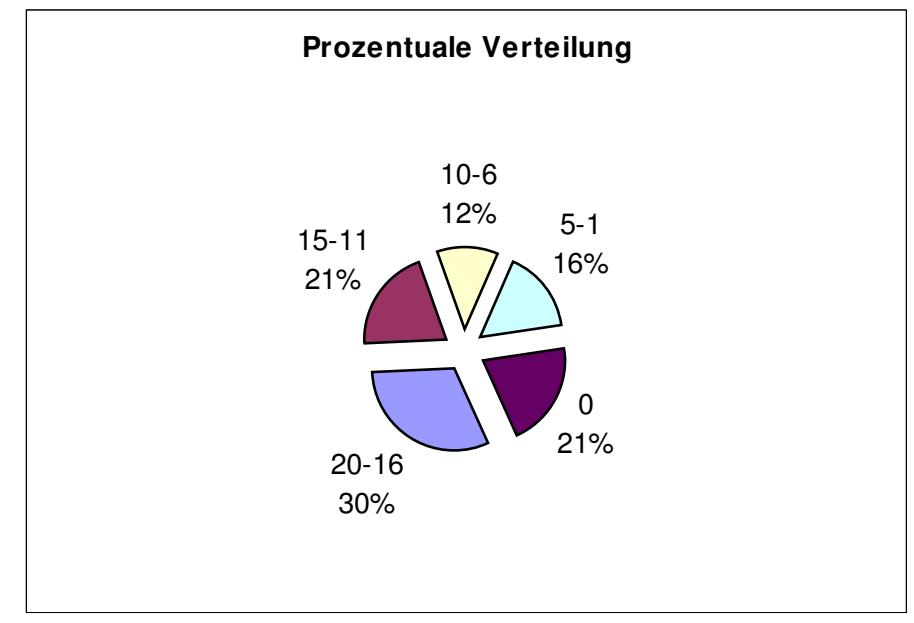

Abbildung 16: Prozentuale Verteilung der Skelettelemente in den jeweiligen Güte-Kategorien:

sehr guter Amplifikationserfolg = 20-16 sicher typisierte Allele, gut $=15-11$, mittel $=10-6$, schlecht $=5-1$ und kein Ergebnis $=0$.

Schultes (2000) ermittelte eine Erfolgsquote von 38\%, bei der für die Proben mindestens 6 Systeme bestimmt werden konnten. Die Amplifikationsergebnisse sind nicht direkt vergleichbar, da zum einen auf Schultes Daten (s.o.) zurückgegriffen wurde und zum anderen hier ein weiteres Amplifikationssystem und ein STR-Locus mehr 
untersucht wurden. Dennoch deutet das Ergebnis von 30\% der Proben, bei denen etwa acht STR-Loci bestimmt werden konnten, darauf hin, dass die Ausgangsvermutung der besseren DNA-Erhaltung aus Zahnproben auch für diese Arbeit zutrifft. Die Annahme einer sehr guten DNA-Erhaltung in Felsenbeinen konnte ebenfalls bestätigt werden. Verglichen mit der aus Zähnen, könnte hier sogar eine leicht bessere für die Felsenbeine angenommen werden. Diese Arbeit hatte jedoch nicht zum Schwerpunkt dieses auszutesten und so kann diese Behauptung statistisch nicht nachgewiesen werden. In einer separaten Studie an der Abteilung Historische Anthropologie der Universität Göttingen wird zurzeit differenziert, welches Skelettelement die besten DNA-Erhaltung aufweist (Kleindorp in prep.). Hier zeigt sich der Trend, dass die DNA-Erhaltung in Felsenbeinen vergleichbar gut ist wie die aus Zähnen (pers. Mitteilung Kleindorp).

Eines kann darüber hinaus mit großer Sicherheit festgestellt werden, aufgrund der chromosomalen Typisierungsergebnisse ist die DNA-Erhaltung und -Qualität des 3000 Jahre alten Probenmaterial als einzigartig gut einzustufen.

Die Analyseergebnisse der alten Proben zeigen aber auch erwartungsgemäß die für aDNA-Analysen bekannten Phänomene, wie allelic dropout und Stotterartefakte. Diese Artefakte korrelieren eng mit der DNA-Menge und -Qualität. Für Proben mit guten Ausgangsbedingungen treten diese Phänomene weniger stark in Erscheinung. Eine Abnahme der Produktintensitäten mit zunehmender Fragmentlänge (Hummel et al. 1999a) ist für die Vielzahl der Proben gegeben. Bevorzugt kommt es bei den langen Produkten der STRs zu einem allelic dropout. Für den ProfilerPlus ${ }^{\mathrm{TM}}$ Kit trifft das für die Systeme D7S818 und D18S51 zu. Beide Systeme liegen in Bereichen über 250bp. In vielen untersuchten Proben sind es auch beide Systeme, die nicht typisiert werden konnten. Das trifft dementsprechend weniger auf die STR-Loci mit kurzen Fragmentlängen zu, da Targets mit kurzen Fragmentlängen häufiger intakt vorliegen (Clayton et al. 1998).

\section{Molekulargenetische Geschlechtsbestimmung}

Die Geschlechtsbestimmung wurde mithilfe des molekulargenetischen Markers Amelogenin vorgenommen, der sowohl in der Oktaplex-PCR als auch im ProfilerKlus ${ }^{\mathrm{TM}}$ Kit mitanalysiert wird. Dabei handelt es sich um ein Gen, welches auf den Geschlechtschromosomen lokalisiert ist. Dieser Genabschnitt weist auf dem XChromosom eine 6bp Deletion auf. Bei der Verwendung der Primer von Sullivan et al. 
(1993) haben beide Allele der Frau eine Fragmentlänge von 106bp. Bei männlichen Individuen wird ein 106bp langes Produkt für ihr X-Chromosom und ein 112bp langes Produkt für ihr Y-Chromosom amplifiziert. Letztendlich ist über dieses Muster eine Geschlechtsbestimmung möglich. An historischem Probenmaterial konnte dieser Marker erfolgreich u.a. an den archäologischen Skelettserien Wremen/Fallward (Hummel et al. 1995) und den Neugeborenen- und Kinderskeletten von Aegerten/Kanton Bern (Lassen et al. 2000) angewendet werden. Es muss berücksichtigt werden, dass das Phänomen des allelic dropout naturgemäß auch diesen Locus betrifft. Bei dem Ausfall des Y-Signals würde eine falsche Typisierung der männlichen Individuen geschehen, aufgrund von Mehrfachamplifikationen ist dies aber überprüfbar. Die Ergebnisse der Geschlechtsbestimmung sind für die einzelnen Skelettelemente in den Typisierungstabellen der genetischen Fingerabdrücke zu finden. Das Geschlecht der einzelnen Individuen ist in Tabelle 27, Kapitel 11.1.3 aufgeführt. Die Geschlechterrelation wird in Kap.7.2 und 11.1.2 aufgegriffen.

\section{Zusammenfassung der genetischen Daten und Zuordnung von Skelettelementen}

Mithilfe des genetischen Fingerabdrucks lassen sich isoliert vorliegende Skelettelemente einem Individuum zuordnen. Eine solche Zusammenführung von Knochen konnte bereits für eine geringe Anzahl von Skelettelementen der Lichtensteinhöhle vorgenommen werden (Schultes et al. 1997).

Schultes (2000) konnte in seiner Arbeit an vorwiegend linken Femora 21 verschiedene Individuen anhand ihrer genetischen Fingerabdrücke identifizieren. In den überwiegenden Fällen konnten nun in dieser Arbeit diesen linken Femora craniale Skelettelemente zugeordnet werden. Zusätzlich konnten durch die Arbeiten zum Verteilungsmuster der Knochen weitere Skelettelemente in ihrer Zugehörigkeit zu anderen ermittelt werden (s.Kap. 6.4). Im Hinblick auf die Ansprache ist es nicht mehr praktikabel, die verschiedenen Individuen anhand einer einzelnen Fundnummer zu benennen. Beispielsweise konnten über den genetischen Fingerabdruck die Funde Do3669 (Tibia re.), Do3709 (Mandibula), Do3750 (Femur li.), Do4032 (Calcaneus li.) und Do5517 (Calvarium) ein und demselben weiblichen Individuum zugeordnet werden. Das Individuum wurde bis in das Jahr 2004 mit Do3750 benannt. Eine Vereinheitlichung der Ansprache war daher zwingend notwendig. Aus diesem Grund wurden die Buchstaben $\mathrm{F}$ (=female) und $\mathrm{M}$ (=male) eingeführt und die einzelnen Individuen in dem jeweiligen Geschlecht durchnummeriert. Diese Nummerierung 
unterliegt dabei keiner besonderen Regel. Im obengenannten Beispiel wurde das weibliche Individuum abschließend mit F6 bezeichnet und beinhaltet alle aufgeführten Fundnummern.

Durch die Zuordnung der Skelettelemente ist es möglich, einen Gesamtgenotyp für die einzelnen Individuen zu erstellen. Dabei werden die Genotypen der jeweiligen zusammengehörenden Skelettelemente abgeglichen. Die Typisierungen ergänzten sich in der Art, dass oftmals ein vollständiger genetischer Fingerabdruck angegeben werden kann. Dies soll am Beispiel von Individuum F7 gezeigt werden (s.Tab. 10-13).

Tabelle 10: Genotyp des Neurocranium mit der Fundnummer Do65.

\begin{tabular}{|c|c|c|c|c|c|c|c|c|c|c|c|c|}
\hline F7 & \multicolumn{10}{|c|}{65 [Neurocranium] } \\
\hline PCR & EX & Amelo & D3S1358 & VWA & FGA & D8S1179 & D21S11 & D18S51 & D5S818 & D13S317 & D7S820 & CSF1PO \\
\hline Genotyp & XX & $15 / 16$ & $17 / 17$ & $22 / 25$ & $11 / 13$ & $\begin{array}{c}29 / \\
(32.2)\end{array}$ & $-/$ & $12 / 12$ & $8 / 12$ & $-/-$ & $(11) /-$ \\
\hline
\end{tabular}

Tabelle 11: Genotyp des linken Oberschenkelbeines mit der Fundnummer Do1206.

\begin{tabular}{|c|c|c|c|c|c|c|c|c|c|c|c|c|}
\hline F7 & \multicolumn{10}{|c|}{ Do 1206 [Femur li.] } \\
\hline PCR & EX & Amelo & D3S1358 & VWA & FGA & D8S1179 & D21S11 & D18S51 & D5S818 & D13S317 & D7S820 & CSF1PO \\
\hline Genotyp & XX & $15 / 16$ & $17 / 17$ & $22 / 25$ & $11 / 13$ & $29 /-$ & $15 / 15$ & $12 / 12$ & $8 /-$ & $(8) / 10$ & $-/-$ \\
\hline
\end{tabular}

Tabelle 12: Genotyp des Unterkiefers mit der Fundnummer Do1247.

\begin{tabular}{|c|c|c|c|c|c|c|c|c|c|c|c|c|}
\hline F7 & \multicolumn{10}{|c|}{ Do 1247 [Mandibula] } \\
\hline PCR & EX & Amelo & D3S1358 & VWA & FGA & D8S1179 & D21S11 & D18S51 & D5S818 & D13S317 & D7S820 & CSF1PO \\
\hline Genotyp & $\mathrm{X}$ & $15 / 16$ & $17 /-$ & $22 /-$ & $11 / 13$ & $\begin{array}{c}29 / \\
32.2\end{array}$ & $-/$ & $12 / 12$ & $8 /-$ & $10 /-$ & $-/-$ \\
\hline
\end{tabular}

Tabelle 13: Gesamtgenotyp Individuum F7

\begin{tabular}{|l|c|c|c|c|c|c|c|c|c|c|c|c|}
\hline \multicolumn{10}{|c|}{ Individuum F 7 } \\
\hline PCR & EX & Amelo & D3S1358 & VWA & FGA & D8S1179 & D21S11 & D18S51 & D5S818 & D13S317 & D7S820 & CSF1PO \\
\hline $\begin{array}{l}\text { Gesamt- } \\
\text { Genotyp }\end{array}$ & XX & $\mathbf{1 5 / 1 6}$ & $\mathbf{1 7 / 1 7}$ & $\mathbf{2 2 / 2 5}$ & $\mathbf{1 1 / 1 3}$ & $\mathbf{2 9 /}$ & $\mathbf{1 5 / 1 5}$ & $\mathbf{1 2 / 1 2}$ & $\mathbf{8 / 1 2}$ & $\mathbf{( 8 ) / 1 0}$ & $\mathbf{( 1 1 ) / - ~}$ \\
\hline
\end{tabular}

Legende: $\mathrm{F}$ = female, - = Allel nicht bestimmbar, ( ) = unsicheres Allel

Demnach konnte zwar kein vollständiger genetischer Fingerabdruck für eines der drei Skelettelemente (Neurocranium, Mandibula und Femur) bestimmt werden. Dennoch sind die Übereinstimmungen der einzeln ermittelten Genotypen hoch, sodass eine Zusammengehörigkeit als gesichert gelten kann. Dies wird dadurch bestärkt, dass in keinem der analysierten STR-Systeme ein grundsätzlich abweichendes Allel festgestellt werden konnte. Vielmehr ergänzen sich die Einzelgenotypen in der Art, dass ein zusammengefasster Gesamtgenotyp für das weibliche Individuum F7 ausgewiesen werden kann. Darüber hinaus ist das morphologische Alter der drei Skelettelemente übereinstimmend (Altersklasse Infans 2) und damit ein weiterer stützender Hinweis für die ohnehin sichere Zusammengehörigkeit der Knochenelemente. 
In wenigen Fällen kam es bei dem Abgleich der Genotypen verschiedener Skelettelemente desselben Individuums zu Abweichungen in den einzelnen STR-Loci. Wurde für ein Skelettelement in einem STR-Locus eine Homozygotie festgelegt und in einem weiteren Skelettelement desselben Individuums ein heterozygoter Status, wurde im Gesamtgenotyp nach gründlicher Überprüfung aller Einzelergebnisse der heterozygote Zustand als der wahrscheinlichere angenommen. Lagen dagegen drei Allele in einem Locus vor, deren Ursprung nicht in einer Trisomie, sondern in einem Analyseartefakt liegt, wurde diese Typisierung wenn möglich anhand anderer Skelettelemente überprüft und dann auf die Wahrscheinlichsten reduziert. Diese wurden dann in der Regel in Klammern aufgenommen. Konnte ein Skelettelement nicht zweifelsfrei einem anderen zugeordnet werden, weil sie in einem STR-Locus unterschiedliche Genotypen aufwiesen, z.B. 16/17 und 17/19, dann wurden für diese Knochenproben weitere Analysen durchgeführt um den jeweiligen Status zu überprüfen. Ließ sich dieser Widerspruch nicht klären, wurde die Zugehörigkeit, wenn überhaupt, unsicher gewertet und in Klammern aufgenommen (s.u.).

Die Ergebnislage nach den genetischen Typisierungen dieser Studie kann wie folgt zusammengefasst werden.

Sieben der von Schultes typisierten Individuen waren bereits durch ein craniales Skelettelement belegt, konnten bestätigt und zum Teil dem passenden Gegenstück zugeordnet werden, d.h. zu einem Unterkiefer der Schädel. Für zehn der damals typisierten Oberschenkelbeinbeine ließ sich jeweils mindestens ein craniales Skelettelement sicher bestimmen. Weiterhin konnte jeweils mit geringerer Sicherheit dem Femur Do183 (M11) ein Unterkiefer und dem Femur Do905 (M14) ein Schädel zugewiesen werden. Lediglich für zwei Femora (Do1500 = F2 und Do58.3 = M13) wurde kein zugehöriger Schädel und Unterkiefer gefunden.

Darüber hinaus wurden in dieser Studie über den genetischen Fingerabdruck weitere 12 Individuen mit zum Teil mehreren Skelettelementen sicher aufgeklärt. Weitere zwei Individuen (F20 und F21) können, aufgrund ihres fragmentarischen genetischen Fingerabdruckes, zwar nicht sicher abgegrenzt, aber in Kombination mit den mtAnalysen (s.Kap.5.2) ebenfalls als eigenständige Individuen dargestellt werden. Außerdem wurden eine rechte Tibia (Do153) und ein linker Calcaneus (Do487) typisiert (Croll 2005 und Klingner 2005), die den gleichen genetischen Fingerabdruck aufweisen, welcher bislang nicht bekannt war (M19). Weiterhin konnte als einziges 
Skelettelement ein linker Calcaneus (Klingner 2005) einem linken Femur Do1585 zugeordnet werden. Beide tragen die gleiche Fundnummer Do1585 und bilden das Individuum F19. Abschließend werden die von Schultes (2000) typisierten linken Femora Do57.2 (M17), Do300 (F17) und Do901 (M18), die nicht zu den oben beschriebenen 21 gehören, als eigene Individuen eingestuft. Damit ergibt sich zum Abschluss der genetischen Untersuchungen eine Mindestindividuenzahl von 40. Diese rechnerisch ermittelte Zahl ist durch keines der bislang untersuchten Skelettelemente direkt belegt und konnte somit nur über die genetischen Daten ermittelt werden.

In Tabelle 14 und 15 sind alle Skelettelemente, welche sicher zu einem männlichen oder weiblichen Individuum zusammengefasst werden konnten, dargestellt. Des Weiteren ist zu jedem Individuum der Gesamtgenotyp für die autosomalen STRs angegeben. Letzterer schließt die Geschlechtsbestimmung mit dem Marker Amelogenin ein. Die Tabellen zur Erstellung des Gesamtgenotyps eines Individuums sind im Anhang aufgeführt (Kap.11.5.2, S.207ff). Die Typisierungsergebnisse der DNA-Analysen der Tibiae, Calcanei, Humeri und Radii sind in den jeweiligen Arbeiten zum Verteilungsmuster angegeben (Croll 2005, Gärtner 2005, Klingner 2005, Mußlick 2005). Nur in Einzelfällen wurden sie in das Tabellenwerk im Anhang übernommen. 
Tabelle 14: Gesamtgenotypen für die weiblichen Individuen der Lichtensteinhöhle mit ihren zugehörigen Skelettelementen.

\begin{tabular}{|c|c|c|c|c|c|c|c|c|c|c|c|c|}
\hline № & $\begin{array}{c}\text { Skelettelement } \\
\text { [Do] }\end{array}$ & $\frac{O}{\grave{\Xi}}$ & 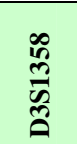 & $\sum^{4}$ & $\bigcup_{\leq 1}^{\longleftarrow}$ & 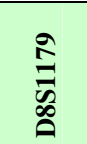 & $\frac{\bar{\sigma}}{\frac{\tilde{D}}{\sigma}}$ & $\begin{array}{l}\vec{n} \\
\infty \\
0\end{array}$ & $\begin{array}{l}\infty \\
\infty \\
\infty \\
\mathscr{\infty}\end{array}$ & $\begin{array}{l}\frac{N}{\tilde{n}} \\
\frac{\tilde{n}}{2}\end{array}$ & 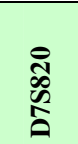 & $\underbrace{0}_{0}$ \\
\hline F1 & $\begin{array}{l}26 \text { [Femur li.] } \\
38 \text { [Mandibula] } \\
152 \text { [Neurocranium] }\end{array}$ & $\mathrm{XX}$ & $16 / 16$ & $16 / 16$ & $20 / 21$ & $8 / 15$ & $28 / 29$ & $12 / 18$ & $9 / 11$ & $11 / 13$ & $9 / 12$ & $11 / 13$ \\
\hline F2 & $\begin{array}{l}319 \text { [Tibia re.] } \\
1500 \text { [Femur li.] } \\
2642 \text { [Calcaneus li.] }\end{array}$ & $\mathrm{XX}$ & $16 / 18$ & $17 / 18$ & $20 / 21$ & $13 / 14$ & $28 / 30$ & $12 / 15$ & $11 / 12$ & $11 / 12$ & $10 / 13$ & $11 / 13$ \\
\hline F3 & $\begin{array}{l}\text { 1746I [Felsenbein re.] } \\
\text { 1746II [Felsenbein li.] } \\
2388 \text { [Mandibula] }\end{array}$ & $\mathrm{XX}$ & $15 / 16$ & $16 / 17$ & $20 / 21$ & $13 / 15$ & $30 / 33.2$ & $15 /-$ & $9 / 11$ & $11 / 11$ & $10 /-$ & $13 /-$ \\
\hline F4 & $\begin{array}{l}4078 \text { [Mandibula] } \\
4494 \text { [Calcaneus li.] } \\
5516 \text { [Calvarium] }\end{array}$ & XX & $15 / 18$ & $14 / 17$ & $20 / 25$ & $11 / 15$ & $29 / 30$ & $14 / 15$ & $12 / 12$ & $8 / 11$ & $10 / 12$ & $11 / 12$ \\
\hline F5 & $\begin{array}{l}3706 \text { [Calvarium] } \\
3756 \text { [Femur li.] }\end{array}$ & $\mathrm{XX}$ & $18 / 18$ & $17 / 19$ & $21 / 23$ & $12 / 15$ & $28 / 29$ & $16 / 16$ & $12 / 12$ & $8 / 9$ & $10 / 10$ & $10 / 11$ \\
\hline F6 & $\begin{array}{l}3669 \text { [Tibia re.] } \\
3709 \text { [Mandibula] } \\
3750 \text { [Femur li.] } \\
4032 \text { [Calcaneus li.] } \\
5517 \text { [Calvarium] }\end{array}$ & $X X$ & $16 / 18$ & $17 / 17$ & $21 / 23$ & $12 / 13$ & $29 / 32.2$ & $16 / 17$ & $11 / 12$ & $9 / 12$ & $8 / 10$ & $10 / 13$ \\
\hline F7 & $\begin{array}{l}65 \text { [Neurocranium] } \\
1206 \text { [Femur li.] } \\
1247 \text { [Mandibula] }\end{array}$ & $\mathrm{XX}$ & $15 / 16$ & $17 / 17$ & $22 / 25$ & $11 / 13$ & $29 / 32.2$ & $15 / 15$ & $12 / 12$ & $8 / 12$ & $(8) / 10$ & (11)/- \\
\hline F8 & 3631 [Calvarium] & $\mathrm{XX}$ & $18 / 18$ & $14 / 17$ & $21 / 25$ & $11 / 13$ & $30 / 30.2$ & $-/-$ & $12 / 12$ & $8 / 12$ & $10 / 11$ & $11 / 13$ \\
\hline F9 & $\begin{array}{l}3654 \text { [Tibia re.] } \\
3705 \text { [Calvarium] } \\
3742 \text { [Femur li.] } \\
3746 \text { [Mandibula] } \\
4460 \text { [Patella] }\end{array}$ & $\mathrm{XX}$ & $14 / 16$ & $13 / 14$ & $24 / 24$ & $13 / 13$ & $29 / 32.2$ & $12 / 15$ & $10 / 13$ & $8 / 10$ & $9 / 10$ & $12 /-$ \\
\hline F10 & $\begin{array}{l}302 \text { [Mandibula] } \\
1046[\text { Calvarium] }\end{array}$ & $\mathrm{XX}$ & $15 / 16$ & $16 / 16$ & $(22 / 24)$ & $13 / 15$ & $28 / 30.2$ & $-/-$ & $9 / 12$ & $9 / 13$ & $(8 / 12)$ & $11 /-$ \\
\hline F11 & 3713 [Mandibula] & $\mathrm{XX}$ & $18 /-$ & $(16) / 19$ & $-/-$ & $12 /(15)$ & $29 /-$ & $-/-$ & $11 /(12)$ & $8 / 9$ & $-/$ & $11 /(11)$ \\
\hline F12 & R1 [Calvarium] & $\mathrm{XX}$ & $16 / 16$ & $14 / 17$ & $21 / 21$ & $13 / 13$ & $29 / 33.2$ & $16 / 17$ & $9 / 12$ & $11 / 12$ & $11 / 12$ & $10 / 11$ \\
\hline F13 & $\begin{array}{l}1044 \text { [Femur li.] } \\
1078 \text { [Mandibula] } \\
4033 \text { [Calcaneus li.] }\end{array}$ & $\mathrm{XX}$ & $16 / 16$ & $15 / 17$ & $21 / 21$ & $13 / 13$ & $27 / 27$ & $13 / 13$ & $9 / 12$ & $11 / 12$ & $8 / 11$ & $10 / 11$ \\
\hline F14 & $\begin{array}{l}1103 \text { [Femur li.] } \\
4309 \text { [Mandibula] }\end{array}$ & $\mathrm{XX}$ & $14 / 16$ & $14 / 15$ & $23 / 24$ & $11 / 14$ & $28 / 30$ & $12 / 15$ & $11 / 12$ & $12 / 13$ & $12 / 12$ & $11 /-$ \\
\hline F15 & $\begin{array}{l}1744.05 \text { [Calcaneus li.] } \\
2588 \text { [Tibia re.] } \\
2589 \text { [Mandibula] }\end{array}$ & $\mathrm{XX}$ & $15 / 16$ & $14 / 15$ & $22 / 24$ & $13 / 13$ & $28 / 30$ & $-/-$ & $11 / 12$ & $11 / 12$ & $-1-$ & $10 / 11$ \\
\hline F16 & R2 [Calvarium] & $\mathrm{XX}$ & $16 / 18$ & $15 / 18$ & $21 / 21$ & $(15) /-$ & $30 /-$ & $-/-$ & $12 / 12$ & $8 / 12$ & $-/-$ & $13 /-$ \\
\hline F17 & 300 [Femur li.] & $\mathrm{X}$ & $15 / 16$ & $16 /-$ & $-/-$ & $11 / 15$ & $30 /-$ & $-/-$ & $-1-$ & $13 /-$ & $10 /-$ & $-1-$ \\
\hline F18 & $\begin{array}{l}199 \text { [Femur li.] } \\
1176 \text { [Calvarium] } \\
2133 \text { [Mandibula] } \\
\end{array}$ & $\mathrm{XX}$ & $15 / 16$ & $14 / 17$ & $19 / 24$ & $14 / 15$ & $29 / 29$ & $14 / 16$ & $10 / 12$ & $10 / 11$ & $11 / 11$ & $10 / 12$ \\
\hline F19 & $\begin{array}{l}1585 \text { [Femur li.] } \\
1585 \text { [Calcaneus] }\end{array}$ & $\mathrm{XX}$ & $15 / 17$ & $14 / 18$ & $20 / 24$ & $12 / 14$ & $30.2 / 31$ & $15 /-$ & $10 / 12$ & $10 / 11$ & $11 /-$ & $11 / 13$ \\
\hline F20 & 3190 [Mandibula] & $\mathrm{XX}$ & $(16) /-$ & $(16) /-$ & $-/-$ & $-/-$ & $-/-$ & $-1-$ & $-/-$ & $(12) /-$ & $-/-$ & $(11) /-$ \\
\hline F21 & E37 [Viscerocranium] & $\mathrm{XX}$ & $16 /-$ & $16 /-$ & $-/-$ & $-/-$ & $-/-$ & $-/-$ & $-/-$ & $8 /-$ & $-1-$ & $-/-$ \\
\hline
\end{tabular}

Legende: $\mathrm{F}=$ female, $-=$ Allel nicht bestimmbar, $(\mathrm{C}$ = unsicheres Allel oder unsicher zugeordnetes Skelettelement. 
Tabelle 15: Gesamtgenotypen für die männlichen Individuen der Lichtensteinhöhle mit ihren zugehörigen Skelettelementen.

\begin{tabular}{|c|c|c|c|c|c|c|c|c|c|c|c|c|}
\hline № & $\begin{array}{c}\text { Skelettelement } \\
\text { [Do] }\end{array}$ & 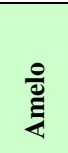 & $\begin{array}{l}\infty \\
\stackrel{n}{n} \\
\frac{\pi}{n} \\
\tilde{n}\end{array}$ & 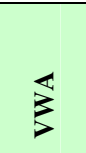 & $\bigcup_{\leq 1}^{\mathbb{1}}$ & 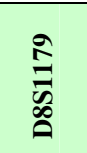 & $\frac{\bar{\sigma}}{\tilde{\sigma}}$ & $\begin{array}{l}\bar{n} \\
\infty \\
\infty \\
0\end{array}$ & $\begin{array}{l}\infty \\
\infty \\
\infty \\
\infty \\
0\end{array}$ & $\begin{array}{c}\frac{N}{n} \\
\frac{\pi}{a}\end{array}$ & $\begin{array}{l}\text { กิ } \\
\text { ஸ્ } \\
\vdots\end{array}$ & 是 \\
\hline M1 & $\begin{array}{l}201 \text { [Tibia re.] } \\
393 \text { [Radius re.] } \\
1076 \text { [Femur li.] } \\
1172 \text { [Mandibula] } \\
1485 \text { [Calvarium] } \\
1492 \text { [Humerus li.] }\end{array}$ & $\mathrm{XY}$ & $15 / 17$ & $15 / 16$ & $21 / 25$ & $12 / 13$ & $30.2 / 33.2$ & $14 / 20$ & $10 / 12$ & $11 / 13$ & $7 / 8$ & $10 / 10$ \\
\hline M2 & $\begin{array}{l}1102 \text { [Femur li.] } \\
3644 \text { [Mandibula] }\end{array}$ & $X Y$ & $15 / 16$ & $16 / 16$ & $20 / 21$ & $12 / 15$ & $29 / 33.2$ & $14 / 18$ & $9 / 10$ & $11 / 11$ & $7 / 9$ & $13 /-$ \\
\hline M3 & $\begin{array}{l}67.3 \text { [Femur re.] } \\
1069 \text { [Tibia re.] } \\
1482 \text { [Mandibula] } \\
1911 \text { [Femur li.] } \\
6525 \text { [Calvarium] }\end{array}$ & $X Y$ & $16 / 18$ & $17 / 19$ & $21 / 22$ & $13 / 13$ & $30.2 / 32.2$ & $15 / 17$ & $11 / 12$ & $12 / 12$ & $8 / 11$ & $11 / 13$ \\
\hline M4 & $\begin{array}{l}\text { 4b [Mandibula] } \\
35 \text { [Femur li.] } \\
107 \text { [Tibia re.] } \\
900 \text { [Neurocranium] }\end{array}$ & $\mathrm{XY}$ & $15 / 17$ & $16 / 17$ & $20 / 25$ & $10 / 14$ & $28 / 29$ & $14 / 19$ & $11 / 12$ & $12 / 13$ & $11 / 12$ & $12 / 12$ \\
\hline M5 & $\begin{array}{l}908 \text { [Calvarium] } \\
2096 \text { [Tibia re.] } \\
2431 \text { [Metacarpus] } \\
3380 \text { [Mandibula] }\end{array}$ & $X Y$ & $15 / 17$ & $16 / 19$ & $20 / 25$ & $10 / 14$ & $28 / 30$ & $15 / 19$ & $11 / 13$ & $8 / 14$ & $(10) / 13$ & $(10) / 12$ \\
\hline M6 & $\begin{array}{l}2030 \text { [Femur li.] } \\
2111 \text { [Mandibula] } \\
\text { R3 [Calvarium] }\end{array}$ & $\mathrm{XY}$ & $16 / 16$ & $17 / 18$ & $21 / 24$ & $10 / 12$ & $29 / 30.2$ & $16 / 18$ & $10 / 13$ & $12 / 13$ & $9 / 9$ & $10 /-$ \\
\hline M7 & $\begin{array}{l}3 \text { [Felsenbein li.] } \\
910 \text { [Calvarium] } \\
929.02 \text { [Calcaneus li.] }\end{array}$ & $\mathrm{XY}$ & $14 / 15$ & $17 / 18$ & $24 / 25$ & $10 / 11$ & $29 / 30$ & $(13 / 18)$ & $12 / 12$ & $8 / 12$ & $(10) / 11$ & $10 / 10$ \\
\hline M8 & $\begin{array}{l}3703 \text { [Tibia re.] } \\
3757 \text { [Calvarium] } \\
4003 \text { [Mandibula] }\end{array}$ & $X Y$ & $17 / 18$ & $17 / 18$ & $21 / 25$ & $10 / 11$ & $30.2 /-$ & $12 /-$ & $10 / 12$ & $10 / 12$ & 9/- & $12 / 13$ \\
\hline M9 & $\begin{array}{l}1084 \text { [Tibia re.] } \\
1473 \text { [Calvarium] } \\
1905 \text { [Femur re.] } \\
1916 \text { [Femur li.] } \\
2749 \text { [Mandibula] }\end{array}$ & $\mathrm{XY}$ & $16 / 19$ & $14 / 16$ & $21 / 23$ & $13 / 13$ & $27 / 32.2$ & $12 / 14$ & $12 / 12$ & $11 / 14$ & $10 / 13$ & $11 /-$ \\
\hline M10 & $\begin{array}{l}186 \text { [Tibia re.] } \\
902 \text { [Femur li.] } \\
480 \text { [Mandibula] }\end{array}$ & $X Y$ & $14 / 15$ & $13 / 15$ & $22 / 24$ & $13 / 13$ & $31.2 / 32.2$ & $10 / 12$ & $12 /(13)$ & $9 / 13$ & $9 / 9$ & $-1-$ \\
\hline M11 & $\begin{array}{l}183 \text { [Femur li.] } \\
\text { (398 [Mandibula]) }\end{array}$ & $X Y$ & $14 / 16$ & $14 / 19$ & $24 /(24)$ & $13 /(13)$ & $(29 / 33.2)$ & $-/-$ & $10 / 12$ & $11 /-$ & $10 /-$ & $-/-$ \\
\hline M12 & E33 [Mandibula] & $\mathrm{XY}$ & $-/-$ & $16 / 18$ & $21 /-$ & $-/-$ & $30 / 33.2$ & $-1-$ & $9 / 11$ & $11 /-$ & $-/-$ & $-1-$ \\
\hline M13 & 58.3 [Femur li.] & $\mathrm{XY}$ & $15 / 18$ & $16 / 18$ & $25 /-$ & $13 / 13$ & $29 / 30$ & $-1-$ & $11 /(11)$ & $(13) /-$ & $-/-$ & $-/-$ \\
\hline M14 & $\begin{array}{l}905 \text { [Femur li.] } \\
(918 \text { [Neurocranium] })\end{array}$ & $\mathrm{XY}$ & $15 /(17)$ & $16 /(17)$ & $22 / 24$ & $-/-$ & $(29) /-$ & $17 /(19)$ & $11 / 12$ & $(8) / 11$ & $-/-$ & $(10 / 12)$ \\
\hline M15 & 2263 [Mandibula] & $\mathrm{X}(\mathrm{Y})$ & $15 / 16$ & $-/-$ & $22 / 24$ & $13 /-$ & $29 /-$ & $(16 / 18)$ & $12 / 13$ & $12 /-$ & $-1-$ & $10 /(11)$ \\
\hline M16 & 3886 [Felsenbein li.] & $\mathrm{XY}$ & $17 / 18$ & $14 / 17$ & $24 / 25$ & $10 / 13$ & $29 / 30.2$ & $12 / 15$ & $10 / 12$ & $8 / 10$ & $8 / 11$ & $11 / 12$ \\
\hline M17 & 57.2 [Femur li.] & $\mathrm{XY}$ & $15 / 17$ & $17 /-$ & $22 / 24$ & $-/-$ & $29 /-$ & $-/$ & $11 /-$ & $-1-$ & $10 /-$ & $-1-$ \\
\hline M18 & 901 [Femur li.] & $\mathrm{X}(\mathrm{Y})$ & $16 /-$ & $14 / 15$ & $22 /-$ & (14)/- & $-/-$ & $(15) /-$ & $(12) /-$ & $-/-$ & $-/-$ & $-/-$ \\
\hline M19 & $\begin{array}{l}153 \text { [Tibia re.] } \\
487 \text { [Calcaneus li.] }\end{array}$ & $\mathrm{XY}$ & $15 / 17$ & $16 / 18$ & $23 / 25$ & $(10 / 13)$ & $28 / 29$ & $(14 / 15)$ & $12 / 13$ & $8 / 13$ & $(10 / 12)$ & $10 / 12$ \\
\hline
\end{tabular}

Legende: $\mathrm{M}=$ male, - = Allel nicht bestimmbar, ()$=$ unsicheres Allel oder unsicher zugeordnetes Skelettelement. 


\section{Sonderfall Individuum F18}

Im Anschluss an die Gesamtgenotypentabelle müssen hier die Typisierungsdaten für das weibliche Individuum F18 näher besprochen werden, da es im Hinblick auf die Einzeltypisierungen der zugeordneten Skelettelemente zum Teil abweichende Ergebnisse aufweist, die ohne Erläuterung nicht selbsterklärend sind.

Es wird angenommen, dass die Mandibula Do2133 und das linke Femur Do199 zusammen mit dem Calvarium Do1176 das Individuum F18 repräsentieren. Die biologischen Alter, die für die drei Skelettelemente ermittelt wurden, weichen nicht voneinander $\mathrm{ab}$ (=madult-sadult). Der direkte morphologische Vergleich zeigt, dass Schädel und Unterkiefer zusammengehören können. Die mtDNA-Analysen ergeben für alle drei Proben den gleichen mt-Haplotypen.

Die STR-Typisierungen für das Calvarium (Do1176) ergaben einen vollständigen genetischen Fingerabdruck. Die Geschlechtsdiagnose mithilfe des Amelogeninmarkers zeigte ausschließlich ein X-chromosomales Signal, woraufhin das Individuum als weiblich eingestuft werden konnte.

Die Typisierungen des Unterkiefers weisen für zwei der vier Extrakte (I und II) zum Teil mehr als zwei Allele für einzelne STR-Loci auf sowie eine Abweichung zu den Typisierungsergebnissen des Calvariums in STR D21S11 (Allel 33.2). Des Weiteren konnte für DNA-Extrakt I ein Y-Signal für Amelogenin amplifiziert werden und die YSTR-Analysen ergaben für die ersten beiden DNA-Extrakte vereinzelte, sich aber widersprechende, Allele. Die Typisierungen aus den Extrakten III und IV zeigen dagegen für den Unterkiefer ausschließlich und reproduziert den genetischen Fingerabdruck des Calvariums. Darüber hinaus konnte kein Produkt mehr für ein YChromosom amplifiziert werden. Für eine weitere Klärung des Geschlechts wurden die DNA-Extrakte mit einer geschlechtsdiskriminanten XY-Multiplex-PCR (Schmidt et al. 2003) untersucht. Die Ergebnisse dieser Analysen lassen für Calvarium und Mandibula auf ein weibliches Individuum schließen (Ergebnisse in dieser Arbeit nicht dargestellt). Bei den Amplifikationen aus den Extrakten I und II des Unterkiefers Do2133 handelt es sich sehr wahrscheinlich um eine Mischspur. Die ersten beiden DNA-Extrakte wurden aus dem Zahnmehl des Molaren 36 und die Extrakte III und IV aus dem von Zahn 37 hergestellt. Deshalb wird eine Kontamination für das Zahnmehl 36 in Betracht gezogen. Aufgrund der geringen Signalintensität handelt es sich nicht um eine Rezentkontamination, d.h. von einem Laborbearbeiter. 
Der von Schultes (2000) ermittelte genetische Fingerabdruck des linken Oberschenkelbeines Do199 liegt fragmentiert vor und zum Teil wurden einzelne Allele in Klammern aufgenommen, da sie als nicht gesichert eingestuft wurden. Die Typisierungsergebnisse von Schultes (2000) weichen an drei Stellen vom Fingerabdruck des Calvariums ab. Diese Abweichungen betreffen STR-Loci, in denen bei einem von beiden ein homozygoter Zustand angenommen wird. Wie beim Unterkiefer wurde auch bei diesem Skelettelement vereinzelt ein Y-Signal für Amelogenin typisiert. Die Y-STR-Analysen ergaben für einen von zwei untersuchten DNA-Extrakten einen nicht gesicherten Y-Haplotypen (vgl. Schultes 2000, 83). Diese Typisierungsergebnisse wurden in einer PCR ermittelt (Y23), in der für vier andere Proben eine Y-chromosomale Kontamination nachgewiesen werden konnte (vgl. Schultes 2000, 58 und Tabelle 28, S.145-147). Obwohl das Y-Allelmuster der Kontamination von dem für Do199 ermittelten Y-Haplotypen abweicht, wird hier von einer weiteren Kontamination in der angesprochenen PCR Y23 ausgegangen.

In der vorliegenden Studie wurden, in weiterführenden Analysen an neu angefertigten DNA-Extrakten dieser Fundnummer, keine Ergebnisse für ein mögliches männliches Muster im Amelogeninmarker gefunden. Darüber hinaus konnte der genetische Fingerabdruck des Oberschenkelbeines nahezu vervollständigt werden. Diese Untersuchungen zeigen nur noch die Allele, die auch für das Calvarium typisiert werden konnten.

Aus der dargestellten Sachlage sollte eine Zusammengehörigkeit der drei Skelettelemente gesichert sein. 


\section{2 mtDNA-Analyse, Haplotypen und Haplogruppen}

In Vorversuchen wurden die in Kapitel 4.2.2 beschriebenen Primersysteme für die HVR-Analyse an rezenter DNA aus Speichelproben getestet. Dabei konnten für die möglichen Kombinationen sehr gute Ergebnisse generiert werden. Die Amplifikationsprodukte der einzelnen Amplifikate weisen die jeweiligen theoretisch berechneten Fragmentlängen auf. Unspezifische Produkte, welche die Analyse stören würden, werden nicht generiert. Die durch Direktsequenzierung ermittelten Sequenzen konnten durch Abgleich mit der CRS in stimmige Haplogruppen eingeteilt werden.

Für die rezenten Proben scheint die Generierung von kurzen Fragmenten, d.h. unter 300bp, unkritisch. Für die Untersuchungen der historischen Proben könnten, bei kurzen Fragmenten und hohen Zyklenzahlen, Kontaminationen aus den Reaktionsgefäßen begünstigt werden. Der ausschließliche Nachweis kurzer Fragmente aus einer historischen Probe ist nicht gleichzeitig ein Authentizitätsnachweis, da Kontaminationen der Reaktionsgefäße in der Regel durch den Produktionsprozess ebenfalls degradiert vorliegen. Schmidt et al (1995) konnten bereits zeigen, dass die Nachweisrate von Kontaminationen in Reaktionsgefäßen mit der Abnahme der Fragmentlänge eines Amplifikats und einer gleichzeitigen Erhöhung der Zyklenzahlen zunimmt. Diese Rate schwankt dabei von Hersteller zu Hersteller und bei verschiedenen Gefäß-Chargen.

Die DNA-Erhaltung der historischen Proben aus der Lichtensteinhöhle erlaubt es, Amplifikationsprodukte über 300bp zu amplifizieren. Aus diesem Grund wurde für die HVR I-Analyse ausschließlich das 339bp Fragment, für die HVR II-Analyse das 321bp lange Fragment untersucht. Damit werden Kontaminationen aus den Reaktionsgefäßen, die weiterhin präsent sein können, nicht weiter begünstigt. Trotzdem kam es sporadisch in den Leerkontrollen $\mathrm{zu}$ Kontaminationen (Abb.17). Diese Produkte wurden sequenziert und anschließend mit den übrigen Ergebnissen verglichen. Darüber hinaus wurden reproduzierte Analysen durchgeführt, um Kontaminationsereignisse aufzudecken (s.Kap.4.6).

Nahezu alle cranialen Skelettelemente wurden einer mtDNA-Analyse für ihre HVR I und II unterzogen. Die Ergebnisse zeigen, dass für das historische Probematerial beide Analysesysteme gleichermaßen erfolgreich sind. Aufgrund der sehr guten DNAErhaltung der historischen Proben lassen sich mit für aDNA verhältnismäßig niedrigen Zyklenzahlen (35-40), starke Amplifikationsprodukte für beide Systeme generieren. 
Dies ist beispielhaft für einige der Lichtensteiner Proben in den Abbildungen 17 und 18 zu sehen.

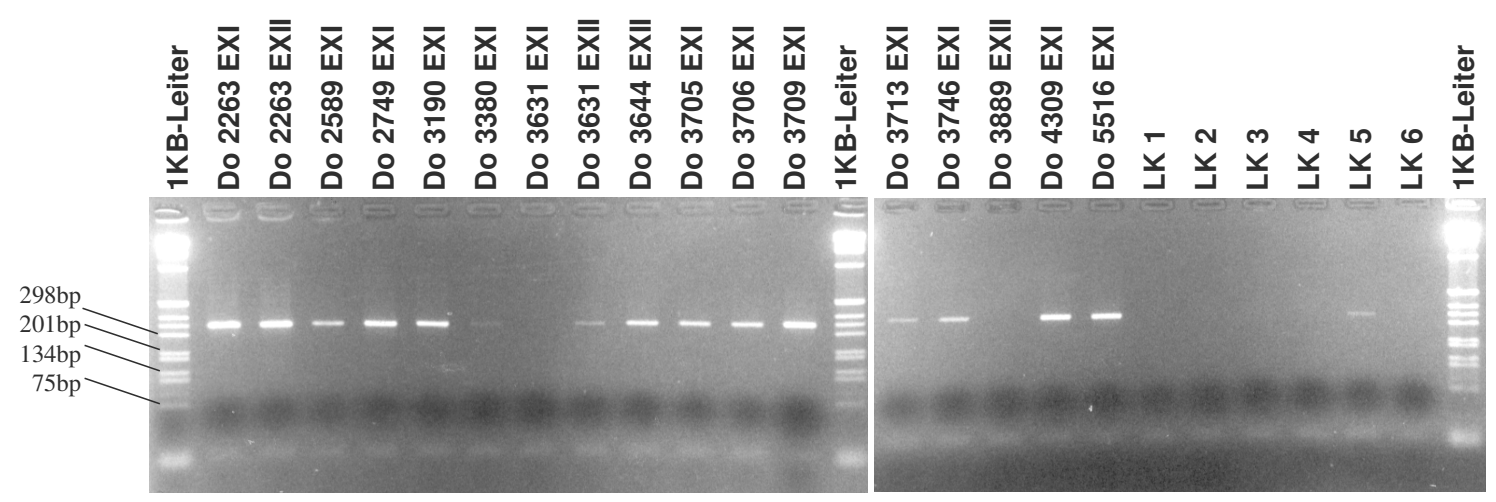

Abbildung 17: Agarosegelbild einer HVR I-Analyse (PCR 33) mit verschiedenen bronzezeitlichen Proben aus der Lichtensteinhöhle (Do) und 6 Leerkontrollen (LK1-6). Die Amplifikationsprodukte haben eine Fragmentlänge von 339bp. LK 5 weist ein spezifisches Produkt auf, deren Ursache am wahrscheinlichsten eine Kontamination aus dem Reaktionsgefäß ist. Unter $\mathbf{7 5 b p}$ befinden sich unspezifische Produkte und freie Primer. Als Längenstandard diente die 1KB-Leiter.

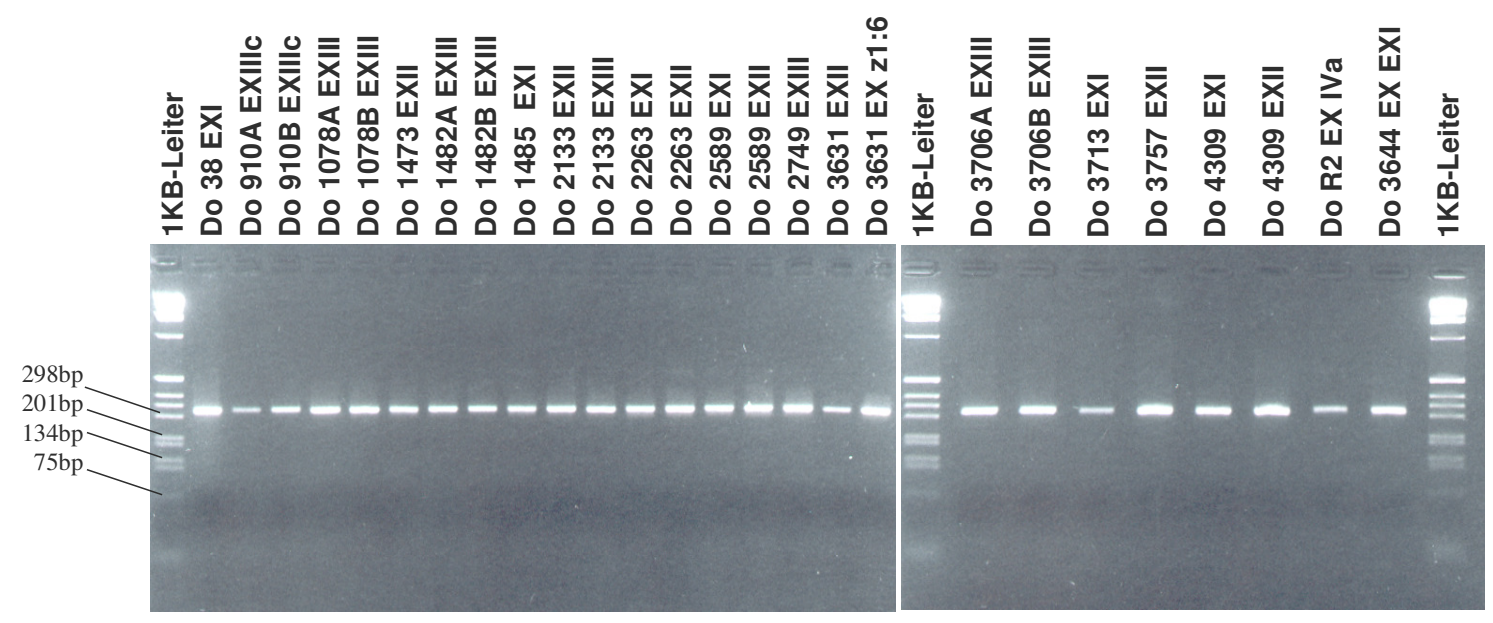

Abbildung 18: Agarosegelbild einer HVR II-Analyse (PCR 63) mit verschiedenen bronzezeitlichen Proben aus der Lichtensteinhöhle (Do). Die Amplifikationsprodukte haben eine Fragmentlänge von 321bp. Unter 75bp befinden sich unspezifische Produkte und freie Primer. Als Längenstandard diente die 1KB-Leiter.

Die in Abbildung 17 dargestellten Signalintensitäten der HVR I-Analyse spiegeln die DNA-Qualität für die verwendeten DNA-Extrakte der einzelnen Funde wieder. Extrakte, aus denen ein nahezu vollständiger genetischer Fingerabdruck ermittelt werden konnte, zeigten auch in diesen Analysen sehr starke Amplifikationsprodukte. Für die beiden Proben die kein Produkt aufweisen (Abb.17, Proben Do3631 EXI und Do3889 EXII) sind auch die chromosomalen Ergebnisse aus den jeweiligen DNAExtrakten schlecht. 
In den überwiegenden Fällen konnten die Amplifikationsprodukte störungsfrei und erfolgreich direktsequenziert werden (Abb.19 \& 20). Die Einzeltypisierungsergebnisse dieser Untersuchungen sind im Anhang (Kap.11.5.3) tabellarisch aufgeführt. Proben, für die in wiederholten HVR-Analysen kein Produkt amplifiziert werden konnte, wurden nicht in diese Tabellen aufgenommen.

In wenigen Fällen ließen sich Proben schlecht oder gar nicht sequenzieren, obwohl aufgrund des Agarosegelbildes ein sequenziertaugliches PCR-Produkt vorzuliegen scheint. Mögliche Ursachen dafür könnten Sequenzier-PCR-Inhibitoren sein. Beispielsweise kann die Anwesenheit von Ethanol in der Reaktion zu einem Totalausfall führen (Qiagen 1998). Dieses Problem ist jedenfalls nicht gänzlich auszuschließen, da bei der Aufreinigung der PCR-Produkte Ethanol eingesetzt wird.

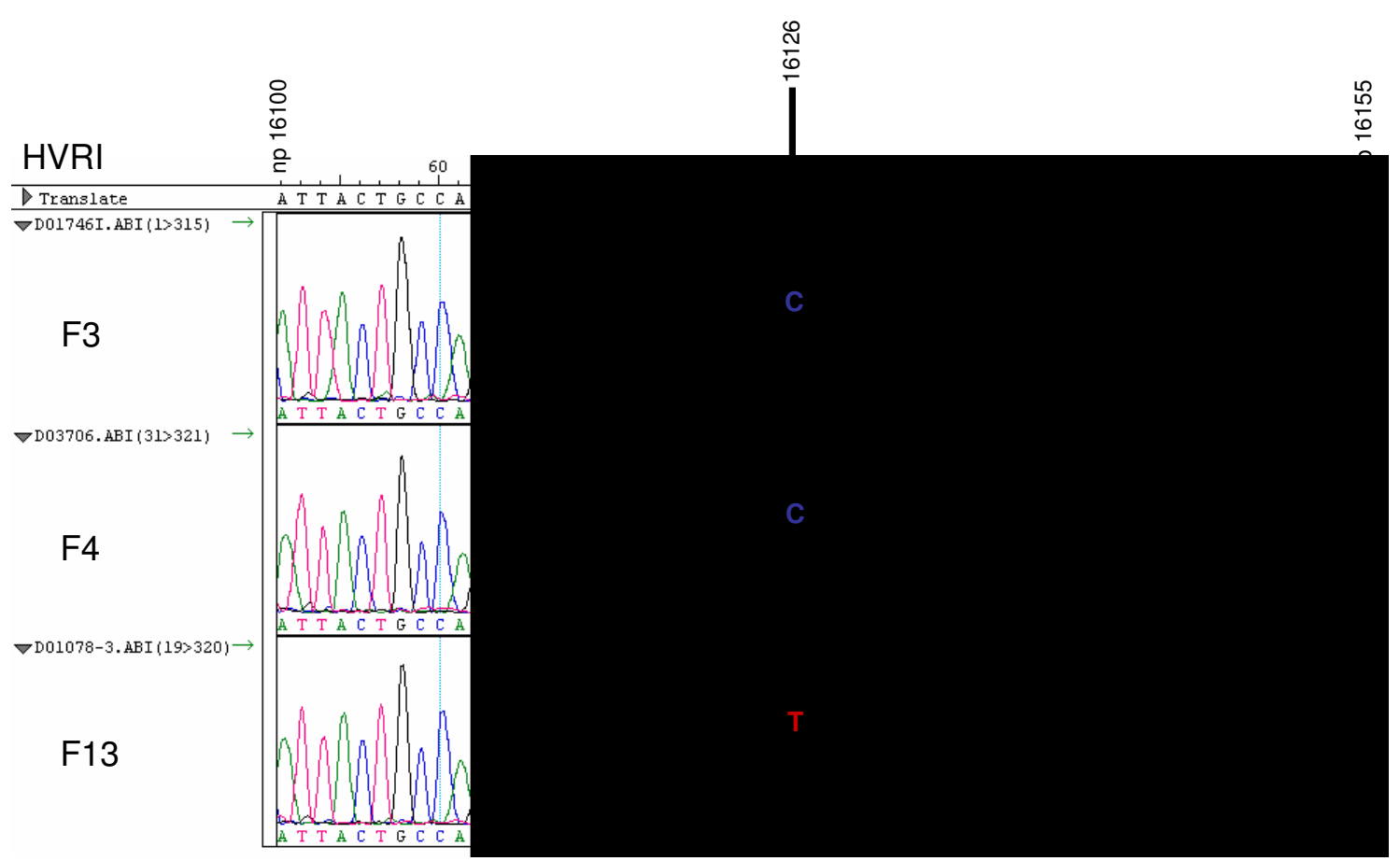

Abbildung 19: Sequenzausschnitt aus der HVR I für drei bronzezeitliche Proben. Die vier Basen werden durch die Computersoftware mit unterschiedlichen Farben belegt. Dadurch ist die Bestimmung der Sequenzabfolge möglich. Durch die Gegenüberstellung der Sequenzen können Sequenzpolymorphismen aufgeklärt werden. In diesem Fall an np 16126. Zwei Proben weisen ein Cytosin an dieser Position auf, eine Probe ein Thymin (T). 


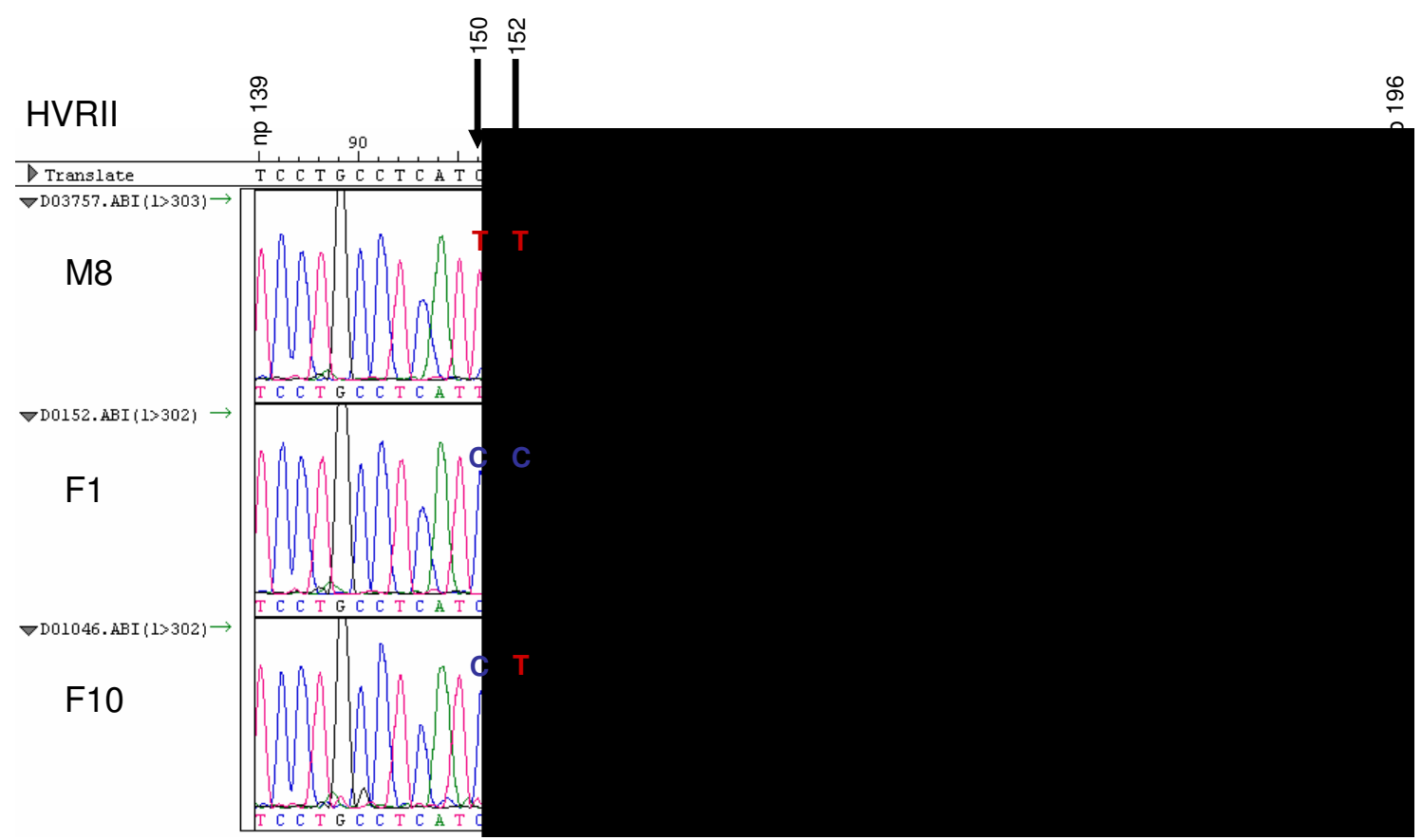

Abbildung 20: Sequenzausschnitt aus der HVR II für drei bronzezeitliche Proben. Die vier Basen werden durch die Computersoftware mit unterschiedlichen Farben belegt. Dadurch ist die Bestimmung der Sequenzabfolge möglich. Durch die Gegenüberstellung der Sequenzen können Sequenzpolymorphismen aufgeklärt werden. In diesem Fall an np 150 und 152. Die drei Individuen unterscheiden sich in ihren Sequenzmustern ganz deutlich voneinander. Während das Individuum M8 an diesen Positionen jeweils ein Thymin (T) aufweist, hat F1 in beiden Fällen ein Cytosin (C) und $\mathrm{F10}$ wiederum ein $\mathrm{C}$ an np 150 und ein $\mathrm{T}$ an Nucleotidposition 152.

Zum Teil konnten für einzelne Skelettelemente nur Ergebnisse für das HVR I- oder das HVR II-System ermittelt werden. Der Grund hierfür liegt im begrenzten

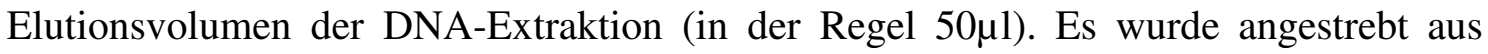
einem DNA-Extrakt jeweils zwei Analysen für autosomale STRs, HVR I und HVR II sowie bei männlichen Individuen zusätzlich für Y-STRs durchzuführen. Diese umfangreichen Analysen sind an einem DNA-Extrakt nur dann zu bewerkstelligen, wenn der DNA-Volumeneinsatz pro PCR-Reaktion dies auch quantitativ zulässt. Musste, aufgrund der DNA-Qualität, viel Extrakt pro PCR-Reaktion eingesetzt oder mussten Analysen für ein Amplifikationssystem mehrfach wiederholt werden, dann reichte der Extrakt für die Anzahl der angestrebten Analysen nicht aus.

Darüber hinaus konnte vereinzelt festgestellt werden, dass für ein Knochenelement die angefertigten DNA-Extrakte unterschiedliche Qualitäten aufwiesen. In einzelnen Fällen kam es dazu, dass die DNA-Qualität eines zweiten Extraktes nicht mehr ausreichend 
war um damit einen Marker wiederholt zu bestätigen. Waren die vorhergehenden Analysen übereinstimmend, wurde auch ein einfach reproduziertes Ergebnis, z.B. bei der HVR I-Analyse von Do3190 (F21), in Klammern aufgenommen.

Aus den Einzeltypisierungen der Proben setzt sich der Gesamthaplotyp zusammen. Auch hier wurden, wenn vorhanden, die Ergebnisse von Schultes (2000) mit in die Ergebnisse einbezogen. Dies konnte nur für Teilabschnitte der hypervariablen Region geschehen. Die in diesem Projekt amplifizierten Produkte überspannen die in der ersten Studie untersuchten Bereiche der HVR, d.h. es werden weitere Abschnitte untersucht, die vorher nicht erfasst waren. Für HVR II wird ein längerer Abschnitt, u.a. mit der für die Einteilung in die Haplogruppen wichtigen np 73, analysiert.

Durch die autosomalen STR-Analysen konnten bereits einzelne Skelettelemente zugeordnet werden. Daher können auch die HVR-Ergebnisse der Knochen, die zu einem Individuum gehören, abgeglichen werden. Im Anhang sind dafür alle erzielten mt-Sequenzmuster für die jeweiligen Individuen in einer Tabelle (Tab.11.5.3) zusammengestellt. Daraus resultieren die vollständigen mt- Haplotypen. Abweichungen in den Sequenzmustern von sicher zusammengehörenden Skelettelementen wurden in lediglich zwei Fällen festgestellt und werden zu einem späteren Zeitpunkt besprochen (S.88 und S.111). Die übrigen Proben weisen in den untersuchten Bereichen übereinstimmende Sequenzmuster auf.

Bei zwei Proben (Mandibulae Do4b und Do4003), die nur stark fragmentierte genetische Fingerabdrücke aufweisen, gelang eine Zuordnung zu einem Individuum über die HVR-Analyse und ihrem morphologischen Alter.

Bei der HVR II-Analyse wurde bei einer Sequenzierung für die Probe Do3631 ein Sequenzmuster ermittelt, welches eindeutig von den restlichen sechs Folgebestimmungen, sowohl aus dem gleichen, als auch aus weiteren DNA-Extrakten, abweicht. Dieses Sequenzmuster weist Polymorphismen auf, wie sie für den HVR II Abschnitt anderer Proben aus der Lichtensteinhöhle bekannt sind. Eine Kontamination des DNA-Extraktes kann sicher ausgeschlossen werden, da die weiterführenden autosomalen STR-Analysen an diesem Extrakt eine solche aufgedeckt hätten. Möglichkeiten für das Entstehen dieses Ereignisses bleiben eine Kreuzkontamination zwischen Proben beim Ansetzen der PCR-Reaktion, eine hochamplifizierte Reaktionsgefäßkontamination oder eine Vertauschung von Proben beim Sequenziervorgang. Da bei den anderen Proben keine abweichenden 
Sequenzierergebnisse festgestellt werden konnten, ist eine Vertauschung ausgeschlossen. An diesem Beispiel zeigt sich, dass durch Anwendung der vorgestellten Typisierungsstrategien, d.h. Mehrfachamplifikation, unkorrekte Ergebnisse auch bei mtDNA-Analysen eindeutig erkannt und isoliert werden können.

\section{Bestimmung der mt-Haplotypen und ihre Einordnung in die offiziellen Haplogruppen}

Es wurden insgesamt 20 verschiedene mt-Haplotypen identifiziert (Tab.16). Davon lassen sich 19 in die offiziellen Haplogruppen einteilen (z.B. Richards et al. 1998, Macaulay et al. 1999, Richards et al. 2000).

Es konnten zehn maternale Linien der Haplogruppe H, vier der Haplogruppe U, zwei der Haplogruppe $\mathbf{J}$ und drei der Haplogruppe $\mathrm{T}$ zugeordnet werden. Eine weitere Untergliederung in die Untergruppen gelang sicher in drei Fällen (U5b, T2 und J1b1). In einem weiteren Fall ist die Zugehörigkeit zur Untergruppe U2 sehr wahrscheinlich. War es nicht möglich die Linien in verschiedene Untergruppen einzuteilen, wie z.B. bei Haplogruppe H, wurden sie zur besseren Unterscheidung mit dem Symbol \# und einer Ziffer belegt, z.B. H \#1.

Tabelle 16: Gesamtübersicht der mt-Haplotypen aus der Lichtensteinhöhle. Die Einteilung in die Haplogruppen (H, J, U und T) geschah nach Richards et al. (1999) und Macaulay et al. (1999). Die Sequenzen werden mit der CRS verglichen. In der Kopfzeile ist hinter den Nucleotidpositionen die jeweilige Base der CRS angegeben. Mögliche Abweichungen zur CRS sind farblich hinterlegt.

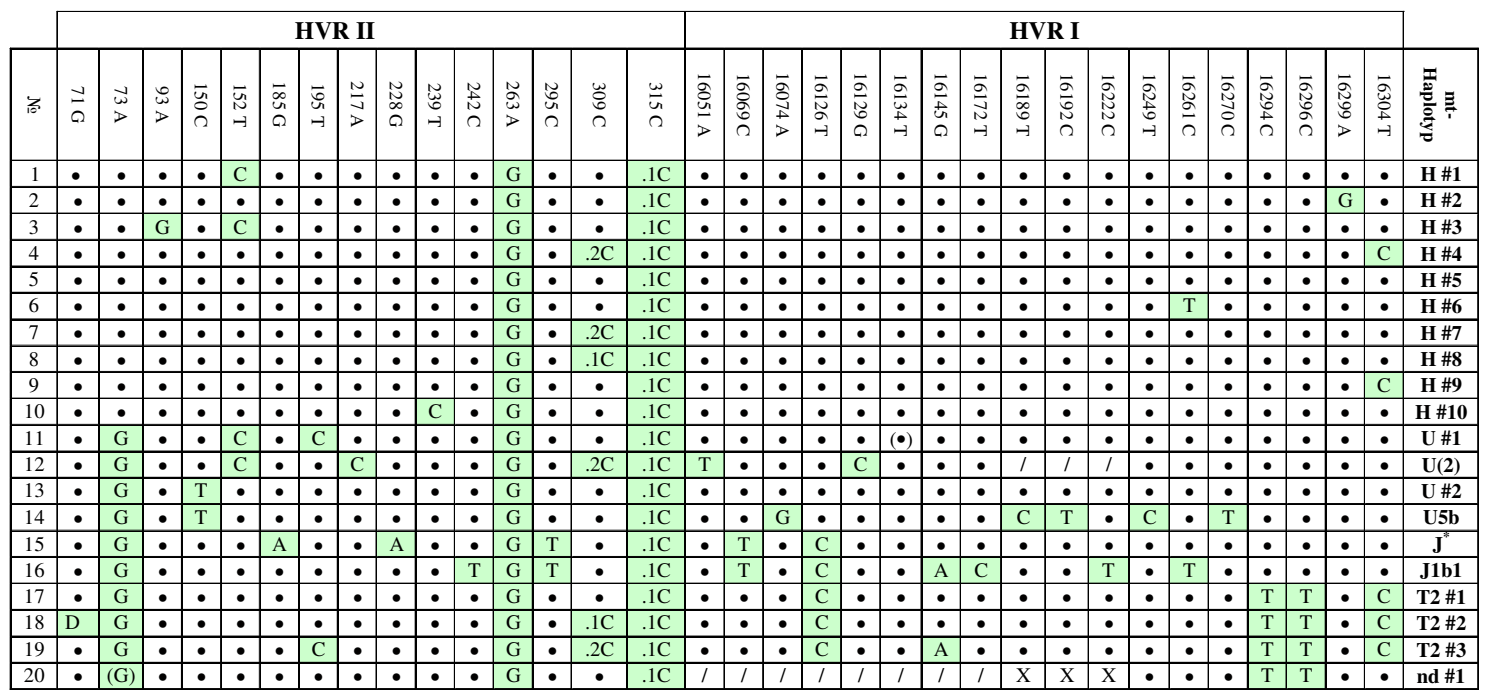

Legende: $\bullet=$ keine Abweichung zu CRS, $/=$ Position nicht bestimmbar, $(\quad)=$ unsicherer Sequenzpolymorphismus, $\mathrm{X}=$ Abschnitt nicht sequenziert, $\mathrm{D}=$ Deletion, $\mathrm{nd}=$ nicht determiniert

Zusätzlich zu den 19 Sequenzen ist in Tabelle 16 eine aufgeführt (Nr. 20), bei welcher eine Einteilung in eine Haplogruppe nicht möglich war. Sie stellt, aufgrund ihres 
Sequenzmusters, eine eigenständige Familienlinie dar. Diese Sequenz wurde für ein linkes Oberschenkelbein (Do58.3 = M13) ermittelt und entstammt zum Teil den Typisierungen von Schultes (2000). Da für diese Probe weite Bereiche der HVR I nicht analysiert werden konnte, ist eine sichere Zuordnung zu einer Haplogruppe nicht möglich. Die Sequenzpolymorphismen $73 \mathrm{G}$ und 16294T könnten auf eine Zugehörigkeit zu Haplogruppe $\mathrm{T}$ hinweisen. Für diese Arbeit wird diese maternale Linie jedoch als nd \#1 (nd =nicht determiniert) bezeichnet.

Für die weiteren Individuen, die lediglich durch ein von Schultes (2000) untersuchtes linkes Femur repräsentiert sind, gelang in der Regel eine Zuordnung zu den bestehenden maternalen Linien. Im Fall von F2, welches durch das linke Femur Do1500 repräsentiert wird, liegen sieben Sequenzpolymorphismen im untersuchten Bereich vor. Zwei davon (16069T und 16126C) sind charakteristisch für die Haplogruppe J. Alle sieben Polymorphismen liegen in gleicherweise im mt-Haplotyp $\mathrm{J}^{*}$ vor. Obwohl der Status an Position 73 für F2 nicht bekannt ist, kann eine Zugehörigkeit zu J* mit sehr hoher Wahrscheinlichkeit angenommen werden.

Die Ergebnisse der Einteilung der 40 Individuen aus der Lichtensteinhöhle in die 20 verschiedenen mt-Haplotypen bzw. Haplogruppen ist in Tabelle 17 wiedergegeben.

Tabelle 17: Einordnung der Individuen aus der Lichtensteinhöhle in die verschiedenen mt-Haplotypen bzw. Halogruppen.

\begin{tabular}{|c|c|c|c|}
\hline $\mathrm{Nr}$. & $\begin{array}{c}\text { mt-Haplotyp / } \\
\text { mt-Haplogruppe }\end{array}$ & Individuum & $\sum$ \\
\hline 1 & $\mathrm{H} \# 1$ & $\mathrm{~F} 1, \mathrm{M} 2, \mathrm{M} 6$ & 3 \\
\hline 2 & $\mathrm{H} \# 2$ & F12, F13, F20 & 3 \\
\hline 3 & H \#3 & M1 & 1 \\
\hline 4 & $\mathrm{H} \# 4$ & F19 & 1 \\
\hline 5 & $\mathrm{H} \# 5$ & F21, M4, M5 & 3 \\
\hline 6 & H \#6 & M9 & 1 \\
\hline 7 & $\mathrm{H} \# 7$ & M7 & 1 \\
\hline 8 & H \#8 & M3 & 1 \\
\hline 9 & $\mathrm{H} \# \mathbf{9}$ & M14 & 1 \\
\hline 10 & $\mathrm{H} \# 10$ & M19 (M17) & $1(2)$ \\
\hline 11 & U \#1 & F18 & 1 \\
\hline 12 & U \#2 & F9, M11 & 1 \\
\hline 13 & $\mathrm{U}(2)$ & F15 & 2 \\
\hline 14 & U5b & F4, F7, F8, M8, M16 & 5 \\
\hline 15 & $\mathbf{J}^{*}$ & F2, F3, M12, M15 & 4 \\
\hline 16 & J1b1 & F14 & 1 \\
\hline 17 & T2 \#1 & F5, F6 & 2 \\
\hline 18 & T2 \#2 & $\mathrm{F} 10,(\mathrm{M} 10)$ & $1(2)$ \\
\hline 19 & T2 \#3 & F16 & 1 \\
\hline \multirow[t]{2}{*}{20} & nd \#1 & M13 & 1 \\
\hline & 1 & F11, F17, M18 & 3 \\
\hline
\end{tabular}

Legende: ( ) = unsichere Eingruppierung, / = keine Einordnung möglich. 
Für 34 Individuen war eine Einordnung damit sicher möglich, zwei ließen sich mit geringerer Wahrscheinlichkeit einordnen (M10 und M17), drei konnten nicht zugeordnet werden (F11, F17 und M18).

Für M10 könnte eine Zugehörigkeit zum mt-Haplotypen T2 \#2 wahrscheinlich sein. Da für dieses Individuum Bereiche seiner HVR II unbekannt sind, ist die Zuordnung jedoch nicht zweifelsfrei erwiesen. Für das männliche Individuum M17 konnten anhand des bestehenden Sequenzabschnittes die Haplogruppen K, T, V, X jedoch nicht H, U und J ausgeschlossen werden. Durch den Polymorphismus 239C in der HVR II, der für M19 festgestellt wurde, ist es wahrscheinlich, dass M17 ebenfalls zur mütterlichen Linie $\mathrm{H}$ \#10 gehört. In den bestehenden Sequenzabschnitten sind die Muster von M17 und M19 übereinstimmend.

Das Individuum M18 könnte aufgrund seiner Sequenzpolymorphismen der Haplogruppe J angehören, F17 der Haplogruppe T. Aufgrund fehlender Daten aus Bereichen der HVR II können F17 und M18 zu diesem Zeitpunkt nicht zugeordnet werden. Für das weibliche Individuum F11 konnte kein HVR II-Genotyp ermittelt werden. Da dieses Individuum keine weiteren Polymorphismen in der HVR I aufweist, gehört es entweder zur Haplogruppe U oder H.

Nach der Einordnung der mt-Haplotypen der Individuen in die offiziellen Haplogruppen zeigt sich, dass sie alle europäischer Herkunft sind. Die prozentuale Aufteilung der 36 Individuen auf die Haupthaplogruppen ergibt (Abb.21), dass die Haplogruppe H, wie schon für den europäischen Genpool in Kapitel 3.2.2 beschrieben wurde, auch für die Lichtensteinhöhle mit $47 \%$ die häufigste Haplogruppe darstellt. Die Haplogruppe U weisen $26 \%$ der Individuen auf und jeweils $14 \%$ die Haplogruppen $\mathrm{J}$ und $\mathrm{T}$. Die Haplogruppen K, V und X sind nicht vertreten.

Die Prozentangaben sollten hinsichtlich des bereits bekannten verwandtschaftlichen Verhältnisses in der Lichtensteinhöhle betrachtet werden. Da die Mütter ihre maternale Linie an die Kinder weitergeben, führt dies zu einer Anhäufung von bestimmten Haplotypen bzw. Haplogruppen, welches bei einer Gruppe nichtverwandter Personen so nicht festzustellen wäre. 


\section{mt-Haplogruppenverteilung (Gesamt)}

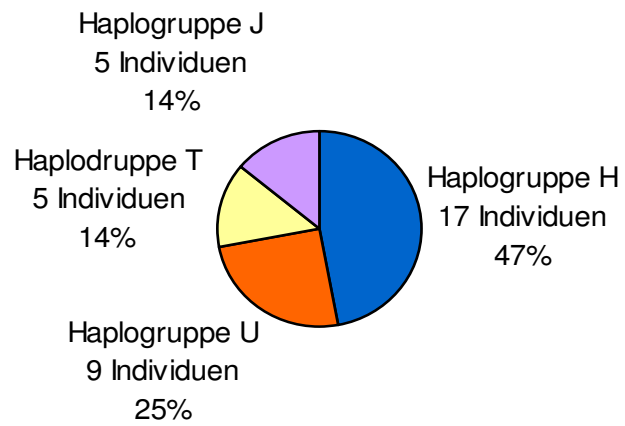

Abbildung 21: mt-Haplogruppenverteilung von 36 bronzezeitlichen Individuen. Der Prozentsatz gibt an, wie viele der Individuen zu einer der Haplogruppen $\mathbf{H}, \mathbf{U}$, J oder $\mathbf{T}$ gehören.

Im direkten Vergleich zeigt sich, dass die Variabilität der Männer bezüglich ihrer mtHaplogruppen geringer ist, als die der Frauen. Bei den Männern bildet die Haplogruppe H mit 65\% den größten Anteil, bei den Frauen sind die Haplogruppen nahezu gleich verteilt (Abb. 22 und 23).

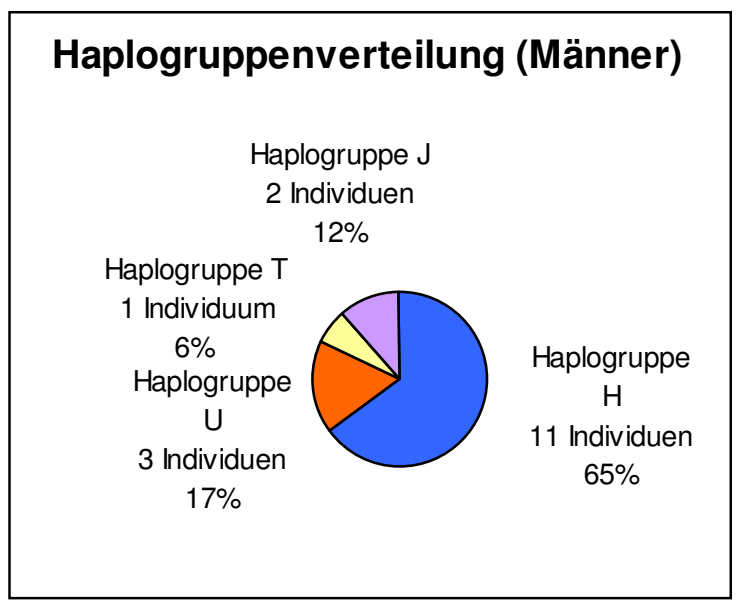

Abbildung 22: mt-Haplogruppenverteilung von 17 männlichen Individuen aus der Lichtenstein-höhle. Der Prozentsatz gibt an wie viele der Individuen zu einer der Haplogruppen H, U, J und $\mathrm{T}$ gehören.

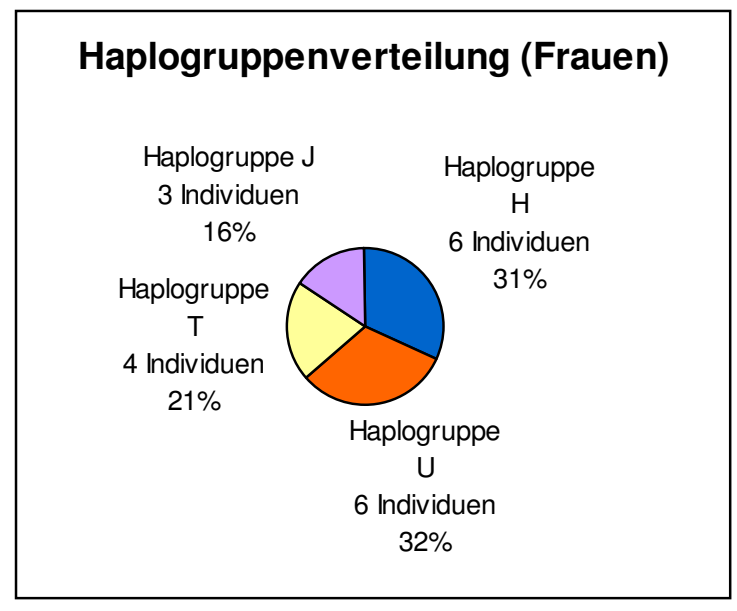

Abbildung 23: mt-Haplogruppenverteilung von 19 weiblichen Individuen aus der Lichtensteinhöhle. Der Prozentsatz gibt an wie viele der Individuen zu einer der Haplogruppen H, U, J und $\mathbf{T}$ gehören. 
Hinsichtlich der Sequenzen fiel auf, dass sie in den Sequenzabschnitten 303 - 309 und 311 - 315 der HVR II vermehrt Insertionen aufweisen. Dieses wurde bereits von Torroni et al. (1994) beschrieben. Für die C-stretches sind Insertionen allgemein bekannt und relativ häufig.

Die Haplotypen $\mathrm{H} \# 5, \mathrm{H} \# 7$ und $\mathrm{H}$ \#8, unterscheiden sich nur innerhalb des C-stretches der HVR II zwischen np 303-309. Bei H \#8 liegt die Insertion eines C's (309.1C) vor, bei H \#7 zwei Cytosine (309.2C), H \#5 weicht an dieser Stelle nicht von der CRS ab, d.h. es liegt keine Insertion vor. Für die geschilderte np liegt das Auftreten einer Spontaninsertion eines C's, ausgelöst durch eine Keimbahnmutation, bei 2,7\% (vgl. Schultes 2000, 83). Durch diese hohe Wahrscheinlichkeit können die beschriebenen Linien, bei sonstiger Sequenzgleichheit, über die mütterliche Linie trotz des Unterschiedes verwandt sein.

An dieser Stelle soll einer der Fälle beschrieben werden (s.S.83), bei dem zwischen sicher zusammengehörenden Knochenelementen eine Abweichung im mtSequenzmuster vorliegt. Der Schädel mit der Fundnummer Do6525 und das Femur Do1911 bilden mit Unterkiefer Do 1482 das Individuum M3. Während für Schädel und Femur die Insertion 309.1C bestimmt wurde, konnte dieser Polymorphismus für den Unterkiefer bislang nicht nachgewiesen werden. Ansonsten sind die Sequenzen der drei Elemente in den untersuchten Abschnitten gleich. Der unterschiedliche Status an np309 könnte auf eine Spontaninsertion zurückgeführt werden oder auf eine Heteroplasmie innerhalb des mt-Genoms.

Eine Heteroplasmie im mt-Genom ist nicht ungewöhnlich. Im Normalfall sind bei einem Individuum 99,9 \% der mtDNA-Genome identisch (z.B. Sykes 1999). Kommt es zu einer Mutation innerhalb des mt-Genoms und breitet sich die Mutation aus, können innerhalb eines Individuums mehrere mtDNA-Genotypen nebeneinander vorliegen. Dabei sind zwei Auslöser für Heteroplasmien bekannt. Zum einen kann es durch Keimbahnmutation in der weiblichen Eizelle und zum anderen durch Mutationen bei der somatischen Zellteilung zu Heteroplasmien kommen (z.B. Rudin und Inman 2002). Generell konnte festgestellt werden, dass die meisten Individuen mehr oder weniger in ihrer mtDNA heteroplasmisch sind (Rudin und Inman 2002). Es kann daher an einer np zur Detektion zweier verschiedener Basen kommen. Des Weiteren sind die Raten der Heteroplasmien zwischen verschiedenen Gewebeproben einer Person unterschiedlich stark. In einer Studie konnte gezeigt werden, dass mtDNA aus Haaren extrahiert und 
typisiert die häufigste Heteroplasmierate zeigte, Knochen waren weniger betroffen und Blut zeigte die geringste Rate (Melton \& Nelson 2001). Da die Zusammengehörigkeit der drei Skelettelemente (Do1482, Do1911 und Do6525) über den genetischen Fingerabdruck sichergestellt ist, kann der Unterschied an np309 für das Individuum M3 entweder mit Heteroplasmie oder Spontaninsertion begründet werden.

Für fünf Individuen (F4, F7, F8, M8 und M16), welche die Haplogruppe U5b, aufweisen, konnte ebenfalls eine Heteroplasmie festgestellt werden. Diese liegt innerhalb des C-Stretches zwischen np 16184 und 16189 in der HVR I vor. Hierbei handelt es sich um zwei verschiedene Allelformen unterschiedlicher Länge. Das heißt, es liegen zwei Varianten vor, zum einen mit acht $\mathrm{C}$ und zum anderen mit neun $\mathrm{C}$. Längenheteroplasmie in diesem Bereich tritt häufig auf, wenn eine Transition $(T \rightarrow C)$ an der np 16189 vorliegt (Pfeiffer et al. 1999, Bär et al. 2000). Die Sequenzen von U5b zeigen, dass die Heteroplasmie von Amplifikation zu Amplifikation innerhalb der fünf Individuen in ihren prozentualen Zusammensetzungen variieren. Dass dieses Muster nicht konstant bleiben muss, ist ebenfalls in dieser Art und Weise bekannt (Rudin und Inman 2002). Für die Verwandtschaftsrekonstruktion ist die Erkenntnis, dass Heteroplasmien über mehrere Generationen bestehen können (z.B. Sykes 1999), von großem Interesse. Der Prozess welche Allelausprägung letztendlich die Oberhand gewinnt ist willkürlich und endet damit, dass eine Form verschwindet und die Zweite bestehen bleibt (z.B. Sykes 1999).

Heteroplasmien können jedoch die Typisierung erschweren. Sie müssen als solche identifiziert werden, da sonst der Eindruck einer Mischspur, z.B. bedingt durch Kontamination, entsteht. Zusätzlich kommt es bei Heteroplasmien die durch Längenunterschiede gekennzeichnet sind, ab der Stelle an der sie auftreten zu einer schwerer auszuwertenden Sequenz. In Fällen, in denen eine Auswertung der Restsequenz nicht mehr möglich ist, empfiehlt sich neben der Durchführung einer forward-Sequenzierung eine anschließende reverse-Sequenzierung des PCR-Produktes. Bär et al. (2000, 195) empfehlen für vergleichende Studien in denen die Anzahl der Cytosine nicht eindeutig zu bestimmen ist, alle Sequenzen so zu behandeln, als wäre ihre Anzahl gleich. Für die Individuen mit dem maternalen Linie U5b wurde dies so durchgeführt. 


\subsection{Y-STRs und Haplotypen}

Der Erfolg der Y-STR-Amplifikationen kann ebenfalls mit sehr gut beschrieben werden. Mit den Erkenntnissen zur DNA-Qualität der angefertigten Extrakte aus den autosomalen STR-Untersuchungen war ein sicheres Abschätzen des DNAMengeneinsatzes in die PCR möglich. Anfänglich wurden die Proben mit der YNonaplex typisiert. Der Amplifikationserfolg dieses Analysesystems ist für die bronzezeitlichen Proben in Abbildung $24 \mathrm{zu}$ sehen. Mit dieser Multiplex ist die Bestimmung des minHt (=neun Y-STR-Allele, s.Kap.3.2.3) möglich. Es stellte sich heraus, dass die ermittelten Y-Haplotypen zum Teil wenig variabel sind. Es war nicht auszuschließen, dass Individuen aufgrund ihres minHt zusammen in einem YHaplotypen gruppiert werden, obwohl sie sich in weiteren Y-STRs unterscheiden. Aufgrund dessen wurde im Folgenden ausschließlich der PowerPlex ${ }^{\circledR}$ Y System Kit (12 Y-STR-Allele, Promega) verwendet und damit der extended haplotype bestimmt. Die bei Krenke et al. $(2005,2)$ getätigte Aussage, dass dieser Kit auch für degradierte DNA aus anthropologischen Studien höchst geeignet ist, kann in dieser Arbeit bestätigt werden.

Häufig konnten vollständige Y-Haplotypen mit einer Amplifikation generiert werden. Der Erfolg dieses Analysesystem für die historischen Proben kann beispielsweise anhand eines Agarosegelbildes (Abb.25) veranschaulicht werden. Wesentlich besser zu beurteilen ist der Erfolg anhand der Elektropherogramme. In den Abbildungen 26 und 27 ist jeweils der in der Lichtensteinhöhle am Häufigsten vorkommende Y-Haplotyp (Y1, s.u.) dargestellt. Im ersten Fall wurde er mit der Y-Nonaplex und im zweiten mit dem PowerPlex ${ }^{\circledR}$ Y System Kit amplifiziert. Die Ergebnisse der Einzeltypisierungen sind für alle untersuchten Proben im Anhang (Kap. 11.5.4) tabellarisch aufgeführt. 


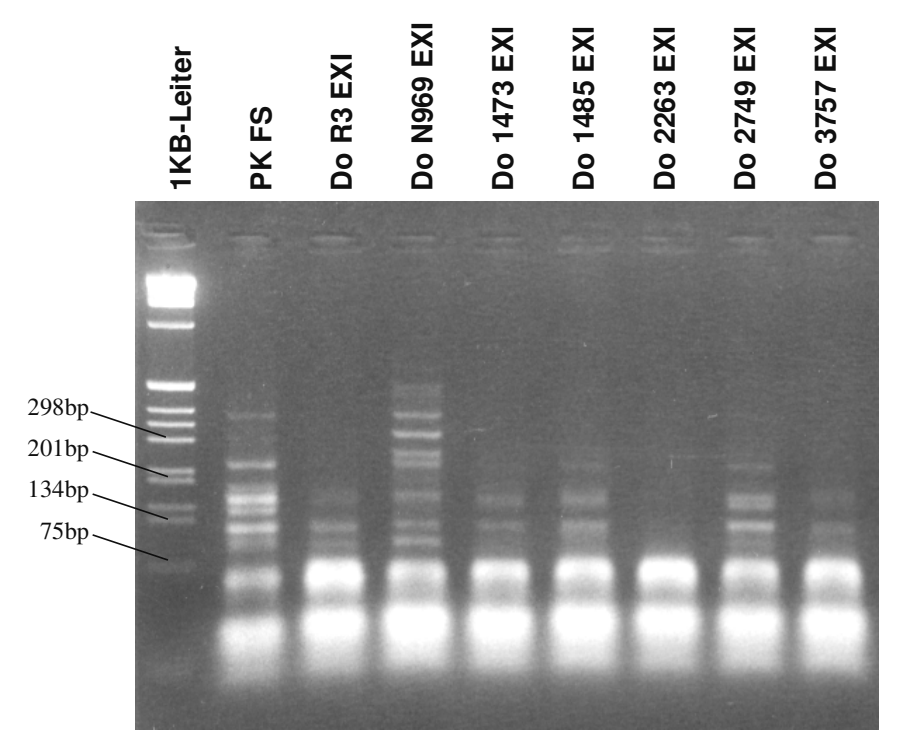

Abbildung 24: Agarosebild der Y-NonaplexAmplifikationen (PCR 11 und 16) verschiedener bronzezeitlicher Proben aus der Lichtensteinhöhle (Do). Die Amplifikationsprodukte liegen zwischen 90 und 250bp. Die historische Probe DoN969 sowie die Positivkontrolle FS (=PK $\quad$ FS $)$ zeigen unspezifische Produkte im größeren Fragmentlängenbereich. Unter $75 \mathrm{bp}$ befinden sich unspezifische Produkte und freie Primer. Als Längenstandard diente die $1 \mathrm{~KB}$-Leiter.

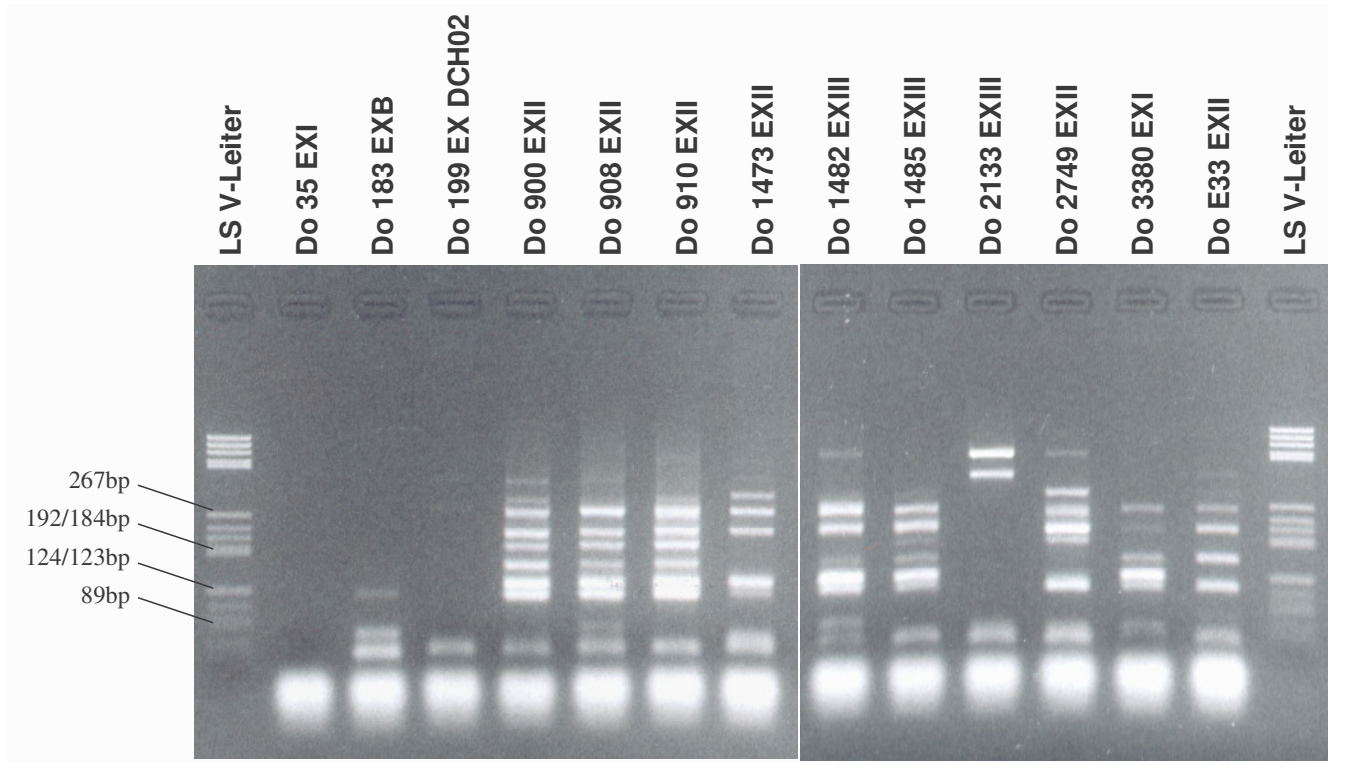

Abbildung 25: Agarosebild der PowerPlex ${ }^{\circledR}$ Y System-Amplifikationen (PCR 47) verschiedener bronzezeitlicher Proben aus der Lichtensteinhöhle (Do). Die Amplifikationsprodukte liegen zwischen 80-340bp. Unter 89bp befinden sich unspezifische Produkte und freie Primer. Als Längenstandard diente hier die LS V-Leiter. 


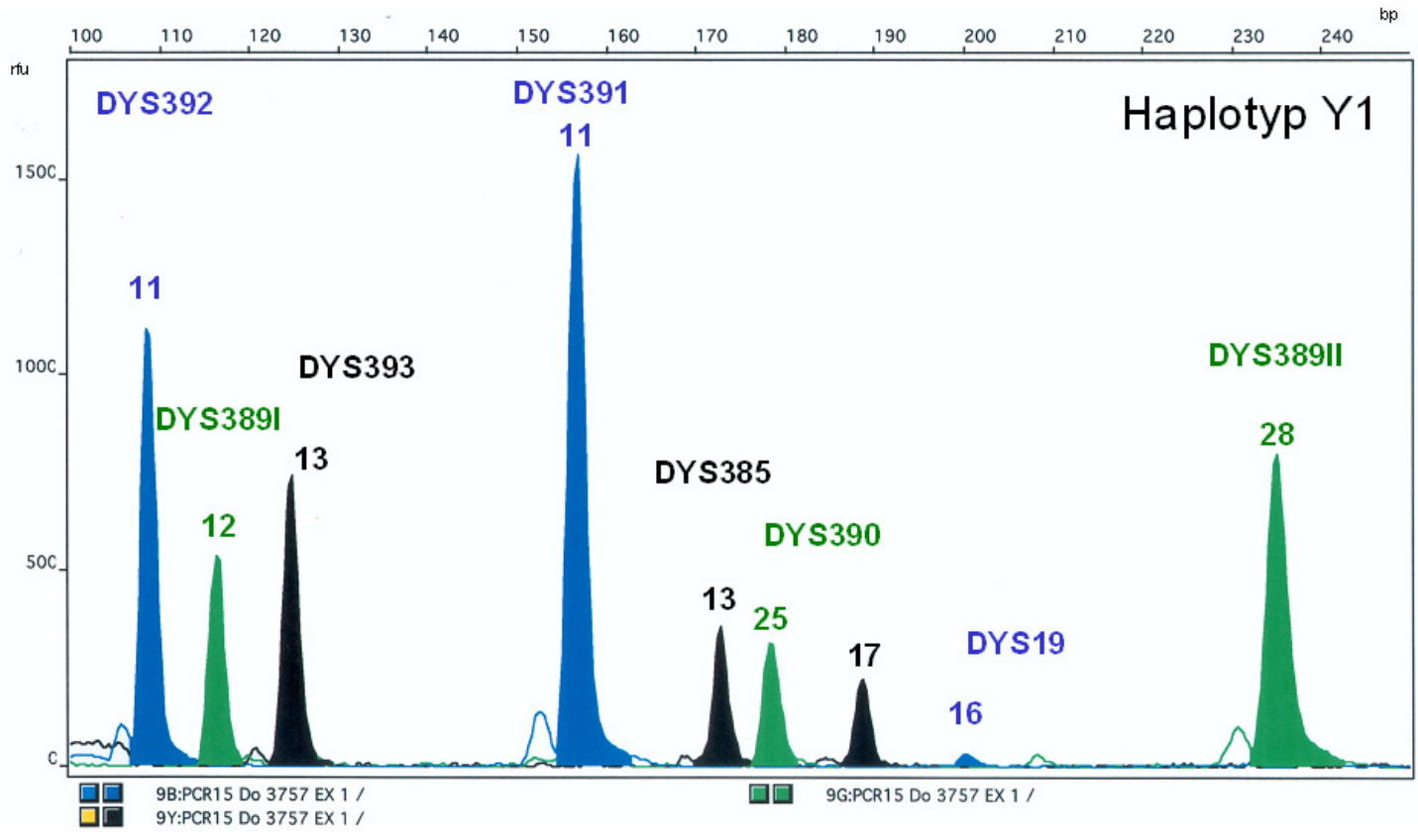

Abbildung 26: Elektropherogramm von Fund Do3757 (M8), amplifiziert mit der YNonaplex-PCR. Auf der $\mathbf{x}$-Achse ist die Fragmentlänge der Produkte in Basenpaaren (bp) dargestellt, die y-Achse gibt die Peakhöhen in relativen Fluoreszenzeinheiten (rfu) wieder. Dargestellt ist das Y-Allelmuster für den Haplotyp Y1, welches für diese Probe vollständig analysiert werden konnte (= neun Allele).

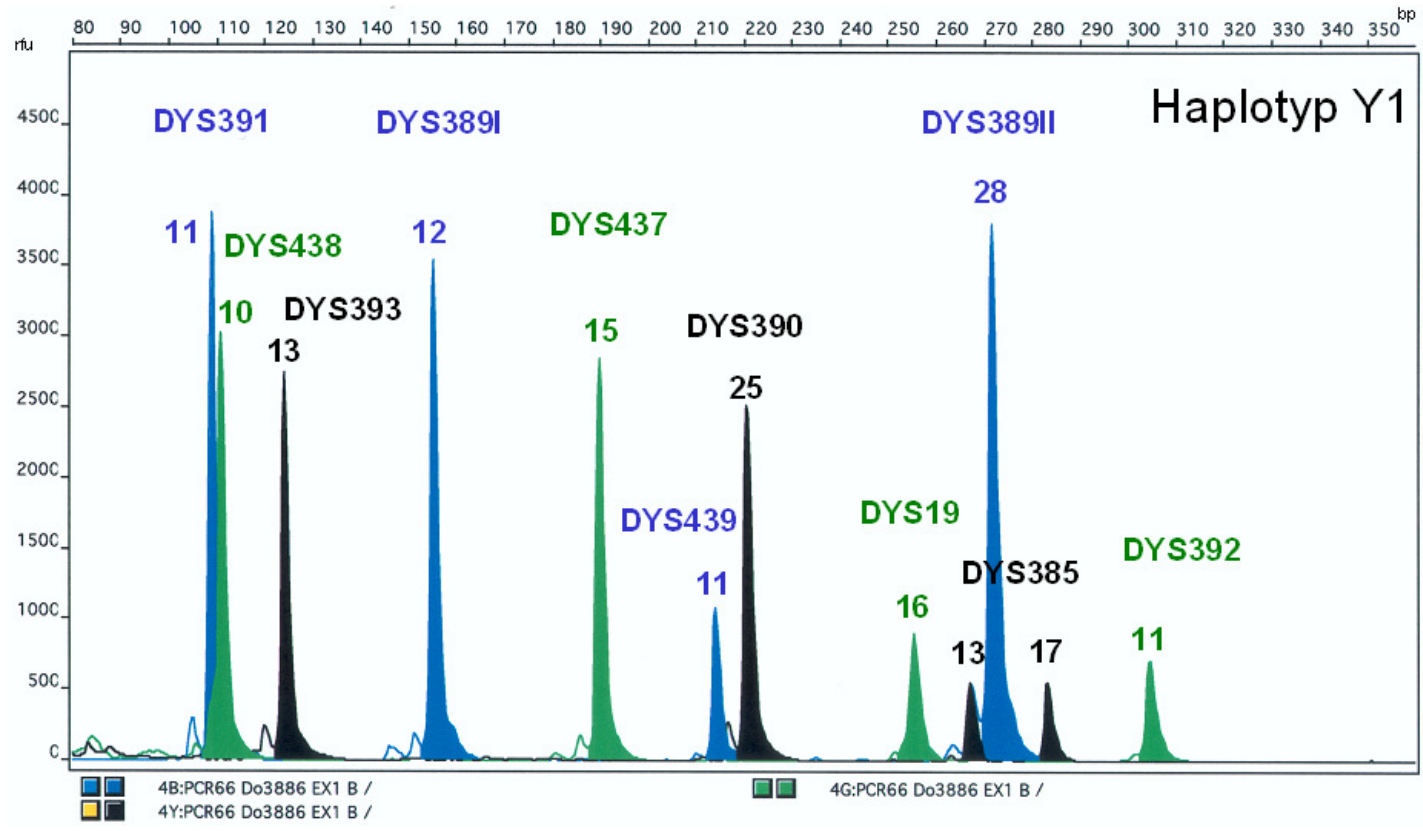

Abbildung 27: Elektropherogramm von Fund Do3886 (M16), amplifiziert mit dem PowerPlex $^{\circledR}$ Y System Kit. Auf der $x$-Achse ist die Fragmentlänge der Produkte in Basenpaaren (bp) dargestellt, die $y$-Achse gibt die Peakhöhen in relativen Fluoreszenzeinheiten (rfu) wieder. Dargestellt ist das Allelmuster für den Haplotyp Y1, welches für diese Probe vollständig analysiert werden konnte (= 12 Allele). 
Bestimmung der Y-Haplotypen

Für die Y-STR-Analysen wurden die DNA-Extrakte ausgewählt, welche gute Amplifikationsergebnisse bei den autosomalen STR-Analysen zeigten und sicher einem männlichen Individuum zugeordnet werden konnten. Wenn dabei für ein Individuum Ergebnisse aus mehreren Skelettelementen ermittelt wurden, z.B. sowohl für Calvarium als auch für Mandibula, ließen sich auch hier aus den jeweiligen Einzelhaplotypen Gesamthaplotypen für das Individuum ermitteln (Anhang, Tab.11.5.4). Für die Zusammenstellung der Y-Haplotypen wurden die von Schultes (2000) erzielten Daten der linken Femora mit verwendet. Die Y-STR-Analysen wurden in den Jahren 1998 bis 2000 mit einer, vier Y-STR-Loci (DYS19, DYS389 I, DYS 389 II und DYS 390) enthaltenen, Multiplex-PCR durchgeführt (vgl. Schultes 2000, 39-40). Da für diese Arbeit der extended haplotype (= 12 Y-STR-Loci) erhoben wurde, können die Daten (=vier Y-STR-Loci) von Schultes (2000, 145-147) hier nur ergänzend berücksichtigt werden.

In den durchgeführten Y-STR-Analysen konnten sechs verschiedene Y-Haplotypen identifiziert werden (Tab.18). Der in dieser Arbeit mit Y1 bezeichnete Haplotyp ist mit sechs Individuen bei Weitem am Häufigsten vertreten.

Tabelle 18: Y-STR-Haplotypen der 19 männlichen Individuen.

\begin{tabular}{|c|c|c|c|c|c|c|c|c|c|c|c|c|c|}
\hline Y-Haplotyp & $\begin{array}{l}\text { DYS } \\
391 \\
\end{array}$ & $\begin{array}{l}\text { DYS } \\
\text { 389I } \\
\end{array}$ & $\begin{array}{l}\text { DYS } \\
439 \\
\end{array}$ & $\begin{array}{l}\text { DYS } \\
\text { 389II } \\
\end{array}$ & $\begin{array}{c}\text { DYS } \\
438 \\
\end{array}$ & $\begin{array}{c}\text { DYS } \\
437 \\
\end{array}$ & $\begin{array}{c}\text { DYS } \\
19 \\
\end{array}$ & $\begin{array}{l}\text { DYS } \\
392 \\
\end{array}$ & $\begin{array}{c}\text { DYS } \\
393 \\
\end{array}$ & $\begin{array}{c}\text { DYS } \\
390 \\
\end{array}$ & $\begin{array}{c}\text { DYS } \\
385 \\
\end{array}$ & Individuen & $\sum$ \\
\hline$Y 1$ & 11 & 12 & 11 & 28 & 10 & 15 & 16 & 11 & 13 & 25 & $13-17$ & $\begin{array}{c}\text { M1,M2,M7,M8, } \\
\text { (M13), M16 }\end{array}$ & 6 \\
\hline$Y 2$ & 11 & 12 & 11 & 27 & 10 & 15 & 15 & 11 & 13 & 25 & $13-17$ & M3, M6, (M14) & 3 \\
\hline Y3 & 11 & 13 & 12 & 29 & 12 & 15 & 14 & 13 & 13 & 23 & $11-14$ & M9 & 1 \\
\hline Y4 & (11) & 12 & (11) & - & 10 & - & (17) & - & - & - & - & M12 & 1 \\
\hline$Y 5$ & 11 & 13 & 11 & 30 & 11 & 14 & 15 & 11 & 13 & 25 & $11-(13)$ & M10, (M11) & 2 \\
\hline Y6 & 11 & 12 & 11 & 28 & 10 & 15 & 16 & 11 & 13 & 24 & $13-17$ & M4, M5, M19 & 3 \\
\hline nd & & & & & & & & & & & & M15, M17, M18 & 3 \\
\hline
\end{tabular}

Legende : unterlegte Felder sind Abweichungen jeweils zu Haplotyp Y1, ( ) = unsicheres Allel, bzw. unsichere Zuordnung eines Individuums, nd = nicht determinierbar 
In Tabelle 18 sind drei Individuen (M11, M13 und M14) aufgeführt, welche den YHaplotypen unsicher (in Klammern aufgeführt), sowie weitere drei (M15, M17 und M18) die keinem Y-Haplotypen zugeordnet werden konnten $(\mathrm{nd}=$ nicht determinierbar).

Mit Ausnahme von M15 (Mandibula, Do2263) sind diese männlichen Individuen durch ein von Schultes (2000) untersuchtes linkes Femur repräsentiert.

Für M11 (Do183, li. Femora) konnte bis zum Jahr 2000 kein Y-Haplotyp ermittelt werden, für M14 (Do905, li. Femur) lagen zwei unsicher typisierte Allele vor, für M13 (Do58.3, li. Femur) konnten zwei Systeme sicher und eins unsicher bestimmt werden und die Individuen M17 (Do57.2, li. Femur) und M18 (Do901, li. Femur) wurden nicht untersucht.

Um die paternale Linie dieser Individuen nachträglich aufzuklären, wurde in dieser Studie versucht, an bestehenden DNA-Extrakten, eine Y-STR-Analyse nachzuholen. Diese Versuche hatten nur bedingt Erfolg. Für M11 konnte lediglich ein fragmentiertes Y-Allelmuster ermittelt werden, welches aufgrund der Ergebnislage zu Haplotyp Y5 gehören könnte. Für M13 (Do58.3) und M14 (Do905) wurden keine weiterführenden Analysen erarbeitet. Für M13 liegen hier zum Vergleich weiterhin nur drei Y-STRs vor. Aufgrund des Allelmusters könnte er zu Y1 gehören, eventuell auch zu Y4. M14 weist ebenfalls nur ein sehr fragmentiertes Allelmuster auf, welches unter Umständen Y2 zugeschrieben werden könnte. Aufgrund der Unsicherheit dieser Ergebnislage werden die Y-Haplotypen der Individuen M11, M13 und M14 in Klammern in der Tabelle aufgeführt. Damit wird der Tatsache Rechnung getragen, dass diese Einteilung eine deutlich geringere Bestimmungssicherheit aufweist.

Für die Individuen M17 und M18 konnten auch in dieser Studie keine Y-Allelmuster identifiziert werden. Diese beiden werden zusammen mit Individuum M15 (Mandibula, Do2263), für das ebenfalls kein Y-Haplotyp bestimmt werden konnte, in der Gruppe nd zusammengefasst.

Neben der geringen Anzahl an Y-Haplotypen fällt außerdem ihre geringe Variabilität auf. Y6 weicht beispielsweise in nur einem Y-STR-Locus (DYS390) um eine Repeateinheit von Y1 ab (Abb. 28 und 29). Y2 unterscheidet sich lediglich in zwei von 12 typisierten STR-Allelen und ist in beiden Fällen jeweils nur um eine Wiederholungseinheit kleiner. Auch Y4 unterscheidet sich allein in einem Locus (DYS19) von Y1. Jedoch ist dieser Haplotyp einzig für ein Individuum nachzuweisen 
und liegt zusätzlich sehr fragmentarisch vor. Die Haplotypen Y3 und Y5 zeigen dagegen fünf, respektive sieben Abweichungen zu Y1 auf und sind somit gänzlich unterschiedlich.

In den Fällen von Y1,Y2, Y4 und Y6 ist eine mögliche Verwandtschaft zwischen den Individuen nicht völlig ausgeschlossen, es müsste aber durch Mutationsereignisse begründet werden. Solche Abweichungen der Y-Haplotypen konnten bereits bei sicher verwandten Personen festgestellt werden (z.B. Rolf et al. 2001). Kayser \& Sajantila (2001) konnten in sicher nachgewiesenen Vater-Sohn-Paaren das Auftreten von zwei Mutationen nachweisen und empfehlen für einen Vaterschaftsausschluss mindestens drei Mutationsereignisse in neun Y-STR-Loci nachzuweisen. Dennoch sind innerhalb eines Vater-Sohn-Paares Mehr-Schritt-Mutationen eines Y-STR-Locus sowie mehrere Mutationen in verschiedenen Systemen sehr selten (Kayser et al. 2000). Der oben beschriebene Fall einer one-step mutation in 12 untersuchten Y-STRs hingegen ist sehr wahrscheinlich. Im anschließenden Kapitel wird die paternale Verwandtschaft zwischen den Y-Haplotypen Y1 und Y6 sowie zwischen Y1 und Y4 näher untersucht. 


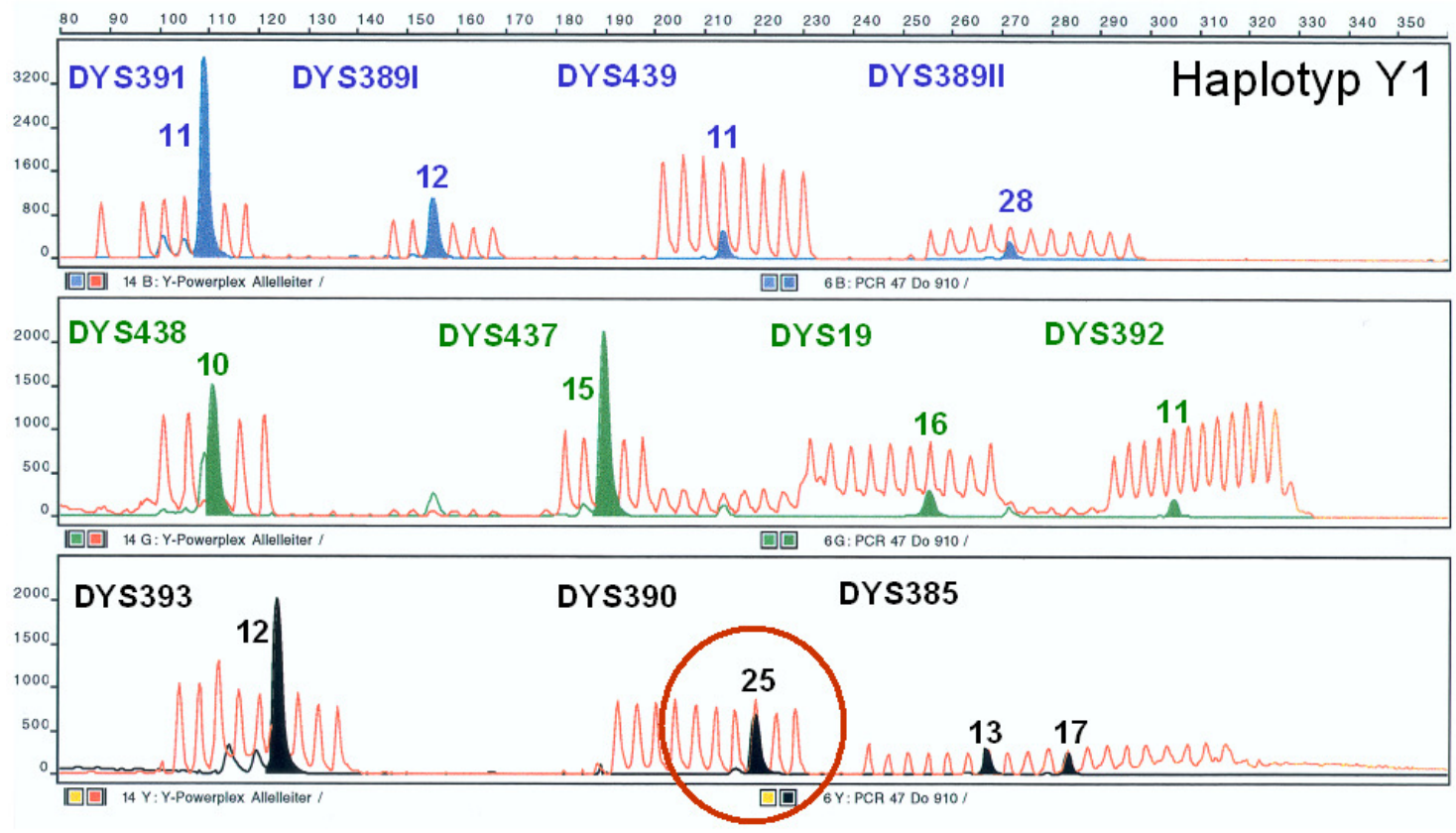

Abbildung 28: Elektropherogramm des Fundes Do910 (M7), amplifiziert mit dem PowerPlex ${ }^{\circledR}$ Y System Kit. Dargestellt ist der Y-Haplotyp Y1, welcher in DYS390 das Allel 25 aufweist (roter Kreis). Auf der x-Achse ist die Fragmentlänge der Produkte in Basenpaaren (bp) dargestellt, die y-Achse gibt die Peakhöhen in relativen Fluoreszenzeinheiten (rfu) wieder.

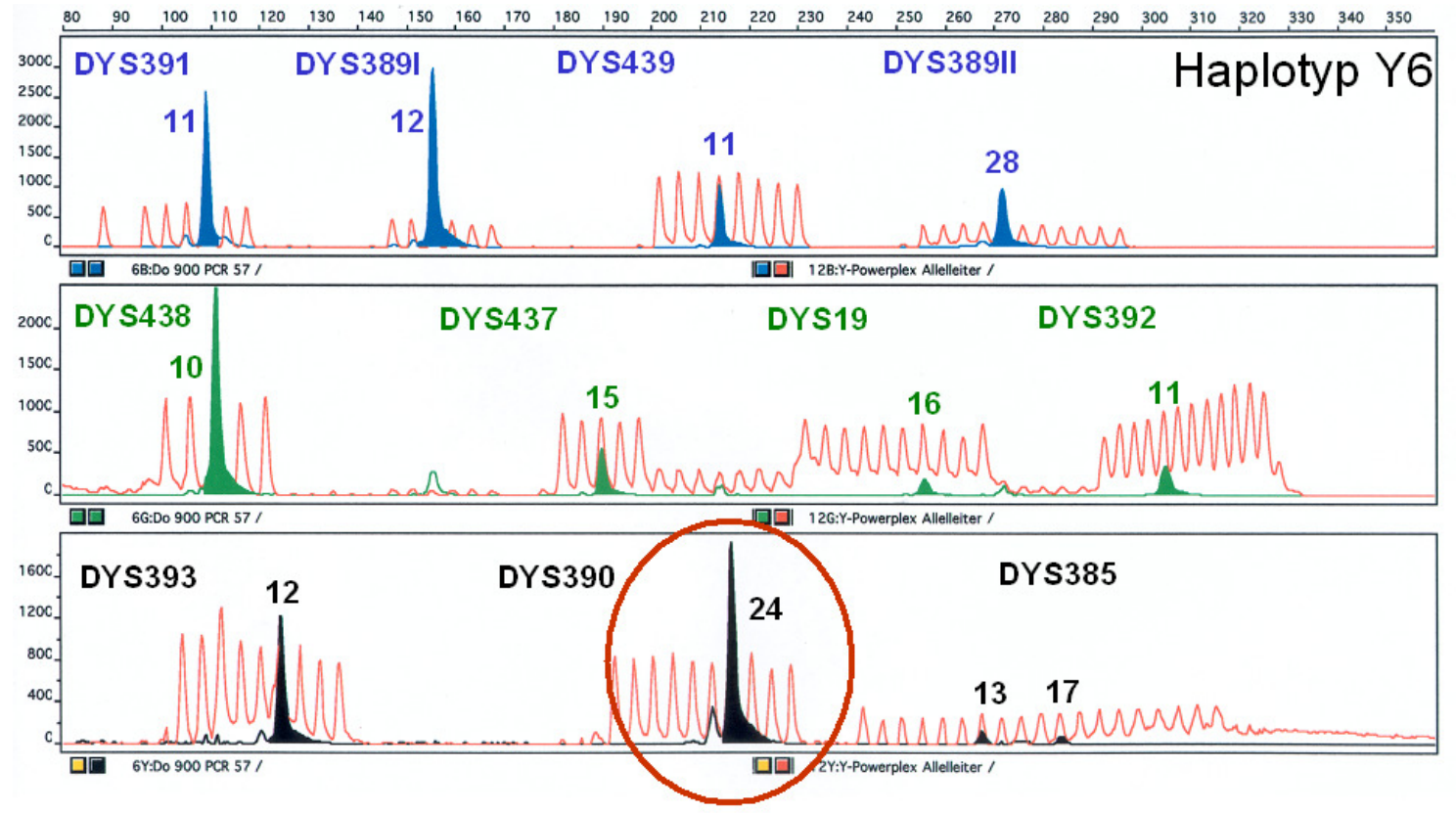

Abbildung 29: Elektropherogramm des Fundes Do900 (M4), amplifiziert mit dem PowerPlex ${ }^{\circledR}$ Y System Kit. Abgebildet ist der Y-Haplotyp Y6, welcher in DYS390 das Allel 24 aufweist (roter Kreis). Dieses ist die einzige Abweichung zu Y1 und ist mit hoher Wahrscheinlichkeit auf eine one-step-mutation zurückzuführen. Auf der x-Achse ist die Fragmentlänge der Produkte in Basenpaaren (bp) dargestellt, die y-Achse gibt die Peakhöhen in relativen Fluoreszenzeinheiten (rfu) wieder. 


\section{Auswertung der genetischen Daten}

Die in Kapitel 5 vorgestellten Typisierungsdaten sind nun Grundlage für die Verwandtschaftsrekonstruktion. Darüber hinaus werden aus den Daten in diesem Kapitel das Residenzverhalten der Gruppe und die regionale Herkunft abgeleitet.

Im Folgenden gelten die zusammengetragenen Typisierungsergebnisse als besprochen und werden ggf. in Auszügen zur Veranschaulichung wiederholt. Für die mt- und YHaplotypen werden die im Kapitel 5.2 und 5.3 vorgestellten Abkürzungen verwendet.

\subsection{Verwandtschaftsrekonstruktion am Skelettkollektiv der Lichtensteinhöhle}

Die Haplotypisierungsergebnisse gaben bereits erste Hinweise auf potenzielle engere verwandtschaftliche Beziehungen zwischen den Individuen. Dies überrascht wenig, da Schultes (2000) bereits nach Abschluss der ersten wissenschaftlichen Studie für einzelne Individuen eine genealogische Verbindung ermitteln konnte. Anhand der Typisierungsergebnisse dieser Arbeit kann nahezu der gesamte verwandtschaftliche Bezug aufgeklärt werden. Für die Verwandtschaftsrekonstruktion werden mehrere Vorgehensweisen verfolgt. Aus den Arbeiten von Schultes (2000) und Schmidt (2004) gehen zwei Verwandtschaftsgruppierungen hervor (s.Kap.6.1.1), welche mit den Typisierungsdaten aus dieser Arbeit in völliger Kongruenz stehen. Diese Verwandtschaften gelten als gesichert und bilden den Ausgangspunkt für die weitere Verwandtschaftsrekonstruktion. Diese fortführende Vorgehensweise orientiert sich an der in Kapitel 3.1 dargestellten Strategie.

Für die meisten Individuen konnten mehr als vier autosomale STR-Loci typisiert werden, womit eine mögliche Elternschaft nahezu eindeutig belegt werden kann (vgl. Schultes 2000, 85). Für die Verwandtschaftsrekonstruktion mithilfe der autosomalen STRs können daher nahezu alle vorgestellten Individuen herangezogen werden. Liegt ein unvollständiger genetischer Fingerabdruck vor, eignen sich diese Teilabdrücke weiterhin für zweierlei Aussagen. (i) Wird ein vorliegendes Allel nicht im Genotyp der Eltern gefunden, kann ein Ausschluss erfolgen. (ii) Ist eine direkte biologische Verwandtschaft trotz fragmentarischer genetischer Fingerabdrücke möglich, gelten nicht vollständig typisierte STR-Loci als stützendes Ergebnis. 
Zwei weibliche (F11 und F17) sowie ein männliches Individuum (M18) eignen sich nicht für eine Verwandtschaftsanalyse, da ihre Typisierungsdaten als nicht ausreichend eingestuft werden. Zwei weitere weibliche Individuen (F20 und F21) eignen sich nur bedingt für eine Verwandtschaftsanalyse. Es ist möglich, sie über ihre maternale Linie einer genealogischen Verbindung zuzuordnen, ihre Anknüpfungspunkte an diese Personen sind jedoch aufgrund fehlender STR-Daten nicht ermittelbar. Diese beiden Frauen werden im Kontext ihrer zugehörigen genealogischen Verbindung noch einmal besprochen.

\subsubsection{Genealogische Rekonstruktion einzelner Verwandtschaftsbeziehungen}

Im Vorfeld zur Verwandtschaftsrekonstruktion wurden die einzelnen Individuen auf gleiche maternale und paternale Linien überprüft (s.Kap.3.1). Hier wurden vorerst die Individuen berücksichtigt, die in den analysierten Abschnitten der HVR völlig sequenzgleich sind, bzw. denselben Y-Haplotypen aufweisen. Des Weiteren wurden die Paternitätsindices aus dem Verwandtschafts-,,screening “, die mit der Computersoftware DNA $\bullet V I E W$ berechnet wurden und ein Maß für direkte biologische Verwandtschaft sind (Kap.3.3, S.42-43) sowie die Daten aus der Verwandtschaftsanalyse, die mithilfe der Computersoftware aDNA-Typing (Kap. 3.1, S.32) ermittelt wurden, herangezogen.

Aus diesen Daten konnte die Mehrzahl der Individuen in sechs genealogische Verbindungen (= genealogische Verbindung $I-V I)$ eingeteilt werden. Die jeweilige Gruppengröße, d.h. Individuenanzahl pro Gruppe, ist dabei unterschiedlich. Die Nummerierung I-VI unterliegt keiner speziellen Hierarchie. Die Reihenfolge, in der die Verbindungen hier vorgestellt werden, dient der besseren Veranschaulichung der Ergebnisse. Die genealogische Rekonstruktion, der in die einzelnen Gruppen eingeteilten Individuen, wird in den jeweiligen Abschnitten detailliert beschrieben. Wenn direkte biologische Verwandtschaften nachgewiesen werden konnten (Defizienzfälle und/oder Eltern-Kind-Verbindungen), dann wurden die Elternschaftswahrscheinlichkeiten berechnet (vgl. Kap.3.3, S.40-43). Diese Berechnungen basieren dabei nicht immer auf 10 STR-Loci, da einige der genetischen Fingerabdrücke nicht vollständig typisiert wurden. Es wurden nur die STR-Systeme berücksichtigt, für die ein Kind und ein Putativelternteil sichere Genotypen aufweisen. Die Genotypen entstammen dabei den Tabellen 14 und 15, Seite 75 und 76. 
Individuen, für die kein verwandtschaftlicher Bezug zu einem anderen Individuum hergestellt werden konnte, werden nach den genealogischen Verbindungen näher besprochen.

Im Anschluss an dieses Unterkapitel werden die einzelnen Gruppen in Kapitel 6.1.2 auf ihren verwandtschaftlichen Bezug zueinander überprüft und damit abschließend der Familienstammbaum der Lichtensteinhöhle rekonstruiert.

Mit den eigenen Daten konnten zwei Familiengruppen (hier mit A und B bezeichnet), die aus den vorangegangenen Arbeiten von Schultes (2000) und Schmidt (2004) resultieren, bestätigt werden. Dabei handelt es sich zum einen um vier Individuen die in dieser Studie der genealogischen Verbindung I und zum anderen um fünf Individuen, die der genealogischen Verbindung II zugeordnet sind. Die Familiengruppen wurden von den genannten Autoren wie folgt beschrieben und sind in den Abbildungen 30 und 31 dargestellt.

$>\quad$ Familiengruppe A (Abb.30): Die Individuen F5 und M3 sind die Eltern von F6 und bilden eine Kernfamilie. M3 ist darüber hinaus der Vater von F7, F5 ist jedoch nicht die Mutter dieses Kindes (Schultes 2000).

Familiengruppe B (Abb.31): Die Individuen F1 und M1 sind die Eltern von M2 und bilden eine Kernfamilie (Schultes 2000). Die Individuen M2 und F2 sind die Eltern von F3 (Schmidt 2004).

Innerhalb der genealogischen Verbindungen I und II dienen diese, zusätzlich mit eigenen Daten abgesicherten (z.B. Wahrscheinlichkeitsberechnungen), Verwandtschaftsverhältnisse als Ausgangspunkte für die weitere genealogische Rekonstruktion. Die Verwandtschaftsanalysen in den weiteren Gruppen basieren auf den in dieser Arbeit erzielten Daten. In Einzelfällen wurden Erkenntnisse aus den Studien von Schultes (2000) und Schmidt (2004) aufgegriffen und in den eigenen Kontext mit eingebunden. In den jeweiligen Abschnitten wird darauf hingewiesen. 


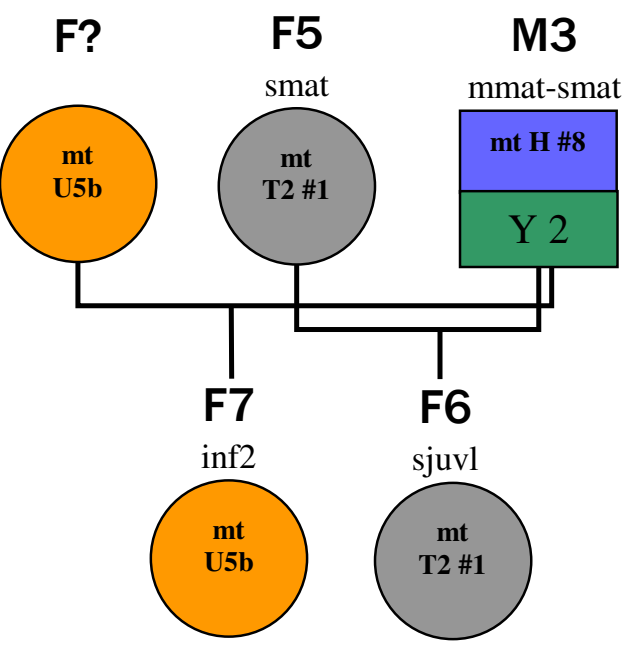

Abbildung 30: Familiengruppe A (nach Schultes 2000): Das männliche Individuum M3 hat zusammen mit dem weiblichen Individuum F5 das Kind F6 und darüber hinaus mit einer unbekannten Frau (F?) eine weitere Tochter (F7). Die Altersstufen sind unter den Namen, die maternalen $(=m t)$ und paternalen Linien $(=Y)$ sind innerhalb der Symbole angegeben. Die hier dargestellten Individuen gehören zur genealogischen Verbindung I.

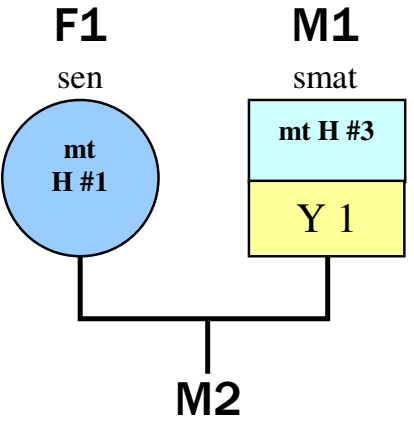

F2
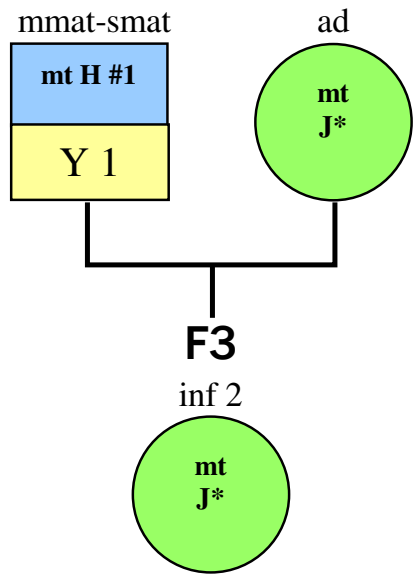

Abbildung 31: Familiengruppe B (nach Schultes 2000 und Schmidt 2004): Das weibliche Individuum F1 und das männliche Individuum M1 sind die Eltern von M2. Dieses bildet mit F2 und einer Tochter F3 wiederum eine Kernfamilie. Die Altersstufen sind unter den Namen, die maternalen $(=m t)$ und paternalen Linien $(=\mathrm{Y})$ sind innerhalb der Symbole angegeben Die hier dargestellten Individuen gehören zur genealogischen Verbindung II. 


\section{Genealogische Verbindung I}

Aufbauend auf der Familiengruppe A wurden alle Individuen auf das Vorliegen der möglichen mt-Haplotypen U5b, T2 \#1 und H \#8 geprüft.

Innerhalb des Skelettkollektivs konnten jedoch von diesen drei mt-Haplotypen allein Träger des Haplotypen U5b ermittelt werden. Neben F7 weisen weitere vier Individuen (F4, F8, M8 und M16) diese maternale Linie auf. Es kann davon ausgegangen werden, dass diese Individuen in einem engeren verwandtschaftlichen Bezug $\mathrm{zu}$ den bereits bekannten vier Individuen (F5, F6, F7 und M3) stehen. Dabei handelt es sich um zwei erwachsene Frauen und zwei männliche Individuen der Altersklasse Infans. Die Verwandtschaftsanalyse über die autosomalen STRs ergab folgende Ergebnisse (Tab.19):

Tabelle 19: Verwandtschaftsanalyse der Individuen mit der maternalen Linie U5b in Verbindung mit den bereits bekannten Individuen der Familiengruppe A. Über die autosomalen STRs wurden die Individuen auf direkte biologische Verwandtschaft überprüft. Teilen sich Individuen 50\% ihrer Allele, wird der MI bzw. PI mit jeweiliger Wahrscheinlichkeit ermittelt. Erfolgt der Ausschluss, ist dies durch - gekennzeichnet. Der PI/MI-Wert basiert nicht immer auf vollständigen Typisierungsdaten, d.h. 10 STRs (s.Seite 98).

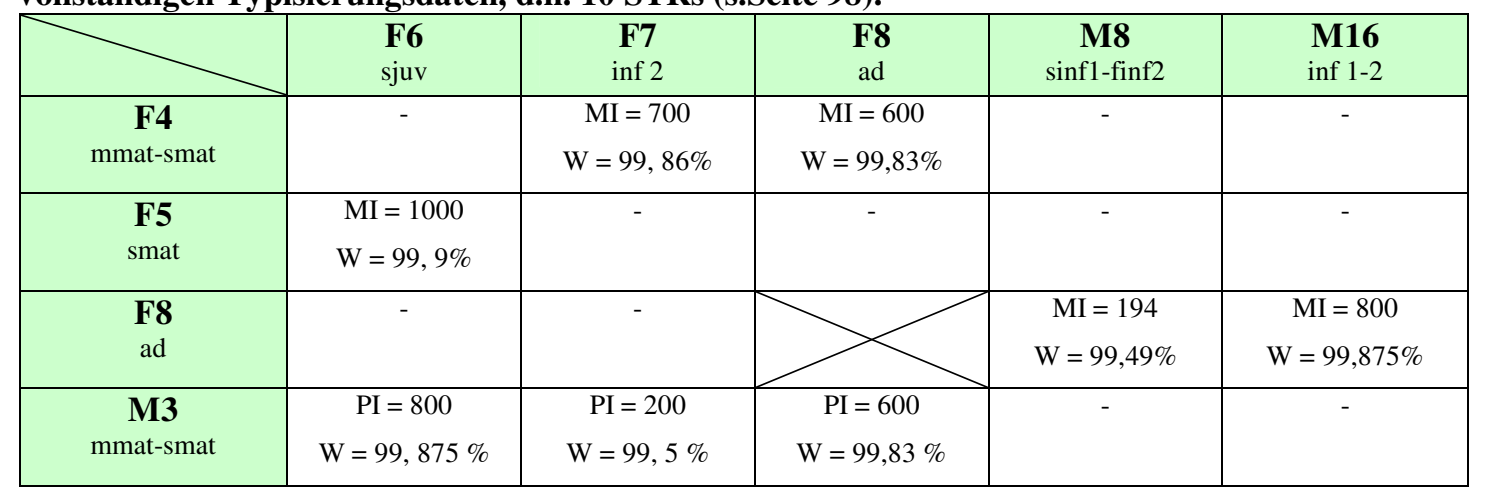

Legende: $\mathrm{MI}=$ Maternitätsindex, $\mathrm{PI}=$ Paternitätsindex, $\mathrm{W}=$ Elternschaftswahrscheinlichkeit

Aufgrund der Tatsache, dass F4 und F7 die gleiche maternale Linie aufweisen und die Analyse der autosomalen STRs die Mutterschaft praktisch erweist (W =99,86\%), wird F4 als Mutter von F7 angenommen. In Kombination mit dem Putativvater M3 errechnet sich für diese Dreierkonstellation ein PI von 9726 (W = 99,99\%). Damit liegt neben der ersten Triade M3, F5 und F6 (Schultes 2000), mit M3, F4 und F7 eine weitere in diesem Familienverband vor.

Zwischen F4 und F8 konnte ebenfalls eine direkte Beziehung nachgewiesen werden, da auch sie sich genau 50\% der Allele teilen. Aufgrund des Individualalters ist nicht zu sagen, wer Mutter und wer Tochter ist. Jedoch wurde zusätzlich ein hoher Verwandtschaftsindex zwischen M3 und F8 festgestellt. Der ermittelte PI mit dem 
Putativvater M3 beträgt 47900 und basiert auf neun autosomalen STRs, damit liegt auch für diese Verbindung eine Elternschaftswahrscheinlichkeit von 99,99\% vor. Die Allelkonstellation ergibt eine einzig so mögliche dritte Triade mit Mutter F4, Kind F8 und Vater M3.

Des Weiteren konnte F8 wiederum mit hoher Wahrscheinlichkeit als Mutter der Kinder M8 und M16 bestätigt werden. Für die Kinder ist der Vater, welcher den Y-Haplotyp Y1 aufweisen müsste, allerdings unbekannt. Dieser Y-Haplotyp konnte bei weiteren drei Individuen (M1, M2, M7) sicher und für M13 mit geringerer Sicherheit typisiert werden. Von diesen vier Individuen waren drei im reproduktionsfähigen Alter. Über den Abgleich ihrer autosomalen STR-Allelmuster konnte kein Putativvater für M8 und M16 ermittelt werden (Tab. 20).

Tabelle 20: Verwandtschaftsanalyse der männlichen Individuen mit dem Y-Haplotyp Y1. Die Elternschaft wird anhand der autosomalen STRs überprüft. Über die autosomalen STRs wurden die Individuen auf direkte biologische Verwandtschaft überprüft. Teilen sich Individuen 50\% ihrer bestimmbaren Allele, wird der PI mit jeweiliger Wahrscheinlichkeit ermittelt. Erfolgt der Ausschluss, wird dies durch - gekennzeichnet. Der PI/MI-Wert basiert nicht immer auf vollständigen Typisierungsdaten, d.h. 10 STRs (s.Seite 98).

\begin{tabular}{|c|c|c|c|c|c|c|}
\hline & $\begin{array}{c}\text { M1 } \\
\text { smat }\end{array}$ & $\begin{array}{c}\text { M2 } \\
\text { mmat-smat }\end{array}$ & $\begin{array}{c}\text { M13 } \\
\text { sjuv-fad }\end{array}$ & $\begin{array}{c}\text { M7 } \\
\text { inf 1-2 }\end{array}$ & $\begin{array}{c}\text { M8 } \\
\text { sinf1-finf2 }\end{array}$ & $\begin{array}{c}\text { M16 } \\
\text { inf 1-2 }\end{array}$ \\
\hline $\begin{array}{c}\text { M1 } \\
\text { smat }\end{array}$ & & $\begin{array}{c}\text { PI }=300 \\
\text { W=99,66\% }\end{array}$ & - & - & - & - \\
\hline $\begin{array}{c}\text { M2 } \\
\text { mmat-smat }\end{array}$ & $\begin{array}{c}\mathrm{PI}=300 \\
\mathrm{~W}=99,66 \%\end{array}$ & - & - & - & - \\
\hline $\begin{array}{c}\text { M13 } \\
\text { sjuv-fad }\end{array}$ & - & - & & - & - & - \\
\hline
\end{tabular}

Legende: PI = Paternitätsindex, $\mathrm{W}=$ Elternschaftswahrscheinlichkeit

M1 und M2 weisen jeweils in mindestens vier STR-Loci kein Allel auf, welches bei den beiden Jungen (M8 und M16) repräsentiert ist. Der fragmentarische genetische Fingerabdruck von M13 weicht, in seinen vier sicher zu beurteilenden STRs, jeweils in einem ab. Legt man die sehr wahrscheinliche Mutterschaft von F8 zugrunde, würde M13 in einem weiteren System (D3S1358) nicht das nötige zweite Allel zur Verfügung stellen können. Damit ist auch diese Vaterschaft ausgeschlossen.

Für M8 und M16 konnte ein hoher SI-Wert von 600 ermittelt werden (s.Kap.3.3, 43). Die Höhe dieses Wertes unterstützt die Annahme, dass es sich hier um Geschwister handelt. In Verbindung mit der gemeinsamen Mutter F8 und damit der gleichen maternalen Linie sowie dem gleichen Y-Haplotypen, kann diese Verbindung als gesichert gelten. 
Damit liegen für diesen Familienzweig acht Individuen vor, welche über drei Generationen miteinander verbunden sind (Abb.32).

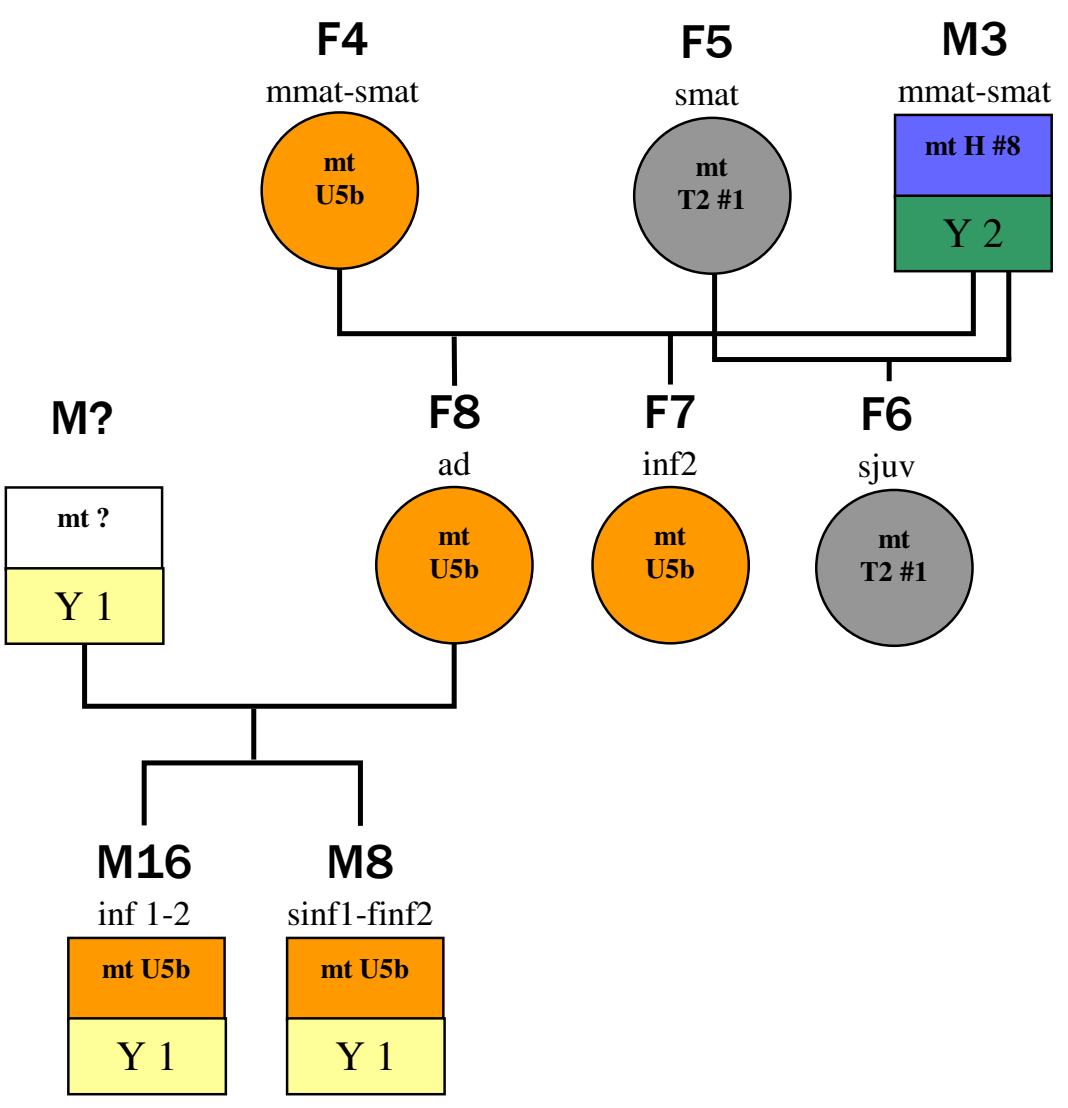

\begin{abstract}
Abbildung 32: Genealogische Verbindung I: Aus den Typisierungsergebnissen läßt sich eine Großfamilie über drei Generationen rekonstruieren. Der Mann (M?) von F8, und damit der Vater der Kinder M8 und M16, ist unbekannt. Die Altersstufen sind unter den Namen, die maternalen (=mt) und paternalen Linien $(=Y)$ sind innerhalb der Symbole angegeben.
\end{abstract}

\title{
Genealogische Verbindung II
}

Eine direkte biologische Verwandtschaft der männlichen Individuen mit dem YHaplotypen Y1 liegt ausschließlich zwischen M1 und M2 vor (s.Tab. 20). M1 ist der Vater von M2, obwohl das Allelmuster die Auswertung auch in die andere Richtung zulassen würde (vgl. Schultes 2000, 87). Diese Verbindung wurde bereits als gesichert angesprochen. Zusammen mit F1, F2 und F3 bilden M1 und M2 die einführend besprochene 3-Generationenfamilie (= Familiengruppe B). 
Vier Personen weisen den mt-Haplotyp $\mathrm{J}^{*}$ auf (F2, F3, M12 und M15). Der verwandtschaftliche Bezug von F2 als Mutter des Kindes F3 war bereits bekannt. Der MI zwischen der Putativmutter F2 und dem Kind F3 ist jedoch gering (= ca. 3). Dies kann damit begründet werden, dass die Berechnung auf sechs STR-Loci basiert und die Mutter sich statistisch häufige Allele mit dem Kind teilt. Da das männliche Individuum M2 sicher der Vater von F3 ist, berechnet sich mit einer Putativmutter F2 ein MI von ca. 42. Dies entspricht einer Wahrscheinlichkeit von 97,6\%. Damit ist es sehr wahrscheinlich, dass F2 die Mutter von F3 ist. Außerdem sollte man berücksichtigen, dass F2 und F3 denselben mt-Haplotypen und einen gemeinsamen X-Haplotypen (Schmidt 2004) aufweisen, welches Wahrscheinlichkeit zusätzlich erhöht.

Die weitere Verwandtschaftsanalyse der vier Personen ergab, dass M12 sich in fünf zu beurteilenden autosomalen STRs jeweils ein Allel mit F2 teilt. Somit ließe sich auf eine Mutter - Sohn - Dyade schließen. Dagegen ist eine Mutterschaft zu M15 aufgrund von mindestens einer Abweichung unwahrscheinlich. Es ist darauf hinzuweisen, dass für beide Kinder, d.h. sowohl für M12 als auch für M15, lediglich fragmentarische Fingerabdrücke vorliegen.

Neben der Verbindung von Mutter F2 zu Kind M12 käme das männliche Individuum M2 als Vater von M12 in Betracht. Der PI zwischen dem Putativvater M2 und dem Kind M12 beträgt auf der Basis von fünf autosomalen STRs bereits 1000. Eine Vaterschaft wäre damit sehr wahrscheinlich, jedoch weisen die beiden Individuen unterschiedliche Y-Haplotypen auf. Der fragmentarische Y-Haplotyp des Jungen zeigt im Locus DYS19 das Allel 17 und würde damit um eine repeat unit von Y1 abweichen. Handelt es sich bei diesem Allel nicht um ein Stotterartefakt (s.Kap.4.4), müsste an dieser Stelle von einem Mutationsereignis zwischen Vater und Sohn ausgegangen werden. Dupuy et al. (2004) geben einen Überblick über die Mutationsraten verschiedener Y-STR-Loci bei Vater-Sohn-Paaren. Die Mutationsrate von DYS19 wird hier mit 1.7 x $10^{-3}$ angegeben. Würde an dieser Stelle die Vaterschaft von M2 zum Kind M12 anhand von Y-STRs berechnet, dann müsste die Mutationsrate des Y-STR-Locus DYS19 berücksichtigt werden. Von einer solchen Berechnung wird hier allerdings abgesehen, da der Y-Haplotyp des Individuums M12 einzig zwei sicher bestimmte YSTR-Loci aufweist. Für die letztendliche Klärung der Verwandtschaft dieses Kindes müssten sowohl genetischer Fingerabdruck als auch Y-STRs mehr analysierbare Loci aufweisen. Hinweise auf die Triade F2, M2 und M12 liegen hingegen vor. Des 
Weiteren weisen die möglichen beiden Kinder (F3 und M12) in den zu beurteilenden Systemen sehr ähnliche genetische Fingerabdrücke auf, welche zu einem hohen SI-Wert (=2000) führen. Demnach spricht vieles für ein geschwisterliches Verhältnis.

Für M15 konnte kein Y-Haplotyp ermittelt werden, weshalb eine Vaterschaftsanalyse über die autosomalen STRs stattfinden muss. Die Vaterschaft von M2 zu M15 schließt sich in zwei der zu beurteilenden Systeme sicher aus (D21S11 und D5S818). Des Weiteren ergab die Analyse aller untersuchten männlichen Individuen ebenfalls keine Übereinstimmung. Es sollte angenommen werden, dass M15 in enger verwandtschaftlicher Beziehung zu dem Träger des mt-Haplotypen $\mathrm{J} *$ steht, da dieser mit acht Sequenzpolymorphismen sehr individuell ist. Denkbar wäre daher eine geschwisterliches Verhältnis mit F2. Um dieses Überprüfen zu können, müssten die Eltern bekannt sein. Es konnte jedoch keine weitere weibliche Person mit der Haplogruppe $\mathrm{J}^{*}$ nachgewiesen werden, weshalb die biologische Mutter nicht ermittelbar ist.

Die Ergebnisse der besprochenen autosomalen STR-Verwandtschaftsanalyse sind in Tabelle 21 zusammengefasst.

Tabelle 21: Verwandtschaftsrekonstruktion für die Individuen mit der maternalen Linie J*. Zusätzlich wird hier die Vaterschaft von M2 zu den Kindern F3, M12 und M15 überprüft. Teilen sich Individuen 50\% ihrer bestimmbaren Allele, wird der MI bzw. PI mit jeweiliger Wahrscheinlichkeit ermittelt. Erfolgt der Ausschluss, wird dies durch - gekennzeichnet. Der PI/MI-Wert basiert nicht immer auf vollständigen Typisierungsdaten, d.h. 10 STRs (s.Seite 98).

\begin{tabular}{|c|c|c|c|}
\hline & F3 & M12 & M15 \\
infans 2 & - \\
\hline F2 & MI $=3^{*}$ & MI $=$ nd. & \\
\hline M2 & $\mathrm{W}=75 \% *$ & $\mathrm{~W}=$ nd. & - \\
smatur & $\mathrm{PI}=6003$ & $\mathrm{PI}=1000$ & \\
\hline
\end{tabular}

Legende: $\mathrm{MI}=$ Maternitätsindex, $\mathrm{PI}=$ Paternitätsindex, $\mathrm{W}=$ Elternschaftswahrscheinlichkeit, nd. $=$ nicht determinierbar, $*$ Für nähere Erläuterungen dieser Konstellation siehe Text Seite 104.

Die männlichen Individuen mit dem Y-Haplotyp Y1 wurden bereits bei der genealogischen Verbindung I auf eine Verwandtschaft 1.Grades untersucht. Es konnte dabei weder der Junge M7, noch das frühadulte Individuum M13, mit einem anderen männlichen Individuum mit dem Haplotyp Y1 direkt verknüpft werden. Die für M13 ausschließlich fragmentiert vorliegenden STR-Daten erschweren eine Zuordnung. Die jeweilige maternale Linie zeigt, dass keine Putativmutter für diese beiden Individuen infrage kommt. Eine mögliche Vater-Tochter-Relation ist einzig für das Ältere der beiden Individuen möglich, wobei die von Schultes (2000) bevorzugte Vaterschaft von 
M13 zu F2 bereits über die Analyse der X-Marker ausgeschlossen werden konnte (Schmidt 2004). Weitere Verbindungen sind aufgrund des Fragmentierungsgrades des genetischen Fingerabdruckes nicht nachweisbar. Vermutlich gehört M13 ebenso wie M7 zur väterlichen Linie Y1, jedoch mit geringerer Wahrscheinlichkeit als M7. Beide könnten mit jeweils unterschiedlichen maternalen Linien z.B. Cousins väterlicherseits von M1 sein. Aus diesen Ergebnissen ergibt sich folgende parsimonische graphische Darstellung für die genealogische Verbindung II (Abb.33).

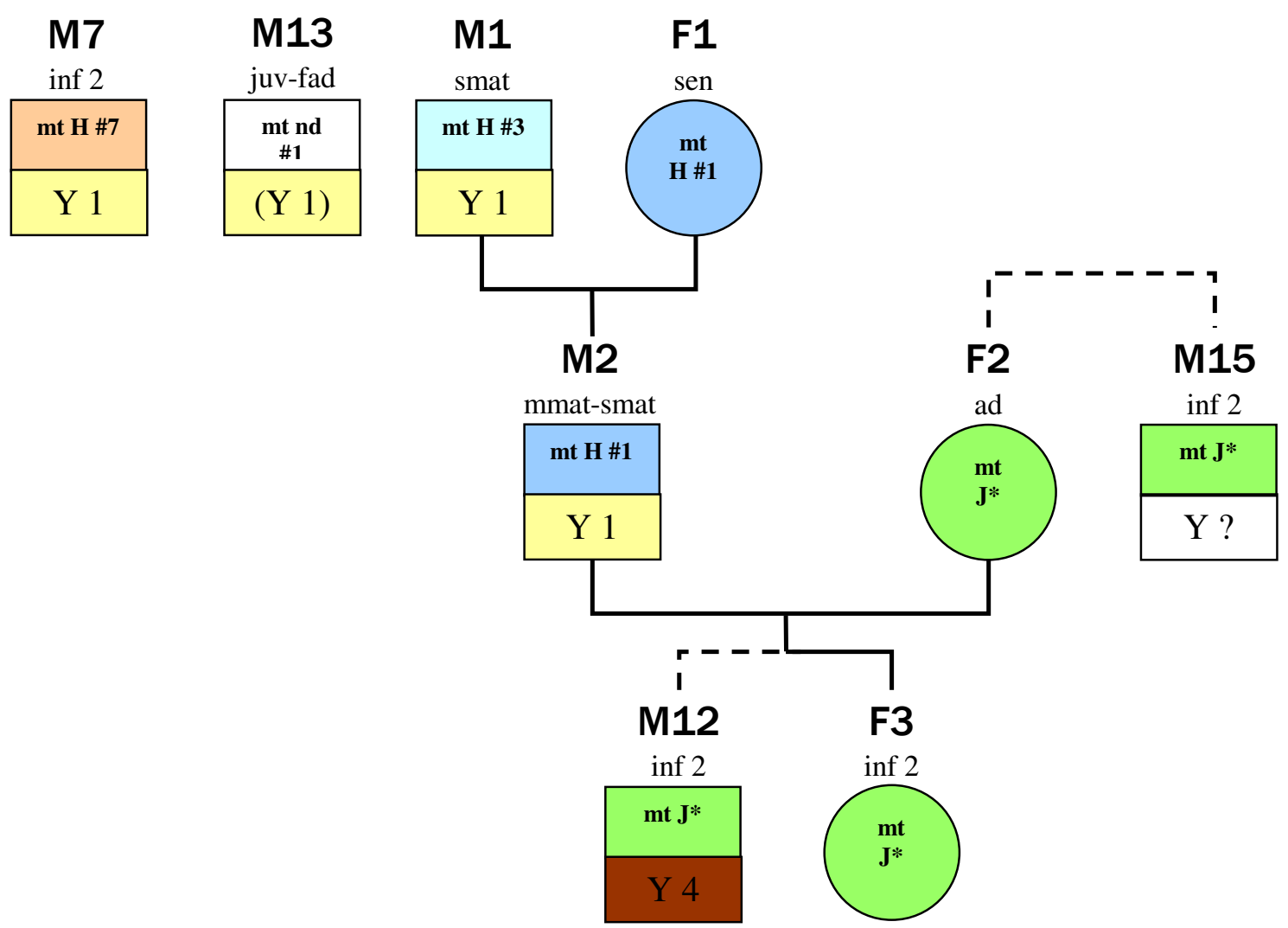

\begin{abstract}
Abbildung 33: Genealogische Verbindung II: Aus den Typisierungsergebnissen konnte die bereits bekannte Großfamilie (= Familiengruppe B) erweitert werden. Aufgrund der autosomalen Ergebnisse könnten F2, M2 und M12 eine Eltern-Kind-Beziehung bilden. In diesen Fall muss ein Mutationsereignis im Y-Haplotyp des Kindes stattgefunden haben. Diese Verbindung ist daher nicht vollständig gesichert (=gestrichelte Verbindung). M15 gehört mit Sicherheit zu dieser Gruppe, seine Verknüpfung kann jedoch nicht gesichert angegeben werden. Die hier dargestellte Gruppierung entspricht der nächst möglichen Verbindung der Individuen. Die beiden männlichen Individuen M7 und M13 gehören über ihre väterliche Linie weitläufig zur Familie, bsp. Cousins väterlicherseits. Die Altersstufen sind unter den Namen, die maternalen $(=m t)$ und paternalen Linien (=Y) sind innerhalb der Symbole angegeben.
\end{abstract}

\title{
Genealogische Verbindung III
}

Die maternale Linie H \#1 des weiblichen Individuums F1 (= genealogische Verbindung II) wurde außer bei ihrem Sohn (M2) noch ein drittes mal gefunden (M6). Bei diesem 
Individuum handelt es sich um einen ca. 8 jährigen Jungen. Die Elternschaft von F1 zu diesem Individuum ist ebenso ausgeschlossen wie die des Mannes M3 (= genealogische Verbindung I), welcher den gleichen Y-Haplotyp wie M6 trägt. Ein weiterer Mann (M14) dessen genetischer Fingerabdruck fragmentiert vorliegt, scheidet, obwohl er auch den Y-Haplotyp Y2 aufweist, aufgrund von mindestens zwei Abweichungen (D5S818 und D3S1358) als Vater aus. Ausgehend von der väterlichen Linie könnte es sich nächstmöglich um einen Onkel handeln. Damit konnten innerhalb des Skelettkollektivs keine Eltern ${ }^{1}$ für das Kind (M6) ausgemacht werden (Abb.34).

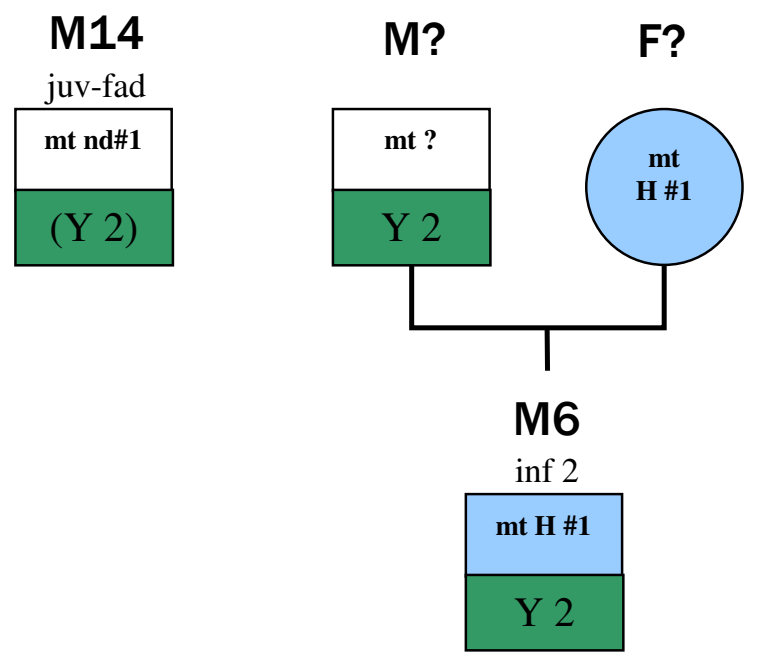

\begin{abstract}
Abbildung 34: Genealogische Verbindung III: Es konnten keine Eltern für das Individuum M6 ausgemacht werden. Seine maternale (mt H \#1) und paternale Linie (Y2) stellen dieses Kind als Verbindungsglied der bereits vorgestellten genealogischen Verbindungen I und II dar. Das Individuum M14 könnte eventuell über die väterliche Linie mit M6 verwandt sein. Die Altersstufen sind unter den Namen, die maternalen (=mt) und paternalen Linien $(=Y)$ sind innerhalb der Symbole angegeben.
\end{abstract}

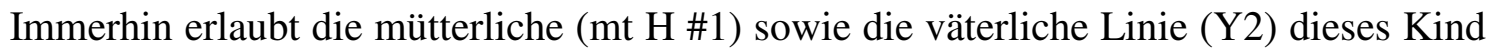
als Verbindungsglied der bereits vorgestellten Großfamilien zu sehen. Dies wird bei der Erstellung des Familienstammbaumes näher erläutert.

\title{
Genealogische Verbindung IV
}

Durch die Ermittlung ihrer mt- und Y-Haplotypen konnten fünf weitere Individuen (F21, M4, M5, M17 und M19) festgestellt werden, welche einen Familienverband darstellen könnten. Mit Ausnahme des männlichen Individuums M17, dessen Y-

\footnotetext{
${ }^{1}$ Hier könnte ein Hinweis auf ein praktiziertes Sozialverhalten der bronzezeitlichen Gruppe vorliegen (s.Kap.6.2.3).
} 
Allelmuster nicht bekannt ist, weisen die männlichen Individuen gemeinschaftlich den Y-Haplotyp Y6 auf. M4, M5 und F21 tragen darüber hinaus die gleiche maternale Linie. Für F21 liegen lediglich Ergebnisse aus drei autosomalen STRs mit jeweils einem Allel vor, womit für die Verwandtschaftsrekonstruktion nicht die nötige Datenmenge erreicht ist (Kap.6.1, S.97). Die Verwandtschaft über die mütterliche Linie zu den beiden anderen Individuen (M4 und M5) kann nur vermutet werden. Die nächstmögliche Verbindung wäre eine Geschwisterschaft zu M4 und M5.

Für M19 wurde die maternale Linie $\mathrm{H} \# 10$ bestimmt, zu der mit großer Wahrscheinlichkeit auch M17 gehört. Für letzteres Individuum liegt kein Y-Allelmuster vor (s.o.). Der nächstmögliche Verknüpfungspunkt wäre auch hier eine Geschwisterschaft von M17 zu M19. Über die Analysen der autosomalen STRs wird der Verwandtschaftsgrad zwischen M4, M5, M17 und M19 aufgeklärt (Tab.22).

Tabelle 22: Direkte biologische Verwandtschaft für die männlichen Individuen der genealogischen Verbindung IV. Teilen sich Individuen 50\% ihrer bestimmbaren Allele, wird der PI mit jeweiliger Wahrscheinlichkeit ermittelt. Erfolgt der Ausschluss, wird dies durch - gekennzeichnet. Der PI-Wert basiert nicht immer auf vollständigen Typisierungsdaten, d.h. 10 STRs (s.Seite 98).

\begin{tabular}{|c|c|c|c|c|}
\hline & $\begin{array}{c}\text { M4 } \\
\text { inf 2 }\end{array}$ & $\begin{array}{c}\text { M5 } \\
\text { adult }\end{array}$ & $\begin{array}{c}\text { M17 } \\
\text { mad }\end{array}$ & $\begin{array}{c}\text { M19 } \\
\text { sad-mat }\end{array}$ \\
\hline $\begin{array}{c}\text { M5 } \\
\text { adult }\end{array}$ & - & & - & \\
\hline $\begin{array}{c}\text { M17 } \\
\text { mad }\end{array}$ & - & - & & \\
\hline $\begin{array}{c}\text { M19 } \\
\text { sad-mat }\end{array}$ & PI $=500$ & PI $=300$ & \\
\hline
\end{tabular}

Legende: $\mathrm{PI}=$ Paternitätsindex, $\mathrm{W}=$ Elternschaftswahrscheinlichkeit

M4 war nicht im reproduktionsfähigen Alter, d.h. eine Vaterschaft zu einem anderen Individuum ist ausgeschlossen. M5 kann nicht der Vater von M4 sein, welches durch zwei Abweichungen in den STR-Loci D5S818 und D7S820 belegt ist. Er weist jedoch genau die Hälfte der Allele von M19 auf und könnte damit dessen Vater sein. Es wäre allerdings auch möglich, dass M19 sowohl der Vater von M4 als auch M5 ist.

Die wahrscheinlichste Konstellation dieses Verwandtschaftsverhältnisses ist in Abbildung 35 dargestellt. Sie zeigt, dass M4 und M5 die gleiche mütterliche sowie väterliche Linie aufweisen und somit höchstwahrscheinlich Geschwister sind. Die Mutter der Kinder konnte nicht ermittelt werden. Eine andere, eher zweifelhafte Variante wäre, dass M5 der Vater von M19 und dieser wiederum der Vater von M4 ist. In diesem Fall würden jedoch zwei Frauen fehlen, welche den gleichen mt-Haplotypen 
jeweils an die Söhne vererbt hätten. Der Paternitätsindex des Putativvaters M19 zu Kind M4 beträgt 500 (W=99,8\%), der von M19 zu M5 300 ( $\mathrm{W=99,67 \% ).} \mathrm{Damit} \mathrm{ist} \mathrm{die}$ Vaterschaft im ersten Fall praktisch erwiesen und im Zweiten höchst wahrscheinlich (vgl. http://www.dna-view.com/hummel.htm, 20.01.2006).

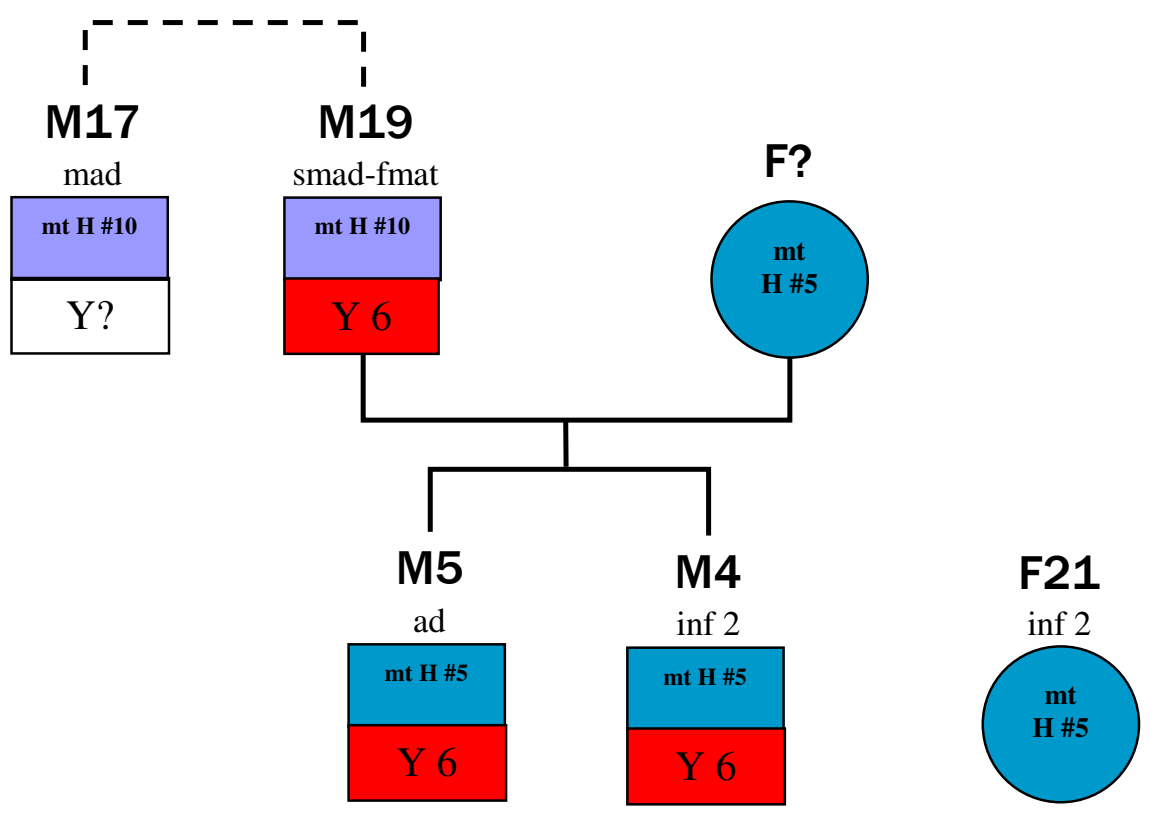

\begin{abstract}
Abbildung 35: Genealogische Verbindung IV: Dargestellt ist die nächst mögliche Verwandtschaftsbeziehung der fünf Individuen. M4 und M5 sind Geschwister mit einem gemeinsamen Vater M19. Die Mutter (F?) der beiden ist nicht bekannt. Das weibliche Individuum F21 ist dafür mit ca. 8 Jahren zu jung. Ihr stark fragmentarischer genetischer Fingerabdruck ermöglicht keinen genauen Verknüpfungspunkt mit den anderen. Die maternale Linie stellt es aber in die Nähe des Geschwisterpaares. M19 könnte wiederum mit M17 verschwistert sein. Die Altersstufen sind unter den Namen, die maternalen (=mt) und paternalen Linien (=Y) sind innerhalb der Symbole angegeben.
\end{abstract}

\title{
Genealogische Verbindung $V$
}

Zwischen dem weiblichen Individuum F9 und dem männlichen Individuum M11 besteht mit hoher Wahrscheinlichkeit ein engeres verwandtschaftliches Verhältnis. Beide weisen den mt-Haplotyp $\mathrm{U} \# 2$ auf und teilen sich in den zu bewertenden autosomalen STRs jeweils ein Allel. In einer weiterführenden genetischen Analyse (s.Kap.11.2.1, S.189ff) konnte für beide das Blutgruppenallel $0_{1 \mathrm{v}}$ bestimmt werden und obwohl diese Merkmalsverteilung auch eine Mutter-Sohn-Beziehung zulassen würde, spricht das Alter der beiden eher für ein Geschwisterverhältnis. Das Individuum F9 hat ein Alter von ca. 18 Jahren erreicht, M11 ist ca. 9 Jahre alt geworden. Eine sichere Aufklärung dieser Konstellation würde allein über die Eltern der beiden gelingen. Eine weitere Frau mit gleicher maternaler Linie konnte nicht gefunden werden und innerhalb 
der männlichen Individuen kommt keines als Putativvater in Frage. Für den Jungen M11 konnten einzig zwei Y-STRs bestimmt werden, in DYS438 weist er das Allel 11 auf. Dieses Allel kommt in der Lichtensteinhöhle nur bei Haplotyp Y5, bzw. dem Individuum M10, vor. Die Vaterschaft von M10 zu M11 wird in zwei autosomalen STRs und die Vaterschaft von M10 zu F9 in einem STR (D5S818) ausgeschlossen.

Weiterführende genetische Analysen am Skelettkollektiv der Lichtensteinhöhle zeigen, dass diese drei Individuen trotzdem in einem engeren verwandtschaftlichen Verhältnis stehen können. Mit nur einer weiteren Ausnahme konnte die sehr seltene $\Delta$ 32CCR5Variante (s.Kap.11.2.2) nur bei diesen drei Individuen festgestellt werden. Wenn die Individuen M11 und F9 Geschwister sind, dann könnte das männliche Individuum M10 zum Beispiel der Onkel väterlicherseits sein (Abb.36).

M10 weist vermutlich die maternale Linie T2 \#2 auf. Die Zugehörigkeit ließ sich nicht zweifelsfrei klären, da Anfangsbereiche der HVR II nicht sequenziert werden konnten. In den übrigen Bereichen ist die HVR sequenzgleich mit der des weiblichen Individuums F10. Sie könnten damit zur gleichen maternalen Linie gehören, jedoch lässt sich der genaue Verwandtschaftsgrad nicht ohne weitere direkte Verwandte beantworten. Eine Verwandtschaft 1.Grades schließt sich über den genetischen Fingerabdruck aus.

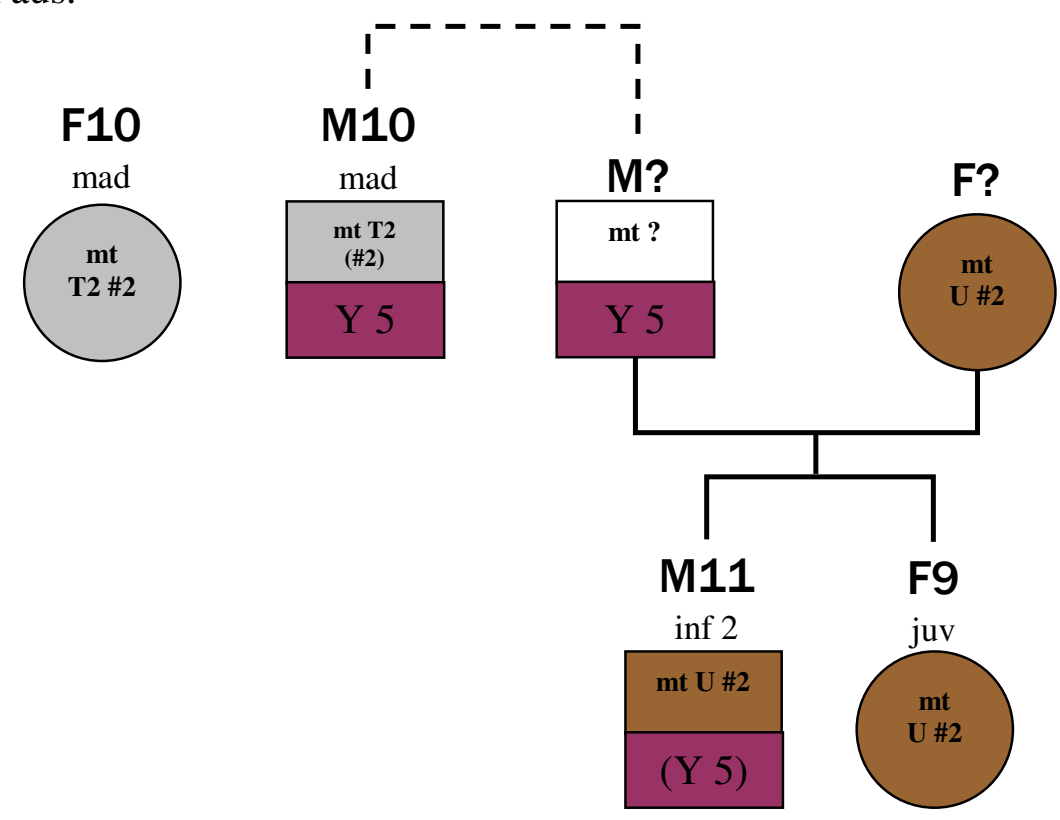

\begin{abstract}
Abbildung 36: Genealogische Verbindung V: Obwohl die autosomalen STRs auch eine Mutterschaft von F9 zu dem Jungen M11 zulassen würde, sind die beiden aufgrund ihres Individualalters am ehesten Geschwister. Zu den beiden Individuen konnten keine Eltern ermittelt werden. Das männliche Individuum (M10) ist höchst wahrscheinlich näher mit den beiden verwandt (s.Text, S. 110). Das weibliche Individuum F10 ist u.U. mit M10 über die mütterliche Linie verwandt. Die Altersstufen sind unter den Namen, die maternalen $(=m t)$ und paternalen Linien (=Y) sind innerhalb der Symbole angegeben. Unsichere Verwandtschaftsbeziehungen sind mit gestrichelten Linien dargestellt.
\end{abstract}




\title{
Genealogische Verbindung VI
}

Die erwachsenen Frauen F12 und F13 sowie das weibliche Kind F20 weisen die gleiche maternale Linie H \#2 auf. Für eine verbindliche Verwandtschaftsanalyse scheidet das Mädchen, aufgrund des Ausfalls nahezu aller autosomalen STRs, aus. Die Frauen sind höchstwahrscheinlich Schwestern, da ihre genetischen Fingerabdrücke eine große Ähnlichkeit aufweisen, d.h. sechs von zehn STRs sind identisch. Eine Mutter-TochterRelation wird über lediglich zwei STRs ausgeschlossen (D21S11 und D18S51). Für F13 wurden diese beiden Loci als homozygot bestimmt. Dieses Ergebnis wurde in zwei Skelettelementen in weit mehr als den in Kapitel 4.6 geforderten Wiederholungen reproduziert. Die Wahrscheinlichkeit, dass dieses Phänomen gleichermaßen in zwei unterschiedlichen Skelettelementen und in zwei unabhängigen Loci auftritt, ist eher gering, aber nicht auszuschließen. Am wahrscheinlichsten sind die beiden weiblichen Individuen Geschwister (Abb.37).

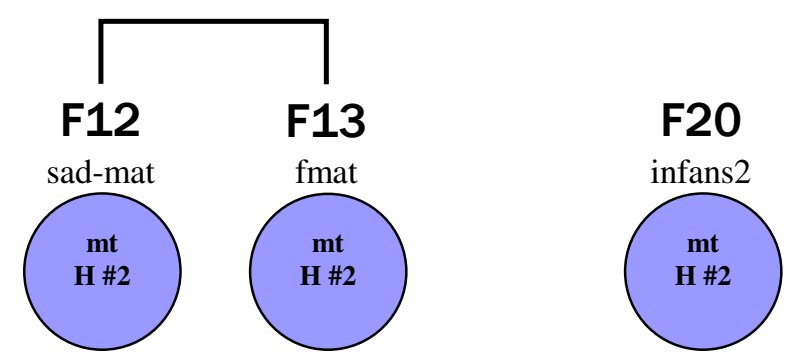

\begin{abstract}
Abbildung 37: Genealogische Verbindung VI: Die Frauen F12 und F13 sind am wahrscheinlichsten Geschwister. Aufgrund fehlender autosomaler STRDaten kann das nähere Verwandtschaftsverhältnis von F20 nicht bestimmt werden. Die Altersstufen sind unter den Namen die maternalen $(=m t)$ und paternalen Linien (=Y) sind innerhalb der Symbole angegeben.
\end{abstract}

Für F12 wurde in der ersten Studie ein Geschwisterverhältnis zu M3 beschrieben (Schultes 2000). Die Annahme stützte sich auf den HVR I - Sequenzabschnitt, da die HVR II zum damaligen Zeitpunkt nicht bestimmt werden konnte. An dieser Stelle muss nun die in Kap.5.2, S.83 erwähnte zweite festgestellte Sequenzabweichung in der HVRRegion besprochen werden. Die Sequenzierungen in dieser Arbeit deckten eine andere maternale Linie für F12 auf. In der HVR I - Analyse wurde in vier unabhängigen Sequenzierreaktionen ein G an der np16299 ermittelt. Die HVR II - Analyse zeigte zusätzlich nicht die bei M3 vorkommende Insertion an np 309 (=309.1C) an. Das erzielte Sequenzmuster für F12 ist dagegen mit dem von F13 deckungsgleich. 
Die X-STR-Analysen ergaben (Tab.23), dass der Mann M3 ein X-chromosomales Allelmuster aufweist, welches auch zur Hälfte in F12 realisiert ist (Schmidt 2004). Dies diente zur Verifizierung der Geschwisterschaft zwischen F12 und M3, basierte aber auf der Annahme, dass die beiden die gleiche maternale Linie aufweisen. Diese Ergebnisse stehen nun im Widerspruch zur oben postulierten Verwandtschaft zwischen F12 und F13.

Tabelle 23: X-Haplotypen der Individuen M3, F12 und F13 (nach Schmidt 2004)

\begin{tabular}{|c|c|c|c|c|c|c|c|}
\hline № & DXS7424 & $\begin{array}{c}\text { GATA } \\
172 \mathrm{D} 05\end{array}$ & Amelo & DXS9898 & DXS6800 & DXS6789 & DXS101 \\
\hline M3 & 16 & 9 & XY & 12 & 15 & 20 & 25 \\
\hline F12 & $13 / 16$ & $9 / 10$ & XX & $11 / 12$ & $15 / 20$ & $20 /(20)$ & $20 / 25$ \\
\hline F13 & $13 / 17$ & $7 / 9$ & XX & $8.3 / 11$ & $15 / 20$ & $20 /(21)$ & $23 / 25$ \\
\hline
\end{tabular}

Legende: ()$=$ unsicheres Allel, $\mathrm{M}=$ male, $\mathrm{F}=$ female

Betrachtet man die X-Haplotypen (Tab. 23) von F12 und F13 fällt jedoch auf, dass auch sie sich je ein Allel teilen. Das sich überschneidende X-Allelmuster stellt folglich den $\mathrm{X}$-Haplotypen des gemeinsamen Vaters dar. Dieser gemeinsame X-Haplotyp ist jedoch nicht der gleiche den M3 aufweist (Ausschluss in DXS7424 und DXS9898). In Verbindung mit dem mt-Haplotyp, wäre eine weitere verwandtschaftliche Verknüpfung, über Eltern oder Großeltern, nicht mehr möglich.

Unter Betrachtung der neuen Sequenzierungsdaten ist die Überschneidung zwischen F12 und M3 ein zufälliges Ereignis. Aufgrund der maternalen Linie, der noch höheren Ähnlichkeit der autosomalen STR-Loci und des sich ebenfalls überschneidenden XAllelmusters ist die Geschwisterschaft zwischen F12 und F13 sehr viel wahrscheinlicher als die Verbindung zu M3.

Individuen ohne verwandtschaftlichen Bezug

Unter den verbleibenden Individuen befinden sich fünf Frauen (F14, F15, F16, F18 und F19) und ein Mann (M9), die nicht über ihre Familienlinien zugeordnet werden konnten.

Für die fünf Frauen kann eine biologische Verwandtschaft höchstens noch über eine Vater-Tochter-Relation vorliegen. Aus diesem Grund werden ihre genetischen Fingerabdrücke mit allen im reproduktionsfähigen Alter befindlichen männlichen Individuen (incl. M9) verglichen (Tab.24). M17 und M18 werden aufgrund ihres stark lückenhaften autosomalen STR-Musters nicht einbezogen. 
Tabelle 24: Überprüfung möglicher Vater-Tochter Relationen über die autosomalen STR-Allelmuster.

\begin{tabular}{|c|c|c|c|c|c|}
\hline & F14 & F15 & F16 & F18 & F19 \\
\hline M1 & - & - & - & - & - \\
\hline M2 & - & - & - & - & - \\
\hline M3 & - & - & - & - & - \\
\hline M5 & - & - & - & - & - \\
\hline M9 & - & - & - & - & - \\
\hline M10 & - & - & - & - & - \\
\hline M13 & - & - & - & - & - \\
\hline M14 & - & - & - & - & - \\
\hline M19 & - & - & - & - & - \\
\hline
\end{tabular}

Legende: $\mathrm{M}=$ male, $\mathrm{F}=$ female,

- keine Elternschaft möglich

Aus Tabelle 24 geht hervor, dass die Verwandtschaftsanalyse für diese fünf weiblichen Individuen ohne Erfolg bleibt. Ihre biologische Zugehörigkeit zu einer genealogischen Verbindung ist damit ausgeschlossen. Die Vermutung einer Vater-Tochter-Relation von M10 zu F15 (Schultes 2000) schloss sich bereits über die X-Marker aus (Schmidt 2004). Diesen Ausschluss untermauerte die Analyse des genetischen Fingerabdrucks nach Abschluss dieser Arbeit.

Die autosomalen STR-Daten des männlichen Individuums M9 wurden mit denen der weiblichen Individuen, deren Väter nicht bekannt sind, auf eine mögliche VaterTochter-Relation abgeglichen. Aufgrund fehlender autosomaler Daten wurden die Individuen F20 und F21 hier nicht berücksichtigt. Die Untersuchungen ergaben keine biologische Vaterschaft von M9, womit er nach dieser Datenlage nicht mit einem der vorgestellten Individuen direkt verwandt sein kann. 


\subsubsection{Der Familienstammbaum der Lichtensteinhöhle}

Die genealogischen Verbindungen I-IV lassen sich über ihre maternalen und paternalen Familienlinien mit hoher Wahrscheinlichkeit verknüpfen, daher entsteht eine Großfamilie im Sinne eines Familienclans. Der Stammbaum wird nach dem Prinzip der Parsimonie zusammengesetzt, da direkte Verbindungsglieder zwischen den einzelnen Familienbeziehungen fehlen. Das bedeutet, dass wie schon bei den vorgestellten Einzelbeziehungen die jeweils nächstmögliche Verknüpfung angenommen wird.

Eine bereits von Schultes (2000) bekannte Verknüpfung der Familienzweige I und II gelingt mit dem Individuum M6. Der Anschluss zur genealogischen Verbindung I erfolgt über die väterliche Linie Y2 und dem Individuum M3, welcher unter Umständen Onkel oder Großvater (väterlicherseits) sein könnte. Eine geschwisterliches Verhältnis mit gleicher Mutter ist ausgeschlossen, da ihre mt-Haplotypen verschieden sind. Zur genealogischen Verbindung II erfolgt die Verknüpfung über die mütterliche Linie. Mithilfe der X-STRs konnte keine Klärung der zeitlichen Nähe des Anschlusses von M6 erfolgen (Schmidt 2004). Die nächstmöglichen Verbindungen können aber benannt werden, beispielsweise könnte F1 Großmutter oder Tante mütterlicherseits sein. Ist sie die Großmutter, müsste M2 demnach eine Schwester haben. Für den Stammbaum wird F1 als Tante und M3 als Onkel von M6 angenommen.

Durch die beiden Kinder M8 und M16 und ihrem Y-Haplotyp Y1 gelingt in dieser Arbeit ein weiterer Brückenschlag zwischen den genealogischen Verbindungen I und II. Aufgrund der Tatsache, dass der Vater der beiden Kinder nicht bekannt ist und damit auch nicht dessen maternale Linie, kann deren genauer Verknüpfungspunkt nicht festgelegt werden. Der ermittelte Y-Haplotyp umfasst 12 Allele. Damit ist es sehr wahrscheinlich, dass eine engere verwandtschaftliche Verknüpfung zu dem Mann M1 und dessen Sohn M2 vorliegt.

In gleichem Maße kann für das im Vorfeld unbekannte Individuum M7 (Altersklasse Infans I-II), über seine paternale Linie, eine enge Verwandtschaftsbeziehung zur Gruppe angenommen werden. Seine Eltern sind nicht bekannt und aufgrund der eigenen maternalen Linie, bleibt er zwar nah verwandt, ist aber nicht direkt in den Stammbaum einzuordnen. Gleiche Begründung gilt für das schon von Schultes (2000) beschriebene männliche Individuum M13. Sein Y-Haplotyp weist lediglich drei Allele auf, deshalb ist die Wahrscheinlichkeit zur Großfamilie zugehören geringer. Sowohl M7 als auch M13 
könnten Cousins väterlicherseits zu M1 oder aber auch Onkel zu den Geschwistern M8 und M16 sein.

Damit können bereits 18 Individuen über ihre Elternlinien genealogisch verknüpft werden. Weiteren Zuwachs könnte die Großfamilie über die genealogische Verbindung IV erfahren.

Ein möglicher Verknüpfungspunkt der genealogischen Verbindung IV zu II könnte über die Y-Haplotypen vorliegen. Bereits in Kap.5.3 wurde darauf hingewiesen, dass der YHaplotyp Y6 nur in einem von 12 Allelen (DYS390) von dem Y-Haplotyp Y1 abweicht. Aufgrund der geringen Variabilität zwischen Y6 und Y1 scheint es sehr wahrscheinlich, dass diese Familienlinien zusammengehören. In einer der beiden paternalen Linien läge dann eine one-step mutation im besagten System vor.

Über die autosomalen STRs werden alle männlichen Individuen mit den Haplotypen Y1 und Y6 nachträglich auf Verwandtschaft 1.Grades untersucht. Sie werden einander gegenübergestellt, da die Verbindungen innerhalb der einzelnen Familiengruppen bereits geklärt sind (Tab.25).

Tabelle 25: Überprüfung der direkten biologischen Verwandtschaft über den genetischen Fingerabdruck für die männlichen Individuen mit dem Y-Haplotyp Y1 (Spalten) und der Individuen mit dem Y-Haplotyp Y6 (Reihen).

\begin{tabular}{|c|c|c|c|c|c|c|}
\hline & $\begin{array}{l}\text { M1 } \\
\text { smat }\end{array}$ & $\begin{array}{c}\text { M2 } \\
\text { mmat-smat }\end{array}$ & $\begin{array}{c}\text { M7 } \\
\text { inf 1-2 }\end{array}$ & $\begin{array}{c}\text { M8 } \\
\text { sinf1-finf2 }\end{array}$ & $\begin{array}{c}\text { M13 } \\
\text { juv-fad }\end{array}$ & $\begin{array}{c}\text { M16 } \\
\text { inf 1-2 }\end{array}$ \\
\hline $\begin{array}{c}\text { M4 } \\
\text { inf } 2\end{array}$ & - & - & & & $(-)$ & \\
\hline $\begin{array}{c}\text { M5 } \\
\text { adult }\end{array}$ & - & - & - & - & $(-)$ & - \\
\hline $\begin{array}{c}\text { M19 } \\
\text { sad-fmat }\end{array}$ & - & - & $(-)$ & - & $(-)$ & - \\
\hline
\end{tabular}

Ein direktes biologisches Verhältnis zwischen M1, M2, M4 und M5 kann unter allen Umständen ausgeschlossen werden (jeweils Ausschluss in mindestens vier autosomalen Systemen). Das Gleiche trifft für das Verhältnis zwischen M2 und M19 zu. Für M1 und M19 erfolgt der Vaterschaftsausschluss in zwei autosomalen STRs. Der Ausschluss zwischen M19 und M7 erfolgt dagegen nur in einem System (D18S51). Dieser Locus ist bei M19 unsicher typisiert. Ein höherer Verwandtschaftsgrad kann nicht kategorisch ausgeschlossen werden.

Aufgrund des hohen Fragmentierungsgrades des autosomalen und Y-chromosomalen Allelmusters von M13 kann der sichere Ausschluss einer direkten biologischen Verwandtschaft zu M4, M5 und M19 nicht vorgenommen werden. Die Allelmuster sind 
sich partiell ähnlich. Die Vaterschaft von M19 zu den beiden Geschwistern M4 und M5 ist mit hoher Wahrscheinlichkeit abgesichert, daher kann M13 definitiv nicht als Vater der Geschwister in Frage kommen. Weitere Verbindungen wären spekulativ und aufgrund der Datenmenge nicht zielführend.

Eine mögliche Verbindung wäre über die Männer M1 und M19 denkbar. Aufgrund der unterschiedlichen mt-Haplotypen sind M1 und M19 keine Brüder. Es sei denn, sie wären Halbgeschwister mit unterschiedlichen Müttern, wovon hier nicht ausgegangen wird. Das Mutationsereignis sollte demnach nicht bei einem gemeinsamen Vater zu suchen sein, da es in paternalen Verwandtschaften höheren Grades aufgrund der Mutationshäufigkeit wahrscheinlicher wäre. Eine definitive Aussage über den genauen Verwandtschaftsgrad lässt sich nicht treffen. Die nächstmögliche gemeinsame Verbindung wäre der gemeinsame Großvater väterlicherseits (Abb.38).

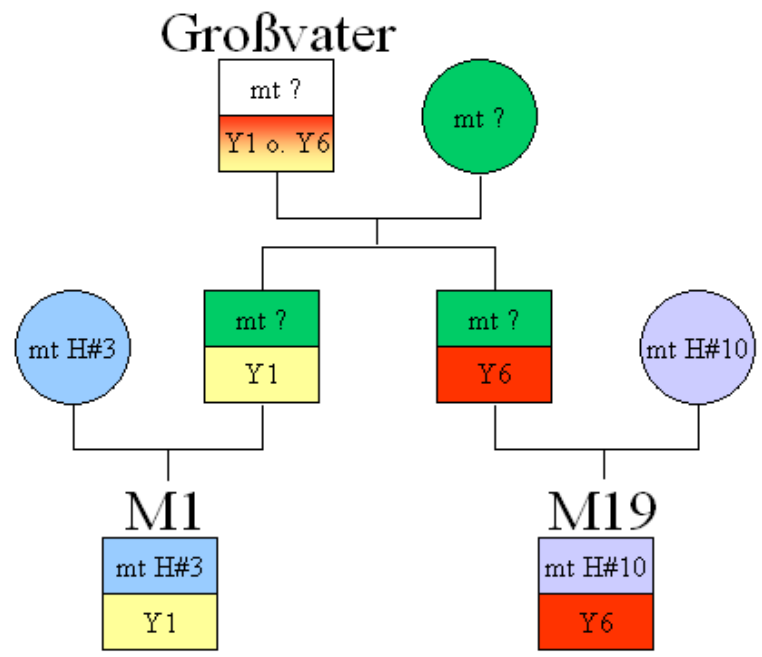

\begin{abstract}
Abbildung 38: Mögliche genealogische Verknüpfung der Individuen M1 und M19. Bei der Vererbung des YChromosoms des gemeinsamen Großvaters väterlicherseits auf dessen Söhne wäre es zu einer one-step-mutation im Y-STRLocus DYS390 gekommen.
\end{abstract}

Bei Abbildung 38 handelt es sich um ein Konstrukt, indem das System DYS390 eine Mutationsmöglichkeit in zwei Generationen gehabt hätte. Die Anzahl der Generationen die zwischen zwei vermutlich verwandten Personen liegen, ist für die Berechnung der väterlichen Verwandtschaft wichtig. Diese Angabe wird, neben der Mutationsrate des STR-Locus, bei den Berechnungen mit einbezogen. Die Mutationsrate für DYS390 beträgt $\mu=2,27 \times 10^{-3} \quad$ (http://www.ystr.org/index.html; Stand 27.01.2006). Dieser Mutationsschritt müsste sich in diesem Fall in zwei Generationen ereignet haben. Die 
Wahrscheinlichkeit für eine Mutation in zwei Vater-Sohn-Paaren mit 2x13 Meiosen und einer angenommenen durchschnittlichen Mutationsrate für alle Y-STR-Loci von $\mu=0,0028$ (Kayser et al. 2000) beträgt nach Formel Kayser et al. (1997a, 128) $\phi=0,06$.

Die Wahrscheinlichkeit für eine väterliche Verwandtschaft kann unter Berücksichtigung der Frequenzen der jeweiligen Y-Haplotypen im europäischen Raum unter http://www.ystr.org/index.html (Stand 27.01.06) berechnet werden. Für die sehr seltenen Y-Haplotypen ergeben sich Frequenzen von $\mathrm{f}_{B}=7 \times 10^{-5}$ (Y1) und $\mathrm{f}_{A}=3,4 \times 10^{-5}$ (Y6). Aufgrund der Tatsache, dass eine Zunahme von Repeatunits wahrscheinlicher ist als der Verlust (s.Kap.3.2.1) wird angenommen, dass für den gemeinsamen Großvater der Haplotyp Y6 vorlag.

Bei einer angenommenen prior probability von $\mathrm{p}=0,5$ und unter Verwendung der Formeln nach Trumme (2003, 28) und Rolf et al. (2001), ergibt sich die Wahrscheinlichkeit für eine väterliche Verwandtschaft von 99,8\% (PI=502). Demnach wäre eine väterliche Verwandtschaft dieser beiden Individuen möglich, bzw. eine onestep-mutation zwischen den beiden paternalen Linien sehr wahrscheinlich. Ohne die fehlenden Bindeglieder zu kennen, kann nicht beantwortet werden, über wie viele Generationen die Familienlinien tatsächlich verknüpft sind. Selbstverständlich sind auch andere Verknüpfungsmodelle zwischen den erwachsenen Individuen mit diesen beiden Y-Haplotypen möglich. Diese wären allerdings unwahrscheinlicher und sollen hier nicht weiter erläutert werden.

Für die hier vorgestellte Verknüpfung der vier genealogischen Verbindungen (=I-IV) könnten über die maternalen und paternalen Linien weitere Hinweise auf ein enges Verwandtschaftsverhältnis innerhalb der Gruppe vorliegen. Die mt-Haplotypen H \#5 (=IV), H \#7 (=II) und H \#8 (=I) unterscheiden sich nur innerhalb des ersten C-Stretches zwischen np303-309 in der HVR II-Region. Bereits beschrieben wurde, dass es innerhalb dieses Bereiches zu Spontanmutationsereignissen kommen kann (Torroni et al. 1994). Bonné-Tamir et al. (2003) konnten zeigen, dass Mutationsereignisse bei sicher miteinander verwandten Individuen ausschließlich in den homopolymeren $C$ stretches der HVR I und II vorkamen. Zusätzlich weicht der Y-Haplotyp von Individuum M3 (=I) nur in zwei Y-STR-Systemen von den Haplotypen Y1 (=I \& II) sowie Y6 (=IV) ab. Diese zusätzlichen Ähnlichkeiten in den Haplotypen und damit der Möglichkeit die Individuen über viele verschiedene Punkte zu verbinden, legen den 
Verdacht nahe, dass es sich hier um eine sehr komplexe Familienstruktur im Sinne einer Großfamilie handelt.

Zusammenfassend kann gesagt werden, dass von den 24 aufgezählten Individuen mindestens 17 mit einem anderen Individuum in direkter biologischer Verbindung stehen. Für zwei Individuen (F21 und M15) ist die Verknüpfung mit anderen Familienmitgliedern sicher über die maternale Linie möglich und für eines (M7) sicher über die paternale Linie. Für M6 erfolgt die Zuordnung sicher über beide Linien. Die Zuordnung der Individuen M13, M14 und M17 ist aufgrund fragmentarischer Typisierungsergebnisse unsicherer zu bewerten, als die der übrigen 21 .

Die komplexe Familienstruktur der 24 Individuen lässt auf eine Großfamilie im Sinne eines Familienclans schließen (Abb.39, Stammbaum A).

Die übrigen 16 Individuen sind nicht mit dem Familienclan in Verbindung zu bringen. Schultes (2000) vermutete eine verwandtschaftliche Beziehung über die maternale Linie zwischen F1 (genealogische Verbindung II) und den Individuen F9 und M11 (genealogische Verbindung V). Dies resultierte aus der Annahme, dass diese Individuen ebenfalls Träger der maternalen Linie H \#1 sind. Der größere Sequenzausschnitt der HVR II, welcher in dieser Studie analysiert wurde, gruppiert die beiden letzteren aber in die Haplogruppe U \#2. Die Verbindung zu F1 kann daher nicht weiter angenommen werden. Somit bildet diese Kleingruppe mit mutmaßlich vier Individuen (die Zugehörigkeit von F10 zu M10 ist nicht vollständig gesichert) und die Individuen der Verwandtschaftsbeziehung VI mit drei weiblichen Individuen separate Familienzweige (Abb.40, Stammbaum B). Die verbleibenden neun Individuen konnten nicht zugeordnet werden. In drei Fällen ermöglichten die Typisierungsdaten keine genealogische Untersuchungen (F11, F17 und M18, Abb. 41) und bei fünf Frauen (F14, F15, F16, F18 und F19) und einen Mann (M9) erlaubten deren genetische Daten keine Zuordnung zum Stammbaum (Abb.42). 

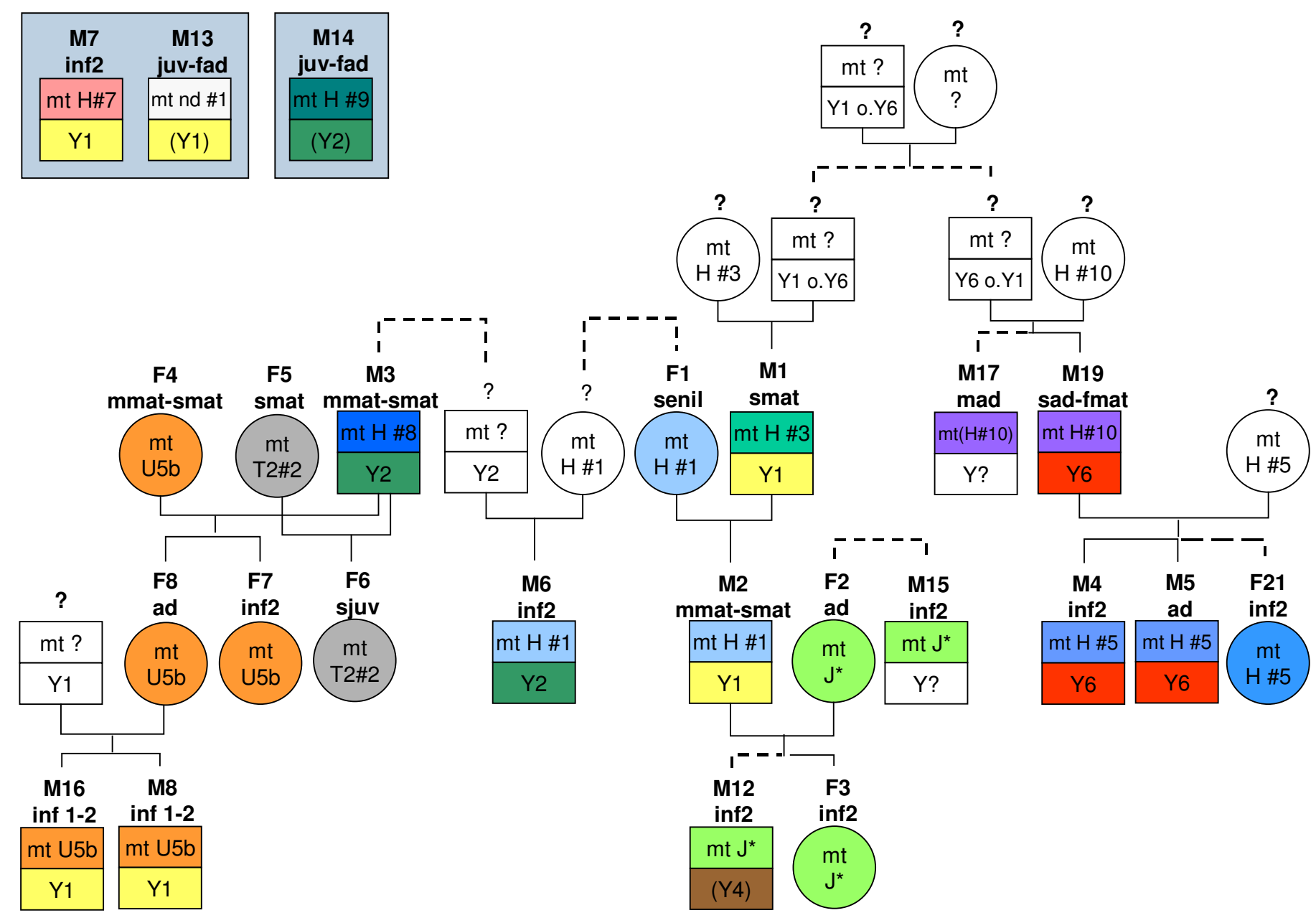

Abbildung 39: Stammbaum der Lichtensteinhöhle A: Genealogische Verbindung der einzelnen Familiengruppen (I-IV) zu einer Großfamilie. Dargestellt ist die jeweils nächst mögliche Verknüpfung der Familiengruppen. Die Individuen M7, M13 und M14 lassen sich über ihre paternalen Linien dieser Großfamilie zuordnen, ihre direkte Anknüpfung ist jedoch nicht möglich. Hypothetische Verbindungen sind durch gestrichelte Linien angegeben. Unter den Bezeichnungen der Individuen

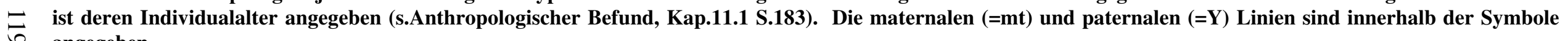
angegeben. 


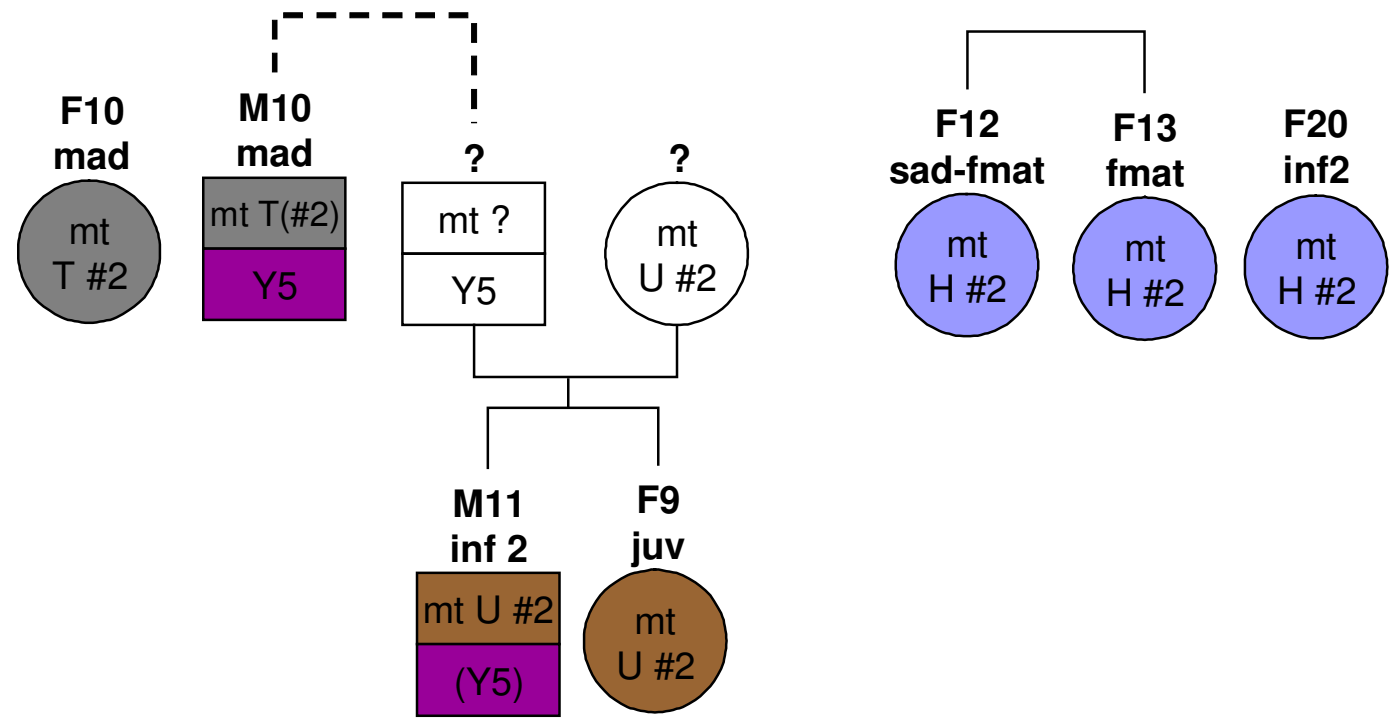

Abbildung 40: Stammbaum der Lichtensteinhöhle B: Genealogische Verbindungen der zwei möglichen Verwandtschaftsbeziehungen V und VI. Beide Kleingruppen lassen sich nicht mit der Großfamilie in Verbindung bringen. Hypothetische Verbindungen sind durch gestrichelte Linien angegeben. Unter den Namen der Individuen ist deren Individualalter angegeben (s. Anthropologischer Befund, Kap.11.1 Seite 183). Die maternalen (=mt) und paternalen (=Y) Linien sind innerhalb der Symbole angegeben.

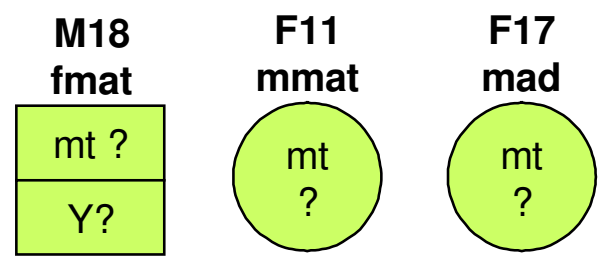

Abbildung 41: Dargestellt sind die drei Individuen, für die aufgrund zu fragmentierter genetischer Daten, keine Verwandtschaftsanalyse möglich war. Unter den Namen der Individuen ist deren Individualalter angegeben (s. Anthropologischer Befund, Kap.11.1 Seite 183). Die maternalen (=mt) und paternalen (=Y) Linien sind innerhalb der Symbole angegeben, konnten jedoch bei diesen drei Individuen nicht bestimmt werden $(=$ ?).

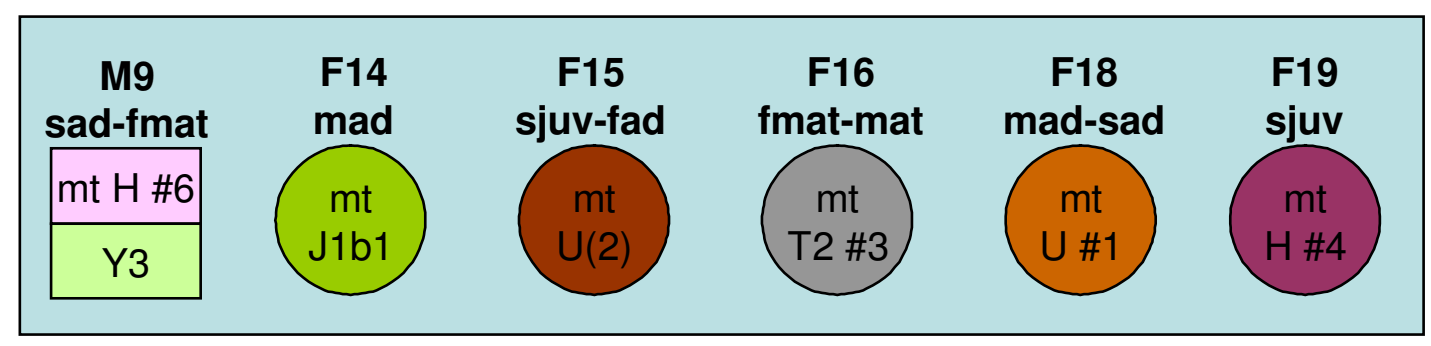

Abbildung 42: Dargestellt sind die sechs Individuen, für die keine genealogische Verbindung zu einem anderen Individuum besteht. Unter den Namen der Individuen ist deren Individualalter angegeben (s. Anthropologischer Befund, Kap.11.1 S. 183). Die maternalen (=mt) und paternalen (=Y) Linien sind innerhalb der Symbole angegeben. 


\subsubsection{Abschlussbewertung der Verwandtschaftsrekonstruktion}

Durch die genealogischen Analysen lassen sich mehr als die Hälfte der Individuen zu einer Großfamilie im Sinne eines Familienclans verknüpfen. Darüber hinaus liegen zwei weitere Kleingruppen vor, für welche ebenfalls ein Verwandtschaftsverhältnis aufgedeckt werden konnte. Damit ist für 31 der 40 Individuen sehr wahrscheinlich ein verwandtschaftliches Verhältnis gegeben.

Bei den Frauen, für die keine biologische Verwandtschaft nachgewiesen werden konnte, sollte bedacht werden, dass es sich um potenzielle Mütter handelt, d.h. sie waren im reproduktionsfähigen Alter. Es ist möglich, dass sie mit Männern aus der Gruppe verheiratet waren, d.h. Affinität vorliegt, und ihr möglicher Nachwuchs nicht mit ihnen in der Höhle bestattet wurde. Dies könnte in gleicher Weise für den Mann (M9) zutreffen. Bleibt seine Verbindung mit einer Frau ohne Nachwuchs oder ist der verstorbene Nachwuchs an einer anderen Stelle niedergelegt, ist seine Zugehörigkeit zur Gruppe nicht zu beweisen. Eine soziale Verwandtschaft mit der Gruppe (=assoziative Verwandtschaft) wäre aber auch bei Kinderlosigkeit gegeben.

Für die rekonstruierten Familien konnten in der Regel nicht mehr als zwei Kinder pro Paar ermittelt werden. Dies ist für die eingangs formulierte Familienstruktur der Bronzezeit, wonach Familien aus ca. 5 - 10 Individuen bestanden haben sollen, eher untypisch. Für die Erhaltung der Populationsgröße (=Ersatzfortpflanzung) sollten zumindest zwei Kinder pro Paar geboren werden (Nentwig 1995, 29). Für die Gruppe aus der Lichtensteinhöhle kann das hier, über die genetischen Analysen, nachgewiesen werden. Aus der Sterblichkeitsverteilung geht jedoch hervor, dass ein Kleinkinderdefizit für die Gruppe vorliegt. Des Weiteren können erwachsene Kinder auch aus der Gruppe abgewandert sein. Es muss somit für möglich gehalten werden, dass die einzelnen Familien mehr Kinder hatten.

Aus den Verwandtschaftsanalysen geht ebenfalls hervor, dass für den Großteil der Kinder zumindest ein Elternteil nicht in den Funden repräsentiert ist. Beispielsweise liegen innerhalb der genealogischen Verbindungen I und IV sichere Defizienzfälle vor, da zu den Kindern M8 und M16 (I) der Vater und für M4 und M5 (IV) die Mutter nicht im Skelettkollektiv nachgewiesen werden konnte. Für das Geschwisterpaar F9 und M11 (V) sowie für die Kinder M6 (III) und M7 (II) fehlen sogar beide Elternteile. 
Zusammengefasst bilden diese Elternteile bereits eine Gruppe von acht erwachsenen Personen, d.h. vier männliche und vier weibliche Individuen. Bei diesen Personen könnte es sich um diejenigen handeln, die in der Höhle die letzten Bestattungstätigkeiten für ihre Familienangehörigen durchgeführt haben. Da sie selbst nicht innerhalb des Fundkollektivs repräsentiert sind, wäre es denkbar, dass die Gruppe als ökonomische Funktionseinheit, die Region um die Lichtensteinhöhle verlassen hat und somit die Nutzung der Lichtensteinhöhle als Bestattungsplatz endet.

Die Konstellation, in denen beide leibliche Elternteile fehlen, könnte aber auch Ausdruck eines praktizierten Sozialverhaltens der Gruppe sein. Wenn die Eltern aus der Gruppe ausscheiden, z.B. aus der Region wegziehen, und das Kind in der Obhut der Großeltern zurücklassen, oder in die Großfamilie zur Aufsicht schicken, könnte dies ein Hinweis auf ein gesteigertes soziales Engagement der bronzezeitlichen Gruppe sein.

Interessant ist ebenfalls, dass der Mann M3 mit zwei Frauen (F4 und F5) drei Kinder (F6, F7 und F8) hatte. Eventuell bildete der Mann zuerst eine Lebensgemeinschaft mit der einen, dann mit der anderen Frau oder lebte mit beiden gleichzeitig zusammen. Es darf jedoch nicht zwangsläufig davon ausgegangen werden, dass eine Verbindung zwischen Mann und Frau im gleichen Individualalter erfolgt sein muss. War der Mann sehr viel jünger als seine erste Frau, könnte diese im Alter von ca. 60 Jahren gestorben sein und die Verbindung zur zweiten Frau schloss sich an.

Bei der weiteren Altersstruktur dieser Kleinfamilie fällt außerdem auf, dass zumindest die Halbgeschwister F6 und F7 nicht das Erwachsenenalter erreicht haben, während ihre Mütter (F4 und F5) jeweils weit über 50 Jahre alt wurden. Es wäre denkbar, dass die Halbgeschwister bedeutend früher gestorben sind als ihre Mütter. Dieser Sachverhalt ist im Zusammenhang mit einem möglichen Kollektivtod dieses Familienzweiges von Belang. Der große Altersunterschied könnte darauf schließen lassen, dass diese Familie nicht gemeinschaftlich an einem zeitgleichen Ereignis starb. Andernfalls müsste zumindest die Mutter F4 im Alter von ca. 50 Jahren schwanger geworden sein. Die Menopause setzt in der Regel bei Frauen in einem Alter von 45 Jahren ein (z.B. Grupe et al. 2005, 368ff). Demnach wäre eine Schwangerschaft möglich jedoch unwahrscheinlich.

Für zwei Familienzweige lassen sich jeweils drei Generationen nachweisen. Diese Tatsache ist für die Fragestellung zur Nutzungsart der Höhle von Relevanz. Der Nachweis eng miteinander verwandter Individuen über einen längeren Belegungszeitraum würde die Höhle als Bestattungsplatz plausibel machen (Schultes 
2000). Aus der Anzahl der Generationen lassen sich direkte Rückschlüsse auf die Nutzungsdauer der Höhle ziehen. Der Familienstammbaum A (Abb.39, 119) resultiert aus den jeweils nächstmöglichen genealogischen Verbindungen und wird gleichfalls durch die Notwendigkeit einer übersichtlichen Grafik beeinflusst. Der dargestellte Familienstammbaum stellt somit lediglich eine der möglichen Verbindungen zwischen den Familiengruppen I und II dar. Die gewählte Darstellungsform suggeriert, dass die Familienlinien I und II zur gleichen Zeit existiert haben, was aber bisher noch strittig ist. Die Verbindung zwischen den beiden Familiengruppen wird, in der gewählten Darstellung (Abb.39) über das Kind M6 (genealogischen Verbindung III) hergestellt.

Wählt man einen anderen Verknüpfungspunkt zwischen den Familiengruppen I und II hat dies Einfluss auf den Verwandtschaftsgrad und auf die Anzahl an Generationen der Großfamilie. Hält man z.B. eine Geschwisterschaft, nachgewiesen über den Y-Haplotyp Y1, zwischen dem männlichen Individuum M1 (genealogische Verbindung II) und dem nicht bekannten Vater der Geschwister M8 und M16 (I) für wahrscheinlich, ergeben sich bereits vier Familiengenerationen (s.Abb.43).

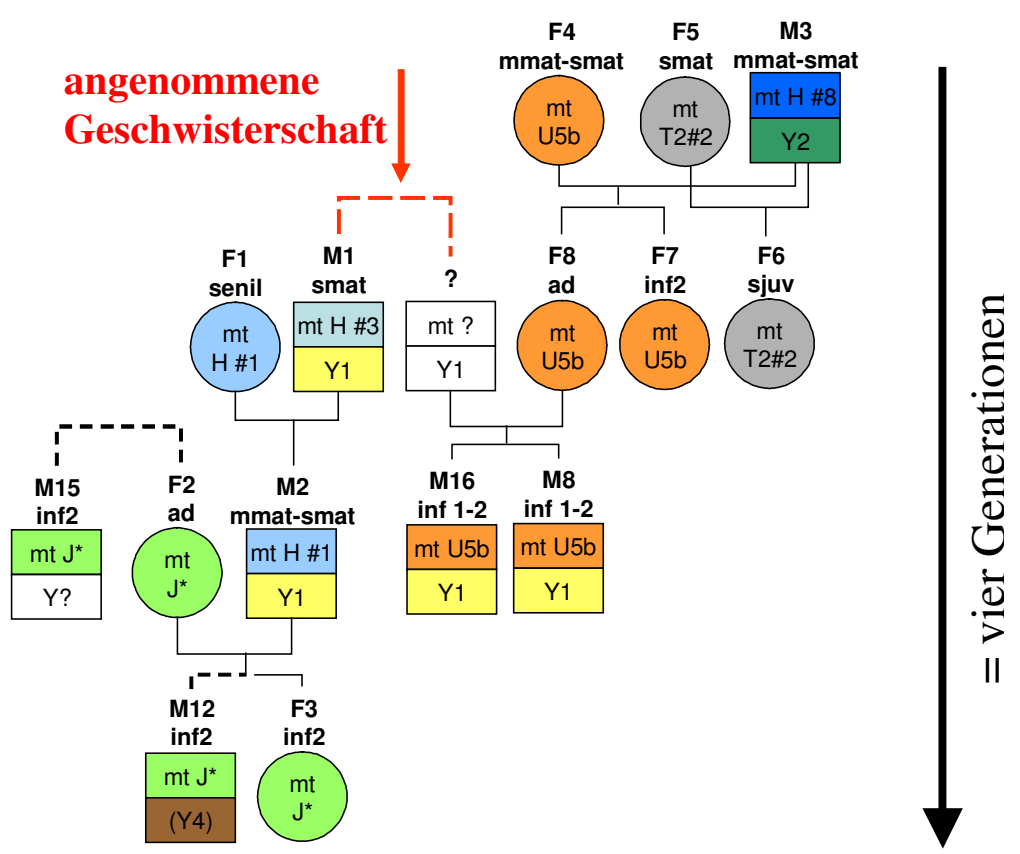

\footnotetext{
Abbildung 43: Mögliche Stammbaumvariante für die Individuen der Familienlinien I und II. Wäre der unbekannte Vater (?) der Kinder M8 und M16 der Bruder von M1 (roter Pfeil), würde eine Großfamilie entstehen, welche sich über vier Generationen erstreckt. Im gezeigten Fall ist die gesamte Genealogie der 24 Individuen nicht mehr darstellbar, deshalb wurden ausschließlich die Individuen der Familien I und II berücksichtigt. Unter den Namen der Individuen ist deren Individualalter angegeben (s. Anthropologischer Befund Kap.11.1, S.183). Die maternalen (=mt) und paternalen (=Y) Linien sind innerhalb der Symbole angegeben.
} 
Die verwandtschaftliche Verknüpfung der beiden größten Familiengruppen kann demnach sowohl über das Kind M6 geschehen, als auch über den Y-Haplotyp Y1.

In beiden Fällen liegen jedoch Generationslücken vor, d.h. es fehlen zumindest die Eltern von M6 sowie der Vater von M8 und M16. Ohne das Wissen, über wie viele Generationen die beiden Familienlinien (I\&II) tatsächlich verknüpft sind, stellt der dargestellte Stammbaum A in Abbildung 39 nur eine der nächstmöglichen Verwandtschaftsverbindungen zwischen den beiden Familiengruppen dar. Theoretisch sind weitere Stammbaumvarianten möglich, welche sich über die Familienlinien ergeben könnten, diese sollen hier jedoch nicht mehr gezeigt werden.

Es soll verdeutlicht werden, dass der Stammbaum nicht belegen kann, dass alle Individuen gleichzeitig in einem großen Familienverband existiert haben müssen, oder dass sie die Höhle nur innerhalb eines kurzen Zeitfensters als Bestattungsplatz genutzt haben. Es wäre auch vorstellbar, dass die beiden Familiengruppen zeitlich versetzt gelebt haben und die Höhlennutzungsdauer weit länger als drei oder vier Generationen war. In diesem Fall würden sich die jeweiligen Generationslücken nicht nur aus den Eltern, sondern zusätzlich noch aus Großeltern zusammensetzen.

Abschließend kann das Ergebnis der Verwandtschaftsanalyse als einzigartig für die Anthropologie und Archäologie bezeichnet werden. Der Umstand, dass mit chromosomalen Markern in einem 3000 Jahre alten Skelettkollektiv ein komplexes Verwandtschaftssystem aufgeklärt werden konnte, ist nach derzeitigem Kenntnisstand weltweit einzigartig. Darüber hinaus gibt die Verwandtschaftsstruktur Einblicke in die soziale Organisation der Gruppe. Offensichtlich hatte die Kernfamilie, bestehend aus beiden Elternteilen und Kindern, auch in der Bronzezeit eine herausragende Bedeutung. Dies kann daraus abgeleitet werden, dass mit den Kindern beide Elternteile in der Höhle abgelegt worden sind. Die Stellung des biologischen Vaters zu seinen Kindern wird in verschiedenen Kulturen durchaus unterschiedlich bewertet (vgl. Schultes 2000, 114). Für die Großfamilie aus der Lichtensteinhöhle sollte das Verwandtschaftskonzept der kognaten Deszendenz, d.h. als verwandt gelten die Nachkommen beider Geschlechter, verwirklicht sein, da aus Sicht der Kinder in der genealogischen Verbindung I die Großeltern mütterlicherseits und bei der genealogischen Verbindung II die Großeltern väterlicherseits gemeinsam mit der Kernfamilie abgelegt wurden. 
Die Ableitungen aus der Familienstruktur können nun helfen die archäologische Fragestellung zur Nutzung der Höhle zu beantworten. Damit zeigt die Arbeit, dass die interdisziplinäre Verknüpfung der Fachbereiche Anthropologie und Archäologie Fragestellungen in größerem Kontext beantworten können.

\subsection{Residenzverhalten}

Unter der Annahme, dass es sich bei der vorliegenden Gruppe um einen repräsentativen Ausschnitt einer zusammenlebenden Gruppe handelt, weisen die Ergebnisse auf Patrilokalität hin. Der hohe Verwandtschaftsgrad zwischen den Individuen der Lichtensteinhöhle erlaubt keine Anwendung verlässlicher statistischer Verfahren (vgl. Schmidt 2004). Die Auswertung kann dagegen an Modellen deskriptiv abgehandelt werden. Nach Oota et al. (2001) sollte bei patrilokalen Residenzverhalten einer Gruppe die mt-Variabilität größer sein als die Y-Variabilität. Für die Individuen aus der Lichtensteinhöhle konnten lediglich sechs Y-Haplotypen ermittelt werden. Dabei lassen sich mit Ausnahme von drei männlichen Individuen alle in die sehr ähnlichen Haplogruppen Y1 (=sechs Individuen), Y2 (=drei Individuen), Y4 (ein Individuum) und Y6 (=drei Individuen) einteilen, deren Träger jeweils auch eng miteinander verwandt sind. Dagegen wurden 20 maternale Linien aufgeklärt. Durch den Zuzug von Frauen aus anderen, nicht verwandten Gruppen kommt es zum Eintrag neuer mt-Haplotypen. Aus diesem Grund ist die Variabilität der mt-Haplotypen groß. Innerhalb der Geschlechter fallen die Abweichungen dagegen nicht besonders auf, da die maternale Linie der Männer durch ihre Mütter, d.h. durch den Zuzug, ebenfalls beeinflusst wird. Nach Schmidt $(2004,101)$ ist bei patrilokalen Residenzverhalten im Idealfall die Variabilität der weiblichen mt-Haplotypen hoch (=Frauen teilen sich keinen mt-Haplotyp) und die der Männer zwar hoch aber niedriger als bei den Frauen (einige Männer, z.B. Brüder tragen den gleichen mt-Haplotyp). Betrachtet man ausschließlich die erwachsenen Frauen der Lichtensteinhöhle und lässt dabei ihren möglichen Nachwuchs außer acht, weisen mit Ausnahme eines Geschwisterpaares (F12 und F13) alle eine gänzlich andere mt-Linie auf. Die erwachsenen Männer zeigen erwartungsgemäß eine genauso hohe Variabilität ihrer mtDNA. Nur zwei erwachsene Männer (M17 und M19) teilen sich eine mütterliche Linie. Ausschließlich über die Variabilität der maternalen Linien der Männer und Frauen könnte keine sichere Beurteilung zum praktizierten 
Residenzverhalten der Gruppe gemacht werden. Aufgrund der viel geringen Variabilität der Y-Haplotypen zu den mt-Haplotypen ist die Patrilokalität jedoch gesichert. Die Analysen der X-STRs (Schmidt 2004) hatten bereits sichere Hinweise zugunsten der Patrilokalität erbracht. Dabei fiel die Entscheidung aufgrund der niedrigen Variabilität der Y-Haplotypen im Verhältnis zu der sehr hohen Diversität X-chromosomaler Haplotypen.

Weitere Erkenntnisse zum Residenzverhalten der Gruppe könnten durch einen Vergleich ihrer Y- und mtDNA-Variabilität mit anderen Populationen gewonnen werden. Diese sollten aus gleicher Zeitstellung und gleicher Region stammen. An thailändischen Populationen mit bekanntem Residenzverhalten konnte gezeigt werden, dass zwischen patrilokalen Populationen die Y-Variabilität hoch und die mt-Variabiltät gering ist (Oota et al. 2001, Hamilton et al. 2005). Demnach könnte ein Interpopulationsvergleich weitere Erkenntnisse zum Residenzverhalten der Gruppe aus der Lichtensteinhöhle bringen. Derzeit liegen solche Vergleichsdaten nicht vor. Denkbar für einen solchen Vergleich wären Populationen aus der Unstrutgruppe.

Das Fazit lautet, dass die männlichen Individuen in der Regel ortsfest geblieben sind und Frauen von außen zur Gruppe dazugestoßen sind. Die fünf Frauen (F14, F15, F16, F18 und F19), für die jeweils keine biologische Verwandtschaft zu einem anderen Individuum besteht, könnten dabei die These eines „Frauenimports“ weiter stützen.

Das hier festgestellte Residenzverhalten der Gruppe ordnet sich damit der häufigsten Form des menschlichen Zusammenlebens zu. Gegenüber Matrilokalität stellt Patrilokalität 70\% der realisierten sozialen Systeme dar (z.B. Burton et al. 1996). Für die soziale Organisation der Gruppe sind die Erkenntnisse zum Residenzverhalten nicht uninteressant. Hamilton et al. (2005) konnten an thailändischen Bevölkerungen zeigen, dass die Männer in patrilokalen Sozietäten den Zuzug von neuen Männern zur Gruppe stark regulieren, während in matrilokalen Gruppen der Zuzug von Frauen nicht in gleicher Weise reglementiert wird. Vorstellbar ist demnach, dass die beiden erwachsenen Männer mit gänzlich abweichenden Y-Allelmustern eventuell solche darstellen, die von den anderen männlichen Familienmitgliedern als Neuzugänge akzeptiert wurden.

Aus dem Residenzverhalten können Rückschlüsse auf das praktizierte Heiratssystem einer Gruppe gezogen werden. Gerstenberger (2002) konnte beispielsweise über das Residenzverhalten einer frühmittelalterlichen Bevölkerung auf deren Heiratsmuster schließen. Das patrilokale Residenzverhalten der Lichtensteiner könnte auf ein 
patrilokales Heiratssystem hindeuten, d.h. die genetische Variabilität zwischen den Markern bedingt nicht nur das Residenzverhalten, sondern kann auch ein praktiziertes Heiratssystem anzeigen.

\subsection{Regionale Herkunft}

Neben Identifikations- und Verwandtschaftsanalysen und der Aussage zum Residenzverhalten einer Gruppe erlauben die Ergebnisse der Haplotypenanalyse auch die räumliche Zuordnung einzelner Linien. Die Auswertung geschieht im Allgemeinen über Datenbanken, die im Internet abrufbar sind, oder als sog. freeware heruntergeladen werden können. Diese Datenbanken basieren auf publizierten Forschungsergebnissen. Aus diesem Grund sind die Sequenzmuster auch „,manuell“ in der Literatur zu finden.

Für die mitochondriale DNA wurde vermutet, dass sie aufgrund eines höheren Selektionseinflusses kein brauchbares demographisches Markersystem sei (vgl. Richards et al. 2002, 1168). Die genetischen Unterschiede zwischen einzelnen Populationen sind für das Y-Chromosom höher (z.B. Cavalli-Sforza 1998, Oota et al. 2001). Das Y-Chromosom weist einen nachvollziehbaren demographischen Gradienten auf (z.B. Cavalli-Sforza 1998). Ein möglicher Grund dafür könnte im überwiegend praktizierten patrilokalen Residenzverhalten liegen, in dem die Frauen ein höheres Migrationsverhalten zeigen (z.B. Cavalli-Sforza 1998, Oota et al. 2001). Richards et al. (2002) konnten jedoch auch für mt-Haplotypen zeigen, dass es mit einer ausreichend großen Stichprobenanzahl möglich ist, signifikante geographische Strukturen zwischen verschiedenen Regionen Europas aufzudecken. Die Strukturierung ist dabei weiträumiger gedacht, z.B. Nordwesteuropa oder nördliches Zentraleuropa. 


\subsubsection{Väterliche Linien}

Die YHRD str database (Roewer et al. 2001) umfasst zurzeit ca. 39.000 verschiedene Y-Haplotypen die in 316 weltweit registrierten Populationen ermittelt wurden (Stand: 08.03.2006). Die Mehrzahl dieser Y-Haplotypen wurden als minHt in die Datenbank eingetragen, ca. 13.000 Datensätze sind als extended haplotype (plus DYS438 und 439) gespeichert. Mit dieser Datenbank kann man einen Y-Haplotypen in Relation zu gespeicherten rezenten Referenzpopulationen setzen. Wird der eingegebene Haplotyp innerhalb einer Population gefunden, wird er als Treffer auf einer Landkarte angezeigt. Die weltweite Trefferverteilung und deren Häufigkeit lässt dann Rückschlüsse auf die regionale Herkunft einer Person oder einer Gruppe zu. Werden die Lichtensteiner YHaplotypen in die Datenbank eingegeben lassen sich folgende Ergebnisse erzielen.

Die Haplotypen Y1, Y2 und Y6 konnten in Form des extended haplotype in keiner Population gefunden werden. Daraus ist jedoch nicht $\mathrm{zu}$ schließen, dass diese Haplotypen in dieser Form einmalig nur in Verbindung mit den männlichen Individuen der Lichtensteinhöhle vorkommen, sondern dass es sich mit ausreichender Wahrscheinlichkeit um sehr seltene Haplotypen handelt. Gibt man für Y1 ausschließlich den minHt in die Datenbank ein, bekommt man weltweit drei Treffer (Berlin, Chemnitz und Hamburg). Entspricht die Verteilung der heute gefundenen Haplotypen der aus prähistorischen Zeiten, würde es sich um einen Mittel- bis Norddeutschen Haplotyp handeln. Dieser hätte sich dann innerhalb der letzten 3000 Jahre nicht weit verbreitet. Es könnte damit angenommen werden, dass die Männer nicht über weite Distanzen in die Region gereist sind und an diesem Ort blieben. Eine interessante Fragestellung in diesem Zusammenhang ist, ob heute lebende Männer in der Region der Lichtensteinhöhle auch noch denselben Y-Haplotyp aufweisen und somit mögliche Nachfahren der Individuen aus der Lichtensteinhöhle sind. Bis dato wurde keine bekannte Population aus der Region um die Lichtensteinhöhle untersucht. Eventuell handelt es sich um einen für die Region typischen Y-Haplotyp.

Die Eingabe der Haplotypen Y2 und Y6 als minHt in die Datenbank ergibt für Y2 einen Treffer (Niederlande) und für Y6 ebenfalls einen Treffer (Maryland, USA), dessen Ursprung 1t. Datenbank ebenfalls europäisch ist. Für beide Haplotypen kann aufgrund nur eines Treffers keine regionale Herkunft bestimmt werden. Aber die große Ähnlichkeit zu Y1 lässt vermuten, dass die Träger dieser Haplotypen aus derselben Region stammen. 
Aufgrund der Unvollständigkeit von Haplotyp Y4 und der unsicheren Allele ist eine Eingabe in die Datenbank nicht sinnvoll.

Gibt man den extended haplotype für Y3 in die Datenbank ein, können weltweit in den 13.000 Datensätzen 69 Treffer festgestellt werden. Davon wurden 49 Treffer für europäische Populationen ermittelt. Weiterhin konnte für nordamerikanische Populationen 16, für Lateinamerika drei und für eine arktische Population ein Treffer festgestellt werden. Die Herkunft der außereuropäischen Treffer wird laut Datenbank überwiegend mit europäischem Ursprung angegeben (=europäische Auswanderer), sie können jedoch keiner Population näher zugeordnet werden. Die Mehrzahl der europäischen Treffer liegt im westlichen Europa (Abb.44), vorwiegend in Portugal (zehn Treffer), Spanien (sechs), Deutschland (fünf) und Großbritannien (13).

Wenn man die Treffer auf die jeweils getestete Gesamtgröße der Population bezieht, dann ergeben sich die höchsten Frequenzen des Y-Haplotyps für Birmingham mit ca. 3,1\% (=Großbritannien, drei Treffer von 97 untersuchten Individuen), London 2,8\% (=Großbritannien, 8/285) und Madrid 2,6\% (=Spanien 4/152). Die portugiesischen und deutschen Treffer machen, bezogen auf die Gesamtzahl der untersuchten Personen, nie mehr als $1 \%$ aus. Die vereinzelten Treffer in Osteuropa, d.h. Ungarn (1/193) und Tschechien (2/252), liegen noch darunter.

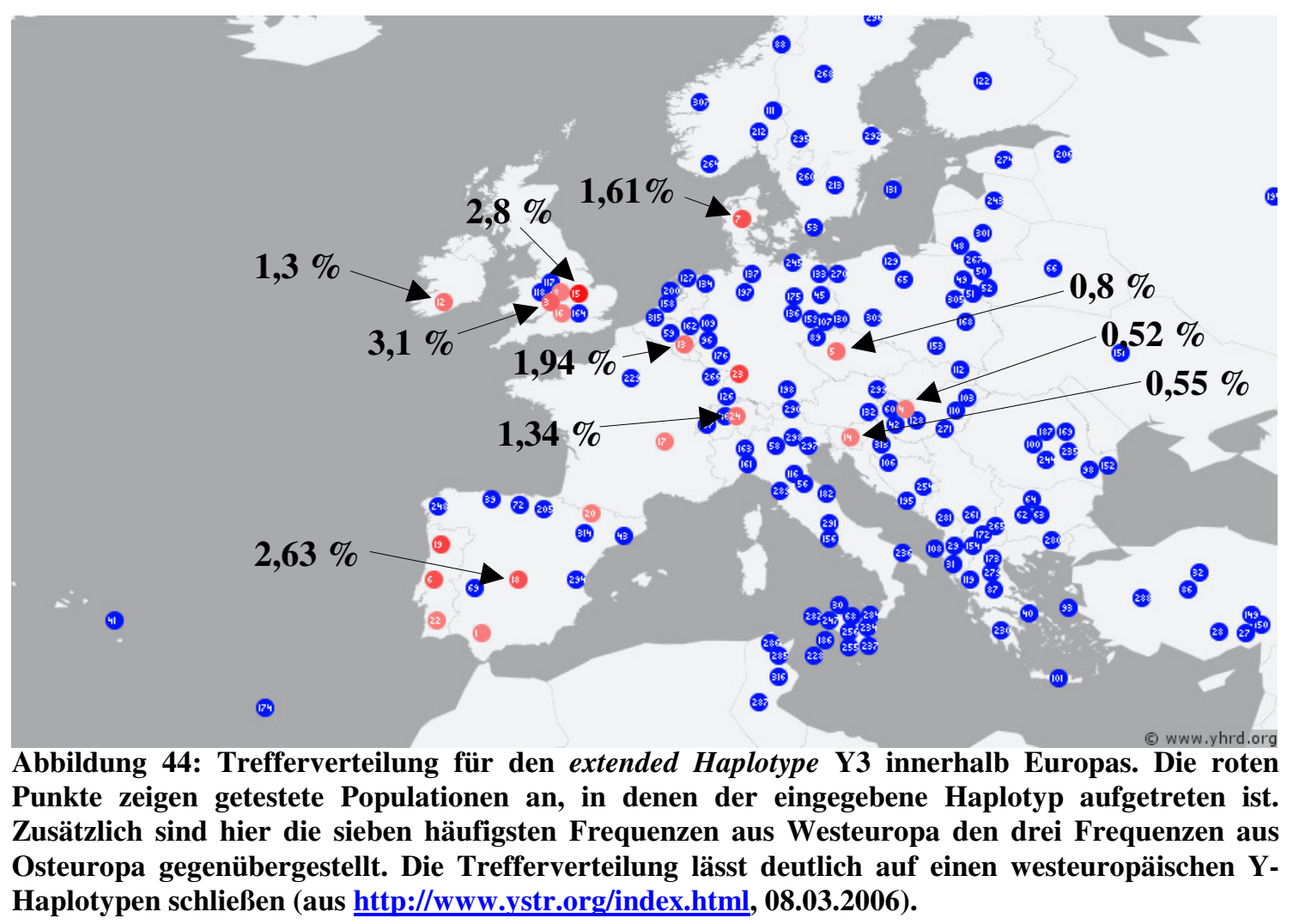


Wird für Y3 nur der minHt in die Datenbank eingegeben, beträgt die weltweite Trefferanzahl 357. Davon sind fast 280 in Europa und wiederum 99 in Deutschland zu finden. Die mit Abstand höchsten Frequenzen für den minHt von Y3 werden für eine französische Population (Straßburg 6/99) mit ca. 6\%, eine niederländische Population (4/87) mit ca. 4,6\% und für eine belgische Population (Brüssel 6/125) mit ca. 4,8\% erzielt. In Deutschland sind die Frequenzen durchschnittlich zwischen 2 - 3\%, z.B. Freiburg 2,8\% (9/433), Chemnitz 2,9\% (24/820) und Stuttgart 2,42\% (11/453). Die Trefferverteilungen des extended und minHt Y3 deuten stark daraufhin, dass die väterliche Linie dieses Y-Haplotyps seine regionale Herkunft im westlichen Europa, wahrscheinlich Nordwesteuropa, hat.

Der Haplotyp Y5 konnte in Form des extended haplotype weltweit nur in einer Population aus Malaysien/Indonesien gefunden werden. Wird nur der minHt eingegeben, so bekommt man vier weitere Treffer, wovon zwei in deutschen Populationen (Berlin und Chemnitz), einer in Polen und einer in der Türkei gefunden wurde. Für Haplotyp Y5 ist die Einbeziehung der sog. haplotype neighbours von besonderem Interesse. Das heißt, wäre für Y5 eine 11 - 14 in DYS385 realisiert, anstatt 11 - 13, werden in den ca. 39.000 Datensätzen bereits 102 Treffer ermittelt. 83 der 102 Treffer sind wieder in europäischen Populationen $\mathrm{zu}$ finden. Davon befinden sich alleine 31 Treffer in Polen, 15 in Deutschland (vorwiegend Nord- und Ostdeutschland) und sieben im skandinavischen Bereich. Die höchsten Frequenzen erreicht dieser Haplotyp in einer norwegischen Population mit ca. 4\% (1/25), einer polnischen Bevölkerung mit 3,66\% (3/82) und einer russischen mit 3,53\% (3/85). Errechnet man die Frequenzen dieses Haplotyps für die europäischen Treffer, dann zeigt sich, dass dieser in Skandinavien und Osteuropa am häufigsten vorkommt (Abb.45). In Richtung West- und Südeuropa nimmt die Häufigkeit deutlich ab. In Abbildung 45 sind die 11 häufigsten Frequenzen dargestellt.

Die Trefferverteilung würde in diesem Fall eine Herkunft der väterlichen Linie aus dem östlichen und nördlichen Europa belegen. Dieser Gesichtspunkt ist in Hinblick auf die in Kap.11.2.2 beschriebenen weiteren genetischen Untersuchungen am immungenetischen Marker CCR5 höchst bemerkenswert. 


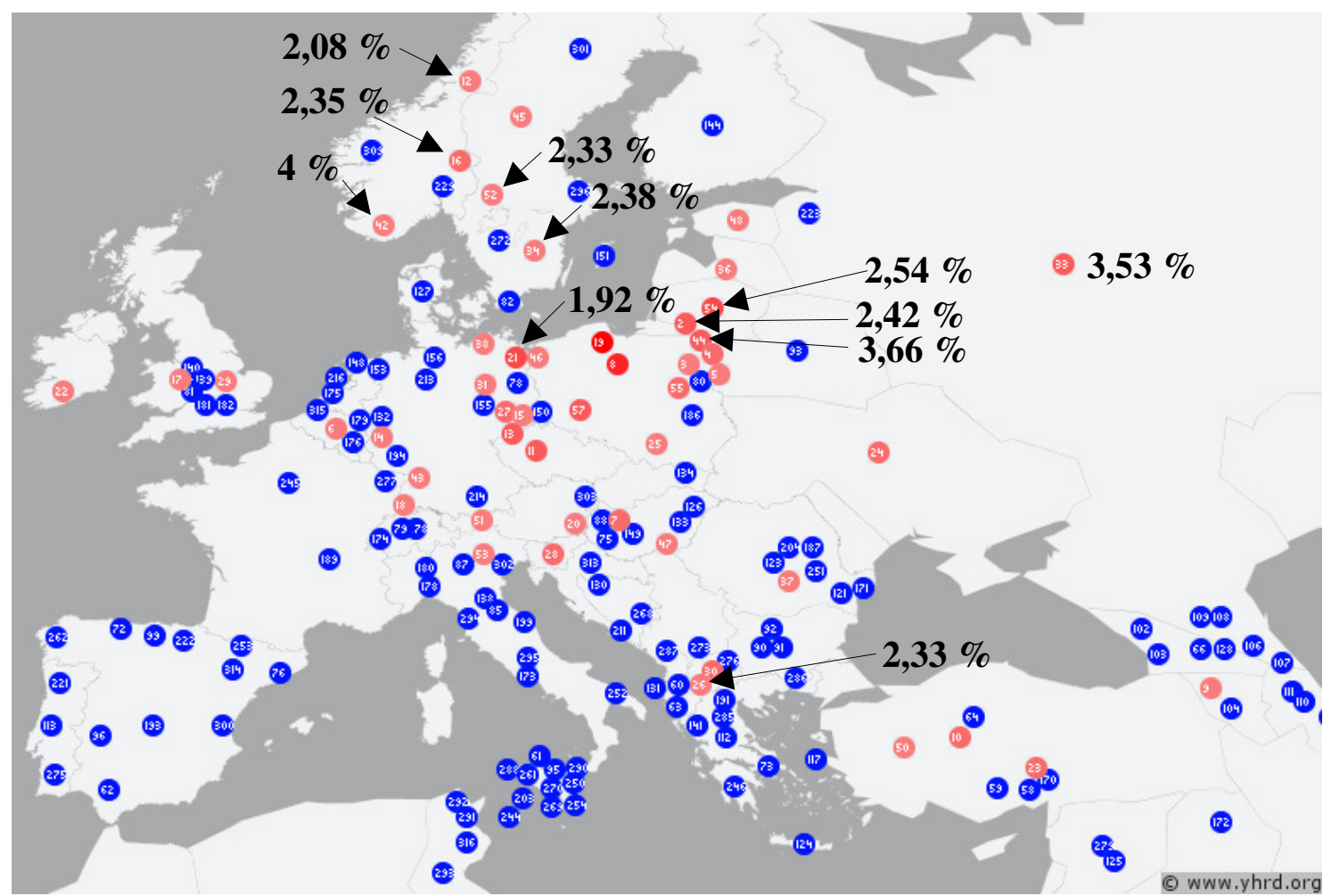

Abbildung 45: Trefferverteilung für den haplotype neighbour von Y5 (Abweichung in DYS385, minHt). Die roten Punkte zeigen getestete Populationen an, in denen der eingegebene Y-Haplotyp aufgetreten ist. Zusätzlich sind die 11 häufigsten Frequenzen angegeben. Die Abbildung zeigt, dass dieser Haplotyp seinen Ursprung sehr wahrscheinlich im nördlichen oder östlichen Europa hat (aus http://www.ystr.org/ index.html, 20.01.2006).

Der Haplotyp Y3 ist mit nur einem Individuum in der Lichtensteinhöhle repräsentiert (M9) und Y5 mit M10 und eventuell M11. Die regionale Herkunft von M9 und M10 legt den Verdacht nahe, dass sie, oder einer ihrer väterlichen Vorfahren, von weiter entfernten Regionen angereist sind und sich dann bei der Gruppe niederließen. Solche „Reisen“ könnten z.B. durch Handel erklärt werden. Für die Bronzezeit ist bekannt, dass der neue Werkstoff Bronze Handelsbeziehungen zwischen den bronzezeitlichen Bevölkerungen begünstigte. Dabei wurden der Rohstoff und die Endprodukte, z.B. Schmuck, über große Distanzen befördert (Jockenhövel 1984, 10).

\subsubsection{Mütterliche Linien}

In diesem Kapitel sollen die ermittelten mt-Haplotypen mit denen von rezenten Populationen abgeglichen und so einer größeren Region zugeordnet werden. Die regionale Einteilung geschieht ausschließlich deskriptiv.

Die mt-Haplotypen wurden in die mtDNA Population Database des FBIs eingegeben. Dabei handelt es sich um eine freeware software, die über das Internet erhältlich ist 
(http://www.fbi.gov/hq/lab/fsc/backissu/april2002/miller1.htm, 20.01.2006). In diese Datenbank sind zurzeit über 10.000 HVR-Profile eingestellt, die sich in zwei Kategorien aufteilen. Zum Einen kann innerhalb einer forensischen Datenbank, mit derzeit ca. 4800 Profilen, gesucht werden. Diese Datensätze wurden von forensischen Instituten wie u.a. dem Armed Forces DNA Identification Laboratory oder dem FBI Laboratory gesammelt. Zum anderen basiert die zweite Kategorie auf publizierten Datensätzen aus 73 Artikeln (bis zum Jahr 2000). Hier sind ca. 6100 Profile aller Kontinente und verschiedener Nationen gespeichert. In der überwiegenden Zahl beruhen die Profile nur auf der HVR I, teilweise auf beiden Abschnitten, selten nur auf der HVR II. Unter den 73 Publikationen befinden sich auch Studien an deutschen Populationen. Lutz et al. (1998) typisierte 200 Individuen aus Süddeutschland und Pfeiffer et al. (1999) 109 aus Nordwestdeutschland. Diese Datensätze eignen sich für den direkten regionalen Vergleich der Lichtensteiner mt-Haplotypen.

Die Einstellungen der software erfolgte wie im user manual beschrieben, welches ebenfalls von obengenannter Internetseite heruntergeladen werden kann. Für die elektronische Auswertung wurden die publizierten Datensätze gewählt. Neben der elektronischen Eingabe der Sequenzmuster wurde zusätzlich weiterführende Literatur verwendet.

\section{Regionale Zuordnung der Individuen mit der Haplogruppe $H$}

Etwa 50\% der Individuen weisen die Haplogruppe $\mathrm{H}$ auf. Dies entspricht auch der generellen Häufigkeit in europäischen Populationen (Richards et al. 2002). Von den 10 nachgewiesenen maternalen Linien der Haplogruppe $\mathrm{H}$ weisen \#1, \#3, \#5, \#7, \#8 und \#10 keine Polymorphismen im Bereich der HVR I auf. Die Variabilität dieser Linien ist ebenfalls im Bereich der HVR II sehr gering. Drei der sechs Linien (\#5, \#7 und \#8) haben keine charakteristischen Polymorphismen in der HVR II. Sie weisen die Polymorphismen 263G und 315.1C auf und unterscheiden sich lediglich durch ihre Anzahl an Insertionen zwischen np 303 - 309. Diese Polymorphismen sind u.a. für europäische Bevölkerung sehr häufig. Die Ausprägung der Andersonsequenz ist an diesen np atypisch (z.B. Lutz et al. 1998, Andrews et al. 1999). Die Eingabe in die Datenbank ergibt mehrere, über Europa verteilte, Treffer. Für Deutschland und Österreich sind die mt-Haplotypen mit den Polymorphismen 263G, 309.1C, 309.2C, 315.1C die häufigsten Muster (Lutz et al. 1998, Parson et al. 1998, Pfeiffer et al. 1999). 
Dennoch ist für diesen mt-Haplotyp aufgrund seiner generellen Häufigkeit in Europa keine regionale Zuordnung möglich.

Der mt-Haplotyp H \#10 weist in der HVR II den Polymorphismus 239C auf. Die Datenbankrecherche ergab für diesen Polymorphismus zwei Treffer in Italien und in der Schweiz, aber auch mehrfach in deutschen Populationen. Eventuell weisen die Treffer auf einen zentraleuropäischen Haplotypen hin. Aufgrund der Tatsache, dass die meisten Studien lediglich die sehr viel variablere HVR I-Region untersuchen, kann dies aufgrund mangelnder Vergleichsdaten nicht weiter bestimmt werden. Ähnliches trifft für die Linien $\mathrm{H}$ \#1 und $\mathrm{H}$ \#3 zu. Diese Polymorphismen sind ebenfalls gleich häufig in verschiedenen Teilen Europas vertreten.

Die Haplotypen H \#4 und H \#9 weisen beide den Polymorphismus 16304C auf. Richards et al (1996) geben für diesen Haplotypen 18 Treffer innerhalb Europas an. Diese verteilen sich über neun Regionen. Allein sieben Treffer davon konnten für eine britische Population (Wales, $\mathrm{n}=92$ ) nachgewiesen werden, welches einer Häufigkeit von $7,6 \%$ entspricht. Für eine schweizer Population ergibt sich eine Frequenz von 2,7\% (= 2 Treffer von 74 untersuchten Individuen).

Die Datenbankrecherche, die diesen Text mitberücksichtigt, spiegelt die Trefferverteilung in Europa wieder. Darüber hinaus konnten auch vereinzelte Treffer in Asien festgestellt werden. In Europa sind die häufigsten Treffer in Großbritannien, der Schweiz, Deutschland und in Spanien ermittelt worden. Darüber hinaus konnte der mtHaplotyp viermal in Russland festgestellt werden. Aufgrund der höheren Trefferverteilung in westeuropäischen Ländern sollte hier ein westeuropäischer Haplotyp vorliegen.

Der mt-Haplotyp H \#2, der sich durch den Polymorphismus 16299G auszeichnet, ist dagegen sehr selten. Er konnte jeweils einmal in einer isländischen $(n=14)$ und einer britischen Population $(n=100)$ ermittelt werden (vgl. Richards et al. 1996) sowie jeweils einmal in der süddeutschen $(n=200$, Lutz et al. 1998) und einer österreichischen Population ( $n=101$, Parson et al. 1998). Auch hier könnte ein westeuropäischer Haplotyp in Frage kommen.

Der mt-Haplotyp H \#6 von Individuum M9, dessen Y-Haplotyp auf eine westeuropäische Herkunft hindeutet, hat in der HVR I den Polymorphismus 16261T. Richards et al. (1996) konnten diesen Haplotyp viermal ermitteln, zweimal in der Schweiz $(n=74)$ und je einmal in Süddeutschland $(n=49)$ und Norddeutschland $(n=107)$. Zusätzlich konnte mit der Datenbankrecherche jeweils ein sequenzgleicher Treffer in 
Bulgarien, Estland und Russland ermittelt werden. Die Verteilung der Treffer lässt hier kein eindeutiges Muster erkennen.

\section{Regionale Zuordnung der Individuen mit der Haplogruppe $J$}

Für das Individuum F14 konnte mit J1b1 eine sehr charakteristische mt-Haplogruppe ermittelt werden. Sie zeichnet sich durch die Polymorphismen 16069T-16126C16145A-16172C-16222T-16261T aus (Richards et al. 2000). Die Suche ergab für Europa drei Treffer in Großbritannien und zwar einmal für eine walisische (n=92, 1,1\%) und zweimal für eine hier nicht näher zuzuordnende Population $(n=100,2 \%)$ (vgl. Richards et al. 1996). Dieser Haplotyp konnte aber auch einmal in Kirgisien/Asien $(\mathrm{n}=47,2,1 \%$; Comas et al. 1998) und fünfmal innerhalb von zwei südsibirischen Populationen (Derenko et al. 2003) festgestellt werden. Vier dieser Treffer konnten für eine Population $(n=90)$ ermittelt werden, deren geographische Verbreitung im Grenzgebiet der Mongolei liegt. Die Häufigkeit dieses mt-Haplotypen beträgt für diese Population 4,4\% und gibt Hinweise auf einen möglichen östlichen Einfluss. Dieser Sachverhalt ist von weiterführenden Interesse. Im vorherigen Kapitel wurde für das Individuum M10, aufgrund seiner väterlichen Linie, eine osteuropäische Herkunft bestimmt. Dies ist aus dem Grund interessant, da er Träger der seltenen Mutationsvariante des immungenetischen Marker CCR5 (Kap.11.2.2, S.190ff) ist, deren Ursprung im nördlichen Osteuropa gesehen wird. Die CCR5-Variante konnte auch bei diesem Individuum ermittelt werden. Damit könnte in Kombination der beiden Markersysteme tatsächlich ein östlicher Einfluss für das Individuum F14 vorliegen.

Die mt-Haplogruppe $\mathbf{J}$ ist für Europa die zweit häufigste Haplogruppe. Wenn die Datenbanksuche ausschließlich auf die Polymorphismen 16069T und 16126C beschränkt wird, dann ist dieser Haplotyp auch häufig außerhalb Europas anzutreffen. Seine Hauptverbreitung scheint jedoch das nordwestliche Europa zu sein. Die Suche nach dem mt-Haplotyp J* mit den Polymorphismen 73G-185A-228A-263G-295T315.1C-16069T-16126C ergibt ausschließlich Treffer in Westeuropa. Mit der gleichen Sequenzabfolge konnte der Haplotyp einmal in Italien $(n=49$, Francalacci et al. 1996), zweimal in der Schweiz ( $\mathrm{n}=154$, Dimo-Simonin et al. 2000), zweimal in Großbritannien $(n=100$, Piercy et al. 1993) und dreimal in Österreich (Parson et al. 1998) ermittelt werden. Für letztere Studie stellt dieser Haplotyp in der 101 Individuen umfassenden Studie auch einen der prozentual häufigsten Haplotypen dar (ca. 3\%). Für die Studien, die auf deutschen Populationen basieren, konnte der Haplotyp zwar nicht genau 
übereinstimmend gefunden werden, jedoch weichen die Sequenzen vielfach nur um eine Basensubstitution ab. Die Auswertung würde bei diesem Sachstand eher von einem westeuropäischen Haplotypen, vielleicht einem zentraleuropäischen ausgehen.

\section{Regionale Zuordnung der Individuen mit der Haplogruppe $U$}

Für fünf eng verwandte Lichtensteiner konnte die Haplogruppe U5b ermittelt werden. Sie ist eine Untergruppe von U5. Haplogruppe U5 zeichnet sich durch das Motiv 73G und 16270T aus. Sie ist die älteste für Europa spezifische Haplogruppe (Richards et al 1998, Macaulay et al. 1999, 242+245). Die Untergruppe U5b zeichnet sich zusätzlich durch das Motiv 16189C aus und ist in West und Zentraleuropa weit verbreitet (Richards et al. 1998). Wird eine Datenbankrecherche nur anhand der HVR IPolymorphismen des mt-Haplotypen (16074G-16189C-16192T-16249C-16270T) durchgeführt, dann können keine Treffer erzielt werden.

Für deutsche und österreichische Populationen (Lutz et al. 1998, Parson et al. 1998, Pfeiffer et al. 1999) können zwar, mit Ausnahme von 16074G, die einzelnen Polymorphismen gefunden werden, jedoch lassen sich nie mehr als zwei gleichzeitig kombinieren. Das bedeutet, dass dieser Haplotyp äußerst selten sein muss. Dies scheint insbesondere für den Polymorphismus 16074G zu gelten. Eine Bestimmung der regionalen Herkunft ist folglich nicht möglich.

F18 hat den mt-Haplotypen U \#1. Dieser weist die Basensubstitutionen 73G-152C195C-263G-315.1C im untersuchten HVR II-Abschnitt auf. Auch für diesen mtHaplotypen ist eine regionale Zuordnung nicht möglich. Diese Polymorphismen sind, auch in Kombination, für Europa relativ häufig.

Das Individuum F15 weist höchstwahrscheinlich die Haplogruppe U2 auf. Charakteristische Polymorphismen sind hier 16051T und 16129C (Macaulay et al. 1999, 242). Es konnte kein sequenzgleicher Treffer bei der Eingabe des gesamten Haplotypen von F15 festgestellt werden. Hier scheint der Polymorphismus 16051T selten zu sein. In Verbindung mit weiteren Polymorphismen konnte die Kombination 16051T und 16129C einmal in der süddeutschen (Lutz et al. 1998) und einmal in der österreichischen Population (Parson et al. 1998) gefunden werden. Die geringe Trefferquote macht eine Aussage zur Regionalität des Haplotypen nicht möglich. 
Regionale Zuordnung der Individuen mit der Haplogruppe T

Die Haplogruppe T2 weist die Polymorphismen 16126C-16294T-16304C auf (Richards et al. 2000). In der Lichtensteinhöhle konnten drei verschiedene maternale Linien der Haplogruppe T2 nachgewiesen werden. Alle drei weisen zusätzlich den Polymorphismen 16296T auf. Die Nucleotidsubstitutionen auf den Positionen 16294 und 16296 sind jedoch oft miteinander verbunden (Lutz et al. 1998). Bei Eingabe in die FBI Datenbank zeigt sich, dass diese Kombination offensichtlich europaspezifisch ist. Die häufigsten Treffer kommen aus Deutschland (9), Finnland (7) und der Schweiz (6). Darüber hinaus ist dieser Haplotyp in Populationen aus Dänemark (2), Russland (4) Island (1) Großbritannien (2) und Spanien (4) ermittelt worden. Hier deutet die Trefferverteilung auf Nordeuropa hin. Der mt-Haplotyp T2 \#3 weist in der HVR I zusätzlich die Basensubstitution 16145A auf. In dieser Kombination war keine Übereinstimmung zu finden. Aus diesem Grund ist keine weitere Einteilung möglich.

\section{Zusammenfassung der Ergebnisse zur regionalen Herkunft}

Die ermittelten mt-Haplotypen lassen sich ausnahmslos den westeurasischen Haplogruppen und zum Teil deren Untergruppen zuordnen (z.B. Macaulay et al. 1999). Es scheint sich in der überwiegenden Zahl der Fälle um westeuropäische Haplotypen zu handeln. In einem Fall (=J1b1) könnte auch ein östlicher Einfluss vorliegen und für T2 ein nördlicher. Der Vergleich mit den rezenten Populationen aus Deutschland zeigt aber auch, dass die meisten mt-Haplotypen durchaus die „,normale“ Verteilung dieser Region wiederspiegeln könnte. Eine regionale Einordnung $\mathrm{zu}$ einer bestimmten kleinräumigeren Region, z.B. Norddeutschland, kann mit den Datensätzen nicht vorgenommen werden. Ein möglicher Grund dafür könnte sein, dass von den 20 analysierten mt-Haplotypen allein zehn zur Haplogruppe H gehören. Diese Haplogruppe lässt sich schlecht in Untergruppen einteilen, was phylogeographische Studien an dieser Haplogruppe in Europa deutlich einschränken (vgl. Richards \& Macaulay et al. 2001, 1318, Pereira et al. im Druck). Die generelle Häufigkeit von ca. 50\% in europäischen Bevölkerungen erschwert die Zuordnung zusätzlich. Für eine bessere Untergliederung dieser Haplogruppe schlagen Pereira et al. (im Druck) vor, neben den HVR-Bereichen, zusätzlich verschiedene SNPs im mt-Genom zu untersuchen. Hier zeigt sich, dass eine feinere Untergliederung der Haplogruppe $\mathrm{H}$ möglich ist und damit regionale Ursprünge besser festzulegen sind. 
In den Fällen der mt-Haplotypen $\mathrm{H}$ \#2, U5b und U2 scheinen bestimmte Basensubstitutionen deutlich seltener zu sein als andere Polymorphismen. Aus diesem Grund konnten diese Haplotypen nicht gefunden oder wenige Treffer bei der Datenbankrecherche festgestellt werden. In diesem Zusammenhang könnte eine mtHaplotypenanalyse regionaler Bevölkerungsgruppen aus dem Umfeld der Lichtensteinhöhle weiterführende Erkenntnisse bringen. Ließen sich diese seltenen Basensubstitutionen vermehrt in diesen Gruppen nachweisen, würde sich zwar zwangsläufig keine regionale Herkunft für den Haplotypen ergeben, aber es könnte gezeigt werden, ob dieser noch Einfluss auf den Genpool der rezenten Bevölkerung hat. Hieraus könnte auf mögliche Nachfahren geschlossen werden. 


\subsection{Verteilungsmuster der Knochenelemente: prähistorischer Eingang und Ablagereihenfolge der Verstorbenen in die Lichtensteinhöhle}

\section{Aufgabenstellung}

Die Arbeiten zu den Verteilungsmustern der Knochen hatten zum Ziel den Streuungsgrad der Skelettelemente von den in dieser Arbeit ermittelten Individuen zu bestimmen. Anhand dieser Daten sollte die Bewegungsrichtung der Menschen in der Höhle abgelesen werden, um dadurch den ursprünglichen prähistorischen Eingang zu finden. Darüber hinaus sollte nach einem eventuellen Muster gesucht werden, das einen Hinweis darauf gibt, in welcher Reihenfolge die Verstorbenen in der Höhle abgelegt wurden.

Im Folgenden werden Methoden, Probenauswahl und Ergebnisse aus den wissenschaftlichen Studien zum Verteilungsmuster der Knochen von Croll (2005), Gärtner (2005), Klingner (2005) und Mußlick (2005) zusammengefasst. Im Anschluss daran werden diese Daten in die eigenen Erkenntnisse zum Verteilungsmuster eingebunden und hinsichtlich des Archäologischen Kontextes diskutiert.

\section{Methoden und Probenauswahl}

Die Zusammenführung der Skelettelemente erfolgte über den genetischen Fingerabdruck. Die STR-Analyse wurde im Wesentlichen mit der Oktaplex-PCR durchgeführt, selten wurde der Profiler Plus ${ }^{\mathrm{TM}}$ Kit verwendet. Um den Streuungsgrad der Skelettelemente eines Individuums zu ermitteln, wurden die zu untersuchenden Skelettelemente so ausgewählt, dass das Skelett über seine gesamte Länge belegt ist. Es wurden Arbeiten an Calcanei (Klingner 2005), Humeri (Mußlick 2005), Radii (Gärtner 2005) und Tibiae (Croll 2005) durchgeführt. Die Typisierungsdaten wurden dann sowohl untereinander, als auch mit den Ergebnissen der Typisierungen der cranialen Elemente aus dieser Studie und der Femora (Schultes 2000) abgeglichen.

Das Maß der Streuung ergab sich über die Distanzen zwischen den einzelnen Elementen eines Individuums. Diese Distanzen wurden nach einem bestimmten Modell berechnet (s. Klingner 2005, 24-25). Dies geschah raumübergreifend anhand des archäologischen Quadrantenplanes (Abb.46). Die Höhle wurde bei der Grabung komplett kartiert und jeder Knochen, der die Höhle mit den Archäologen verließ, wurde hinsichtlich seiner Lage und des Fundhorizontes dokumentiert. 
Die Fundorte und Quadranten der cranialen Skelettelemente sind im Anhang in Tabelle 28 aufgeführt.
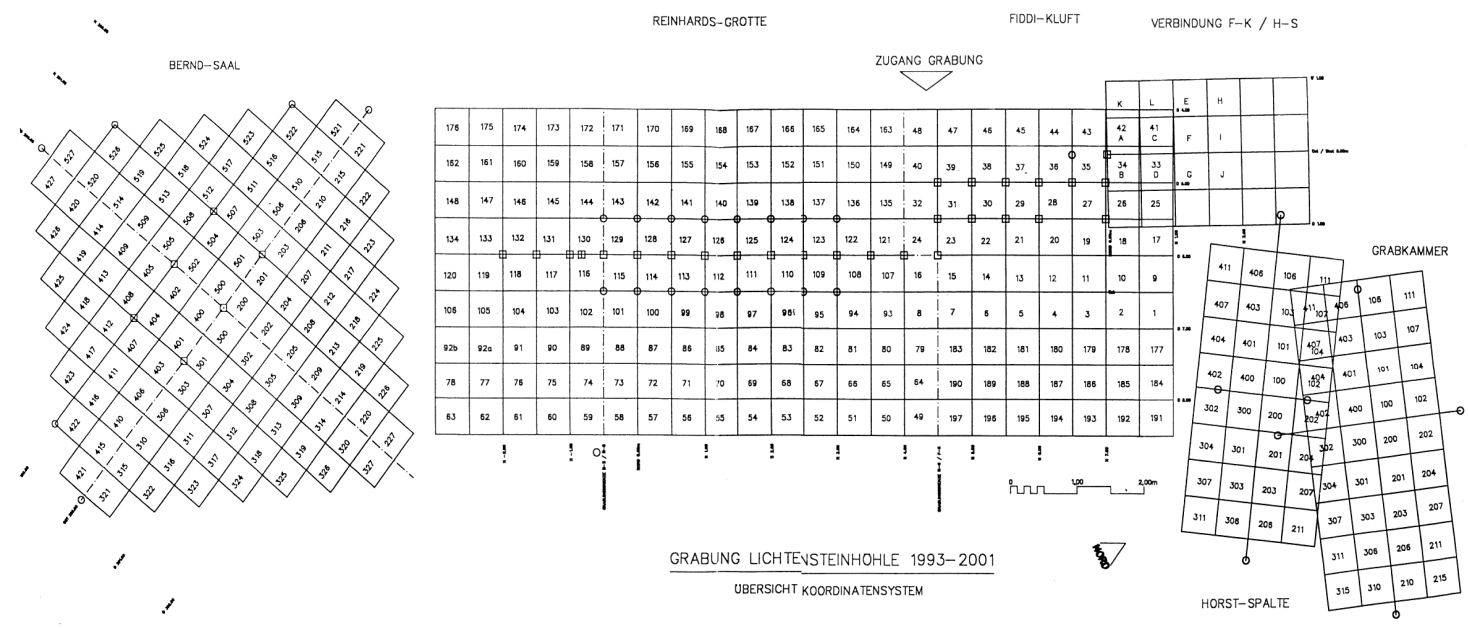

Abbildung 46: Schematischer Quadrantenplan der Lichtensteinhöhle. Übersicht über die fünf fundführenden Bereiche der Höhle. Anhand des Quadrantenplanes ist die Lage der Knochen in der Höhle bestimmbar. Die Quadranten haben eine Seitenlänge von 50cm. In der realen Situation überlappen sich Abschnitte des Bernd-Saals und der Reinhardsgrotte.

\section{Ergebnisse}

Die Ergebnisse der wissenschaftlichen Studien werden im Folgenden zusammengefasst dargestellt.

Die Typisierungsdaten waren von unterschiedlicher Qualität. Die Analysen zu den Verteilungsmustern der Radii konnten keine weiterführenden Erkenntnisse liefern. Nur für einen rechten Radius (Do393) wurde ein individualspezifisches Allelmuster ermittelt, welches eine Zuordnung zu M1 ermöglichte. Damit war die zu untersuchende Fragestellung an den Radii nicht $\mathrm{zu}$ beantworten. Für die Tibiae gelangen 22 Zuordnungen, für die Humeri 12 und für die Calcanei 20. Der Großteil der Zuordnungen kann über den genetischen Fingerabdruck als gesichert angenommen werden. Die sicheren Zuordnungen wurden in die eigenen Tabellen 14 und 15, Seite 75 und 76 übernommen.

Im Bernd-Saal lag der Großteil der zugeordneten Skelettelemente gehäuft auf einer Fläche von $2 \mathrm{~m} \times 2,50 \mathrm{~m}$. Geringfügig weniger zugeordnete Knochen konnte man auf einer Fläche von 1,5m x 2m in der Reinhardsgrotte finden (Klingner 2005). Sehr viel 
geringer war die Anzahl in den übrigen Höhlenabschnitten. In der Regel befanden sich die zusammengehörenden Skelettelemente in lediglich einem Höhlenabschnitt.

Wenn die Skelettelemente nah beieinander lagen, waren sie in der Regel nicht in ihrer anatomischen Ordnung. Die wenigen Ausnahmen wurden im Bernd-Saal gefunden. Hier gab es zusammengehörende Skelettelemente, die sich fast in ihrer ursprünglichen anatomisch richtigen Position befanden (Klingner 2005).

Mitunter waren Elemente über mehrere Höhlenabschnitte verstreut. Beispielsweise lag der Schädel des Individuums M5 in der Fiddi-Kluft, während ein Handwurzelknochen und der Unterkiefer im Bernd-Saal geborgen wurden. Bei der Verlagerung der Knochen, zum Teil über mehrere Höhlenabschnitte, ist am ehesten an eine intentionale Verschleppung der Knochen durch die Höhlennutzer $\mathrm{zu}$ denken. Eine Tierverschleppung kommt nicht in Frage, da keiner der Knochen Anzeichen von Nageoder Bissspuren zeigt.

Die Streuung der Skelettelemente nimmt vom Bernd-Saal über die Reinhardsgrotte zur Fiddi-Kluft zu.

Abbildung 45 zeigt das Verteilungsmuster cranialer Elemente sowie rechter und linker Femora für einen Ausschnitt der Reinhardsgrotte. Die Knochen wurden anhand des Fundkataloges einem Quadranten zugewiesen, ihre Lage in den jeweiligen Quadranten ist für diese Darstellung frei gewählt.

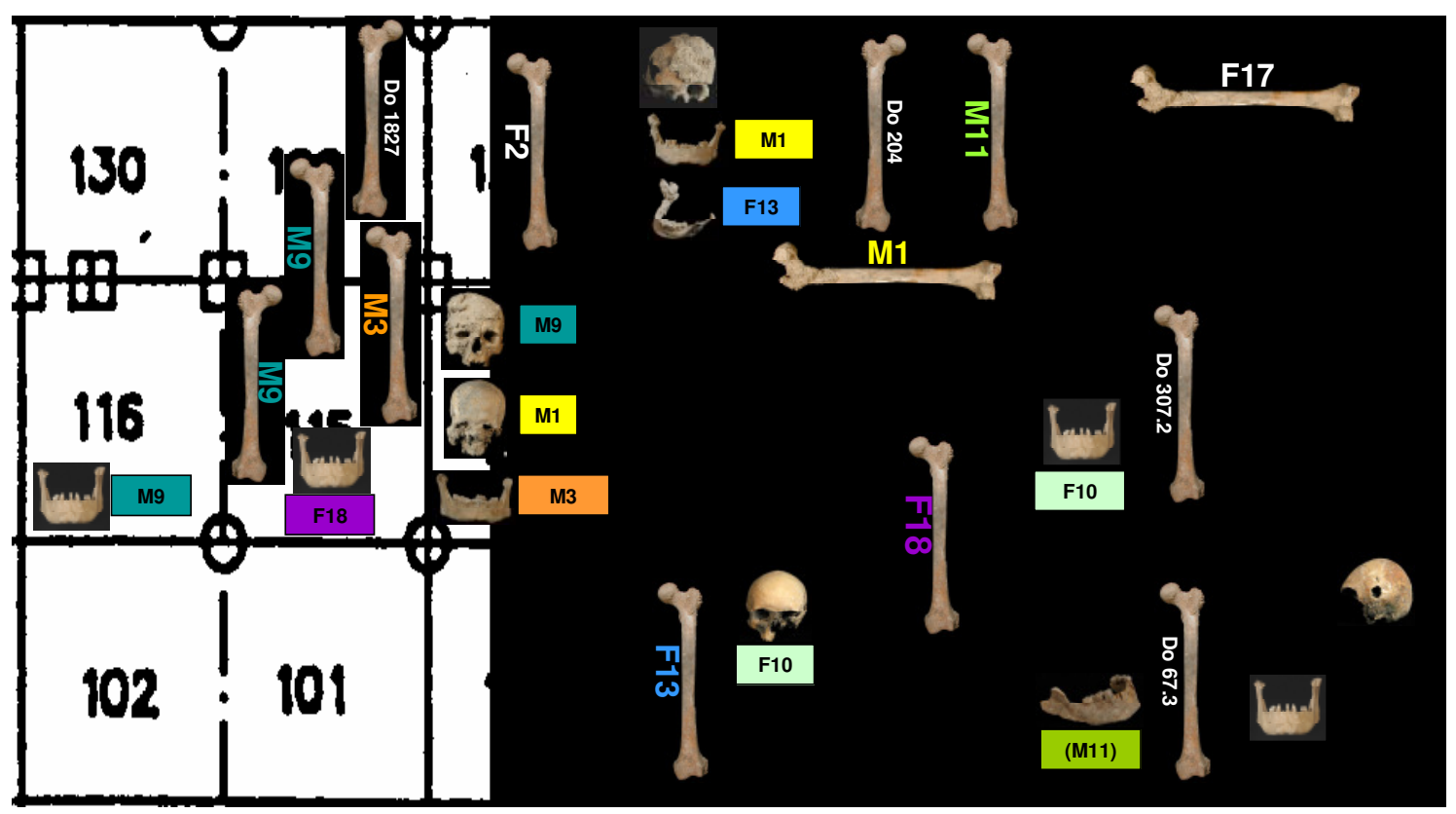

Abbildung 47: Schematisiertes Verteilungsmuster der cranialen Skelettelemente sowie rechter und linker Femora für einen Abschnitt der Reinhardsgrotte (Seitenlänge eines Quadranten 50cm). Farblich gleich unterlegte Kästchen und Ziffern symbolisieren Knochenelemente, welche zu einem Individuum gehören. Wurde nur die Fundnummer angegeben, konnte das Skelettelement bislang nicht zugeordnet werden. Individuen, für die nur eins der dargestellten Skelettelemente in diesem Bereich gefunden wurde, sind farblich nicht gekennzeichnet. 
Der Abbildung kann entnommen werden, dass die Skelettelemente von einzelnen Individuen, z.B. M1 und M9, nahe beieinander liegen, wogegen für andere Individuen, z.B. F2, in diesem Abschnitt ausschließlich ein isoliertes Oberschenkelbein gefunden wurde. Des Weiteren ist ersichtlich, dass die Unterkiefer in der Regel weit von ihrem zugehörigen Schädel entfernt liegen.

\section{Diskussion}

Zwei mögliche Hypothesen zur Lage des prähistorischen Eingangs kommen in Betracht. Von den Archäologen wurde die Hypothese bevorzugt, dass der prähistorische Eingang im Bereich der geringsten Störung der Knochen zu suchen sei. Dies begründet sich auf der Vermutung, dass die letzten Leichen in die Nähe des Eingangs gelegt wurden, kurz bevor man die Höhle als Kultstätte aufgab. Wäre die Höhle schließlich seltener besucht wurden, dann wären die am Eingang deponierten Skelette weniger aus ihrer anatomischen Ordnung gerissen.

Theoretisch wäre jedoch eine weitere Alternative denkbar. Im Prinzip könnte der Höhleneingang auch an der Stelle liegen, wo die Streuung am höchsten ist. In diesem Fall würde die Verstreuung der Knochen aus dem ständigen Durchqueren der Höhlennutzer resultieren, die in entferntere Bereiche der Höhle gelangen wollten. Wurden die ersten Toten nahe dem Eingang abgelegt, hätten die Höhlennutzer über die Skelette steigen müssen. Sie hätten die Knochen an die Seite geräumt, um dies zu verhindern. Letztlich würde sich auch so eine dislozierte Lage der Knochen erklären.

Eine klare Entscheidung zugunsten der einen oder anderen Möglichkeit konnte nicht getroffen werden. Würde die von den Archäologen bevorzugte Hypothese zutreffen, dann sollte der prähistorische Eingang in der Nähe des Bernd-Saals liegen. Diese Möglichkeit scheint auch aus anderen Gesichtspunkten die wahrscheinlichere zu sein.

Die letzte Ausgrabungskampagne der Archäologen brachte neuere Erkenntnisse zum prähistorischen Einstieg. Vom Bernd-Saal aus zieht die ca. $7 \mathrm{~m}$ lange kaminartige Helmarsspalte nach oben. Abdrücke im Gestein zeigen hier, dass an dieser Stelle ein Steigbaum gestanden hat (pers. Mitteilung S.Flindt). Die Helmarsspalte mündet dann in einem Bereich, welcher in der Nähe der Heinfriedhöhle liegt. Diese überlagert den Bernd-Saal. Jedoch zeigen auch hier die archäologischen Arbeiten, dass ein natürlicher Einstieg nicht in der Heinfriedhöhle liegen kann. Oberhalb der Helmarsspalte konnte dagegen ein natürlicher Versturz gefunden werden. Dieser ist nicht mehr passierbar, 
doch sehr wahrscheinlich mündete ein Weg außerhalb des Berges am Hang. Es wäre denkbar, dass die Menschen über die Helmarspalte in die Höhle kletterten. Bis zum jetzigen Zeitpunkt konnte dies nicht hinreichend geklärt werden, ist jedoch aus der Sicht der Archäologen zu vermuten.

Unterstützung erhält diese Theorie aus einer ganz anderen Forschungsrichtung, der forensischen Entomologie. Bei einer stichprobenartigen Kontrolle von Fundmaterial aus dem Bernd-Saal konnten Fliegenexuvien, d.h. abgestreifte Häute von Fliegenlarven, der Familie Muscidae festgestellt werden (pers. Mitteilung A. Scholten). Ein häufiger Vertreter dieser Fliegenfamilie ist Musca domestica (=Stubenfliege). Sie ist eine der ersten Fliegenarten ${ }^{2}$ die von Aas angezogen wird (Byrd \& Castner 2001, 55). Aufgrund der Tatsache, dass sehr gängige Fliegenvertreter der Leichenfauna, z.B. Calliphoridae (Byrd \& Castner 2001, 45) in der Lichtensteinhöhle komplett fehlen, muss davon ausgegangen werden, dass die Leichen sehr schnell in die Höhle gebracht und mit Erdreich bedeckt wurden. Muscidae ist eine der wenigen Fliegenarten, die in der Lage ist auch mit Erdreich bedeckte Leichen zu besiedeln. Hierfür werden die Eier auf das Erdreich abgelegt und die Maden bohren sich nach dem Schlüpfen durch das lockere Erdreich zur Leiche (Smith 1986, 128). Dies könnte ein Grund sein, warum keine anderen gängigen Fliegenarten festgestellt werden konnten.

M. domestica beginnt erst bei Temperaturen zwischen 14 und $18{ }^{\circ} \mathrm{C}$ mit der Eiablage. Die Larvenentwicklung von forensisch relevanten Fliegenarten haben bei Temperaturen zwischen $6-10^{\circ} \mathrm{C}$ ein Minimum (Higley \& Haskell 2001, 290). Die Larvenentwicklung von $M$. domestica kommt dagegen bei Temperaturen unter $10^{\circ} \mathrm{C}$ zum Stillstand (pers. Mitteilung A. Scholten) ${ }^{3}$.

Diese vom Normalzustand abweichenden Temperaturbedingungen könnten im BerndSaal durch anhaltende Kultfeuer vorgelegen haben. Der Eingang der Höhle sollte sich jedoch in räumlicher Nähe zum Bernd-Saal befunden haben, da die Fliegen nicht dem Weg durch die Klüfte zur Leiche gefolgt wären.

Aus dem vorliegenden Gesamtergebnis spricht daher vieles für einen prähistorischen Eingang in der Nähe des Bernd-Saals. Sehr wahrscheinlich ist dieser über die

\footnotetext{
2 Aas gehört nicht zur präferierten Nahrung von M. domestica, besiedelt aber alles mit einer feuchter Oberfläche.

${ }^{3}$ Es gibt noch keine entsprechenden Isomegalendiagramme, die unter $16^{\circ} \mathrm{C}$ gehen. Da aber die adulte Fliege erst ab $10^{\circ} \mathrm{C}$ wieder startet (vgl. Smith 1986, 126), kann dementsprechend darunter nicht oviporiert werden.
} 
Helmarspalte $\mathrm{zu}$ erreichen gewesen. Ein Leichentransport wäre auf diese Weise denkbar. Man könnte die toten Körper mit einem Seil nach unten in den Bernd-Saal abgelassen haben. Ein Transport der Leichen über den 1972 entdeckten Weg wird von den Archäologen ausgeschlossen (s. Einleitung Kap.1.1.4).

Die geringere Streuung der Knochen im Bernd-Saal könnte auch auf die Bestattungsreihenfolge zurückzuführen sein. Der Bernd-Saal war nachweislich der zentrale Kultraum der Höhle. Anfänglich wurde er kultisch rituell genutzt und in der jüngsten und letzten Nutzungsphase der Höhle diente er sicher als Grabstätte (Flindt 2001). Es ist denkbar, dass die Leichen zunächst in diesem Abschnitt deponiert wurden. Als die Skelette später nicht mehr von Sehnen zusammengehalten wurden, haben die Höhlennutzer sie, um „Platz zu schaffen“, in die hinteren Höhlenbereiche transportiert (Klingner 2005). Zum Teil blieben dabei Knochen zurück, sodass Skelettelemente einiger Individuen, sowohl im Bernd-Saal, als auch in anderen Höhlenabschnitten lagen. Hierfür könnten ebenso die deponierten Langknochenbündel sprechen. Die Höhlenbenutzer hätten in diesem Fall die Knochen nicht einfach an den Rändern der Höhle zusammengeschoben, sondern sie regelrecht eingesammelt und letztendlich in den hinteren Höhlenbereichen niedergelegt.

Es fällt auf, dass die Individuen der einzelnen Familienzweige häufig in denselben Bereichen der Höhle lagen. Die sieben Mitglieder des größten Familienzweiges (genealogische Verbindung I: F4, F5, F6, F7, F8, M8 und M16) wurden beispielsweise ausnahmslos im Bernd-Saal geborgen. Damit liegt nur der Vater bzw. Großvater M3 nicht bei seiner Familie. Der Bernd-Saal könnte für einen bestimmten, eventuell den letzten, Zeitabschnitt als Begräbnisstätte dieser Familie gedient haben.

Die Mitglieder der genealogischen Verbindung II teilen sich dagegen auf die verschiedenen Höhlenabschnitte auf. M1, F1 und F2 wurden in der Reinhardsgrotte geborgen, während M2, F3 und M15 im Bernd-Saal und M12 in der Grabkammer gefunden worden. Selbst die Individuen, die nicht in den Stammbaum zu integrieren waren, verteilen sich auf die verschiedenen Höhlenabschnitte. Somit kann nicht davon ausgegangen werden, dass ein Höhlenabschnitt ganz bestimmten Familienzweigen vorbehalten war. Ein generelles Muster ist mit Ausnahme der Familie I nicht zu sehen. In wie weit bei dieser Tatsache der Todeszeitpunkt eine Rolle spielt, d.h. ob die zusammenliegenden Individuen zum selben Zeitpunkt in die Höhle gebracht wurden, ist 
aus dem Muster nicht ableitbar. Durchaus denkbar wäre, dass die Skelette aus den, vom Bernd-Saal aus gesehen, hinteren Höhlenabschnitten die ersten Leichen sind, die in die Höhle gelangten. Nachdem die Feierlichkeiten im Bernd-Saal beendigt und schließlich die Weichteile vergangen waren, verlagerte man die Knochen in die hinteren Bereiche und begann im Bernd-Saal mit neuen Bestattungszeremonien. Aus dem archäologischen Befund konnte man ableiten, dass die Höhle über mehrere Generationen genutzt wurde. Aus diesem Grund wäre ein solches Vorgehen denkbar.

Es wurde jeweils eine Knochenprobe aus dem Bernd-Saal und der Reinhardsgrotte einer $\mathrm{C}^{14}$-Datierung unterzogen, um einen konkreteren Hinweis zur zeitlichen Belegung der beiden Höhlenabschnitte zu bekommen. Die Ergebnisse liegen zum Zeitpunkt der Fertigstellung dieser Arbeit noch nicht vor. Bei erfolgreicher Analyse könnte ein Mindestbelegungszeitraum der Höhle ermittelt werden sowie gezeigt werden, ob tatsächlich die Knochen mit der geringsten Streuung im Bernd-Saal, die wahrscheinlich letzten niedergelegten Toten repräsentieren. Wären nach ihrer Bestattung die rituellen Handlungen im Bernd-Saal aufgegeben worden, hätte kein Grund mehr vorgelegen, die Knochen aus dem Bernd-Saal in andere Höhlenabschnitte zu verlagern. 


\section{Bestattungsplatz oder Menschenopferstätte?}

Das abschließende Kapitel befasst sich mit der Fragestellung nach der Nutzungsart der Höhle. Handelt es sich hier um einen Bestattungsplatz, eine Menschenopferstätte oder gab es einen Nutzungswechsel? Die Interpretation der Höhlennutzung sollte einzig hinsichtlich dieser Fragestellungen geführt werden, da eine alltägliche Nutzung der Höhle, z.B. als Wohnstätte, über das archäologische Fundinventar ausgeschlossen werden kann (vgl. Schultes 2000, Flindt 2001).

Für die Interpretation fließen die erhobenen Basisdaten aus dem Anthropologischen Befund, z.B. Individualalter, Altersstruktur der Gruppe und Pathologien (s.Kap.11.1), mit ein. Die molekulargenetischen Analysen liefern u.a. die Geschlechtsdiagnose und die Genealogie. Letzteres ist das Kernstück dieser Arbeit und könnte die entscheidende Interpretationshilfe zur Nutzungsart der Lichtensteinhöhle sein.

\subsection{Zusammenführung der Ergebnisse des Anthropologischen Befundes und der molekulargenetischen Analysen}

In dieser Studie konnte eine Mindestindividuenzahl von 40 ermittelt werden. Diese Zahl wurde mithilfe genetischer Analysen aus einer Vielzahl verschiedener Skelettelemente gewonnen. Die Grabungskampagnen für die fünf fundführenden Höhlenabschnitte sind abgeschlossen, womit für diese Bereiche mit keinen weiteren Knochenfunden zu rechnen ist.

Es ist denkbar, dass die einzelnen Knochenelemente in Unterzahlen vorliegen, z.B. konnten für diese Studie lediglich 34 Unterkiefer unterschieden werden. Ebenso erreichen auch die Skelettelemente, welche für die Analysen zum Verteilungsmuster untersucht wurden (Kap.6.4), in keinem Fall die ermittelte Mindestindividuenzahl. Es ist nicht auszuschließen, dass die Anzahl der Individuen bei weiteren Analysen weiter ansteigen könnte. Dieser Anstieg sollte jedoch minimal sein, da bereits ein großes Spektrum des Knochenmaterials molekulargenetisch untersucht wurde.

Bei den 40 Individuen handelt es sich um 21 weibliche und 19 männliche Individuen, womit die Zusammensetzung der Gruppe hinsichtlich der Geschlechterrelation ausgeglichen ist. 
Die Altersstruktur der Gruppe zeigt ein Kleinkinderdefizit im Infans I auf. Während zehn Individuen der Altersklasse Infans II zugeordnet werden konnten, ließen sich lediglich zwei Individuen ermitteln, welche im Übergangsbereich zwischen Infans I und Infans II liegen. Der repräsentierte Altersbereich liegt zwischen spätem Infans I (ca. fünf Jahre) und Senilis (ab 60Jahre). Zwischen den männlichen und weiblichen Individuen gibt es keine grundlegenden Abweichungen ihrer Anzahl in den jeweiligen Altersklassen.

An den Knochen konnten keine Anzeichen von äußeren Gewalteinwirkungen festgestellt werden. Die einzigen traumatischen Ereignisse sind hier eine verheilte Claviculafraktur und eine Trepanation. Pathologien, welche am Knochen nachweisbar wären und einen möglichen Tod zur Konsequenz gehabt hätten, sind nicht vorhanden.

Die genealogischen Analysen ergaben, dass zwischen dem Großteil der Individuen ein komplexes Verwandtschaftsverhältnis besteht. Es ließen sich einzelne Familiengruppen rekonstruieren, die sich mehrheitlich über ihre mütterlichen und väterlichen Linien zu einer Großfamilie verknüpfen ließen. Lediglich für fünf Frauen und einen Mann war kein biologisches Verwandtschaftsverhältnis $\mathrm{zu}$ einem anderen Individuum nachzuweisen.

\subsection{Ergebnisinterpretation und deren Einordnung in den archäologischen Kontext}

Der kultische Charakter der Lichtensteinhöhle ist fraglos sichergestellt (Flindt 1998, 17). Dies wurde von den Archäologen aus der Lage und Form der Höhle sowie aus dem geborgenen Fundmaterial geschlossen. Es stellt sich somit die Frage, ob die Lichtensteinhöhle als eine Art Opferstätte in Frage kommt. Die Höhle wurde gezielt für die Durchführung ritueller Handlungen, auch in direkter Verbindung mit der Einbringung von Menschen, hergerichtet (Flindt 2001). Für die Nutzungsart der Höhle können die kultischen Handlungen für beide Interpretationen herangezogen werden. So könnten die Bestattungen mit begleitenden Totenritualen sowie auch die Opferungen mit rituellen Zeremonien durchgeführt worden sein. Infolgedessen werden mit den 
Begriffen „kultisch und rituell“ sowohl Bestattungsplätze als auch Opferstätten in Verbindung gebracht.

Die Interpretation einer Höhle als Kultstätte sollte sich vor allem auf den direkten Vergleich mit anderen Höhlenfundplätzen stützen, um mögliche Gemeinsamkeiten oder Unterschiede aufzuzeigen.

Hier erscheint ein Vergleich mit Höhlen z.B. aus der Kyffhäuser Region nahe liegend, da die Lichtensteinhöhle von den Archäologen mit der Unstrutgruppe in Verbindung gebracht wird. Hierbei handelt es sich um mindestens zwanzig, zum Teil miteinander verbundene Höhlen und Spalten, die von 1950 - 1957 untersucht wurden. Insgesamt ließen sich hier ungefähr 15.000 Knochenteile von ca. 130 Menschen finden (Flindt 1998, Speitel \& Walter 1999). Für die Höhlen im Kyffhäuser liegen klare Hinweise vor, dass in ihnen über einen Zeitraum von 1000 Jahren Menschenopfer durchgeführt wurden (Speitel \& Walter 1999). Charakteristisch für die Menschenknochenfunde ist, dass an ihnen direkte Gewalteinwirkungen zu erkennen sind. Viele dieser Menschen wurden mit stumpfen Geräten und Hiebwerkzeugen getötet und anschließend zerlegt (Speitel \& Walter 1999). Darüber hinaus geben Schnittspuren an Gelenkenden, Wirbeln und Rippen Hinweise auf postmortale Zerstückelungen (Walter 1998). Ähnliche Situationen konnten auch bei anderen Menschenopferstätten festgestellt werden. Für einen neolithischen Fundkomplex wurde gezeigt, dass Schädel zertrümmert und anschließend die Köpfe vom Rumpf getrennt worden sind (vgl. Grimm 1956, 177). Hinweise auf Anthropophagie, d.h. kultischen Kannibalismus, liegen sowohl für Höhlen im Ith (Leiber 1998), als auch für die im Kyffhäuser vor (Speitel \& Walter 1999) und werden von den Archäologen aus Schnitt- und Feuerspuren am Knochen abgeleitet. Zeichen derartiger Eingriffe konnten nicht an den Knochen der Lichtensteinhöhle festgestellt werden. Ein gewaltsamer Tod einzelner Individuen kann dennoch nicht kategorisch ausgeschlossen werden, da gleichfalls Tötungspraktiken denkbar wären, welche nur das Weich- nicht aber das Hartgewebe betroffen haben und daher nicht am Skelett nachweisbar sind.

Ein weiteres Kriterium für eine Menschenopferstätte könnte sein, dass alle gefundenen Individuen unverbrannt vorliegen. Weicht die Befundsituation von dem in der Region üblichen Bestattungsritus ab, spricht dies im Allgemeinen gegen einen Bestattungscharakter (Flindt 1998, 16). Ebenso stellt die stark gestörte Fundsituation der Knochen einen abweichenden Befund für einen Bestattungsplatz dar. Der 
Archäologie fehlen zusätzlich die für einen Begräbnisplatz üblichen, typischen Grabbeigaben. Jedoch könnten die Toten auch ganz bewusst mit ihrem Schmuck, aber ohne größere Beigaben in die Höhle gebracht worden sein (pers. Mitteilung S.Flindt). Darüber hinaus vertreten einige Archäologen die Ansicht, dass es sich bei den unverbrannten Toten um Angehörige einer privilegierten Schicht, z.B. Adel, Häuptlinge oder Priester, handeln könnte und es sich somit nicht um Opfer handelt (pers. Mitteilung S.Flindt).

Flindt (1998, 16) nennt in seinem Katalog zur Bestimmung urgeschichtlicher Kulthöhlen das Kriterium der Normabweichungen bei Geschlechterverteilung und Altersstruktur. Vorwiegend Frauen, Jugendliche und Kinder fielen einer rituellen Tötung zum Opfer (Grimm 1956, 177, Kuhbach 1994, 74). Für die Menschenopfer aus den Kyffhäuserhöhlen ließ sich ein ausgeglichenes Geschlechterverhältnis mit einem Anteil von über 50\% subadulter Individuen ermitteln (vgl. Schultes 2000, 113). Ähnliches trifft für die Individuen der Lichtensteinhöhle zu, deren Geschlechterrelation ebenfalls nahezu ausgeglichen ist und die subadulten Individuen fast $50 \%$ der Gesamtzahl ausmachen. Jedoch entspricht das Sterblichkeitsprofil der LichtensteinerGruppe, mit Ausnahme der fehlenden Kinder im Infans I, den Erwartungen über die Sterblichkeit historischer Populationen (s. Anthropologischer Befund Kap. 11.1).

Das Fehlen der Kleinkinder deutet dabei nicht auf eine Menschenopferstätte hin. Eine hohe Mortalität im Kleinkindalter, in Relation zu den Altersgruppen Infans II und Juvenis, ist ein für die Mehrzahl prähistorischer und rezenter Bevölkerungen typischer Befund (Herrmann et al. 1990). Geht man davon aus, dass die Individuen der Lichtensteinhöhle einen repräsentativen Ausschnitt aus der Lebendbevölkerung darstellen, sollte das Fehlen der Kleinkinder auf eine Sonderbestattung zurückzuführen sein. Aus dieser Epoche ist sehr wenig zur gesellschaftlichen Stellung der Kinder bekannt. Eine Sonderbestattung für Kinder scheint jedoch nichts ungewöhnliches zu sein, da für bronzezeitliche Gesellschaften altersdifferenzierte Behandlungen im Grabbrauch bekannt sind. Möglich wäre, dass die Kinder in einem bisher unbekannten Abschnitt der Höhle, oder außerhalb dieser, beigesetzt wurden.

Wenn keines der Individuen eines gewaltsamen Todes starb, dann könnten neben einem natürlichen Tod auch noch weitere Gründe, wie z.B. ein krankheitsbedingter Tod, vorliegen. Am Skelettkollektiv der Lichtensteinhöhle wurden genetische Analysen zur 
Bestimmung von Allelfrequenzen erbkrankheitsassoziierter Loci durchgeführt. Aus diesen Studien konnte abgeleitet werden, dass die zystische Fibrose (= Mukoviszidose), als eine der in europäischen Bevölkerungen heute häufigsten und nicht heilbaren Erkrankungen (Kap.11.2.4) sowie die hereditäre Haemochromatose (=erbliche Eisenspeicherkrankheit, Kap.11.2.5) nicht als Todesursache für die Individuen in Frage kommen kann. Für die Zukunft sollte man diese Arbeiten fortsetzen, da der Nachweis eines möglichen krankheitsbedingten Todes die Interpretation erheblich vereinfachen würde.

Ein weiteres und in Betracht zu ziehendes Ereignis, welches für den Tod aller oder einzelner Individuen verantwortlich sein könnte, stellt sich in Infektionskrankheiten dar. Durch Erreger ausgelöste Erkrankungen bilden weltweit bis zum 19 Jhd. die häufigste Todesursache (Cohen 2000). Jedoch lassen die wenigsten Infektionskrankheiten Spuren am Knochen zurück. Über aDNA-Analysen konnte der Zugang zu Infektionskrankheiten an historischem humanen Probenmaterial gelingen (Übersicht in Herrmann \& Hummel 2003). Eventuell können damit Hinweise auf ein epidemiologisches Ereignis geklärt werden. Dies könnte, wie im Fall der Immunerkrankungen, weiterführenden klärenden Einfluss auf die Interpretation haben. Zurzeit bleibt jedoch eine mögliche Todesursache für die Individuen unklar. Berücksichtigt werden sollte hierbei, dass sich über die Hälfte der Individuen bereits im erwachsen Alter, bzw. 1/4 der Gesamtgruppe bereits im maturen Alter, befanden. Daher sollte, bis zum Beweis des Gegenteils, eine natürliche Todesursache, d.h. aus den üblichen lebensbegrenzenden Faktoren, angenommen werden.

Aus den molekulargenetischen Verwandtschaftsanalysen gehen sicher nachgewiesene familiäre Strukturen hervor. In vielen Fällen liegen direkte biologische Verwandtschaftsverhältnisse vor, in zwei Familienzweigen sogar über drei Generationen. Darüber hinaus konnte für alle Kinder ein genealogischer Bezug zu einem anderen Individuum hergestellt werden, in sieben von 12 Fällen handelt es sich dabei um eine direkte biologische Verwandtschaft. Die Familienlinien verknüpfen die überwiegende Zahl der 40 Individuen $\mathrm{zu}$ einer Großfamilie. Damit scheint sichergestellt, dass Verwandtschaft ein Kriterium für die Belegung der Lichtensteinhöhle war (vgl. Schultes 2000, 115). Der hohe Verwandtschaftsgrad macht es sehr plausibel, dass es sich bei der Lichtensteinhöhle um eine Familienbegräbnisstätte handelte. 
Ein männliches Individuum (M2) konnte ermittelt werden, das zumindest das Alter seines Vaters erreichte (Schultes 2000). Zusätzlich lässt die Altersstruktur in einem Familienzweig darauf schließen, dass Mütter ihre Kinder überlebten. Aufgrund dessen ist sichergestellt, dass die Höhle nicht zu einem punktuellen Ereignis (=Kollektivtod) mit den Familienmitgliedern belegt worden ist. Diese Annahme wird durch den archäologischen Befund gestärkt, da die Knochen zum Zeitpunkt der Grabungen in unterschiedlichen Fundhorizonten lagen. Damit liegt ein längerer Belegungszeitraum der Höhle vor, was ein weiteres Indiz für einen Bestattungsplatz ist.

Zur Überprüfung, ob Verwandtschaft ein mögliches Opferkriterium bildete, müssten Verwandtschaftsanalysen an den Individuen aus den Opferstätten im Kyffhäuser durchgeführt werden (Schultes 2000, 113). Der archäologische Kontext hält dagegen eine bewusste Opferauswahl aus bestimmten Familien für unwahrscheinlich (Flindt 2001).

Für die Zukunft empfiehlt es sich, alle geborgenen Skelettelemente aus der Lichtensteinhöhle auszuzählen. Es wäre von Interesse, ob die Skelette tatsächlich vollständig in der Höhle vorhanden waren. Vor allem bei den Schädeln könnte es sich um ein unterrepräsentiertes Skelettelement handeln, da hier nur ca. 20 nahezu intakt gefunden wurden. Die fehlenden Schädel könnten jedoch auch stark fragmentiert in der Höhle vorliegen, da ebenfalls einzelne Schädelknochen, z.B. isolierte Felsenbeine, in größerer Zahl vorhanden sind. Dass den Schädeln ein wichtiger Stellenwert beigemessen wurde, könnte aus deren Fundsituation abgeleitet werden. In vielen Fällen wurden sie an sicheren Stellen entlang der Wände abgelegt (Flindt 2001, 71). Es ergibt sich die Frage, ob sie zum Schutz vor Zerstörung an die Seiten gelegt wurden, oder ob sie eine Rolle bei den kultischen Handlungen in der Höhle gespielt haben. Den Schädeln könnte eine wichtige Stellung bei der Interpretation in Richtung Menschenopferstätte beigemessen werden. Nach Burkert $(1972,14)$ wurden Schädel von Opfertieren aufbewahrt, als dauerhafte Zeugen der „Tat“ der „Heiligung“. Aus diesem Grund könnte das Fehlen einiger Schädel als Indiz gedeutet werden, dass sie nach einem rituellen Akt mit aus der Höhle genommen wurden. Dies hätten die Menschen bei einem regulären Bestattungsplatz ihrer Familienmitglieder vermutlich nicht getan. 
In den vorliegenden anthropologischen Ergebnissen weist vieles darauf hin, dass sich die Fundsituation in der Lichtensteinhöhle an einigen wesentlichen Punkten von Menschenopferstätten unterscheidet. Solange nicht aufgezeigt werden kann, dass Verwandtschaft in der Bronzezeit ein Opferkriterium darstellte, sollte die ermittelte Großfamilie ein deutliches und sicheres Indiz gegen die Menschenopferstätte und für einen Bestattungsplatz sein. Es konnte darüber hinaus kein Hinweis auf einen Nutzungswechsel festgestellt werden. Dies ist begründet in der Tatsache, dass die Familienmitglieder in allen Höhlenbereichen zu finden waren und dass nicht verwandte Individuen zwischen den Familienmitgliedern und nicht gesondert lagen. Von den Archäologen selbst wird zumindest für die Endphase der Lichtensteinhöhle die Nutzung als Bestattungsplatz einer sozial und wirtschaftlich bessergestellten Bevölkerungsschicht angenommen. 


\section{Zusammenfassung}

Die prähistorische Anthropologie befasst sich mit den Lebensbedingungen und Lebensweisen der Menschen vergangener Zeiträume. Im Fokus der anthropologischen Forschung liegt dabei die Aufklärung verwandtschaftlicher Beziehungen von historischen Bevölkerungen, da komplexe Sozialstrukturen Einblicke in kulturhistorische Fragestellungen geben können. Der sichere Verwandtschaftsnachweis gelingt in der Historischen Anthropologie, seit der Aufnahme von ancientDNAAnalysen in die anthropologischen Arbeitsmethoden. Am Skelettkollektiv aus der Lichtensteinhöhle kann gezeigt werden, wie Ableitungen aus molekulargenetischen Verwandtschaftsanalysen maßgeblich bei der Interpretation von anthropologischen und archäologischen Fragestellungen helfen können.

Die Lichtensteinhöhle in Südniedersachsen ist eine der herausragenden bronzezeitlichen Fundplätze Deutschlands. In der Höhle wurden Skelettüberreste gefunden, welche von den Archäologen auf 3000 Jahre datiert werden konnten. Die Skelette befanden sich nicht mehr in ihrem anatomischen Verband, sondern lagen in einem sehr stark dislozierten Zustand vor, was die Zuordnung der Knochenelemente $\mathrm{zu}$ einem bestimmten Individuum aus morphologischer Sicht nicht zuließ. Gingen die Archäologen aufgrund der Fundsituation in der Höhle anfangs von einer rituellen Menschenopferstätte aus, schlagen die molekulargenetischen Verwandtschaftsanalysen ein anderes prähistorisches Geschehen vor.

In dieser Studie wurden, an vorwiegend cranialen Skelettelementen, d.h. Zähne und Felsenbeinen, umfangreiche DNA-Typisierungen durchgeführt. Diese hatten zum Ziel, die einzelnen Skelette der Lichtensteinhöhle zu individualisieren und einen möglichen verwandtschaftlichen Bezug zwischen ihnen aufzuklären. Für diese Analysen wurden etablierte forensische DNA-Markersysteme angewendet. Eine Individualisierung gelingt sicher über die Bestimmung des genetischen Fingerabdrucks. Hierfür wurden autosomale STRs mithilfe des kommerziellen Typisierungskits AmpFISTR ${ }^{\circledR}$ ProfilerPlus $^{\mathrm{TM}}$ und eines selbst generierten Oktaplex-Analysesystems untersucht. Die Ergebnisse aus diesen Analysen ergaben eine Mindestindividuenzahl von 40. Darüber hinaus lassen sich, über den kodominaten Vererbungsweg der autosomalen STRs, direkte biologische Verwandtschaften, d.h. Eltern-Kind-Verbindungen, nachweisen. Innerhalb des Skelettkollektivs konnten so zwei Familiengruppen, mit acht und sieben 
Individuen, nachgewiesen werden, welche sich über drei Generationen erstrecken. In zwei weiteren Fällen wurden sog. Defizienzfälle, d.h. Familien in denen ein Elternteil fehlt, ermittelt. Die Ergebnisse aus den autosomalen Daten werden mit zwei weiteren Markern, welche familientypische und generationsübergreifende Muster anzeigen, unterstützt. Dabei handelt es sich um Y-chromosomale STRs und um die hypervariable Region (=HVR) des mitochondrialen Genoms. Die Y-STR-Analysen wurden mit dem PowerPlex ${ }^{\circledR}$ Y System Kit, die HVR-Analyse mit eigens etablierten Systemen durchgeführt. Die Ergebnisse aus diesen Untersuchungen halfen bei der genealogischen Rekonstruktion und verknüpften mehr als die Hälfte der Individuen zu einer Großfamilie. Darüber hinaus ließen sich zwei weitere Kleingruppen identifizieren, deren jeweilige Individuen ebenfalls in einem verwandtschaftlichen Verhältnis, z.B. Geschwister, zueinander stehen. Die Ergebnisse der Verwandtschaftsrekonstruktion legen Nahe, dass die Lichtensteinhöhle als Bestattungsplatz von einem weit verzweigten Familienclan genutzt wurde. Die Authentizität der Ergebnisse wird dabei, durch die Bestimmung des genetischen Fingerabdruckes, auf einem sehr hohen Niveau gesichert.

Die Aussagekraft der angewendeten genetischen Marker endete für die Lichtensteinhöhle nicht mit der Verwandtschaftsrekonstruktion. Die ermittelte Verwandtschaftsstruktur der Gruppe gibt Einblicke in deren soziale Organisation. Es konnte geschlussfolgert werden, dass die Kernfamilie, bestehend aus beiden Elternteilen und Kindern, auch in der Bronzezeit eine herausragende Bedeutung hatte und dass für die Sozialgemeinschaft das Verwandtschaftskonzept der kognaten Deszendenz verwirklicht sein sollte.

Aus dem direkten Vergleich der Variabilität ihrer maternalen und paternalen Linien konnte ein patrilokales Residenzverhalten der Gruppe bestimmt und damit auf ein patrilokales Heiratssystem geschlossen werden. Zusätzlich konnten Hinweise zur überregionalen Herkunft einzelner Familienlinien, z.B. in einem Fall nach Osteuropa, gefunden werden.

In zusätzlichen wissenschaftlichen Projekten sind an weiteren Skelettelementen genetische Fingerabdrücke generiert worden. Das Ziel bestand darin, die Skelettelemente den einzelnen Individuen zuzuordnen und somit die topographische Verteilung der Knochen in der Höhle aufzuzeigen, um Hinweise zum prähistorischen Eingang der Höhle und zur zeitlichen Ablagereihenfolge der Toten zu finden. Es konnte geschlussfolgert werden, dass die meisten Individuen ursprünglich im größten Höhlenabschnitt, dem Bernd-Saal, bestattet wurden und anschließend einige Individuen 
von dort in die hinteren Höhlenabschnitte verlagert wurden. Der ursprüngliche Eingang in die Höhe ist nach dieser Ergebnislage in der Nähe des Bernd-Saals zu vermuten. Des Weiteren sollten hier auch die letzten Leichen niedergelegt worden sein.

Die herausragend gute DNA-Erhaltung der 3000 Jahre alten Knochen aus der Lichtensteinhöhle, die eine Analyse von chromosomalen Markern erlaubt, ermöglichte in den letzten Jahren wissenschaftliche Studien, die das Skelettkollektiv als herausragendes genetisches Archiv ausweisen. Neben dem immungenetischen Marker CCR5 und dem Zytokin Interleukin-6, wurden Arbeiten zur Laktose(in)toleranz, Mukoviszidose, hereditären Hämochromatose und zur molekulargenetischen Blutgruppenbestimmung durchgeführt. Die Zusammenfassungen dieser Forschungsarbeiten geben einen Einblick in die Lebensbedingungen dieser prähistorischen Population. 


\section{Literatur}

Ajioka RS, Kushner JP (2002) Hereditary Hemochromatosis. Semin Hematol. 39(4):235-41.

Alonso A, Andelinovic S, Martin P, Sutlovic D, Erceg I, Huffine E, de Simon LF, Albarran C, Definis-Gojanovic M, Fernandez-Rodriguez A, Garcia P, Drmic I, Rezic B, Kuret S, Sancho M, Primorac D (2001) DNA typing from skeletal remains: evaluation of multiplex and megaplex STR systems on DNA isolated from bone and teeth samples. Croat Med J 42: 260-266

Andelinovic S, Sutlovic D, Erceg I, I, Skaro V, Ivkosic A, Paic F, Rezic B, DefinisGojanovic M, Primorac D (2005) Twelve-year experience in identification of skeletal remains from mass graves. Croat Med J 46: 530-539

Anderson S, Bankier AT, Barrell BG, de Bruijn MHL, Coulson AR, Drouin J, Eperon IC, Nierlich DP, Roe BA, Sanger F, Schreier PH, Smith AJH, Staden R, Young IG (1981) Sequence and organisation of the human mitochondrial genome. Nature 290, 457-465

Andrews RM, Kubacka I, Chinnery PF, Lightowlers RN, Turnbull DM, Howell N (1999) Reanalysis and revision of the Cambridge reference sequence for human mitochondrial DNA. Nat Genet 23: 147.

Ascádi G und Nemeskéri J (1970) History of Human lifespan and mortility. Akademiai Kiado, Budapest

Aufderheide AC, Rodríguez-Martin C (1998) The Cambridge Encyclopedia of Human Paleopatholgy. Cambridge University Press, Cambridge

Bär W, Brinkmann B, Budowle B, Carracedo A, Gill P, Holland M, Lincoln PJ, Mayr W, Morling N, Olaisen B, Schneider PM, Tully G, Wilson M (2000) DNA Commission of the International Society for Forensic Genetics: guidelines for mitochondrial DNA typing. Int J Legal Med 113: 193-196

Bär W, Brinkmann B, Budowle B, Carracedo A, Gill P, Lincoln P, Mayr W, Olaisen B (1997) DNA recommendations. Further report of the DNA Commission of the ISFH regarding the use of short tandem repeat systems. Int J Legal Med 110: 175-176

Barnes I, Matheus P, Shapiro B, Jensen D, Cooper A (2002) Dynamics of Pleistocene Population Extinctions in Beringian Brown Bears. Science 295: 2267-2270

Bennermo M, Held C, Stemme S, Ericsson CG, Silveira A, Green F, Tornvall P (2004) Genetic Predisposition of the Interleukin-6 Response to Inflammation: Implicationfor a Variety of Major Diseases? Clin Chem 50(11): 2136-2140

Binladen J, Wiuf C, Gilbert TP, Bunce M, Barnett R, Larson G, Greenwood AD, Haile J, Ho SWY, Hansen AJ, Willerslev E (2005) Assessing the fidelity of ancient DNA sequences amplified from nuclear genes. Genetics. 2005 Nov 19; [Epub ahead of print] 
Blatter RH, Jacomet S, Schlumbaum A (2002) Spelt-specific alleles in HMW glutenin genes from modern and historical European spelt (Triticum spelta L.). Theor Appl Genet 104: 329-337

Bohnhage I (2004) Vier enthauptete Ratsherren aus Zwickau - Identifikation der hochmittelalterlichen Bestattungen durch genetische Typisierung der Skelette. Staatsexamensarbeit, Universität Göttingen, Biologische Fakultät

Bosch E, Lee AC, Calafell F, Arroyo E, Henneman P, De Knijff P, Jobling MA (2002) High resolution Y chromosome typing: 19 STRs amplified in three multiplex reactions. Forensic Sci Int, 125: 42-51

Bramanti B, Hummel S, Chiarelli B, Herrmann B (2003) Ancient DNA Analysis of the Delta F508 Mutation. Human Biology 75, 1: 105-115

Bramanti B, Hummel S, Schultes T, Herrmann B (2000) STR allelic frequencies in a German skeleton collection. Anthrop Anz 58: 45-49

Brenner $\mathrm{CH}$ (1993) A note on paternity computation in cases lacking a mother. Transfusion 33: 51-54

Brinkmann B und Wiegand P (1997) DNA Technologie in der Medizinischen Kriminalistik. Verlag Schmidt-Römhild, Lübeck. 95; 52-55

Brinkmann B, Junge A, Meyer E, Wiegand P (1998b) Population Genetic Diversity in Relation to Microsatellite Heterogeneity. Human Mutation 11: 135-144

Brinkmann B, Klintschar M, Neuhuber F, Hühne J, Rolf B (1998a) Mutation Rate in Human Microsatellites: Influence of the Structure and Length of the Tandem Repeat. Am J Hum Genet 62: 1408-1415

Brown WM, George MJ, Wilson AC (1979) Rapid evolution of animal mitochondrial DNA. Proc. Natl. Acad. Sci. USA: 1967-1971

Budowle B, Masibay A, Anderson SJ (2001) STR primer concordance study. Forensic Sci Int 124: 47-54

Budowle B, Moretti TR, Niezgoda SJ, Brown BL (1998) CODIS and PCR-based short tandem repeat loci: Law enforcement tools. Second European Symposium on Human Identification: 73-88

Budowle B, Moretti TR, Baumstark AL, Defenbaugh DA, Keys KM (1999) Population data on the thirteen CODIS core short tandem repeat loci in African Americans, U.S. Caucasians, Hispanics, Bahamians, Jamaicans, and Trinidadians. J Forensic Sci 44: $1277-1286$

Burger J, Hummel S, Herrmann B (1997) Nachweis von DNA-Einzelkopien aus prähistorischen Zähnen. Liegemillieu als Faktor für den Erhalt von DNA. Anthrop Anz 55: 193-198

Burger J, Hummel S, Herrmann B, Henke W (1999) DNA preservation: a microsatellite-DNA study on ancient skeletal remains. Electrophoresis 20: 17221728 
Burger J, Schoon R, Zeike B, Hummel S, Herrmann B (2002) Species determination using Species-discriminating PCR-RFLP of Ancient DNA from Prehistoric Skeletal Remains. Ancient Biomol 4: 19-23

Burkert W (1972) Homo Necans. Walter de Gruyter Verlag, Berlin, New York

Burton ML, Moore CC, Whiting JWM (1996) Regions based on social structure. Curr. Anthropol 37:87-123

Butler JM (2001) Forensic DNA Typing. Biology \& Technology behind STR Markers. Academic Press, San Diego, San Francisco, New York, Boston, London, Sydney, Tokyo

Butler JM, Schoske R, Vallone PM, Kline MC, Redd AJ, Hammer MF (2002) A novel multiplex for simultaneous amplification of $20 \mathrm{Y}$ chromosome STR markers. Forensic Sci Int 129: 10-24

Byrd JH, Castner JL (2001) Insects of Forensic Importance. In Byrd JH, Castner JL (eds) CRC Press, Boca Raton London, New York, Washington D.C.Forensic Entomology - The Utility of Arthropods in Legal Investigations : 43-80

Cann RL, Stoneking M, Wilson AC (1987) Mitochondrial DNA and human evolution. Nature 325(6099):31-36.

Capelli C, Tschentscher F, Pascali VL (2003) "Ancient" protocols for the crime scene? Similarities and differences between forensic genetics and ancient DNA analysis. Forensic Sci Int 131: 59-64

Caramelli D, Lalueza-Fox C, Vernesi C, Lari M, Casoli A, Mallegni F, Chiarelli B, Dupanloup I, Bertranpetit J, Barbujani G, Bertorelle G (2003) Evidence for a genetic discontinuity between Neandertals and 24,000-year-old anatomically modern Europeans. Proc Natl Acad Sci U S A 100: 6593-6597

Cavalli-Sforza LL (1990) Cultural transmission and nutrition. World Rev. Nutr. Diet. 63:35-48

Cavalli-Sforza LL (1998) The DNA revolution in population genetics. Trends Genet 14: 60-65

Chakraborty R, Jin L, Zhong Y (1994) Paternity evaluation in cases lacking a mother and nondetectable alleles. Int J Leg Med 107: 127-131

Chakraborty R, Stivers DN, Su B, Zhong Y, Budowle B (1999) The utility of short tandem repeat loci beyond human identification: implications for development of new DNA typing systems. Electrophoresis 20: 1682-1696

Chen YS, Torroni A, Excoffier L, Santachiara-Benercetti AS, Wallace DC (1995) Analysis of mtDNA variation in African populations reveals the most ancient of all human continent-specific haplogroups. Am J Hum Genet 57:133-149

Clayton TM, Whitaker JP, Maguire CN (1995) Identification of bodies from the scene of a mass diseaster using DNA amplification of short tandem repeat (STR) loci. Forensic Sci Int 76: 7-15 
Clayton TM, Whitaker JP, Sparkes R, Gill P (1998) Analysis and interpretation of mixed forensic stains using DNA STR profiling. Forensic Sci Int 91: 55-70

Cohen ML (2000) Changing patterns of infectious disease. Nature 406: 762-767

Comas D, Calafell F, Mateu E, Perez-Lezaun A, Bosch E, Martinez-Arias R, Clarimon J, Facchini F, Fiori G, Luiselli D, Pettener D, Bertranpetit J. (1998) Trading Genes along the Silk Road: mtDNA sequences and the origin of Central Asian populations. Am J Hum Genet 63:1824-1838

Cone RW, Fairfax MR (1993) Protocol for ultraviolet irradiation of surfaces to reduce PCR contamination. PCR Meth Appl 3: 15-17

Cooper A, Poinar HN (2000) Ancient DNA: do it right or not at all. Science 289: 1139

Croll S (2005) Fingerprinting an Tibiae aus der Lichtensteinhöhle Molekulargenetische Analysen an short tandem repeats zur Aufdeckung von Verteilungsmustern isoliert vorliegender Skelettelemente aus einer bronzezeitlich gestörten Fundsituation. Diplomarbeit, Universität Göttingen, Biologische Fakultät

Dean M, Carrington M, Winkler C, Huttley GA, Smith MW, Allikmets R, Goedert JJ, Buchbinder SP, Vittinghoff E, Gomperts E, Donfield S, Vlahov D, Kaslow R, Saah A, Rinaldo C, Detels R, O'Brien SJ (1996) Genetic restriction of HIV-1 infection and progression to AIDS by deletion allele of the CKR5 structural gene. Science 273: 1856-1862

Derenko MV, Grzybowski T, Malyarchuk BA, Dambueva IK, Denisova GA, Czarny J, Dorzhu CM, Kakpakov VT, Miscicka-Sliwka D, Wozniak M, Zakharov IA (2003) Diversity of mitochondrial DNA lineages in South Siberia. Ann Hum Genet 67: 391-411

Dimo-Simonin N, Grange F, Taroni F, Brandt-Casadevall C, Mangin P (2000) Forensic evaluation of mtDNA in a population from south west Switzerland. Int J Legal Med 113:89-97

Dixon RA, Roberts CA (2001) Modern and ancient scourges: the application of ancient DNA to the analysis of tuberculosis and leprosy from archaeologically derived human remains. Ancient Biomol 3: 181-193

Dupuy BM, Stenersen M, Egeland T, Olaisen B (2004) Y-chromosomal microsatellite mutation rates: differences in mutation rate between and within loci. Hum Mutat 23: $117-124$

Edwards A, Civitello A, Hammond HA, Caskey CT (1991) DNA typing and genetic mapping with trimeric and tetrameric tandem repeats. Am J Hum Genet 49: 746756

Eggert M (2001) Prähistorische Archäologie: Konzepte und Methoden. A. Francke Verlag, Tübingen und Basel 
Elder JK, Souther EM (1987) Computer aided analysis of one-dimensional restriction fragment gels. In Biskop MJ, Rawlings CJ (Hrsg): Nucleic acid and protein sequence analysis. IRL Press, Oxford: 165-172

Endicott P, Gilbert MT, Stringer C, Lalueza-Fox C, Willerslev E, Hansen AJ, Cooper A (2003) The genetic origins of the Andaman Islanders. Am J Hum Genet 72: 178184

Faruque ASG, Mahalanabis D, Hoque SS, Albert MJ (1994) The relationship between ABO blood groups and susceptibility to diarrhea due to Vibrio cholerae 0139. Clinical Infectious Diseases $18: 827-828$

Fishman D, Faulds G, Jeffrey R, Mohamed-Ali V, Yudkin JS, Humphries S, Woo P (1998) The Effect of Novel Polymorphisms in the Interleukin-6 (IL-6) Gene on IL-6 Transcription and Plasma IL-6 Levels, and an Assoziation with SystemicOnset Juvenile Chronic Arthritis. J Clin Invest. 102(7): 1369-1376

Flindt S (1996a) Die Lichtensteinhöhle bei Osterode, Ldkr. Osterode am Harz. Eine Opferhöhle der jüngeren Bronzezeit im Gipskarst des südwestlichen Harzrandes.Berichte Die Kunde N.F.47 :435-466

Flindt S (1996b) Eine Opferhöhle der jüngeren Bronzezeit bei Osterode am Harz. In Wegner G (Hrsg) Leben - Glauben - Sterben. Bronzezeit in Niedersachsen.Eine niedersächsische Austellung zur Bronzezeit-Kampagne des Europarates. Isensee Verlag, Oldenburg: 219-232

Flindt S (1998) Die Lichtensteinhöhle. In Flindt S, Leiber C (Hrsg) Kulthöhlen und Menschenopfer im Harz, Ith und Kyffhäuser. Verlag Jörg Mitzkat, Holzminden: $50-80$

Flindt S (2001) Die Lichtensteinhöhle. In Flindt S, Knolle F, Fricke U (Hrsg) Höhlen im Westharz und Kyffhäuser: Geologie, Speläologie, Archäologie. Verlag Jörg Mitzkat, Holzminden: 62-85

Foster EA, Jobling MA, Taylor PG, Donelly P, de Knijff P, Mieremet R, Zerjal T, Tyler-Smith C (1998) Jefferson fathered slave's last child. Nature 396: 27-28

Francalacci, P, Bertranpetit, J, CalaFell, F, Underhill, P (1996) Sequence Diversity of the Control Region of Mitochondrial DNA in Tuscany and Its Implications for the Peopling of Europe 100:443-460

Fulge M (2005) Laktosetoleranz in der bronzezeitlichen Lichtensteinhöhle Molekulargenetischer Nachweis des Polymorphismus C/T 13910 an prähistorischer DNA. Staatsexamensarbeit, Universität Göttingen, Biologische Fakultät

Gagneux P, Boesch C, Woodruff DS (1997) Microsatellite scoring errors associated with nonivasive genotyping based on nuclear DNA amplified from shed hair. Mol Ecol 6: 861-868 
Gärtner S (2005) Fingerprinting an bronzezeitlichen Ossa radii - Molekulargenetische Analysen an short tandem repeats zur Aufdeckung von Verteilungsmustern isoliert vorliegender Skelettelemente aus einer gestörten Fundsituation. Staatsexamensarbeit, Universität Göttingen, Biologische Fakultät

Gerstenberger J (2002) Analyse alter DNA zur Ermittlung von Heiratsmustern in einer frühmittelalterlichen Bevölkerung. Dissertation, Universität Göttingen, Biologische Fakultät

Gerstenberger J, Hummel S, Schultes T, Häck B, Herrmann B (1999) Reconstruction of a historical genealogy by means of STR analysis and Y-haplotyping of ancient DNA. Eur J Hum Genet 7: 469-477

Geschwinde M (1988) Höhlen im Ith. Urgeschichtliche Opferstätten im südniedersächsischen Bergland. Verlag August Lax, Hildesheim

Gilbert MTP, Hansen AJ, Willerslev E, Rudbeck L, Barnes I, Lynnerup N, Cooper A (2003a) Characterization of genetic miscoding lesions caused by postmortem damage. Am J Hum Genet 72: 48-61

Gilbert MTP, Willerslev E, Hansen AJ, Barnes I, Rudbeck L, Lynnerup N, Cooper A (2003b) Distribution patterns of postmortem damage in human mitochondrial DNA. Am J Hum Genet 72: 32-47

Giles RE, Blanc H, Cann HM, Wallace DC (1980) Maternal inheritance of human mitochondrial DNA. Proc Natl Acad Sci USA 77: 6715-6719

Gill P, Brenner C, Brinkmann B, Budowle B, Carracedo A, Jobling MA, de Knijff P, Kayser M, Krawczak M, Mayr WR, Morling N, Olaisen B, Pascali V, Prinz M, Roewer L, Schneider PM, Sajantila A, Tyler-Smith C (2001) DNA commission of the International Society of Forensic Genetics: recommendations on forensic analysis using Y-chromosome STRs. Int J Legal Med 114: 305-309

Gill P, Ivanov PL, Kimpton C, Piercy R, Benson N, Tully G, Evett I, Hagelberg E, Sullivan K (1994) Identification of the remains of the Romanov family by DNA analysis. Nat Genet 6: 130-135

Gill P, Kimpton CP, Urquhart A, Oldroyd N, Millican ES, Watson SK, Downes TJ (1995) Automated short tandem repeat (STR) analysis in forensic casework - a strategy for the future. Electrophoresis 16: 1543-1552

Grimm H (1956) Altern, Lebensdauer, Krankheit und Tod bei vorgeschichtlichen und frühgeschichtlichen Bevölkerungsgruppen. Wissenschaftliche Annalen V/3: 171-180

Großkopf B (1990) Individualalterbestimmung mithilfe von Zuwachsringen im Zement bodengelagerter menschlicher Zähne. Zeitschrift für Rechtsmedizin 103: 351359

Grupe G, Christiansen K, Schröder I, Wittwer-Backofen U (2005) Anthropologie - Ein einführendes Buch. Springer Verlag, Heidelberg 
Gusmão L, Butler JM, Carracedo A, Gill P, Kayser M, Mayr WR, Morling N, Prinz M, Roewer L, Tyler-Smith C, Schneider PM (2005a) DNA Commission of the International Society of Forensic Genetics (ISFG): an update of the recommendations on the use of Y-STRs in forensic analysis. Int J Legal Med. 2005 Aug 26;:1-10

Gusmão L, Sánchez-Diz P, Calafell F, Martin P, Alonso CA, Álvarez-Fernández F, Alves C, Borjas-Fajardo L, Bozzo WR, Bravo ML, Builes JJ, Capilla J, Carvalho M, Castillo C, Catanesi CI, Corach D, Di Lonardo AM, Espinheira R, Fagundes de CarvalhoE, Farfán MJ, Figueiredo HP, Gomes I, Lojo MM, Marino M, Pinheiro MF, Pontes ML, Prieto V, Ramos-Luis E, Riancho JA, Souza Góes AC, Santapa OA, Sumita DR, Vallejo G, Rioja V, Vide MC, Viera da Silva CI, Whittle MR, Zabala W, Zarabeitia MT, Alonso A, Carracedo A, Amorim A (2005b) Mutation Rates at Y-Chromosome Specific Microsatellites. Human Mutation 26(6): 520-528

Haack K, Hummel S, Herrmann B (2000) Ancient DNA fragments longer than 300 bp. Anthrop Anz 58: 51-56

Haak W, Forster P, Bramanti B, Matsumura S, Brandt G, Tänzer M, Villems R, Renfrew C, Gronenborn D, Alt, KW, Burger J (2005) Ancient DNA from the First European Farmers in 7500-Year-Old Neolithic Sites. Science 310: 10161018

Hamilton G, Stoneking M, Excoffier L (2005) Molecular analysis reveals tighter social regulation of immigration in patrilocal populations than in matrilocal populations. PNAS 102, 21:7476-7480

Handt O, Richards M, Trommsdorf M, Kilger C, Simanainen J, Georgiev O, Bauer K, Stone A, Hedges R, Schaffner W, Utermann G, Sykes B, Pääbo S (1994) Molecular genetic analyses of the Tyrolean Ice Man. Science 264: 1775-1778

Hansson GC (1988) Cystic fibrosis and chloride-secreting diarrhoea. Nature 23; 333(6175): 711.

Hauser G, DeStefano GF (1989) Epigenetic Variants of the Human Skull. Stuttgart, Germany

Herrmann B, Grupe G, Hummel S, Piepenbrink H, Schutkowski H (1990) Prähistorische Anthropologie. Springer Verlag, Heidelberg

Herrmann B, Hummel S (1993) Ancient DNA. Recovery and analysis of genetic material from palaeontological, archaeological, museum, medical, and forensic specimens. Springer New York.

Herrmann B, Hummel S (2003) Ancient DNA can identify disease elements. In Greenblatt CL, Spigelman M (eds) Emerging pathogens. Archaeology, ecology $\&$ evolution of infectious disease. Oxford University Press, Oxford, NewYork: $143-150$ 
Herrmann B, Hummel S, Bramanti B, Gerstenberger J, Schultes T (2001) Genealogische Rekonstruktionen durch DNA-Analysen an historischen Skelettserien. Nova Acta Leopoldina NF 84, Nr.320: 21-33

Higley LG, Haskell NH (2001) Insect Development and Forensic Entomology. In Byrd JH, Castner JL (eds) CRC Press, Boca Raton London, New York, Washington D.C.Forensic Entomology - The Utility of Arthropods in Legal Investigations. : 287-302

Hite JM, Eckert KA, Cheng KC (1996) Factors affecting fidelity of DNA synthesis during PCR amplification of d(C-A)n d(G-T)n microsatellite repeats. Nucleic Acids Res 24: 2429-2434

Hofreiter M, Jaenicke V, Serre D, von Haeseler A, Pääbo S (2001) DNA sequences from multiple amplifications reveal artifacts by cytosine deamination in ancient DNA. Nucleic Acids Res 29: 4793-4799

Holland MM, Cave CA, Holland CA, Bille TW (2003) Development of a quality, high throughput DNA analysis procedure for skeletal samples to assist with the identification of victims from the World Trade Center attacks. Croat Med J 44: 264-272

Holland MM, Fisher DL, Mitchell LG, Rodriquez WC, Canik JJ, Merril CR, Weedn VW (1993) Mitochondrial DNA sequence analysis of human skeletal remains: identification of remains from the Vietnam war. J Forensic Sci 38: 542-553

Hühne-Osterloh (1987) Pathologische und subpathologische Veränderungen an Skeletten on Kindern und Jugendlichen des Hochmittelalterlichen Friedhofes von Schleswig, Rathausmarkt. Diplomarbeit Göttingen, Biologische Fakultät

Hummel S (2003) Ancient DNA Typing. Methods, Strategies and Applications. Springer Verlag, Berlin, Heidelberg, New York

Hummel S, Bramanti B, Schultes T, Kahle M, Haffner S, Herrmann B (2000) Megaplex DNA typing can provide a strong indication of the authenticity of ancient DNA amplifications by clearly recognizing any possible type of modern contamination. Anthrop Anz 58: 15-21

Hummel S, Herrmann B (1996) aDNA typing for reconstruction of kinship. Homo 47: 215-222

Hummel S, Herrmann B, Rameckers J, Müller D, Sperling K, Neitzel H, Tönnies H (1999b) Proving the authenticity of ancient DNA (aDNA) by comparative genome hybridization (CGH). Naturwissenschaften 86:500-503

Hummel S, Lassen C, Herrmann B, Schön MD (1995) aDNA-Analyse an Knochenproben von einem Gräberfeld des 4./5. Jhs. n. Chr. an der Fallward bei Wremen (Ldkr. Cuxhaven). Archä Korrespondenzbl 25: 243-252

Hummel S, Schmidt D, Kahle M, Herrmann B (2002) ABO blood group genotyping of ancient DNA by PCR-RFLP. Int J Legal Med 116: 327-333 
Hummel S, Schmidt D, Kremeyer B, Herrmann B, Oppermann M (2005) Detection of the CCR5- $\Delta 32$ HIV resistance gene in Bronze Age skeletons. Genes and Immunity 6, 371-374

Hummel S, Schultes T (2000) From skeletons to fingerprints - STR typing of ancient DNA. Ancient Biomol 3 : 103-116

Hummel S, Schultes T, Bramanti B, Herrmann B (1999a) Ancient DNA profiling by megaplex amplifications. Electrophoresis 20: 1717-1721

Hummel S, Schutkowski H, Rameckers J, Grupe G, Herrmann B (unveröffentlicht) Vereinfachtes Verfahren zur histologischen Altersdiagnose. Göttingen, München

Jaenicke-Despres V, Buckler ES, Smith BD, Gilbert MT, Cooper A, Doebley J, Paabo S (2003) Early allelic selection in maize as revealed by ancient DNA. Science 302: 1206-1208

Jeffreys AJ, Allen MJ, Hagelberg E, Sonnberg A (1992) Identification of the skeletal remains of Josef Mengele by DNA analsis. Forensic Sci Int 56: 65-76

Jobling MA, Pandya A, Tyler-Smith C (1997) The Y chromosome in forensic analysis and paternity testing. Int J Legal Med 110: 118-124

Jockenhövel A (1994) An der Schwelle der Geschichte - Bronzezeit als historische Epoche. In Jockenhövel A, Kubach W (Hrsg) Bronzezeit in Deutschland. C. Konrad Theiss Verlag GmbH \& Co., Stuttgart: 7-10

Jockenhövel A (1994) Raum und Zeit - Gliederung der Bronzezeit. In Jockenhövel A, Kubach W (Hrsg) Bronzezeit in Deutschland. C. Konrad Theiss Verlag GmbH \& Co., Stuttgart: 11-14

Jockenhövel A (1994) Herd, Haus und Hof - Siedlungswesen. In Jockenhövel A, Kubach W (Hrsg) Bronzezeit in Deutschland. C. Konrad Theiss Verlag GmbH \& Co., Stuttgart: $18-121$

Jockenhövel A (1994) Schutz und Repräsentation: Burgenbau - Eine Neuerung im Siedlungswesen. In Jockenhövel A, Kubach W (Hrsg) Bronzezeit in Deutschland. C. Konrad Theiss Verlag GmbH \& Co., Stuttgart: 22-26

Jockenhövel A (1994) Umwelt - Landwirtschaft - Ernährung. In Jockenhövel A, Kubach W (Hrsg) Bronzezeit in Deutschland. C. Konrad Theiss Verlag GmbH \& Co., Stuttgart: 30-35

Kaestle FA, Smith DG (2001) Ancient mitochondrial DNA evidence for prehistoric population movement: the Numic expansion. Am J Phys Anthropol 115: 1-12

Kaiser J (2004) American Society of Human Genetics meeting. Ural farmers got milk gene first? Science 306: 1284-1285 
Kaiser P, Rothwell L, Goodchild M, Bumstead N (2004) The chicken proinflammatory cytokines interleukin $1 \beta$ and Interleukin-6: differences in gene structure and genetic location compared with their mammalian orthologues. Animal Genetics 35(3): $169-175$

Kallioniemi A, Kallioniemi O-P, Sudar D, Rutovitz D, Gray JW, Waldmann F, Pinkel D (1992) Comparative genome hybridization for molecular cytogenetic analysisof solid tumors. Science 258: 818-821

Kayser M, Caglià A, Corach D, Fretwell N, Gehrig C, Graziosi G, Heidorn F, Herrmann S, Herzog B, Hidding M, Honda K, Jobling M, Krawczak M, Leim K, Meuser S, Meyer E, Oesterreich W, Pandya A, Parson W, Penacino G (1997a) Evaluation of Y-chromosomal STRs: a multicenter study. Int J Legal Med 110: 125-129

Kayser M, Kittler R, Erler A, Hedman M, Lee AC, Mohyuddin A, Mehdi SQ, Rosser Z, Stoneking M, Jobling MA, Sajantila A, Tyler-Smith C (2004) A Comprehensive Survey of Human Y-Chromosomal Microsatellites. Am J Hum Genet 74:11831197

Kayser M, de Knijff P, Dieltjes P, Krawczak M, Nagy M, Zerjal T, Pandya A, TylerSmith C, Roewer L (1997b) Applications of microsatellite-based Y chromosome haplotyping. Electrophoresis 18: 1602-1607

Kayser M, Lao O, Anslinger K, Augustin C, Bargel G, Edelmann J, Elias S, Heinrich M, Henke J, Henke L, Hohoff C, Illing A, Jonkisz A, Kuzniar P, Lebioda A, Lessig R, Lewicki S, Maciejewska A, Monies DM, Pawlowski R, Poetsch M, Schmid D, Schmid S, Schmidt U, Schneider PM, Stradmann-Bellinghausen B, Szibor R, Wegener R, Wozniak M, Zoledziewska M, Roewer L, Dobosz T, Ploski R (2005) Significant genetic differentiation between Poland and Germany follows present-day political borders, as revealed by Y-chromosome analysis. Hum Genet 117: 428-443

Kayser M, Roewer L, Hedman M, Henke L, Henke J, Brauer S, Kruger C, Krawczak M, Nagy M, Dobosz T, Szibor R, de Knijff P, Stoneking M, Sajantila A (2000) Characteristics and frequency of germline mutations at microsatellite loci from the human Y chromosome, as revealed by direct observation in father/son pairs. Am J Hum Genet 66: 1580-1588

Kayser M, Sajantila A (2001) Mutations at Y-STR loci: implications for paternity testing and forensic analysis. Forensic Sci Int 118: 116-121

Kerem B, Rommens JM, Buchanan JA, Markiewicz D, Cox TK, Chakravarti A, Buchwald M, Tsui LC (1989) Identification of the cystic fibrosis gene: genetic analysis. Science 8; 245(4922):1073-80.

Kimpton CP, Fisher D, Watson SK, Adams M, Urquhart AJ, Lygo JE, Gill P (1994) Evaluation of an automated DNA profiling system employing multiplex amplification of four tetrameric STR loci. Int J Legal Med 106: 302-311

Kimpton CP, Gill P, Walton A, Urquhart A, Millican ES, Adams M (1993) Automated DNA profiling employing multiplex amplification of Short Tandem Repeat loci. PCR Meth Appl 3: 13-22 
Kitchin PA, Szotyori Z, Fromholc C, Almond N (1990) Avoidance of false positives. Nature 344: 201

Kleindorp $\mathrm{R}$ (in prep.) Vergleichende Untersuchung der DNA-Erhaltung an verschiedenen Skelettelementen. Diplomarbeit, Universität Göttingen, Biologische Fakultät

Klingner S (2005) Fingerprinting an Calcanei aus der Lichtensteinhöhle Molekulargenetische Analysen an short tandem repeats zur Aufdeckung von Verteilungsmustern isoliert vorliegender Skelettelemente aus einer bronzezeitlich gestörten Fundsituation. Diplomarbeit, Universität Göttingen, Biologische Fakultät

Kraemer S (2000) The fragile man. BMJ 321; 1609-1612

Kratzer A, Bär W (1997) Forensische Hämogenetik - Abstammungsbegutachtung. Therapeutische Umschau 54(5): 280-285

Krause S (2006) Genetische Analysen zur Bestimmung der Allelfrequenz von C282Y/H63D (erbliche Eisenspeicherkrankheit) an Skelettelementen eines bronzezeitlichen Fundkomplexes. Staatsexamensarbeit, Universität Göttingen, Biologische Fakultät

Krenke BE, Viculis L, Richard ML, Prinz M, Milne SC, Ladd C, Gross AM, Gornall T, Frappier JR, Eisenberg AJ, Barna C, Aranda XG, Adamowicz MS, Budowle B (2005) Validation of male-specific, 12-locus fluorescent short tandem repeat (STR) multiplex. Forensic Sci Int 151: 111-124

Krings M, Stone A, Schmitz RW, Krainitzki H, Stoneking M, Pääbo S (1997) Neandertal DNA Sequences and the Origin of Modern Humans. Cell 90: 19-30

Kubach W (1994) Der Weg ins Totenreich - Bestattungs- und Beigabensitten. In Jockenhövel A, Kubach W (Hrsg) Bronzezeit in Deutschland. C. Konrad Theiss Verlag GmbH \& Co., Stuttgart: 48-53

Kubach W (1994) Vergraben, versenkt, verbrannt - Opferpfunde und Kultplätze. In Jockenhövel A, Kubach W (Hrsg) Bronzezeit in Deutschland. C. Konrad Theiss Verlag GmbH \& Co., Stuttgart: 65-74

Kwok S (1990) Procedures to minimize PCR-product carry-over. In: Innis MA, Gelfand DH, Sninsky JJ, White TJ (eds) PCR Protocols: A Guide to Methods and Applications. Accademic Press, San Diego, pp 142-145

Lambert DM, Ritchie PA, Millar CD, Holland B, Drummond AJ, Baroni C (2002) Rates of Evolution in Ancient DNA from Adélie Pengiuns. Science 295: 22702273

Lassen C, Hummel S, Herrmann B (2000) Molecular sex identification of stillborn and neonate individuals ("Traufkinder") from the burial site Aegerten. Anthropol Anz 58: 1-8 
Leonard JA, Wayne RK, Wheeler J, Valadez R, Guillen S, Vila C (2002) Ancient DNA evidence for Old World origin of New World dogs. Science 298: 1613-1616

Libert F, Cochaux P, Beckman G, Samson M, Aksenova M, Cao A, Czeizel A, Claustres M, de la Rúa C, Ferrari M, Ferrec C, Glover G, Grinde B, Güran S, Kucinskas V, Lavinha J, Mercier B, Ogur G, Peltonen L, Rosatelli C (1998) The deltaccr5 mutation conferring protection against HIV-1 in Caucasian populations has a single and recent origin in Northeastern Europe. Hum Mol Genet 7: 399-406

Litt M, Luty JA (1989) A hypervariable microsatellite revealed by in vitro amplification of a dinucleotide repeat within the cardiac muscle gene. Am J Hum Genet 44: $397-401$

Loreille O, Orlando L, Patou-Mathis M, Philippe M, Taberlet P, Hänni C (2001) Ancient DNA analysis reveals divergence of the cave bear, Ursus spelaeus, and brown bear, Ursus arctos, lineages. Curr Biol 11: 200-203

Lowe A, Harris S, Ashton P (2004) Ecological Genetics. Design, Analysis and Application. Blackwell Publishing Ltd.

Lutz S, Weisser HJ, Heizmann J, Pollak S (1996) mtDNA as a tool for identification of human remains. Identification using mtDNA. Int J Legal Med 109: 205-209

Lutz S, Weisser H-J, Heizmann J, Pollak S (1998) Location and frequency of polymorphic positions in the mtDNA control region of individuals from Germany. Int J Legal Med 111:67-77

Macaulay V, Richards M, Hickey E, Vega, E, Cruciani F, Guida V, Scozzari R, BonnéTamir B, Sykes B, Torroni A (1999) The Emerging Tree of West Eurasian mtDNAs: A Synthesis of Control-Region Sequences and RFLPs. Am J Hum Genet 64:232-249

Maier R, Linke FA (1985) Die Lichtensteinhöhle bei Dorste, Stadt Osterode am Harz. pp 150-154

Mayer JF (1992) Metabolische und sozialmedizinische Gesichtspunkte der Hämochromatose. Disseration, Würzburg.

Melton T, Nelson K (2001) Forensic mitochondrial DNA analysis: two years of commercial casework experience in the United States. Croat Med J 42(3):298303.

Müller (2002) Design einer Multiplex-PCR zur Typisierung von Y-STR Haplotypen aus degradierter DNA. Diplomarbeit, Universität Göttingen, Biologische Fakultät

Montiel R, Malgosa A, Francalacci P (2001) Authenticating ancient human mitochondrial DNA. Hum Biol 73: 689-713

Montpetit SA, Fitch IT, O'Donnell PT (2005) A simple automated instrument for DNA extraction in forensic casework. J Forensic Sci 50: 555-563 
Mulligan CJ, Hunley K, Cole S, Long JC (2004) Population genetics, history, and health patterns in native americans. Annu Rev Genomics Hum Genet 5:295-315

Mullis KB, Faloona FA (1987) Specific Synthesis of DNA in vitro via a PolymeraseCatalysed Chain Reaction. Meth Enzymol 155: 335-350

Murken J, Cleve H (1996) Humangenetik. Ferdinand Enke Verlag, Stuttgart

Mußlick D (2005) Fingerprinting an humeri aus der Lichtensteinhöhle Molekulargenetische Analysen an short tandem repeats zur Aufdeckung von Verteilungsmustern isoliert vorliegender Skelettelemente aus einer bronzezeitlich gestörten Fundsituation. Diplomarbeit, Universität Göttingen, Biologische Fakultät

Nentwig W (1995) Humanökologie. Fakten - Argumente - Ausblicke. Springer Verlag, Heidelberg

Oota H, Saitou N, Matsushita T, Ueda S (1995) A Genetic Study of 2000 Year-Old Human Remains From Japan Using Mitochondrial DNA Sequences. Am J Phys Anthropol 98: 133-145

Oota H, Settheetham-Ishida W, Tiwawech D, Ishida T, Stoneking M (2001) Human mtDNA and Y-chromosome variation is correlated with matrilocal versus patrilocal residence. Nat Genet 29: 20-21

Orlando L, Bonjean D, Bocherens H, Thenot A, Argant A, Otte M, Hanni C (2002) Ancient DNA and the population genetics of cave bears (Ursus spelaeus) through space and time. Mol Biol Evol 19: 1920-1933

Ortner DJ, Putschar WGJ (1985) Identification of Pathological conditions in human skeletal remains. Smithsonian Institution press, Washington)

Ovchinnikov IV, Götherström A, Romanova GP, Kharitonov VM, Lidén K, Goodwin W (2000) Molecular analysis of Neanderthal DNA from the northern Caucasus. Nature 404: 490-493

Pääbo S, Gifford JA, Wilson AC (1988) Mitochondrial DNA sequences from a 7000year old brain. Nucleic Acids Res 16: 9775-9787

Pakendorf B, Stoneking M (2005) Mitochondrial DNA and Human Evolution. Annu Rev Genomics Hum Genet 6:165-183

Parkin R, Stone L (2004) General Introduction. In Parkin R, Stone L (eds) Kinship and Family. An Anthropolgical Reader.Blackwell Publishing Ltd, Malden

Parson W, Parsons TJ, Scheithauer R, Holland MM (1998) Population data for 101 Austrian Caucasian mitochondrial DNA d-loop sequences: application of mtDNA sequence analysis to a forensic case. Int J Legal Med 111:124-32

Pascali VL, Dobosz M, Brinkmann B (1999) Coordinating Y-chromosomal STR research for the Courts. Int J Legal Med 112: 1 
Pearson (1899) Mathematical contributions of the theory of evolution. V. On the reconstruction of the stature of prehistoric races. Phil Transact R Soc London. Ser A Vol 192: 169-245

Pereira L, Richards M, Goios A, Alonso A, Albarran C, Garcia O, Behar DM, Golge M, Hatina J, Al-Gazali L, Bradley DG, Macaulay V, Amorim A (im Druck) Evaluating the forensic informativeness of mtDNA haplogroup $\mathrm{H}$ sub-typing on a Eurasian scale. Forensic Sci Int

Pfeiffer H, Brinkmann B, Huhne J, Rolf B, Morris AA, Steighner R, Holland MM, Forster P (1999) Expanding the forensic German mitochondrial DNA control region database: genetic diversity as a function of sample size and microgeography. Int J Legal Med 112:291-298

Piercy, R, Sullivan, K, Benson, N, Gill, P (1993) The application of mitochondrial DNA typing to the study of white Caucasian genetic identification. Int. J. Leg. Med. 106:85-90

Ploski R, Wozniak M, Pawlowski R, Monies DM, Branicki W, Kupiec T, Kloosterman A, Dobosz T, Bosch E, Nowak M, Lessig R, Jobling MA, Roewer L, Kayser M (2002) Hum Genet 110: 592-600

Prinz M, Boll K, Baum H, Shaler B (1997) Multiplexing of Y chromosome specific STRs and performance for mixed samples. Forensic Sci Int 85: 209-218

Puder Y (2005) Molekulargenetische Identifikation der Allelhäufigkeit eines immungenetischen Markers der IL-6-Promoterregion bei bronzezeitlichen Individuen Individuen aus Mitteleuropa. Diplomarbeit, Universität Göttingen, Biologische Fakultät

Qiagen (1998) The Qiagen Guide to Template Purification and DNA Sequencing (2nd Edition). Qiagen, Hilden

Rafi A, Spigelman M, Stanford J, Lemma E, Donoghue H, Zias J (1994) Mycobacterium leprae DNA from ancient bone detected by PCR. Lancet 343: 1360-1361

Raport CJ, Gosling J, Schweickart VL, Gray PW, Charo IF (1996) Molecular cloning and functional characterization of a novel human $\mathrm{CC}$ chemokine receptor (CCR5) for RANTES, MIP-1 $\beta$, and MIP- $1 \alpha$. Journal of Biological Chemistry 271: 17161-17166

Renz-Polster H, Krautzig S, Braun J (2004) Basislehrbuch Innere Medizin-kompaktgreifbar-verständlich. Urban Fischer, München, Jena.

Richards M, Côrte-Real H, Forster P, Macauly V, Wilkinson-Herbots H, Demaine A, Papiha S, Hedges R, Bandelt HJ, Sykes B (1996) Paleolithic ans Neolithic Lineages in the European Mitochondrial Gene Pool. Am J Hum Genet 59: 185203

Richards MB, Macaulay V (2001) The Mitochondrial Gene Tree Comes of Age. Am. J. Hum. Genet. 68:1315-1320 
Richards MB, Macaulay VA, Bandelt H-J, Sykes BC (1998) Phylogeography of mitochondrial DNA in western Europe. Ann Hum Genet 62 ( Pt 3): 241-260

Richards M, Macaulay V, Hickey E, Vega E, Sykes B, Guida V, Rengo C, Sellitto D, Cruciani F, Kivisild T, Villems R, Thomas M, Rychkov S, Rychkov O, Rychkov Y, Golge M, Dimitrov D, Hill E, Bradley D, Romano V, Cali F, Vona G, Demaine A, Papiha S, Triantaphyllidis C, Stefanescu G, Hatina J, Belledi M, Di Rienzo A, Novelletto A, Oppenheim A, Norby S, Al-Zaheri N, SantachiaraBenerecetti S, Scozari R, Torroni A, Bandelt HJ. (2000) Tracing European Founder Lineages in the Near Eastern mtDNA Pool. Am. J. Hum. Genet. 67: $1251-1276$

Richards M, Macaulay V, Torroni A, Bandelt HJ (2002) In search of geographical patterns in European mitochondrial DNA. Am J Hum Genet 71:1168-74.

Robin ED, Wong R (1988) Mitochondrial DNA molecules and virtual number of mitochondria per cell in mammalian cells. J. Cell. Physiol. 136:507-13

Roewer L, Arnemann J, Spurr NK, Grzeschik KH, Epplen JT (1992) Simple repeat sequences on the human $\mathrm{Y}$ chromosome are equally polymorphic as their autosomal counterparts. Hum Genet 89: 389-394

Roewer L, Croucher PJP, Willuweit S, Lu TT, Kayser M, Lessig R, de Knijff P, Jobling MA, Tyler-Smith C, Krawczak M (2005) Signature of recent historical events in the Eurpean Y-chromosomal STR haplotype distribution. Hum Genet 116: 279291

Roewer L, Krawczak M, Willuweit S, Nagy M, Alves C, Amorim A, Anslinger K, Augustin C, Betz A, Bosch E, Cagliá A, Carracedo A, Corach D, Dekairelle A, Dobosz T, Dupuy BM, Füredi S, Gehrig C, Gusmao L, Henke J (2001) Online reference database of European Y-chromosomal short tandem repeat (STR) haplotypes. Forensic Sci Int 118: 106-113

Rolf B, Keil W, Brinkmann B, Roewer L, Fimmers R (2001) Paternity testing using YSTR haplotypes: assigning a probability for paternity in cases of mutations. Int $\mathrm{J}$ Legal Med 115: 12-15

Rosenbaum H (1998) Verwandtschaft in hstorischer Perspektive. In Wagner M, Schütze Y (Hrsg) Verwandtschaft. Sozialwissenschaftliche Beiträge zu einem vernachlässigten Thema. Ferdinand Enke Verlag, Stuttgart: 17-33

Rösing FW (1986) Kith or kin? On the feasibility of kinship reconstructions in skeletons. In: David AR (ed) Science in Egyptology. Manchester University Press, Manchester, pp 223-237

Rudin N, Inman K (2002) An Introduction to Forensic DNA Analysis. Second Edition. CRC Press, Boca Raton, London, New York, Washington D.C.

Ruitberg CM, Reeder DJ, Butler JM (2001) STRBase: a short tandem repeat DNA database for the human identity testing community. Nucleic Acids Res 29: 320322 
Saiki RK, Scharf S, Faloona F, Mullis KB, Horn GT, Erlich HA, Arnheim N (1985) Enzymatic amplification of P-globulin genomic sequences and restriction site analysis for diagnosis of sickle cell anemia. Science 230: 1350-1354

Sanger F, Nicklen S, Coulson AR (1977) DNA sequencing with chain-terminating inhibitors. Proc Natl Acad Sci USA 74: 5463-5467

Schilz F, Hummel S, Herrmann B (2004) Desing of a multiplex PCR for genotyping 16 short tandem repeats in degraded DNA samples. Anthrop Anz 62: 369-378

Schlenk J, Seidl S, Braunschweiger G, Betz P, Lederer T (2004) Development of a 13locus PCR multiplex system for paternity testing. Int J Legal Med 118: 55-61

Schmerer W, Hummel S, Herrmann B (1997) Reproduzierbarkeit von aDNA-typing. Anthrop Anz 55: 199-206

Schmerer WM, Hummel S, Herrmann B (2000) STR-genotyping of archaeological human bone: experimental design to improve reproducibility by optimisation of DNA extraction. Anthrop Anz 58: 29-35

Schmidt D (2004) Entwicklung neuer Markersysteme für die ancient DNA-Analyse. Erweiterung des molekulargenetischen Zugangs $\mathrm{zu}$ kultur- und sozialgeschichtlichen Fragestellungen der Prähistorischen Anthropologie. Dissertation, Universität Göttingen, Biologische Fakultät

Schmidt D, Hummel S, Herrmann B (2003) Brief: Communication: Multiplex X/YPCR Improves Sex Identification in aDNA Analysis. Amer J of Phys Anthrop 121: 337-341

Schmidt T, Hummel S, Herrmann B (1995) Evidence of contamination in PCR laboratory disposables. Naturwissenschaften 82: 423-431

Schmitz RW, Serre D, Bonani G, Feine S, Hillgruber F, Krainitzki H, Paabo S, Smith FH (2002) The Neandertal type site revisited: interdisciplinary investigations of skeletal remains from the Neander Valley, Germany. Proc Natl Acad Sci U S A 99: $13342-13347$

Scholten A (2006) Genetische Analysen zur Bestimmung der Allelfrequenz von Delta F508 an menschlichen Skelettelementen eines bronzezeitlichen Fundkomplexes. Diplomarbeit, Universität Göttingen, Biologische Fakultät

Scholz M, Hengst S, Broghammer M, Pusch CM (2001) Intrapopulational relationships in ancient societies: a multidisciplinary study. Z Morphol Anthropol 83: 5-21

Schoon R (2003) Vorläufiger Abschlussbericht über die Untersuchungen Tierknochenresten aus der Lichtensteinhöhle bei Dorste am Harz. Göttingen

Schütt R (2005) Molekulargenetische Methoden zur Individualbefundung und Verwandtschaftsrekonstruktion am Beispiel einer keltischen Sonderbestattung aus Manching. Diplomarbeit, Universität Göttingen, Biologische Fakultät 
Schütze Y, Wagner M (1998) Verwandtschaft - Begriff und Tendenzen der Forschung. In Wagner M, Schütze Y (Hrsg) Verwandtschaft. Sozialwissenschaftliche Beiträge zu einem vernachlässigten Thema. Ferdinand Enke Verlag, Stuttgart: 716

Schultes T (1997) Zuordnung isolierter Skelettelemente mittels Typisierung von alter DNA. Diplomarbeit, Göttingen, Biologische Fakultät

Schultes T (2000) Typisierungen alter DNA zur Rekonstruktion von Verwandtschaft in einem bronzezeitlichen Skelettkollektiv. Dissertation, Universität Göttingen, Cuvillier Verlag

Schultes T, Hummel S, Herrmann B (1997) Zuordnung isolierter Skelettelemente mittels aDNA-typing. Anthrop Anz 55: 207-216

Schultz M (1994) Leben, Krankheit und Tod - Skelettfunde als Spiegel der Lebensbedingungen. In Jockenhövel A, Kubach W (Hrsg) Bronzezeit in Deutschland. C. Konrad Theiss Verlag GmbH \& Co., Stuttgart: 15-17

Schutkowski H, Grupe G (1997) Zusammenhänge zwischen Cribra orbitalia, archäometrischen Befunden am Skelett und Habitatbedingungen. Anthrop Anz 55: 155-166,

Schutkowski H, Hummel S (1991) Vorgeschichtliche Bevölkerungen in SchleswigHolstein. Leichenbranduntersuchungen von Urnenfriedhöfen Mittel- und Ostholsteins im diachronen Vergleich. In Offa. Berichte und Mitteilungen zur Urgeschichte, Frühgeschichte und Mittelalterarchäologie, Band 48. Karl Wachholtz Verlag, Neumünster:133-262

Schwartz M, Vissing J. (2003) New patterns of inheritance in mitochondrial disease. Biochem Biophys Res Commun. 17;310(2):247-51.

Shapiro B, Sibthorpe D, Rambaut A, Austin J, Wragg GM, Bininda-Emonds ORP, Lee PLM, Cooper A (2002) Flight of the Dodo. Science 295: 1683

Siemoneit B (1996) Das Kind in der Bronzezeit. Archäologische und anthropologische Befunde aus Niedersachsen. Die Kunde N. F. 47, 341-371

Simoni L, Calafell F, Pettener D, Bertranpetit J, Barbujani G. (2000) Geographic patterns of mtDNA diversity in Europe. Am J Hum Genet 66:262-78

Smith KG (1986) A manual of forensic entomology. The trustees of british museum. London

Smouse PE, Chakraborty R (1986) The use of restriction fragment length polymorphisms in paternity analysis. Am J Hum Genet 38(6):918-939

Speitel S, Walter D (1999) Bronze- Faszination des goldenen Glanzes. In Dušek S (Hrsg) Ur- und Frühgeschichte Thüringens. Konrad Theiss Verlag GmbH, Stuttgart. 71-94 
Stauch J (2006) Die Lichtensteinhöhle im Harz - Acrhäologisch-anthropologische Untersuchungen anhand isolierter Skelettreste eines Individuums mit Trepanation aus einem bronzezeitlichen Skelettkollektiv. Staatsexamensarbeit, Universität Göttingen, Biologische Fakultät

Stephens JC, Reich DE, Goldstein DB, Shin HD, Smith MW, Carrington M, Winkler C, Huttley GA, Allikmets R, Schriml L, Gerrard B, Malasky M, Ramos MD, Morlot S, Tzetis M, Oddoux C, di Giovine FS, Nasioulas G, Chandler D, Aseev M (1998) Dating the origin of the CCR5-Delta32 AIDS-resistance allele by the coalescence of haplotypes. Am J Hum Genet 62: 1507-1515

Stone AC, Starrs JE, Stoneking M (2001) Mitochondrial DNA analysis of the presumptive remains of Jesse James. J Forensic Sci 46: 173-176

Stoneking M, Hedgecock D, Higuchi R, Vigilant L, Erlich HA (1991) Population variation of human mtDNA control region sequences detected by enzymatic amplification and sequence-specific oligonucleotide. Am J Hum Genet 48: 370382

Sullivan KM, Hopgood R, Gill P (1992) Identification of human remains by amplification and automated sequencing of mitochondrial DNA. Int J Legal Med 105: 83-86

Sullivan KM, Mannucci A, Kimpton CP, Gill P (1993) A rapid and quantitative DNA sex test: fluorescence-based PCR analysis of X-Y homologous gene amelogenin. BioTechniques 15(4): 637-641

Sykes B (1999) The molecular genetics of European ancestry. Philos Trans R Soc Lond B Biol Sci 354: 131-138

Sykes B, Irven C (2000) Surnames and the Y chromosome. Am J Hum Genet 66: 14171419

Telkkä A, Palkama A, Virtama P (1962) Prediction of stature from radiographs of long bones in children. J Forens Sci 7: 474-479

Torroni A, Huoponen K, Francalacci P, Petrozzi M, Morelli L, Scozzari R, Obinu D, Savontaus ML, Wallace DC (1996) Classification of European mtDNAs from an analysis of three European populations. Genetics 144: 1835-1850

Torroni A, Lott, M, Cabell M, Chen Y, Lavergne L, Wallace D (1994) mtDNA and the origin of Caucasians: identification of ancient caucasian-specific haplogroups, one of which is prone to a recurrent somatic duplication in the D-loop region. Am J Hum Genet 55: 760-776

Torroni, A, Richards M, Macaulay V, Forster P, Villems R, Norby S, Savontaus M, Huoponen K, Scozzari R, Bandelt H (2000) mtDNA haplogroups and frequency patterns in Europe. Am J Hum Genet 66: 1173-1177.

Trumme T (2003) Die Familie Zierdt - Molekulargenetische Analysen zur Prüfung und Rekonstruktion eines Familienstammbaumes. Staatsexamensarbeit, Universität Göttingen, Biologische Fakultät 
Trumme T, Hummel S, Herrmann B (2004) Genetics in genealogical research Reconstruction of a family tree by means of Y-Haplotyping. Anthrop Anz 62: 379-386

Ullrich H (1969) Interpretation morphologisch-metrischer Ähnlichkeiten an ur- und frühgeschichtlichen Skeletten in verwandtschaftlicher Hinsicht. Z Archäol 3: 4888

Urquhart A, Kimpton CP, Downes TJ, Gill P (1994) Variation in short tandem repeat sequences - a survey of twelve microsatellite loci for use as forensic identification markers. Int J Legal Med 107: 13-20

Urquhart AJ, Oldroyd NJ, Kimpton CP, Gill P (1995) Highly discriminating heptaplex short tandem repeat PCR system for forensic identification. BioTechniques 18: 116-121

van Oorschot AH, Gutowski SJ, Robinson SL (1994) HUMTH01: Amplification, species specifity, population genetics and forensic applications. Int J Legal Med 107: $121-126$

Vernesi C, Di Benedetto G, Caramelli D, Secchieri E, Simoni L, Katti E, Malaspina P, Novelletto A, Marin VTW, Barbujani G (2001) Genetic characterization of the body attributed to the evangelist Luke. Proc Natl Acad Sci U S A 98: 1346013463

Vivello FR (ed) (1981) Handbuch der Kulturanthropologie: Eine gundlegende Einführung. Klett-Cotta Verlag, Stuttgart

Vilà C, Leonard JA, Götherström A, Marklund S, Sandberg K, Lidén K, Wayne RK, Ellegren H (2001) Widespread origins of domestic horse lineages. Science 291: 474-477

Walsh PS, Metzger DA, Higuchi R (1991) Chelex 100 as a Medium for Simple Extraction of DNA for PCR-BasedTyping from Forensic Material. BioTechniques 10: 506-513

Zeller M (2000) Molekulare Geschlechts- und Verwandtschafts-Bestimmung in historischen Skelettresten. Eberhard-Karls-Universität Tübingen, Fakultät für Biologie

Zink AR, Grabner W, Nerlich AG (2005) Molecular identification of human tuberculosis in recent and historic bone tissue samples: The role of molecular techniques for the study of historic tuberculosis. Am J Phys Anthropol 126: 3247 


\section{Internetadressen}

http://www.cstl.nist.gov/div831/strbase/

http://www.dna-view.com/

http://www.fbi.gov/hq/lab/fsc/backissu/april2002/miller1.htm

http://www.mitomap.org/

http://www.uni-duesseldorf.de/WWW/MedFak/Serology/dna.html

http://www.yhrd.org/index.html 


\section{Anhang}

\subsection{Anthropologischer Befund}

Die Grabungen in der Lichtensteinhöhle konnten im Jahr 2006 abgeschlossen werden. Die Archäologen gehen nicht mehr davon aus, dass in den bekannten Höhlenbereichen noch menschliche Knochen zu finden sind (pers. Mitteilung S. Flindt). Seit der ersten Grabungskampagne im Jahr 1993 sind annähernd 7000 Fundnummern beschrieben worden. Dabei repräsentiert nicht jede Fundnummer nur ein Skelettelement. Es wurden auch Sammeltüten verwendet, die Knochenelemente im mittleren zweistelligen Zahlenbereich beinhalten. Neben den menschlichen Skelettelementen ließen sich zusätzlich tausende tierische Knochen finden, dazu zählen u.a. Schweine-, Rinder-, Fuchs-, Hunde- und Fledermausknochen. Die Bearbeitung dieser Knochen oblag Dr. R.Schoon und ist nicht Gegenstand dieser Arbeit. Jeder menschliche Knochen wurde einzeln morphologisch begutachtet und in einem Fundkatalog aufgenommen. Neben der Fundnummer gibt der Katalog weiterhin Auskunft über die Lage (Raum, Fläche und Quadrant) sowie die jeweilige Deskription (Element, Zustand, Alter, Geschlecht und Diskreta).

Der in diesem Kapitel vorgestellte Befund stellt einen Minimalausschnitt anthropologischer Arbeitsmethoden dar. Er dient hier vornehmlich der Erhebung wichtiger Basisdaten, die für die Verwandtschaftsanalyse oder für die Fragestellung zur Nutzungsart der Höhle wichtig sind.

Sollte es sich bei den 40 Individuen um Opfer handeln, müssten sich zumindest an einzelnen Knochen Zeichen von Gewalteinwirkung finden lassen. Schultes (2000) hatte bereits die Knochen, die bis zum Jahr 2000 geborgen wurden, morphologisch untersucht. Er konnte dabei keine Zeichen von Gewalteinwirkungen am Hartgewebe feststellen. In dieser Studie wurden die seit dem Jahr 2000 ausgegrabenen Knochen auf mögliche Spuren eines gewaltsamen Todes untersucht.

Im Folgenden werden die anthropologischen Basisdaten zum Alter, dem Geschlecht und der Körpergröße der Individuen erhoben sowie pathologische Veränderungen an den Knochenelementen gesammelt. 


\subsubsection{Geschlechtsdiagnose}

Die morphologische Geschlechtsbestimmung beruht am menschlichen Skelett auf den Bewertungen von Form- und Größenmerkmalen (Herrmann et al. 1990). Deskriptive Geschlechtsmerkmale sind am Becken gut zu erkennen. Dies ist aus der Funktionalität des Beckens bei Frauen (Schwangerschaft und Geburt) zu erklären. Da die Skelette nicht in ihrem anatomischen Verband liegen ist, ohne den genetischen Fingerabdruck zu bestimmen, eine Zuordnung der Becken zu einzelnen Individuen nicht möglich. Daher wurde keine morphognostische Bewertung der Becken in dieser Arbeit durchgeführt. Weitere Merkmale, die auf das Geschlecht eines Individuums hinweisen, sind am Cranium zu ermitteln. Jedoch ist auch hier nicht immer eine direkte Zuordnung möglich gewesen. Einzelne Schädel sind zusätzlich stark fragmentiert, d.h. lediglich einzelne geschlechtsdiskriminante Strukturen hätten bewertet werden können.

Wenn ein Knochen chromosomale DNA aufweist, dann kann eine sichere Geschlechtsdiagnose unabhängig vom Knochenelement mithilfe von molekulargenetischen Markern erfolgen.

Die DNA-Qualität der Knochen aus der Lichtensteinhöhle lässt eine solche Analyse zu. Daher geschah die Geschlechtsdiagnose molekulargenetisch. Das Verfahren wird in Kap. 5.1 beschrieben. Die Ergebnisse der Analysen sind für die einzelnen Individuen in den Tabellen 14, S.75 und 15, S.76 aufgeführt.

Die Geschlechtsdiagnose ergab eine ausgeglichene Geschlechterrelation. Von den 40 ermittelten Individuen sind 21 weiblichen und 19 männlichen Geschlechts.

\subsubsection{Altersdiagnose}

Das Skelettalter wird u.a. durch Ernährung, Umwelt- oder Arbeitsbelastung beeinflusst. Daher stimmt das Skelettalter nicht immer exakt mit einem chronologischen Alter überein (Hermann et al. 1990, 52). Die Einstufung geschieht daher in Altersklassen nach Herrmann et al. (1990): Infans 1 (0-6 Jahre), Infans 2 (7-12 Jahre), Juvenis (1320), Adultas (20-40 Jahre), Maturitas (40-60 Jahre) und Senilis (60- $\omega$ ). Die weitere Unterteilung der einzelnen Klassen geschieht durch den Zusatz früh, mittel oder spät, 
z.B. fadult. Der Umfang der Klassen umfasst ca. sieben Jahre, d.h. ein frühadultes Individuum ist zwischen 20 und 27 Jahre alt.

Eine morphologische Altersdiagnose kann am Skelett in der Regel über die komplexe Methode (nach Ascádi \& Nemeskéri 1970) erfolgen. Dabei werden vier unterschiedliche Strukturen, die. Facies symphysialis, die proximale Femurepiphyse, die proximale Humerusepiphyse und die Verknöcherung der Schädelnähte (=Obliteration), nach ihren jeweiligen Stadien der Altersveränderung bewertet. Dies ist jedoch nur dann in Kombination möglich, wenn die einzelnen Skelettelemente eindeutig zugeordnet werden können. Da dies in der Lichtensteinhöhle nicht möglich ist, wurde in der vorliegenden Arbeit auf weiterführende Methoden der Altersbestimmung zurückgegriffen, wie sie in Hermann et al. (1990) zusammengefasst sind. Durch die genetischen Typisierungen war es möglich mehrere Skelettelemente einzelnen Individuen zuzuordnen. Deshalb wurde für jedes Individuum mindestens ein Element ausgewählt und mit den im Folgenden beschriebenen Methoden altersbestimmt.

Das Alter von Kindern und Jugendlichen bis 15 Jahre kann recht genau anhand ihrer Zahnentwicklung bestimmt werden. Dabei werden vor allem der Wechsel von Milchgebiss auf Dauergebiss sowie die Entwicklungsstadien und der Abrasionsgrad der Zähne beurteilt. Neben der morphologischen Inspektion wurden die Ober- und Unterkiefer radiologisch untersucht (Abb.48). Dafür wurde der Philips BT-S2/Super M80-Röntgengenerator benutzt. Die Röntgenbilder wurden mit folienloser Aufnahmetechnik erstellt, bei der die Filme (AGFA Curix Cronex 5) direkt belichtet werden. Die Aufnahmen wurden im freien Betrieb durchgeführt, wobei die einzelnen Belichtungswerte individuell eingestellt wurden. Für die Entwicklung der Bilder wurden folgende Zeiten eingehalten: Entwickler (TETENAL Roentogen liquid) $5 \mathrm{~min}\left(20^{\circ} \mathrm{C}\right)$,

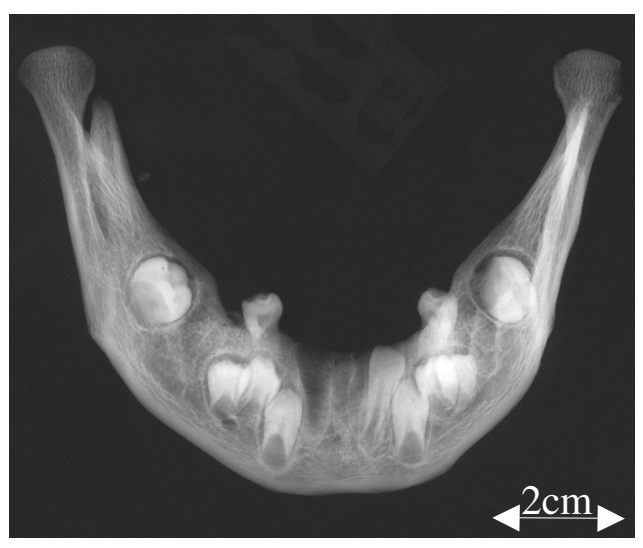

Abbildung 48: Röntgenaufnahme des kindlichen Unterkiefers Do2263 (Röntgeneinstellungen: 60KV, $\sim 125 \mathrm{~mA}$, 2,0s, FFA $=130 \mathrm{~cm}$ im freien Betrieb). Zwischenwasserbad 1min, Fixierer (TETENAL

Roentogen Superfix) 10min, Endwasserbad 30min. Der Zahnstatus wurde dann mit der schematischen Darstellung der Zahnentwicklung bei Hermann et al. (1990, 54) verglichen. 
Die Altersdiagnose für erwachsene Individuen kann mithilfe von lichtmikroskopischhistologischen Methoden erfolgen. Die hier angewendeten Verfahren sind weitgehend unabhängig vom Erhaltungszustand und der Vollständigkeit eines Skelettes und daher besonders für das Skelettkollektiv der Lichtensteinhöhle geeignet.

Eines dieser Verfahren basiert auf dem Auszählen von Zuwachsringen des Zahnzementes (Großkopf 1990). Für eine altersbekannte Skelettserie zeigte die Methode eine durchschnittliche Abweichung von \pm 3,23 Jahren (Großkopf 1990). Damit eignet sich das Verfahren für die Einstufung in die Altersklassen. Die Vorbereitung der Präparate und die Methode werden bei Großkopf (1990) detailliert vorgestellt. Die Abbildung 49A zeigt exemplarisch eine lichtmikroskopische Aufnahme eines solchen Präparates. Eine Altersdiagnose am menschlichen Knochen kann auch über die qualitative Beurteilung von histologischen Dünnschliffen der Langknochenkompakta erfolgen. Dafür steht ein vereinfachtes Verfahren zur histologischen Altersdiagnose zur Verfügung (Hummel et. al. unveröffentlicht). Das Verfahren basiert auf einer qualitativen Beurteilung der im Altersgang charakteristischen Veränderungen der Knochenbinnenstruktur. Die Untersuchungen wurden in fast allen Fällen an der Femurkompakta vorgenommen (Abb.49B). Für Individuum M19 geschah die Altersdiagnose an einer Tibia. Die Anfertigung der Knochenpräparate erfolgte, wie bei Schultes (2000) beschrieben.
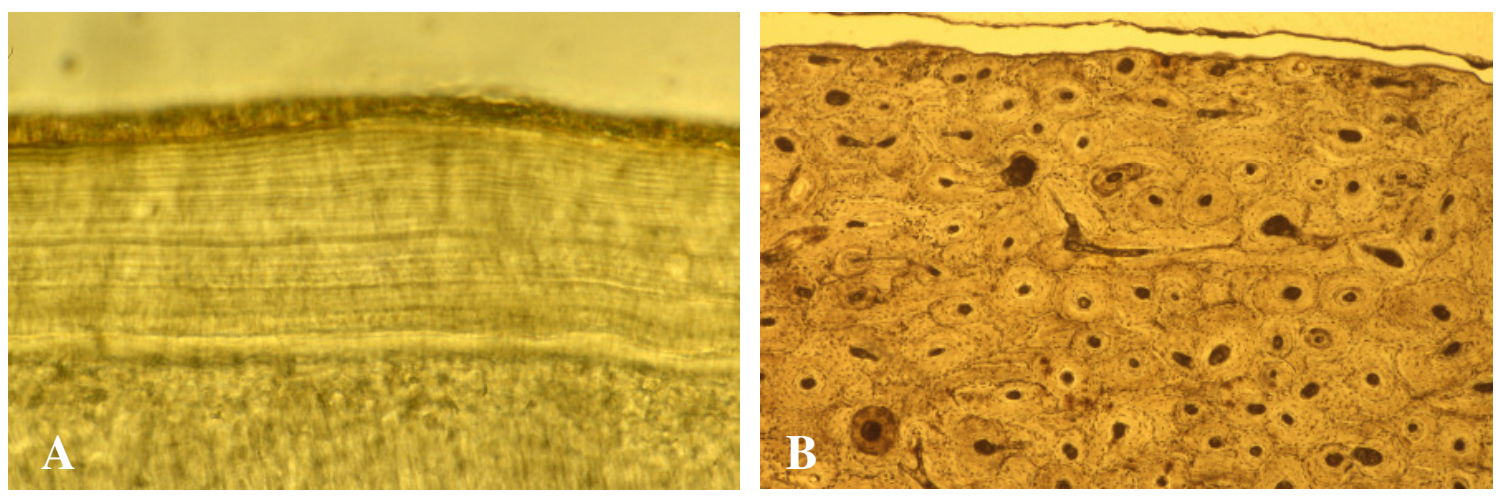

Abbildung 49: (A) Zuwachsringe in der Zementschicht eines mmaturen-smaturen Individuums (Fund Do 193, Dünnschliffpräparat, Durchlicht, ca. 270-fache Vergrößerung). (B) Querschnitt einer Knochenkompakta (periostal) in ca. 20-facher Vergrößerung. Die Knochenstruktur entspricht einem smaturen Individuum (Fund Do 3756).

Zusätzlich zu den vorgestellten Verfahren wurde bei Langknochen die Synostose von Epi- und Apophysen (nach Herrmann et al. 1990, Abb.3.2.1.2, 58) und bei Schädeln die Obliteration der Schädelnähte (nach Herrmann et al. 1990, 63) und der Verschluss der Sphenobasilarfuge (Herrmann et al. 1990, 57) beurteilt. 
Die für die einzelnen Individuen ermittelten Altersklassen sind in Tabelle 27, S. 183 aufgeführt. Die Altersverteilung ist in Tabelle 26, S.179 dargestellt. Wenn für ein Individuum ein Alter ermittelt wurde, welches zwischen zwei Altersklassen liegt, z.B. sadult-fmatur, dann wurde dieses Individuum mit halber Wertigkeit beiden Klassen zugewiesen (vgl. Schultes 2000, 18). Konnte hingegen nur eine Altersangabe ohne genauere Differenzierung ermittelt werden, z.B. adult, dann wurde das Individuum mit der Umrechnungsformel 0,3-0,4-0,3 auf die Altersklasse verteilt. Aus diesem Grund können sich in der Tabelle ungerade Werte ergeben.

Tabelle 26: Sterblichkeitsverteilung der männlichen und weiblichen Individuen aus der Lichtensteinhöhle auf die Altersklassen.

\begin{tabular}{|l|c|c|c|}
\hline & weibliche Individuen & männliche Individuen & $\sum$ \\
\hline infans I & - & 1 & 1 \\
\hline infans II & 4 & 7 & 11 \\
\hline juvenis & 3,5 & 0,5 & 4 \\
\hline fadult & 1,1 & 1,3 & 2,4 \\
\hline madult & 4,3 & 2,9 & 7,2 \\
\hline sadult & 1,6 & 1,3 & 2,9 \\
\hline fmatur & 2 & 2 & 4 \\
\hline mmatur & 2 & 1 & 3 \\
\hline smatur & 1,5 & 2 & 3,5 \\
\hline senil & 1 & - & 1 \\
\hline
\end{tabular}

Die Ergebnisse aus Tabelle 26 sind in Abbildung 50 graphisch dargestellt. Die ermittelten Altersklassen für die einzelnen Individuen sind in Tabelle 27, S.183 aufgeführt.

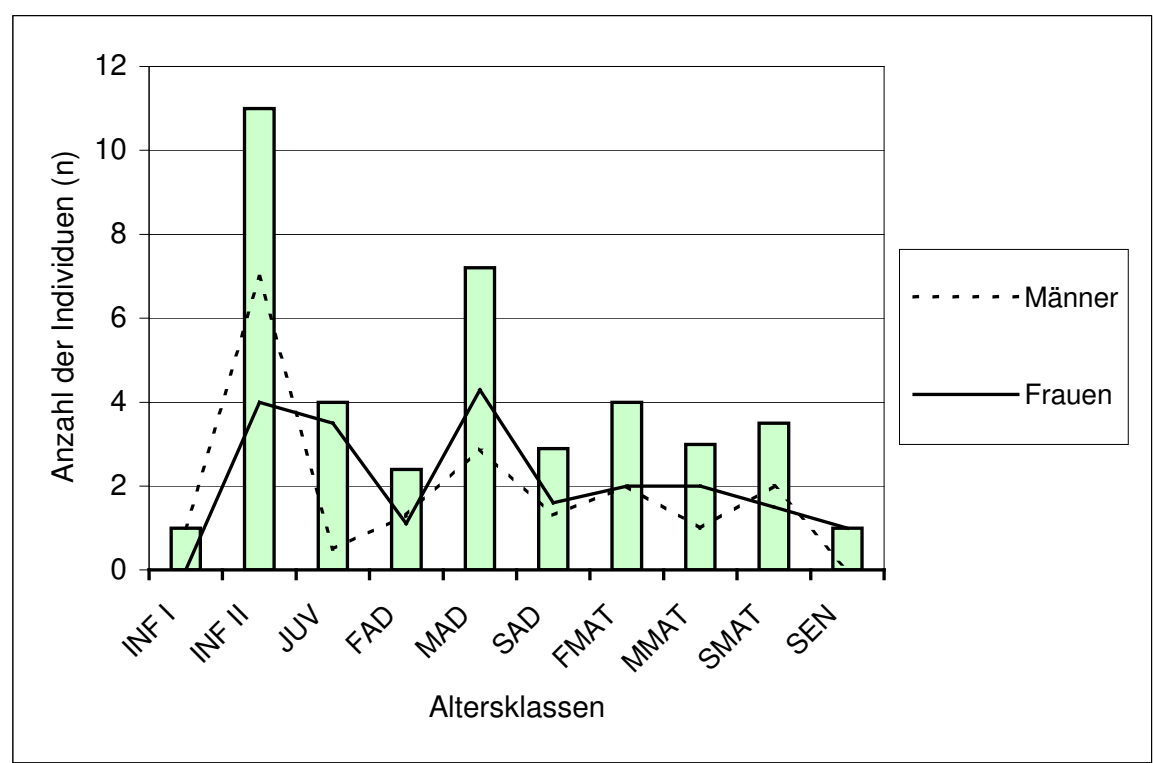

Abbildung 50: Verteilung der Sterblichkeit der Individuen aus der Lichtensteinhöhle auf die Altersklassen. Abkürzungen der Altersklassen INF I = Infans I, INF II = Infans II, Juv = Juvenis, FAD, MAD, SAD = frühes, mittleres und spätes Adultas, FMAT, MMAT, SMAT = frühes, mittleres und spätes Maturitas, SEN = Senilis. 
Abbildung 50 ist $\mathrm{zu}$ entnehmen, dass hier ein scheinbarer Sterbegipfel in der Altersklasse Infans II vorliegt. Individuen der Altersklasse Infans I fehlen nahezu vollständig (s.u.). Die ergab, dass kein Kind unter fünf Jahren in den bekannten Höhlenabschnitten lag. Die Sterbehäufigkeit der Erwachsenen verteilt sich gleichmäßig, wobei ein Anstieg in der Altersklasse Mitteladult $\mathrm{zu}$ beobachten ist. Die Sterblichkeitsrate der Frauen in der Altersstufe Adultas könnte in Verbindung mit einem gesteigerten Mortalitätsrisiko bei Schwangerschaft und Geburt stehen (Herrmann et al. 1990).

Die Geschlechterrelation in den Altersklassen ist mit Ausnahme der subadulten Individuen ausgeglichen. Geschlechterstudien an rezenten Populationen zeigen, dass die Mortalitätsrate der männlichen Individuen insbesondere in den jüngeren Altersklassen im Gegensatz zu den weiblichen Individuen höher ist (Kraemer 2000). Für das Mittelalter konnte gezeigt werden, dass häufig ältere Kinder und Jugendliche zu Tode kamen (vgl. Siemoneit 1996, 348). Dieses wird u.a. auf eine relativ frühe Einbeziehung der Kinder in den Arbeitsprozess zurückgeführt.

Aus der Urnenfelderzeit sind relevante demographische Erhebungen selten. Aus der Region um die Lichtensteinhöhle fehlen größere Stichproben vollständig. Um einen ungefähren Eindruck über die Binnenstruktur einer jungbronzezeitlichen Population zu bekommen, wurden die Ergebnisse der Lichtensteinhöhle mit den Daten von 63 Individuen aus Neumünster-Oberjörn I, (Schutkowski \& Hummel 1991, 143) verglichen (Abb.51).

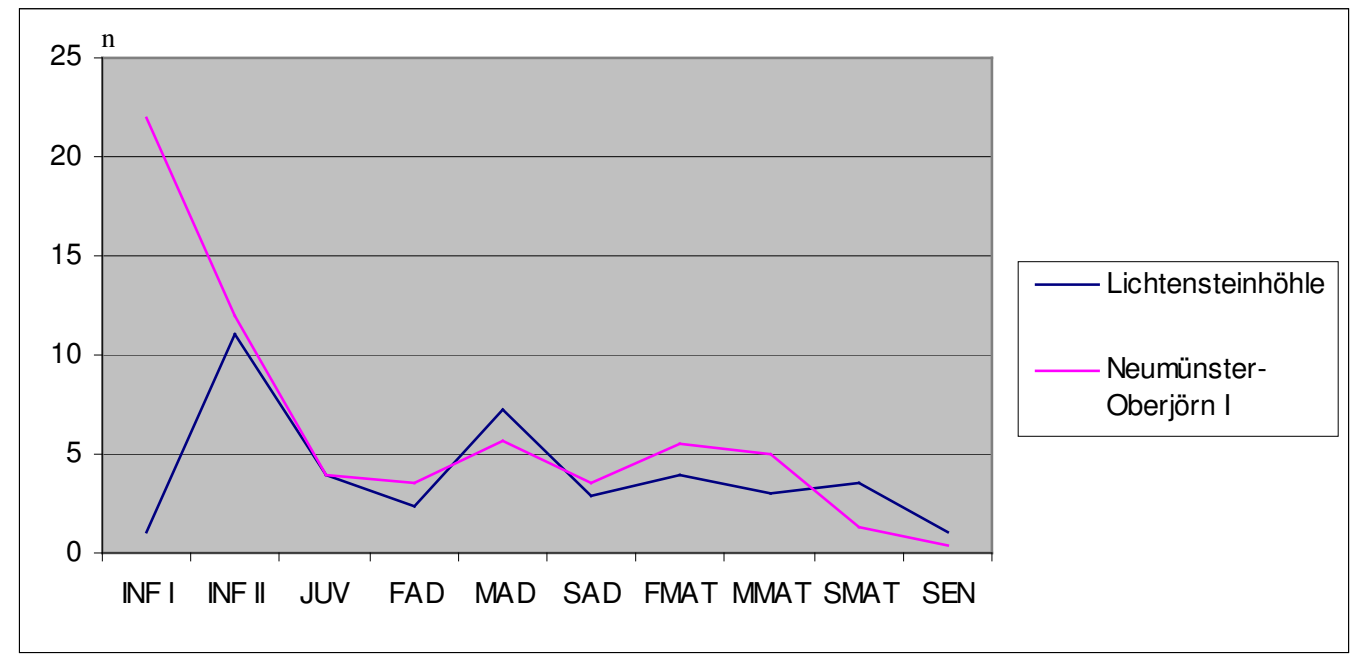

Abbildung 51: Vergleich der Sterblichkeitsprofile der Lichtensteinhöhle und dem jungbronzezeitlichen Urnenfeld Neumünster-Oberjörn 1. Die x-Achse gibt die Altersklasse an, die y-Achse die Anzahl der Individuen (n). Abkürzungen der Altersklassen siehe Abb. 50. 
Bei der Beurteilung der Daten muss berücksichtigt werden, dass es sich bei der Population von Neumünster-Oberjörn I um Leichenbrandbestimmungen handelt. Durch die sehr anspruchsvolle Grabungssituation bei Leichenbrandfunden ist grundsätzlich nicht mit großer Sicherheit zu sagen, ob alles anthropologisch Relevante auch gesichert worden ist. Je nach Qualität der Überlieferung des Leichenbrandes sind auch Altersund Geschlechtsbestimmungen mit Vorsicht zu bewerten.

Im Wesentlichen unterscheiden sich die Sterblichkeitsprofile der beiden Fundplätze nur in der Altersklasse Infans I. An dieser Stelle weichen sie jedoch signifikant voneinander ab. Historische Bevölkerungen weisen in der Regel eine hohe Kindersterblichkeit auf. Im Vergleich zur Kindersterblichkeit im Infans I ist die Sterblichkeit in den Altersgruppen Infans II und Juvenis deutlich geringer (Herrmann et al. 1990, 308). Dies sollte auch für die Bronzezeit gelten. Diese Epoche fällt in die Späte Warmzeit, d.h. feuchtes und kühles Klima wurde von warmem und trockenem abgelöst. In der Jungbronzezeit kam es teilweise zu regelrechten Dürreperioden (Jockenhövel 1994, 30). Mangelhafte Ernährung führte insbesondere im Säuglings- und Kleinkinderalter zu einer hohen Kindersterblichkeitsrate (Schultz 1994, 17). Vor allem der Übergang von der Muttermilch zur erwachsenen Nahrung könnte Unverträglichkeitsreaktionen hervorgerufen haben, welche nicht selten zum Tod führten (Schultz 1994, 17). In einer frühbronzezeitlichen Population aus der Slowakei verstarben beispielsweise $15 \%$ der Kinder vor Erreichen des zweiten Lebensjahres (Schultz 1994, 17).

Das Sterblichkeitsprofil der Lichtensteiner-Gruppe entspricht, mit Ausnahme der fehlenden Kinder im Infans I, den Erwartungen über die Sterblichkeit historischer Populationen. Paläodemographische Aussagen zur Sterblichkeitsverteilung der Gruppe sollten aber mit größter Vorsicht vorgenommen werden, da es sich hier um eine Sonderbestattung mit überwiegend verwandten Individuen handelt. Aus diesem Grund verliert die Lichtensteinhöhle ihre demographische Relevanz. Als eine mögliche Erklärung für den geringen Anteil an Kindern der Altersklasse Infans I wird eine Bestattung an einem bisher nicht bekannten Ort angenommen. Andernfalls hätte man bei der Befundung zumindest vereinzelt Knochen dieser Kinder finden müssen. Es gibt keinen Grund anzunehmen, dass sie in der Höhle schneller vergangen wären, als beispielsweise die knöchernen Reste von Kindern der Altersklasse Infans II. 


\subsubsection{Schätzung der Körperhöhe}

Die Schätzung der Körperhöhe erfolgt an einem Langknochen, in der Regel an einem Femur. Dabei wird davon ausgegangen, dass die Länge des jeweiligen Skelettelementes in einem regelhaften Verhältnis zur Körperhöhe steht (Hermann et al. 1990, 91). Die existierenden Formeln zur Bestimmung der Körperhöhe haben jedoch nur Schätzcharakter. Für die Rekonstruktion der Körperhöhe erwachsener Individuen wurden die Formeln von Pearson (1899) angewendet. Seit dem letzten Jahrhundert hat sich die Entwicklung der körperlichen Reifung beschleunigt (=säkulare Akzeleration). Die Formeln nach Pearson (1899) beziehen sich auf Daten die vor diesem Wandel erhoben wurden und sind daher für prähistorische Bevölkerungen am besten geeignet. Für die Schätzung der Körperhöhe bei nicht erwachsenen Individuen wurden die Formeln nach Telkkä et al. (1962) herangezogen.

Eine Körperhöhenschätzung konnte nicht für alle 40 Individuen vorgenommen werden, da nicht für jedes Individuum das repräsentative Femur bekannt ist und zum Teil die Femora auch zu stark fragmentiert sind. In einem Fall gelang es auf eine Tibia zurückzugreifen (M19). In Tabelle 27 sind die Schätzungen für 19 Individuen angegeben.

Für bronzezeitliche Bevölkerungen zeigen Untersuchungen an Skelettserien, dass Männer Körperhöhen zwischen 169,5 und 170,4 cm erreichten, die mittlere Körperhöhe der Frauen betrug ca. 160cm (z.B. Schulz 1994, 15, Siemoneit 1996, 343). Die in der Lichtensteinhöhle ermittelten Körperhöhenschätzungen für erwachsene Männer liegen genau in dem angegebenen Bereich. Auch die Frauen weisen überwiegend Größen um die $160 \mathrm{~cm}$ auf. Ausnahme bildet Individuum F5. Sie ist mit ca. 1,50m deutlich kleiner.

Für lediglich vier Kinder (F7, M4, M6 und M11) kann eine Schätzung zu ihren Körperhöhen gemacht werden. Sie wurden alle der Altersklasse Infans II zugeordnet. Während für F7 und M6 über den Zahnstatus eine recht genaue Altersangabe gelang, konnte für M4 und M11 nur die Altersklasse angegeben werden. Hühne-Osterloh (1987) führte an Skeletten subadulter Individuen eines Hochmittelalterlichen Skelettkollektives u.a. Körperhöhenschätzung durch. Dabei berücksichtigte sie u.a. die Berechnungsformeln anhand des Femur nach Telkkä et al. (1962). Für den Altersbereich zwischen 8-9 Jahre ergab sich eine durchschnittliche Körperhöhe von 115,4 \pm 4,1 cm (Hühne-Osterloh 1987, 26). Das Individuum M6 wurde auf ca. 8 Jahre eingestuft und weist eine Körperhöhe von $115,3 \pm 5,3 \mathrm{~cm}$ und für F7 wurde ein Alter 
von ca. 9 Jahre und eine Körperhöhe von 122,6 \pm 4,1 cm festgelegt. Damit liegen die hier ermittelten Werte für die beiden Kinder im Bereich des mittelalterlichen Skelettkollektives. Für M11 konnte nur der Altersbereich Infans 2 angegeben werden. Die Körperhöhenschätzung ergab 112,6 $\pm 5,3 \mathrm{~cm}$. Die Körperhöhe lässt darauf schließen, dass dieses Kind eher dem frühen Infans II zugerechnet werden kann. Dagegen muss man aufgrund der Körperhöhe von M4 (135,6 $\pm 5,3 \mathrm{~cm})$ am wahrscheinlichsten vom späten Infans II ausgehen.

Bei diesen Aussagen sollte man jedoch berücksichtigen, dass krankheitsbedingte Belastungen sich in der Größenentwicklung bemerkbar machen können, sowie individuelle Körperhöhenunterschiede möglich sind.

Tabelle 27: Gesamtübersicht der ermittelten Daten zum Geschlecht ( $F=$ female, $M=$ male), dem Alter, und der Körperhöhenschätzung.

\begin{tabular}{|c|c|c|c|c|c|}
\hline № & Altersstadium & $\begin{array}{l}\text { Körperhöhen- } \\
\text { schätzung }\end{array}$ & № & Altersstadium & $\begin{array}{l}\text { Körperhöhen- } \\
\text { schätzung }\end{array}$ \\
\hline F1 & senil $^{1}$ & $162 \pm 3,3 \mathrm{~cm}$ & M1 & smatur $^{1,3}$ & $172,3 \pm 3,3 \mathrm{~cm}$ \\
\hline $\mathrm{F} 2$ & adult $^{1}$ & $159,5 \pm 3,4 \mathrm{~cm}$ & M2 & mmatur-smatur ${ }^{1,3}$ & $174 \pm 3,3 \mathrm{~cm}$ \\
\hline F3 & $\inf 2$ ca. $\mathrm{JJ}^{2}$ & & M3 & mmat-smat $^{1}$ & $172,5 \pm 3,3 \mathrm{~cm}$ \\
\hline F4 & mmatur-smatur $^{3}$ & & M4 & infans $2^{1}$ & $135,6 \pm 5,3 \mathrm{~cm}$ \\
\hline F5 & smatur $^{1,3}$ & $150,3 \pm 3,3 \mathrm{~cm}$ & M5 & adult $^{4}$ & $172,5 \pm 3,5 \mathrm{~cm}$ \\
\hline F6 & sjuvenil 16-18J. $^{1,2,3}$ & $146,6 \pm 3,3 \mathrm{~cm}$ & M6 & infans 2 ca. $8 \mathrm{~J}^{2}{ }^{2}$ & $115,3 \pm 5,3 \mathrm{~cm}$ \\
\hline F7 & infans 2 ca.9J. $^{2}$ & $122,6 \pm 4,1 \mathrm{~cm}$ & M7 & ${\text { infans } 2 \text { ca. } 10 \mathrm{~J}^{2}}^{2}$ & \\
\hline F8 & adult $^{4}$ & & M8 & $\begin{array}{c}\text { sinfans1-finfans } 2 \text { ca. } \\
6-7 \mathrm{~J}^{2}\end{array}$ & \\
\hline F9 & juvenil 15-18J. ${ }^{1,2,5}$ & $142,8 \pm 6,8 \mathrm{~cm}$ & M9 & sadult-fmatur ${ }^{1,3}$ & $170 \pm 3,3 \mathrm{~cm}$ \\
\hline F10 & madult $^{3}$ & & M10 & madult $^{1,3}$ & \\
\hline F11 & mmatur $^{3}$ & & M11 & infans $2^{1}$ & $112,6 \pm 5,3 \mathrm{~cm}$ \\
\hline F12 & sadult-fmatur $^{3}$ & & M12 & 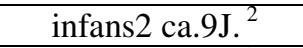 & \\
\hline F13 & fmatur ${ }^{1,3}$ & $160,4 \pm 3,3 \mathrm{~cm}$ & M13 & juvenil-fadult $^{1}$ & \\
\hline F14 & madult $^{1,3}$ & $159,4 \pm 3,3 \mathrm{~cm}$ & M14 & fadult-madult $^{1}$ & \\
\hline F15 & sjuvenil-fadult $^{3}$ & & M15 & ${\text { infans } 2 \text { ca. } 8 \mathrm{~J}^{2}}^{2}$ & \\
\hline F16 & fmatur-mmatur ${ }^{3}$ & & M16 & infans $1-$ infans $2^{5}$ & \\
\hline F17 & madult $^{1}$ & $155,5 \pm 3,3 \mathrm{~cm}$ & M17 & madult $^{1}$ & \\
\hline F18 & madult-sadult $^{3}$ & $163,3 \pm 3,3 \mathrm{~cm}$ & M18 & fmatur $^{1}$ & \\
\hline F19 & sjuvenil $^{1}$ & & M19 & sadult-fmatur $^{1}$ & $169,2 \pm 3,5 \mathrm{~cm}$ \\
\hline F20 & infans 2 ca. $7 \mathrm{~J} .^{2}$ & & & & \\
\hline F21 & infans 2 ca. $8 \mathrm{~J} .^{2}$ & & & & \\
\hline
\end{tabular}

Legende: Die Altersdiagnose geschah durch : ${ }^{1}=$ eine histologische Altersdiagnose am Knochen, ${ }^{2}=$ den Zahnstatus, ${ }^{3}=$ das Auszählen von Zuwachsringen im Zahnzement, ${ }^{4}=$ die Beurteilung der Obliteration der Schädelnähte, ${ }^{5}=$ dem morphologischen Vergleich an altersbekannten Gegenstücken. Für die Individuen F1, M13 und M17 wurden die Ergebnisse der histologischen Altersbestimmung aus der Arbeit von Schultes (2000) übernommen. 


\subsubsection{Erhaltungszustand der Knochen, anatomische Varianten und Pathologien}

Der ermittelte Erhaltungszustand der Knochen, die seit 2000 geborgen wurden, fügt sich nahtlos an dem von Schultes (2000) festgestellten Befund an. Der Fragmentierungsgrad der Knochen ist verhältnismäßig gering. Vereinzelnd weisen die Knochen einen stärkeren Dekompositionsgrad auf.

Im Rahmen dieser Arbeit ließen sich an den untersuchten Schädeln anatomische Varianten feststellen, welche auch als epigenetische Merkmale oder Discreta bezeichnet werden. Unter diesem Begriff versteht man kleinräumige, diskontinuierlich variierende, morphologische Merkmale (Rösing 1982). An dieser Stelle soll jedoch nur ein Auszug aus dem Formenspektrum gegeben werden. Es konnte unter anderen eine persistierende Sutura metopica, Wormsche Knochen, Gefäßimpressionen auf den Ossa frontale sowie eine Facies condylaris bipartia festgestellt werden (Abb.52).

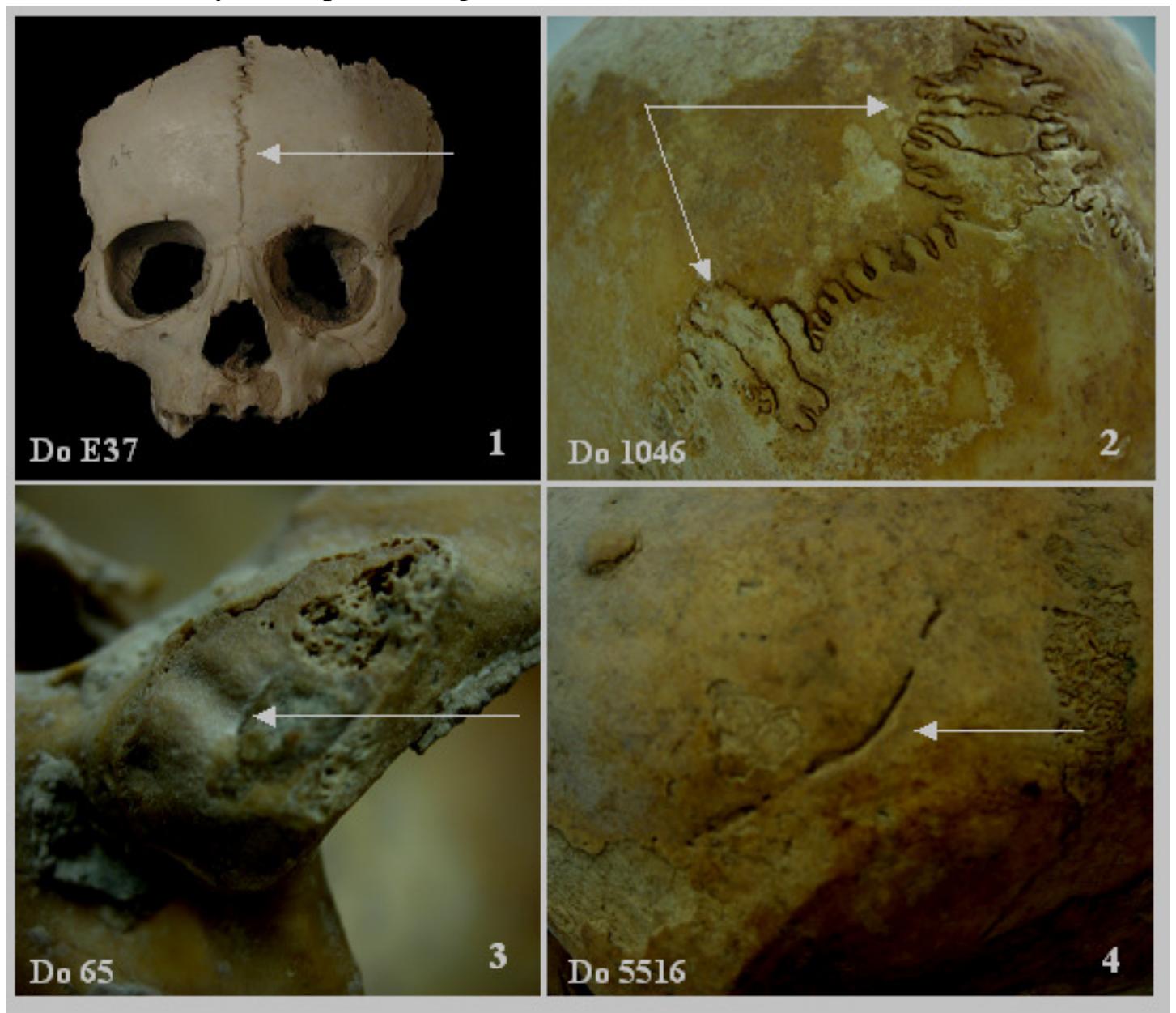

Abbildung 52: Anatomische Varianten am Schädel (1-4, jeweils durch Pfeile gekennzeichnet): Frontalansicht von DoE37 mit persistierender Sutura metopica (1), Occipitalansicht von Do1046 mit Wormschen Knochen (2); Basalansicht von Do65 mit Facies condylaris bipartita (3) ; Frontal/Lateralansicht von Do5516 mit einer Gefäßimpression im Os frontale (4). 
Für Discreta wird angenommen, dass sie für einen Verwandtschaftsnachweis herangezogen werden können. Die Aussagekraft einer molekulargenetischen Untersuchung ist ungleich höher und wenn möglich immer vorzuziehen. Deshalb basieren die in dieser Arbeit aufgestellten verwandtschaftlichen Beziehungen ausschließlich auf molekulargenetischen Methoden.

Nur Wormsche Knochen kommen in Verbindung mit Pathologien vor. Intracranielle Drucksteigerungen, die über einen längeren Zeitraum vorliegen, können z.B. zum Ausbilden solcher Knocheninseln führen (Herrmann et al. 1990, 112, Ortner und Putschar 1985). Ein Hinweis darauf, dass ein erhöhter intracranieller Druck bei einem Individuum pathologisch wurde, konnte durch andere morphologische Merkmale nicht bestätigt werden.

Vereinzelt konnten Pathologien festgestellt werden, wovon jedoch keine als Todesursache in Frage kommt. Im Folgenden werden die Ergebnisse kurz zusammengefasst.

Die Untersuchungen ergaben keinen Hinweis auf Traumata. Dieser, für die Ansprache als Menschenopferstätte, wichtige Sachverhalt konnte abschließend in der Höhle nicht festgestellt werden.

Schultes $(2000,19)$ beschreibt eine Knochenfraktur an einer Clavicula (Do 1474). Diese Fraktur scheint die einzige Verletzung dieser Art an den Knochen zu sein.

An einem kindlichen Schädelfragment (Do78, Abb.53) konnte eine Trepanation festgestellt werden (Schultes 2000, 20).

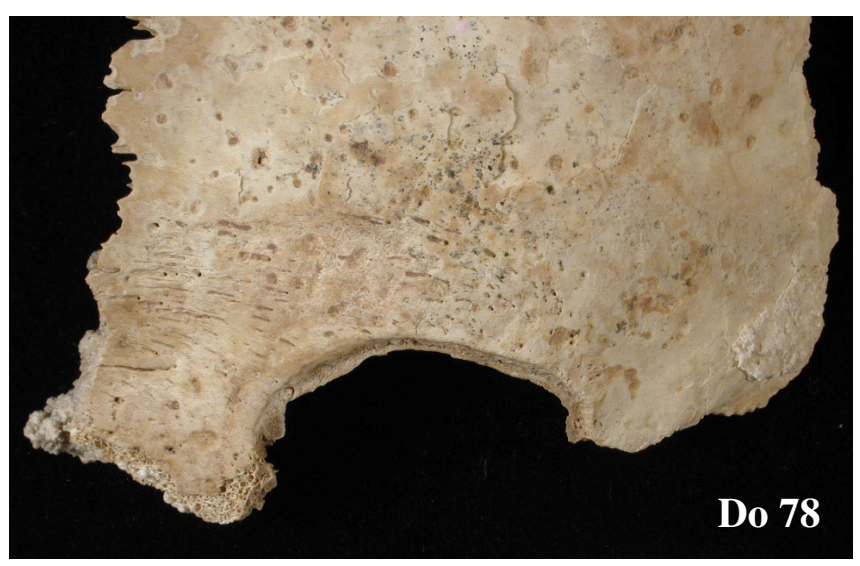

Abbildung 53: Linkes Os temporale von Fund Do 78 mit einer Trepanation. 
Trepanationen sind intendierte Eröffnungen des Schädels und stellen rituelle oder therapeutische Eingriffe dar (Herrmann et al. 1990, 120). Sie sind für prähistorische Epochen nicht ungewöhnlich. In Europa konnten solche Eingriffe bereits im Mesolithikum festgestellt werden (Aufderheide \& Rodriguez-Martin 1998, 31). Bei vielen bronzezeitlich, europäischen Populationen sind Trepanationen ebenfalls nachgewiesen worden (Schulz 1994, 15). Bei 90\% der Fälle handelt es sich um gezielte Eingriffe, denen ein Trauma voranging. Die Überlebenswahrscheinlichkeiten einer Trepanation liegen bei untersuchten prähistorischen Populationen bei ca. 50\% (Aufderheide \& Rodriguez-Martin 1998, 33). Auch das Kind aus der Lichtensteinhöhle muss den Eingriff überlebt haben, da der Knochen Heilungsprozesse aufweist (Schultes 2000, 20).

Alle vorhandenen Schädel wurden auf weitere Trepanationsereignisse untersucht. An einem Schädel (Do 3757) wurde ein Lochdefekt im Os occipitale festgestellt. Hierbei könnte es sich vielleicht um einen intendierten Eingriff handeln. Aufgrund einer starken und nicht zerstörungsfrei zu entfernenden Übersinterung konnte dies morphologisch nicht geklärt werden. In einer Magisterarbeit (Stauch 2006) wurde versucht, über den genetischen Fingerabdruck, weitere Skelettelemente zu den beiden Funden (Do78 und Do3757) aufzuklären. An diese Untersuchungen hätte sich eine CGH-Analyse (engl. comparative genome hybridization; z.B. Kallioniemi et al. 1992) anschließen lassen. Damit hätten sich Hinweise ergeben können, ob die Trepanationen auf mögliche Chromosomenanomalien und den damit verbundenen Pathologien zurückzuführen sind. Für eine Probe der Lichtensteinhöhle konnte diese Technik, im Zusammenhang mit der Authentifizierung von aDNA, bereits erfolgreich angewendet werden (Hummel et al. 1999b). Da bei dieser Technik kein Vermehrungsschritt genomischer DNA durchgeführt wird, werden größere Mengen an Probenmaterial benötigt. Für den Fund Do78 konnte kein genetischer Fingerabdruck ermittelt werden und damit ließ sich auch kein weiteres Skelettelement zuordnen. Für Do3757 ließ sich nur mit geringer Wahrscheinlichkeit eine rechte Tibia zuordnen. Sollten in weiteren Studien noch Skelettelemente sicher zugeordnet werden, dann empfiehlt sich die Durchführung einer CGH-Analyse. Die Tatsache, dass bei Do78 eine gesicherte Trepanation vorliegt, könnte dafür sprechen, dass es sich bei dem Lochdefekt des Schädels Do3757 ebenfalls um eine Trepanation handelt (Stauch 2006).

Weitere lochartige Strukturen, die an Schädeln gefunden wurden, sind sämtlich auf liegezeitbedingte Substanzverluste zurückzuführen. 
Die Kinder aus der Lichtensteinhöhle könnten durch Nahrungsmangel oder Nährstoffdefizit verstorben sein. Zusätzlich fördern diese Mangelzustände das Auftreten von Infektionskrankheiten, die ebenfalls als Todesursache in Betracht kommen.

Sowohl Mangelernährung als auch Infektionskrankheiten (z.B. Grippe und Masern) können wachstumshemmende Stresssituationen darstellen. Diese können in Form von Harris-Linien am Skelett nachgewiesen werden. Dabei handelt es sich um transversal verlaufende, röntgendichte Linien, die an den Enden der Langknochen auftreten (Aufderheide \& Rodriguez-Martin 1998, 33). Sie werden mithilfe der Röntgentechnik dargestellt. Ihre Entstehung korreliert mit der höchsten Wachstumsrate in der Kindheit. Mit zunehmenden Alter ist es möglich, dass Harris-Linien wieder zurückgebildet werden. Es wurden die intakten distalen Enden von 16 linken Femora geröntgt. Die restlichen Femora eigneten sich aufgrund der starken Fragmentierung im Epiphysenbereich nicht für diese Analyse. Die Durchführung der Röntgenanalyse geschah wie in Kap. 11.1.2 beschrieben. Lediglich bei einem

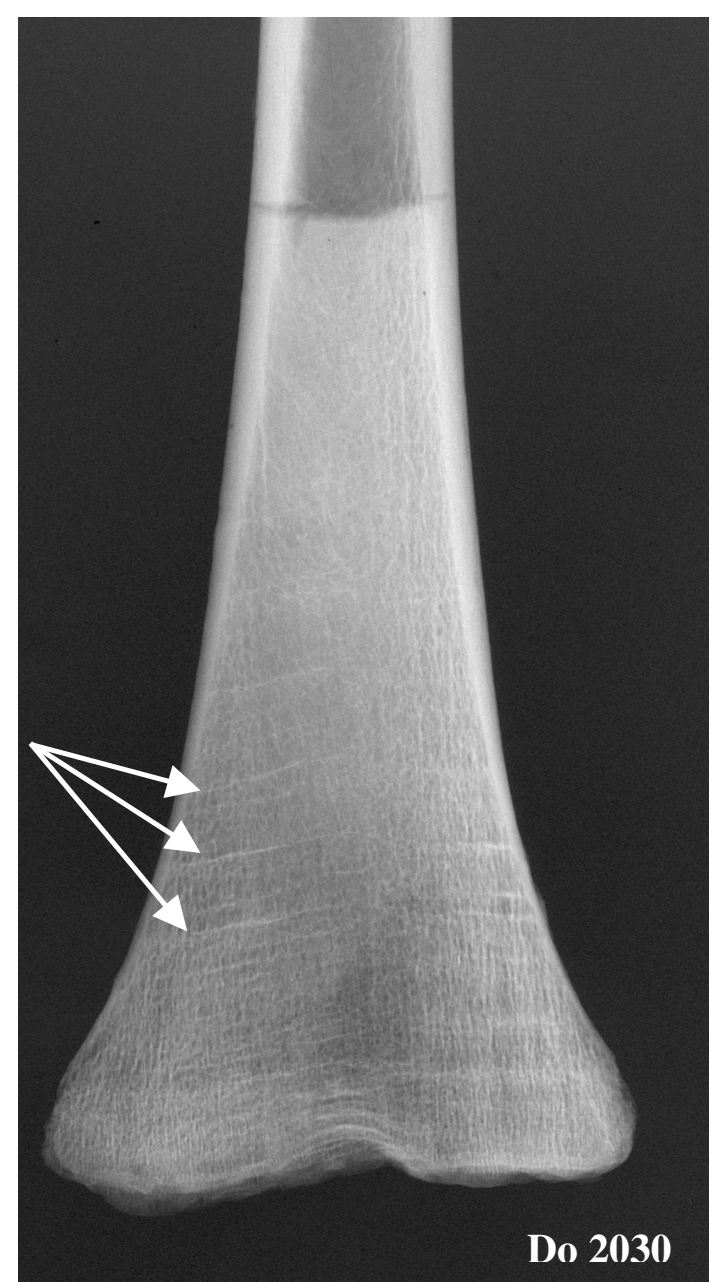

Abbildung 54: Frontalansicht (Radiologie) des linken Femur Do2030 mit Harris-Linien im distalen Femurende (durch Pfeile gekenzeichnet). In der Diaphyse ist deutlich die Beprobung des Femurs für die DNA-Analyse zu sehen. Die Röntgeneinstellungen waren wie bei Abb. 46 beschrieben.

Individuum der Altersklasse Infans II konnten Harris-Linien nachgewiesen werden (Abb.54). Für dieses Kind könnte eine Mangelernährung oder eine Infektionskrankheit über einen längeren Zeitraum vorgelegen haben. Das Fehlen dieser Strukturen bei den anderen untersuchten Individuen deutet darauf hin, dass deren Gesundheitszustand mehrheitlich gut war und sie nicht unter wachstumshemmenden Stresssituationen standen.

Das pathologische Symptom Cribra orbitalia konnte am Schädel des 6-7 Jahre alten Jungen M8 (Fundnr. Do 3757) festgestellt werden (Abb.55). Cribra orbitalia wird als Stoffwechselerkrankung eingestuft und wird vorwiegend auf Eisen- bzw. Vitamin C- 
Mangel zurückgeführt, kann aber auch mit dem Befall von Endoparasiten in Verbindung gebracht werden (Schutkowski und Grupe 1997). Sie ist durch Porositäten im Orbitadach zu erkennen und ist bei prähistorischen und historischen Skelettfunden, insbesondere bei Kindern, häufig festzustellen (Schutkowski und Gruppe 1997). Der Ausprägungsgrad ist bei diesem Kind allerdings gering, sodass eine Beeinträchtigung zu Lebzeiten auszuschließen ist.

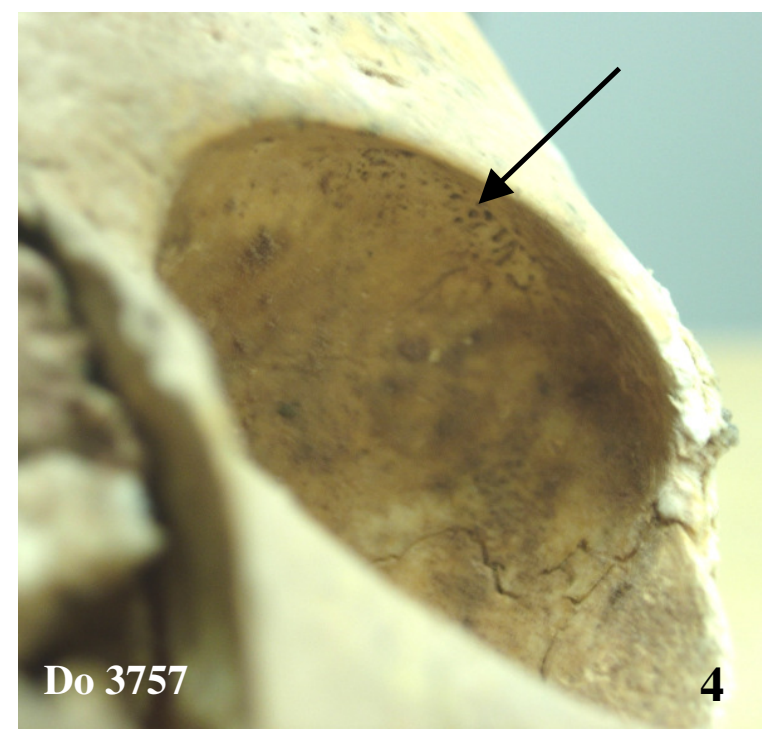

Abbildung 55: Cribra orbitalia in der Augenhöhle des Schädels Do3757 (durch Pfeil gekennzeichnet).

An den Zähnen und den Zahnhalteapparaten der bronzezeitlichen Individuen konnten vereinzelte Pathologien festgestellt werden. Dabei handelt es sich im Wesentlichen um Parodontose und Karies (Abb.56). Darüber hinaus konnte vereinzelt eine Zahnunterzahl beobachtet werden.

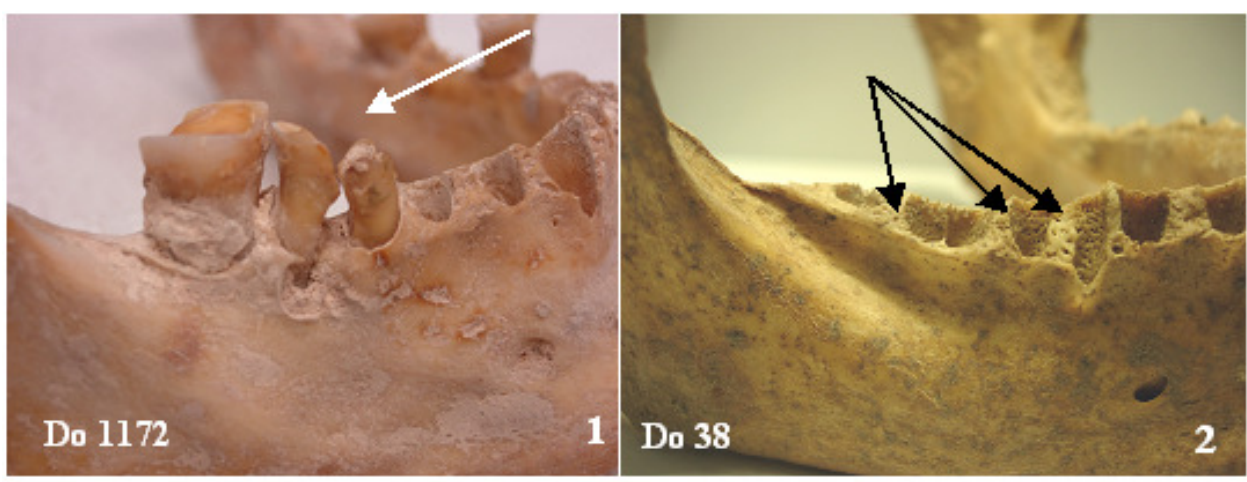

Abbildung 56: Pathologische Veränderungen an den Zähnen und am Zahnhalteapparat: Lateralansicht Do 1172 mit Karies (1), Lateralansicht Do 38 mit Parodontitis ( jeweils durch Pfeile gekennzeichnet).

An den Zahnhalteapparaten der älteren Individuen konnte zum Teil altersbedingter Zahnverlust festgestellt werden. Dies ist als physiologischer Gebrauchsverlust anzusehen. 


\subsection{Die Lichtensteinhöhle als biologisch-genetisches Archiv}

Aufgrund der außergewöhnlich guten DNA-Erhaltung kann die Lichtensteinhöhle als biologisch-genetisches Archiv begriffen werden. In den letzten Jahren wurden an den Knochen weitere umfangreiche wissenschaftliche Projekte durchgeführt.

Die vorgestellten Forschungsarbeiten zeigen den Bezug zu wichtigen anthropologischen Fragestellungen. Weiterhin geben sie Einsichten in die Lebensbedingungen der Lichtensteiner-Gruppe in der Bronzezeit. Insbesondere die Studien an dem immungenetischen Marker CCR5, dem Zytokin Interleukin-6 und der Hämochromatose zeigen, dass mithilfe von aDNA-Analysen ein direkter Bezug zu modernsten Forschungsthemen hergestellt werden kann. In den einzelnen Unterkapiteln werden die Forschungsberichte zusammengefasst. Am Abschluss werden die Ergebnisse zusammen graphisch dargestellt (Abb.57 und 58).

\subsubsection{AB0-Blutgruppen}

Die weltweite unterschiedliche Verteilung der AB0-Allelfrequenzen lässt darauf schließen, dass selektive Drücke für die Entstehung der AB0-Blutgruppen verantwortlich sein können. Es ist bekannt, dass die ABO-Blutgruppen in Verbindung mit menschlichen Infektionskrankheiten stehen. Beispielsweise scheinen Träger der Blutgruppe 0 ein deutlich erhöhtes Morbiditäts- und Mortalitätsrisiko bei Infektionskrankheiten wie der Cholera aufzuweisen (z.B. Faruque et al. 1994). Das heißt, sie zeigen deutlich schwerere Krankheitsverläufe und haben ein höheres Risiko an den Begleiterscheinungen der Krankheit zu sterben. Blutgruppenbestimmungen könnten sich damit für die Anthropologie eignen, Hinweise auf epidemiologische Ereignisse in historischen Fundkollektiven zu erbringen.

Es bedarf geeigneter Analysesysteme, um solche Untersuchungen auch an historischem Probenmaterial durchführen zu können. Serologisch lassen sich die Blutgruppen allein phänotypisch bestimmen. Außerdem sind diese Untersuchungen sehr vom Erhaltungszustand des Probenmaterials abhängig (vgl. Hummel 2003). Molekulargenetisch können die Blutgruppen dagegen sicher auf Genotypenniveau bestimmt werden. Aus diesem Grund wurde u.a. an den Knochen der Lichtensteinhöhle ein Analysesystem zur Blutgruppenbestimmung an degradierter aDNA etabliert 
(Hummel et al. 2002, Hummel 2003). Damit ist es möglich die Blutgruppenallele A, B, $0_{1}, 0_{1 \mathrm{v}}$ und $0_{2}$ auch an sehr alten Probenmaterial nachzuweisen.

Die Blutgruppen können auch für die Verwandtschaftsanalysen von großem Interesse sein. Da ein Kind jeweils ein Allel von seinen Eltern vererbt bekommt, eignen sie sich für den Nachweis direkter Verwandtschaft.

Mithilfe der Blutgruppenanalyse konnte das vermutete enge verwandtschaftliche Verhältnis zwischen Individuum F9 und M11 (s. Kap.6.1.2, Abb.40) weiter gefestigt werden. F9 weist die Blutgruppe A/ $0_{1 \mathrm{v}}$ und M11 $0_{1 \mathrm{v}} / 0_{1 \mathrm{v}}$ auf. Damit teilen sie sich das Allel $0_{1 v}$, und eine Geschwisterschaft wird wahrscheinlicher (Hummel 2003). Für die zweite angesprochene Variante einer verwandtschaftlichen Beziehung, d.h. einer Mutterschaft von F9 zu M11, die aufgrund des Alters von F9 ausgeschlossen wurde (s. Kap. 6.1.2), bietet das Ergebnis hier ebenfalls keine Lösungsmöglichkeit.

Neben dem hier geschilderten Fall liegen noch weitere Blutgruppenergebnisse für nah verwandte Individuen vor. Sämtliche Ergebnisse stehen im Einklang mit der in dieser Arbeit aufgestellten Genealogie.

\subsubsection{Immungenetischer Marker CCR5}

Der humane CCR5-Rezeptor (cysteine-cysteine-linked chemokine receptor 5) ist ein Zelloberflächenrezeptor und spielt eine wichtige Rolle bei inflammatorischen Prozessen des Immunsystems (z.B. Raport et al. 1996). Eine 32 bp umfassende Deletion im Gen für den Rezeptor ( $\triangle 32 \mathrm{CCR} 5)$ bewirkt, dass dieser nicht an der Zelloberfläche exprimiert wird. Im homozygoten Zustand verschafft u.a. das $\Delta 32$ CCR5 Allel seinen Trägern fast vollständige genetische Immunität gegen den HIV-Virus und der heterozygote Status führt zum langsameren Fortschreiten der Immunschwächekrankheit AIDS (z.B. Dean et al. 1996). Angenommen wird, dass das Auftreten des Mutationsereignisses auf ein einmaliges Ereignis in historischer Zeit zurückzuführen ist und dass der Ursprung der Mutation in Nordosteuropa liegt (Libert et al. 1998). Die Allelfrequenzen des $\Delta 32-$ Allels zeigen einen deutlichen Nord-Süd-Gradienten (Stephens et al. 1998). Das Allelalter wurde von Stephens (1998) auf 700 Jahre geschätzt. Anhand der Lichtensteiner Individuen wurde untersucht, wie häufig das Auftreten des $\Delta 32$-Allel in dem bronzezeitlichen Skelettkollektiv ist (Schmidt 2004, Hummel et al. 2005). Es konnte gezeigt werden, dass die Mutationsform $\Delta 32$ bereits in der Bronzezeit mit 
ähnlich hohen Frequenzen wie in heutiger Zeit präsent war. Damit müssen die Altersschätzungen für $\Delta 32$ korrigiert werden.

Für vier von 17 getesteten Individuen konnte der heterozygote Zustand festgestellt werden. Dabei handelt es sich erneut um die beiden Individuen F9 und M11, sowie deren mutmaßlicher Onkel M10 und ein weiteres nicht in der Genealogie befindliches weibliches Individuum (F14).

Damit wird die Verbindung der Geschwister weiter gestärkt und das verwandtschaftliche Verhältnis zu M10 immer wahrscheinlicher. Interessant ist in diesem Zusammenhang die regionale Herkunft dieser vier Individuen. Für den YHaplotyp von M10 und seines vermutlichen Neffen M11, konnte gezeigt werden, dass der Y-Haplotyp seinen Ursprung in Nordosteuropa haben könnte. Damit läge hier ein Hinweis auf den vermuteten Ursprung der Deletion vor. Auch für das weibliche Individuum F14 könnte mit ihrem mt-Haplotyp J1b1 ein solcher Hinweis vorliegen. Die gleiche HVR I-Sequenzabfolge konnte zumindest auch mehrfach in südsibirischen Populationen nachgewiesen werden (Derenko et al. 2002). Damit hätten zumindest die väterlichen bzw. mütterlichen Linien für alle vier Treffer einen möglichen Ursprung östlich von Mitteleuropa.

\subsubsection{Laktose(in)toleranz}

Für 27 Skelettproben konnte der Laktosegenotyp erfolgreich bestimmt werden (Fulge 2005). Aus dem Normalzustand der Laktoseintoleranz, d.h. Milchzuckerunverträglichkeit, entwickelte sich die Laktosetoleranz. Zwei Theorien zur Entstehung der Verträglichkeit existieren dabei. Die eine sieht die Laktosetoleranz parallel zur Sesshaftwerdung des Menschen vor 10.000-8.000 Jahren mit Ursprung im Nahen Osten (Cavalli-Sforza 1990), während eine andere den Ursprung vor 4.500-3.500 Jahren mit Nomadenvölker aus dem Ural in Zusammenhang bringt (Kaiser 2004).

Ziel der Arbeit von Fulge (2005) war es, dem Ursprung der Laktosetoleranz näher zu kommen. Die Knochen aus der Lichtensteinhöhle eignen sich für diese Art der Untersuchung, da zum Zeitpunkt der Höhlennutzung zum einen die Sesshaftwerdung der Menschen abgeschlossen war und zum anderen in der Höhle zahlreiche Rinderknochen gefunden wurden. Letzteres wirft die Frage auf, ob die Gruppe nur das Fleisch der Rinder gegessen hat, oder ob es ihnen prinzipiell auch möglich war, die Milch der Rinder für eine höhere Proteinzufuhr zu verwerten. 
Untersucht wurde ein C/T-Polymorphismus der 13910 Basenpaare vom 5'-Ende des Lactasegens entfernt liegt (Chromosom 2). Dieser SNP (single nucleotide polymorphism) ist an das Gen gekoppelt (Enattah et al. 2002). Die Laktosetoleranz wird autosomal dominant vererbt, d.h. ist der Genotyp homozygot für das T-Allel, oder heterozygot $\mathrm{C} / \mathrm{T}$, dann ist ein Mensch in der Lage Laktose $\mathrm{zu}$ verwerten. Ist ein Individuum dagegen homozygot $\mathrm{C} / \mathrm{C}$, dann liegt eine Laktoseintoleranz vor.

Für die Lichtensteiner Individuen konnte festgestellt werden, dass 55\% den Genotyp $\mathrm{C} / \mathrm{T}$ aufwiesen, $41 \% \mathrm{C} / \mathrm{C}$ und 4\% T/T. Damit waren 59\% der Individuen laktosetolerant und $41 \%$-intolerant.

Fulge (2005, 34-36) versuchte über eine Modellrechnung einen Hinweis zum Entstehungszeitpunkt der Laktoseverträglichkeit zu bekommen. Jedoch konnte die Frage zum Ursprung nicht abschließend beantwortet werden. Berücksichtigt man in der Berechnung einen Selektionsvorteil von $5 \%$ für die Rohmilchverträglichkeit, dann spräche dieses für die Ural-Hypothese. Wäre aber der Selektionsvorteil geringer, würde das den Ursprung der Laktosetoleranz schon vor 10.000 Jahren favorisieren.

Theoretisch könnte man Hinweise zum Ursprung der Laktosetoleranz über die regionale Herkunft der Lichtensteiner-Gruppe bekommen und zwar dann, wenn man die überwiegende Zahl der mütterlichen oder väterlichen Linien der Individuen die ein TAllel aufweisen, regional z.B. nach Osteuropa einordnen könnte. Leider konnten keine stichhaltigen Hinweise dafür erzielt werden (s.Kap.6.3).

Für zwei Individuen konnte Fulge den homozygoten Genotyp T/T bestimmen (=Laktosetolerant). Hier sind die genetischen Daten für die Personen zu fragmentarisch, als dass man ihre regionale Herkunft bestimmen könnte. Zumindest für die Individuen M10 und M11, deren Y-Haplotyp vermutlich osteuropäischer Herkunft ist, liegt der Genotyp C/T vor. Damit könnte eventuell über ihre väterliche Linie ein Nachweis für den osteuropäischen Ursprung der Laktosetoleranz vorliegen. Die weiteren Individuen mit dem Genotyp C/T konnten dagegen regional nicht nach Osteuropa eingeordnet werden. Damit kann an dieser Stelle kein Beitrag zum Ursprung der Laktosetoleranz geleistet werden. $\mathrm{Ob}$ die Lichtensteiner-Population die Viehwirtschaft auch als Milchquelle genutzt hat, kommt zumindest für die Hälfte der Individuen in Betracht. 


\subsubsection{Zystische Fibrose}

Die hohe Sterblichkeitsrate in der Altersgruppe Infans II führte zu Untersuchungen, die sich mit genetisch nachweisbaren Erkrankungen beschäftigen, hier mit dem Ziel krankheitsbedingte Todesarten auszuschließen. Die erste Studie zeigt, dass keines der Individuen an zystischer Fibrose (cystic fibrosis, Abk. CF, auch Mukoviszidose genannt) erkrankt war (Scholten 2006). Die CF gehört mit einer Heterozygotenrate von 1:23 zu den häufigsten Erbkrankheiten (Kerem et al. 1989). Die Krankheit schränkt die Funktionalität der Atemwege und des Verdauungstraktes ein. In europäischen Bevölkerungen sind 70\% der CF-Fälle auf eine 3bp Deletion des CFTR-Codons 508 ( $\Delta$ F508) zurückzuführen (z.B. Murken \& Cleve 1996). Die Analyse dieses Markers konnte bereits an historischem Skelettmaterial nachgewiesen werden, aus der auch das Analysesystem dieser Studie stammt (Bramanti et al. 2003).

Das Skelettkollektiv der Lichtensteinhöhle wurde auf eine genetische Disposition für Delta F508 untersucht. Insgesamt konnte für 33 untersuchte Individuen nachgewiesen werden, dass sie homozygot für das Wildtyp-Allel waren und somit nicht an der häufigsten Mutationsform von CF erkrankt sein konnten (Scholten 2006). Bei keinem der Individuen konnte das $\Delta$ F508 Allel nachgewiesen werden. Damit weichen diese Ergebnisse von bekannten Allelfrequenzen ab (Kerem et al. 1989).

Es wird vermutet, dass bei dieser Mutationsform ein möglicher Heterozygotenvorteil gegenüber Infektionskrankheiten vorliegen könnte (Hansson 1988). Infektionskrankheiten traten regelmäßig in Epidemien auf, übten einen starken Selektionsdruck auf die Populationen aus.

Für die europäische Bronzezeit kommt eine urbane Lebensweise der Menschen noch nicht in Betracht. Aus diesem Grund sollte eine bessere Nahrungs- und Trinkwasserqualität vorgelegen haben und durch Infektionskrankheiten ausgelöste Epidemien deutlich geringer aufgetreten sein. Demnach hätte kein Selektionsdruck bestanden und ein Heterozygotenvorteil vorgelegen. Letztlich würde dies zu einer nach unten korrigierten Allelverteilung führen. 


\subsubsection{Hereditäre Hämochromatose}

Neben der CF konnte eine wissenschaftliche Studie zur hereditären Hämochromatose (=erbliche Eisenspeicherkrankheit) durchgeführt werden (Krause 2006). Die Hämochromatose ist eine Stoffwechselerkrankung, die $\mathrm{zu}$ einer gesteigerten Eisenresorption im Dünndarm führt. Dies kann $\mathrm{zu}$ einer pathologischen Eisenspeicherung mit Gewebeschädigung und Verschlechterung von Organfunktionen führen. Die Symptome treten in der Regel erst in einem Alter zwischen 40 - 60 Jahren auf (Renz-Polster et al. 2004). Mit der Krankheit werden zwei Punktmutationen, die zu den Aminosäuresubstitutionen C282Y und H63D führen, im humanen HFE-Gen in Verbindung gebracht (Mayer 1992). Der genaue Pathomechanismus der Hämochromatose ist jedoch nicht im Detail bekannt.

Die klassische hereditäre Hämochromatose (Typ I) kann durch die homozygot vorliegende Mutation C282Y ausgelöst werden. Typ I ist in europäischen Populationen die häufigste autosomal-rezessiv vererbte Erkrankung (Mayer 1992). Die Penetranz der Krankheit ist jedoch gering, d.h. ein homozygoter Träger muss nicht zwangsläufig an der Hämochromatose erkranken. Die Punktmutation H63D kann dagegen nur in einer bestimmten Kombination mit C282Y zu einer Hämochromatosemanifestation führen. Eine Disposition der Erkrankung liegt hier erst dann vor, wenn die beiden Mutationen nicht zusammen auf einem Chromosom des Autosomenpaares liegen (pers. Mitteilung von Ahsen, siehe Krause 2006). Sind zwei verschiedene Genpositionen mutiert, spricht man von Compound-Heterozygotie (Murken \& Cleve 1996).

Die Ergebnisse von Krause (2006) können wie folgt zusammengefasst werden. Für 25 untersuchte Proben konnte eine sichere Typisierung für C282Y erfolgen. 92\% der Individuen sind homozygot für den Wildtyp (G/G) und $8 \%$ heterozygot $(\mathrm{G} / \mathrm{A})$. Der Locus H63D konnte für 22 Individuen typisiert werden und ergab, dass 13,5\% homozygot für die Mutation (G/G) sind, 23\% heterozygot (C/G) und 63,5\% homozygot für den Wildtyp $(\mathrm{C} / \mathrm{C})$. Eine phänotypische Hämochromatoseausprägung ist auszuschließen. Es konnte kein homozygoter Anlageträger für den Locus C282Y typisiert werden. Ebenfalls weist kein Individuum beide Mutationsformen gleichzeitig, d.h. C282Y und H63D, auf. Damit kann auch ein durch Hämochromatose ausgelöster krankheitsbedingter Tod für die untersuchte Gruppe ausgeschlossen werden.

Dagegen konnte mit dieser Studie gezeigt werden, dass die Mutation für den Locus C282Y älter sein muss, als bisher angenommen wurde. Ajioka \& Kushner (2002) 
schätzen das erstmalige Auftreten der Mutation C282Y auf ca. 2000 Jahre. Aufgrund der Ergebnislage an den Skeletten aus der Lichtensteinhöhle ist die Mutation demnach bedeutend älter. Der Manifestationszeitraum der Punktmutation für den Locus H63D war bisher nicht bekannt. Da sie auch in den bronzezeitlichen Proben nachgewiesen wurde, liegt auch für sie ein Mindestalter von ca. 3000 Jahren vor.

\subsubsection{Interleukin-6 (IL-6)}

Das Signalprotein Interleukin-6 (IL-6) gehört zur Gruppe der Zytokine. Diese Proteine wirken als Regulationsfaktoren des Immunsystems und ihre Aktivität beeinflusst die Stärke und Dauer einer Immunantwort. Das humane IL-6-Gen ist auf Chromosom 7 im Bereich p21 lokalisiert (Kaiser et al. 2004) und seine Proteinexpression wird von der Promoterregion reguliert. Der im Rahmen der Arbeit von Puder (2005) thematisierte SNP IL-6 G(-174)C ist in der Promoterregion innerhalb des Regulationselementes NRD (negative regulatory domain) lokalisiert. Der $\mathrm{G} \rightarrow \mathrm{C}$ Polymorphismus hat im Bereich des NRD einen negativen regulatorischen Effekt auf die IL-6-Transkription und folglich auch auf die Genexpression von IL-6 (Fishman et al. 1998). Der SNP bewirkt eine unterschiedliche IL-6-Ausschüttung im Organismus. Bei gesunden C-Allel-Trägern ist der IL-6-Spiegel im Organismus geringer als bei gesunden G-Allel- Trägern (Bennermo et al. 2004). Bei Erkrankungen, wie beispielsweise Entzündungen und Infektionen, wird der Protein-Spiegel erhöht. Dem biallelischen Polymorphismus G(-174)C wird eine Einflussnahme auf das Erkrankungsrisiko von bestimmten Krankheiten, deren Krankheitsverlauf, deren Behandlungserfolg und deren Heilungsprozess zugewiesen. Assoziationen zwischen dem SNP und einer Vielzahl von Erkrankungen ließen sich dabei für beide Allel-Varianten feststellen (Übersicht in Puder 2005, 10).

Das G-Allel ist die Ursprungsform und damit die Wildtyp-Variante (Fishman et al. 1998). Der Zeitpunkt an dem das C-Allel entstanden ist, kann zurzeit noch nicht beantwortet werden. In europäischen Bevölkerungen beträgt die C-Allelhäufigkeit über 40\%, in Deutschland sogar 44,9\% (vgl. Puder 2005, 12), In außereuropäischen Bevölkerungen dagegen ist die C-Allelhäufigkeit geringer. Gründe dafür könnten Selektionsfaktoren, Migration und Gründereffekte sein. Die Studie von Puder (2005) hatte zum Ziel die Allelhäufigkeit des SNP G(-174)C im bronzezeitlichen Skelettkollektiv der Lichtensteinhöhle zu ermitteln und damit einen Beitrag zur 
Datierung des Polymorphismus zu leisten. Dafür wurden DNA-Extrakte aus 32 linken Calcanei hergestellt und typisiert. Für den Nachweis des SNP wurde ein 162bp Fragment amplifiziert und der Genotyp über anschließende RFLP-Analyse bestimmt. Die Ergebnisse von Puder (2005) lassen sich wie folgt zusammenfassen. Es konnten 15 der 32 Calcanei erfolgreich typisiert werden. Dabei ließen sich alle drei Genotypen (GG, GC, CC) nachweisen. In der bronzezeitlichen Population konnten anteilsmäßig mehr C-Allele identifiziert werden und die Anzahl des Genotypen $\mathrm{C} / \mathrm{C}$ ist häufiger vertreten als $\mathrm{G} / \mathrm{C}$ und $\mathrm{G} / \mathrm{G}$.

Die G-Allelhäufigkeit wird für die untersuchten Individuen bei Puder (2005) mit 35,3 $38 \%$, die C-Allelhäufigkeit mit 62 - 64,7\% angegeben. Die rezente Verteilung einer deutschen Population beträgt dagegen 55\% für das G-Allel und 45\% für das C-Allel. Damit ist die Allelhäufigkeit im Skelettkollektiv höher als gegenwärtig.

Im Vergleich der Verteilung der Genotypen zwischen Lichtensteinhöhle und rezenter deutscher Population zeigte sich, dass auch hier die Daten abweichend sind. Für die bronzezeitliche Population ergab sich eine Genotypenverteilung von 17,6-23,5\% G/G, 29-35,3\% G/C und 47,1\% C/C. Dagegen weist die rezente deutsche Bevölkerung eine Genotypenverteilung von $31 \% \mathrm{G} / \mathrm{G}, 48 \% \mathrm{G} / \mathrm{C}$ und $21 \% \mathrm{C} / \mathrm{C}$ auf. Mithilfe des FisherExakter-Tests konnte jedoch kein signifikanter Unterschied für eine höhere CAllelhäufigkeit zwischen den beiden Populationen festgestellt werden (Puder 2005). Ob dies auch auf die Gesamtpopulation der Bronzezeit übertragen werden kann, ist zurzeit nicht zu beurteilen. Der gehäufte Nachweis des C-Allels im Skelettkollektiv der Lichtensteinhöhle bestätigt jedoch die Existenz des C-Allels vor 3000 Jahren.

Veränderte Lebensbedingungen im Laufe der Menschheitsgeschichte, z.B. Hygiene, Ernährung oder medizinische Versorgung, könnten sich in der Anreicherung von Coder G-Allelen niedergeschlagen haben. „Eine Rekonstruktion der Dynamik der CAllelhäufigkeit könnte bei der Identifizierung in Frage kommender Selektionsfaktoren hilfreiche Hinweise geben (Puder 2005, 74).“ „Bei einer Epidemie als Beispiel für einen Selektionsfaktor kann sich die C- oder G-Variante als Selektionsvorteil oder - nachteil für das erkrankte Individuum erweisen (Puder 2005, 74).“

Für die Historische Anthropologie können diese Studien damit einen Beitrag zur Epidemiologie und weiterführend zur Rekonstruktion der Lebensbedingungen früherer Bevölkerungen leisten. 


\subsubsection{Graphische Darstellung der ergänzenden genetischen Studien an den Knochen aus der Lichtensteinhöhle}

Die Ergebnisse der zuvor besprochenen Markersysteme werden in diesem Unterkapitel den Individuen der Lichtensteinhöhle zugewiesen und graphisch dargestellt (Abb.57\&58).

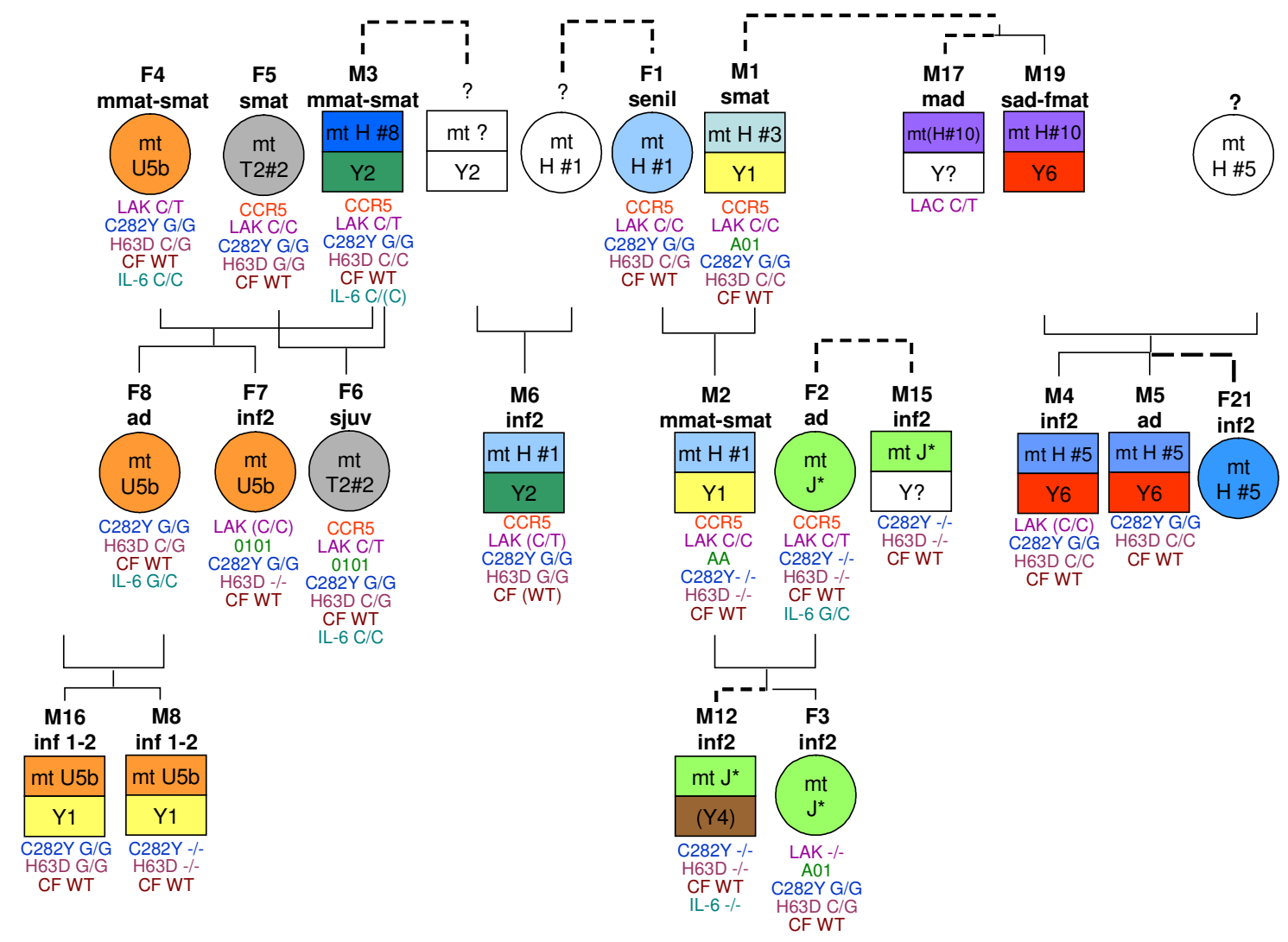

Abbildung 57: Genetische Zusatzinformationen für die bekannten Individuen aus der Lichtensteinhöhle (Erster Teil). Wurde ein Marker für ein Individuum untersucht, dann ist das Ergebnis der Analysen unter seinem Symbol aufgeführt. Konnte ein Allel nicht sicher bestimmt werden, dann wurde das Ergebnis in Klammern ( ) aufgenommen. War die Analyse nicht erfolgreich, dann ist dies durch - gekennzeichnet. Aufgeführt sind die Ergebnisse zu den Untersuchungen der Marker: CCR5, Laktose(in)toleranz (LAK), ABO-Blutgruppen, hereditäre Hämochromatose (C282Y und H63D), zystische Fibrose (CF) sowie Interleukin 6 (IL-6). Die Buchstaben WT bei zystischer Fibrose stehen für den Wildtyp. 


\begin{tabular}{|c|c|c|}
\hline $\begin{array}{c}\text { M7 } \\
\text { inf2 }\end{array}$ & $\begin{array}{c}\text { M13 } \\
\text { juv-fad }\end{array}$ & $\begin{array}{c}\text { M14 } \\
\text { juv-fad }\end{array}$ \\
\hline $\mathrm{mt} \mathrm{H \# 7}$ & $\mathrm{mt} n d \# 1$ & mt H \#9 \\
\hline Y1 & (Y1) & (Y2) \\
\hline $\begin{array}{c}\text { C282Y G/G } \\
\text { H63D C/C } \\
\text { CF WT } \\
\text { IL-6 G/C }\end{array}$ & $\begin{array}{c}\text { CCR5 } \\
\text { LAK (C/T) } \\
\text { C282Y G/G } \\
\text { H63D C/C } \\
\text { CF WT } \\
\text { IL-6 -/- }\end{array}$ & $\begin{array}{l}\text { LAK C/T } \\
\text { C282Y -/- } \\
\text { H63D -/- } \\
\text { CF WT } \\
\text { IL-6 G/- }\end{array}$ \\
\hline
\end{tabular}
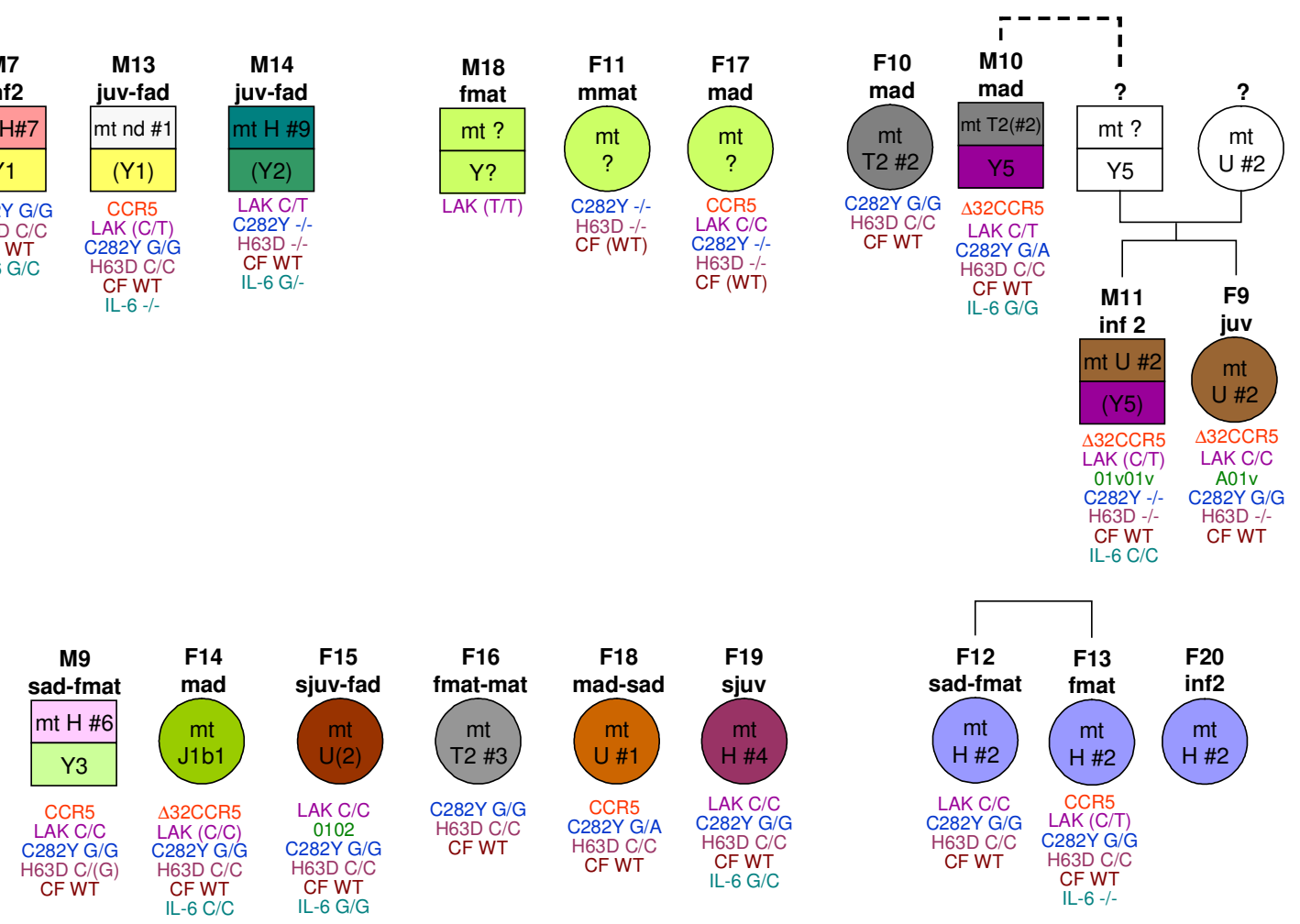

Abbildung 58: Genetische Zusatzinformationen für die bekannten Individuen aus der Lichtensteinhöhle (Zweiter Teil). Wurde ein Marker für ein Individuum untersucht, dann ist das Ergebnis der Analysen unter seinem Symbol aufgeführt. Konnte ein Allel nicht sicher bestimmt werden, dann wurde das Ergebnis in Klammern ( ) aufgenommen. War die Analyse nicht erfolgreich, dann ist dies durch - gekennzeichnet. Aufgeführt sind die Ergebnisse zu den Untersuchungen der Marker: CCR5, Laktose(in)toleranz (LAK), ABO-Blutgruppen, hereditäre Hämochromatose (C282Y und H63D) zystische Fibrose (CF) sowie Interleukin 6 (IL-6). Die Buchstaben WT bei zystischer Fibrose stehen für den Wildtyp. 


\subsection{Abkürzungen}

Abb.

Abk.

aDNA

APS

bp

bidest

bzw.

${ }^{\circ} \mathrm{C}$

ca.

$\mathrm{cm}$

CODIS

CXR

DNA

dATP

dCTP

d.h.

dGTP

dNTP

dTTP

eds.

EDTA

engl.

et al.

event.

6-FAM

g

ggf.

$\mathrm{h}$

HEX

Hrsg.

i.d.R.

ISFG
Abbildung

Abkürzung

ancient DNA

Ammoniumpersulfat

Basenpaare

bidestillata, zweifach destilliert

beziehungsweise

Grad-Celsius

Circa

Zentimeter

engl. Combined DNA Index system

carboxy-X-rhodamine

engl. deoxyribonucleic acid

Desoxyadenintriphosphat

Desoxycytidintriphosphat

das heißt

Deoxyguanosintriphosphat

Desoxynucleotidtriphosphat

Desoxythymidintriphosphat

engl. editor(s), Herausgeber

Ethylendiamintetraacetat

englisch

et alii, und Weitere

eventuell

6-Carbofluorescein

Gramm

gegebenenfalls

Stunde(n)

6-Carboxyl-2',4',7’,4,7-Hexachlorofluorescein

Herausgeber

in der Regel

International Society for Forensic Genetics 


\begin{tabular}{|c|c|}
\hline Jhd.(s) & Jahrhundert(s) \\
\hline JOE & 6-carboxy-4', $5^{\prime}$-dichloro-2', $7^{\prime}$-dimethoxy-fluorescein \\
\hline Kap. & Kapitel \\
\hline $\mathrm{Kb}$ & Kilobasenpaare \\
\hline 1 & Liter \\
\hline M & Molar, mol/1 \\
\hline $\mathrm{mA}$ & Milliampère, $10^{-3} \mathrm{~A}$ \\
\hline $\mathrm{MgCl}_{2}$ & Magnesiumchlorid \\
\hline $\min$ & Minute(n) \\
\hline $\mathrm{ml}$ & Milliliter \\
\hline $\mathrm{mM}$ & millimolar, mmol/l \\
\hline mtDNA & mitochondriale DNA \\
\hline n.b. & nicht bekannt \\
\hline $\mathrm{NED}^{\mathrm{TM}}$ & n.b. \\
\hline$\mu 1$ & Mikroliter, $10^{-6} 1$ \\
\hline$\mu \mathrm{M}$ & Mikromolar \\
\hline n.d. & non determinandum, nicht zu bestimmen \\
\hline ng & Nanogramm \\
\hline $\mathrm{nm}$ & Nanometer, $10^{-9} \mathrm{~m}$ \\
\hline PAGE & Polyacrylamid-Gelelektrophorese \\
\hline PCR & engl. polymerase chain reaction \\
\hline pers. & persönlich \\
\hline $\mathrm{pH}$ & potentia hydrogenii, Protonenaktivitätsexponent \\
\hline $\mathrm{pM}$ & picomolar, pmol/l \\
\hline pmol & picomol, $10^{-12} 1$ \\
\hline ( ) & rechtlich geschützt \\
\hline RFLP & Restriktionsfragmentlängenpolymorphismus \\
\hline \multirow[t]{2}{*}{$\mathrm{rfu}$} & engl. relative fluorescent unit(s), Maß für die Signalintensität der \\
\hline & Peaks im PAGE-Elektropherogramm \\
\hline ROX & 6-Carboxylrhodamin \\
\hline RT & Raumtemperatur \\
\hline s & Sekunde(n) \\
\hline s. & siehe \\
\hline S. & Seite \\
\hline
\end{tabular}




\begin{tabular}{ll} 
s. Kap & siehe Kapitel \\
STR & engl. short tandem repeat \\
s.o. & siehe oben \\
s.u. & siehe unten \\
s/w & schwarz/weiß \\
Tab. & Tabelle \\
Taq-Polymerase & Thermus aquaticus - DNA Polymerase \\
TBE & Tris-Borat-EDTA-Puffer \\
TEMED & N,N,N',N'-Tetramethylethylendiamin \\
TM & engl. Trade Mark \\
TMR & carboxy-tetramethylrhodamine \\
Tris & Tri[hydroxymethyl]aminomethan \\
U & unit, Einheit für Enzymaktivität \\
u.a. & unter anderem \\
U/min & Umdrehungen pro Minute \\
UV & Ultraviolett \\
usw. & ileich \\
V & Wellenlänge \\
v.Chr. & ind so weiter \\
vgl. & Volt \\
w/v & vor Christi Geburt \\
z.B. & vergleiche \\
\& & und \\
= & engeispiel per volume \\
\hline &
\end{tabular}


11.4 Verwendete Geräte, Chemikalien, Hilfsmittel und Einwegmaterialien

\section{Geräte}

Demineralisationsanlage Typ LAB-UPW, TKA Wasseraufbereitungsanlage GmbH

DNA-Extraktor Biorobot ${ }^{\circledR}$ EZ1, Qiagen

DNA-Sequenzer Modell 310, PE Applied Biosystems

DNA-Sequenzer Modell 373A stretch mit 672 Genescan-Analysis Software und 672 Genescan-Collection Software (Version 2.0.2.) zur Fragmentlängenanalyse, PE Applied Biosystems

DNA Thermal Cycler Typ TC1, Perkin Elmer Cetus

DNA Thermal Cycler Typ Mastercycler ${ }^{\circledR}$ gradient, Eppendorf

DNA Thermal Cycler Typ Mastercycler ${ }^{\circledR}$ personal, Eppendorf

Dremel ${ }^{\circledR M u l t i}{ }^{\mathrm{TM}}$ Handbohrer 395 mit 3,2mm Hochgeschwindigkeitsfräser-Aufsatz

Elektrophoresekammern Horizon ${ }^{\mathrm{TM}} 1060$ BD 58 (5x8 cm), Gibco BRL

Elektrophoresekammern Horizon $^{\mathrm{TM}} 1060$ BD 11-14 (11x14 cm), Gibco BRL

Glaskapillaren, 310Capillaries 47-cm x 50 um 5/pkg, PE Applied Biosystems

Kugelschwingmühle Typ MM 2, mit Zirkonium-Mahlbechern, Retsch

Magnetrührer Ikamag ${ }^{\circledR}$ RET, Ikamag® MTC. Ikamag® RH, Janke \& Kunkel Ika-Werk

Polaroid $^{\mathrm{TM}}$-Film , ISO 3000 , Typ 667, Polaroid $^{\circledR}$

Polaroid $^{\mathrm{TM}}-$ Kamera, MP4 Land Camera, Polaroid ${ }^{\mathrm{TM}}$ mit Orangfilter Typ 15 für

Ethidiumbromidfärbung, Polaroid ${ }^{\mathrm{TM}}$

Power Macintosh 7100/66, Apple Computer Inc.

Power Macintosh G3, Apple Computer Inc.

Präzisionswaage excellence Typ E 1200 S, Sartorius

Quadra 650, Apple Computer Inc.

Stromversorgung Typ ST606 Electrophoresis Power Supply, Gibco BRL

Test-tube-rotator, Fa Snijders

Thermomixer Typ 5437, Eppendorf

Transilluminator Typ IL-350K, 254 nm, Bachofer

Varipetten ${ }^{\circledR}$ Typ 4810, Satz: 0,5-10 $\mu 1,10-100 \mu 1,100-1000 \mu 1$, Eppendorf

Wasser-Destilliergerät Typ Muldestor, Wagner \& Munz

Zentrifuge Typ 5402, Eppendorf

Zentrifuge Typ 5415C, Eppendorf 
Zentrifuge Typ 5415R, Eppendorf

\section{Chemikalien und Kits}

$1 \mathrm{~Kb}$ DNA-Leiter (Molekulargewichtsstandard); Life Technologies

310 10X Buffer with EDTA, PE Applied Biosystems

310 POP-6 ${ }^{\mathrm{TM}}$ Polymer, PE Applied Biosystems

ABI Prism ${ }^{\circledR}$ BigDye $^{\circledR}$ Terminator v1.1 Cycle Sequencing Kit, PE Applied Biosystems

Acrylamid / Bisacrylamid 29:1, 40\% w/v, Rotiphorese®, Roth

Agarose Roti ${ }^{\circledR}$ Agarose, Roth

Alconox (Detergenz), Aldrich

Ammoniumpersulfat 98+\% ACS grade, Aldrich

AmpFISTR $^{\circledR}$ Profiler Plus ${ }^{\mathrm{TM}}$ PCR Amplification Kit, PE Applied Biosystems

AmpliTaq-Gold ${ }^{\mathrm{TM}}$ DNA-Polymerase (5U/ $\left.\mu 1\right)$, Perkin Elmer Cetus

Ampuwa $^{\circledR}$ (steriles Wasser), Fresenius

Aqua bidestillata, eigene Herstellung

Borsäure, p.a., Merck

Bromphenolblau, p.a., Serva

Chelex ${ }^{\circledR} 100$ Resin, BioRad

dATP,dCTP,dGTP,dTTP, Sigma

Dextran-Blau, Fluka

DNA Molecular Weight Marker V, Roche

EDTA (Ethylendinitrotetraacetat Dinatriumsalz-Dihydrat):Titriplex ${ }^{\circledR} \mathrm{III}$, Merck

Ethanol absolut, p.a., Abgabestelle der Bundesmonopolverwaltung: Zander-Göttingen, Nordbrand-Nordhausen (Abfüllung Universitätsklinikumsapotheke Göttingen)

Ethidiumbromid, wässrige Lösung $1 \%$ (w/v), 10 mg/ml, Serva

EZ1 DNA Tissue Kit, Qiagen

Formamid, Fluka

GeneAmp® 10x PCR Buffer II \& $\mathrm{MgCl}_{2}$ Solution 25 mM, Perkin Elmer Cetus

Genescan-500 ${ }^{\mathrm{TM}}$ ROX-Kit (spurinterner Standard, loading buffer), PE Applied Biosystems

Harnstoff, Rotiphorese ${ }^{\circledR}$, Roth

Internal Lane Standard 600 (spurinterner Standard, loading buffer), Promega

Isopropanol p.a.,. Merck 
LiChrosolv $^{\circledR}$, HPLC-Wasser zur Chromatographie, Merck

MinElute $^{\mathrm{TM}}$ PCR Purification Kit, Qiagen

Mineralöl NUJOL, Perkin Elmer Cetus

NucleoSeq Kit Dye Terminator Removal, Macherey-Nagel

Qiagen ${ }^{\circledR}$ Multiplex PCR Kit, Qiagen

PowerPlex ${ }^{\circledR}$ Y System, Promega

Proteinase K (Qiagen)

TEMED (Tetramethylethylendiamin), Bio-Rad

Tris (Tri[hydroxymethyl]aminoethan), Trizma ${ }^{\mathrm{TM}}$ Base, p.a., Sigma

\section{Längenstandards}

$1 \mathrm{~Kb}$ Leiter (Größen in bp)

$\begin{array}{llllllllllll}75 & 134 & 154 & 201 & 220 & 298 & 344 & 396 & 506 & 517 & 1018 & 1636\end{array}$

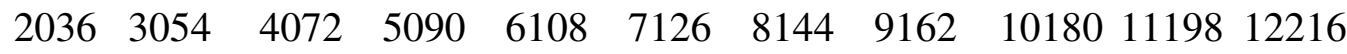

LS V Leiter (Größen in bp)

$\begin{array}{llllllllllll}51 & 57 & 64 & 80 & 89 & 104 & 123 & 124 & 184 & 192 & 213 & 234\end{array}$ 267

GS-500 ROX (Größen in bp)

$\begin{array}{lllllllllllll}35 & 50 & 75 & 100 & 139 & 150 & 160 & 200 & 250 & 300 & 340 & 350 & 400\end{array}$
$450 \quad 490 \quad 500$

ILS 600 (Größen in bp)

$\begin{array}{lllllllllllll}60 & 80 & 100 & 120 & 140 & 160 & 180 & 200 & 225 & 250 & 275 & 300 & 325 \\ & 350 & 375 & 400 & 425 & 450 & 475 & 500 & 550 & 600 & & & \end{array}$

\section{Einwegmaterialien und Hilfsmittel}

Dental-Diamantsägeblätter Typ Diaflex-T H 350 220, Horico

Einmaluntersuchungshandschuhe Safeskin Satin Plus Powder-free, Kimberley-Clark ${ }^{\circledR}$

Eppendorf Reaktionsgefäße $(0,5 \mathrm{ml})$ safe-lock, Eppendorf

Eppendorf Reaktionsgefäße (2,0 ml) safe-lock, Eppendorf

Gesichtsmasken: Surgine face mask, Johnson + Johnson

Kimwipes ${ }^{\circledR}$ Lite, Kinberley Clark $^{\circledR}$

OP-Haube Astronautenform Surgine ${ }^{\circledR}$, Mölnlycke Health Care, Inc. 
Parafilm ${ }^{\circledR} \mathrm{M}$, American National Clan ${ }^{\mathrm{TM}}$

PE-Zentrifugationsgefäße, Blue Max ${ }^{\mathrm{TM}} 50 \mathrm{ml}$ Conical Tubes 2070, Falcon ${ }^{\circledR}$

Pipettenspitzen: blaue Spitzen 1ml, Sarstedt

Pipettenspitzen: gelbe Spitzen 100 $\mu 1$, Sarstedt

Pipettenspitzen: Standardtips 10 $\mu 1$, Eppendorf 


\subsection{Tabellen}

\subsubsection{Fundorte und Quadrantenangabe der cranialen Skelettelemente}

Tabelle 28: Angabe über die Fundorte und die Quadrantenzahl der cranialen Skelettelemente.

\begin{tabular}{|c|c|c|c|c|c|c|c|c|}
\hline Nr. & $\begin{array}{c}\text { Fundnr. } \\
\text { [Do] }\end{array}$ & Fundort & Nr. & $\begin{array}{c}\text { Fundnr. } \\
\text { [Do] }\end{array}$ & Fundort & $\mathrm{Nr}$. & $\begin{array}{c}\text { Fundnr. } \\
\text { [Do] }\end{array}$ & Fundort \\
\hline 1 & 3 & F-K/H-S & 26 & 1078 & R-G 127 & 51 & 3713 & B-S 411 \\
\hline 2 & $4 \mathrm{a}$ & F-K/H-S & 27 & 1172 & R-G 127 & 52 & 3746 & B-S 406/403 \\
\hline 3 & $4 b$ & F-K/H-S & 28 & 1176 & B-S 217 & 53 & 3757 & B-S 406 \\
\hline 4 & 38 & F-K 15 & 29 & 1247 & B-S 213 & 54 & 3886 & B-S 418 \\
\hline 5 & 46 & F-K/H-S & 30 & 1473 & R-G 114 & 55 & 3889 & F-K \\
\hline 6 & 58 & R-G 96 & 31 & 1482 & R-G 114 & 56 & 4003 & B-S 403 \\
\hline 7 & 65 & R-G 96 & 32 & 1485 & R-G 114 & 57 & 4078 & B-S 400 \\
\hline 8 & 71 & R-G 93 & 33 & 1744-1 & H-S 200/300301 & 58 & 4309 & B-S 406 \\
\hline 9 & $87 \mathrm{a}$ & nb. & 34 & $1745 \mathrm{a}$ & B-S 500er & 59 & 5516 & B-S 303 \\
\hline 10 & $87 \mathrm{~b}$ & nb. & 35 & $1745 \mathrm{~b}$ & B-S 500er & 60 & 5517 & B-S 303 \\
\hline 11 & $87 \mathrm{c}$ & nb. & 36 & 1746 I & B-S 500er & 61 & 6525 & D-S 114c \\
\hline 12 & 126 & R-G 96 & 37 & 1746 II & B-S 500er & 62 & E33 & G-K \\
\hline 13 & 152 & R-G 16 & 38 & 2111 & B-S 502 & 63 & E35 & nb. \\
\hline 14 & 159 & R-G 16 & 39 & 2133 & R-G 115 & 64 & E37 & G-K \\
\hline 15 & 193 & R-G 94 & 40 & 2263 & B-S 503-506 & 65 & E39 & G-K \\
\hline 16 & 302 & R-G 111 & 41 & 2388 & B-S 502 & 66 & N969 & G-K \\
\hline 17 & 398 & R-G 97 & 42 & 2589 & G-K- 311 & 67 & R1 & nb. \\
\hline 18 & 480 & R-G 96 & 43 & 2749 & R-G 116 & 68 & $\mathrm{R} 2$ & nb. \\
\hline 19 & 900 & F-K 35 & 44 & 3190 & K-S 103 & 69 & R3 & nb. \\
\hline 20 & 908 & F-K 36 & 45 & 3380 & B-S 400er & & & \\
\hline 21 & 910 & F-K & 46 & 3631 & B-S 400/401 & & & \\
\hline 22 & 918 & F-K & 47 & 3644 & B-S 402 & & & \\
\hline 23 & 934.02 & $\begin{array}{c}\text { F-K } \\
19 / 20 \\
\end{array}$ & 48 & 3705 & B-S 406 & & & \\
\hline 24 & 1046 & R-G 99 & 49 & 3706 & B-S 406 & & & \\
\hline 25 & 1075 & R-G 127 & 50 & 3709 & B-S 4011 & & & \\
\hline
\end{tabular}

Legende: BS = Bernd-Saal, D-S = Damokles-Schluff, F-K = Fiddi-Kluft, G-K = Grabkammer, $\mathrm{H}-\mathrm{S}=$ Horstspalte, K-S = Kathrins-Spalte, $\mathrm{R}-\mathrm{G}=$ Reinhardsgrotte; nb. = nicht bekannt. 


\subsubsection{Autosomale STR-Typisierungsergebnisse}

Tabelle 29: Zusammenstellung der autosomalen STR Gesamtgenotypen für die Individuen aus den Typisierungsergebnissen verschieder Skelettelemente.

\begin{tabular}{|c|c|c|c|c|c|c|c|c|c|c|c|c|}
\hline № & $\begin{array}{c}\text { Skelettelement } \\
{[\text { Do] }}\end{array}$ & $\frac{0}{\stackrel{2}{\Xi}}$ & $\begin{array}{l}\infty \\
\stackrel{n}{n} \\
\frac{\pi}{n} \\
\tilde{n}\end{array}$ & $\sum_{1}^{4}$ & $\underset{\underbrace{}}{ు}$ & 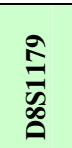 & $\frac{\bar{\sigma}}{\frac{\sigma}{\sigma}}$ & $\begin{array}{l}\bar{n} \\
\infty \\
\infty\end{array}$ & $\begin{array}{l}\infty \\
\infty \\
\infty \\
\infty \\
0\end{array}$ & $\frac{\bar{a}}{\tilde{n}}$ & 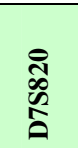 & 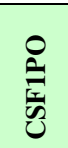 \\
\hline \multirow[t]{2}{*}{ F1 } & $\begin{array}{l}26 \text { [Femur li.] } \\
38 \text { [Mandibula] } \\
152 \text { [Neurocranium] }\end{array}$ & $\begin{array}{l}\mathrm{XX} \\
\mathrm{XX} \\
\mathrm{XX}\end{array}$ & $\begin{array}{c}16 \\
16 / 16 \\
16 / 16\end{array}$ & $\begin{array}{l}16 / 17 \\
16 / 16 \\
16 / 16\end{array}$ & $\begin{array}{c}20 \\
20 / 21 \\
20 / 21\end{array}$ & $\begin{array}{l}8 / 15 \\
8 / 15 \\
8 / 15\end{array}$ & $\begin{array}{l}28 / 29 \\
28 / 29 \\
28 / 29\end{array}$ & $\begin{array}{c}-/- \\
12 / 18 \\
12 / 18\end{array}$ & $\begin{array}{l}9 / 11 \\
9 / 11 \\
9 / 11\end{array}$ & $\begin{array}{l}11 / 13 \\
11 / 13 \\
11 / 13\end{array}$ & $\begin{array}{c}-/- \\
9 / 12 \\
9 / 12\end{array}$ & $\begin{array}{l}11 / 13 \\
11 / 13\end{array}$ \\
\hline & Gesamt-Genotyp & $\mathbf{X X}$ & $16 / 16$ & $16 / 16$ & $20 / 21$ & $8 / 15$ & $28 / 29$ & $12 / 18$ & $9 / 11$ & $11 / 13$ & $9 / 12$ & $11 / 13$ \\
\hline \multirow[t]{2}{*}{ F2 } & $\begin{array}{l}2624 \text { [Calcaneus li.] } \\
1500 \text { [Femur li.] }\end{array}$ & $\begin{array}{l}X X \\
X X\end{array}$ & $\begin{array}{l}16 / 18 \\
16 / 18\end{array}$ & $\begin{array}{l}17 / 18 \\
17 / 18\end{array}$ & $\begin{array}{l}20 / 21 \\
(21) /-\end{array}$ & $\begin{array}{c}-/- \\
13 / 14\end{array}$ & $\begin{array}{l}28 / 30 \\
28 / 30\end{array}$ & $\begin{array}{c}-/- \\
12 / 15\end{array}$ & $\begin{array}{l}11 / 12 \\
11 / 12\end{array}$ & $\begin{array}{c}11 / 12 \\
11 /-\end{array}$ & $\begin{array}{c}-/- \\
10 / 13\end{array}$ & $11 / 13$ \\
\hline & Gesamt-Genotyp & $\mathbf{X X}$ & $16 / 18$ & $17 / 18$ & $20 / 21$ & $13 / 14$ & $28 / 30$ & $12 / 15$ & $11 / 12$ & $11 / 12$ & $10 / 13$ & $11 / 13$ \\
\hline
\end{tabular}

\begin{tabular}{|c|c|c|c|c|c|c|c|c|c|c|c|c|}
\hline \multirow[t]{2}{*}{ F3 } & $\begin{array}{l}\text { 1746I [Felsenbein re.] } \\
\text { 1746II [Felsenbein li.] } \\
2388 \text { [Mandibula] }\end{array}$ & $\begin{array}{c}\mathrm{XX} \\
- \\
\mathrm{XX}\end{array}$ & $\begin{array}{c}15 / 16 \\
-/- \\
15 / 16\end{array}$ & $\begin{array}{l}16 / 17 \\
(16) /- \\
16 / 17\end{array}$ & $\begin{array}{c}20 / 21 \\
-/- \\
20 / 21\end{array}$ & $\begin{array}{c}(15) /- \\
-/- \\
13 / 15\end{array}$ & $\begin{array}{c}30 / 33.2 \\
-/- \\
30 / 33.2\end{array}$ & $\begin{array}{l}-/- \\
-/- \\
15 /-\end{array}$ & $\begin{array}{l}9 / 11 \\
(9) /- \\
11 /-\end{array}$ & $\begin{array}{c}11 / 11 \\
11 /- \\
11 / 11\end{array}$ & $\begin{array}{l}-/- \\
-/- \\
10 /-\end{array}$ & $\begin{array}{c}13 /- \\
-/- \\
13 /-\end{array}$ \\
\hline & Gesamt-Genotyp & $\mathbf{X X}$ & $15 / 16$ & $16 / 17$ & $20 / 21$ & $13 / 15$ & $30 / 33.2$ & $15 /-$ & $9 / 11$ & $11 / 11$ & $10 /-$ & $13 /-$ \\
\hline
\end{tabular}

\begin{tabular}{|c|c|c|c|c|c|c|c|c|c|c|c|c|}
\hline \multirow[t]{2}{*}{ F4 } & $\begin{array}{l}4078 \text { [Mandibula] } \\
5516 \text { [Calvarium] }\end{array}$ & $\begin{array}{l}\mathrm{XX} \\
\mathrm{XX}\end{array}$ & $\begin{array}{l}15 / 18 \\
15 / 18\end{array}$ & $\begin{array}{l}14 / 17 \\
14 / 17\end{array}$ & $\begin{array}{l}20 / 25 \\
20 / 25\end{array}$ & $\begin{array}{l}11 / 15 \\
11 / 15\end{array}$ & $\begin{array}{l}29 / 30 \\
29 / 30\end{array}$ & $\begin{array}{l}14 / 15 \\
(14 / 15)\end{array}$ & $\begin{array}{l}12 / 12 \\
12 / 12\end{array}$ & $\begin{array}{l}8 / 11 \\
8 / 11\end{array}$ & $\begin{array}{l}10 / 12 \\
10 / 12\end{array}$ & $\begin{array}{c}11 /- \\
11 / 12\end{array}$ \\
\hline & Gesamt-Genotyp & $\mathbf{X X}$ & $15 / 18$ & $14 / 17$ & $20 / 25$ & $11 / 15$ & $29 / 30$ & $14 / 15$ & $12 / 12$ & $8 / 11$ & $10 / 12$ & $11 / 12$ \\
\hline
\end{tabular}

\begin{tabular}{|c|c|c|c|c|c|c|c|c|c|c|c|c|}
\hline \multirow[t]{2}{*}{ F5 } & $\begin{array}{l}3706 \text { [Calvarium] } \\
3756 \text { [Femur li.] }\end{array}$ & $\begin{array}{l}\mathrm{XX} \\
\mathrm{XX}\end{array}$ & $\begin{array}{c}18 / 18 \\
18\end{array}$ & $\begin{array}{l}17 / 19 \\
17 / 19\end{array}$ & $\begin{array}{l}21 / 23 \\
21 / 23\end{array}$ & $\begin{array}{l}12 / 15 \\
12 / 15\end{array}$ & $\begin{array}{l}28 / 29 \\
28 / 29\end{array}$ & $\begin{array}{c}16 / 16 \\
16 /-\end{array}$ & $\begin{array}{c}12 / 12 \\
12 /-\end{array}$ & $\begin{array}{c}8 / 9 \\
8 /(9)\end{array}$ & $\begin{array}{l}10 /- \\
10 /-\end{array}$ & $10 / 11$ \\
\hline & Gesamt-Genotyp & $\mathbf{X X}$ & $18 / 18$ & $17 / 19$ & $21 / 23$ & $12 / 15$ & $28 / 29$ & $16 / 16$ & $12 / 12$ & $8 / 9$ & $10 / 10$ & $10 / 11$ \\
\hline
\end{tabular}

\begin{tabular}{|l|l|c|c|c|c|c|c|c|c|c|c|c|}
\hline \multirow{2}{*}{ F6 } & 3709 [Mandibula] & $\mathrm{XX}$ & $16 / 18$ & $17 / 17$ & $21 / 23$ & $12 / 13$ & $29 / 32.2$ & $16 / 17$ & $11 / 12$ & $9 / 12$ & $8 / 10$ & $10 / 13$ \\
& 3750 [Femur li.] & $\mathrm{XX}$ & $16 / 18$ & $17 /-$ & $21 / 23$ & $12 / 13$ & $29 / 32.2$ & $16 / 17$ & $11 / 12$ & $9 / 12$ & $8 / 10$ & \\
& 5517 [Calvarium] & $\mathrm{XX}$ & $16 / 18$ & $17 / 17$ & $21 / 23$ & $-/-$ & $29 / 32.2$ & $-/-$ & $11 / 12$ & $9 / 12$ & $-/ 10$ & $10 / 13$ \\
\cline { 2 - 12 } & Gesamt-Genotyp & $\mathbf{X X}$ & $\mathbf{1 6 / 1 8}$ & $\mathbf{1 7 / 1 7}$ & $\mathbf{2 1 / 2 3}$ & $\mathbf{1 2 / 1 3}$ & $\mathbf{2 9 / 3 2 . 2}$ & $\mathbf{1 6 / 1 7}$ & $\mathbf{1 1 / 1 2}$ & $\mathbf{9 / 1 2}$ & $\mathbf{8 / 1 0}$ & $\mathbf{1 0 / 1 3}$ \\
\hline
\end{tabular}

\begin{tabular}{|l|l|c|c|c|c|c|c|c|c|c|c|c|}
\hline \multirow{2}{*}{ F7 } & 65 [Neurocranium] & $\mathrm{XX}$ & $15 / 16$ & $17 /-$ & $22 / 25$ & $11 / 13$ & $29 /(32.2)$ & $-/-$ & $12 /(12)$ & $8 / 12$ & $-/-$ & $(11) /-$ \\
& 1206 [Femur li.] & $\mathrm{XX}$ & $15 / 16$ & $17 / 17$ & $22 / 25$ & $11 / 13$ & 29 & $15 / 15$ & $12 / 12$ & $8 /-$ & $(8) / 10$ & \\
& 1247 [Mandibula] & $\mathrm{X}$ & $15 / 16$ & $17 /-$ & 22 & $11 / 13$ & $29 / 32.2$ & $-/-$ & $12 / 12$ & $8 /-$ & $10 /-$ & $-/-$ \\
\cline { 2 - 22 } & Gesamt-Genotyp & $\mathbf{X X}$ & $\mathbf{1 5} / \mathbf{1 6}$ & $\mathbf{1 7 / 1 7}$ & $\mathbf{2 2 / 2 5}$ & $\mathbf{1 1 / 1 3}$ & $\mathbf{2 9 / 3 2 . 2}$ & $\mathbf{1 5 / 1 5}$ & $\mathbf{1 2 / 1 2}$ & $\mathbf{8 / 1 2}$ & $\mathbf{( 8 ) / 1 0}$ & $\mathbf{( 1 1 ) / -}$ \\
\hline
\end{tabular}

\begin{tabular}{|l|l|l|l|l|l|l|l|l|l|l|l|l|}
\hline \multirow{2}{*}{ F8 } & $3631[$ Calvarium] & $\mathrm{XX}$ & $18 / 18$ & $14 / 17$ & $21 / 25$ & $11 / 13$ & $30 / 30.2$ & $-/-$ & $12 / 12$ & $8 / 12$ & $10 / 11$ & $11 / 13$ \\
\cline { 2 - 11 } & Gesamt-Genotyp & $\mathbf{X X}$ & $\mathbf{1 8} / \mathbf{1 8}$ & $\mathbf{1 4} / \mathbf{1 7}$ & $\mathbf{2 1 / 2 5}$ & $\mathbf{1 1 / 1 3}$ & $\mathbf{3 0 / 3 0 . 2}$ & $-/-$ & $\mathbf{1 2 / 1 2}$ & $\mathbf{8 / 1 2}$ & $\mathbf{1 0 / 1 1}$ & $\mathbf{1 1 / 1 3}$ \\
\hline
\end{tabular}

\begin{tabular}{|c|c|c|c|c|c|c|c|c|c|c|c|c|}
\hline \multirow[t]{2}{*}{ F9 } & $\begin{array}{l}3705 \text { [Calvarium] } \\
3742 \text { [Femur li.] } \\
3746 \text { [Mandibula] }\end{array}$ & $\begin{array}{c}X X \\
X \\
X(X)\end{array}$ & $\begin{array}{l}14 / 16 \\
14 / 16 \\
14 / 16\end{array}$ & $\begin{array}{l}13 / 14 \\
13 / 14 \\
13 / 14\end{array}$ & $\begin{array}{c}24 /- \\
24 /- \\
24 / 24\end{array}$ & $\begin{array}{c}13 / 13 \\
13 /- \\
13 /-\end{array}$ & $\begin{array}{l}29 / 32.2 \\
29 / 32.2 \\
29 / 32.2\end{array}$ & $\begin{array}{c}-/- \\
12 / 15 \\
15 /-\end{array}$ & $\begin{array}{l}10 / 13 \\
10 / 13 \\
10 / 13\end{array}$ & $\begin{array}{c}8 / 10 \\
8 /- \\
8 /-\end{array}$ & $\begin{array}{c}-/- \\
9 / 10 \\
10 /-\end{array}$ & $\begin{array}{l}12 /- \\
12 /-\end{array}$ \\
\hline & Gesamt-Genotyp & $\mathbf{X X}$ & $14 / 16$ & $13 / 14$ & $24 / 24$ & $13 / 13$ & $29 / 32.2$ & $12 / 15$ & $10 / 13$ & $8 / 10$ & $9 / 10$ & $12 /-$ \\
\hline
\end{tabular}

\begin{tabular}{|c|c|c|c|c|c|c|c|c|c|c|c|c|}
\hline \multirow[t]{2}{*}{ F10 } & $\begin{array}{l}302 \text { [Mandibula] } \\
1046 \text { [Calvarium] }\end{array}$ & $\begin{array}{l}\mathrm{XX} \\
\mathrm{XX}\end{array}$ & $\begin{array}{l}15 / 16 \\
15 / 16\end{array}$ & $\begin{array}{l}16 / 16 \\
16 / 16\end{array}$ & $\begin{array}{c}-/- \\
(22 / 24)\end{array}$ & $\begin{array}{c}-/- \\
13 / 15\end{array}$ & $\begin{array}{c}30.2 /- \\
28 / 30.2\end{array}$ & $\begin{array}{l}-1- \\
-/-\end{array}$ & $\begin{array}{l}9 / 12 \\
9 / 12\end{array}$ & $\begin{array}{l}9 / 13 \\
9 / 13\end{array}$ & $\begin{array}{c}-/- \\
(8 / 12)\end{array}$ & $\begin{array}{l}-/- \\
11 /-\end{array}$ \\
\hline & Gesamt-Genotyp & $\mathbf{X X}$ & $15 / 16$ & $16 / 16$ & $(22 / 24)$ & $13 / 15$ & $28 / 30.2$ & $-/-$ & $9 / 12$ & $9 / 13$ & $(\mathbf{8 / 1 2})$ & 11/- \\
\hline
\end{tabular}

\begin{tabular}{|c|c|c|c|c|c|c|c|c|c|c|c|c|}
\hline \multirow[t]{2}{*}{ F11 } & 3713 [Mandibula] & $\mathrm{XX}$ & 18/- & $(16) / 19$ & $-1-$ & $12 /(15)$ & $29 /-$ & $-1-$ & $11 /(12)$ & $8 / 9$ & $-1-$ & $11 /(11)$ \\
\hline & Gesamt-Genotyp & $\mathbf{X X}$ & $18 /-$ & $(16) / 19$ & $-/$ & $12 /(15)$ & 29/- & $-/$ & $11 /(12)$ & $8 / 9$ & $-/$ & 11/(11) \\
\hline
\end{tabular}

Legende: $\mathrm{F}$ = female, - = Allel nicht bestimmbar, $(\mathrm{)}=$ unsicheres Allel oder unsicher zugeordnetes Skelettelement. Die Typisierungsergebnisse der Calcanei entstammen der Arbeit von Klingner (2005) und der Femora von Schultes (2000). 
Fortsetzung Tabelle 29: Zusammenstellung der autosomalen STR Gesamtgenotypen.

\begin{tabular}{|c|c|c|c|c|c|c|c|c|c|c|c|c|}
\hline № & $\begin{array}{c}\text { Skelettelement } \\
\text { [Do] }\end{array}$ & 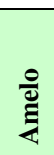 & $\begin{array}{l}\stackrel{\infty}{0} \\
\stackrel{0}{0} \\
\tilde{n}\end{array}$ & $\frac{\pi}{3}$ & છ્ય & 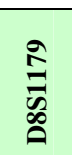 & $\begin{array}{l}\overline{\bar{n}} \\
\bar{\Xi} \\
\bar{\Omega}\end{array}$ & $\begin{array}{l}\bar{n} \\
\infty \\
\overrightarrow{0}\end{array}$ & 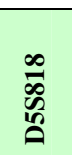 & $\frac{\hat{n}}{\stackrel{n}{a}}$ & $\begin{array}{l}\text { त्र } \\
\text { م } \\
\hat{0}\end{array}$ & 己 \\
\hline \multirow[t]{2}{*}{ F12 } & R1 [Calvarium] & $\mathrm{XX}$ & $16 / 16$ & $14 / 17$ & $21 / 21$ & $13 / 13$ & $29 / 33.2$ & $16 / 17$ & $9 / 12$ & $11 / 12$ & $11 / 12$ & $10 / 11$ \\
\hline & Gesamt-Genotyp & $\mathbf{X X}$ & $16 / 16$ & $14 / 17$ & $21 / 21$ & $13 / 13$ & 29/33.2 & $16 / 17$ & $9 / 12$ & $11 / 12$ & $11 / 12$ & $10 / 11$ \\
\hline \multirow{4}{*}{ F13 } & & & & & & & & & & & & \\
\hline & 1044 [Femur li.] & $\mathrm{XX}$ & $16 / 16$ & $15 / 17$ & $21 / 21$ & $13 / 13$ & $27 / 27$ & $13 / 13$ & $9 / 12$ & $11 / 12$ & $8 / 11$ & \\
\hline & 1078 [Mandibula] & $\mathrm{xX}$ & $16 / 16$ & $15 / 17$ & $21 / 21$ & $13 / 13$ & $27 / 27$ & 13/- & $9 / 12$ & $11 / 12$ & $8 / 11$ & $10 / 11$ \\
\hline & Gesamt-Genotyp & $\mathbf{X X}$ & $16 / 16$ & $15 / 17$ & $21 / 21$ & $13 / 13$ & $27 / 27$ & $13 / 13$ & 9/12 & $11 / 12$ & $8 / 11$ & $10 / 11$ \\
\hline \multirow[t]{3}{*}{ F14 } & 1103 [Femur li.] & $\mathrm{XX}$ & $14 / 16$ & $14 / 15$ & $23 / 24$ & $11 / 14$ & $28 / 30$ & $12 / 15$ & $11 / 12$ & $12 / 13$ & $12 / 12$ & \\
\hline & 4309 [Mandibula] & $\mathrm{xX}$ & $14 / 16$ & $14 / 15$ & $23 / 24$ & $11 / 14$ & $28 / 30$ & $12 / 15$ & $11 / 12$ & $12 / 13$ & $12 /-$ & $11 /-$ \\
\hline & Gesamt-Genotyp & $\mathbf{x x}$ & $14 / 16$ & $14 / 15$ & $23 / 24$ & $11 / 14$ & $28 / 30$ & $12 / 15$ & $11 / 12$ & $12 / 13$ & $12 / 12$ & $11 /-$ \\
\hline \multirow{3}{*}{ F15 } & & & & & & & & & & & & \\
\hline & 2589 [Mandibula] & $\mathrm{XX}$ & $15 / 16$ & $14 / 15$ & $22 / 24$ & $13 / 13$ & $28 / 30$ & $-1-$ & $11 / 12$ & $11 / 12$ & $-1-$ & $10 / 11$ \\
\hline & Gesamt-Genotyp & $\mathbf{x x}$ & $15 / 16$ & $14 / 15$ & $22 / 24$ & $13 / 13$ & $28 / 30$ & - & $11 / 12$ & $11 / 12$ & $-\%$ & $10 / 11$ \\
\hline \multirow{3}{*}{ F16 } & & & & & & & & & & & & \\
\hline & R2 [Calvarium] & $\mathrm{XX}$ & $16 / 18$ & $15 / 18$ & $21 / 21$ & $(15) /-$ & $30 /-$ & $-1-$ & $12 / 12$ & $8 / 12$ & $-1-$ & $13 /-$ \\
\hline & Gesamt-Genotyp & $\mathbf{x x}$ & $16 / 18$ & $15 / 18$ & $21 / 21$ & $(15) /-$ & 30/- & $-/-$ & $12 / 12$ & 8/12 & - & $13 /-$ \\
\hline
\end{tabular}

\begin{tabular}{|l}
\begin{tabular}{|l|l|c|c|c|c|c|c|c|c|c|c|c|}
\hline \multirow{2}{*}{ F17 } & 300 [Femur li.] & $\mathrm{X}$ & $15 / 16$ & $16 /-$ & $-/-$ & $11 / 15$ & $30 /-$ & $-/-$ & $-/-$ & $13 /-$ & $10 /-$ & $-/-$ \\
\cline { 2 - 11 } & Gesamt-Genotyp & $\mathbf{X}$ & $\mathbf{1 5 / 1 6}$ & $\mathbf{1 6 / -}$ & $-/-$ & $\mathbf{1 1 / 1 5}$ & $\mathbf{3 0 / -}$ & $-/-$ & $-/-$ & $\mathbf{1 3 / -}$ & $\mathbf{1 0 / -}$ & $-/-$ \\
\hline \multirow{2}{*}{ F18 } & 199 [Femur li.] & $\mathrm{XX}$ & $15 / 16$ & $14 / 17$ & $(19) / 24$ & $14 /(15)$ & $29 /-$ & $14 / 16$ & $10 / 12$ & $10 / 11$ & $(9) / 11$ & $-/-$ \\
& 1176 [Calvarium] & $\mathrm{XX}$ & $15 / 16$ & $14 / 17$ & $19 / 24$ & $14 / 15$ & $29 / 29$ & $14 / 16$ & $10 / 12$ & $10 / 11$ & $11 /-$ & $10 / 12$ \\
& 2133 [Mandibula] & $\mathrm{XX}$ & $15 / 16$ & $14 / 17$ & $19 / 24$ & $14 / 15$ & $29 /-$ & $14 / 16$ & $10 / 11$ & $10 / 11$ & $11 / 11$ & $10 / 12$ \\
\cline { 2 - 11 } & Gesamt-Genotyp & $\mathbf{X X}$ & $\mathbf{1 5 / 1 6}$ & $\mathbf{1 4 / 1 7}$ & $\mathbf{1 9 / 2 4}$ & $\mathbf{1 4 / 1 5}$ & $\mathbf{2 9 / 2 9}$ & $\mathbf{1 4 / 1 6}$ & $\mathbf{1 0 / 1 2}$ & $\mathbf{1 0 / 1 1}$ & $\mathbf{1 1 / 1 1}$ & $\mathbf{1 0 / 1 2}$ \\
\hline
\end{tabular}
\end{tabular}

\begin{tabular}{|c|c|c|c|c|c|c|c|c|c|c|c|c|}
\hline \multirow[t]{2}{*}{ F19 } & $\begin{array}{l}1585 \text { [Femur li.] } \\
1585 \text { [Calcaneus li.] }\end{array}$ & $\begin{array}{l}\mathrm{XX} \\
\mathrm{XX}\end{array}$ & $\begin{array}{l}15 / 17 \\
15 / 17\end{array}$ & $\begin{array}{c}-/- \\
14 / 18\end{array}$ & $\begin{array}{c}-/- \\
20 / 24\end{array}$ & $\begin{array}{c}14 /- \\
12 / 14\end{array}$ & $\begin{array}{c}-/- \\
30.2 / 31\end{array}$ & $\begin{array}{l}-/- \\
15 /-\end{array}$ & $\begin{array}{c}-/- \\
10 / 12\end{array}$ & $\begin{array}{l}10 /- \\
10 / 11\end{array}$ & $\begin{array}{c}-/- \\
11 /-\end{array}$ & $11 / 13$ \\
\hline & Gesamt-Genotyp & $\mathbf{X X}$ & $15 / 17$ & $14 / 18$ & $20 / 24$ & $12 / 14$ & $30.2 / 31$ & $15 /-$ & $10 / 12$ & $10 / 11$ & $11 /-$ & $11 / 13$ \\
\hline
\end{tabular}

\begin{tabular}{|l|l|l|l|l|l|l|l|l|l|l|l|l|}
\hline \multirow{2}{*}{ F20 } & $3190[$ [Mandibula] & $\mathrm{XX}$ & $(16) /-$ & $(16) /-$ & $-/-$ & $-/-$ & $-/$ & $-/-$ & $-/-$ & $(12) /-$ & $-/-$ & $(11) /-$ \\
\cline { 2 - 10 } & Gesamt-Genotyp & $\mathbf{X X}$ & $\mathbf{( 1 6 ) / -}$ & $\mathbf{( 1 6 )} /-$ & $-/-$ & $-/-$ & $-/-$ & $-/-$ & $-/-$ & $\mathbf{( 1 2}) /-$ & $-/-$ & $(\mathbf{1 1}) /-$ \\
\hline
\end{tabular}

\begin{tabular}{|l|l|l|l|l|l|l|l|l|l|l|l|l|}
\hline \multirow{2}{*}{ F21 } & E37 [Viscerocranium] & $\mathrm{XX}$ & $16 /-$ & $16 /-$ & $-/-$ & $-/-$ & $-/-$ & $-/-$ & $-/-$ & $8 /-$ & $-/-$ & $-/-$ \\
\cline { 2 - 11 } & Gesamt-Genotyp & $\mathbf{X X}$ & $\mathbf{1 6 / -}$ & $\mathbf{1 6} /-$ & $-/-$ & $-/-$ & $-/-$ & $-/-$ & $-/-$ & $\mathbf{8} /-$ & $-/-$ & $-/-$ \\
\hline
\end{tabular}

\begin{tabular}{|c|c|c|c|c|c|c|c|c|c|c|c|c|}
\hline \multirow[t]{2}{*}{ M1 } & $\begin{array}{l}1076 \text { [Femur li.] } \\
1172 \text { [Mandibula] } \\
1485 \text { [Calvarium] }\end{array}$ & $\begin{array}{l}X Y \\
X Y \\
X Y\end{array}$ & $\begin{array}{l}15 / 17 \\
15 / 17 \\
15 / 17\end{array}$ & $\begin{array}{l}15 / 16 \\
15 / 16 \\
15 / 16\end{array}$ & $\begin{array}{c}21 / 25 \\
21 /(25) \\
21 / 25\end{array}$ & $\begin{array}{l}12 / 13 \\
12 / 13 \\
12 / 13\end{array}$ & $\begin{array}{l}30.2 / 33.2 \\
30.2 / 33.2 \\
30.2 / 33.2\end{array}$ & $\begin{array}{c}14 / 20 \\
-/- \\
14 / 20\end{array}$ & $\begin{array}{l}10 / 12 \\
10 / 12 \\
10 / 12\end{array}$ & $\begin{array}{l}11 / 13 \\
11 / 13 \\
11 / 13\end{array}$ & $\begin{array}{c}7 / 8 \\
(8) /- \\
7 / 8\end{array}$ & $\begin{array}{c}-/- \\
10 / 10\end{array}$ \\
\hline & Gesamt-Genotyp & $\mathbf{X Y}$ & $15 / 17$ & $15 / 16$ & $21 / 25$ & $12 / 13$ & $30.2 / 33.2$ & $14 / 20$ & $10 / 12$ & $11 / 13$ & $7 / 8$ & $10 / 10$ \\
\hline \multirow{3}{*}{ M2 } & & & & & & & & & & & & \\
\hline & $\begin{array}{l}1102 \text { [Femur li.] } \\
3644 \text { [Mandibula] }\end{array}$ & $\begin{array}{l}\mathrm{XY} \\
\mathrm{XY}\end{array}$ & $\begin{array}{c}15 / 16 \\
15 /(16)\end{array}$ & $\begin{array}{l}16 / 16 \\
16 / 16\end{array}$ & $\begin{array}{c}20 / 21 \\
21 /-\end{array}$ & $\begin{array}{l}12 / 15 \\
(12) /-\end{array}$ & $\begin{array}{l}29 / 33.2 \\
29 /-\end{array}$ & $\begin{array}{l}14 / 18 \\
(18) /-\end{array}$ & $\begin{array}{c}9 / 10 \\
9 /(10)\end{array}$ & $\begin{array}{l}11 / 11 \\
11 / 11\end{array}$ & $\begin{array}{l}7 / 9 \\
-/-\end{array}$ & $13 /-$ \\
\hline & Gesamt-Genotyp & $\mathbf{X Y}$ & $15 / 16$ & $16 / 16$ & $20 / 21$ & $12 / 15$ & $29 / 33.2$ & $14 / 18$ & 9/10 & $11 / 11$ & $7 / 9$ & $13 /-$ \\
\hline
\end{tabular}

Legende: $\mathrm{F}$ = female, $\mathrm{M}=$ male, - = Allel nicht bestimmbar, ( ) = unsicheres Allel oder unsicher zugeordnetes Skelettelement. Die Typisierungsergebnisse der Calcanei entstammen der Arbeit von Klingner (2005) und der Femora von Schultes (2000). 
Fortsetzung Tabelle 29: Zusammenstellung der autosomalen STR Gesamtgenotypen.

\begin{tabular}{|c|c|c|c|c|c|c|c|c|c|c|c|c|}
\hline № & $\begin{array}{c}\text { Skelettelement } \\
\text { [Do] }\end{array}$ & $\frac{\varrho}{\mathbb{\Xi}}$ & $\frac{\infty}{\infty}$ & $\widehat{s}$ & 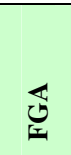 & $\begin{array}{l}\stackrel{\vartheta}{=} \\
\stackrel{0}{0}\end{array}$ & $\begin{array}{l}\overline{\bar{D}} \\
\bar{\Xi}\end{array}$ & $\begin{array}{l}\vec{n} \\
\infty \\
\overrightarrow{0}\end{array}$ & $\begin{array}{l}\infty \\
\infty \\
0 \\
0 \\
0\end{array}$ & $\frac{5}{n}$ & 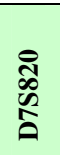 & $\stackrel{0}{\varrho}$ \\
\hline M3 & $\begin{array}{l}67.3 \text { [Femur re.] } \\
1482 \text { [Mandibula] } \\
1911 \text { [Femur li.] } \\
6525 \text { [Calvarium] }\end{array}$ & $\begin{array}{l}(X Y) \\
X Y \\
X Y \\
X Y\end{array}$ & $\begin{array}{c}-/- \\
16 / 18 \\
16 / 18 \\
16 / 18\end{array}$ & $\begin{array}{l}17 / 19 \\
17 / 19 \\
17 / 19 \\
17 / 19\end{array}$ & $\begin{array}{c}-/- \\
21 / 22 \\
21 / 22 \\
21 / 22\end{array}$ & $\begin{array}{c}(13 / 15) \\
13 / 13 \\
13 / 13 \\
-/\end{array}$ & $\begin{array}{c}(30.2) \\
30.2 / 32.2 \\
(30.2) / 32.2 \\
30.2 /(30.2)\end{array}$ & $\begin{array}{c}-/- \\
15 / 17 \\
15 / 17 \\
-/-\end{array}$ & $\begin{array}{c}-/- \\
11 / 12 \\
11 / 12 \\
11 / 12\end{array}$ & $\begin{array}{c}-/- \\
12 / 12 \\
12 / 12 \\
12 /-\end{array}$ & $\begin{array}{c}-/- \\
8 / 11 \\
8 / 11 \\
-/-\end{array}$ & $11 / 13$ \\
\hline & Gesamt-Genotyp & $\mathbf{X Y}$ & $16 / 18$ & $17 / 19$ & $21 / 22$ & $13 / 13$ & $30.2 / 32.2$ & $15 / 17$ & $11 / 12$ & $12 / 12$ & 8/11 & $11 / 13$ \\
\hline
\end{tabular}

\begin{tabular}{|c|c|c|c|c|c|c|c|c|c|c|c|c|}
\hline \multirow[t]{2}{*}{ M4 } & \begin{tabular}{|l|} 
4b [Mandibula] \\
35 [Femur li.] \\
900 [Neurocranium]
\end{tabular} & $\begin{array}{l}- \\
X Y \\
X Y\end{array}$ & $\begin{array}{c}-/- \\
17 /- \\
15 / 17\end{array}$ & $\begin{array}{c}-/- \\
16 / 17 \\
16 / 17\end{array}$ & $\begin{array}{c}-/- \\
(25) \\
20 / 25\end{array}$ & $\begin{array}{c}-/- \\
14 /- \\
10 / 14\end{array}$ & $\begin{array}{c}-1- \\
29 /- \\
28 / 29\end{array}$ & $\begin{array}{c}-/- \\
-/- \\
14 / 19\end{array}$ & $\begin{array}{c}-/- \\
11 / 12 \\
11 / 12\end{array}$ & $\begin{array}{c}-/- \\
-/- \\
12 / 13\end{array}$ & $\begin{array}{l}-/- \\
-/- \\
11 / 12\end{array}$ & $\begin{array}{l}-/- \\
12 / 12\end{array}$ \\
\hline & Gesamt-Genotyp & $\mathbf{X Y}$ & $15 / 17$ & $16 / 17$ & $20 / 25$ & $10 / 14$ & $28 / 29$ & $14 / 19$ & $11 / 12$ & $12 / 13$ & $11 / 12$ & $12 / 12$ \\
\hline & & & & & & & & & & & & \\
\hline \multirow[t]{3}{*}{ M5 } & 908 [Calvarium] & $\mathrm{XY}$ & $15 / 17$ & $16 / 19$ & $20 / 25$ & $10 / 14$ & $28 / 30$ & $15 / 19$ & $11 / 13$ & $8 / 14$ & $(10) / 13$ & $(10) / 12$ \\
\hline & 3380 [Mandibula] & $\mathrm{XY}$ & $(15) / 17$ & $(16) / 19$ & $(25) /-$ & $10 / 14$ & $28 / 30$ & $-1-$ & $11 / 13$ & $8 /(14)$ & $-/-$ & $-1-$ \\
\hline & Gesamt-Genotyp & $\mathbf{X Y}$ & $15 / 17$ & $16 / 19$ & $20 / 25$ & $10 / 14$ & $28 / 30$ & $15 / 19$ & $11 / 13$ & $8 / 14$ & $(10) / 13$ & $(10) / 12$ \\
\hline \multirow{5}{*}{ M6 } & & & & & & & & & & & & \\
\hline & 2030 [Femur li.] & $\mathrm{XY}$ & $16 / 16$ & $17 / 18$ & $21 / 24$ & $10 / 12$ & $29 / 30.2$ & $16 / 18$ & $10 / 13$ & $12 / 13$ & 9/9 & \\
\hline & 2111 [Mandibula] & $\mathrm{XY}$ & $16 /-$ & $18 /-$ & $21 /-$ & $10 /-$ & $30.2 /-$ & $16 /-$ & $(10) / 13$ & 13/- & $9 /(9)$ & -1 \\
\hline & R3 [Calvarium] & $\mathrm{XY}$ & $16 / 16$ & $17 / 18$ & $21 / 24$ & $10 / 12$ & $29 / 30.2$ & $16 /-$ & $10 / 13$ & $12 /-$ & 9/- & 10/- \\
\hline & Gesamt-Genotyp & $\mathbf{X Y}$ & $16 / 16$ & $17 / 18$ & $21 / 24$ & $10 / 12$ & $29 / 30.2$ & $16 / 18$ & $10 / 13$ & $12 / 13$ & 9/9 & $10 /-$ \\
\hline & & & & & & & & & & & & \\
\hline \multirow[t]{3}{*}{ M7 } & 3 [Felsenbein li.] & $\mathrm{XY}$ & $14 / 15$ & $17 / 18$ & $24 / 25$ & $(10 / 11)$ & $29 / 30$ & $(13 / 18)$ & $12 / 12$ & $8 / 12$ & $(10 / 11)$ & $10 /-$ \\
\hline & 910 [Calvarium] & $\mathrm{XY}$ & $14 / 15$ & $17 / 18$ & $24 / 25$ & $10 / 11$ & $29 / 30$ & $-/-$ & $12 / 12$ & $8 / 12$ & $11 /-$ & $10 /-$ \\
\hline & Gesamt-Genotyp & $\mathbf{X Y}$ & $14 / 15$ & $17 / 18$ & $24 / 25$ & $10 / 11$ & $29 / 30$ & $(13 / 18)$ & $12 / 12$ & $8 / 12$ & (10)/11 & $10 / 10$ \\
\hline & & & & & & & & & & & & \\
\hline \multirow[t]{2}{*}{ M8 } & $\begin{array}{l}3757 \text { [Calvarium] } \\
4003 \text { [Mandibula] }\end{array}$ & $\begin{array}{c}\mathrm{XY} \\
\mathrm{X}(\mathrm{Y})\end{array}$ & $\begin{array}{c}17 / 18 \\
-/-\end{array}$ & $\begin{array}{l}17 / 18 \\
18 /-\end{array}$ & $\begin{array}{c}21 / 25 \\
-/-\end{array}$ & $\begin{array}{c}10 / 11 \\
(10 / 11)\end{array}$ & $\begin{array}{l}30.2 /- \\
-/-\end{array}$ & $\begin{array}{l}-1- \\
-1-\end{array}$ & $\begin{array}{c}10 / 12 \\
-/\end{array}$ & $\begin{array}{c}10 / 12 \\
-/-\end{array}$ & $\begin{array}{l}9 /- \\
-/-\end{array}$ & $\begin{array}{c}12 / 13 \\
-/-\end{array}$ \\
\hline & Gesamt-Genotyp & $\mathbf{X Y}$ & $17 / 18$ & $17 / 18$ & $21 / 25$ & $10 / 11$ & 30.2/- & $12 /-$ & $10 / 12$ & $10 / 12$ & 9/- & $12 / 13$ \\
\hline & & & & & & & & & & & & \\
\hline \multirow[t]{5}{*}{ M9 } & 1473 [Calvarium] & $\mathrm{XY}$ & $16 / 19$ & $14 / 16$ & $21 / 23$ & $13 /-$ & $27 / 32.2$ & $-1-$ & $12 / 12$ & $11 / 14$ & $-/$ & $11 /-$ \\
\hline & 1905 [Femur re.] & $\mathrm{XY}$ & $16 / 19$ & $14 / 16$ & $21 / 23$ & $13 / 13$ & $27 / 32.2$ & $12 / 14$ & $12 / 12$ & $11 / 14$ & $10 /(13)$ & \\
\hline & 1916 [Femur li.] & $\mathrm{XY}$ & $16 / 19$ & $14 / 16$ & $21 / 23$ & 13/- & $27 / 32.2$ & $12 / 14$ & $12 /-$ & $11 / 14$ & $10 /(10)$ & \\
\hline & 2749 [Mandibula] & $\mathrm{XY}$ & $16 / 19$ & $14 / 16$ & $21 / 23$ & (13)- & $27 / 32.2$ & $(12) / 14$ & $12 / 12$ & $11 / 14$ & $10 / 13$ & $11 /-$ \\
\hline & Gesamt-Genotyp & $\mathbf{X Y}$ & $16 / 19$ & $14 / 16$ & $21 / 23$ & $13 / 13$ & $27 / 32.2$ & $12 / 14$ & $12 / 12$ & $11 / 14$ & $10 / 13$ & $11 /-$ \\
\hline \multirow{4}{*}{ M10 } & & & & & & & & & & & & \\
\hline & 902 [Femur li.] & $\mathrm{XY}$ & $14 / 15$ & $13 / 15$ & $22 / 24$ & $13 / 13$ & $31.2 / 32.2$ & $10 / 12$ & $12 /(13)$ & $9 / 13$ & 9/9 & \\
\hline & $\mathrm{Cos}+\mathrm{Con}$ & $X(1)$ & 14/15 & & anes & 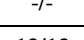 & $(32.2) /-$ & 20 & $121-$ & $(13) /=$ & - & $-1-$ \\
\hline & Gesamt-Genotyp & $\mathbf{X Y}$ & $14 / 15$ & $13 / 15$ & $22 / 24$ & $13 / 13$ & $31.2 / 32.2$ & $10 / 12$ & $12 /(13)$ & 9/13 & 9/9 & $-/-$ \\
\hline
\end{tabular}

\begin{tabular}{|l|l|c|c|c|c|c|c|c|c|c|c|c|}
\hline \multirow{2}{*}{ M11 } & 183 [Femur li.] & $\mathrm{XY}$ & $14 / 16$ & $14 / 19$ & $24 /(24)$ & $13 /(13)$ & $(29 / 33.2)$ & $-/-$ & $10 / 12$ & $11 /-$ & $10 /-$ & \\
& $(398$ [Mandibula] $)$ & $\mathrm{X}$ & $-/-$ & $-/-$ & $-/-$ & $-/-$ & $-/-$ & $-/-$ & $-/-$ & $8 /-$ & - & $(12) /-$ \\
\cline { 2 - 11 } & Gesamt-Genotyp & $\mathbf{X Y}$ & $\mathbf{1 4 / 1 6}$ & $\mathbf{1 4 / 1 9}$ & $\mathbf{2 4 / ( 2 4 )}$ & $\mathbf{1 3 / ( 1 3 )}$ & $\mathbf{( 2 9 / 3 3 . 2 )}$ & $-/-$ & $\mathbf{1 0 / 1 2}$ & $\mathbf{1 1 / -}$ & $\mathbf{1 0 / -}$ & $-/-$ \\
\hline
\end{tabular}

\begin{tabular}{|l|l|c|c|c|c|c|c|c|c|c|c|c|}
\hline \multirow{2}{*}{ M12 } & E33 [Mandibula] & XY & $-/-$ & $16 / 18$ & $21 /-$ & $-/-$ & $30 / 33.2$ & $-/-$ & $9 / 11$ & $11 /-$ & $-/-$ & $-/-$ \\
\cline { 2 - 11 } & Gesamt-Genotyp & XY & $-/-$ & $\mathbf{1 6 / 1 8}$ & $\mathbf{2 1 / -}$ & $-/-$ & $\mathbf{3 0 / 3 3 . 2}$ & $-/-$ & $\mathbf{9 / 1 1}$ & $\mathbf{1 1 / -}$ & $-/-$ & $-/-$ \\
\hline
\end{tabular}

Legende: $\mathrm{M}=$ male, - = Allel nicht bestimmbar, ( ) = unsicheres Allel oder unsicher zugeordnetes Skelettelement. Die Typisierungsergebnisse der Tibien entstammen der Arbeit von Croll 2005 und der Femora von Schultes (2000). 
Fortsetzung Tabelle 29: Zusammenstellung der autosomalen STR Gesamtgenotypen.

\begin{tabular}{|c|c|c|c|c|c|c|c|c|c|c|c|c|}
\hline № & $\begin{array}{c}\text { Skelettelement } \\
\text { [Do] }\end{array}$ & $\stackrel{ }{\stackrel{\Xi}{\sharp ~}}$ & 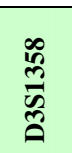 & 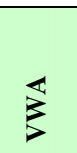 & 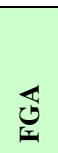 & 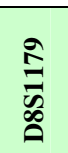 & $\frac{\bar{\sigma}}{\stackrel{\Xi}{\widetilde{N}}}$ & $\frac{\overline{0}}{\infty}$ & $\begin{array}{l}\infty \\
\infty \\
\infty \\
\infty \\
0\end{array}$ & $\frac{\sqrt{n}}{\stackrel{0}{a}}$ & 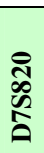 & $\stackrel{0}{0}$ \\
\hline \multirow[t]{2}{*}{ M13 } & 58.3 [Femur li.] & $\mathrm{XY}$ & $15 / 18$ & $16 / 18$ & $25 /-$ & $13 / 13$ & $29 / 30$ & $-/-$ & $11 /(11)$ & $(13) /-$ & $-/-$ & $-/-$ \\
\hline & Gesamt-Genotyp & $\mathbf{X Y}$ & $15 / 18$ & $16 / 18$ & $25 /-$ & $13 / 13$ & $29 / 30$ & $-/-$ & $11 /(11)$ & $(13) /-$ & - & $-/-$ \\
\hline
\end{tabular}

\begin{tabular}{|c|c|c|c|c|c|c|c|c|c|c|c|c|}
\hline \multirow[t]{2}{*}{ M14 } & $\begin{array}{l}905 \text { [Femur li.] } \\
\text { (918 [Neurocranium]) }\end{array}$ & $\begin{array}{l}X Y \\
X Y\end{array}$ & $\begin{array}{l}15 /(17) \\
15 /(15)\end{array}$ & $\begin{array}{c}16 /(17) \\
16 /-\end{array}$ & $\begin{array}{c}22 / 24 \\
(20) / 22\end{array}$ & $\begin{array}{l}-1- \\
-1-\end{array}$ & $\begin{array}{l}-/- \\
29 /-\end{array}$ & $\begin{array}{c}17 /(19) \\
-/-\end{array}$ & $\begin{array}{l}11 / 12 \\
11 / 12\end{array}$ & $\begin{array}{l}(11) /- \\
8 / 11\end{array}$ & $\begin{array}{c}(9 / 10) \\
-/-\end{array}$ & $10 / 12$ \\
\hline & Gesamt-Genotyp & $\mathbf{X Y}$ & $15 /(17)$ & $16 /(17)$ & $22 / 24$ & $-/-$ & $(29) /-$ & $17 /(19)$ & $11 / 12$ & $(8) / 11$ & $-/-$ & $(10 / 12)$ \\
\hline
\end{tabular}

\begin{tabular}{|c|c|c|c|c|c|c|c|c|c|c|c|c|}
\hline \multirow[t]{2}{*}{ M15 } & 2263 [Mandibula] & $\mathrm{X}(\mathrm{Y})$ & $15 / 16$ & $-/$ & $22 / 24$ & $13 /-$ & $29 /-$ & $(16 / 18)$ & $12 / 13$ & $12 /-$ & $-/-$ & $10 /(11)$ \\
\hline & Gesamt-Genotyp & $\mathbf{X}(\mathbf{Y})$ & $15 / 16$ & $-/-$ & $22 / 24$ & $13 /-$ & $29 /-$ & $(16 / 18)$ & $12 / 13$ & $12 /-$ & $-/-$ & $10 /(11)$ \\
\hline
\end{tabular}

\begin{tabular}{|c|c|c|c|c|c|c|c|c|c|c|c|c|}
\hline \multirow[t]{2}{*}{ M16 } & 3886 [Felsenbein li.] & $\mathrm{XY}$ & $17 / 18$ & $14 / 17$ & $24 / 25$ & $10 / 13$ & $29 / 30.2$ & $12 / 15$ & $10 / 12$ & $8 / 10$ & $8 / 11$ & $11 / 12$ \\
\hline & Gesamt-Genotyp & $\mathbf{X Y}$ & $17 / 18$ & $14 / 17$ & $24 / 25$ & $10 / 13$ & $29 / 30.2$ & $12 / 15$ & $10 / 12$ & $8 / 10$ & $8 / 11$ & $11 / 12$ \\
\hline
\end{tabular}

\begin{tabular}{|c|c|c|c|c|c|c|c|c|c|c|c|c|}
\hline \multirow[t]{2}{*}{ M17 } & 57.2 [Femur li.] & $\mathrm{XY}$ & $15 / 17$ & $17 /-$ & $22 / 24$ & $-/-$ & $29 /-$ & $-/-$ & $11 /-$ & $-/-$ & $10 /-$ & $-1-$ \\
\hline & Gesamt-Genotyp & $\mathbf{X Y}$ & $15 / 17$ & $17 /-$ & $22 / 24$ & $-/-$ & $29 /-$ & $-/-$ & $11 /-$ & $-/-$ & $10 /-$ & $-/-$ \\
\hline
\end{tabular}

\begin{tabular}{|c|c|c|c|c|c|c|c|c|c|c|c|c|}
\hline \multirow[t]{2}{*}{ M18 } & 901 [Femur li.] & $\mathrm{X}(\mathrm{Y})$ & $16 /-$ & $14 / 15$ & $22 /-$ & $(14) /-$ & $-/-$ & $(15) /-$ & $(12) /-$ & $-1-$ & $-1-$ & $-1-$ \\
\hline & Gesamt-Genotyp & $\mathbf{X}(\mathbf{Y})$ & $16 /-$ & $14 / 15$ & $22 /-$ & (14)/- & $-/-$ & $(15) /-$ & $(12) /-$ & $-/-$ & $-/-$ & $-/-$ \\
\hline \multirow[t]{3}{*}{ M19 } & 153 [Tibia re.] & $\mathrm{XY}$ & $15 / 17$ & $16 / 18$ & $23 / 25$ & $(10 / 13)$ & $28 / 29$ & $(14 / 15)$ & $12 / 13$ & $8 / 13$ & $(10 / 12)$ & $10 / 12$ \\
\hline & 487 [Calcaneus li.] & $\mathrm{XY}$ & $(15 / 17)$ & $16 /-$ & $(23) /-$ & (13) & $(28 / 29)$ & $-1-$ & $13 /-$ & $8 / 13$ & $-1-$ & $10 /-$ \\
\hline & Gesamt-Genotyp & $\mathbf{X Y}$ & $15 / 17$ & $16 / 18$ & $23 / 25$ & $(10 / 13)$ & $28 / 29$ & $(14 / 15)$ & $12 / 13$ & $8 / 13$ & $(10 / 12)$ & $10 / 12$ \\
\hline
\end{tabular}

Legende: $\mathrm{M}=$ male, - = Allel nicht bestimmbar, $(\mathrm{)}$ = unsicheres Allel oder unsicher zugeordnetes Skelettelement. Die Typisierunsergebnisse der Tiba entstammen der Arbeit von Croll 2005, des Calcaneus der von Klingner 2005 und der Femora von Schultes (2000). 
Anhang : Tabellen autosomale STR-Typisierungsergebnisse

Tabelle 30: Einzeltypisierungsergebnisse der autosomale STR-Analysen. Die Bestimmung des autosomalen Allelmusters wurde mit der Oktaplex-PCR und dem ProfilerPlus Kit duchgeführt. Neben der Fundnummer ist das jeweilige Skelettelement angegeben und wenn möglich zu welchem Individuum es gehört.

\begin{tabular}{|c|c|c|c|c|c|c|c|c|c|c|c|c|}
\hline M7 & \multicolumn{10}{|c|}{ 3 [Felsenbein li.] } \\
\hline PCR & EX & Amelo & D3S1358 & VWA & FGA & D8S1179 & D21S11 & D18S51 & D5S818 & D13S317 & D7S820 & CSF1PO \\
\hline 58 & I & XY & $14 / 15$ & $-/-$ & $24 / 25$ & & $29 / 30$ & & 12 & $8 / 12$ & & 10 \\
\hline 59 & I & XY & $14 / 15$ & $17 / 18$ & $24 / 25$ & & $29 / 30$ & & 12 & $8 / 12$ & & 10 \\
\hline 62 & I & XY & $14 / 15$ & $17 / 18$ & $24 / 25$ & $10 / 11$ & $29 / 30$ & $13 / 18$ & 12 & $8 / 12$ & $10 / 11$ & $10 /-$ \\
\hline
\end{tabular}

\begin{tabular}{|c|c|c|c|c|c|c|c|c|c|c|c|c|}
\hline & \multicolumn{12}{|c|}{ 4a [Mandibula] } \\
\hline PCR & EX & Amelo & D3S1358 & VWA & FGA & D8S1179 & D21S11 & D18S51 & $\begin{array}{l}\text { D5S818 } \\
\end{array}$ & D13S317 & D7S820 & CSF1PO \\
\hline 29 & $\mathrm{I}$ & $\mathrm{X}$ & $-1-$ & $-1-$ & $-1-$ & $\sum$ & $-1-$ & $\sum<$ & $-/-$ & 13.2 & $\sum$ & 10.2 \\
\hline 32 & I & $\mathrm{X}$ & $-1-$ & $-1-$ & $-/-$ & $>$ & $-1-$ & 3 & $-/-$ & $-1-$ & $>$ & $-/-$ \\
\hline 35 & II & - & $-1-$ & $-1-$ & $-1-$ & $\sum<$ & 29 & $\sum<$ & $-1-$ & (13) & $\sum<$ & $-1-$ \\
\hline Ger & & $\mathrm{X}$ & $-/-$ & $-1-$ & $-/-$ & $-/-$ & $-/-$ & $-/-$ & /- & $-/-$ & $-/-$ & $-1-$ \\
\hline
\end{tabular}

\begin{tabular}{|c|c|c|c|c|c|c|c|c|c|c|c|c|}
\hline M4 & \multicolumn{12}{|c|}{ 4b [Mandibula] } \\
\hline $\begin{array}{l}\text { PCR } \\
\end{array}$ & EX & Amelo & $\begin{array}{l}\text { D3S1358 } \\
\end{array}$ & VWA & FGA & D8S1179 & $\mathrm{D} 21 \mathrm{~S} 11$ & D18S51 & $\begin{array}{l}\text { D5S818 } \\
\end{array}$ & D13S317 & D7S820 & CSF1PO \\
\hline 29 & I & - & $-1-$ & $-/-$ & $-1-$ & 3 & $-/-$ & $3<$ & 12 & 13 & $>$ & 10 \\
\hline 32 & I & $\mathrm{Y}$ & $-/-$ & $-1-$ & $-/-$ & $\sum<$ & $-1-$ & $\sum<$ & 11 & $-/-$ & $\sum<$ & $-1-$ \\
\hline 35 & II & - & $-1-$ & $-1-$ & $-/-$ & $><$ & 28 & $><$ & 10.2 & $12 / 13$ & $\sum<$ & $-/-$ \\
\hline 35 & III & - & $-1-$ & $-1-$ & $-1-$ & $\sum$ & $-1-$ & 3 & $-1-$ & $-/-$ & 3 & $-1-$ \\
\hline Gen & typ & - & $-1-$ & $-1-$ & $-1-$ & $-/-$ & $-/-$ & $-/-$ & $-/-$ & 13/- & $-/$ & $-/-$ \\
\hline
\end{tabular}

\begin{tabular}{|c|c|c|c|c|c|c|c|c|c|c|c|c|}
\hline $\mathrm{F} 1$ & \multicolumn{12}{|c|}{38 [Mandibula] } \\
\hline PCR & EX & Amelo & $\begin{array}{l}\text { D3S1358 } \\
\end{array}$ & VWA & FGA & D8S1179 & D21S11 & D18S51 & D5S818 & D13S317 & D7S820 & CSF1PO \\
\hline 29 & I & $\mathrm{X}$ & $(15) / 16$ & $(15) / 16$ & $20 / 21$ & $S<$ & $28 / 29$ & $3<$ & $9 / 11$ & $11 / 13$ & $3<$ & $11 / 13$ \\
\hline 31 & I & $\mathrm{X}$ & 16 & 16 & $20 / 21$ & $8 / 15$ & $28 / 29$ & $12 / 18$ & $9 / 11$ & $11 / 13$ & $9 / 12$ & $\sum<$ \\
\hline 34 & $\mathrm{I}$ & $\mathrm{X}$ & 16 & 16 & $20 / 21$ & $\sum$ & $28 / 29$ & $><$ & $9 / 11$ & $11 / 13$ & $><$ & $11 / 13$ \\
\hline 35 & II & $\mathrm{X}$ & 16 & 16 & $20 / 21$ & $\sum$ & $28 / 29$ & $\sum$ & $9 / 11$ & $11 / 13$ & $\sum$ & $11 / 13$ \\
\hline 41 & II & $\mathrm{X}$ & 16 & 16 & $20 / 21$ & $8 / 15$ & $28 / 29$ & $12 / 18$ & $9 / 11$ & $11 / 13$ & $9 / 12$ & $\sum<$ \\
\hline \multicolumn{2}{|c|}{ Genotyp } & $\mathrm{XX}$ & $16 / 16$ & $16 / 16$ & $20 / 21$ & $8 / 15$ & $28 / 29$ & $12 / 18$ & 9/11 & $11 / 13$ & $9 / 12$ & $11 / 13$ \\
\hline
\end{tabular}

\begin{tabular}{|c|c|c|c|c|c|c|c|c|c|c|c|c|}
\hline & \multicolumn{12}{|c|}{46 [Maxilla] } \\
\hline PCR & EX & Amelo & D3S1358 & VWA & FGA & D8S1179 & D21S11 & D18S51 & D5S818 & D13S317 & D7S820 & CSFIPO \\
\hline 29 & $\mathrm{I}$ & - & 17 & 17 & 24 & $3<$ & 30 & $S<$ & $-/-$ & $8 / 11 / 13$ & $><$ & 10 \\
\hline 31 & $\mathrm{I}$ & $\mathrm{X}$ & $18 / 19$ & 17 & $-1-$ & $8 / 12$ & $28 / 31.2$ & $-/-$ & 9 & $-1-$ & $-/-$ & $\sum<$ \\
\hline 34 & $\mathrm{I}$ & $X$ & 16 & $16 / 17$ & $-1-$ & $\sum<$ & $-/-$ & $\sum<$ & 10 & $-1-$ & $\sum<$ & 10 \\
\hline 35 & II & - & $((16))$ & $-/-$ & $-1-$ & $\sum<$ & $-1-$ & $\sum<$ & $-1-$ & $-1-$ & $\sum<$ & $-/-$ \\
\hline 39 & II & - & $-1-$ & $15 / 16$ & $-1-$ & $-/-$ & $-1-$ & $-/-$ & $-1-$ & $-1-$ & $-/-$ & $\sum<$ \\
\hline \multicolumn{2}{|c|}{ Genotyp } & $\mathrm{X}$ & $-/-$ & $(16 / 17)$ & $-1-$ & $-1-$ & $-/-$ & $-/-$ & $-1-$ & $-1-$ & $-/-$ & $(10) /-$ \\
\hline
\end{tabular}

\begin{tabular}{|c|c|c|c|c|c|c|c|c|c|c|c|c|}
\hline & \multicolumn{12}{|c|}{58 [Felsenbein li.] } \\
\hline PCR & EX & Amelo & D3S1358 & VWA & FGA & D8S1179 & D21S11 & D18S51 & D5S818 & D13S317 & D7S820 & CSF1PO \\
\hline 58 & I & - & $-1-$ & $-1-$ & $-1-$ & $3<$ & $-1-$ & $3<$ & $-1-$ & $-1-$ & $\sum$ & $-1-$ \\
\hline 59 & I & - & 14 & $-1-$ & $-1-$ & $\sum<$ & $-1-$ & $\sum<$ & $-I-$ & $-1-$ & $\sum$ & 12 \\
\hline 69 & II & - & $-/-$ & $-/-$ & $-1-$ & $\sum$ & $-1-$ & $\sum$ & $(9) / 11$ & $-1-$ & $\sum<$ & $-1-$ \\
\hline 79 & III & $X$ & $-1-$ & $-1-$ & $-1-$ & $\sum<$ & $-1-$ & $S<$ & 11 & $-1-$ & $\sum<$ & $-1-$ \\
\hline \multicolumn{2}{|c|}{ Genotyp } & - & $-/-$ & $-/-$ & $-/-$ & $-/-$ & $-1-$ & $-/-$ & $11 /-$ & $-1-$ & $-/-$ & $-/-$ \\
\hline
\end{tabular}

\begin{tabular}{|c|c|c|c|c|c|c|c|c|c|c|c|c|c|}
\hline F7 & \multicolumn{10}{|c|}{ 65 [Neurocranium] } \\
\hline PCR & EX & Amelo & D3S1358 & VWA & FGA & D8S1179 & D21S11 & D18S51 & D5S818 & D13S317 & D7S820 & CSF1PO \\
\hline 35 & I & X & 16 & 19 & $24 / 25$ & & & 31 & & 12.2 & $8 / 12$ & & 11 \\
\hline 39 & I & $\mathrm{X}$ & $-/-$ & 17 & 22 & $11 / 13$ & $-/-$ & $-/-$ & $-/-$ & $-/-$ & $-/-$ & \\
\hline 41 & I & $\mathrm{X}$ & 15 & $(16)$ & 25 & $-/$ & 29 & $-/-$ & 12 & $-/-$ & $-/-$ & $11 / 12$ \\
\hline 45 & II & $\mathrm{X}$ & $15 / 16$ & 17 & $22 / 25$ & & $29 /(32.2)$ & & 12 & $8 / 12$ & & $8 / 12$ & \\
\hline 46 & II & $\mathrm{X}$ & $15 / 16$ & 17 & $22 / 25$ & $11 / 13$ & $29 / 32.2$ & $15 / 17$ & 12 & $8 / 12$ & $8 / 10$ & $(11) /-$ \\
\hline
\end{tabular}

Legende: $\mathrm{M}=$ male, $\mathrm{F}$ = female, - = Allel nicht bestimmbar, $(\mathrm{C}$ = unsicheres Allel 
Fortsetzung Tabellen 30: autosomale STR-Einzeltypisierungen.

\begin{tabular}{|c|c|c|c|c|c|c|c|c|c|c|c|c|}
\hline & \multicolumn{12}{|c|}{71 [Felsenbein] } \\
\hline PCR & EX & Amelo & D3S1358 & VWA & FGA & D8S1179 & D21S11 & D18S51 & D5S818 & D13S317 & D7S820 & CSF1PO \\
\hline 58 & I & - & $-1-$ & $-/-$ & $-1-$ & $3<$ & $-1-$ & $><$ & $-1-$ & $-1-$ & $>$ & $-/-$ \\
\hline 59 & I & - & $-1-$ & $-1-$ & $-1-$ & $3<$ & $-1-$ & $3<$ & $-1-$ & $-1-$ & $3<$ & $-1-$ \\
\hline 69 & II & - & $-1-$ & $-1-$ & $-1-$ & $3<$ & $-1-$ & $3<$ & (8) & $-1-$ & 3 & $-/-$ \\
\hline 79 & III & - & $-1-$ & $-1-$ & $-1-$ & $3<$ & 30 & $3<$ & $-/-$ & $-1-$ & $3<$ & $-1-$ \\
\hline \multicolumn{2}{|c|}{ Genotyp } & - & $-1-$ & $-/-$ & $-1-$ & $-/-$ & $-1-$ & $-/-$ & $-/-$ & $-/-$ & $-/-$ & $-/-$ \\
\hline
\end{tabular}

\begin{tabular}{|c|c|c|c|c|c|c|c|c|c|c|c|c|}
\hline & \multicolumn{12}{|c|}{ 87a [Mandibula] } \\
\hline PCR & EX & Amelo & D3S1358 & VWA & FGA & D8S1179 & D21S11 & D18S51 & D5S818 & D13S317 & D7S820 & CSF1PO \\
\hline 18 & I & $\mathrm{X}$ & $-/-$ & $-/-$ & $-1-$ & $3<$ & $-/-$ & $8<$ & $-1-$ & $-/-$ & $S<$ & $-/-$ \\
\hline 19 & I & $\mathrm{X}$ & $-1-$ & 18 & $-1-$ & 16 & 32.2 & $-/-$ & $-1-$ & 12 & 12 & $3<$ \\
\hline 30 & I & $\mathrm{X}$ & $-/-$ & $-/-$ & 22 & $S$ & $29 / 32.2$ & $S<$ & 11 & $8 / 12$ & $3<$ & 11 \\
\hline 32 & I & $\mathrm{XY}$ & 15 & $16 / 18 / 19$ & $20 / 21$ & 3 & $31.2 / 32.2$ & 3 & 13 & 8 & 3 & 10 \\
\hline 35 & II & $\mathrm{X}$ & 16 & $-/-$ & $-/-$ & $><$ & $28.2 / 30$ & $><$ & 12 & $11 / 13$ & 3 & (11) \\
\hline \multicolumn{2}{|c|}{ Genotyp } & $\mathrm{X}(\mathrm{X})$ & $-1-$ & $-/-$ & $-1-$ & $-/-$ & $32.2 /-$ & $-/-$ & $-/-$ & $-/-$ & $-/-$ & $-1-$ \\
\hline
\end{tabular}

\begin{tabular}{|c|c|c|c|c|c|c|c|c|c|c|c|c|}
\hline & \multicolumn{12}{|c|}{ 87b [Mandibula] } \\
\hline PCR & EX & Amelo & D3S1358 & VWA & FGA & D8S1179 & D21S11 & D18S51 & D5S818 & D13S317 & D7S820 & CSF1PO \\
\hline 18 & I & $-/-$ & $-/-$ & $-1-$ & $-1-$ & $3<$ & $-/-$ & $><$ & $-/-$ & $-1-$ & $B<$ & $-1-$ \\
\hline 19 & I & $\mathrm{X}$ & $-1-$ & $-1-$ & $-1-$ & $-/-$ & $-1-$ & $-/-$ & $-1-$ & $-1-$ & $-/-$ & $3<$ \\
\hline 30 & I & $\mathrm{X}$ & $-1-$ & 20 & $-1-$ & $3<$ & $-1-$ & $3<$ & 12 & 11 & $3<$ & 10 \\
\hline 35 & II & - & $-/-$ & $-1-$ & $-1-$ & $3<$ & $-1-$ & $3<$ & $-/-$ & $-1-$ & $3<$ & $-1-$ \\
\hline \multicolumn{2}{|c|}{ Genotyp } & - & $-1-$ & $-/-$ & $-/-$ & $-/$ & $-/$ & $-/-$ & $-/$ & $-/$ & $-/-$ & $-/-$ \\
\hline
\end{tabular}

\begin{tabular}{|c|c|c|c|c|c|c|c|c|c|c|c|c|}
\hline & \multicolumn{12}{|c|}{ 87c [Mandibula] } \\
\hline PCR & EX & Amelo & D3S1358 & VWA & FGA & D8S1179 & D21S11 & D18S51 & D5S818 & D13S317 & D7S820 & CSF1PO \\
\hline 29 & I & - & $-/-$ & $-/-$ & $-1-$ & $><$ & $-/-$ & $\infty$ & $-/-$ & $-/-$ & $\varnothing$ & $-/-$ \\
\hline 32 & I & - & $-/-$ & $-1-$ & $-1-$ & $\sum$ & $-1-$ & $\sum$ & $-/-$ & $-/-$ & $\sum<$ & $-1-$ \\
\hline 45 & II & $\mathrm{XY}$ & $-/-$ & 15 & $-/-$ & $\sum<$ & $-1-$ & $\sum$ & $-/-$ & $-1-$ & $\sum$ & $-/-$ \\
\hline 46 & II & - & $-1-$ & $-1-$ & $-1-$ & $-1-$ & $-/-$ & $-/-$ & $-1-$ & $-1-$ & $-/-$ & $\sum<$ \\
\hline \multicolumn{2}{|c|}{ Genotyp } & - & $-1-$ & $-1-$ & $-1-$ & $-/-$ & $-1-$ & $-/-$ & $-1-$ & $-1-$ & $-/-$ & $-/-$ \\
\hline
\end{tabular}

\begin{tabular}{|c|c|c|c|c|c|c|c|c|c|c|c|c|}
\hline & \multicolumn{12}{|c|}{126 [Felsenbein li.] } \\
\hline $\begin{array}{l}\text { PCR } \\
\end{array}$ & EX & Amel & D3S1358 & VWA & FGA & D8S1179 & D21S11 & D18S51 & D5S818 & D13S317 & D7S820 & CSF1PO \\
\hline 58 & I & - & $-1-$ & $-1-$ & $-/-$ & 3 & $-1-$ & $><$ & 12 & $-1-$ & $>$ & $-/-$ \\
\hline 59 & I & $\mathrm{X}$ & $-/-$ & 18 & $-/-$ & $\sum<$ & $-/-$ & $\sum<$ & $-/-$ & 11 & $\sum$ & $-/-$ \\
\hline 69 & II & $\mathrm{X}$ & $-1-$ & 17 & $-/-$ & $\sum$ & $-1-$ & $>$ & $-/-$ & $-1-$ & $\sum$ & $-/-$ \\
\hline 75 & $\mathrm{IIb}$ & - & $-1-$ & $-1-$ & $-1-$ & $\sum$ & $-1-$ & $>$ & $-/-$ & $-1-$ & $\sum<$ & $-/-$ \\
\hline 79 & III & - & $-1-$ & $-1-$ & $-1-$ & $\sum<$ & $-1-$ & $\sum<$ & $-1-$ & $-1-$ & $\sum<$ & $-/-$ \\
\hline \multicolumn{2}{|c|}{ Genotyp } & $\mathrm{X}$ & $-/-$ & $-/-$ & $-1-$ & $-1-$ & $-/-$ & $-1-$ & $-1-$ & $-1-$ & $-/-$ & $-1-$ \\
\hline
\end{tabular}

\begin{tabular}{|c|c|c|c|c|c|c|c|c|c|c|c|c|}
\hline F1 & \multicolumn{12}{|c|}{152 [Neurocranium] } \\
\hline PCR & EX & Amelo & D3S1358 & VWA & FGA & D8S1179 & D21S11 & D18S51 & D5S818 & D13S317 & D7S820 & CSFIPO \\
\hline 35 & I & $\mathrm{X}$ & 16 & 16 & $20 / 21$ & $3<$ & $28 / 29$ & $3<$ & $9 / 11$ & $11 / 13$ & $><$ & $11 / 13$ \\
\hline 36 & I & $\mathrm{X}$ & 15.3 & 16 & $20 / 21$ & $8 / 15$ & $28 / 29$ & $12 / 18$ & $9 / 11$ & $11 / 13$ & $9 / 12$ & $><$ \\
\hline 41 & I & $\mathrm{X}$ & 16 & 16 & $20 /(21)$ & $8 / 15$ & 29 & $(12)$ & $9 / 11$ & $11 / 13$ & $9 / 12$ & $\sum$ \\
\hline 45 & II & $\mathrm{X}$ & 16 & 16 & $20 / 21$ & $3<$ & $(28) / 29$ & $><$ & 9 & $11 / 13$ & $><$ & $11 / 13$ \\
\hline 46 & II & $\mathrm{X}$ & 16 & 16 & $20 / 21$ & $8 / 15$ & 29 & $12 / 18$ & $9 / 11$ & $11 / 13$ & $9 / 12$ & 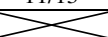 \\
\hline Gen & & $\mathrm{XX}$ & $16 / 16$ & $16 / 16$ & $20 / 21$ & $8 / 15$ & $28 / 29$ & $12 / 18$ & 9/11 & $11 / 13$ & $9 / 12$ & $11 / 13$ \\
\hline
\end{tabular}

\begin{tabular}{|l|c|c|c|c|c|c|c|c|c|c|c|c|}
\hline M19 & \multicolumn{10}{|c|}{153 [Tibia re.] } \\
\hline PCR & EX & Amelo & D3S1358 & VWA & FGA & D8S1179 & D21S11 & D18S51 & D5S818 & D13S317 & D7S820 & CSF1PO \\
\hline \multicolumn{2}{|c|}{ Croll 2005 } & XY & $15 / 17$ & $16 / 18$ & $23 / 25$ & $(10 / 13)$ & $28 / 29$ & $(14 / 15)$ & $12 / 13$ & $8 / 13$ & $(10 / 12)$ & $10 / 12$ \\
\hline 79 & $\begin{array}{c}\text { SC } \\
\text { II }\end{array}$ & XY & 17 & $16 / 18$ & 23 & & 28 & & $12 / 13$ & $8 / 13$ & & $10 / 12$ \\
\hline \multicolumn{2}{|l|}{ Genotyp } & XY & $15 / 17$ & $16 / 18$ & $23 / 25$ & $(10 / 13)$ & $28 / 29$ & $(14 / 15)$ & $12 / 13$ & $8 / 13$ & $(10 / 12)$ & $10 / 12$ \\
\hline
\end{tabular}

Legende: $\mathrm{M}=$ male, $\mathrm{F}=$ female, - = Allel nicht bestimmbar, $(\mathrm{)}$ = unsicheres Allel 
Fortsetzung Tabellen 30: autosomale STR-Einzeltypisierungen.

\begin{tabular}{|c|c|c|c|c|c|c|c|c|c|c|c|c|}
\hline & \multicolumn{12}{|c|}{159 [Mandibula] } \\
\hline $\begin{array}{l}\text { PCR } \\
\end{array}$ & EX & Amelo & D3S1358 & VWA & FGA & D8S1179 & D21S11 & D18S51 & D5S818 & D13S317 & D7S820 & CSF1PO \\
\hline 35 & I & - & $-1-$ & $-1-$ & $-1-$ & 3 & $-1-$ & $3<$ & $-1-$ & $-1-$ & $\sum$ & $-1-$ \\
\hline 64 & II & - & $-1-$ & $-1-$ & $-1-$ & $3<$ & $-1-$ & $3<$ & 13 & $-1-$ & 3 & $-1-$ \\
\hline 65 & II & - & $-1-$ & $-1-$ & $-1-$ & $-/-$ & $-1-$ & $-/-$ & $-1-$ & $-1-$ & $-/-$ & $3<$ \\
\hline \multicolumn{2}{|c|}{ Genotyp } & - & $-/-$ & $-/-$ & $-/-$ & $-/-$ & $-/-$ & $-/-$ & $-/-$ & $-/-$ & $-/-$ & $-/-$ \\
\hline
\end{tabular}

\begin{tabular}{|c|c|c|c|c|c|c|c|c|c|c|c|c|}
\hline & \multicolumn{12}{|c|}{193 [Mandibula] } \\
\hline PCR & EX & Amelo & D3S1358 & VWA & FGA & D8S1179 & D21S11 & D18S51 & D5S818 & D13S317 & D7S820 & CSF1PO \\
\hline 18 & I & - & $-/-$ & $-/-$ & $-/-$ & $S<$ & $-/-$ & $S<$ & $-/-$ & $-/-$ & $S<$ & $-/-$ \\
\hline 19 & I & - & $-/-$ & $17 / 19$ & $-/$ & $-/-$ & 28 & $-/-$ & $-/-$ & $-/-$ & $-/-$ & $>$ \\
\hline 30 & I & - & 16 & 11 & $-/-$ & 3 & $-/-$ & 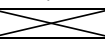 & $-1-$ & $11 / 14$ & $\sum$ & 10 \\
\hline 35 & II & - & $-/-$ & $-/-$ & $-/-$ & 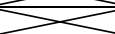 & $-/-$ & 3 & $-/$ & $-/-$ & $\sum$ & $-1-$ \\
\hline 75 & I & - & $-1-$ & $-1-$ & (25) & 3 & $-/-$ & 3 & $-1-$ & $-1-$ & $\sum$ & $-/-$ \\
\hline \multicolumn{2}{|c|}{ Genotyp } & - & $-/-$ & $-1-$ & $-/-$ & $-/-$ & $-/-$ & $-/-$ & $-1-$ & $-1-$ & $-/-$ & $-/-$ \\
\hline
\end{tabular}

\begin{tabular}{|c|c|c|c|c|c|c|c|c|c|c|c|c|}
\hline & \multicolumn{12}{|c|}{199 [Femur li.] } \\
\hline $\begin{array}{l}\text { PCR } \\
\end{array}$ & EX & Amelo & D3S1358 & VWA & FGA & D8S1179 & D21S11 & D18S51 & D5S818 & D13S317 & D7S820 & CSF1PO \\
\hline \multicolumn{2}{|c|}{$\begin{array}{c}\text { Schultes } \\
2000\end{array}$} & $\mathrm{X}(\mathrm{Y})$ & (16) & $14 / 17$ & 24 & $14 /(15)$ & $29 /(30)$ & $14 /(16)$ & $12 / 12$ & $11 / 11$ & $(9) / 11$ & \\
\hline $84 \mathrm{~A}$ & I & - & $-1-$ & $-1-$ & $-1-$ & $2<$ & $-1-$ & $2<$ & $-1-$ & 11 & 8 & $-1-$ \\
\hline $84 \mathrm{~B}$ & I & - & $-1-$ & $-1-$ & $-1-$ & $3<$ & (29) & $3<$ & 12 & 11 & $3<$ & $-1-$ \\
\hline $86 \mathrm{~A}$ & $\mathrm{I}$ & - & $-/-$ & 14 & $-1-$ & $-/-$ & 29 & $-/-$ & 12 & $-1-$ & $-/-$ & 3 \\
\hline $86 \mathrm{~B}$ & $\mathrm{I}$ & $\mathrm{X}$ & $15 / 16$ & $-1-$ & $-1-$ & $-/-$ & $-1-$ & $-/-$ & (12) & $-1-$ & $-1-$ & $2<$ \\
\hline $88 \mathrm{~A}$ & $\mathrm{I}$ & - & 16 & $-1-$ & 19 & $3<$ & 29 & $3<$ & 10 & 10 & 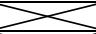 & $-/-$ \\
\hline $88 \mathrm{~B}$ & $\mathrm{I}$ & $\mathrm{X}$ & $-1-$ & $-1-$ & $19 / 20$ & $3<$ & 29 & $3<$ & $-1-$ & 10 & $\sum$ & $-1-$ \\
\hline $88 \mathrm{~A}$ & II & - & 15 & $-1-$ & $-/-$ & $3<$ & $-/-$ & $3<$ & 12 & 10 & $\sum$ & 13 \\
\hline $88 \mathrm{~B}$ & II & $\mathrm{X}$ & $-1-$ & $-1-$ & $-1-$ & $M<$ & $-1-$ & $><$ & 10 & $10 / 11$ & $2<$ & $-1-$ \\
\hline $91 \mathrm{~A}$ & $\mathrm{I}$ & $\mathrm{X}$ & 15 & $-1-$ & $-1-$ & $-/-$ & 29 & 16 & 10 & $-/-$ & $-/-$ & 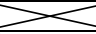 \\
\hline 91B & II & $\mathrm{X}$ & $15 / 16$ & 14 & 24 & $-/-$ & $-/-$ & $-/-$ & 10 & $-/-$ & $-/-$ & $\sum<$ \\
\hline \multicolumn{2}{|c|}{ Genotyp } & $\mathrm{XX}$ & $15 / 16$ & $14 / 17$ & (19)/24 & $14 /(15)$ & $29 /-$ & $14 / 16$ & $10 / 12$ & $10 / 11$ & $\begin{array}{l}(9) / 11 \\
\end{array}$ & $-/-$ \\
\hline
\end{tabular}

\begin{tabular}{|c|c|c|c|c|c|c|c|c|c|c|c|c|}
\hline F10 & \multicolumn{12}{|c|}{302 [Mandibula] } \\
\hline PCR & EX & Amelo & D3S1358 & VWA & FGA & D8S1179 & D21S11 & D18S51 & D5S818 & D13S317 & D7S820 & CSF1PO \\
\hline 64 & I & - & 16 & $-/-$ & $-/-$ & $3<$ & 30.2 & $3<$ & 13 & $-/-$ & $3<$ & $-/-$ \\
\hline 65 & I & $\mathrm{X}$ & $-1-$ & $-1-$ & $-1-$ & $13 / 15$ & $-/-$ & $-/-$ & $-1-$ & $-1-$ & $-1-$ & $3<$ \\
\hline 69 & II & $\mathrm{X}$ & 15 & 16 & 22 & $3<$ & $-1-$ & $\sum<$ & $9 / 12$ & $9 / 13$ & $\sum$ & $-/-$ \\
\hline 75 & II & $\mathrm{X}$ & $15 / 16$ & 16 & $-/-$ & $\sum<$ & 30.2 & $S<$ & (8) & $11 / 13$ & $\sum$ & 12 \\
\hline 75 & $\mathrm{IIb}$ & $\mathrm{X}$ & $-/-$ & 16 & (25) & $3<$ & $-/-$ & $3<$ & $9 / 12$ & $9 / 13$ & $3<$ & $-/-$ \\
\hline 79 & II & $\mathrm{X}$ & $15 / 16$ & 16 & $-/-$ & $3<$ & $-/-$ & $\sum 3$ & 12 & 9 & $3<$ & $(10)$ \\
\hline \multicolumn{2}{|c|}{ Genotyp } & $\mathrm{XX}$ & $15 / 16$ & $16 / 16$ & $-1-$ & $-/-$ & $30.2 /-$ & $-/-$ & $9 / 12$ & $9 / 13$ & $-/-$ & $-/-$ \\
\hline
\end{tabular}

\begin{tabular}{|c|c|c|c|c|c|c|c|c|c|c|c|c|}
\hline M11 & \multicolumn{12}{|c|}{398 [Mandibula] } \\
\hline PCR & EX & Amelo & D3S1358 & VWA & FGA & D8S1179 & D21S11 & D18S51 & D5S818 & D13S317 & D7S820 & CSF1PO \\
\hline 29 & I & $\mathrm{X}$ & 17 & $-/-$ & $-/-$ & $3<$ & 29 & $3<$ & $-/-$ & $8 / 11$ & $3<$ & $-/-$ \\
\hline 31 & I & - & $-/-$ & $-1-$ & $-1-$ & $-/-$ & $-/-$ & $-/-$ & $-1-$ & $-/-$ & $-1-$ & $3<$ \\
\hline 32 & I & - & $-/-$ & $(18) / 19$ & $-1-$ & & $-/-$ & & 10 & $-/-$ & & $\begin{array}{c}11 /(12) \\
/ 14\end{array}$ \\
\hline 34 & I & $\mathrm{X}$ & 14 & 14 & $-1-$ & $3<$ & $-1-$ & $>$ & 13 & 8 & $\sum$ & 12 \\
\hline 45 & II & - & $-1-$ & 17 & $-1-$ & $3<$ & $-1-$ & $\sum<$ & $-1-$ & $-1-$ & $<$ & $-/-$ \\
\hline 46 & II & - & $-1-$ & $-1-$ & $-1-$ & $-/-$ & $-/-$ & $-/-$ & $-1-$ & $-1-$ & $-1-$ & $3<$ \\
\hline Genc & yp & $\mathrm{X}$ & $-1-$ & $-1-$ & $-1-$ & $-1-$ & $-/-$ & $-/-$ & $-1-$ & $8 /-$ & $-1-$ & $(12) /-$ \\
\hline
\end{tabular}

\begin{tabular}{|c|c|c|c|c|c|c|c|c|c|c|c|c|}
\hline M10 & \multicolumn{12}{|c|}{480 [Mandibula] } \\
\hline PCR & EX & Amelo & D3S1358 & VWA & FGA & D8S1179 & D21S11 & D18S51 & D5S818 & D13S317 & D7S820 & CSF1PO \\
\hline 29 & I & - & $-1-$ & $-1-$ & $-1-$ & 3 & $-1-$ & $S<$ & $-1-$ & $-/-$ & 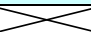 & $-/-$ \\
\hline 32 & I & - & $-1-$ & $-1-$ & $-1-$ & $3<$ & $-1-$ & $3<$ & $-1-$ & $-1-$ & $3<$ & $-1-$ \\
\hline 45 & II & $\bar{X}$ & $15 / 16$ & $16 / 17$ & $-/-$ & $3<$ & $-1-$ & $3<$ & $-1-$ & $-1-$ & $S<$ & $-1-$ \\
\hline 46 & II & - & $-/-$ & $-/-$ & $-1-$ & $-/-$ & $-/-$ & $-/-$ & $-1-$ & $-/-$ & $-1-$ & $3<$ \\
\hline 69 & III & - & 14 & $-1-$ & $-1-$ & $3<$ & $-1-$ & $3<$ & 12 & 13 & $\infty$ & $-/-$ \\
\hline 75 & IIIb & $(\mathrm{Y})$ & $-1-$ & $13 / 15$ & $-1-$ & $3<$ & $31.2 / 32.2$ & $><$ & $8 / 12$ & $(9 / 13)$ & $3<$ & 10 \\
\hline 78 & III & $\mathrm{XY}$ & $14 / 15$ & $-/-$ & $-1-$ & 13 & 32.2 & $-/-$ & $-/-$ & $-/-$ & $-/-$ & $3<$ \\
\hline Genc & yp & $\mathrm{X}(\mathrm{Y})$ & $14 / 15$ & $-1-$ & $-1-$ & $-1-$ & $32.2 /-$ & $-1-$ & $12 /-$ & $(13) /-$ & $-1-$ & $-/-$ \\
\hline
\end{tabular}

Legende: $\mathrm{M}=$ male, $\mathrm{F}=$ female, $-=$ Allel nicht bestimmbar, $(\mathrm{)}$ = unsicheres Allel 
Fortsetzung Tabellen 30: autosomale STR-Einzeltypisierungen.

\begin{tabular}{|c|c|c|c|c|c|c|c|c|c|c|c|c|}
\hline M4 & \multicolumn{12}{|c|}{900 [Neurocranium] } \\
\hline PCR & EX & Amelo & D3S1358 & VWA & FGA & D8S1179 & D21S11 & D18S51 & D5S818 & D13S317 & D7S820 & CSF1PO \\
\hline 35 & $\mathrm{I}$ & $\mathrm{XY}$ & $15 / 17$ & $16 / 17$ & $20 / 25$ & 3 & $28 / 29$ & 3 & $11 / 12$ & $12 / 13$ & 8 & 12 \\
\hline 36 & I & $\mathrm{XY}$ & $15 / 17$ & $16 / 17$ & $20 / 25$ & $10 / 14$ & $28 / 29$ & $14 / 19$ & $11 / 12$ & $12 / 13$ & $11 / 12$ & $\sum<$ \\
\hline 39 & $\mathrm{I}$ & $\mathrm{XY}$ & $15 / 17$ & $16 / 17$ & $20 / 25$ & $10 / 14$ & $28 / 29$ & $14 /(19)$ & $11 / 12$ & $12 / 13$ & $11 / 12$ & $\sum$ \\
\hline 45 & II & $\mathrm{XY}$ & $15 / 17$ & $(16) / 17$ & $20 / 25$ & $3<$ & $28 / 29$ & $3<$ & $11 / 12$ & $12 / 13$ & $><$ & 12 \\
\hline 46 & II & $\mathrm{XY}$ & $15 / 17$ & $16 / 17$ & $20 / 25$ & $10 / 14$ & $28 / 29$ & $14 / 19$ & $11 / 12$ & $12 / 13$ & $11 / 12$ & 3 \\
\hline 50 & IIIa & $\mathrm{XY}$ & $15 / 17$ & $16 / 17$ & $20 / 25$ & 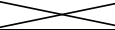 & $28 / 29$ & 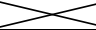 & $11 / 12$ & $12 / 13$ & $>$ & 12 \\
\hline 50 & $\begin{array}{l}\text { IIIb } \\
\end{array}$ & $\mathrm{XY}$ & $15 / 17$ & $16 / 17$ & $20 / 25$ & $S$ & $28 / 29$ & $\sum$ & $11 / 12$ & $12 / 13$ & $>$ & 12 \\
\hline 50 & IIIc & $\mathrm{XY}$ & $15 / 17$ & $16 / 17$ & $20 / 25$ & $3<$ & $28 / 29$ & $3<$ & $11 / 12$ & $12 / 13$ & $3<$ & 12 \\
\hline \multicolumn{2}{|c|}{ Genotyp } & $\mathrm{XY}$ & $15 / 17$ & $16 / 17$ & $20 / 25$ & $10 / 14$ & $28 / 29$ & $14 / 19$ & $11 / 12$ & $12 / 13$ & $11 / 12$ & $12 / 12$ \\
\hline
\end{tabular}

\begin{tabular}{|c|c|c|c|c|c|c|c|c|c|c|c|c|}
\hline M5 & \multicolumn{12}{|c|}{908 [Calvarium] } \\
\hline PCR & $\mathrm{EX}$ & Amelo & D3S1358 & VWA & FGA & D8S1179 & D21S11 & D18S51 & D5S818 & D13S317 & D7S820 & CSF1PO \\
\hline 35 & I & $\mathrm{XY}$ & $15 / 17$ & $16 / 19$ & $20 / 25$ & 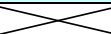 & $28 / 29 / 30$ & $>$ & $11 / 13$ & $8 / 14$ & & $10 / 12$ \\
\hline 36 & I & XY & $15 / 17$ & $16 / 19$ & $20 / 25$ & $10 / 14$ & $28 / 30$ & $15 / 19$ & $11 / 13$ & $8 / 14$ & $10 / 13$ & $<$ \\
\hline 39 & I & XY & $15 / 17$ & $16 / 19$ & $20 / 25$ & $10 / 14$ & $28 / 30$ & $15 / 19$ & $11 / 13$ & $8 / 14$ & $-1-$ & $>$ \\
\hline 45 & II & XY & $15 / 17$ & $16 / 19$ & $20 / 25$ & $3<$ & $28 / 30$ & $3<$ & $11 / 13$ & $8 / 14$ & $S<$ & 12 \\
\hline 46 & II & $\mathrm{XY}$ & $15 / 17$ & $16 / 19$ & $20 / 25$ & $10 / 14$ & $28 / 30$ & $15 / 19$ & $11 / 13$ & $8 / 14$ & $(10) / 13$ & $S<$ \\
\hline \multicolumn{2}{|c|}{ Genotyp } & $\mathrm{XY}$ & $15 / 17$ & $16 / 19$ & $20 / 25$ & $10 / 14$ & $28 / 30$ & $15 / 19$ & $11 / 13$ & $8 / 14$ & $(10) / 13$ & $(10) / 12$ \\
\hline
\end{tabular}

\begin{tabular}{|c|c|c|c|c|c|c|c|c|c|c|c|c|}
\hline M7 & \multicolumn{12}{|c|}{910 [Calvarium] } \\
\hline PCR & EX & Amelo & D3S1358 & VWA & FGA & D8S1179 & D21S11 & D18S51 & D5S818 & D13S317 & D7S820 & CSF1PO \\
\hline 35 & $\mathrm{I}$ & $\mathrm{XY}$ & 14 & $17 / 18$ & 24 & $3<$ & 29 & $><$ & 12 & 12 & $><$ & 10 \\
\hline 36 & $\mathrm{I}$ & $\mathrm{Y}$ & $14 / 15$ & $(14 / 15)$ & $-/-$ & $-/-$ & 30 & 18 & 12 & $9 / 15$ & 11 & $\sum<$ \\
\hline 39 & I & $\mathrm{Y}$ & $-/-$ & 17 & 25 & $10 / 11$ & $-1-$ & $-1-$ & 12 & 12 & $-/-$ & $3<$ \\
\hline 45 & II & $X Y$ & $14 / 15$ & $17 / 18$ & $24 / 25$ & $3<$ & $29 / 30$ & $>$ & $(8) / 12$ & $8 / 12$ & $\$$ & 11 \\
\hline 46 & II & $X Y$ & $14 / 15$ & $17 / 18$ & $24 / 25$ & $10 / 11$ & $29 / 30$ & 13 & 12 & $8 / 12$ & $10 / 11$ & $3<$ \\
\hline 54 & IIIa & $\mathrm{XY}$ & $14 / 15$ & $-1-$ & $-/-$ & 3 & 30 & 3 & 12 & 9 & $><$ & $-/-$ \\
\hline 54 & IIIb & - & 15 & $-/-$ & 25 & 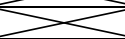 & $-1-$ & $3<$ & 12 & 12 & $3<$ & 10 \\
\hline 54 & IIIc & $\mathrm{XY}$ & 15 & $(17 / 18)$ & 25 & $3<$ & $-1-$ & $3<$ & 12 & $8 / 12$ & 3 & 10 \\
\hline 56 & IIIc & - & 15 & $-/-$ & $-1-$ & $-/-$ & $-1-$ & $-/-$ & $-1-$ & $-1-$ & $-/-$ & $2<$ \\
\hline SK & IV & $\mathrm{Y}$ & $-1-$ & $18 /-$ & $-1-$ & $3<$ & $-1-$ & 3 & $12 /-$ & $8 /-$ & $3<$ & $-1-$ \\
\hline \multicolumn{2}{|c|}{ Genotyp } & XY & $14 / 15$ & $17 / 18$ & $24 / 25$ & $10 / 11$ & $29 / 30$ & $-/-$ & $12 / 12$ & $8 / 12$ & $11 /-$ & $10 /-$ \\
\hline
\end{tabular}

\begin{tabular}{|c|c|c|c|c|c|c|c|c|c|c|c|c|}
\hline M14 & \multicolumn{12}{|c|}{918 [Neurocranium] } \\
\hline PCR & EX & Amelo & D3S1358 & VWA & FGA & D8S1179 & D21S11 & D18S51 & D5S818 & D13S317 & D7S820 & CSF1PO \\
\hline 35 & I & - & $15 /(16)$ & 16 & $19 /(24)$ & $3<$ & 29 & $3<$ & $11 / 12$ & $8 / 11$ & $3<$ & 10 \\
\hline 36 & I & - & $-/-$ & $-/-$ & $-/-$ & $-1-$ & $-/-$ & $-/-$ & $-/-$ & $-/-$ & $-/-$ & 3 \\
\hline 41 & I & (X) & $-/-$ & $-/-$ & $-1-$ & $-/-$ & $-/-$ & $-/-$ & $(7) / 12$ & $-/-$ & $-/-$ & 3 \\
\hline 52 & II & $\mathrm{XY}$ & 15 & $-1-$ & 20 & $3<$ & 31.2 & $3<$ & 11 & $8 / 11$ & $3<$ & 12 \\
\hline 53 & II & $\mathrm{XY}$ & 15 & $-/-$ & $20 / 22$ & 12 & $-/-$ & $-/-$ & 12 & 11 & $-/-$ & \\
\hline 56 & II & $\mathrm{Y}$ & 15 & 16 & 22 & 13 & $-/-$ & $-1-$ & $-/-$ & $-/-$ & $-1-$ & $\gg$ \\
\hline SK & III & $X Y$ & 15 & 16 & $-/-$ & $><$ & $-/-$ & $><$ & $11 /-$ & $8 / 11$ & $\gg$ & $-/-$ \\
\hline 75 & III & $\mathrm{X}(\mathrm{Y})$ & 15 & 16 & (25) & $3<$ & 29 & $3<$ & $11 / 12$ & $8 / 11$ & $3<$ & $10 / 12$ \\
\hline \multicolumn{2}{|c|}{ Genotyp } & $\mathrm{XY}$ & $15 /(15)$ & $16 /-$ & $(20) / 22$ & $-/-$ & $29 /-$ & $-/-$ & $11 / 12$ & $8 / 11$ & $-/-$ & $10 / 12$ \\
\hline
\end{tabular}

\begin{tabular}{|c|c|c|c|c|c|c|c|c|c|c|c|c|}
\hline & \multicolumn{12}{|c|}{934.02 [Mandibula] } \\
\hline PCR & EX & Amelo & D3S1358 & VWA & FGA & D8S1179 & D21S11 & D18S51 & D5S818 & D13S317 & D7S820 & CSF1PO \\
\hline 18 & I & $\mathrm{X}$ & $-/-$ & $-/-$ & $-/-$ & $3<$ & $-/-$ & $3<$ & $-/-$ & 8 & $3<$ & $-/-$ \\
\hline 19 & I & - & 16 & $-/-$ & $-1-$ & $-/-$ & $-/-$ & $-1-$ & $-1-$ & $-1-$ & $-1-$ & $3<$ \\
\hline 30 & I & - & 16 & $-/-$ & $-1-$ & $-/-$ & $-1-$ & $-/-$ & $-/-$ & $11 / 14$ & $-/-$ & 12 \\
\hline 35 & II & - & $-1-$ & $-1-$ & $-1-$ & 3 & $-/-$ & $3<$ & $-/-$ & $-/-$ & $3<$ & $-/-$ \\
\hline \multicolumn{2}{|c|}{ Genotyp } & - & (16)/- & $-/-$ & $-1-$ & $-/-$ & $-/-$ & $-/-$ & $-/-$ & $-/-$ & $-/-$ & $-/-$ \\
\hline
\end{tabular}

\begin{tabular}{|c|c|c|c|c|c|c|c|c|c|c|c|c|}
\hline F10 & \multicolumn{12}{|c|}{1046 [Calvarium] } \\
\hline PCR & EX & Amelo & D3S1358 & VWA & FGA & D8S1179 & D21S11 & D18S51 & D5S818 & D13S317 & D7S820 & CSF1PO \\
\hline 35 & I & $\mathrm{X}$ & $15 / 16$ & 16 & 24 & & $28 / 30.2$ & & $9 / 12$ & $9 / 13$ & & $11 / 12$ \\
\hline 36 & I & $\mathrm{X}$ & $15 / 16$ & 16 & $22 / 24$ & $13 / 15$ & $28 / 30.2$ & 18 & 12 & $9 / 13$ & $8 / 12$ & $S<$ \\
\hline 39 & I & $\mathrm{X}$ & $15 / 16$ & 16 & $22 / 24$ & $13 / 15$ & $28 / 30.2$ & $-/-$ & $9 / 12$ & $-/-$ & $8 / 12$ & $3<$ \\
\hline 45 & II & $\mathrm{X}$ & $-/-$ & $-1-$ & $-/-$ & $3<$ & $28 / 30.2$ & $><$ & $9 / 12$ & 13 & $><$ & 11 \\
\hline 46 & II & $\mathrm{X}$ & $15 / 16$ & 16 & $-/-$ & $13 / 15$ & $28 / 30.2$ & 16 & $-/-$ & $9 / 13$ & $-/-$ & $3<$ \\
\hline \multicolumn{2}{|c|}{ Genotyp } & $\mathrm{XX}$ & $15 / 16$ & $16 / 16$ & $(22 / 24)$ & $13 / 15$ & $28 / 30.2$ & $-/-$ & $9 / 12$ & $9 / 13$ & $(8 / 12)$ & $11 /-$ \\
\hline
\end{tabular}

Legende: $\mathrm{M}=$ male, $\mathrm{F}=$ female, - = Allel nicht bestimmbar, ()$=$ unsicheres Allel 
Anhang : Tabellen autosomale STR-Typisierungsergebnisse

Fortsetzung Tabellen 30: autosomale STR-Einzeltypisierungen.

\begin{tabular}{|c|c|c|c|c|c|c|c|c|c|c|c|c|}
\hline & \multicolumn{12}{|c|}{1075 [Neurocranium] } \\
\hline PCR & $\mathrm{EX}$ & Amelo & D3S1358 & VWA & FGA & D8S1179 & D21S11 & D18S51 & D5S818 & D13S317 & D7S820 & CSF1PO \\
\hline 29 & I & - & (15) & $-/-$ & $-/-$ & $3<$ & $-/-$ & $3<$ & $-/-$ & $-/-$ & $3<$ & (10) \\
\hline 32 & $\mathrm{I}$ & - & $-1-$ & $-/-$ & $-1-$ & & $-1-$ & & $-/-$ & $-/-$ & & $-1-$ \\
\hline 45 & II & $\mathrm{X}$ & 16 & (17) & 21 & $3<$ & 27 & $3<$ & 11 & $11 /(12)$ & 3 & 10 \\
\hline 46 & II & $\mathrm{X}$ & (16) & $16 / 17$ & 21 & $8 / 13 /(15)$ & $-1-$ & $-/-$ & $((9 / 12))$ & $10 / 11$ & $-/-$ & $3<$ \\
\hline 50 & IIIa & $\mathrm{X}$ & 16 & 15 & 21 & $3<$ & $-/-$ & $3<$ & 12 & $11 / 12$ & $\sum$ & 11 \\
\hline 50 & $\mathrm{IIIb}$ & $\mathrm{X}$ & 14 & $15 / 17$ & $-1-$ & $\sum<$ & $29 / 31$ & 3 & 12 & $11 / 12$ & 3 & 12 \\
\hline 50 & IIIc & - & 17 & $-/-$ & 21 & $3<$ & 29 & $3<$ & 12 & $9.2 / 11$ & $\sum$ & 12 \\
\hline 56 & $\mathrm{IIIb}$ & $\mathrm{X}$ & 16 & 15 & $-1-$ & 13 & $-1-$ & 13 & 12 & 11 & $-/-$ & 3 \\
\hline \multicolumn{2}{|c|}{ Genotyp } & $\mathrm{XX}$ & $16 /-$ & $15 / 17$ & $21 / 21$ & (13)/- & (29)/- & $-/-$ & $12 /-$ & $11 / 12$ & $-/-$ & $-/-$ \\
\hline
\end{tabular}

\begin{tabular}{|c|c|c|c|c|c|c|c|c|c|c|c|c|}
\hline F13 & \multicolumn{10}{|c|}{1078 [Mandibula] } \\
\hline PCR & EX & Amelo & D3S1358 & VWA & FGA & D8S1179 & D21S11 & D18S51 & D5S818 & D13S317 & D7S820 & CSF1PO \\
\hline 29 & I & $\mathrm{X}$ & 16 & $15 / 17$ & $(20) / 21$ & & 27 & & $(9) / 12$ & $11 / 12$ & & $10 / 11$ \\
\hline 31 & I & $\mathrm{X}$ & 16 & $15 / 17$ & 21 & 13 & 27 & 13 & $9 / 12$ & $11 / 12$ & 11 & \\
\hline 34 & I & $\mathrm{X}$ & 16 & $15 / 17$ & 21 & & $27 / 31.2$ & & $9 / 12$ & $11 / 12$ & & $10 / 11$ \\
\hline YP & II & $\mathrm{X}$ & 16 & $15 / 17$ & 21 & & $27 /(30)$ & & $9 / 12$ & $11 / 12$ & & 10 \\
\hline 39 & II & $\mathrm{X}$ & 16 & 17 & 21 & 13 & 27 & 13 & $9 / 12$ & $11 / 12$ & $8 / 11$ & \\
\hline 45 & III & $\mathrm{X}$ & 16 & $15 / 17$ & 21 & & 27 & & $9 / 12$ & $11 / 12$ & & 10 \\
\hline 46 & III & $\mathrm{X}$ & 16 & 17 & 21 & 13 & 27 & 13 & $9 / 12$ & $11 / 12$ & $8 / 11$ & \\
\hline \multicolumn{2}{l}{ Genotyp } & $\mathrm{XX}$ & $16 / 16$ & $15 / 17$ & $21 / 21$ & $13 / 13$ & $27 / 27$ & $13 /-$ & $9 / 12$ & $11 / 12$ & $8 / 11$ & $10 / 11$ \\
\hline
\end{tabular}

\begin{tabular}{|c|c|c|c|c|c|c|c|c|c|c|c|c|}
\hline M1 & \multicolumn{10}{|c|}{1172 [Mandibula] } \\
\hline PCR & EX & Amelo & D3S1358 & VWA & FGA & D8S1179 & D21S11 & D18S51 & D5S818 & D13S317 & D7S820 & CSF1PO \\
\hline $\begin{array}{c}\text { Schultes } \\
2000\end{array}$ & XY) & $(15 / 17)$ & $(15 / 16)$ & $(21 / 25)$ & $(12 / 13)$ & $\begin{array}{c}(30.2 / \\
33.2)\end{array}$ & $-/$ & $(10 / 12)$ & $(11)$ & $(8)$ & \\
\hline 64 & I & XY & $15 / 17$ & $15 / 16$ & $-/-$ & & $30.2 / 33.2$ & & $-/-$ & $11 / 13$ & & 10 \\
\hline 65 & I & XY & $15 / 17$ & $15 / 16$ & 21 & $12 / 13$ & $30.2 / 33.2$ & $-/-$ & $10 / 12$ & $(11) / 13$ & $(7 / 8)$ & - \\
\hline \multicolumn{2}{|l|}{ Genotyp } & XY & $15 / 17$ & $15 / 16$ & $21 /(25)$ & $12 / 13$ & $30.2 / 33.2$ & $-/-$ & $10 / 12$ & $11 / 13$ & $(8) /-$ & $-/-$ \\
\hline
\end{tabular}

\begin{tabular}{|c|c|c|c|c|c|c|c|c|c|c|c|c|}
\hline F18 & \multicolumn{12}{|c|}{1176 [Calvarium] } \\
\hline PCR & EX & Amelo & D3S1358 & VWA & FGA & D8S1179 & D21S11 & D18S51 & D5S818 & D13S317 & D7S820 & CSF1PO \\
\hline 0 & I & $\mathrm{X}$ & $15 / 16$ & $14 / 17$ & $19 / 24$ & $14 / 15$ & 29 & $14 / 16$ & $10 / 12$ & $10 / 11$ & 11 & $>$ \\
\hline 6 & I & $\mathrm{X}$ & $15 / 16$ & $14 / 17$ & $19 / 24$ & $S<$ & 29 & $\sum<$ & $10 / 12$ & $10 / 11$ & $><$ & $10 / 12$ \\
\hline 7 & I & $\mathrm{X}$ & $15 / 16$ & $14 / 17$ & $19 / 24$ & $\sum$ & 29 & $\sum$ & $10 / 12$ & $10 / 11$ & $\sum$ & $10 / 12$ \\
\hline 18 & II & $X$ & $15 / 16$ & $14 / 17$ & $21 / 24$ & $\sum$ & 29 & 3 & $10 / 12$ & $10 / 11$ & $\sum$ & $10 / 12$ \\
\hline 19 & II & $\mathrm{X}$ & $15 / 16$ & $14 / 17$ & $19 / 24$ & $14 / 15$ & 29 & $14 / 16$ & $10 / 12$ & $10 / 11$ & 11 & 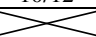 \\
\hline \multicolumn{2}{|c|}{ Genotyp } & $\mathrm{XX}$ & $15 / 16$ & $14 / 17$ & $19 / 24$ & $14 / 15$ & $29 / 29$ & $14 / 16$ & $10 / 12$ & $10 / 11$ & $11 /-$ & $10 / 12$ \\
\hline
\end{tabular}

\begin{tabular}{|c|c|c|c|c|c|c|c|c|c|c|c|c|}
\hline F7 & \multicolumn{10}{|c|}{1247} & [Mandibula] \\
\hline PCR & EX & Amelo & D3S1358 & VWA & FGA & D8S1179 & D21S11 & D18S51 & D5S818 & D13S317 & D7S820 & CSF1PO \\
\hline $\begin{array}{c}\text { Schultes } \\
2000\end{array}$ & $\mathrm{X}(\mathrm{Y})$ & $15 / 16$ & 17 & 22 & $11 / 13$ & 29 & $-/-$ & $12 / 12$ & 8 & 10 & \\
\hline 64 & $\mathrm{I}$ & - & $-/-$ & 17 & $-/-$ & & 32.2 & & $-/-$ & $-/-$ & & $-/-$ \\
\hline 65 & $\mathrm{I}$ & - & 15 & $-/-$ & $-/-$ & $-/-$ & 32.2 & $-/-$ & $-/-$ & 8 & $-/-$ & 12 \\
\hline 75 & $\mathrm{I}$ & $\mathrm{X}$ & $-/-$ & $-/-$ & $-/-$ & & $-/-$ & & 12 & 12 & - & 12 \\
\hline
\end{tabular}

\begin{tabular}{|c|c|c|c|c|c|c|c|c|c|c|c|c|}
\hline M9 & \multicolumn{12}{|c|}{1473 [Calvarium] } \\
\hline PCR & EX & Amelo & D3S1358 & VWA & FGA & D8S1179 & D21S11 & D18S51 & D5S818 & D13S317 & D7S820 & CSF1PO \\
\hline 0 & I & $\mathrm{XY}$ & 16 & $14 / 15$ & $21 /(23)$ & 13 & 27 & $-1-$ & 12 & $-1-$ & $-/-$ & $S<$ \\
\hline 6 & I & $\mathrm{XY}$ & $16 / 19$ & 14 & $21 / 23$ & & $\begin{array}{c}(27) /(31.2) \\
/ 32.2\end{array}$ & & 12 & $(11) / 14$ & & 11 \\
\hline 7 & I & $\mathrm{XY}$ & 16 & 16 & $21 / 23$ & $\infty$ & 31 & $\infty$ & 12 & $11 / 13 / 14$ & 8 & $10 / 11$ \\
\hline 32 & I & $\mathrm{XY}$ & $16 / 19$ & $14 / 16$ & (23) & $\sum$ & $27 / 32.2$ & $\sum$ & $-1-$ & 14 & $\sum$ & 11 \\
\hline 45 & II & $\mathrm{X}$ & 16 & $14 / 16$ & 20 & $\sum$ & $27 / 32.2$ & $\sum$ & $-1-$ & 14 & $\sum$ & 11 \\
\hline 46 & II & $\mathrm{XY}$ & 16 & $14 / 16$ & 23 & 13 & $-1-$ & $-/-$ & 12 & $11 / 14$ & 13 & $\sum<$ \\
\hline \multicolumn{2}{|c|}{ Genotyp } & $\mathrm{XY}$ & $16 / 19$ & $14 / 16$ & $21 / 23$ & $13 /-$ & $27 / 32.2$ & $-1-$ & $12 / 12$ & $11 / 14$ & $-1-$ & $11 /-$ \\
\hline
\end{tabular}

Legende: $\mathrm{M}=$ male, $\mathrm{F}$ = female, - = Allel nicht bestimmbar, $(\mathrm{C}$ = unsicheres Allel 
Anhang : Tabellen autosomale STR-Typisierungsergebnisse

Fortsetzung Tabellen 30: autosomale STR-Einzeltypisierungen.

\begin{tabular}{|c|c|c|c|c|c|c|c|c|c|c|c|c|}
\hline M3 & \multicolumn{12}{|c|}{1482 [Mandibula] } \\
\hline PCR & EX & Amelo & D3S1358 & VWA & FGA & D8S1179 & D21S11 & D18S51 & D5S818 & D13S317 & D7S820 & CSF1PO \\
\hline 18 & I & $\mathrm{XY}$ & (16) & $16 / 19$ & $21 / 22$ & $3<$ & $30.2 / 32.2$ & $3<$ & $11 /(12)$ & 12 & 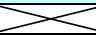 & $11 / 13$ \\
\hline 19 & I & $\mathrm{XY}$ & $16 / 18$ & $17 / 19$ & $21 /(22)$ & 13 & 30.2 & 15 & $11 / 12$ & 12 & 11 & $3<$ \\
\hline 22 & $\mathrm{I}$ & $\mathrm{XY}$ & $16 / 18$ & 19 & 22 & 13 & 30.2 & $15 / 17$ & $11 / 12$ & $-1-$ & $8 / 11$ & $3<$ \\
\hline YP & II & $\mathrm{XY}$ & $16 / 18$ & $17 / 19$ & $21 / 22$ & $3<$ & $30.2 / 32.2$ & $3<$ & $11 / 12$ & 12 & $3<$ & $11 / 13$ \\
\hline 41 & II & $\mathrm{XY}$ & $16 / 18$ & $17 / 19$ & $21 / 22$ & 13 & $30.2 / 32.2$ & (17) & $11 / 12$ & 12 & $8 /(11)$ & $3<$ \\
\hline 45 & III & $\mathrm{XY}$ & $(16) / 18$ & $17 / 19$ & $21 / 22$ & $3<$ & 30.2 & $3<$ & $11 / 12$ & 12 & $3<$ & 11 \\
\hline 46 & III & $\mathrm{X}$ & $16 / 18$ & $17 / 19$ & $21 / 22$ & 13 & 30.2 & 15 & 12 & 12 & $8 / 11$ & $3<$ \\
\hline Genc & & $\mathrm{XY}$ & $16 / 18$ & $17 / 19$ & $21 / 22$ & $13 / 13$ & $30.2 / 32.2$ & $15 / 17$ & $11 / 12$ & $12 / 12$ & $8 / 11$ & $11 / 13$ \\
\hline
\end{tabular}

\begin{tabular}{|c|c|c|c|c|c|c|c|c|c|c|c|c|}
\hline M1 & \multicolumn{12}{|c|}{1485 [Calvarium] } \\
\hline PCR & EX & Amelo & D3S1358 & VWA & FGA & D8S1179 & $\mathrm{D} 21 \mathrm{~S} 11$ & D18S51 & D5S818 & D13S317 & D7S820 & CSF1PO \\
\hline 0 & I & $\mathrm{X} /(\mathrm{Y})$ & $(15) / 17$ & $(15) / 16$ & $21 / 25$ & 12 & $-1-$ & $-1-$ & 12 & $-1-$ & $-1-$ & $\sum$ \\
\hline 6 & I & $\mathrm{XY}$ & 15 & $15 / 16$ & $21 / 25$ & 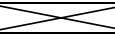 & 30.2 & $S$ & $10 / 12 / 13$ & $11 / 13$ & $\sum$ & 10 \\
\hline 7 & I & $\mathrm{XY}$ & $15 / 17$ & $15 / 16$ & $21 / 25$ & 3 & 31 & $3<$ & $10 / 11 / 12$ & $11 / 13$ & 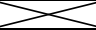 & 10 \\
\hline 17 & I & $\mathrm{XY}$ & 15 & $15 / 16$ & $21 / 25$ & $12 / 13$ & $30.2 / 33.2$ & $14 / 20$ & $10 / 12$ & $11 / 13$ & $7 / 8$ & $\infty$ \\
\hline YP & II & $\mathrm{XY}$ & $\begin{array}{c}15 /(16) \\
/ 17\end{array}$ & $\begin{array}{c}(14) / 15 / \\
16\end{array}$ & $21 /(25)$ & & $\begin{array}{l}(29) / 30.2 / \\
32.2 / 33.2 \\
\end{array}$ & & $\begin{array}{c}10 /(11) / 1 \\
2\end{array}$ & $11 / 13$ & & 10 \\
\hline 41 & II & $\mathrm{XY}$ & $15 / 17$ & $15 / 16$ & $21 / 25$ & $12 / 13$ & $30.2 / 33.2$ & $14 /-$ & $10 / 12$ & $9 / 11 / 13$ & $7 / 8$ & 2 \\
\hline 45 & III & $\mathrm{X}$ & $-1-$ & $15 / 16$ & $-/-$ & $3<$ & 33.2 & 3 & 10 & 11 & $3<$ & 10 \\
\hline 46 & III & $\mathrm{XY}$ & $15 / 17$ & $14 / 15$ & $\begin{array}{c}21 / 24 \\
/ 25\end{array}$ & $12 / 13$ & 30.2 & 20 & $10 / 11 / 12$ & $13 / 14$ & $8 / 11$ & \\
\hline Gen & & $\mathrm{XY}$ & $15 / 17$ & $15 / 16$ & $21 / 25$ & $12 / 13$ & $30.2 / 33.2$ & $14 / 20$ & $10 / 12$ & $11 / 13$ & $7 / 8$ & $10 / 10$ \\
\hline
\end{tabular}

YP = PCR von Puder (2005) durchgeführt

\begin{tabular}{|c|c|c|c|c|c|c|c|c|c|c|c|c|}
\hline F19 & \multicolumn{12}{|c|}{1585 [Femur li., Calcaneus li.] } \\
\hline $\begin{array}{l}\text { PCR } \\
\end{array}$ & EX & Amelo & D3S1358 & VWA & FGA & D8S1179 & D21S11 & D18S51 & D5S818 & D13S317 & D7S820 & CSF1PO \\
\hline \multicolumn{2}{|c|}{$\begin{array}{c}\text { Klingner } \\
2005 \\
\text { Calcaneus } \\
\end{array}$} & $\mathrm{XX}$ & $15 / 17$ & $14 / 18$ & $20 / 24$ & $12 / 14$ & $30.2 / 31$ & 15 & $10 / 12$ & $10 / 11$ & 11 & $11 / 13$ \\
\hline \multicolumn{2}{|c|}{$\begin{array}{c}\text { Schultes } \\
2000\end{array}$} & $\mathrm{XX}$ & $15 / 17$ & $-1-$ & $-/-$ & 14 & $-1-$ & $-1-$ & $-1-$ & 10 & $-1-$ & \\
\hline \multicolumn{2}{|c|}{ Genotyp } & $\mathrm{XX}$ & $15 / 17$ & $14 / 18$ & $20 / 24$ & $12 / 14$ & $30.2 / 31$ & $15 /-$ & $10 / 12$ & $10 / 11$ & $11 /-$ & $11 / 13$ \\
\hline
\end{tabular}

\begin{tabular}{|c|c|c|c|c|c|c|c|c|c|c|c|c|}
\hline & \multicolumn{12}{|c|}{1744.01 [Mandibula] } \\
\hline $\begin{array}{l}\text { PCR } \\
\end{array}$ & EX & Amelo & D3S1358 & VWA & FGA & D8S1179 & D21S11 & D18S51 & D5S818 & D13S317 & D7S820 & CSF1PO \\
\hline 64 & I & - & $-1-$ & $-1-$ & $-1-$ & 3 & $-1-$ & $3<$ & $-1-$ & $-1-$ & 3 & $-1-$ \\
\hline 65 & $\begin{array}{ll}I \\
\end{array}$ & - & $-1-$ & $-1-$ & $-1-$ & $-/-$ & $-1-$ & $-1-$ & $-1-$ & $-1-$ & $-1-$ & $\sum$ \\
\hline $\mathrm{Ger}$ & & - & $-/-$ & $-1-$ & $-1-$ & $-1-$ & $-1-$ & $-1-$ & $-1-$ & $-1-$ & $-1-$ & $-/-$ \\
\hline
\end{tabular}

\begin{tabular}{|c|c|c|c|c|c|c|c|c|c|c|c|c|}
\hline & \multicolumn{12}{|c|}{ 1745a [Maxilla] } \\
\hline PCR & EX & Amelo & D3S1358 & VWA & FGA & D8S1179 & D21S11 & D18S51 & D5S818 & D13S317 & D7S820 & CSF1PO \\
\hline 29 & I & - & $-/-$ & $-1-$ & $-/-$ & 3 & $-/-$ & $\sum<$ & $-1-$ & $-/-$ & 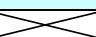 & $-1-$ \\
\hline 32 & I & - & 15 & 17 & $-1-$ & $\sum<$ & 33.2 & $\sum<$ & $-1-$ & $-/-$ & $\sum<$ & $-1-$ \\
\hline 34 & I & - & 15 & $-1-$ & $-1-$ & $\sum$ & $-/-$ & $\sum$ & $-1-$ & 9 & $\sum<$ & $-1-$ \\
\hline 35 & II & $\mathrm{X}$ & $(16 / 18)$ & (16) & $-1-$ & $\sum<$ & $(29 / 30.2)$ & $\sum<$ & $11 /(12)$ & $\begin{array}{l}9 / 13) \\
\end{array}$ & $\sum<$ & 13 \\
\hline 41 & II & $\mathrm{X}$ & $-1-$ & 17 & $-1-$ & $9.3 / 15$ & $-/-$ & $-1-$ & $-1-$ & $-1-$ & $-1-$ & $><$ \\
\hline \multicolumn{2}{|c|}{ Genotyp } & $\mathrm{X}$ & $(15) /-$ & $17 /-$ & $-/-$ & $-/-$ & - - & $-/-$ & $-1-$ & $-1-$ & $-/-$ & $-1-$ \\
\hline
\end{tabular}

\begin{tabular}{|c|c|c|c|c|c|c|c|c|c|c|c|c|}
\hline & \multicolumn{12}{|c|}{ 1745b [Mandibula] } \\
\hline $\begin{array}{l}\text { PCR } \\
\end{array}$ & EX & Amelo & D3S1358 & VWA & FGA & D8S1179 & D21S11 & D18S51 & D5S818 & D13S317 & D7S820 & CSF1PO \\
\hline 29 & I & - & $-1-$ & $-1-$ & $-1-$ & $\sum$ & $-1-$ & $>$ & $-1-$ & $-1-$ & $>$ & $-1-$ \\
\hline 32 & I & - & $-/-$ & $-/-$ & $-1-$ & $K_{1}$ & $-/-$ & $<$ & $-/-$ & $-1-$ & $<<$ & $-/-$ \\
\hline 35 & II & $\mathrm{X}$ & $15 / 16 / 18$ & $(18 / 19)$ & (21) & 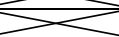 & $-1-$ & $\sum$ & 11 & $8 / 11$ & $\sum<$ & $-1-$ \\
\hline 41 & II & $\mathrm{X}$ & $16 /(17)$ & $14 / 18$ & 21 & $-/-$ & $-1-$ & $-1-$ & $-/-$ & $-1-$ & 9 & $S<$ \\
\hline \multicolumn{2}{|c|}{ Genotyp } & $\mathrm{X}$ & $-/-$ & $-/-$ & $-/-$ & $-1-$ & $-1-$ & $-1-$ & $-/-$ & $-/-$ & $-/-$ & $-/-$ \\
\hline
\end{tabular}

Legende: $\mathrm{M}=$ male, $\mathrm{F}=$ female, $-=$ Allel nicht bestimmbar, $(\mathrm{)}$ = unsicheres Allel 
Fortsetzung Tabellen 30: autosomale STR-Einzeltypisierungen.

\begin{tabular}{|c|c|c|c|c|c|c|c|c|c|c|c|c|}
\hline F3 & \multicolumn{12}{|c|}{1746 I [Felsenbein re.] } \\
\hline PCR & EX & Amelo & D3S1358 & VWA & FGA & D8S1179 & D21S11 & D18S51 & D5S818 & D13S317 & D7S820 & CSF1PO \\
\hline 58 & I & $\mathrm{X}$ & $15 /(16)$ & $-1-$ & 21 & 3 & $-/-$ & $3<$ & $9 / 11$ & 11 & $3<$ & $12 / 13$ \\
\hline 59 & I & $\mathrm{X}$ & $(15) / 16$ & $16 / 17$ & 21 & $3<$ & $30 / 33.2$ & $3<$ & $-/-$ & 11 & $3<$ & 13 \\
\hline 62 & I A & $\mathrm{X}$ & $15 / 16$ & $16 / 17$ & 20 & 15 & 33.2 & 14 & 9 & 11 & $-/-$ & 3 \\
\hline 62 & I B & $\mathrm{X}$ & $15 / 16$ & 16 & $20 / 21$ & 15 & $30 / 33.2$ & $-/-$ & $9 / 11$ & 11 & 10 & $\sum<$ \\
\hline 69 & II & $\mathrm{X}$ & $15 / 16$ & $16 / 17$ & $20 / 21$ & $3<$ & 33.2 & 3 & $9 / 11$ & 11 & 3 & 13 \\
\hline 75 & $\mathrm{IIb}$ & $\mathrm{X}$ & $15 / 16$ & $16 / 17$ & $20 / 21$ & $3<$ & $30 / 33.2$ & $3<$ & $9 / 11$ & 11 & $<$ & 13 \\
\hline \multicolumn{2}{|c|}{ Genotyp } & $\mathrm{XX}$ & $15 / 16$ & $16 / 17$ & $20 / 21$ & $(15) /-$ & $30 / 33.2$ & $-/-$ & $9 / 11$ & $11 / 11$ & $-/-$ & $13 /-$ \\
\hline
\end{tabular}

\begin{tabular}{|c|c|c|c|c|c|c|c|c|c|c|c|c|}
\hline F3 & \multicolumn{10}{|c|}{ 1746 II [Felsenbein li.] } \\
\hline PCR & EX & Amelo & D3S1358 & VWA & FGA & D8S1179 & D21S11 & D18S51 & D5S818 & D13S317 & D7S820 & CSF1PO \\
\hline 69 & II & - & $-/-$ & 16 & $-/-$ & & $-/-$ & & 9 & 11 & & $-/-$ \\
\hline 75 & I & - & $-/-$ & $-/-$ & $-/$ & & $-/-$ & & $-/-$ & $7 / 11$ & - & $-/-$ \\
\hline 75 & II & X & $15 / 16$ & $16 / 17$ & $-/-$ & & 30 & & 9 & 11 & $-/-$ & - \\
\hline
\end{tabular}

\begin{tabular}{|c|c|c|c|c|c|c|c|c|c|c|c|c|}
\hline M6 & \multicolumn{10}{|c|}{ 2111 [Mandibula] } \\
\hline PCR & EX & Amelo & D3S1358 & VWA & FGA & D8S1179 & D21S11 & D18S51 & D5S818 & D13S317 & D7S820 & CSF1PO \\
\hline $\begin{array}{c}\text { Schultes } \\
2000\end{array}$ & XY & 16 & 18 & 21 & 10 & $(30.2)$ & 16 & $(10) / 13$ & $(13)$ & $9 /(9)$ & \\
\hline 64 & I & - & $-/-$ & $13 / 14$ & $-/-$ & & $-/-$ & & $-/-$ & 13 & & $-/-$ \\
\hline 65 & I & - & 16 & $-/-$ & $-/-$ & $-/-$ & 30.2 & $-/-$ & $-/-$ & 13 & $-/-$ & $-/-$ \\
\hline
\end{tabular}

\begin{tabular}{|c|c|c|c|c|c|c|c|c|c|c|c|c|}
\hline (F18) & \multicolumn{12}{|c|}{2133 [Mandibula] } \\
\hline PCR & EX & Amelo & D3S1358 & VWA & FGA & D8S1179 & D21S11 & D18S51 & $\begin{array}{l}\text { D5S818 } \\
\end{array}$ & D13S317 & D7S820 & CSF1PO \\
\hline 6 & I & $\mathrm{X}$ & $15 / 16$ & $14 / 17$ & $19 / 24$ & & $28 / 29 / 30$ & & $10 / 12 / 13$ & $10 / 11$ & & $10 / 11 / 12$ \\
\hline 7 & I & $\mathrm{XY}$ & $15 / 16$ & $\begin{array}{l}14 / 15 / \\
16 / 17\end{array}$ & $19 / 24$ & & $\begin{array}{c}28 / 29 / 30 \\
33.2\end{array}$ & & $(10) / 12$ & $10 / 11$ & & $10 / 12$ \\
\hline 8 & $\mathrm{I}$ & $\mathrm{X} /(\mathrm{Y})$ & $-1-$ & $14 / 17$ & $-/-$ & $10 / 14 /-$ & 29 & $14 / 16$ & $10 / 12$ & $-/-$ & 11 & \\
\hline 17 & $\mathrm{I}$ & $\mathrm{XY}$ & $15 / 16$ & $14 / 17$ & $19 / 22 / 24$ & $14 / 15$ & $28 / 29$ & $\begin{array}{c}(12 / 14 / 15 \\
/ 16)\end{array}$ & $10 / 12$ & $\begin{array}{c}10 / 11 /(12 / \\
13)\end{array}$ & 11 & \\
\hline 18 & II & $\mathrm{X}$ & $\begin{array}{c}14 / 15 / 16 / \\
17\end{array}$ & $14 / 17$ & $19 / 20 / 24$ & & $(28) / 29$ & & $10 / 11 / 12$ & $\begin{array}{c}10 / 11 / 12 / \\
13\end{array}$ & & $10 / 11 / 12$ \\
\hline 19 & II & $\mathrm{X}$ & $15 / 16$ & $14 / 17$ & $19 / 24$ & $13 / 14 / 15$ & $29 / 33.2$ & $14 / 18$ & $10 / 12$ & $10 / 11$ & $11 / 13$ & $\sum$ \\
\hline 41 & II & $\mathrm{X}$ & $15 / 16$ & $14 / 17$ & $19 /-$ & $13 / 14 / 15$ & $29 / 33.2$ & $\begin{array}{c}12 / 14 / 15 / \\
16\end{array}$ & $\begin{array}{c}9 / 10 / 12 / \\
13\end{array}$ & $10 / 11 / 12$ & 11 & \\
\hline 45 & III & $\mathrm{X}$ & $15 / 16$ & $14 / 17$ & $19 / 24$ & 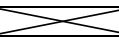 & 29 & $\sum<$ & $10 / 12$ & $10 / 11$ & $\sum<$ & $10 / 12$ \\
\hline 46 & III & $\mathrm{X}$ & $15 / 16$ & $14 /(17)$ & $19 / 24$ & $14 / 15$ & 29 & $14 / 16$ & 10 & $10 / 11$ & 11 & $S<$ \\
\hline $84 \mathrm{~A}$ & IV & $\mathrm{X}$ & $15 / 16$ & 14 & 19 & $\sum<$ & 29 & $\sum<$ & $10 / 12$ & $10 / 11$ & $\sum$ & $10 / 12$ \\
\hline $84 \mathrm{~B}$ & IV & $\mathrm{X}$ & $15 / 16$ & 14 & $(19) / 24$ & $\sum$ & 29 & $\sum<$ & $10 / 12$ & $10 / 11$ & $\sum$ & 10 \\
\hline $86 \mathrm{~A}$ & IV & $\mathrm{X}$ & $15 / 16$ & $14 / 17$ & 24 & $14 / 15$ & 29 & $-/-$ & $10 / 12$ & 10 & 11 & \\
\hline $86 \mathrm{~B}$ & IV & $\mathrm{X}$ & $15 / 16$ & $14 / 17$ & $19 / 24$ & $14 / 15$ & 29 & 16 & $10 / 12$ & 11 & $-1-$ & $\sum$ \\
\hline \multicolumn{2}{|c|}{ Genotyp } & $\mathrm{XX}$ & $15 / 16$ & $14 / 17$ & 19/24 & $14 / 15$ & 29/- & $14 / 16$ & $10 / 12$ & $10 / 11$ & $11 / 11$ & $10 / 12$ \\
\hline
\end{tabular}

\begin{tabular}{|c|c|c|c|c|c|c|c|c|c|c|c|c|}
\hline M15 & \multicolumn{12}{|c|}{2263 [Mandibula] } \\
\hline PCR & EX & Amelo & D3S1358 & VWA & FGA & D8S1179 & D21S11 & D18S51 & D5S818 & D13S317 & D7S820 & CSF1PO \\
\hline \multicolumn{2}{|c|}{$\begin{array}{c}\text { Schultes } \\
2000 \\
\end{array}$} & $-1-$ & $-1-$ & $-1-$ & $-1-$ & $-1-$ & $-1-$ & $-1-$ & $-1-$ & $-1-$ & $-1-$ & \\
\hline 7 & I & (X) & (15) & (17) & $-1-$ & $\sum<$ & 29 & $\sum<$ & $-1-$ & $(10 / 11)$ & $\infty$ & $10 / 13$ \\
\hline 8 & $\mathrm{I}$ & - & $14 / 17$ & $-1-$ & 24 & $-/-$ & 28 & $-1-$ & $-1-$ & 12 & 7 & 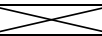 \\
\hline 9 & I & $\mathrm{X}$ & $16 / 17$ & (14) & $-/-$ & $\sum<$ & 30 & $\sum<$ & 12 & $-1-$ & $\sum<$ & $-/-$ \\
\hline 17 & $\mathrm{I}$ & $\mathrm{XY}$ & 15 & $-1-$ & $22 / 24$ & $13 / 14$ & $29 / 30$ & $16 / 19$ & $10 / 12 / 13$ & 11 & $-/-$ & $\sum<$ \\
\hline 18 & II & $\mathrm{X}$ & 15 & $16 / 17$ & 22 & & $29 / 30.2$ & & $11 / 12$ & 12 & & $\begin{array}{c}10 / 11 / 12 / \\
13\end{array}$ \\
\hline 19 & II & $\mathrm{X}$ & 16 & $-1-$ & 24 & 13 & 30 & 18 & 12 & $-1-$ & 8 & $\sum<$ \\
\hline 22 & II & - & 16 & $14 / 15$ & $-1-$ & $-1-$ & $31.2 / 33.2$ & $16 / 18$ & $12 / 13$ & 12 & $-1-$ & $\sum$ \\
\hline 28 & $\mathrm{I}$ & $\mathrm{X}$ & (15) & $17 / 20$ & $-/-$ & $\sum$ & $30.2 / 32.2$ & $\sum<$ & $12 / 13$ & 12 & $\sum$ & $10 / 11$ \\
\hline 28 & II & $\mathrm{XY}$ & $15 / 16$ & $15 / 16$ & $\begin{array}{c}(20) / 22 / \\
24\end{array}$ & & 29 & & 13 & 12 & & 11 \\
\hline \multicolumn{2}{|c|}{ Genotyp } & $\mathrm{X}(\mathrm{Y})$ & $15 / 16$ & $-/-$ & $22 / 24$ & $13 /-$ & $29 /-$ & $(16 / 18)$ & $12 / 13$ & $12 /-$ & $-1-$ & $10 /(11)$ \\
\hline
\end{tabular}

Legende: $\mathrm{M}=$ male, $\mathrm{F}=$ female, - = Allel nicht bestimmbar, () = unsicheres Allel 
Fortsetzung Tabellen 30: autosomale STR-Einzeltypisierungen.

\begin{tabular}{|c|c|c|c|c|c|c|c|c|c|c|c|c|}
\hline F3 & \multicolumn{12}{|c|}{2388 [Mandibula] } \\
\hline PCR & EX & Amelo & D3S1358 & VWA & FGA & D8S1179 & D21S11 & D18S51 & D5S818 & D13S317 & D7S820 & CSF1PO \\
\hline \multicolumn{2}{|c|}{$\begin{array}{c}\text { Schmidt } \\
2004\end{array}$} & XX & $15 / 16$ & $17 /-$ & $-/-$ & $13 / 15$ & $30 / 33.2$ & $-1-$ & $9 / 11$ & $-1-$ & $-1-$ & \\
\hline \multicolumn{2}{|c|}{$\begin{array}{c}\text { Schultes } \\
2000\end{array}$} & $\mathrm{X}$ & $15 / 16$ & $16 / 17$ & $20 / 21$ & $11 / 13 /(15)$ & $30 / 33.2$ & 15 & $11 /(12)$ & $11 / 11$ & 10 & \\
\hline \multicolumn{2}{|c|}{ Genotyp } & $\mathrm{XX}$ & $15 / 16$ & $16 / 17$ & $20 / 21$ & $13 / 15$ & $30 / 33.2$ & $15 /-$ & $11 /-$ & $11 / 11$ & $10 /-$ & $-1-$ \\
\hline
\end{tabular}

\begin{tabular}{|c|c|c|c|c|c|c|c|c|c|c|c|c|}
\hline F15 & \multicolumn{12}{|c|}{2589 [Mandibula] } \\
\hline PCR & EX & Amelo & D3S1358 & VWA & FGA & D8S1179 & D21S11 & D18S51 & $\bar{D} 5 \mathrm{~S} 818$ & D13S317 & D7S820 & CSF1PO \\
\hline \multicolumn{2}{|c|}{$\begin{array}{c}\text { Schultes } \\
2000\end{array}$} & $\mathrm{XX}$ & $15 / 16$ & $14 / 15$ & $22 / 24$ & $13 / 13$ & 28 & $-1-$ & $11 /(12)$ & (11) & $-/-$ & \\
\hline \multicolumn{2}{|c|}{$\begin{array}{c}\text { Schmidt } \\
2004\end{array}$} & $\mathrm{X} /-$ & $16 /-$ & $14 / 15$ & $22 /-$ & $13 /-$ & $29 / 30$ & $-1-$ & $11 /-$ & $11 /-$ & $-1-$ & \\
\hline 7 & I & $\mathrm{X}$ & $-1-$ & 14 & 22 & $3<$ & 30 & $3<$ & $11 / 12$ & $-1-$ & $3<$ & (10) \\
\hline 8 & I & $\mathrm{X}$ & $-1-$ & $14 / 18$ & $-1-$ & 13 & 28 & $-/-$ & 12 & 11 & $8 / 10$ & $3<$ \\
\hline 9 & I & (X) & $15 / 16$ & $-/-$ & 24 & 3 & $28 / 30$ & 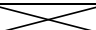 & $11 / 12$ & $(9) / 11 / 12$ & $\sum<$ & 11 \\
\hline 52 & II & - & $14 / 15$ & (15) & $-1-$ & $3<$ & $-/-$ & $><$ & 12 & $12 / 14$ & $\sum$ & $-/-$ \\
\hline 53 & II & $\mathrm{X}$ & 16 & 14 & $-1-$ & 13 & $-/-$ & $-/-$ & 12 & $-/-$ & $-1-$ & $S$ \\
\hline \multicolumn{2}{|c|}{ Genotyp } & $\mathrm{XX}$ & $15 / 16$ & $14 / 15$ & $22 / 24$ & $13 / 13$ & $28 / 30$ & $-1-$ & $11 / 12$ & $11 / 12$ & $-/-$ & $-/-$ \\
\hline
\end{tabular}

\begin{tabular}{|c|c|c|c|c|c|c|c|c|c|c|c|c|}
\hline M9 & \multicolumn{12}{|c|}{2749 [Mandibula] } \\
\hline PCR & EX & Amelo & D3S1358 & VWA & FGA & D8S1179 & D21S11 & D18S51 & D5S818 & D13S317 & $\begin{array}{l}\text { D7S820 } \\
\end{array}$ & CSF1PO \\
\hline \multicolumn{2}{|c|}{$\begin{array}{c}\text { Schultes } \\
2000\end{array}$} & $(\mathrm{XY})$ & $(16 / 19)$ & $(14 / 16)$ & $(21 / 23)$ & (13) & $(27 / 32.2)$ & $(12 / 14)$ & (12) & (11) & (10) & \\
\hline 7 & I & $\mathrm{XY}$ & 16 & 16 & $21 / 23$ & 3 & $32.2 / 33.2$ & $>$ & 12 & $(8 / 10)$ & $>$ & $(10) / 11$ \\
\hline 8 & I & $\mathrm{XY}$ & $16 / 19$ & $14 / 16$ & $21 / 23$ & 12 & $27 / 32.2$ & $14 / 18$ & 12 & $11 / 14$ & $10 / 13$ & $S<$ \\
\hline 9 & I & $\mathrm{XY}$ & $16 / 19$ & $15 / 16$ & $21 / 23$ & $S<$ & $27 / 29 / 32.2$ & $S<$ & 12 & $8 / 11 / 1214$ & $3<$ & 11 \\
\hline YP & II & $\mathrm{XY}$ & $16 / 19$ & $14 / 16$ & $21 / 23$ & $3<$ & $27 / 32.2$ & $3<$ & 12 & $11 / 14$ & $3<$ & 11 \\
\hline 45 & III & $\mathrm{X}(\mathrm{Y})$ & 16 & 16 & $21 / 23$ & $3<$ & $27 / 29 / 32.2$ & $\sum<$ & $12 /(14)$ & 14 & $S$ & 11 \\
\hline 46 & III & $\mathrm{X}$ & 16 & $14 / 16$ & $21 / 23$ & 13 & $27 / 32.2$ & $12 / 14$ & 12 & $8 / 11 / 14$ & $10 / 13$ & $\sum<$ \\
\hline \multicolumn{2}{|c|}{ Genotyp } & $\mathrm{XY}$ & $16 / 19$ & $14 / 16$ & $21 / 23$ & $(13) /-$ & $27 / 32.2$ & $(12) / 14$ & $12 / 12$ & $11 / 14$ & $10 / 13$ & $11 /-$ \\
\hline
\end{tabular}

\begin{tabular}{|c|c|c|c|c|c|c|c|c|c|c|c|c|}
\hline $\mathrm{F} 20$ & \multicolumn{12}{|c|}{3190 [Mandibula] } \\
\hline PCR & EX & Amelo & D3S1358 & VWA & FGA & D8S1179 & D21S11 & D18S51 & D5S818 & D13S317 & D7S820 & CSF1PO \\
\hline 29 & I & $\mathrm{X}$ & 16 & 16 & $-1-$ & $3<$ & $-1-$ & $3<$ & $-1-$ & 12 & $><$ & 11 \\
\hline 31 & I & $\mathrm{X}$ & 16 & $-/-$ & $-/-$ & $-/-$ & $-1-$ & $-1-$ & $-1-$ & $-/-$ & $-/-$ & $3<$ \\
\hline 34 & I & $\mathrm{X}$ & $-1-$ & 16 & $-1-$ & $3<$ & $-1-$ & 3 & (8) & $11 / 12$ & $\infty$ & 11 \\
\hline 35 & II & - & $-1-$ & $-/-$ & $-/-$ & $3<$ & $-1-$ & $3<$ & $-/-$ & $-/-$ & $>$ & $-/-$ \\
\hline 39 & II & - & $-1-$ & $-1-$ & $-1-$ & $-/-$ & $-1-$ & $-/-$ & $-1-$ & $-/-$ & $-/-$ & $3<$ \\
\hline \multicolumn{2}{|c|}{ Genotyp } & $\mathrm{X}(\mathrm{X})$ & $(16) /-$ & $(16) /-$ & $-/-$ & $-1-$ & $-/-$ & $-1-$ & $-/-$ & $(12) /-$ & $-1-$ & $(11) /-$ \\
\hline
\end{tabular}

\begin{tabular}{|c|c|c|c|c|c|c|c|c|c|c|c|c|}
\hline M5 & \multicolumn{12}{|c|}{3380 [Mandibula] } \\
\hline PCR & EX & Amelo & D3S1358 & VWA & FGA & D8S1179 & D21S11 & D18S51 & D5S818 & D13S317 & D7S820 & CSF1PO \\
\hline 29 & $\mathrm{I}$ & $\mathrm{XY}$ & $-1-$ & 16 & 25 & $3<$ & $(29) / 30$ & $3<$ & $11 / 13$ & $8 / 14$ & $3<$ & 12 \\
\hline 31 & I & $\mathrm{X}$ & 17 & $-/-$ & $-1-$ & $10 / 14$ & $-/-$ & $-/-$ & (7)/13 & $-/-$ & (13) & $S<$ \\
\hline 34 & I & $\mathrm{X}$ & $-/-$ & $16 / 19$ & 25 & $3<$ & 28 & $3<$ & 13 & $8 / 14$ & $><$ & (11) \\
\hline 35 & II & XY & $15 / 17$ & $18 / 19$ & 21 & $3<$ & $28 / 30$ & $><$ & 11 & $8 / 11$ & $3<$ & 10 \\
\hline 39 & II & $\mathrm{X}$ & 15 & $-/-$ & $-1-$ & $(9) / 10 / 14$ & $-1-$ & $-/-$ & $11 / 13$ & $-/-$ & $-/-$ & $3<$ \\
\hline \multicolumn{2}{|c|}{ Genotyp } & $\mathrm{XY}$ & $(15) / 17$ & $(16) / 19$ & $(25) /-$ & $10 / 14$ & $28 / 30$ & $-/-$ & $11 / 13$ & $8 /(14)$ & $-/-$ & $-/-$ \\
\hline
\end{tabular}

Legende: $\mathrm{M}=$ male, $\mathrm{F}=$ female,$-=$ Allel nicht bestimmbar, ()$=$ unsicheres Allel 
Fortsetzung Tabellen 30: autosomale STR-Einzeltypisierungen.

\begin{tabular}{|c|c|c|c|c|c|c|c|c|c|c|c|c|}
\hline F8 & \multicolumn{12}{|c|}{3631 [Calvarium] } \\
\hline PCR & EX & Amelo & D3S1358 & VWA & FGA & D8S1179 & D21S11 & D18S51 & D5S818 & D13S317 & D7S820 & CSF1PO \\
\hline 0 & I & $\mathrm{X}$ & $-1-$ & 14 & $21 /(25)$ & $10 / 12$ & $-/-$ & $-1-$ & $-/-$ & $-1-$ & $-1-$ & $S<$ \\
\hline 6 & I & $\mathrm{X}$ & 18 & $-1-$ & 21 & $3<$ & $29 / 33.2$ & 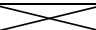 & $-/-$ & 12 & $\infty$ & $-/-$ \\
\hline 7 & I & $\mathrm{X}$ & 16 & $14 / 16$ & $21 / 23$ & $3<$ & 32.2 & $\sum<$ & $12 / 15$ & (8) & $\varnothing$ & $10 / 11$ \\
\hline 17 & I & $\mathrm{X}$ & $16 / 17 / 18$ & $-1-$ & $21 / 25$ & $-/-$ & $(30.2)$ & $-/-$ & $-/-$ & $-1-$ & $-/-$ & $S<$ \\
\hline 18 & II & $\mathrm{X}$ & $-/-$ & 17 & $21 / 24$ & $3<$ & $-/-$ & $s<$ & 12 & $8 / 12$ & $\sum$ & $(10) / 11$ \\
\hline 19 & II & $\mathrm{X}$ & 18 & 17 & $21 / 25$ & $11 / 13$ & 30.2 & $-1-$ & $8 / 12$ & $8 / 12$ & & $3<$ \\
\hline 26 & II & $\mathrm{X}$ & (18) & $14 / 17$ & $21 / 25$ & $11 / 13 /(14)$ & $-/-$ & $-/-$ & 12 & $-1-$ & 11 & \\
\hline 28 & II & $\mathrm{X}$ & 18 & (14)/17 & $21 / 25$ & & 30.2 & & 12 & $8 / 12$ & & 11 \\
\hline 45 & III & $\mathrm{X}$ & 18 & $14 / 17$ & $21 / 25$ & $S<$ & 30.2 & 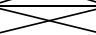 & 12 & $8 / 12$ & & $11 /(13)$ \\
\hline 46 & III & $\mathrm{X}$ & 18 & $14 / 17$ & $21 / 25$ & $11 / 13$ & 30.2 & $15 / 17$ & 12 & $8 / 12$ & $10 / 11$ & $3<$ \\
\hline$\overline{R S}$ & $\begin{array}{l}1: 6 \\
\text { unz }\end{array}$ & $\bar{X}$ & $-1-$ & $-/-$ & $-/-$ & & $-/-$ & & $-/-$ & $-/-$ & & $-/-$ \\
\hline RS & $\begin{array}{l}1: 5 \\
\text { unz }\end{array}$ & $\mathrm{X}$ & $-1-$ & $-1-$ & $-/-$ & & $30 / 30.2$ & & $-/-$ & $-/-$ & & 11 \\
\hline RS & $\begin{array}{c}1: 4 \\
\text { unz }\end{array}$ & $\mathrm{X}$ & $-/-$ & 17 & $-/-$ & & $-/-$ & & 12 & (9) & & $-/-$ \\
\hline RS & $1: 6 \mathrm{z}$ & $\mathrm{X}$ & 18 & $14 / 17$ & $21 / 25$ & $>$ & $30 / 30.2$ & $\infty$ & 12 & $8 / 12$ & & $11 / 13$ \\
\hline RS & $1: 5 \mathrm{z}$ & $\mathrm{X}$ & 18 & $14 / 17$ & $21 / 25$ & 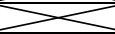 & $30 / 30.2$ & 3 & 12 & $8 / 12$ & $>$ & $11 / 13$ \\
\hline 56 & $1: 6 \mathrm{z}$ & $\mathrm{X}$ & 18 & $14 / 17$ & $21 / 25$ & $11 / 13$ & $30 / 30.2$ & $-1-$ & 12 & $8 / 12$ & $10 / 11$ & \\
\hline Gen & yp & $\mathrm{XX}$ & $18 / 18$ & $14 / 17$ & $21 / 25$ & $11 / 13$ & $30 / 30.2$ & $-/-$ & $12 / 12$ & $8 / 12$ & $10 / 11$ & $11 / 13$ \\
\hline
\end{tabular}

\begin{tabular}{|c|c|c|c|c|c|c|c|c|c|c|c|c|}
\hline M2 & \multicolumn{12}{|c|}{3644 [Mandibula] } \\
\hline PCR & EX & Amelo & D3S1358 & VWA & FGA & D8S1179 & D21S11 & D18S51 & D5S818 & D13S317 & D7S820 & CSFIPO \\
\hline 18 & I & $\mathrm{X}$ & $15 / 18$ & (16) & (26) & $><$ & $29 / 33.2$ & 7 & 9 & - - & $><$ & 13 \\
\hline 19 & I & $\mathrm{XY}$ & $\begin{array}{c}15 / 16 / \\
(19)\end{array}$ & 16 & $-1-$ & 12 & $-/$ & $17 / 18$ & $10 / 11$ & 13 & $-1-$ & \\
\hline 22 & I & $\mathrm{XY}$ & $15 / 16$ & 16 & 21 & 12 & 29 & 18 & 11 & 11 & $-/-$ & \\
\hline 32 & I & $\mathrm{Y}$ & 16 & $-1-$ & 21 & $><$ & 29 & $\sum<$ & $9 / 11$ & 11 & $\sum$ & 10 \\
\hline 35 & II & $\mathrm{X}$ & $-1-$ & 16 & 21 & $><$ & $-1-$ & $8<$ & $-/-$ & 11 & $><$ & (11) \\
\hline YP & III & $\mathrm{XY}$ & 15 & 16 & $20 / 21$ & 3 & $-1-$ & $\sum$ & $9 / 10$ & 11 & $\sum<$ & $12 / 13$ \\
\hline 41 & III & $\mathrm{XY}$ & 15 & 16 & (21) & 13 & 29 & $-1-$ & 10 & $-1-$ & $-/-$ & $8<$ \\
\hline Genc & & $\mathrm{XY}$ & $15 /(16)$ & $16 / 16$ & $21 /-$ & $(12) /-$ & 29/- & $(18) /-$ & $9 /(10)$ & 11/11 & $-1-$ & $13 /-$ \\
\hline
\end{tabular}

YP = PCR von Puder (2005) durchgeführt

\begin{tabular}{|c|c|c|c|c|c|c|c|c|c|c|c|c|}
\hline F9 & \multicolumn{12}{|c|}{3705 [Calvarium] } \\
\hline PCR & EX & Amelo & D3S1358 & VWA & FGA & $\begin{array}{l}\text { D8S1179 } \\
\end{array}$ & D21S11 & D18S51 & D5S818 & $\begin{array}{l}\mathrm{D} 13 \mathrm{~S} 317 \\
\end{array}$ & D7S820 & CSF1PO \\
\hline 0 & I & $-1-$ & 14 & (14) & (24) & $-1-$ & $-1-$ & $-1-$ & $-1-$ & $-1-$ & $-1-$ & 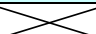 \\
\hline 6 & I & $\mathrm{X}$ & $-1-$ & 13 & 24 & $3<$ & $-1-$ & 7 & 10 & $-1-$ & 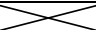 & $-1-$ \\
\hline 7 & I & $\mathrm{X}$ & $15 / 16$ & $13 / 14$ & $-/-$ & $\$<$ & $-1-$ & $\infty$ & $-1-$ & $-1-$ & & $-/-$ \\
\hline 17 & I & $-/-$ & $-/-$ & $-/-$ & 24 & 13 & $-1-$ & $-1-$ & $-/-$ & $-/-$ & $-/-$ & $3<$ \\
\hline 18 & II & $\mathrm{X}$ & 16 & $-1-$ & $-1-$ & & $\begin{array}{c}29 / 30 / \\
32.2\end{array}$ & & $-1-$ & $-/-$ & & 12 \\
\hline 19 & II & $\mathrm{X}$ & $14 / 16$ & $13 / 14$ & 18 & 13 & $-/-$ & $-1-$ & $10 / 13$ & 8 & $-1-$ & \\
\hline 22 & II & $X$ & $-1-$ & 14 & $(23) / 24$ & 13 & 32.2 & 14 & 13 & $10 / 11$ & $-/-$ & $3<$ \\
\hline 28 & II & $\mathrm{X}$ & 17 & $13 / 14$ & $-/-$ & $S$ & 29 & $\$$ & 10 & $8 /(10)$ & 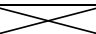 & 12 \\
\hline YP & III & $\mathrm{X}$ & $16 / 18$ & $(17 / 19)$ & $(20 / 21)$ & $S<$ & $-1-$ & $>$ & 13 & $8 / 10$ & $\infty$ & $(10 / 12)$ \\
\hline 45 & IV & $\mathrm{X}$ & $-/-$ & $13 / 14$ & 24 & $3<$ & $29 / 32.2$ & $>$ & $10 / 13$ & $8 / 10$ & $3<$ & 12 \\
\hline 46 & IV & $\mathrm{X}$ & $14 / 16$ & $13 / 14$ & 24 & 13 & 29 & $12 / 15$ & $10 / 13$ & 8 & $-/-$ & $3<$ \\
\hline \multicolumn{2}{|c|}{ Genotyp } & $\mathrm{XX}$ & $14 / 16$ & $13 / 14$ & $24 /-$ & $13 / 13$ & $29 / 32.2$ & $-/-$ & $10 / 13$ & $8 / 10$ & $-/-$ & $12 /-$ \\
\hline
\end{tabular}

YP = PCR von Puder (2005) durchgeführt

\begin{tabular}{|c|c|c|c|c|c|c|c|c|c|c|c|c|}
\hline F5 & \multicolumn{12}{|c|}{3706 [Calvarium] } \\
\hline PCR & EX & Amelo & D3S1358 & VWA & FGA & D8S1179 & D21S11 & D18S51 & D5S818 & D13S317 & D7S820 & CSF1PO \\
\hline 0 & $\mathrm{I}$ & $\mathrm{X}$ & 18 & (17) & $21 / 23$ & $12 / 15$ & (28) & (16) & 12 & $-1-$ & (10) & $><$ \\
\hline 6 & I & $\mathrm{X}$ & 18 & $17 / 19$ & $21 / 23$ & 3 & $28 / 29$ & $>$ & 12 & $8 / 9$ & $>$ & $10 / 11$ \\
\hline 7 & I & $\mathrm{X}$ & 18 & $17 / 19$ & $21 / 23$ & $\sum$ & $28 / 29$ & 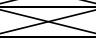 & 12 & $8 / 9$ & $\sum$ & $10 / 11$ \\
\hline YP & II & $\mathrm{XY}$ & $16 / 18$ & $17 / 19$ & $21 / 23$ & $3<$ & $28 / 29 / 30$ & 3 & 12 & $8 / 9 / 12 / 13$ & $2<$ & $10 / 11 / 12$ \\
\hline 41 & $\mathrm{I}$ & $\mathrm{X}$ & 18 & $17 / 19$ & $21 / 23$ & $12 / 15$ & $28 / 29$ & 16 & 12 & $8 / 9$ & 10 & $3<$ \\
\hline 41 & II & $\mathrm{X}$ & 18 & $17 / 19$ & $21 / 23$ & $12 / 15$ & $28 / 29$ & 16 & 12 & $8 / 9$ & 10 & 3 \\
\hline 52 & III & $\mathrm{X}$ & 18 & $17 / 19$ & $21 / 23$ & $3<$ & $28 / 29$ & $><$ & $(11) / 12$ & $8 / 9$ & $3<$ & $10 / 11$ \\
\hline 53 & III & $\mathrm{X}$ & 18 & $17 / 19$ & 23 & $12 / 15$ & $28 / 29$ & 16 & 12 & $8 / 9 / 14$ & $-/-$ & $3<$ \\
\hline \multicolumn{2}{|c|}{ Genotyp } & $\mathrm{XX}$ & $18 / 18$ & $17 / 19$ & $21 / 23$ & $12 / 15$ & $28 / 29$ & $16 / 16$ & $12 / 12$ & $8 / 9$ & $10 /-$ & $10 / 11$ \\
\hline
\end{tabular}

YP = PCR von Puder (2005) durchgeführt

Legende: $\mathrm{M}=$ male, $\mathrm{F}=$ female,$-=$ Allel nicht bestimmbar, $(\mathrm{)}=$ unsicheres Allel 
Fortsetzung Tabellen 30: autosomale STR-Einzeltypisierungen.

\begin{tabular}{|c|c|c|c|c|c|c|c|c|c|c|c|c|}
\hline F6 & \multicolumn{12}{|c|}{3709 [Mandibula] } \\
\hline PCR & EX & Amelo & D3S1358 & VWA & FGA & D8S1179 & D21S11 & D18S51 & D5S818 & D13S317 & D7S820 & CSF1PO \\
\hline 18 & I & $\mathrm{X}$ & 18 & 17 & 23 & $3<$ & 29 & $3<$ & $11 / 12$ & $9 / 11 / 12$ & $3<$ & $10 / 13$ \\
\hline 19 & I & $\mathrm{X}$ & (15) $16 / 18$ & 17 & 23 & $(12) / 13$ & $29 / 32.2$ & $16 / 17$ & $11 / 12$ & $9 / 12$ & $-1-$ & $><$ \\
\hline 26 & $\mathrm{I}$ & $\mathrm{X}$ & 18 & 17 & 21 & $12 / 13$ & 29 & 17 & $11 / 12$ & 12 & $8 / 10$ & $<$ \\
\hline 28 & I & $\mathrm{X} / \mathrm{Y}$ & $16 / 18$ & $15 / 17$ & $21 / 23$ & 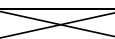 & $29 / 32.2$ & $\$$ & (12) & $9 / 12$ & $>$ & 10 \\
\hline YP & II & $\mathrm{X}$ & $16 / 18$ & 17 & $21 / 23$ & $S<$ & $29 / 32.2$ & $><$ & $11 / 12$ & $9 / 12$ & $>$ & $10 / 13$ \\
\hline 41 & II & $\mathrm{X}$ & $16 / 18$ & 17 & $21 / 23$ & $12 / 13$ & $29 / 32.2$ & $16 / 17$ & $11 / 12$ & $9 / 12$ & 8 & $3<$ \\
\hline 45 & III & $\mathrm{X}$ & $16 / 18$ & 17 & 23 & $S$ & 29 & $S<$ & $10 / 11 / 12$ & $(9) / 11 / 12$ & $S<$ & 10 \\
\hline 46 & III & $\mathrm{X}$ & $16 / 18$ & 17 & $21 / 23$ & $12 / 13$ & $29 / 32.2$ & (16) & 12 & $9 / 12$ & $8 / 10$ & 3 \\
\hline \multicolumn{2}{|c|}{ Genotyp } & $\mathrm{XX}$ & $16 / 18$ & $17 / 17$ & $21 / 23$ & $12 / 13$ & $29 / 32.2$ & $16 / 17$ & $11 / 12$ & $9 / 12$ & $8 / 10$ & $10 / 13$ \\
\hline
\end{tabular}

YP = PCR von Puder (2005) durchgeführt

\begin{tabular}{|c|c|c|c|c|c|c|c|c|c|c|c|c|}
\hline F11 & \multicolumn{12}{|c|}{3713 [Mandibula] } \\
\hline PCR & EX & Amelo & D3S1358 & VWA & FGA & D8S1179 & D21S11 & D18S51 & D5S818 & D13S317 & D7S820 & CSF1PO \\
\hline 29 & I & $\mathrm{X}$ & $(17.1)$ & $((15)) / 19$ & $-1-$ & $3<$ & $30 / 32.2$ & $\triangle<$ & 11 & 9 & $\triangle<$ & 11 \\
\hline 31 & I & $\mathrm{X}$ & $14 / 18$ & $(15) / 16$ & 24 & $12 / 14$ & $-/-$ & $-/-$ & 11 & $-1-$ & $-1-$ & 3 \\
\hline 34 & I & $\bar{X}$ & 16 & $16 / 19$ & $-1-$ & $3<$ & $-/-$ & $S<$ & 12 & $8 / 9$ & $S<$ & 11 \\
\hline 35 & II & $\mathrm{X}$ & 15 & 19 & 23 & $\longrightarrow$ & $29 / 31.2$ & $\sum$ & $12 / 13 /(15)$ & 8 & 3 & 11 \\
\hline 39 & II & $\mathrm{X}$ & 18 & 19 & $-1-$ & 15 & $-/-$ & $-/-$ & $-/-$ & $-1-$ & $-/-$ & $3<$ \\
\hline 41 & II & $\mathrm{X}$ & 18 & $-1-$ & $-1-$ & $11 / 12 /(15)$ & 29 & $-1-$ & $-1-$ & $-1-$ & $-1-$ & $3<$ \\
\hline 69 & III & - & $-/-$ & $-/-$ & $-1-$ & $3<$ & 29 & $3<$ & $-/-$ & $-1-$ & $S<$ & $-1-$ \\
\hline \multicolumn{2}{|c|}{ Genotyp } & $\mathrm{XX}$ & $18 /-$ & $(16) / 19$ & $-1-$ & $12 /-$ & $29 /-$ & $-1-$ & $11 /(12)$ & $8 / 9$ & $-/-$ & $11 /(11)$ \\
\hline
\end{tabular}

\begin{tabular}{|c|c|c|c|c|c|c|c|c|c|c|c|c|}
\hline F9 & \multicolumn{12}{|c|}{3746 [Mandibula] } \\
\hline PCR & EX & Amelo & D3S1358 & VWA & FGA & D8S1179 & D21S11 & D18S51 & D5S818 & D13S317 & D7S820 & CSF1PO \\
\hline 6 & I & $\mathrm{XY}$ & 14 & $13 / 16$ & 24 & & $\begin{array}{c}28 / 29 / 31.2 \\
/ 32.2\end{array}$ & & $10 / 13$ & 8 & & 12 \\
\hline 7 & I & $\mathrm{XY}$ & $14 / 16$ & $(14 / 17)$ & $\begin{array}{c}24 \\
(20 / 23)\end{array}$ & & $29 / 30$ & & $10 / 12 / 13$ & $10 / 12$ & & 10 \\
\hline 8 & I & $\mathrm{X}$ & 16 & $13 / 14$ & 24 & 13 & $\begin{array}{l}28 / 29 / \\
(32.2)\end{array}$ & $-1-$ & $10 / 12 / 13$ & $8 / 11$ & 10 & \\
\hline 17 & I & $\mathrm{X}$ & $14 / 16$ & 14 & 24 & $11 / 13$ & $30.2 / 32.2$ & $13 / 15$ & $11 / 13$ & 8 & $9 / 10$ & $\infty$ \\
\hline 28 & I & $\mathrm{X} / \mathrm{Y}$ & $14 / 16 / 18$ & $13 / 17 / 18$ & 24 & 3 & $29 / 32.2$ & 3 & $10 / 13$ & $8 / 10 / 12$ & 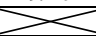 & $9 / 12$ \\
\hline 35 & II & $\mathrm{X}$ & $15 / 17 / 18$ & $13 / 14 / 16$ & $\begin{array}{c}20 / 21 / \\
24\end{array}$ & & $\begin{array}{c}29 / 31.2 / \\
32.2\end{array}$ & & $12 / 13$ & $\begin{array}{c}8 / 10 / 11 \\
12\end{array}$ & & $\begin{array}{c}10 / 11 / \\
(12)\end{array}$ \\
\hline 45 & III & $\mathrm{X}$ & $-1-$ & 14 & 24 & & 32.2 & & 13 & $\begin{array}{l}8 /(10) / \\
(12)\end{array}$ & & 12 \\
\hline 46 & III & $\mathrm{X}$ & $14 / 16$ & $14 / 18$ & 24 & 13 & 32.2 & 15 & $10 / 13$ & $8 / 10$ & 10 & $S<$ \\
\hline \multicolumn{2}{|c|}{ Genotyp } & $\mathrm{X} /(\mathrm{X})$ & $14 / 16$ & $13 / 14$ & $24 / 24$ & $13 /-$ & $29 / 32.2$ & $15 /-$ & $10 / 13$ & 8/- & $10 /-$ & $12 /-$ \\
\hline
\end{tabular}

\begin{tabular}{|c|c|c|c|c|c|c|c|c|c|c|c|c|}
\hline M8 & \multicolumn{12}{|c|}{3757 [Calvarium] } \\
\hline PCR & EX & Amelo & D3S1358 & VWA & FGA & D8S1179 & D21S11 & D18S51 & D5S818 & D13S317 & D7S820 & CSF1PO \\
\hline 7 & I & $\mathrm{XY}$ & 17 & $-1-$ & 21 & $\rightarrow$ & 31 & $><$ & 10 & $10 / 12$ & $><$ & 13 \\
\hline 8 & I & $\mathrm{XY}$ & 17/18 & 17 & 25 & $\begin{array}{l}10 / 11 \\
\end{array}$ & $24.2 / 30.2$ & $-/-$ & $10 / 13$ & $10 / 12$ & 9 & $3<$ \\
\hline 9 & I & $\mathrm{XY}$ & $\begin{array}{l}(17 / 18) \\
\end{array}$ & $16 / 17$ & $21 /(25)$ & & 30.2 & & $10 / 12$ & $10 / 12$ & & $12 / 13$ \\
\hline 17 & $\mathrm{I}$ & $\mathrm{XY}$ & 17 & $17 / 18$ & $21 / 25$ & $10 / 11$ & 30.2 & 12 & $10 / 12$ & 12 & $-1-$ & $\sum$ \\
\hline JSt & I & $\mathrm{XY}$ & $17 / 18$ & $\begin{array}{l}18 \\
\end{array}$ & 21 & $\sum$ & $-/-$ & $\sum$ & 10 & $9 / 10$ & 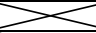 & 13 \\
\hline 28 & $\mathrm{I}$ & $\mathrm{XY}$ & $17 / 18$ & 18 & $21 / 25$ & $\sum<$ & $30.2 / 32.2$ & $\sum$ & $(10) / 13$ & $10 / 12$ & $\sum$ & $(10) / 12 / 13$ \\
\hline 35 & II & $\mathrm{XY}$ & $17 / 18$ & $17 / 18$ & $21 / 25$ & 3 & 30.2 & $3<$ & $10 / 12$ & $10 / 12$ & $\sum$ & $12 /(13)$ \\
\hline 39 & II & $\mathrm{XY}$ & 17/18 & $17 / 18$ & 21 & $(10) / 11$ & 30.2 & $\begin{array}{ll}-1- \\
\end{array}$ & 10 & $\begin{array}{ll}10 / 12 \\
\end{array}$ & 9/11 & $2<$ \\
\hline 41 & II & $\mathrm{XY}$ & $17 / 18$ & $17 / 18$ & 25 & $10 / 11$ & $29 / 30.2$ & 17 & $10 / 12$ & $9 /(10) / 12$ & $-/-$ & 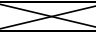 \\
\hline 69 & III & $\mathrm{Y}$ & $-1-$ & $-1-$ & $-1-$ & $3<$ & $-1-$ & $3<$ & $-1-$ & $-/-$ & $3<$ & $-1-$ \\
\hline \multicolumn{2}{|c|}{ Genotyp } & XY & $17 / 18$ & $17 / 18$ & $21 / 25$ & $10 / 11$ & $30.2 /-$ & $-1-$ & $10 / 12$ & $10 / 12$ & 9/- & $12 / 13$ \\
\hline
\end{tabular}

JSt = PCR von Stauch (2006) durchgeführt

\begin{tabular}{|c|c|c|c|c|c|c|c|c|c|c|c|c|}
\hline M16 & \multicolumn{10}{|c|}{3886 [Felsenbein li.] } \\
\hline PCR & EX & Amelo & D3S1358 & VWA & FGA & D8S1179 & D21S11 & D18S51 & D5S818 & D13S317 & D7S820 & CSF1PO \\
\hline 58 & I & XY & $17 / 18$ & $14 / 17$ & $24 / 25$ & & $29 / 30.2$ & & $10 / 12$ & $8 / 10$ & & $11 / 12$ \\
\hline 59 & I & XY & $17 / 18$ & $14 / 17$ & $24 / 25$ & & $29 / 30.2$ & & $-/-$ & $8 / 10$ & & $11 / 12$ \\
\hline 62 & I A & XY & $17 / 18$ & $14 / 17$ & $24 / 25$ & $10 / 13$ & $29 / 30.2$ & $12 / 15$ & $10 / 12$ & $8 / 10$ & $8 / 11$ & \\
\hline 62 & I B & XY & $17 / 18$ & $14 / 17$ & $24 / 25$ & $10 / 13$ & $29 / 30.2$ & $12 / 15$ & $10 / 12$ & $8 / 10$ & $8 / 11$ & \\
\hline 64 & I & XY & $17 / 18$ & $14 / 17$ & $(24 / 25)$ & - & $29 / 30.2$ & & $-/-$ & $8 / 10$ & & $11 / 12$ \\
\hline 65 & II & XY & $17 / 18$ & $14 / 17$ & $24 / 25$ & $10 / 13$ & $29 / 30.2$ & $12 / 15$ & $10 / 12$ & $8 / 10$ & $(8 /-)$ & $1 / 12$ \\
\hline Genotyp & XY & $17 / 18$ & $14 / 17$ & $24 / 25$ & $10 / 13$ & $29 / 30.2$ & $12 / 15$ & $10 / 12$ & $8 / 10$ & $8 / 11$ & $11 / 12$ \\
\hline
\end{tabular}

Legende: $\mathrm{M}=$ male, $\mathrm{F}$ = female, - = Allel nicht bestimmbar, $(\mathrm{)}$ = unsicheres Allel 
Anhang : Tabellen autosomale STR-Typisierungsergebnisse

Fortsetzung Tabellen 30: autosomale STR-Einzeltypisierungen.

\begin{tabular}{|c|c|c|c|c|c|c|c|c|c|c|c|c|}
\hline & \multicolumn{12}{|c|}{3889 [Mandibula] } \\
\hline PCR & EX & Amelo & D3S1358 & VWA & FGA & D8S1179 & D21S11 & D18S51 & D5S818 & D13S317 & D7S820 & CSF1PO \\
\hline 7 & I & $\mathrm{X}$ & $-1-$ & $-1-$ & (20) & $3<$ & 30 & $3<$ & 12 & $(8 / 11)$ & $>$ & 12 \\
\hline 9 & I & $-1-$ & 13.2 & $15 / 17$ & $-/-$ & $3<$ & $-/-$ & $S<$ & 12 & $-/-$ & $S<$ & 13 \\
\hline 18 & II & $\mathrm{X}$ & $-/-$ & 18 & $-1-$ & $3<$ & $-1-$ & $3<$ & $-1-$ & $-1-$ & $3<$ & $-/-$ \\
\hline 19 & II & - & 17 & $-/-$ & $-1-$ & 12 & $(28.2)$ & $-/-$ & $-1-$ & $-1-$ & $-/-$ & $3<$ \\
\hline 28 & II & - & $-1-$ & $18 / 19$ & $-1-$ & $3<$ & $-/-$ & 3 & $-1-$ & 12 & $3<$ & 12 \\
\hline 32 & II & - & 18 & $(17) / 18$ & $-1-$ & $3<$ & $-1-$ & $3<$ & $-1-$ & $-1-$ & $3<$ & $-/-$ \\
\hline \multicolumn{2}{|c|}{ Genotyp } & $\mathrm{X}$ & $-/-$ & $(18) /-$ & $-/-$ & $-/-$ & $-1-$ & $-/-$ & $(12) /-$ & $-/-$ & $-/-$ & $12 /-$ \\
\hline
\end{tabular}

\begin{tabular}{|c|c|c|c|c|c|c|c|c|c|c|c|c|}
\hline M8 & \multicolumn{12}{|c|}{4003 [Mandibula] } \\
\hline PCR & EX & Amelo & D3S1358 & VWA & FGA & D8S1179 & D21S11 & D18S51 & D5S818 & D13S317 & D7S820 & CSF1PO \\
\hline 35 & $\mathrm{I}$ & - & $-1-$ & $-1-$ & $-1-$ & $3<$ & $-1-$ & $3<$ & $-1-$ & $-1-$ & $3<$ & $-/-$ \\
\hline 36 & I & $\mathrm{XY}$ & $-1-$ & 17 & $-1-$ & $10 / 11$ & $-1-$ & 12 & $-1-$ & $-1-$ & $-/-$ & $3<$ \\
\hline 39 & $\mathrm{I}$ & $(\mathrm{Y})$ & $17 / 18$ & 18 & 21 & $10 / 11$ & $-1-$ & $-/-$ & 12 & $-1-$ & $-/-$ & $-/-$ \\
\hline 45 & II & $\mathrm{X}$ & $-/-$ & $-1-$ & $-1-$ & $\sum<$ & $-1-$ & $2<$ & $-1-$ & $-1-$ & $2<$ & $-/-$ \\
\hline 46 & II & - & $-1-$ & 18 & $-1-$ & $-/-$ & $-1-$ & $-/-$ & 11 & $-1-$ & $-/-$ & $3<$ \\
\hline \multicolumn{2}{|c|}{ Genotyp } & $\mathrm{X}(\mathrm{Y})$ & $-1-$ & $18 /-$ & $-1-$ & $(10 / 11)$ & $-/-$ & $-1-$ & $-1-$ & $-1-$ & $-/-$ & $-/-$ \\
\hline
\end{tabular}

\begin{tabular}{|c|c|c|c|c|c|c|c|c|c|c|c|c|}
\hline F4 & \multicolumn{12}{|c|}{4078 [Mandibula] } \\
\hline PCR & EX & Amelo & D3S1358 & VWA & FGA & D8S1179 & D21S11 & D18S51 & D5S818 & D13S317 & D7S820 & CSF1PO \\
\hline 35 & I & $\mathrm{X}$ & $\begin{array}{c}15 / 16 / 17 / \\
18\end{array}$ & $14 / 17$ & $\begin{array}{c}20 / 21 / \\
25\end{array}$ & & $29 / 30$ & & 12 & $8 / 11$ & & $11 / 12$ \\
\hline 36 & $\mathrm{I}$ & $\mathrm{X}$ & $15 / 18$ & $14 / 17$ & $20 / 25$ & $11 / 15$ & $29 / 30$ & $14 / 15$ & 12 & $8 / 11$ & $10 / 12$ & $\infty$ \\
\hline 41 & I & $\mathrm{X}$ & $15 / 18$ & $14 / 17$ & $20 / 25$ & $11 / 15$ & $29 / 30$ & $14 / 15$ & 12 & 11 & $10 / 12$ & $>$ \\
\hline 45 & II & $\mathrm{XY}$ & $15 / 18$ & 14 & $20 / 25$ & $S<$ & $(28) / 29$ & $><$ & 12 & $8 / 11$ & $S<$ & 11 \\
\hline 46 & II & $\mathrm{X}$ & $15 / 18$ & $17 / 20$ & 25 & $11 / 15$ & $((32.2))$ & $-1-$ & 12 & $8 / 11$ & 10 & $3<$ \\
\hline \multicolumn{2}{|c|}{ Genotyp } & XX & $15 / 18$ & $14 / 17$ & $20 / 25$ & $11 / 15$ & $29 / 30$ & $(14 / 15)$ & $12 / 12$ & $8 / 11$ & $10 / 12$ & $11 /-$ \\
\hline
\end{tabular}

\begin{tabular}{|c|c|c|c|c|c|c|c|c|c|c|c|c|}
\hline F14 & \multicolumn{12}{|c|}{4309 [Mandibula] } \\
\hline PCR & EX & Amelo & D3S1358 & VWA & FGA & D8S1179 & D21S11 & D18S51 & D5S818 & D13S317 & D7S820 & CSF1PO \\
\hline 18 & I & $\mathrm{X}$ & $14 / 16 / 17$ & $14 / 15$ & $23 / 24$ & $3<$ & 28 & $S<$ & $11 / 12$ & $12 / 13$ & $S<$ & 11 \\
\hline 19 & I & $\mathrm{X}$ & $14 / 16$ & $14 /(15)$ & $23 / 24$ & $11 / 14$ & $28 / 30$ & 15 & $12 / 13$ & $-/-$ & $-1-$ & 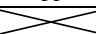 \\
\hline 22 & I & - & $14 / 16$ & $14 / 15$ & $23 / 24$ & $11 / 14$ & 28 & $12 / 15$ & $11 / 12 /(15)$ & 12 & 12 & 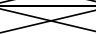 \\
\hline YP & II & $\mathrm{X}$ & $14 / 16$ & $14 / 15$ & $23 / 24$ & $3<$ & $28 / 30$ & 3 & $11 / 12$ & $12 / 13$ & 3 & 11 \\
\hline 41 & II & $\mathrm{X}$ & $14 / 16$ & $14 / 15$ & $23 / 24$ & $11 / 14$ & $28 / 30$ & $12 / 15$ & $11 / 12$ & $12 / 13$ & 12 & $S<$ \\
\hline \multicolumn{2}{|c|}{ Genotyp } & $\mathrm{XX}$ & $14 / 16$ & $14 / 15$ & $23 / 24$ & $11 / 14$ & $28 / 30$ & $12 / 15$ & $11 / 12$ & $12 / 13$ & $12 /-$ & $11 /-$ \\
\hline
\end{tabular}

\begin{tabular}{|c|c|c|c|c|c|c|c|c|c|c|c|c|}
\hline F4 & \multicolumn{12}{|c|}{5516 [Calvarium] } \\
\hline PCR & EX & Amelo & D3S1358 & VWA & FGA & D8S1179 & D21S11 & D18S51 & D5S818 & D13S317 & D7S820 & CSF1PO \\
\hline 7 & I & $\mathrm{X}$ & $15 / 18$ & $14 / 17$ & $20 / 25$ & $><$ & $29 / 30$ & $><$ & 12 & $8 / 11$ & 8 & $11 / 12$ \\
\hline 8 & I & $\mathrm{X}$ & $15 / 18$ & $14 / 17$ & $20 / 25$ & $11 / 15$ & $29 / 30$ & $14 / 15$ & 12 & $8 / 11$ & $10 / 12$ & $S$ \\
\hline 9 & I & $\mathrm{X}$ & $15 / 18$ & 17 & $20 / 25$ & $3<$ & $29 / 30$ & $><$ & 12 & $8 / 11$ & $><$ & $11 / 12$ \\
\hline 35 & II & $\mathrm{X}$ & $15 / 18$ & $14 / 17$ & $20 / 25$ & $3<$ & $29 / 30$ & $3<$ & 12 & $8 / 11$ & 3 & 12 \\
\hline YP & II & $\mathrm{X}$ & $15 / 18$ & $14 / 17$ & $20 / 25$ & 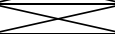 & $29 / 30$ & $3<$ & 12 & $8 / 11$ & $3<$ & $11 / 12$ \\
\hline 41 & II & $\mathrm{X}$ & $15 / 18$ & 17 & $20 / 25$ & $11 / 15$ & $29 / 30$ & $14 / 15$ & 12 & $8 / 11$ & $10 / 12$ & $><$ \\
\hline \multicolumn{2}{|c|}{ Genotyp } & $\mathrm{XX}$ & $15 / 18$ & $14 / 17$ & $20 / 25$ & $11 / 15$ & $29 / 30$ & $14 / 15$ & $12 / 12$ & $8 / 11$ & $10 / 12$ & $11 / 12$ \\
\hline
\end{tabular}

YP = PCR von Puder (2005) durchgeführt

\begin{tabular}{|c|c|c|c|c|c|c|c|c|c|c|c|c|}
\hline F6 & \multicolumn{12}{|c|}{5517 [Calvarium] } \\
\hline PCR & EX & Amelo & D3S1358 & VWA & FGA & D8S1179 & D21S11 & D18S51 & D5S818 & D13S317 & D7S820 & CSF1PO \\
\hline 7 & I & $\mathrm{X}$ & $-/-$ & $-/-$ & $-1-$ & $>$ & 32.2 & 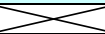 & $11 / 12$ & $-/-$ & $><$ & $-1-$ \\
\hline 8 & I & $\mathrm{X}$ & $13.2 / 16$ & 17 & $-1-$ & $-/-$ & 32.2 & $-/-$ & 12 & 9 & 10 & $3<$ \\
\hline 9 & $\mathrm{I}$ & $\mathrm{X}$ & $16 / 18$ & 17 & 21 & $3<$ & 32.2 & $3<$ & $11 / 12$ & $9 / 12$ & $><$ & 10 \\
\hline 17 & I & $\mathrm{X}$ & $-/-$ & 17 & 21 & $(14 / 15)$ & 29 & $-/-$ & $11 / 12$ & $-/-$ & 10 & $S<$ \\
\hline 28 & I & $\mathrm{X}$ & $16 / 18$ & $15 / 17$ & $-1-$ & 3 & $29 / 32.2$ & 3 & $11 / 12$ & $9 / 11 / 12$ & $3<$ & $10 / 12 / 13$ \\
\hline 45 & II & $\mathrm{X}$ & 16 & 17 & 21 & $3<$ & $29 / 32.2$ & $3<$ & $(11) / 12$ & $9 / 12$ & $3<$ & $10 /(11)$ \\
\hline 46 & II & $\mathrm{X}$ & $(14) / 16 /(18)$ & $-1-$ & $21 / 23$ & $12 / 13$ & $29 / 32.2$ & $-/-$ & $11 / 12$ & 12 & $8 / 10$ & $><$ \\
\hline 54 & IIIa & - & $16 / 18$ & 17 & $21 / 23$ & $3<$ & $29 / 30 / 32.2$ & $3<$ & $11 / 12$ & $9 / 12$ & $><$ & $10 / 13$ \\
\hline 54 & IIIb & - & $16 / 18$ & 17 & $21 / 23$ & $3<$ & $29 / 32.2$ & $3<$ & $11 / 12$ & $9 / 12$ & $3<$ & $10 / 13$ \\
\hline 54 & IIIc & - & $16 / 18$ & 17 & $21 / 23$ & $3<$ & $29 / 32.2$ & $3<$ & $11 / 12$ & $9 / 12$ & $3<$ & $10 / 13$ \\
\hline \multicolumn{2}{|c|}{ Genotyp } & $\mathrm{XX}$ & $16 / 18$ & $17 / 17$ & $21 / 23$ & $-/-$ & $29 / 32.2$ & $-/-$ & $11 / 12$ & $9 / 12$ & $10 /-$ & $10 / 13$ \\
\hline
\end{tabular}

Legende: $\mathrm{M}=$ male, $\mathrm{F}$ = female, - = Allel nicht bestimmbar, $($ = unsicheres Allel 
Anhang : Tabellen autosomale STR-Typisierungsergebnisse

Fortsetzung Tabellen 30: autosomale STR-Einzeltypisierungen.

\begin{tabular}{|c|c|c|c|c|c|c|c|c|c|c|c|c|}
\hline M3 & \multicolumn{12}{|c|}{6525 [Calvarium] } \\
\hline PCR & EX & Amelo & D3S1358 & VWA & FGA & D8S1179 & D21S11 & D18S51 & D5S818 & D13S317 & D7S820 & CSF1PO \\
\hline 64 & I & $\mathrm{XY}$ & 18 & 17 & $-/-$ & $3<$ & 30.2 & $3<$ & $-/-$ & 12 & $3<$ & 11 \\
\hline 65 & I & $\mathrm{Y}$ & 16 & $17 / 19$ & $21 / 22$ & $-/-$ & 30.2 & $-1-$ & $-1-$ & 11 & (11) & $3<$ \\
\hline 69 & II & $\mathrm{XY}$ & 16 & $17 / 19$ & $21 / 22$ & $3<$ & 30.2 & $3<$ & $11 / 12$ & 12 & $3<$ & $11 / 13$ \\
\hline 75 & $\mathrm{IIb}$ & $X Y$ & $16 / 18$ & $17 / 19$ & $21 / 22$ & $><$ & 30.2 & $\sum$ & $11 / 12$ & 12 & $\sum$ & 11 \\
\hline \multicolumn{2}{|c|}{ Genotyp } & $\mathrm{XY}$ & $16 / 18$ & $17 / 19$ & $21 / 22$ & $-/-$ & $30.2 /(30.2)$ & $-/-$ & $11 / 12$ & $12 /-$ & $-/-$ & $11 /-$ \\
\hline
\end{tabular}

\begin{tabular}{|c|c|c|c|c|c|c|c|c|c|c|c|c|}
\hline M12 & \multicolumn{12}{|c|}{ E33 [Mandibula] } \\
\hline PCR & EX & Amelo & D3S1358 & VWA & FGA & D8S1179 & D21S11 & D18S51 & D5S818 & D13S317 & D7S820 & CSF1PO \\
\hline 18 & I & $-/-$ & $-/-$ & $-1-$ & $-1-$ & $3<$ & $-1-$ & $\sum<$ & 9 & 11 & $><$ & $-/-$ \\
\hline 19 & I & $\mathrm{X}$ & $-1-$ & $-/-$ & $-1-$ & $-/-$ & $-/-$ & $-/-$ & $-1-$ & $-/-$ & $-/-$ & 3 \\
\hline 28 & I & $\mathrm{XY}$ & $-1-$ & $16 / 18$ & 21 & $S<$ & $30 / 33.2$ & $\sum$ & 9 & 11 & $S$ & $-/-$ \\
\hline 32 & I & $\mathrm{XY}$ & $-1-$ & 16 & $-/-$ & $3<$ & 30 & $><$ & $11 / 12$ & $-1-$ & $3<$ & 13 \\
\hline 45 & II & - & $-1-$ & (18) & (21) & $3<$ & 33.2 & $>$ & 11 & $11 / 12$ & $\sum<$ & $-/-$ \\
\hline 46 & II & $\mathrm{X}$ & 18 & 18 & 21 & 13 & 30 & $-/-$ & $9 / 11$ & $-/-$ & $-/-$ & $3<$ \\
\hline \multicolumn{2}{|c|}{ Genotyp } & $\mathrm{XY}$ & $-/-$ & $16 / 18$ & $21 /-$ & $-/-$ & $30 / 33.2$ & $-/-$ & $9 / 11$ & $11 /-$ & $-/-$ & $-/-$ \\
\hline
\end{tabular}

\begin{tabular}{|c|c|c|c|c|c|c|c|c|c|c|c|c|}
\hline & \multicolumn{12}{|c|}{ E35 [Felsenbein re.] } \\
\hline PCR & EX & Amelo & D3S1358 & VWA & FGA & D8S1179 & D21S11 & D18S51 & D5S818 & D13S317 & D7S820 & CSF1PO \\
\hline 58 & I & - & $-1-$ & $-1-$ & $-1-$ & $3<$ & $-1-$ & 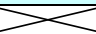 & $-1-$ & $-1-$ & 3 & $-/-$ \\
\hline 59 & I & - & $-/-$ & $-/-$ & $-/-$ & $3<$ & $-/-$ & 3 & $-1-$ & 12 & 3 & $-1-$ \\
\hline \multicolumn{2}{|c|}{ Genotyp } & - & $-1-$ & $-1-$ & $-1-$ & $-/-$ & $-/-$ & $-/-$ & $-1-$ & $-1-$ & $-/-$ & $-1-$ \\
\hline
\end{tabular}

\begin{tabular}{|c|c|c|c|c|c|c|c|c|c|c|c|c|}
\hline F21 & \multicolumn{12}{|c|}{ E37 [Viscerocranium] } \\
\hline PCR & EX & Amelo & D3S1358 & VWA & FGA & D8S1179 & D21S11 & D18S51 & D5S818 & D13S317 & D7S820 & CSF1PO \\
\hline 7 & I & $-1-$ & $-1-$ & $-1-$ & $-1-$ & $3<$ & $-1-$ & $\sum<$ & $-1-$ & 8 & $\sum<$ & $-1-$ \\
\hline 8 & I & (X) & $-1-$ & $-1-$ & $-1-$ & (15) & $-1-$ & $-/-$ & $-1-$ & $-1-$ & 8 & $S<$ \\
\hline 9 & I & $\mathrm{X}$ & 16 & $-1-$ & $-1-$ & $3<$ & $-1-$ & $3<$ & $-1-$ & $-1-$ & $S$ & $-/-$ \\
\hline 18 & II & $\mathrm{X}$ & 13 & $-1-$ & $-1-$ & $S$ & $-1-$ & $S<$ & 11 & 8 & 3 & $-1-$ \\
\hline 19 & II & $\mathrm{X}$ & 16 & $-1-$ & $-1-$ & $-/-$ & $-1-$ & $-/-$ & $-1-$ & $-1-$ & $-/-$ & $3<$ \\
\hline 28 & I & $\mathrm{X}$ & $-1-$ & 16 & $-/-$ & $3<$ & $-1-$ & $3<$ & $-1-$ & 8 & $3<$ & $-/-$ \\
\hline 32 & II & $\mathrm{X} / \mathrm{Y}$ & $-/-$ & 16 & $24(.1)$ & $3<$ & $-1-$ & 3 & 10 & $8 / 13$ & $3<$ & 10 \\
\hline \multicolumn{2}{|c|}{ Genotyp } & $\mathrm{XX}$ & $16 /-$ & $16 /-$ & $-1-$ & $-/-$ & $-/-$ & $-/-$ & $-1-$ & $8 /-$ & $-/-$ & $-/-$ \\
\hline
\end{tabular}

\begin{tabular}{|c|c|c|c|c|c|c|c|c|c|c|c|c|}
\hline & \multicolumn{12}{|c|}{ E39 [Mandibula] } \\
\hline PCR & EX & Amelo & D3S1358 & VWA & FGA & D8S1179 & D21S11 & D18S51 & D5S818 & D13S317 & D7S820 & CSF1PO \\
\hline 29 & I & - & $-/-$ & $-1-$ & $-1-$ & $3<$ & $-1-$ & 3 & $-1-$ & $-/-$ & 3 & $-1-$ \\
\hline 32 & I & - & $-1-$ & $-1-$ & $-1-$ & 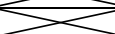 & $-1-$ & $3<$ & $-1-$ & $-1-$ & $3<$ & $-1-$ \\
\hline 45 & II & - & $-1-$ & $-1-$ & $-1-$ & 3 & $-1-$ & 3 & $-1-$ & $-1-$ & 3 & $-1-$ \\
\hline 46 & II & - & $-1-$ & $-/-$ & $-1-$ & $-/-$ & $-1-$ & $-/-$ & $-1-$ & $-1-$ & $-/-$ & 3 \\
\hline \multicolumn{2}{|c|}{ Genotyp } & - & $-1-$ & $-/-$ & $-/-$ & $-1-$ & $-/-$ & $-/-$ & $-1-$ & $-1-$ & $-1-$ & $-/-$ \\
\hline
\end{tabular}

\begin{tabular}{|c|c|c|c|c|c|c|c|c|c|c|c|c|}
\hline & \multicolumn{12}{|c|}{ N969 [Mandibula] } \\
\hline PCR & EX & Amelo & D3S1358 & VWA & FGA & D8S1179 & D21S11 & D18S51 & D5S818 & D13S317 & D7S820 & CSF1PO \\
\hline 6 & I & $\mathrm{X}$ & $14 / 15 / 16$ & $16 / 17 / 18$ & 22 & & $\begin{array}{c}27 / 28 / 29 / \\
30 \\
\end{array}$ & & $11 / 12 / 13$ & $\begin{array}{c}- \\
/ 11 / 12 / 13\end{array}$ & & $\begin{array}{c}10 / 11 / 12 / \\
13\end{array}$ \\
\hline 7 & I & $\mathrm{XY}$ & $14 / 15 / 16 / 17$ & $\begin{array}{c}15 / 16 / 17 / \\
18 \\
\end{array}$ & $\begin{array}{c}20 / 21 / 22 \\
/ 24 \\
\end{array}$ & & $\begin{array}{c}27 / 28 / 29 / \\
30 \\
\end{array}$ & & $\begin{array}{c}0 / 11 / 12 / \\
13 \\
\end{array}$ & $\begin{array}{c}9 / 10 / 11 / \\
12 / 13 \\
\end{array}$ & & $10 / 11 / 12$ \\
\hline 18 & II & $-1-$ & $-1-$ & $-/-$ & $-/-$ & $3<$ & $-1-$ & 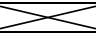 & 10 & $-/-$ & & $-/-$ \\
\hline 19 & II & $-/-$ & $-/-$ & 18 & $-1-$ & $-/-$ & $-1-$ & $-/-$ & $-1-$ & $-/-$ & $-1-$ & $3<$ \\
\hline 28 & II & $\mathrm{Y}$ & 15 & 16 & 22.2 & $3<$ & 31 & 36 & $-1-$ & 11 & $3<$ & $-/-$ \\
\hline 69 & III & $\mathrm{X}$ & $-1-$ & $-1-$ & $-1-$ & $3<$ & 31 & $3<$ & 12 & 10 & $3<$ & $-1-$ \\
\hline 75 & III & $\mathrm{X}$ & 18 & 17 & $-1-$ & $3<$ & $-1-$ & $3<$ & $(10.2)$ & $8 / 11$ & $3<$ & $-1-$ \\
\hline \multicolumn{2}{|c|}{ Genotyp } & $\mathrm{X}(\mathrm{Y})$ & $15 /-$ & $16 / 18$ & $(22) /-$ & $-/-$ & $-1-$ & $-/-$ & $-/-$ & $11 /-$ & $-/-$ & $-/-$ \\
\hline
\end{tabular}

Legende: $\mathrm{M}=$ male, $\mathrm{F}=$ female, - = Allel nicht bestimmbar, ()$=$ unsicheres Allel 
Anhang : Tabellen autosomale STR-Typisierungsergebnisse

Fortsetzung Tabellen 30: autosomale STR-Einzeltypisierungen.

\begin{tabular}{|c|c|c|c|c|c|c|c|c|c|c|c|c|}
\hline F12 & \multicolumn{12}{|c|}{ R1 [Calvarium] } \\
\hline PCR & EX & Amelo & D3S1358 & VWA & FGA & D8S1179 & D21S11 & D18S51 & D5S818 & D13S317 & D7S820 & CSF1PO \\
\hline \multicolumn{2}{|c|}{$\begin{array}{c}\text { Schultes } \\
2000 \\
\end{array}$} & $\mathrm{XX}$ & $16 / 16$ & $14 / 17$ & $21 / 21$ & $13 / 13$ & $29 / 33.2$ & $16 / 17$ & $9 / 12$ & $11 / 12$ & $11 / 12$ & \\
\hline 7 & I & $\mathrm{X}$ & 16 & 17 & 21 & $3<$ & $29 / 33.2$ & $\sum 3$ & $9 / 12$ & $11 / 12$ & 3 & 10 \\
\hline 8 & I & $\mathrm{X}$ & 16 & $14 / 17$ & 21 & 13 & $29 / 33.2$ & $16 / 17$ & $9 / 12$ & $11 / 12$ & 12 & $3<$ \\
\hline 9 & I & $\mathrm{X}$ & 16 & 17 & 21 & $S<$ & $28 / 29 / 33.2$ & $3<$ & $9 / 12$ & $11 / 12$ & $S$ & $10 / 11$ \\
\hline 69 & II & $\mathrm{X}$ & 16 & $14 / 17 / 19$ & 21 & 3 & 33.2 & 3 & $9 / 12$ & $11 / 12$ & 8 & $10 / 11$ \\
\hline 75 & $\mathrm{IIb}$ & $\mathrm{X}$ & 16 & $14 / 17$ & (21) & $3<$ & $29 / 33.2$ & 3 & $9 / 12$ & $11 / 12$ & 3 & $10 / 11$ \\
\hline \multicolumn{2}{|c|}{ Genotyp } & $\mathrm{XX}$ & $16 / 16$ & $14 / 17$ & $21 / 21$ & $13 / 13$ & $29 / 33.2$ & $16 / 17$ & $9 / 12$ & $11 / 12$ & $11 / 12$ & $10 / 11$ \\
\hline
\end{tabular}

\begin{tabular}{|c|c|c|c|c|c|c|c|c|c|c|c|c|}
\hline F16 & \multicolumn{12}{|c|}{ R2 [Calvarium] } \\
\hline PCR & EX & Amelo & D3S1358 & VWA & FGA & D8S1179 & D21S11 & D18S51 & D5S818 & D13S317 & D7S820 & CSF1PO \\
\hline \multicolumn{2}{|c|}{$\begin{array}{c}\text { Schultes } \\
2000\end{array}$} & $\mathrm{X}$ & $(16) / 18$ & (15) & $-/-$ & (13) & (30) & $-1-$ & $12 /(12)$ & $(8 / 12)$ & $-1-$ & \\
\hline 7 & I & $\mathrm{X}$ & (16) & 15 & (21) & $3<$ & $-1-$ & $3<$ & 12 & $(11 / 12)$ & $\infty$ & (10) \\
\hline 8 & I & (XY) & $-1-$ & $-/-$ & $-1-$ & (15) & $-1-$ & $-/-$ & 12 & $-1-$ & $-/-$ & 3 \\
\hline 9 & I & $\mathrm{X}$ & (16) & $(12) / 15$ & $-1-$ & 3 & $-1-$ & $3<$ & $-1-$ & $-1-$ & $><$ & $-1-$ \\
\hline 17 & I & $-1-$ & $-1-$ & $-/-$ & $-1-$ & $-/-$ & $-1-$ & $-/-$ & $-1-$ & $-1-$ & $-/-$ & 3 \\
\hline 18 & II & $\mathrm{X}$ & $-1-$ & $-1-$ & $-1-$ & 3 & 30 & $3<$ & 11 & 8 & $3<$ & 11 \\
\hline 19 & II & $\mathrm{X}$ & $-1-$ & $-1-$ & $-1-$ & $-/-$ & 30 & $-/-$ & $-1-$ & $-1-$ & $-/-$ & $S$ \\
\hline 28 & I & $\mathrm{X}$ & 16 & 18 & $-1-$ & $S$ & $-1-$ & $S$ & 12 & $-/-$ & $\sum$ & $-1-$ \\
\hline 32 & II & - & $-/-$ & 15 & $-1-$ & $3<$ & $-1-$ & $3<$ & $-1-$ & $11 / 12$ & $\sum$ & $-1-$ \\
\hline 45 & III & $\mathrm{X}$ & $-1-$ & 18 & 21 & $3<$ & $-1-$ & $3<$ & $-1-$ & 8 & 3 & $-1-$ \\
\hline 46 & III & $\mathrm{X}$ & $14 / 18$ & $-/-$ & 21 & $14 / 15$ & $-1-$ & (14) & (13) & $-1-$ & $-/-$ & $S<$ \\
\hline 54 & IVa & $\mathrm{X}$ & 16 & $15 / 18$ & 21 & 3 & $-1-$ & $>$ & 12 & $8 / 12$ & $>$ & 13 \\
\hline 54 & $\mathrm{IVb}$ & $\mathrm{X}$ & 17 & 15 & 21 & 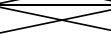 & $-1-$ & $3<$ & 12 & $8 / 12$ & $>$ & $-1-$ \\
\hline 54 & IVc & $\mathrm{X}$ & $-/-$ & (15) & 21 & & 30 & & 12 & $\begin{array}{c}8 / 11 / 12 / \\
14\end{array}$ & & 13 \\
\hline \multicolumn{2}{|c|}{ Genotyp } & $\mathrm{XX}$ & $16 / 18$ & $15 / 18$ & $21 / 21$ & $(15) /-$ & $30 /-$ & $-/-$ & $12 / 12$ & $8 / 12$ & $-1-$ & $13 /-$ \\
\hline
\end{tabular}

\begin{tabular}{|c|c|c|c|c|c|c|c|c|c|c|c|c|}
\hline M6 & \multicolumn{12}{|c|}{ R3 [Calvarium] } \\
\hline PCR & EX & Amelo & D3S1358 & VWA & FGA & D8S1179 & D21S11 & D18S51 & D5S818 & D13S317 & D7S820 & CSF1PO \\
\hline \multicolumn{2}{|c|}{$\begin{array}{c}\text { Schultes } \\
2000\end{array}$} & $\mathrm{XY}$ & $16 / 16$ & $17 / 18$ & $21 / 24$ & $10 / 12$ & $29 /(30.2)$ & 16 & $10 / 13$ & $-1-$ & (9) & \\
\hline 7 & $\mathrm{I}$ & $\mathrm{XY}$ & 16 & $-1-$ & $-1-$ & 2 & 29 & $3<$ & 10 & 12 & 2 & $-1-$ \\
\hline 8 & I & $\mathrm{XY}$ & 16 & 17 & $21 / 24$ & $-/-$ & $29 / 30.2$ & $-1-$ & $10 / 13$ & $-1-$ & 9 & $3<$ \\
\hline 9 & I & $\mathrm{XY}$ & 15 & 19 & $-/-$ & & $28 / 2930.2$ & & $11 / 12$ & 8 & & $\begin{array}{c}10 / \\
(11) /(12)\end{array}$ \\
\hline 28 & I & $\mathrm{XY}$ & $-/-$ & $17 / 18$ & 21/- & & 28 & & $10 / 13$ & 12 & & $-/-$ \\
\hline YP & II & $\mathrm{XY}$ & 16 & $17 / 18$ & $(19 / 20)$ & & 30.2 & & $10 / 12$ & $11 / 12 / 13$ & & $\begin{array}{c}10 / \\
(11) /(12)\end{array}$ \\
\hline 41 & II & $\mathrm{XY}$ & 16 & $17 / 18$ & $-/-$ & 12 & $-1-$ & $14 / 16$ & 13 & $12 / 13$ & $-1-$ & $3<$ \\
\hline \multicolumn{2}{|c|}{ Genotyp } & $\mathrm{XY}$ & $16 / 16$ & $17 / 18$ & $21 / 24$ & $10 / 12$ & $29 / 30.2$ & $16 /-$ & $10 / 13$ & $12 /-$ & 9/- & $10 /-$ \\
\hline
\end{tabular}

\begin{tabular}{|c|c|c|c|c|c|c|c|c|c|c|c|}
\hline \multicolumn{12}{|c|}{ PK FS } \\
\hline & Amelo & D3S1358 & VWA & FGA & D8S1179 & D21S11 & D18S51 & D5S818 & D13S317 & D7S820 & CSF1PO \\
\hline Genotyp & $\mathrm{XY}$ & $17 / 17$ & $16 / 19$ & $22 / 23$ & $12 / 13$ & $29 / 32.2$ & $16 / 17$ & $11 / 12$ & $10 / 11$ & $9 / 12$ & $12 / 12$ \\
\hline
\end{tabular}

Legende: $\mathrm{M}=$ male, $\mathrm{F}=$ female, - = Allel nicht bestimmbar, ()$=$ unsicheres Allel 


\subsection{3 mtDNA-Typisierungsergebnisse}

Tabelle 31: Zusammenstellung der mt-Haplotypen für die weiblichen Individuen. Abweichungen zur CRS sind farblich hinterlegt.

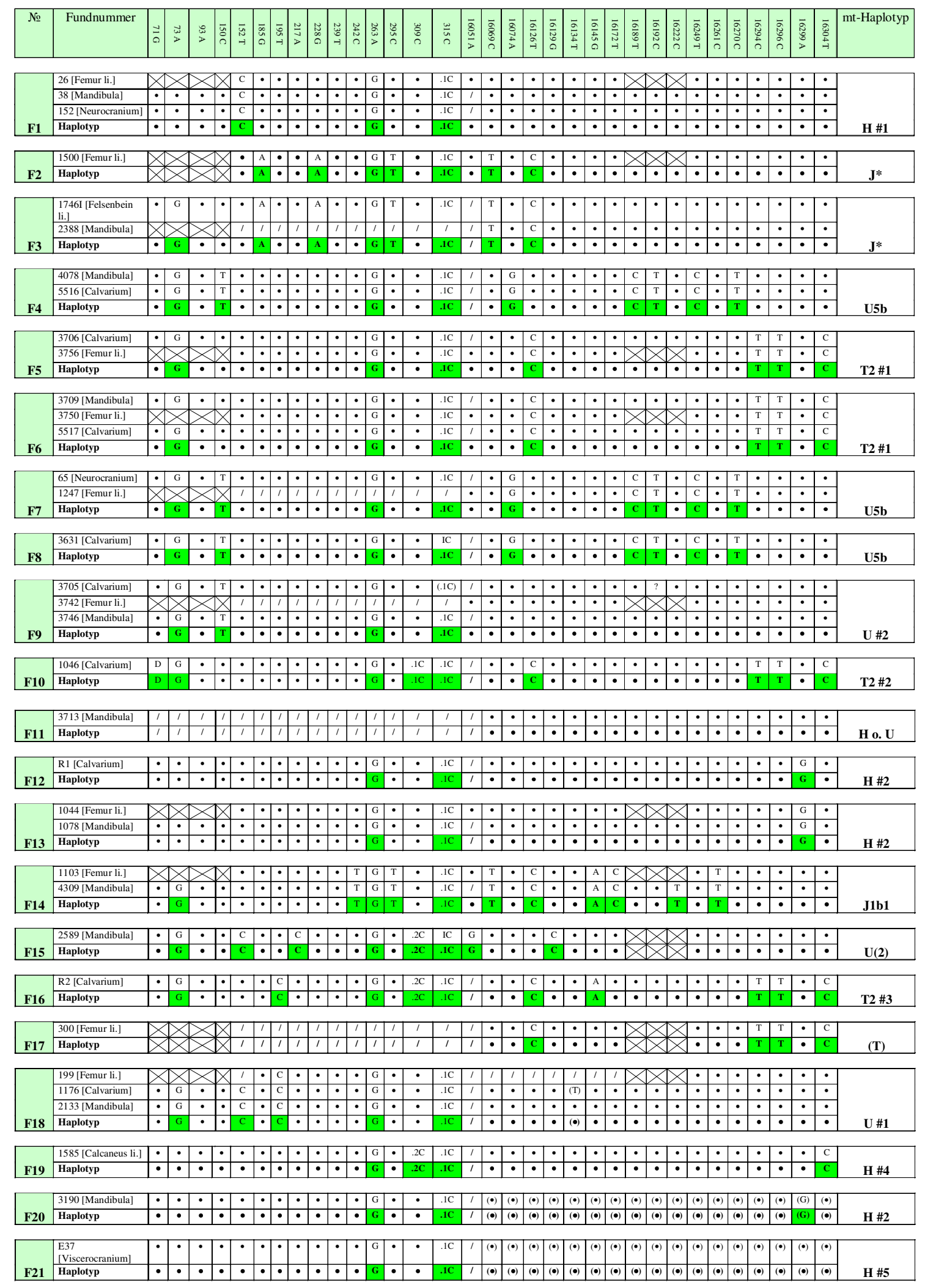

Legende: - = keine Abweichung zu CRS, / = Position nicht lesbar, ( ) = unsicherer Sequenz-

polymorphismus, $\mathrm{X}=$ Abschnitt nicht sequenziert; $\mathrm{F}=$ female 
Tabelle 32: Zusammenführung der mt-Haplotypen für die männlichen Individuen. Abweichungen zur CRS sind farblich hinterlegt.

\begin{tabular}{|c|c|c|c|c|c|c|c|c|c|c|c|c|c|c|c|c|c|c|c|c|c|c|c|c|c|c|c|c|c|c|c|c|c|c|c|c|}
\hline № & Fundnummer & $\frac{1}{2}$ & $\vec{\Delta}$ & $\stackrel{\$}{>}$ & 空 & 䘚 & & & 它 & $\begin{array}{c}\frac{N}{2} \\
\frac{N}{2}\end{array}$ & $\begin{array}{c}\mathbb{Z} \\
\substack{\infty \\
0 \\
0}\end{array}$ & 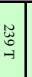 & $\begin{array}{c}\tilde{n} \\
\tilde{D} \\
0\end{array}$ & $\begin{array}{l}\tilde{O} \\
> \\
>\end{array}$ & 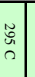 & 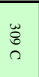 & 岕 & $\begin{array}{l}\overline{8} \\
\frac{\mathrm{d}}{>} \\
\end{array}$ & 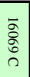 & $\mid \begin{array}{l}\overrightarrow{5} \\
\overline{3} \\
\bar{y} \\
>\end{array}$ & $\mid \begin{array}{c}\overline{2} \\
\overline{2} \\
\overline{7}\end{array}$ & $\left|\begin{array}{|l}\bar{a} \\
\bar{D} \\
\vdots \\
0\end{array}\right|$ & \begin{tabular}{|l}
$\overrightarrow{\bar{a}}$ \\
$\overline{\bar{t}}$ \\
$\vec{y}$
\end{tabular} & \begin{tabular}{|l}
$\overline{\bar{a}}$ \\
$\mathrm{f}$ \\
$\mathrm{a}$
\end{tabular} & 产 & $\mid$\begin{tabular}{|c}
$\overrightarrow{\bar{े}}$ \\
$\overline{\vec{B}}$ \\
$\overrightarrow{-}$
\end{tabular} & 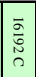 & \begin{tabular}{|l}
$\bar{N}$ \\
N \\
D.
\end{tabular} & 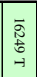 & 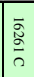 & 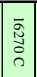 & 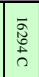 & 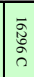 & 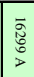 & 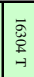 & mt-Haplotyp \\
\hline \multirow[b]{4}{*}{ M1 } & 1076 [Femur li.] & \multicolumn{4}{|c|}{ 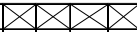 } & $\sqrt{\mathrm{c}}$ & & $\cdot \cdot$ & $\cdot$ & $\cdot$ & $\cdot$ & $\cdot$ & $\cdot$ & \begin{tabular}{l|l}
$\mathrm{G}$ \\
\end{tabular} & $\bullet$ & $\bullet$ & $.1 \mathrm{C}$ & 1 & $\cdot$ & $\cdot$ & $\cdot$ & $\bullet$ & $\bullet$ & $\cdot$ & $\cdot$ & $\bullet$ & $\cdot$ & $\cdot$ & $\cdot$ & $\cdot$ & $\bullet$ & $\bullet$ & • & • & $\bullet$ & \multirow[b]{4}{*}{ H \#3 } \\
\hline & 1172 [Mandibula] & $\cdot$ & 疍 & $\mathrm{G}$ & - & C $\mathrm{C}$ & & $\cdot \cdot \cdot$ & • & - & - & $\cdot$ & $\cdot$ & \begin{tabular}{l|l} 
G \\
\end{tabular} & $\cdot$ & $\cdot$ & $.1 \mathrm{C}$ & 1 & $\cdot$ & - & $\cdot$ & - & - & $\cdot$ & $\cdot$ & $\cdot$ & $\cdot$ & $\cdot$ & $\cdot$ & $\cdot$ & $\cdot$ & $\cdot$ & $\cdot$ & $\cdot$ & $\cdot$ & \\
\hline & 1485 [Calvaria] & $\cdot$ & nd & (G) & $\cdot$ & (C) & & $\cdot \cdot$ & • & • & $\cdot$ & $\cdot$ & $\cdot$ & \begin{tabular}{l|l} 
G \\
\end{tabular} & $\cdot$ & $\cdot$ & $.1 \mathrm{C}$ & 1 & $\cdot$ & $\cdot$ & $\cdot$ & $\cdot$ & $\cdot$ & $\cdot$ & $\cdot$ & $\cdot$ & $\cdot$ & $\cdot$ & $\cdot$ & $\cdot$ & $\cdot$ & $\cdot$ & $\cdot$ & - & $\cdot$ & \\
\hline & \begin{tabular}{|l|} 
Haplotyp \\
\end{tabular} & $\cdot$ & $\cdot$ & $\mathbf{G}$ & $\cdot$ & c & & $\cdot \cdot$ & $\bullet$ & $\bullet$ & $\cdot$ & $\bullet$ & $\cdot$ & \begin{tabular}{l|l}
$\mathbf{G}$ & \\
\end{tabular} & $\bullet$ & $\bullet$ & $.1 \mathrm{C}$ & 1 & $\cdot$ & - & $\cdot$ & $\cdot$ & $\cdot$ & $\cdot$ & $\cdot$ & $\bullet$ & $\cdot$ & $\cdot$ & $\cdot$ & $\cdot$ & $\cdot$ & $\cdot$ & - & $\cdot$ & $\cdot$ & \\
\hline \multirow[b]{3}{*}{ M2 } & 1102 [Femur li.] & X & $\infty$ & 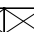 & D & C & & $\cdot \cdot \cdot$ & - & - & - & $\bullet$ & $\cdot$ & G & • & • & $.1 \mathrm{C}$ & • & - & • & - & - & • & - & - & Х & 凶 & $\infty$ & • & - & • & • & - & - & - & \\
\hline & 3644 [Mandibula] & - & 平. & . & . & $\mathrm{C}$ & c & $\cdot \cdot$ & • & - & - & $\cdot$ & $\cdot$ & \begin{tabular}{l|l}
$\mathrm{G}$ \\
\end{tabular} & $\bullet$ & $\cdot$ & $.1 \mathrm{C}$ & 1 & $\bullet$ & - & $\cdot$ & $\cdot$ & • & $\cdot$ & • & 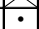 & 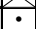 & . & $\bullet$ & $\cdot$ & $\cdot$ & $\cdot$ & $\cdot$ & - & - & \\
\hline & Haplotyp & - & • & - & - & c & $=$ & •. • & • & - & - & $\bullet$ & $\cdot$ & 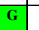 & $\cdot$ & - & $.1 \mathrm{C}$ & - & $\bullet$ & - & $\bullet$ & $\bullet$ & - & $\bullet$ & - & - & $\bullet$ & $\cdot$ & $\bullet$ & $\bullet$ & $\bullet$ & • & - & - & - & H \#1 \\
\hline & 1482 [Mandibula] & - & • & - & $\cdot$ & - & & • & • & - & $\cdot$ & $\bullet$ & $\cdot$ & \begin{tabular}{l|l} 
G & \\
\end{tabular} & $\bullet$ & $\cdot$ & $.1 \mathrm{C}$ & 1 & $\cdot$ & • & • & • & • & $\cdot$ & • & • & $\cdot$ & • & $\bullet$ & - & $\cdot$ & • & • & • & - & \\
\hline & 1911 [Femur li.] & $\bullet$ & $\bullet$ & $\bullet$ & • & • & $\cdot$ & •. • & • & - & $\cdot$ & $\bullet$ & $\cdot$ & \begin{tabular}{l|l}
$\mathrm{G}$ \\
\end{tabular} & $\cdot$ & $.1 \mathrm{C}$ & $.1 \mathrm{C}$ & 1 & $\cdot$ & $\bullet$ & $\cdot$ & $\bullet$ & $\cdot$ & $\bullet$ & $\bullet$ & $x$ & Х & X & $\cdot$ & $\cdot$ & $\bullet$ & $\cdot$ & $\cdot$ & $\cdot$ & • & \\
\hline & \begin{tabular}{|l|}
6525 [Calvaria] \\
\end{tabular} & $\cdot$ & $\cdot$ & $\cdot$ & $\cdot$ & $\dot{\bullet}$ & & $\cdot \cdot$ & - & - & - & $\cdot$ & $\cdot$ & G & $\cdot$ & $.1 \mathrm{C}$ & $.1 \mathrm{C}$ & 1 & $\cdot$ & $\cdot$ & $\cdot$ & $\cdot$ & $\cdot$ & $\cdot$ & $\cdot$ & $\cdot$ & $\bullet$ & $\cdot$ & $\cdot$ & $\cdot$ & $\cdot$ & $\cdot$ & - & $\cdot$ & $\cdot$ & \\
\hline M3 & Haplotyp & - & - & • & - & - & & $\cdot{ }^{\circ} \cdot$ & - & • & - & $\bullet$ & $\cdot 1$ & \begin{tabular}{l|l}
$\mathbf{G}$ & \\
\end{tabular} & $\cdot$ & $.1 \mathrm{C}$ & $.1 \mathrm{C}$ & 1 & $\bullet$ & - & $\bullet$ & - & - & $\bullet$ & - & $\cdot$ & $\bullet$ & $\cdot$ & $\bullet$ & $\bullet$ & $\bullet$ & $\bullet$ & $\bullet$ & - & $\cdot$ & H \#8 \\
\hline & 4 b b [Mandibula] & $\cdot$ & $\bullet$ & • & $\bullet$ & $\bullet$ & & $\cdot \cdot \cdot$ & - & - & - & $\cdot$ & $\cdot$ & G & • & $\bullet$ & $.1 \mathrm{C}$ & 1 & $\bullet$ & $\bullet$ & $\bullet$ & • & $\bullet$ & - & $\bullet$ & • & $\bullet$ & - & $\bullet$ & • & $\bullet$ & $\bullet$ & • & • & $\cdot$ & \\
\hline & 900 [Neurocranium] & • & - & - & - & • & & $\cdot \cdot \cdot$ & • & - & - & $\cdot$ & $\cdot$ & \begin{tabular}{l|l}
$G$ \\
\end{tabular} & - & - & $.1 \mathrm{C}$ & 1 & $\cdot$ & - & - & - & - & - & - & • & - & - & - & - & • & • & • & • & - & \\
\hline M4 & \begin{tabular}{|l|} 
Haplotyp \\
\end{tabular} & $\bullet$ & $\cdot$ & - & $\cdot$ & $\dot{\bullet}$ & & $\cdot \cdot \cdot$ & - & - & - & $\cdot$ & $\cdot$ & \begin{tabular}{l|l} 
G \\
\end{tabular} & $\cdot$ & $\cdot$ & $.1 \mathrm{C}$ & 1 & $\bullet$ & $\cdot$ & $\bullet$ & $\bullet$ & $\cdot$ & $\bullet$ & $\bullet$ & $\cdot$ & $\bullet$ & - & $\bullet$ & - & $\bullet$ & $\cdot$ & $\bullet$ & $\cdot$ & $\cdot$ & $\mathrm{H} \# \mathbf{5}$ \\
\hline & 908 [Calvaria] & - & $\cdot$ & - & $\cdot$ & - & & $\cdot \cdot \cdot$ & • & - & - & $\cdot$ & $\cdot$ & \begin{tabular}{l|l} 
G \\
\end{tabular} & - & $\cdot$ & $.1 \mathrm{C}$ & 1 & - & - & $\bullet$ & - & $\cdot$ & - & $\cdot$ & - & $\cdot$ & - & • & • & • & - & • & • & - & \\
\hline & 3380 [Mandibula] & $\cdot$ & $\cdot$ & $\cdot$ & $\cdot$ & $\cdot$ & $\cdot$ & •. $\cdot$ & • & - & - & $\cdot$ & $\cdot$ & \begin{tabular}{l|l} 
G \\
\end{tabular} & - & - & $.1 \mathrm{C}$ & 1 & $\cdot$ & - & $\cdot$ & - & - & - & - & - & - & - & $\cdot$ & • & • & • & • & - & • & \\
\hline M5 & \begin{tabular}{|l|l|} 
Haplotyp \\
\end{tabular} & $\cdot$ & $\cdot$ & $\bullet$ & $\cdot$ & • & & - & - & • & - & $\bullet$ & $\cdot$ & G & $\cdot$ & $\cdot$ & $.1 \mathrm{C}$ & 1 & $\bullet$ & - & $\cdot$ & $\cdot$ & $\cdot$ & $\bullet$ & $\bullet$ & $\cdot$ & $\cdot$ & $\cdot$ & $\bullet$ & $\cdot$ & - & $\bullet$ & $\bullet$ & $\bullet$ & $\cdot$ & $\mathrm{H} \# \mathbf{5}$ \\
\hline & 2030 [Femur li.] & $\bar{x}$ & X & $\bar{D}$ & X & $\mathrm{c}$ & & $\cdot{ }^{\circ} \cdot$ & $\bullet$ & - & - & $\bullet$ & $\cdot$ & \begin{tabular}{l|l}
$\mathrm{G}$ \\
\end{tabular} & $\bullet$ & $\cdot$ & $.1 \mathrm{C}$ & 1 & $\bullet$ & $\cdot$ & $\bullet$ & $\cdot$ & $\cdot$ & - & $\bullet$ & $\cdot$ & $\bullet$ & • & $\cdot$ & - & $\bullet$ & - & • & • & - & \\
\hline & R3 [Calvaria] & $\cdot$ & $\cdot$ & $\cdot$ & $\cdot$ & $\mathrm{C}$ & & $\cdot \cdot \cdot$ & - & - & - & $\cdot$ & $\cdot$ & G & $\cdot$ & - & $.1 \mathrm{C}$ & 1 & $\cdot$ & - & $\cdot$ & $\cdot$ & - & $\cdot$ & $\cdot$ & - & - & $\cdot$ & $\cdot$ & $\cdot$ & $\cdot$ & $\cdot$ & $\cdot$ & - & $\cdot$ & \\
\hline M6 & \begin{tabular}{|l|} 
Haplotyp \\
\end{tabular} & $\bullet$ & $\cdot$ & $\bullet$ & - & $\mathbf{C}$ & & $\cdot$ & & $\bullet$ & $\bullet$ & $\bullet$ & $\bullet$ & $\mathbf{G}$ & $\bullet$ & $\bullet$ & $.1 \mathrm{C}$ & 1 & $\bullet$ & $\bullet$ & $\bullet$ & $\bullet$ & $\bullet$ & $\bullet$ & $\bullet$ & $\bullet$ & $\bullet$ & $\bullet$ & $\bullet$ & $\bullet$ & $\bullet$ & $\bullet$ & $\bullet$ & $\bullet$ & $\bullet$ & H \#1 \\
\hline & 910 [Calvaria] & $\bullet$ & $\bullet$ & $\cdot$ & $\bullet$ & $\bullet$ & & $\cdot \cdot \cdot$ & - & - & - & $\bullet$ & $\cdot$ & \begin{tabular}{l|l}
$\mathrm{G}$ & \\
\end{tabular} & $\bullet$ & $.2 \mathrm{C}$ & $.1 \mathrm{C}$ & 1 & $\cdot$ & $\bullet$ & $\bullet$ & $\bullet$ & $\bullet$ & $\cdot$ & $\bullet$ & $\bullet$ & $\bullet$ & $\cdot$ & • & - & • & $\bullet$ & • & • & $\cdot$ & \\
\hline M7 & \begin{tabular}{|l} 
Haplotyp \\
\end{tabular} & $\bullet$ & $\bullet$ & $\bullet$ & $\bullet$ & $\bullet$ & & $\cdot \cdot$ & • & - & $\bullet$ & $\bullet$ & $\cdot$ & $\begin{array}{ll}\text { G } \\
\end{array}$ & $\bullet$ & $.2 \mathrm{C}$ & $.1 \mathrm{C}$ & 1 & $\bullet$ & $\bullet$ & $\bullet$ & $\bullet$ & $\bullet$ & $\bullet$ & $\bullet$ & $\bullet$ & $\bullet$ & $\bullet$ & $\bullet$ & $\bullet$ & $\bullet$ & $\bullet$ & $\bullet$ & $\bullet$ & $\bullet$ & H \#7 \\
\hline & \begin{tabular}{|l}
3757 [Calvaria] \\
\end{tabular} & $\cdot$ & G & - & $\mathrm{T}$ & • & & • & - & • & - & • & • & G & • & • & IC & 1 & $\bullet$ & G & $\cdot$ & $\cdot$ & $\cdot$ & • & • & C & $\mathrm{T}$ & • & 1 & 1 & 1 & 1 & 1 & 1 & 1 & \\
\hline & 4003 [Mandibula] & $\cdot$ & $\bar{G}$ & $\cdot$ & $\mathrm{T}$ & • & & $\cdot \cdot$ & • & • & - & $\cdot$ & $\bullet$ & $\mathrm{G}$ & $\cdot$ & $\cdot$ & IC & 1 & 1 & 1 & 1 & 1 & 1 & 1 & 1 & 1 & 1 & 1 & 1 & 1 & 1 & 1 & $T$ & 1 & 1 & \\
\hline M8 & \begin{tabular}{|l|} 
Haplotyp \\
\end{tabular} & $\cdot$ & $\mathbf{G}$ & $\bullet$ & $\mathbf{T}$ & $\bullet$ & & $\cdot \cdot$ & & $\bullet$ & $\cdot$ & $\bullet$ & $\bullet$ & G & $\bullet$ & $\bullet$ & $.1 \mathrm{C}$ & 1 & $\bullet$ & G & $\bullet$ & $\bullet$ & $\bullet$ & $\bullet$ & $\bullet$ & C & $\mathrm{T}$ & $\bullet$ & 1 & 1 & 1 & 1 & 1 & 1 & 1 & (U5b) \\
\hline & 1473 [Calvaria] & - & $\bullet$ & $\cdot$ & $\bullet$ & • & • & $\cdot \cdot$ & • & - & $\bullet$ & $\cdot$ & $\cdot$ & \begin{tabular}{l|l}
$\mathrm{G}$ & \\
\end{tabular} & $\bullet$ & $.1 \mathrm{C}$ & $.1 \mathrm{C}$ & 1 & $\cdot$ & $\bullet$ & $\cdot$ & - & $\bullet$ & • & $\bullet$ & - & $\cdot$ & & • & & $\bullet$ & & • & • & $\cdot$ & \\
\hline & 1916 [Femur li.] & $\bar{x}$ & X & $\bar{x}$ & X & I & & $\cdot$. & - & - & - & • & $\cdot$ & \begin{tabular}{l|l}
$\mathrm{G}$ \\
\end{tabular} & • & $.1 \mathrm{C}$ & $.1 \mathrm{C}$ & 1 & $\cdot$ & - & $\cdot$ & • & • & • & • & X & X & X & $\cdot$ & $\mathrm{T}$ & $\cdot$ & $\bullet$ & - & - & • & \\
\hline & 2749 [Mandibula] & $\bullet$ & $\cdot$ & • & - & - & & $\cdot \cdot \cdot$ & • & - & - & $\cdot$ & $\cdot$ & \begin{tabular}{l|l}
$\mathrm{G}$ \\
\end{tabular} & • & $.1 \mathrm{C}$ & $.1 \mathrm{C}$ & 1 & $\cdot$ & - & $\cdot$ & • & • & $\cdot$ & • & • & $\cdot$ & . & $\cdot$ & $\mathrm{T}$ & • & • & $\cdot$ & - & $\cdot$ & \\
\hline M9 & Haplotyp & 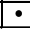 & $\cdot$ & $\bullet$ & - & $\cdot$ & & $\cdot \cdot$ & & - & $\cdot$ & $\cdot$ & $\cdot 1$ & $\begin{array}{l}\text { G } \\
\end{array}$ & $\cdot$ & $.1 \mathrm{C}$ & $.1 \mathrm{C}$ & 1 & $\cdot$ & $\cdot$ & $\cdot$ & $\cdot$ & $\cdot$ & $\cdot$ & $\cdot$ & $\cdot$ & $\cdot$ & $\cdot$ & $\cdot$ & T & $\cdot$ & $\cdot$ & $\cdot$ & $\cdot$ & $\cdot$ & H \#6 \\
\hline & 902 [Femur li.] & D & & $\Phi$ & X & 1 & & $\cdot \cdot \cdot$ & - & - & $\cdot$ & $\cdot$ & $\cdot$ & \begin{tabular}{l|l}
$\mathrm{G}$ & \\
\end{tabular} & $\cdot$ & $.1 \mathrm{C}$ & $.1 \mathrm{C}$ & 1 & $\cdot$ & - & C & • & - & $\cdot$ & $\cdot$ & $凶$ & 凶 & $\infty$ & • & $\cdot$ & $\cdot$ & $\mathrm{T}$ & $\mathrm{T}$ & - & C & \\
\hline M10 & Haplotyp & X & 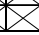 & 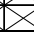 & X & 1 & & $\cdot \cdot$ & $\bullet$ & $\bullet$ & $\bullet$ & $\bullet$ & $\cdot$ & \begin{tabular}{l|l} 
G \\
\end{tabular} & $\bullet$ & $.1 \mathrm{C}$ & $.1 \mathrm{C}$ & 1 & $\bullet$ & $\bullet$ & $\mathrm{C}$ & $\bullet$ & $\bullet$ & $\bullet$ & $\bullet$ & 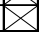 & 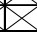 & 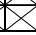 & $\bullet$ & $\bullet$ & $\bullet$ & $T$ & $\mathrm{~T}$ & $\bullet$ & $\mathrm{C}$ & (T2 \#2) \\
\hline & 183 [Femur li.] & $\cdot$ & (G) & - & $\mathrm{T}$ & . & 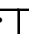 & - & $\cdot$ & - & $\cdot$ & • & $\cdot$ & $\mathrm{G}$ & • & • & $.1 \mathrm{C}$ & 1 & - & $\cdot$ & - & $\bullet$ & • & • & • & $\cdot$ & • & - & $\cdot$ & $\cdot$ & - & • & $\cdot$ & - & $\cdot$ & \\
\hline M11 & Haplotyp & $\bullet$ & $\overline{\text { (G) }}$ & 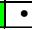 & T & . & 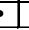 & - & - & - & $\bullet$ & $\bullet$ & $\cdot$ & \begin{tabular}{|l|} 
G \\
\end{tabular} & $\bullet$ & $\bullet$ & $.1 \mathrm{C}$ & 1 & $\bullet$ & $\bullet$ & $\bullet$ & $\bullet$ & $\bullet$ & $\bullet$ & $\bullet$ & $\bullet$ & $\bullet$ & $\bullet$ & $\bullet$ & $\bullet$ & $\bullet$ & $\bullet$ & $\bullet$ & $\bullet$ & $\bullet$ & $\mathrm{U} \# \mathbf{2}$ \\
\hline & E33 [Mandibula] & $\cdot$ & G & • & $\bullet$ & ? & $\bullet$ & A & $\cdot$ & - & A & $\bullet$ & $\cdot$ & \begin{tabular}{|l|}
$G$ \\
\end{tabular} & $T$ & $\cdot$ & $.1 \mathrm{C}$ & 11 & $\begin{array}{c}T \\
\end{array}$ & $\bullet$ & $\mathrm{C}$ & $\cdot$ & $\cdot$ & $\cdot$ & $\cdot$ & $\cdot$ & $\cdot$ & • & $\bullet$ & • & $\cdot$ & • & • & • & • & \\
\hline M12 & \begin{tabular}{|l|} 
Haplotyp \\
\end{tabular} & • & G & - & - & . & • & A & - & $\bullet$ & $\mathrm{A}$ & $\bullet$ & $\bullet$ & G & $T$ & • & $.1 \mathrm{C}$ & 1 & $T$ & $\cdot$ & C & $\cdot$ & • & • & $\bullet$ & $\cdot$ & $\bullet$ & $\cdot$ & • & • & $\bullet$ & $\bullet$ & • & - & • & $J^{*}$ \\
\hline & 58.3[Femur li. & & & $\varnothing$ & & & & I & 1 & 1 & 1 & 1 & 1 & 1 & 1 & 1 & 1 & $t$ & 1 & 1 & 1 & 1 & 1 & 1 & 1 & $Z_{2}$ & & $\nabla$ & - & - & $\cdot$ & T & $\begin{array}{l}T \\
T\end{array}$ & 0 & • & \\
\hline M13 & \begin{tabular}{|l|} 
Haplotyp \\
\end{tabular} & E & * & 米 & 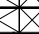 & $\forall$ & $T$ & $T$ & 1 & $T$ & 1 & 1 & 1 & \begin{tabular}{|l|}
1 \\
\end{tabular} & 1 & 1 & 1 & I & 1 & 1 & 1 & 1 & 1 & 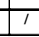 & 1 & $\otimes$ & 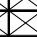 & * & $\bullet$ & $\bullet$ & $\bullet$ & $T$ & $T$ & $\bullet$ & $\bullet$ & nd \#1 \\
\hline & 905 [Femur li.] & $\bar{X}$ & D & $\bar{x}$ & $1 \times$ & 入 & 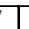 & $t$ & $t$ & $T$ & 1 & 1 & \begin{tabular}{l|l} 
\\
\end{tabular} & 1 & 1 & 1 & 1 & 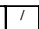 & $\bullet$ & $\bullet$ & $\bullet$ & $\cdot$ & $\cdot$ & $\bullet$ & $\bullet$ & X & $\overline{1}$ & DX & $\bullet$ & $\bullet$ & $\bullet$ & $\bullet$ & • & • & C & \\
\hline & \begin{tabular}{|l|}
918 \\
{$[$ [Neurocranium] }
\end{tabular} & $\bullet$ & $\bullet$ & $\bullet$ & $\cdot$ & 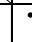 & • & $\bullet$ & - & - & $\cdot$ & $\cdot$ & $\cdot$ & G & $\cdot$ & $\cdot$ &. $\mathrm{IC}$ & 1 & $\cdot$ & $\cdot$ & • & $\cdot$ & $\cdot$ & $\cdot$ & $\bullet$ & $\bullet$ & - & 平 & $\bullet$ & $\bullet$ & $\bullet$ & • & $\cdot$ & $\cdot$ & $\mathrm{C}$ & \\
\hline M14 & Haplotyp & $\bullet$ & $\cdot$ & - & - & . & - & - & - & - & $\cdot$ & - & $\cdot 1$ & G & - & - & $.1 \mathrm{C}$ & 1 & - & $\bullet$ & $\bullet$ & $\bullet$ & $\bullet$ & $\bullet$ & $\bullet$ & - & $\bullet$ & $\cdot$ & - & $\cdot$ & - & - & $\cdot$ & $\bullet$ & C & H \#9 \\
\hline & 2263 [Mandibula] & $\cdot$ & $\mathrm{G}$ & $\cdot$ & $\bullet$ & ? & $\bullet$ & A & $\cdot$ & $\cdot$ & A & $\bullet$ & $\cdot$ & \begin{tabular}{|l|l|}
$\mathrm{G}$ \\
\end{tabular} & $\mathrm{T}$ & $\bullet$ & $.1 \mathrm{C}$ & 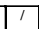 & $\mathrm{T}$ & $\bullet$ & $\mathrm{C}$ & $\bullet$ & $\bullet$ & $\bullet$ & • & - & • & $\bullet$ & - & • & $\bullet$ & - & • & • & • & \\
\hline M15 & \begin{tabular}{|l|} 
Haplotyp \\
\end{tabular} & $\bullet$ & G & $\bullet$ & $\bullet$ & ? & - & $\mathrm{A}$ & - & - & A & $\bullet$ & $\bullet$ & \begin{tabular}{|l|} 
G \\
\end{tabular} & $T$ & $\bullet$ & $.1 \mathrm{C}$ & 1 & $T$ & $\bullet$ & C & $\bullet$ & $\bullet$ & $\bullet$ & $\bullet$ & $\bullet$ & $\bullet$ & $\bullet$ & $\bullet$ & $\bullet$ & $\bullet$ & $\bullet$ & $\bullet$ & $\bullet$ & $\bullet$ & $\mathbf{J}^{*}$ \\
\hline & & $\cdot$ & $\mathrm{G}$ & $\bullet$ & T & ? & • & $\bullet$ & $\cdot$ & $\bullet$ & $\bullet$ & $\bullet$ & $\bullet$ & \begin{tabular}{|l|}
$\mathrm{G}$ \\
\end{tabular} & $\bullet$ & $\bullet$ & IC & 1 & $\bullet$ & G & $\bullet$ & $\bullet$ & $\bullet$ & $\bullet$ & • & $\mathrm{C}$ & $T$ & $\bullet$ & $\mathrm{C}$ & $\bullet$ & $\mathrm{T}$ & $\bullet$ & • & • & • & \\
\hline M16 & \begin{tabular}{|l|} 
Felsenbein 1 \\
Haplotyp
\end{tabular} & - & G & - & $T$ & ? & $\bullet$ & - & - & $\bullet$ & $\bullet$ & $\bullet$ & & & $\bullet$ & $\bullet$ & $.1 \mathrm{C}$ & 1 & $\bullet$ & G & $\bullet$ & $\bullet$ & $\bullet$ & $\bullet$ & $\bullet$ & & & $\bullet$ & C & $\bullet$ & $T$ & $\bullet$ & $\bullet$ & • & $\bullet$ & U5b \\
\hline & & & & & & & & & & & & & & & & & & & & & & & & & & & & & & & & & & & & \\
\hline & 57.2 [Femur li.] & & & & & 1 & I & - & - & - & $\cdot$ & $\mathrm{C}$ & $\cdot$ & \begin{tabular}{|l|l|} 
\\
\end{tabular} & - & $\cdot$ & $.1 \mathrm{C}$ & I & l & I & ' & I & 1 & I & I & $\nabla+2$ & & X & - & - & - & - & - & - & - & \\
\hline M17 & Haplotyp & X & & & & 1 & I & - & - & - & $\bullet$ & C & $\cdot 1$ & G & $\bullet$ & • & $.1 \mathrm{C}$ & 1 & 1 & 1 & 1 & 1 & 1 & 1 & 1 & & & & $\cdot$ & $\cdot$ & • & $\cdot$ & - & - & - & (H \#10) \\
\hline & 901 [Femur li.] & X & D & & $1 \times$ & 7 & & $T$ & $T$ & $T$ & 1 & 1 & 1 & \begin{tabular}{|l|}
1 \\
\end{tabular} & 1 & 1 & 1 & $\cdot$ & $\mathrm{T}$ & $\cdot$ & $\mathrm{C}$ & $\cdot$ & - & $\bullet$ & • & D & $\sqrt{x}$ & $1 \times$ & ] & • & - & $\bullet$ & • & - & - & \\
\hline M18 & \begin{tabular}{|l|} 
Haplotyp \\
\end{tabular} & X & 1 & $1 \times$ & $x$ & 7 & $T$ & 7 & 7 & $T$ & 1 & 1 & \begin{tabular}{l|l}
1 \\
\end{tabular} & \begin{tabular}{|l|}
1 \\
\end{tabular} & 1 & 1 & 1 & $\bullet$ & \begin{tabular}{|l}
$T$ \\
\end{tabular} & $\bullet$ & $\mathrm{C}$ & $\bullet$ & • & $\cdot$ & $\bullet$ & 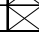 & & & - & $\cdot$ & $\cdot$ & $\bullet$ & $\bullet$ & $\bullet$ & $\bullet$ & (J) \\
\hline & 153 [Tibia re.] & - & $\bullet$ & - & - & - & 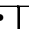 & - & & - & • & • & $\bullet$ & G & - & - & $.1 \mathrm{C}$ & I & • & - & - & - & • & - & - & - & • & • & - & • & - & • & • & • & • & \\
\hline M19 & \begin{tabular}{|l|} 
Haplotyp \\
\end{tabular} & $\cdot$ & $\cdot$ & $\cdot$ & $\cdot$ & . & - & $\cdot$ & $\cdot$ & $\bullet$ & $\cdot$ & $\mathrm{C}$ & $\cdot$ & G & $\bullet$ & $\cdot$ & $.1 \mathrm{C}$ & 1 & • & $\bullet$ & • & $\bullet$ & $\bullet$ & $\cdot$ & $\bullet$ & $\cdot$ & $\bullet$ & $\cdot$ & $\bullet$ & $\cdot$ & $\bullet$ & $\bullet$ & $\bullet$ & $\bullet$ & $\bullet$ & H \#10 \\
\hline
\end{tabular}

Legende: - = keine Abweichung zu CRS, / = Position nicht lesbar, ( ) = unsicherer Sequenzpolymorphismus, $\mathrm{X}=$ Abschnitt nicht sequenziert; $\mathrm{M}=$ male 
Tabelle 33: Ergebnisse der Einzeltypisierungen der HVR I-Analysen. Angegeben sind die Abweichungen zur CRS, welche in der Kopfzeile aufgezählt ist. Für die untersuchte Fundnummer ist das Skelettelement und wenn dies möglich war das Individuum angegeben.

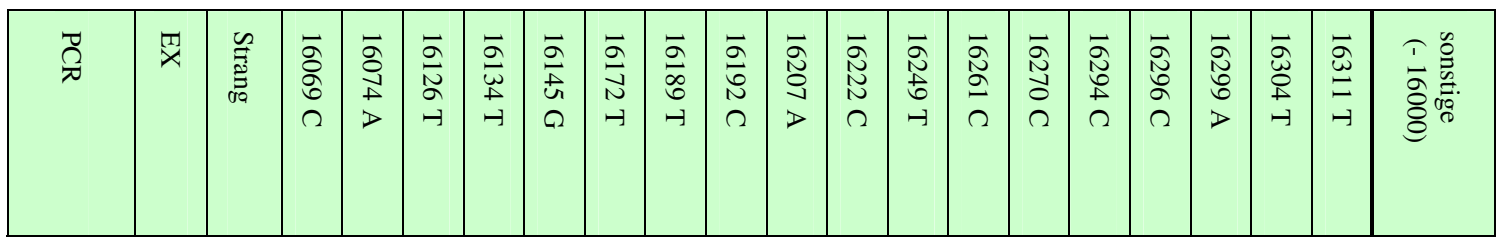

\begin{tabular}{|l|c|c|c|c|c|c|c|c|c|c|c|c|c|c|c|c|c|c|c|c|c|c|}
\hline M4 & \multicolumn{10}{|c|}{ 4b [Mandibula] } \\
\hline 33 & I & H & $/$ & $/$ & $/$ & $/$ & $/$ & $/$ & $/$ & $/$ & $/$ & $/$ & $/$ & $/$ & $/$ & $/$ & $/$ & $/$ & $/$ & $/$ & \\
\hline 55 & II & H & - & - & - & - & - & - & - & - & - & - & - & - & - & - & - & - & - & - & \\
\hline 55 & III & H & - & - & - & - & - & - & - & - & - & - & - & - & - & - & - & - & - & C & \\
\hline 60 & II & H & - & - & - & - & - & - & - & - & - & - & - & - & - & - & - & - & - & - & \\
\hline $\begin{array}{l}\text { mt } \\
\text { Haplotyp }\end{array}$ & & - & - & - & - & - & - & - & - & - & - & - & - & - & - & - & - & - & - & \\
\hline
\end{tabular}

\begin{tabular}{|c|c|c|c|c|c|c|c|c|c|c|c|c|c|c|c|c|c|c|c|c|c|}
\hline F1 & \multicolumn{21}{|c|}{38 [Mandibula] } \\
\hline 33 & I & $\mathrm{H}$ & - & - & - & - & - & - & - & - & - & - & - & - & - & - & - & - & - & - & \\
\hline 33 & I & $\mathrm{H}$ & - & - & - & - & - & - & - & - & - & - & - & - & - & - & - & - & - & - & \\
\hline 55 & I & $\mathrm{H}$ & - & - & - & - & - & - & - & - & - & - & - & - & - & - & - & - & - & - & \\
\hline 60 & II & $\mathrm{H}$ & 1 & 1 & 1 & 1 & 1 & - & - & - & - & - & - & - & - & - & - & - & - & - & \\
\hline $\begin{array}{l}\text { mt } \\
\text { Haploty }\end{array}$ & & & - & - & - & - & - & - & - & - & - & - & - & - & - & - & - & - & - & - & \\
\hline
\end{tabular}

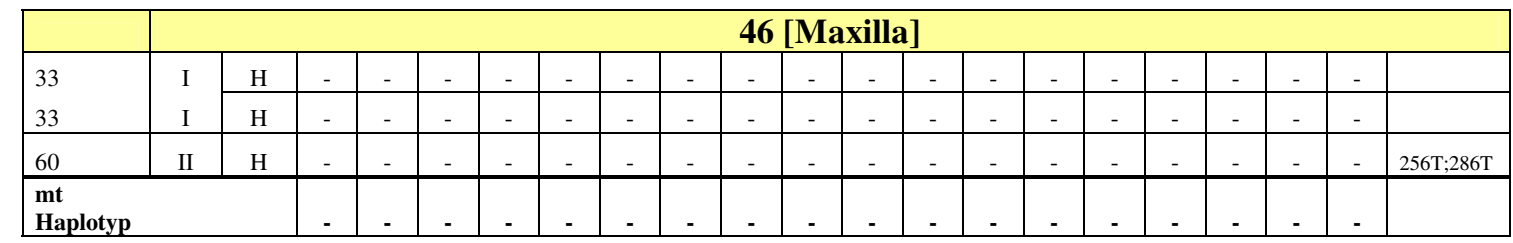

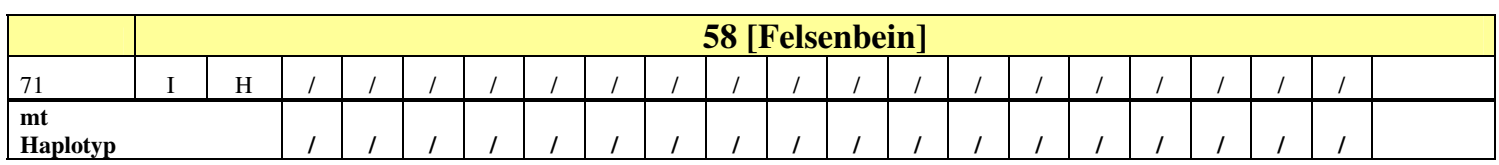

\begin{tabular}{|c|c|c|c|c|c|c|c|c|c|c|c|c|c|c|c|c|c|c|c|c|c|}
\hline F7 & \multicolumn{21}{|c|}{65 [Neurocranium] } \\
\hline 37 & I & $\mathrm{H}$ & - & G & - & - & - & - & $\mathrm{C}$ & $\mathrm{T}$ & - & - & $\mathrm{C}$ & - & $\mathrm{T}$ & - & - & - & - & - & \\
\hline 48 & I & $\mathrm{H}$ & / & I & 1 & / & I & 1 & / & I & I & I & / & 1 & I & I & 1 & 1 & I & 1 & \\
\hline 48 & II & $\mathrm{H}$ & - & G & - & - & - & - & $\mathrm{C}$ & $\mathrm{T}$ & - & - & $\mathrm{C}$ & - & $\mathrm{T}$ & - & - & - & - & - & \\
\hline 51 & I & $\mathrm{H}$ & - & G & - & - & - & - & $\mathrm{C}$ & $\mathrm{T}$ & - & - & $\mathrm{C}$ & - & $\mathrm{T}$ & - & - & - & - & - & $259 \mathrm{~N}$ \\
\hline 51 & II & $\mathrm{H}$ & - & G & - & - & - & - & $\mathrm{C}$ & $\mathrm{T}$ & - & - & $\mathrm{C}$ & - & $\mathrm{T}$ & - & - & - & - & - & \\
\hline $\begin{array}{l}\text { mt } \\
\text { Haploty }\end{array}$ & & & - & G & . & - & - & - & C & $\mathbf{T}$ & - & - & C & - & $\mathbf{T}$ & - & - & - & - & - & \\
\hline
\end{tabular}

\begin{tabular}{|l|l|c|c|c|c|c|c|c|c|c|c|c|c|c|c|c|c|c|c|c|c|}
\hline & \multicolumn{10}{|c|}{ 71 [Felsenbein li.] } \\
\hline 71 & II & H & - & - & - & - & - & - & - & - & - & - & - & - & - & - & - & - & - & - & \\
\hline $\begin{array}{l}\text { mt } \\
\text { Haplotyp }\end{array}$ & & & 1 & $/$ & $/$ & $/$ & $/$ & $/$ & $/$ & $/$ & $/$ & $/$ & $/$ & $/$ & $/$ & $/$ & $/$ & $/$ & $/$ & $/$ & \\
\hline
\end{tabular}

\begin{tabular}{|c|c|c|c|c|c|c|c|c|c|c|c|c|c|c|c|c|c|c|c|c|c|}
\hline & \multicolumn{21}{|c|}{ 87a [Mandibula] } \\
\hline 21 & I & $\mathrm{H}$ & - & - & - & - & - & - & - & - & - & - & - & - & - & - & - & - & - & - & \\
\hline 21 & I & $\mathrm{H}$ & - & - & - & - & - & - & - & - & - & - & - & - & - & - & - & - & - & - & \\
\hline 55 & I & $\mathrm{H}$ & - & - & - & - & - & - & - & - & - & - & - & - & - & - & - & - & - & $\mathrm{C}$ & 278Y;293G \\
\hline 60 & II & $\mathrm{H}$ & - & - & - & - & - & - & - & - & - & - & - & - & - & - & - & - & - & - & \\
\hline $\begin{array}{l}\text { mt } \\
\text { Hap }\end{array}$ & & & & - & & - & & - & - & - & - & - & - & - & - & - & - & - & - & & \\
\hline
\end{tabular}


Fortsetzung Tabelle 33: Ergebnisse der Einzeltypisierungen der HVR I-Analysen.

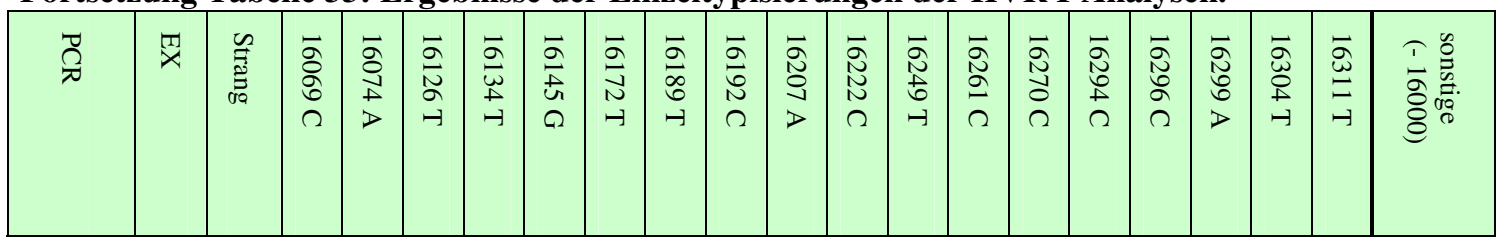

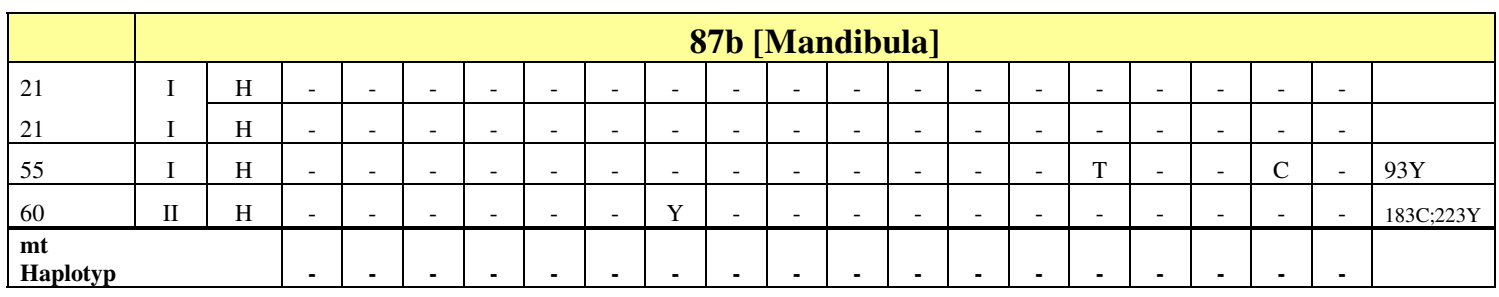

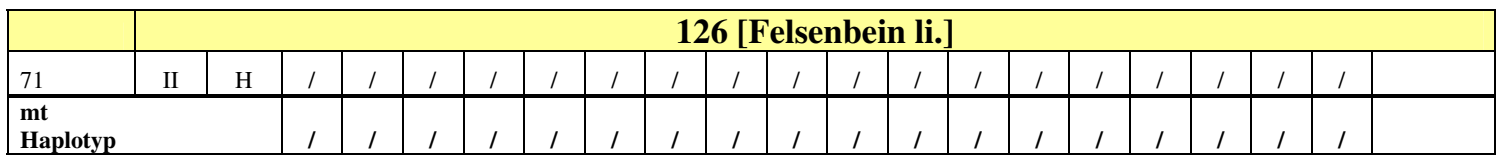

\begin{tabular}{|l|c|c|c|c|c|c|c|c|c|c|c|c|c|c|c|c|c|c|c|c|c|}
\hline F1 & \multicolumn{10}{|c|}{ [152 [Neurocranium] } \\
\hline 37 & I & H & - & - & - & - & - & - & - & - & - & - & - & - & - & - & - & - & - & - & \\
\hline 48 & I & H & - & - & - & - & - & - & - & - & - & - & - & - & - & - & - & - & - & - & \\
\hline 51 & II & H & $/$ & $/$ & $/$ & $/$ & $/$ & - & - & - & - & - & - & - & - & - & - & - & - & - & \\
51 & II & L & - & - & - & - & - & - & - & - & - & - & - & - & $/$ & $/$ & $/$ & $/$ & $/$ & $/$ & \\
\hline 60 & II & H & - & - & - & - & - & - & - & - & - & - & - & - & - & - & - & - & - & - & \\
\hline $\begin{array}{l}\text { mt } \\
\text { Haplotyp }\end{array}$ & & - & - & - & - & - & - & - & - & - & - & - & - & - & - & - & - & - & - & \\
\hline
\end{tabular}

\begin{tabular}{|l|l|l|l|l|l|l|l|l|l|l|l|l|l|l|l|l|l|l|l|l|l|l|}
\hline M19 & \multicolumn{10}{|c|}{153 [Tibia re.] } \\
\hline LFS A & SCII & H & - & - & - & - & - & - & - & - & - & - & - & - & - & - & - & - & - & - & $252 \mathrm{~T}$ \\
\hline LFS B & SCII & H & - & - & - & - & - & - & - & - & - & - & - & - & - & - & - & - & - & - & \\
\hline $\begin{array}{l}\text { mt } \\
\text { Haplotyp }\end{array}$ & & - & - & - & - & - & - & - & - & - & - & - & - & - & - & - & - & - & - & \\
\hline
\end{tabular}

\begin{tabular}{|c|c|c|c|c|c|c|c|c|c|c|c|c|c|c|c|c|c|c|c|c|c|}
\hline & \multicolumn{21}{|c|}{183 [Femur li.] } \\
\hline \multirow{2}{*}{\multicolumn{2}{|c|}{ Schultes 2000}} & & & & & & & & & & & & & & & & & & & & \\
\hline & & & - & - & - & - & - & 1 & $\mathrm{X}$ & $\mathrm{X}$ & $\mathrm{X}$ & $\mathrm{X}$ & - & - & - & - & - & - & - & $\mathrm{X}$ & \\
\hline 72 & A & $\mathrm{H}$ & 1 & 1 & - & - & - & - & - & - & - & - & - & - & - & - & - & - & - & - & $127 \mathrm{M}$ \\
\hline 72 & B & $\mathrm{H}$ & - & - & - & - & - & - & - & - & - & - & - & - & - & - & - & - & - & - & \\
\hline & & & - & - & - & - & - & - & - & - & - & - & - & - & - & - & - & - & - & - & \\
\hline
\end{tabular}

\begin{tabular}{|c|c|c|c|c|c|c|c|c|c|c|c|c|c|c|c|c|c|c|c|c|c|}
\hline & \multicolumn{21}{|c|}{193 [Mandibula] } \\
\hline 21 & I & $\mathrm{H}$ & 1 & - & C & - & - & - & - & - & - & - & - & - & - & $\mathrm{T}$ & $\mathrm{T}$ & - & - & - & \\
\hline 21 & I & $\mathrm{H}$ & - & - & $\mathrm{C}$ & - & - & - & - & - & - & - & - & - & - & $\mathrm{T}$ & $\mathrm{T}$ & - & $\mathrm{Y}$ & - & \\
\hline 21 & I & $\mathrm{H}$ & - & - & C & - & - & - & - & - & - & - & - & - & - & $\mathrm{T}$ & $\mathrm{T}$ & - & $\mathrm{Y}$ & - & \\
\hline 33 & I & $\mathrm{H}$ & 1 & 1 & 1 & 1 & 1 & 1 & 1 & 1 & 1 & 1 & 1 & 1 & 1 & 1 & 1 & 1 & 1 & 1 & \\
\hline 60 & II & $\mathrm{H}$ & - & - & - & - & - & - & - & - & - & - & - & - & - & - & - & - & - & - & \\
\hline 71 & II & $\mathrm{H}$ & 1 & 1 & 1 & 1 & 1 & - & - & - & - & - & - & - & - & - & - & - & - & - & \\
\hline $\begin{array}{l}\mathrm{mt} \\
\text { Haplotyp }\end{array}$ & & & - & - & (C) & - & - & - & - & - & - & - & - & - & - & (T) & (T) & - & $(\mathbf{Y})$ & - & \\
\hline
\end{tabular}

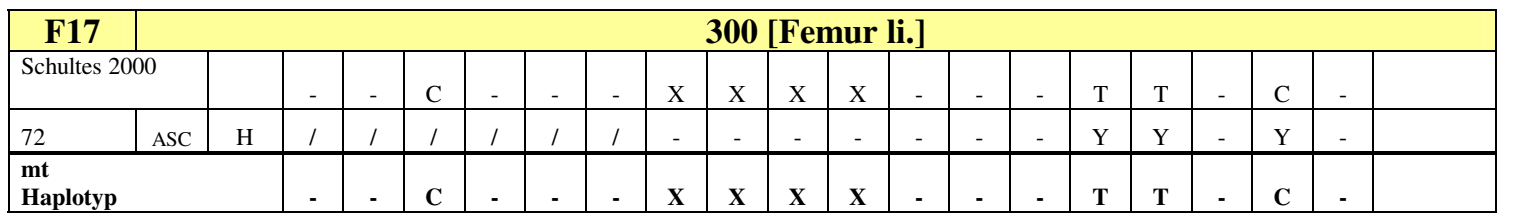

Legende: - = keine Abweichung zu CRS, / = Position nicht lesbar, $($ ) = unsicherer Sequenzpolymorphismus, $\mathrm{X}=$ Abschnitt nicht sequenziert; $\mathrm{H}=$ heavy chain, $\mathrm{L}=$ Light chain; bei mehr als einer Base an einer Position wurde der IUB-Code verwendet, z.B. Y. 
Fortsetzung Tabelle 33: Ergebnisse der Einzeltypisierungen der HVR I-Analysen.

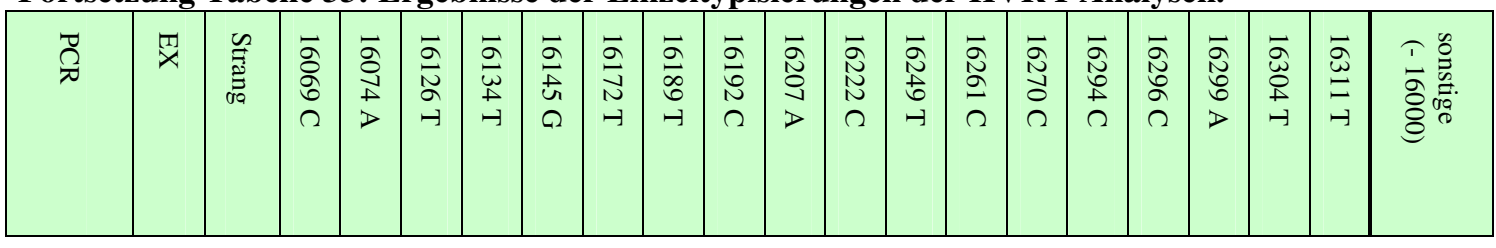

\begin{tabular}{|l|c|c|c|c|c|c|c|c|c|c|c|c|c|c|c|c|c|c|c|c|c|}
\hline M4 & \multicolumn{10}{|c|}{900 [Neurocranium] } \\
\hline 37 & I & H & $/$ & $/$ & - & - & - & - & - & - & - & - & - & - & - & - & - & - & - & - & \\
\hline 48 & I & H & - & - & - & - & - & - & - & - & - & - & - & - & - & - & - & - & - & - & \\
\hline 48 & II & H & - & - & - & - & - & - & - & - & - & - & - & - & - & - & - & - & - & - & \\
\hline 51 & II & H & - & - & - & - & - & - & - & - & - & - & - & - & - & - & - & - & - & - & \\
\hline $\begin{array}{l}\text { mt } \\
\text { Haplotyp }\end{array}$ & & - & - & - & - & - & - & - & - & - & - & - & - & - & - & - & - & - & - & \\
\hline
\end{tabular}

\begin{tabular}{|c|c|c|c|c|c|c|c|c|c|c|c|c|c|c|c|c|c|c|c|c|c|}
\hline & \multicolumn{21}{|c|}{902 [Femur li.] } \\
\hline \multirow{2}{*}{\multicolumn{2}{|c|}{ Schultes 2000}} & & & & & & & & & & & & & & & & & & & & \\
\hline & & & - & - & $\mathrm{C}$ & - & - & - & $\mathrm{X}$ & $\mathrm{X}$ & $\mathrm{X}$ & $\mathrm{X}$ & - & - & - & $\mathrm{T}$ & $\mathrm{T}$ & - & $\mathrm{C}$ & - & \\
\hline 72 & 1.9 & $\mathrm{H}$ & - & - & $\mathrm{Y}$ & - & - & - & - & $\mathrm{Y}$ & - & - & - & - & $\mathrm{Y}$ & $\mathrm{Y}$ & $\mathrm{Y}$ & - & $\mathrm{Y}$ & - & \\
\hline 72 & Test & $\mathrm{H}$ & - & - & $\mathrm{C}$ & - & - & - & - & $\mathrm{Y}$ & - & - & - & - & - & 1 & 1 & 1 & 1 & 1 & $135 \mathrm{~W}$ \\
\hline & & & - & - & C & - & - & - & $\mathbf{x}$ & $\mathbf{X}$ & $\mathbf{x}$ & $\mathbf{X}$ & & - & . & $\mathbf{T}$ & $\mathbf{T}$ & & $\mathbf{C}$ & - & \\
\hline
\end{tabular}

\begin{tabular}{|l|c|c|c|c|c|c|c|c|c|c|c|c|c|c|c|c|c|c|c|c|c|c|}
\hline \multicolumn{10}{|c|}{ M5 } & \multicolumn{10}{|c|}{908 [Calvarium] } \\
\hline 37 & I & H & - & - & - & - & - & - & - & - & - & - & - & - & - & - & - & - & - & - & \\
\hline 48 & I & H & - & - & - & - & - & - & - & - & - & - & - & - & - & - & - & - & - & - & \\
\hline 48 & II & H & - & - & - & - & - & - & - & - & - & - & - & - & - & - & - & - & - & - & \\
\hline 51 & II & H & - & - & - & - & - & - & - & - & - & - & - & - & - & - & - & - & - & - & \\
\hline $\begin{array}{l}\text { mt } \\
\text { Haplotyp }\end{array}$ & & - & - & - & - & - & - & - & - & - & - & - & - & - & - & - & - & - & - & \\
\hline
\end{tabular}

\begin{tabular}{|c|c|c|c|c|c|c|c|c|c|c|c|c|c|c|c|c|c|c|c|c|c|}
\hline M7 & \multicolumn{21}{|c|}{910 [Calvarium] } \\
\hline 37 & I & $\mathrm{H}$ & - & - & - & - & - & - & - & - & - & - & - & - & - & - & - & - & - & - & \\
\hline 48 & II & $\mathrm{H}$ & - & - & - & - & - & - & - & - & - & - & - & - & - & - & - & - & - & - & \\
\hline 51 & II & $\mathrm{H}$ & - & - & - & - & - & - & - & - & - & - & - & - & - & - & - & - & - & - & \\
\hline 60 & III & $\mathrm{H}$ & & & & & & & & & & & & & & & & & & & \\
\hline 60 & IIIa & $\mathrm{L}$ & - & - & - & - & - & - & - & - & - & - & - & - & - & - & - & - & - & - & $186 \mathrm{Y} ; 66 \mathrm{Y}$ \\
\hline $\begin{array}{l}\text { mt } \\
\text { Haplotyp }\end{array}$ & & & - & - & - & - & - & - & - & - & - & - & - & - & - & - & - & - & - & - & \\
\hline
\end{tabular}

\begin{tabular}{|l|c|c|c|c|c|c|c|c|c|c|c|c|c|c|c|c|c|c|c|c|c|}
\hline M14 & \multicolumn{10}{|c|}{918 [Neurocranium] } \\
\hline 55 & I & H & - & - & - & - & - & - & - & - & - & - & - & - & - & - & - & - & C & - & \\
\hline 55 & II & H & - & - & - & - & - & - & - & - & - & - & - & - & - & - & - & - & C & - & $152 \mathrm{~N}$ \\
\hline 60 & I & H & - & - & - & - & - & - & - & - & - & - & - & - & - & - & - & - & C & - & \\
\hline 60 & II & H & - & - & - & - & - & - & - & - & - & - & - & - & - & - & - & - & C & - & \\
\hline $\begin{array}{l}\text { mt } \\
\text { Haplotyp }\end{array}$ & & - & - & - & - & - & - & - & - & - & - & - & - & - & - & - & - & C & - & \\
\hline
\end{tabular}

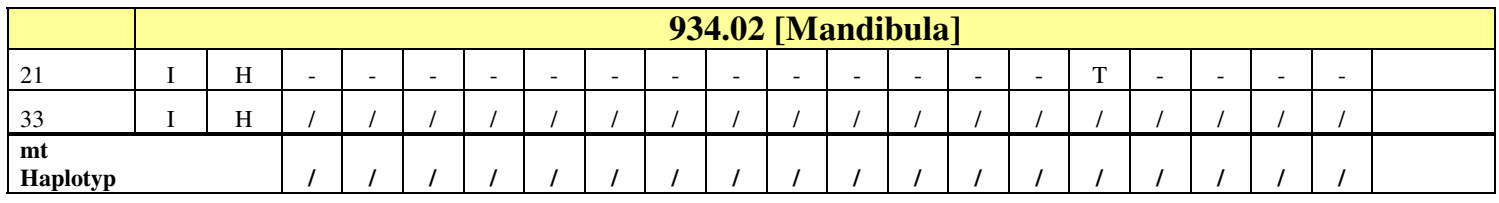

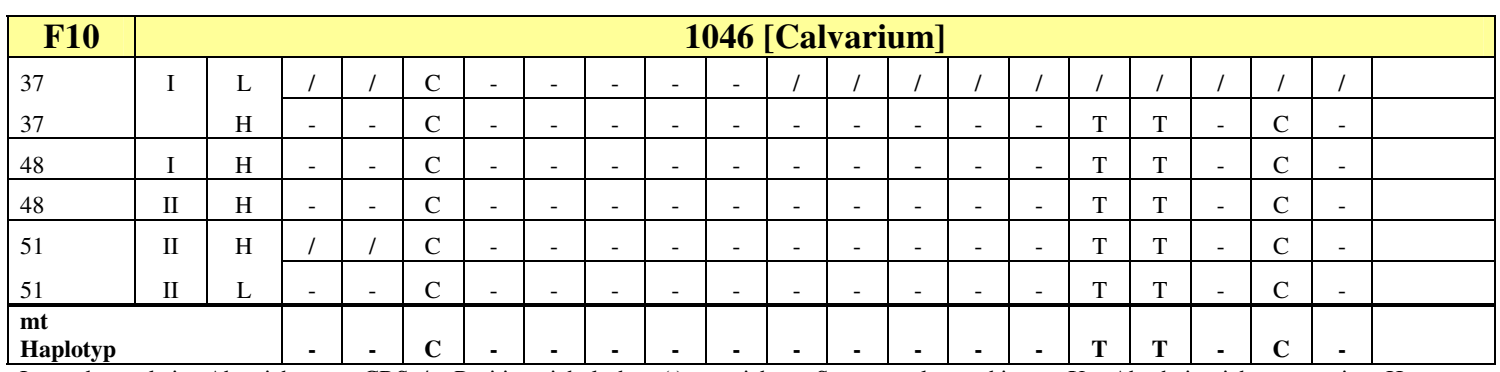

Legende: - = keine Abweichung zu CRS, / = Position nicht lesbar, ( ) = unsicherer Sequenzpolymorphismus, $\mathrm{X}=$ Abschnitt nicht sequenziert; $\mathrm{H}=$ heavy chain, $\mathrm{L}=$ Light chain; bei mehr als einer Base an einer Position wurde der IUB-Code verwendet, $z$.B. Y. 
Fortsetzung Tabelle 33: Ergebnisse der Einzeltypisierungen der HVR I-Analysen.
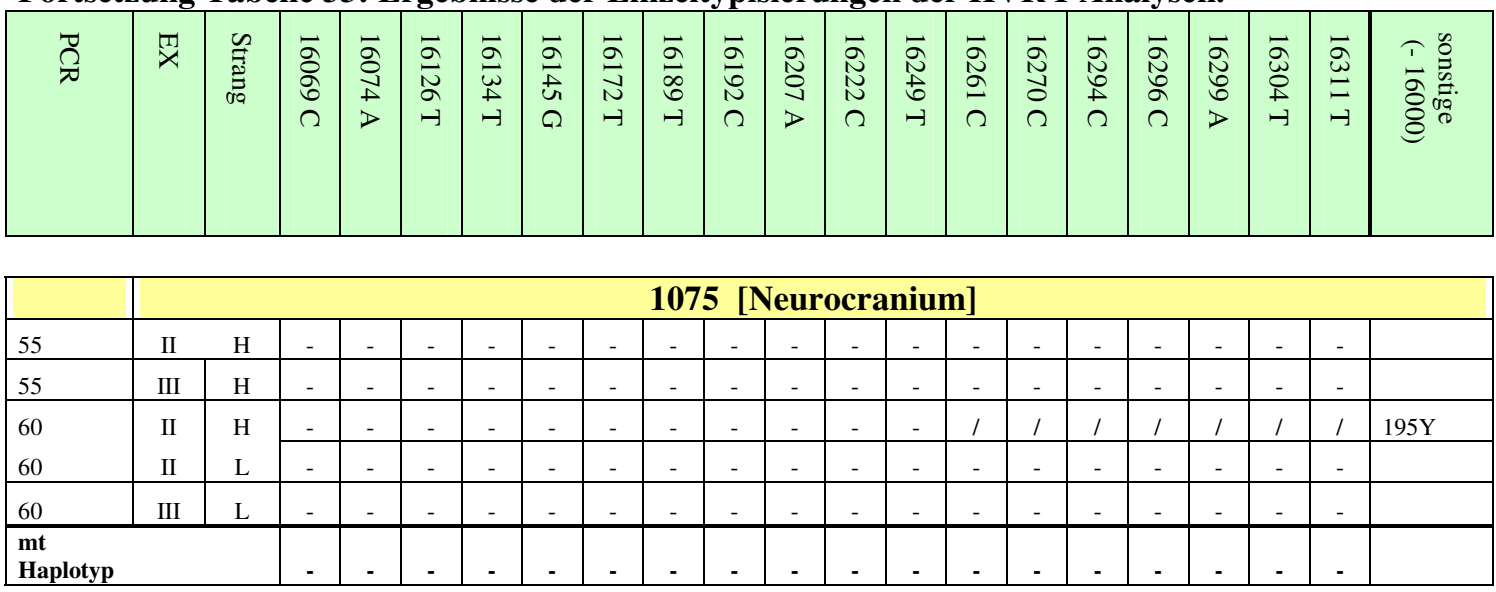

\begin{tabular}{|c|c|c|c|c|c|c|c|c|c|c|c|c|c|c|c|c|c|c|c|c|c|}
\hline F13 & \multicolumn{20}{|c|}{1078 [Mandibula] } & \\
\hline 33 & I & $\mathrm{H}$ & - & - & - & - & - & - & - & - & - & - & - & - & - & - & - & G & - & - & \\
\hline 37 & I & $\mathrm{H}$ & - & - & - & - & - & - & - & - & - & - & - & - & - & - & - & $\mathrm{G}$ & - & - & \\
\hline 37 & I & $\mathrm{H}$ & - & - & - & - & - & - & - & - & - & - & - & - & - & - & - & G & - & - & \\
\hline 51 & III & $\mathrm{L}$ & - & - & - & - & - & - & - & - & - & - & - & - & - & - & - & G & - & - & \\
\hline 55 & III & $\mathrm{H}$ & $\mathrm{Y}$ & - & Y & - & - & - & - & - & - & $\mathrm{Y}$ & - & - & - & - & - & - & - & - & \\
\hline 68 & II & $\mathrm{H}$ & - & - & - & - & - & - & - & - & - & - & - & - & - & - & - & G & - & - & \\
\hline 68 & III & $\mathrm{H}$ & - & - & - & - & - & - & - & - & - & - & - & - & - & - & - & $\mathrm{G}$ & - & - & \\
\hline $\begin{array}{l}\mathrm{mt} \\
\text { Haplotyp }\end{array}$ & & & - & - & - & - & - & - & - & - & - & - & - & - & - & - & - & G & - & - & \\
\hline
\end{tabular}

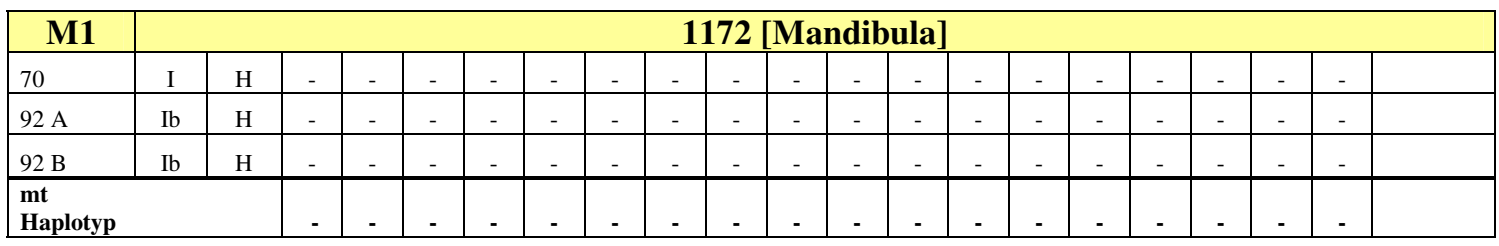

\begin{tabular}{|c|c|c|c|c|c|c|c|c|c|c|c|c|c|c|c|c|c|c|c|c|c|}
\hline F18 & \multicolumn{21}{|c|}{1176 [Calvarium] } \\
\hline 13 & I & $\mathrm{H}$ & - & - & - & $\mathrm{T}$ & - & - & - & - & - & - & - & - & - & - & - & - & - & - & \\
\hline 21 & II & $\mathrm{H}$ & 1 & 1 & - & $\mathrm{T}$ & - & - & - & - & - & - & - & - & - & - & - & - & - & - & $154 \mathrm{~T}$ \\
\hline 33 & II & $\mathrm{H}$ & - & - & - & $\mathrm{Y}$ & - & - & - & - & - & - & - & - & - & - & - & - & - & - & \\
\hline 37 & II & $\mathrm{L}$ & - & - & $\mathrm{Y}$ & - & - & - & - & - & - & $\mathrm{Y}$ & - & - & - & - & - & - & - & - & \\
\hline 55 & I & $\mathrm{H}$ & - & - & - & - & - & - & - & - & - & - & - & - & - & - & - & - & - & - & $298 \mathrm{G}$ \\
\hline $\begin{array}{l}\text { mt } \\
\text { Haplotyp }\end{array}$ & & & - & - & - & $(-)$ & - & - & - & - & - & - & - & - & - & - & - & - & - & - & \\
\hline
\end{tabular}

\begin{tabular}{|l|l|l|l|l|l|l|l|l|l|l|l|l|l|l|l|l|l|l|l|l|l|}
\hline \multicolumn{10}{|c|}{ F7 } & \multicolumn{10}{|c|}{ 1247 [Mandibula] } \\
\hline \multicolumn{1}{|l|}{ Schultes 2000 } & & - & $\mathrm{G}$ & - & - & - & $/$ & $\mathrm{X}$ & $\mathrm{X}$ & $\mathrm{X}$ & $\mathrm{X}$ & $\mathrm{C}$ & - & $\mathrm{T}$ & - & - & - & - & - & \\
\hline 72 & $\mathrm{I}$ & $\mathrm{H}$ & - & $\mathrm{G}$ & - & - & - & - & $\mathrm{C}$ & $\mathrm{T}$ & - & - & $\mathrm{C}$ & - & $\mathrm{T}$ & - & - & - & - & - & $229 \mathrm{~N}$ \\
\hline $\begin{array}{l}\text { mt } \\
\text { Haplotyp }\end{array}$ & & - & $\mathrm{G}$ & - & - & - & - & (C) & (T) & - & - & $\mathrm{C}$ & - & $\mathrm{T}$ & - & - & - & - & - & \\
\hline
\end{tabular}

\begin{tabular}{|l|c|c|c|c|c|c|c|c|c|c|c|c|c|c|c|c|c|c|c|c|c|c|}
\hline \multicolumn{10}{|c|}{ M9 } & \multicolumn{10}{|c|}{ [473 Calvarium] } \\
\hline 13 & I & H & - & - & - & - & - & - & - & - & - & - & - & T & - & - & - & - & - & - & \\
\hline 33 & I & H & - & - & - & - & - & - & - & - & - & - & - & T & - & - & - & - & - & - & \\
\hline 51 & II & H & - & - & - & - & - & - & - & - & - & - & - & T & - & - & - & - & - & - & \\
\hline 55 & II & H & - & - & - & - & - & - & - & - & - & - & - & T & - & - & - & - & - & - & \\
\hline $\begin{array}{l}\text { mt } \\
\text { Haplotyp }\end{array}$ & & - & - & - & - & - & - & - & - & - & - & - & T & - & - & - & - & - & - & \\
\hline
\end{tabular}

Legende: - = keine Abweichung zu CRS, / = Position nicht lesbar, $($ ) = unsicherer Sequenzpolymorphismus, $\mathrm{X}=$ Abschnitt nicht sequenziert; $\mathrm{H}=$ heavy chain, $\mathrm{L}=$ Light chain; bei mehr als einer Base an einer Position wurde der IUB-Code verwendet, z.B. Y. 
Fortsetzung Tabelle 33: Ergebnisse der Einzeltypisierungen der HVR I-Analysen.

\begin{tabular}{|c|c|c|c|c|c|c|c|c|c|c|c|c|c|c|c|c|c|c|c|c|c|}
\hline$\stackrel{\widetilde{\partial}}{\overparen{D}}$ & $\underset{x}{\pi}$ & 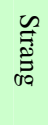 & $\begin{array}{l}\text { के } \\
\text { oे } \\
\text { م. }\end{array}$ & $\begin{array}{l}\vec{a} \\
\overrightarrow{1} \\
\vec{D}\end{array}$ & $\begin{array}{l}\bar{a} \\
\stackrel{\alpha}{-}\end{array}$ & $\begin{array}{l}\vec{a} \\
\vec{\omega} \\
\stackrel{+}{\hookrightarrow} \\
\end{array}$ & $\begin{array}{l}\vec{a} \\
\vec{E} \\
a\end{array}$ & $\begin{array}{l}\vec{\Xi} \\
\underset{N}{G} \\
-1\end{array}$ & $\begin{array}{l}\vec{a} \\
\dot{0} \\
0 \\
-1\end{array}$ & \begin{tabular}{l}
$\vec{a}$ \\
\multirow{0}{N}{} \\
$\Omega$
\end{tabular} & $\begin{array}{l}\overrightarrow{\hat{N}} \\
\text { D } \\
>\end{array}$ & $\begin{array}{l}\text { Na } \\
\text { N } \\
0\end{array}$ & \begin{tabular}{l}
$\overline{\hat{N}}$ \\
\multirow{t}{0}{} \\
$\rightarrow$
\end{tabular} & $\begin{array}{l}\overline{\hat{N}} \\
\stackrel{\Xi}{\Omega}\end{array}$ & $\begin{array}{l}\overrightarrow{\hat{N}} \\
\text { O } \\
\text { م }\end{array}$ & $\begin{array}{l}\overline{\hat{~}} \\
\stackrel{0}{\circ} \\
\Omega\end{array}$ & 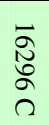 & $\begin{array}{l}\vec{N} \\
\text { ర્ठ } \\
>\end{array}$ & $\begin{array}{l}\vec{a} \\
\stackrel{\tilde{D}}{+} \\
\rightarrow\end{array}$ & $\begin{array}{l}\vec{a} \\
\vec{\Xi}\end{array}$ & 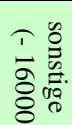 \\
\hline
\end{tabular}

\begin{tabular}{|c|c|c|c|c|c|c|c|c|c|c|c|c|c|c|c|c|c|c|c|c|c|}
\hline M3 & \multicolumn{21}{|c|}{1482 [Mandibula] } \\
\hline 13 & I & $\mathrm{H}$ & 1 & - & 1 & - & - & - & - & - & - & - & - & $\mathrm{T}$ & - & I & - & - & 1 & 1 & \\
\hline 33 & I & $\mathrm{H}$ & - & - & - & - & - & - & - & - & - & - & - & $\mathrm{T}$ & - & - & - & - & - & - & \\
\hline 21 & I & $\mathrm{H}$ & - & - & - & $\mathrm{T}$ & - & - & - & - & - & - & - & - & - & - & - & - & - & - & $\begin{array}{l}72 \mathrm{~T} ; \\
154 \mathrm{G}\end{array}$ \\
\hline 51 & III & $\mathrm{H}$ & - & - & - & - & - & - & - & - & - & - & - & - & - & - & - & - & - & - & \\
\hline 55 & III & $\mathrm{H}$ & - & - & - & - & - & - & - & - & - & - & - & - & - & - & - & - & - & - & \\
\hline $\begin{array}{l}\text { mt } \\
\text { Haplotyp }\end{array}$ & & & - & - & - & - & - & - & - & - & - & - & - & - & - & - & - & - & - & - & \\
\hline
\end{tabular}

\begin{tabular}{|l|c|c|c|c|c|c|c|c|c|c|c|c|c|c|c|c|c|c|c|c|c|}
\hline \multicolumn{1}{|c|}{ M1 } & \multicolumn{10}{|c|}{ [485 Calvarium] } \\
\hline 13 & I & H & - & - & - & - & - & - & - & - & - & - & - & - & - & - & - & - & - & - & \\
\hline 33 & I & H & - & - & - & - & - & - & - & - & - & - & $/$ & $/$ & $/$ & $/$ & $/$ & $/$ & $/$ & $/$ & $183 \mathrm{C}$ \\
\hline 37 & II & L & - & - & - & - & - & - & - & - & - & - & - & - & - & - & - & - & - & - & $223 \mathrm{Y}$ \\
\hline 51 & III & H & - & - & - & - & - & - & - & - & - & - & - & - & - & - & - & - & - & - & \\
\hline $\begin{array}{l}\text { mt } \\
\text { Haplotyp }\end{array}$ & & - & - & - & - & - & - & - & - & - & - & - & - & - & - & - & - & - & - & \\
\hline
\end{tabular}
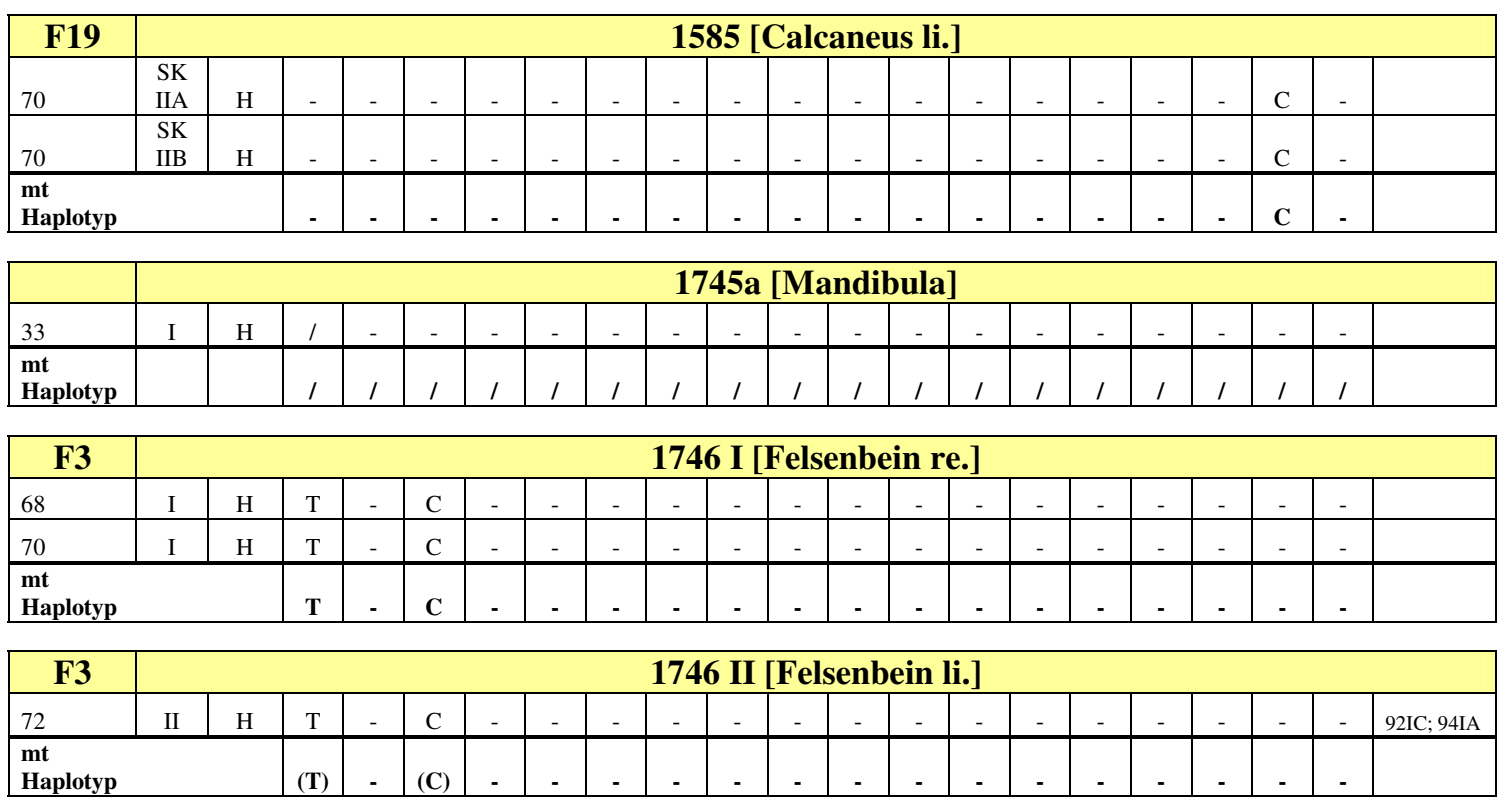

\begin{tabular}{|c|c|c|c|c|c|c|c|c|c|c|c|c|c|c|c|c|c|c|c|c|c|}
\hline F18 & \multicolumn{21}{|c|}{2133 [Mandibula] } \\
\hline 13 & I & $\mathrm{H}$ & - & - & - & - & - & - & - & - & - & - & - & - & - & - & - & - & - & - & \\
\hline 21 & I & $\mathrm{H}$ & - & - & - & - & - & - & - & - & - & - & - & - & - & - & - & - & - & - & \\
\hline 21 & I & $\mathrm{H}$ & 1 & 1 & - & - & - & - & - & - & - & - & - & - & - & - & - & - & - & - & $154 \mathrm{~T}$ \\
\hline 33 & II & $\mathrm{H}$ & $\mathrm{T}$ & - & - & - & - & - & - & - & - & - & - & - & - & - & - & - & - & - & \\
\hline 51 & III & $\mathrm{H}$ & 1 & I & I & I & 1 & I & - & - & - & - & - & - & - & - & - & - & - & - & \\
\hline $\begin{array}{l}\text { mt } \\
\text { Haplotyp }\end{array}$ & & & - & - & - & - & - & - & - & - & - & - & 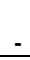 & - & - & - & - & - & - & - & \\
\hline
\end{tabular}

\begin{tabular}{|c|c|c|c|c|c|c|c|c|c|c|c|c|c|c|c|c|c|c|c|c|c|}
\hline M15 & \multicolumn{21}{|c|}{2263 [Mandibula] } \\
\hline 13 & I & $\mathrm{H}$ & 1 & 1 & 1 & 1 & 1 & 1 & 1 & 1 & 1 & 1 & 1 & 1 & 1 & 1 & 1 & 1 & 1 & 1 & \\
\hline 21 & I & $\mathrm{H}$ & $\mathrm{T}$ & - & C & - & - & - & - & - & - & - & - & - & - & - & - & - & - & - & \\
\hline 33 & I & $\mathrm{H}$ & $\mathrm{T}$ & - & - & - & - & - & - & - & - & - & - & - & - & - & - & - & - & - & \\
\hline 33 & II & $\mathrm{H}$ & $\mathrm{T}$ & - & $\mathrm{C}$ & - & - & - & - & - & - & - & - & - & - & - & - & - & - & - & \\
\hline 37 & II & $\mathrm{H}$ & 1 & - & $\mathrm{C}$ & - & - & - & - & - & - & - & - & - & - & - & - & - & - & - & \\
\hline $\begin{array}{l}\text { mt } \\
\text { Haplotyp }\end{array}$ & & & $\mathbf{T}$ & - & C & - & - & - & - & - & - & - & - & - & - & - & - & - & - & - & \\
\hline
\end{tabular}

Legende: - = keine Abweichung zu CRS, / = Position nicht lesbar, ( ) = unsicherer Sequenzpolymorphismus, X=
heavy chain, $\mathrm{L}=$ Light chain; bei mehr als einer Base an einer Position wurde der IUB-Code verwendet, $\mathrm{z}$. B. Y. 
Fortsetzung Tabelle 33: Ergebnisse der Einzeltypisierungen der HVR I-Analysen.
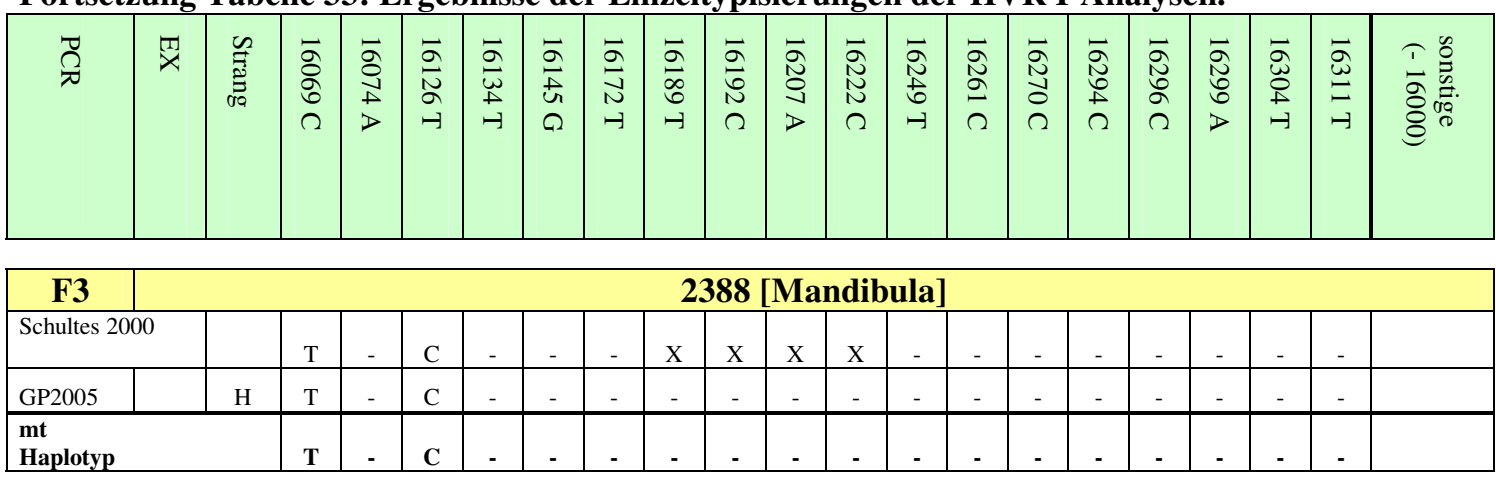

\begin{tabular}{|c|c|c|c|c|c|c|c|c|c|c|c|c|c|c|c|c|c|c|c|c|c|}
\hline F15 & \multicolumn{21}{|c|}{2589 [Mandibula] } \\
\hline \multirow{2}{*}{\multicolumn{2}{|c|}{ Schultes 2000}} & & & & & & & & & & & & & & & & & & & & \\
\hline & & & - & - & - & - & - & 1 & $\mathrm{X}$ & $\mathrm{X}$ & $\mathrm{X}$ & $\mathrm{X}$ & - & - & - & - & - & - & - & - & 51T; 129C \\
\hline 13 & I & $\mathrm{H}$ & 1 & 1 & - & - & - & - & C & - & $\mathrm{G}$ & - & - & - & - & - & - & - & - & - & $264 \mathrm{~T} ; 322 \mathrm{~T}$ \\
\hline 21 & I & $\mathrm{H}$ & 1 & 1 & 1 & 1 & 1 & 1 & 1 & 1 & 1 & 1 & 1 & 1 & 1 & 1 & 1 & 1 & 1 & 1 & \\
\hline 33 & I & $\mathrm{H}$ & I & 1 & 1 & 1 & 1 & 1 & 1 & I & I & - & - & - & - & Y & - & - & - & - & $232 \mathrm{~T}$ \\
\hline 55 & II & $\mathrm{H}$ & I & 1 & 1 & 1 & 1 & I & 1 & I & I & 1 & 1 & I & 1 & 1 & 1 & 1 & 1 & 1 & \\
\hline 60 & II & $\mathrm{L}$ & I & I & I & I & I & I & C & - & - & - & - & - & - & - & - & - & - & - & 192IC \\
\hline $\begin{array}{l}\text { mt } \\
\text { Haplotyp }\end{array}$ & & & - & - & - & - & - & I & $\mathbf{X}$ & $\mathbf{x}$ & $\mathbf{X}$ & $\mathbf{X}$ & - & - & - & - & - & - & - & - & $\begin{array}{l}16051 \mathrm{~T} ; \\
16129 \mathrm{C}\end{array}$ \\
\hline
\end{tabular}

\begin{tabular}{|l|ll|c|c|c|c|c|c|c|c|c|c|c|c|c|c|c|c|c|c|c|}
\hline M9 & \multicolumn{10}{|c|}{ 2749 [Mandibula] } \\
\hline 13 & I & H & - & - & - & - & - & - & - & - & - & - & - & T & - & - & - & - & - & - & \\
\hline 33 & I & H & (T) & - & - & - & - & - & - & - & - & - & - & T & - & - & - & - & - & - & \\
\hline 37 & II & H & - & - & - & - & - & - & - & - & - & - & - & T & - & - & - & - & - & - & \\
\hline 51 & III & H & - & - & - & - & - & - & - & - & - & - & - & T & - & - & - & - & - & - & \\
\hline $\begin{array}{l}\text { mt } \\
\text { Haplotyp }\end{array}$ & & & - & - & - & - & - & - & - & - & - & - & - & T & - & - & - & - & - & - & \\
\hline
\end{tabular}

\begin{tabular}{|l|c|c|c|c|c|c|c|c|c|c|c|c|c|c|c|c|c|c|c|c|c|c|}
\hline F20 & \multicolumn{10}{|c|}{3190 [Mandibula] } \\
\hline 33 & I & H & - & - & - & - & - & - & - & - & - & - & - & - & - & - & - & G & - & - & \\
\hline 60 & I & H & - & - & - & - & - & - & - & - & - & - & - & - & - & - & - & G & - & - & \\
\hline $\begin{array}{l}\text { mt } \\
\text { Haplotyp }\end{array}$ & & $(-)$ & $(-)$ & $(-)$ & $(-)$ & $(-)$ & $(-)$ & $(-)$ & $(-)$ & $(-)$ & $(-)$ & $(-)$ & $(-)$ & $(-)$ & $(-)$ & $(-)$ & $(G)$ & $(-)$ & $(-)$ & \\
\hline
\end{tabular}

\begin{tabular}{|l|l|l|l|l|l|l|l|l|l|l|l|l|l|l|l|l|l|l|l|l|l|l|l|}
\hline \multicolumn{1}{|c|}{ M5 } & \multicolumn{10}{|c|}{3380 [Mandibula] } \\
\hline 33 & I & H & - & - & - & - & - & - & - & - & - & - & - & - & - & - & - & - & - & - & \\
\hline 55 & II & H & - & - & - & - & - & - & - & - & - & - & - & - & - & - & - & - & - & - & \\
\hline $\begin{array}{l}\text { mt } \\
\text { Haplotyp }\end{array}$ & & - & - & - & - & - & - & - & - & - & - & - & - & - & - & - & - & - & - & \\
\hline
\end{tabular}

\begin{tabular}{|c|c|c|c|c|c|c|c|c|c|c|c|c|c|c|c|c|c|c|c|c|c|}
\hline F8 & \multicolumn{21}{|c|}{3631 [Calvarium] } \\
\hline 33 & II & $\mathrm{H}$ & - & - & - & - & - & - & $\mathrm{C}$ & - & - & - & - & 1 & 1 & 1 & 1 & 1 & 1 & 1 & $\begin{array}{l}186 \mathrm{~T} ; 225 \mathrm{~T} \\
232 \mathrm{~T} ; 239 \mathrm{~T}\end{array}$ \\
\hline 51 & III & $\mathrm{L}$ & - & G & - & - & - & - & $\mathrm{C}$ & $\mathrm{Y}$ & - & - & $\mathrm{C}$ & - & $\mathrm{T}$ & - & - & - & - & - & \\
\hline 51 & III & $\mathrm{L}$ & - & G & - & - & - & - & $\mathrm{C}$ & $\mathrm{T}$ & - & - & $\mathrm{C}$ & - & $\mathrm{T}$ & - & - & - & - & - & \\
\hline 55 & II & $\mathrm{L}$ & - & $\mathrm{R}$ & $\mathrm{Y}$ & - & - & - & $\mathrm{C}$ & $\mathrm{Y}$ & - & - & - & - & $\mathrm{Y}$ & $\mathrm{T}$ & - & - & - & - & $150 \mathrm{Y} ; 186 \mathrm{Y}$ \\
\hline 55 & III & $\mathrm{H}$ & - & G & - & - & - & - & $\mathrm{C}$ & $\mathrm{T}$ & - & - & $\mathrm{C}$ & - & $\mathrm{T}$ & - & - & - & - & - & \\
\hline 68 & $1: 6 \mathrm{z}$ & $\mathrm{H}$ & - & $\mathrm{G}$ & - & - & - & - & C & 1 & 1 & 1 & 1 & 1 & 1 & 1 & 1 & 1 & 1 & 1 & \\
\hline 68 & III & $\mathrm{L}$ & - & G & - & - & - & - & C & $\mathrm{T}$ & - & - & $\mathrm{C}$ & - & $\mathrm{T}$ & - & - & - & - & - & \\
\hline $\begin{array}{l}\text { mt } \\
\text { Haplotyp }\end{array}$ & & & - & G & - & - & - & - & C & $\mathbf{T}$ & - & - & C & - & $T$ & - & - & - & - & - & \\
\hline
\end{tabular}

Legende: - = keine Abweichung zu CRS, / = Position nicht lesbar, $($ ) = unsicherer Sequenzpolymorphismus, $\mathrm{X}=$ Abschnitt nicht sequenziert; $\mathrm{H}=$ heavy chain, $\mathrm{L}=$ Light chain; bei mehr als einer Base an einer Position wurde der IUB-Code verwendet, $\mathrm{z}$.B. Y. 
Fortsetzung Tabelle 33: Ergebnisse der Einzeltypisierungen der HVR I

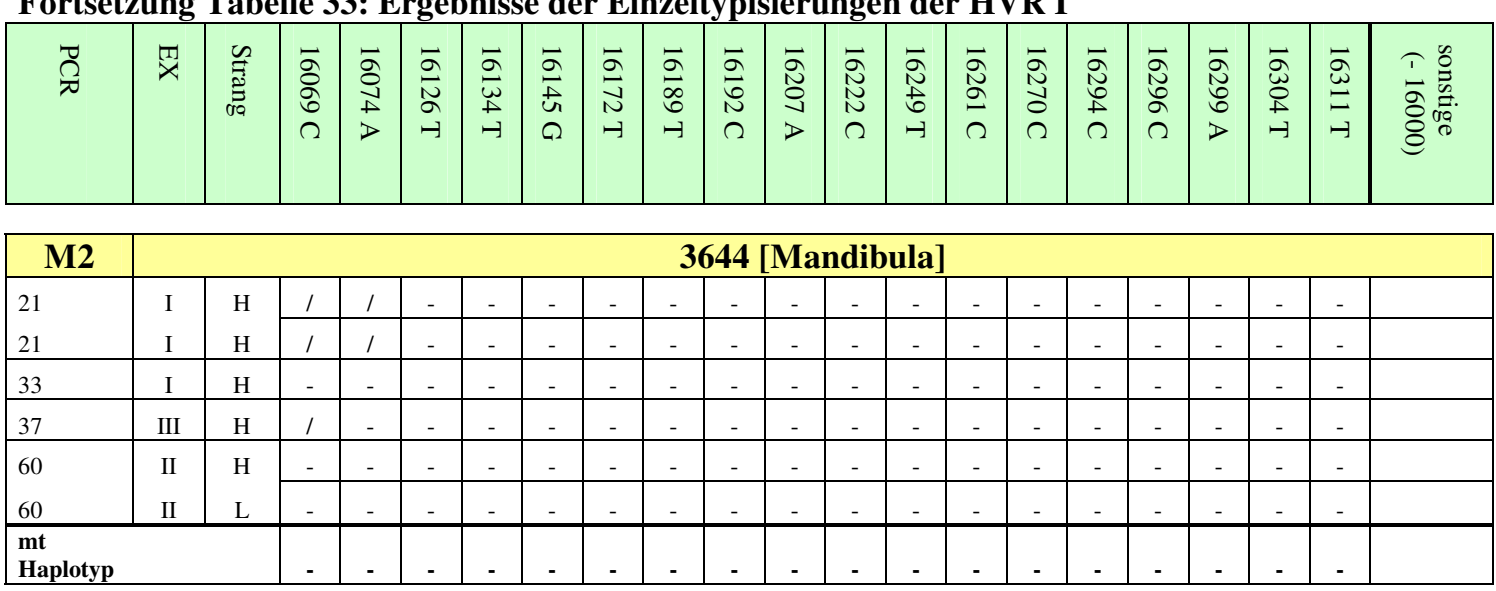

\begin{tabular}{|c|c|c|c|c|c|c|c|c|c|c|c|c|c|c|c|c|c|c|c|c|c|}
\hline F9 & \multicolumn{21}{|c|}{3705 [Calvarium] } \\
\hline 13 & I & $\mathrm{H}$ & I & I & I & 1 & 1 & 1 & 1 & I & 1 & 1 & I & 1 & 1 & 1 & 1 & 1 & 1 & 1 & \\
\hline 21 & II & $\mathrm{H}$ & 1 & I & - & - & - & - & - & $\mathrm{T}$ & - & - & - & - & - & - & - & - & - & - & \\
\hline 21 & II & $\mathrm{H}$ & - & - & - & - & - & - & - & $\mathrm{T}$ & - & - & - & - & - & - & - & - & - & $\mathrm{C}$ & $171 \mathrm{~T}$ \\
\hline 33 & II & $\mathrm{H}$ & - & - & - & - & - & - & - & $\mathrm{T}$ & - & - & - & - & - & - & - & - & - & $\mathrm{C}$ & $16239 \mathrm{~T}$ \\
\hline 21 & I & $\mathrm{H}$ & - & - & - & - & - & - & - & - & - & - & - & - & - & - & - & - & - & - & \\
\hline 51 & IV & $\mathrm{H}$ & 1 & I & 1 & - & - & - & - & - & - & - & - & - & - & - & - & - & - & - & $184 \mathrm{Y}$ \\
\hline 55 & I & $\mathrm{H}$ & 1 & 1 & 1 & 1 & 1 & 1 & 1 & 1 & 1 & 1 & 1 & 1 & 1 & 1 & 1 & 1 & 1 & 1 & \\
\hline $\begin{array}{l}\text { mt } \\
\text { Haploty }\end{array}$ & & & - & - & - & - & - & - & - & $(-)$ & - & - & - & - & - & - & - & - & - & - & \\
\hline
\end{tabular}

\begin{tabular}{|l|c|c|c|c|c|c|c|c|c|c|c|c|c|c|c|c|c|c|c|c|c|}
\hline \multicolumn{1}{|c|}{ F5 } & \multicolumn{10}{|c|}{ 3706 [Calvarium] } \\
\hline 13 & I & H & - & - & C & - & - & - & - & - & - & - & - & - & - & T & T & - & C & - & \\
\hline 33 & I & H & - & - & C & - & - & - & - & - & - & - & - & - & - & T & T & - & C & - & \\
\hline 55 & III & H & - & - & C & - & - & - & - & - & - & - & - & - & - & T & T & - & C & - & \\
\hline 60 & III & L & - & - & C & - & - & - & - & - & - & - & - & - & - & T & T & - & C & - & \\
\hline 68 & III & H & - & - & C & - & - & - & - & - & - & - & - & - & - & T & T & - & C & - & \\
\hline $\begin{array}{l}\text { mt } \\
\text { Haplotyp }\end{array}$ & & - & - & C & - & - & - & - & - & - & - & - & - & - & & T & T & - & C & - & \\
\hline
\end{tabular}
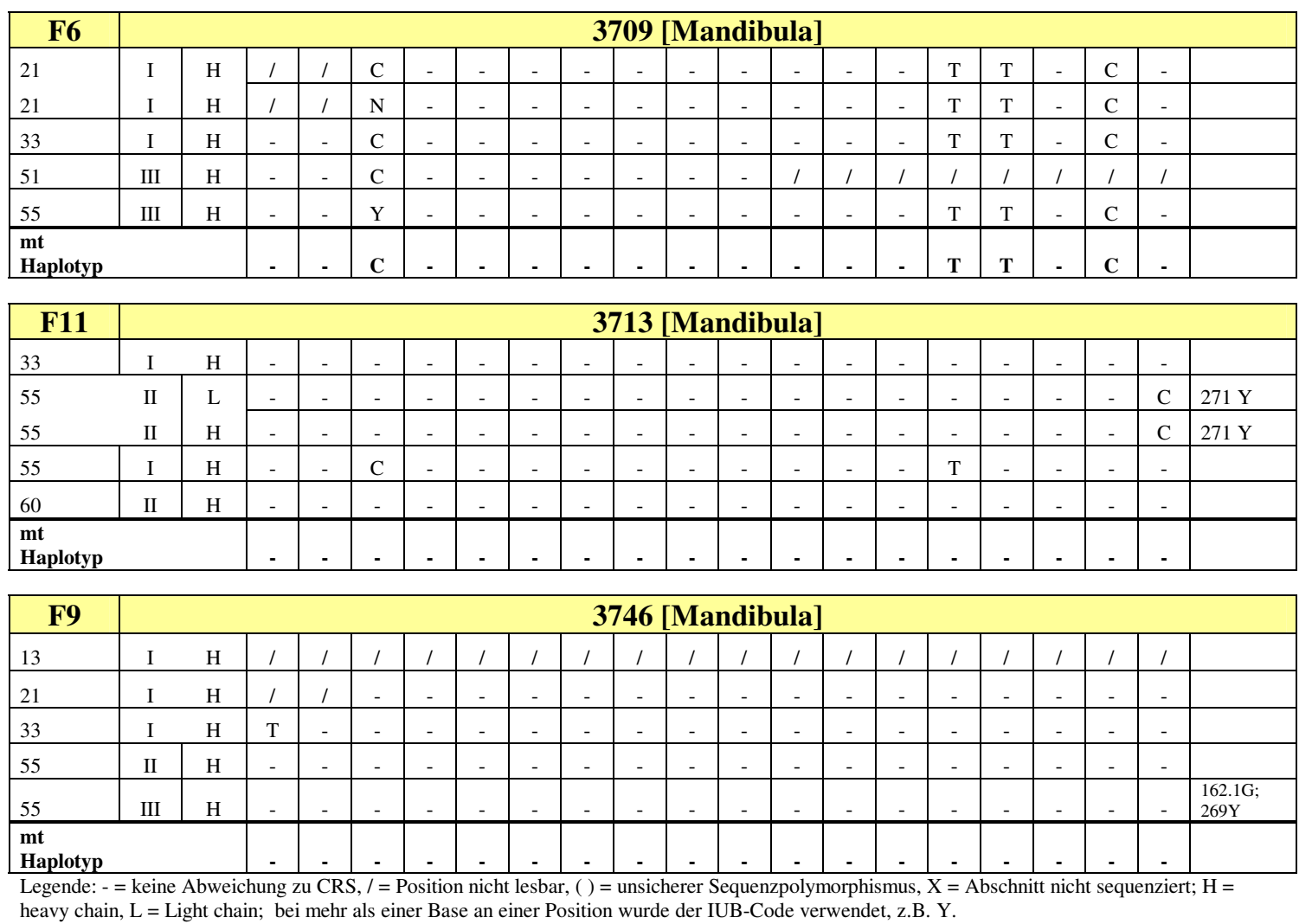
Fortsetzung Tabelle 33: Ergebnisse der Einzeltypisierungen der HVR I-Analysen.

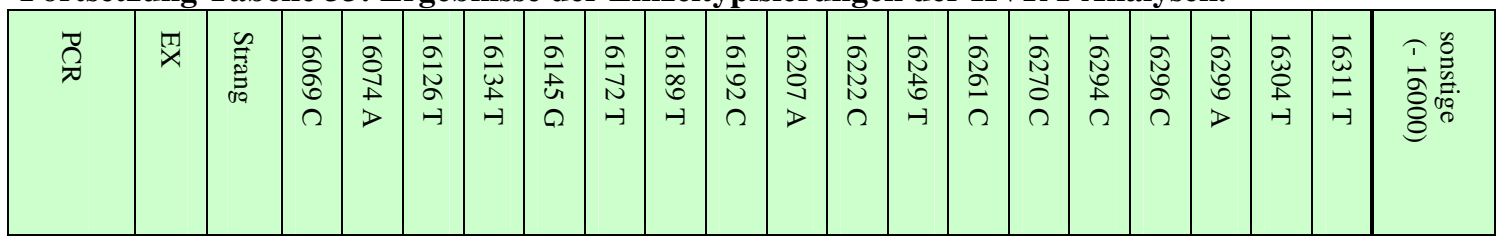

\begin{tabular}{|c|c|c|c|c|c|c|c|c|c|c|c|c|c|c|c|c|c|c|c|c|c|}
\hline M8 & \multicolumn{21}{|c|}{3757 [Calvarium] } \\
\hline 13 & I & $\mathrm{H}$ & 1 & 1 & 1 & 1 & 1 & 1 & 1 & 1 & 1 & 1 & 1 & 1 & 1 & 1 & 1 & 1 & 1 & 1 & \\
\hline 21 & I & $\mathrm{H}$ & - & - & - & - & - & - & - & - & - & - & - & - & - & - & - & - & - & & $72 \mathrm{~T}$ \\
\hline 37 & II & $\mathrm{H}$ & - & - & - & - & - & - & - & - & 1 & 1 & 1 & 1 & 1 & 1 & 1 & 1 & 1 & 1 & \\
\hline 37 & II & L & 1 & 1 & 1 & 1 & 1 & 1 & $\mathrm{Y}$ & $\mathrm{T}$ & - & - & $\mathrm{Y}$ & - & - & - & - & - & - & - & \\
\hline 37 & II & $\mathrm{H}$ & - & G & - & - & - & - & C & 1 & 1 & 1 & 1 & 1 & 1 & 1 & 1 & 1 & 1 & 1 & \\
\hline 51 & II & $\mathrm{H}$ & 1 & $\mathrm{G}$ & - & - & - & - & C & - & 1 & 1 & 1 & 1 & 1 & 1 & 1 & 1 & 1 & 1 & \\
\hline 51 & II & $\mathrm{L}$ & - & G & - & - & - & - & $\mathrm{C}$ & $\mathrm{T}$ & - & - & $\mathrm{Y}$ & - & $\mathrm{T}$ & - & - & - & - & - & \\
\hline 72 & III & $\mathrm{H}$ & 1 & 1 & 1 & 1 & 1 & 1 & I & 1 & 1 & 1 & 1 & 1 & 1 & 1 & 1 & 1 & 1 & 1 & \\
\hline $\begin{array}{l}\mathrm{mt} \\
\text { Haplotyp }\end{array}$ & & & - & G & - & - & - & - & C & $\mathbf{T}$ & - & - & 1 & 1 & I & 1 & I & I & I & I & \\
\hline
\end{tabular}

\begin{tabular}{|l|cc|c|c|c|c|c|c|c|c|c|c|c|c|c|c|c|c|c|c|c|}
\hline M16 & \multicolumn{10}{|c|}{3886 [Felsenbein li.] } \\
\hline 68 & I & H & - & G & - & - & - & - & C & T & - & - & C & - & T & - & - & - & - & - & \\
\hline 68 & II & H & - & G & - & - & - & - & C & T & - & - & C & - & T & - & - & - & - & - & \\
\hline 70 & I & H & - & G & - & - & - & - & C & T & - & - & C & - & T & - & - & - & - & - & \\
\hline 70 & II & H & - & G & - & - & - & - & C & T & - & - & C & - & T & - & - & - & - & - & \\
\hline $\begin{array}{l}\text { mt } \\
\text { Haplotyp }\end{array}$ & & - & G & - & - & - & - & C & T & - & - & C & - & T & - & - & - & - & - & \\
\hline
\end{tabular}

\begin{tabular}{|l|c|c|c|c|c|c|c|c|c|c|c|c|c|c|c|c|c|c|c|c|c|c|c|}
\hline & \multicolumn{10}{|c|}{3889 Mandibula] } \\
\hline 13 & $\mathrm{I}$ & $\mathrm{H}$ & $/$ & $/$ & $/$ & $/$ & $/$ & $/$ & $/$ & $/$ & $/$ & $/$ & $/$ & $/$ & $/$ & $/$ & $/$ & $/$ & $/$ & $/$ & \\
\hline 21 & $\mathrm{I}$ & $\mathrm{H}$ & $\mathrm{T}$ & - & $\mathrm{C}$ & - & - & - & - & - & - & - & - & - & - & - & - & - & - & - & \\
\hline $\begin{array}{l}\text { mt } \\
\text { Haplotyp }\end{array}$ & & $/$ & $/$ & $/$ & $/$ & $/$ & $/$ & $/$ & $/$ & $/$ & $/$ & $/$ & $/$ & $/$ & $/$ & $/$ & $/$ & $/$ & $/$ & \\
\hline
\end{tabular}

\begin{tabular}{|l|c|c|c|c|c|c|c|c|c|c|c|c|c|c|c|c|c|c|c|c|c|c|}
\hline M8 & \multicolumn{11}{|c|}{ 4003 [Mandibula] } \\
\hline 37 & I & L & $/$ & $/$ & $/$ & $/$ & $/$ & $/$ & $/$ & $/$ & $/$ & $/$ & $/$ & $/$ & $/$ & $/$ & $/$ & $/$ & $/$ & $/$ & \\
\hline 55 & II & H & $/$ & $/$ & $/$ & $/$ & $/$ & $/$ & $/$ & $/$ & $/$ & $/$ & $/$ & $/$ & $/$ & $/$ & $/$ & $/$ & $/$ & $/$ & \\
\hline $\begin{array}{l}\text { mt } \\
\text { Haplotyp }\end{array}$ & & & $/$ & $/$ & $/$ & $/$ & $/$ & $/$ & $/$ & $/$ & $/$ & $/$ & $/$ & $/$ & $/$ & $/$ & $/$ & $/$ & $/$ & $/$ & \\
\hline
\end{tabular}

\begin{tabular}{|c|c|c|c|c|c|c|c|c|c|c|c|c|c|c|c|c|c|c|c|c|c|}
\hline F4 & \multicolumn{21}{|c|}{4078 [Mandibula] } \\
\hline 37 & I & $\mathrm{H}$ & - & $\mathrm{G}$ & - & - & - & - & C & $\mathrm{T}$ & 1 & 1 & 1 & 1 & 1 & 1 & 1 & 1 & 1 & 1 & \\
\hline 37 & I & L & 1 & 1 & 1 & 1 & 1 & 1 & C & $\mathrm{T}$ & - & - & C & - & $\mathrm{T}$ & - & - & - & - & - & $183 \mathrm{M}$ \\
\hline 51 & I & $\mathrm{H}$ & - & $\mathrm{G}$ & - & - & - & - & $\mathrm{C}$ & $\mathrm{T}$ & 1 & 1 & 1 & 1 & 1 & 1 & 1 & 1 & 1 & 1 & \\
\hline 51 & II & $\mathrm{H}$ & - & $\mathrm{G}$ & - & - & - & - & $\mathrm{C}$ & $\mathrm{T}$ & - & - & $\mathrm{C}$ & - & $\mathrm{T}$ & - & - & - & - & - & \\
\hline 55 & II & $\mathrm{H}$ & - & G & - & - & - & - & C & $\mathrm{T}$ & - & - & C & - & $\mathrm{T}$ & - & - & - & - & - & \\
\hline $\begin{array}{l}\text { mt } \\
\text { Haplotyp }\end{array}$ & & & - & G & - & - & - & - & C & $\mathbf{T}$ & - & - & C & - & $\mathbf{T}$ & - & - & - & - & - & \\
\hline
\end{tabular}

\begin{tabular}{|c|c|c|c|c|c|c|c|c|c|c|c|c|c|c|c|c|c|c|c|c|c|}
\hline F14 & \multicolumn{21}{|c|}{4309 [Mandibula] } \\
\hline 33 & I & $\mathrm{H}$ & $\mathrm{T}$ & - & C & - & A & $\mathrm{C}$ & - & - & - & $\mathrm{T}$ & - & $\mathrm{T}$ & - & - & - & - & - & - & \\
\hline 33 & $\mathrm{I}$ & $\mathrm{H}$ & T & - & $\mathrm{C}$ & - & $\mathrm{A}$ & $\mathrm{C}$ & - & - & - & $\mathrm{T}$ & - & $\mathrm{T}$ & - & - & - & - & - & - & \\
\hline 37 & II & $\mathrm{H}$ & $\mathrm{T}$ & - & $\mathrm{C}$ & - & $\mathrm{A}$ & $\mathrm{C}$ & - & 1 & 1 & 1 & 1 & 1 & 1 & 1 & 1 & 1 & 1 & 1 & $131 \mathrm{C}$ \\
\hline 37 & II & $\mathrm{H}$ & $\mathrm{T}$ & - & $\mathrm{C}$ & - & $\mathrm{A}$ & $\mathrm{C}$ & - & - & - & $\mathrm{T}$ & - & $\mathrm{T}$ & - & - & - & - & - & - & \\
\hline 21 & $\mathrm{I}$ & $\mathrm{H}$ & $\mathrm{T}$ & - & C & - & A & C & - & - & - & $\mathrm{T}$ & - & $\mathrm{T}$ & - & - & - & - & - & - & \\
\hline 60 & II & $\mathrm{H}$ & 1 & 1 & 1 & 1 & 1 & 1 & - & - & - & $\mathrm{T}$ & - & $\mathrm{T}$ & - & - & - & - & - & - & \\
\hline $\begin{array}{l}\text { mt } \\
\text { Haplotyp }\end{array}$ & & & $\mathbf{T}$ & - & C & - & A & C & - & - & - & $\mathbf{T}$ & - & $\mathbf{T}$ & - & - & - & - & - & - & \\
\hline
\end{tabular}

Legende: - = keine Abweichung zu CRS, / = Position nicht lesbar, $($ ) = unsicherer Sequenzpolymorphismus, $\mathrm{X}=$ Abschnitt nicht sequenziert; H = heavy chain, L = Light chain; bei mehr als einer Base an einer Position wurde der IUB-Code verwendet, z.B. Y. 
Fortsetzung Tabelle 33: Ergebnisse der Einzeltypisierungen der HVR I-Analysen.

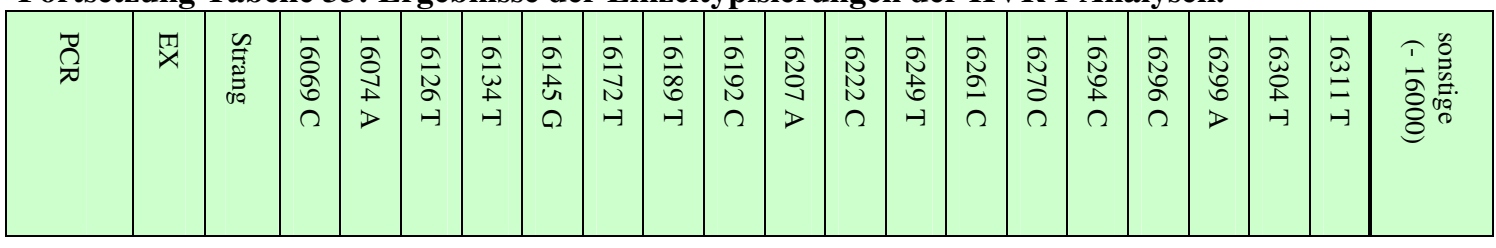

\begin{tabular}{|l|c|c|c|c|c|c|c|c|c|c|c|c|c|c|c|c|c|c|c|c|c|}
\hline F4 & \multicolumn{10}{|c|}{ 5516 [Calvarium] } \\
\hline 13 & I & H & / & / & - & - & - & - & C & - & G & - & C & - & T & - & - & - & - & - & $224 Y ; 232 \mathrm{~T}$ \\
$239 T ; 322 \mathrm{~T}$ \\
\hline 33
\end{tabular}

\begin{tabular}{|l|c|c|c|c|c|c|c|c|c|c|c|c|c|c|c|c|c|c|c|c|c|c|}
\hline F6 & \multicolumn{10}{|c|}{5517 Calvarium] } \\
\hline 13 & II & H & $/$ & $/$ & $/$ & $/$ & $/$ & $/$ & $/$ & $/$ & $/$ & $/$ & $/$ & $/$ & $/$ & $/$ & $/$ & $/$ & $/$ & $/$ & $286 \mathrm{Y}$ \\
\hline 21 & I & H & $/$ & $/$ & $/$ & $/$ & $/$ & $/$ & $/$ & $/$ & $/$ & $/$ & $/$ & $/$ & $/$ & $/$ & $/$ & $/$ & $/$ & $/$ & \\
\hline 51 & II & H & - & - & C & - & - & - & - & Y & - & - & - & - & - & T & T & - & C & - & \\
\hline 55 & II & H & - & - & C & - & - & - & - & - & - & - & - & - & - & T & T & - & C & - & \\
\hline 55 & III & H & - & - & C & - & - & - & - & - & - & - & - & - & - & T & T & - & C & - & \\
\hline 60 & III & H & - & - & C & - & - & - & - & - & - & - & - & - & - & T & T & - & C & - & \\
\hline $\begin{array}{l}\text { mt } \\
\text { Haplotyp }\end{array}$ & & - & - & C & - & - & - & - & - & - & - & - & - & - & T & T & - & C & - & \\
\hline
\end{tabular}

\begin{tabular}{|l|l|l|l|l|l|l|l|l|l|l|l|l|l|l|l|l|l|l|l|l|l|l|l|}
\hline \multicolumn{1}{|c|}{ M3 } & \multicolumn{10}{|c|}{ 6525 [Calvarium] } \\
\hline 70 & II & H & - & - & - & - & - & - & - & - & - & - & - & - & - & - & - & - & - & - & \\
\hline 72 & II & H & - & - & - & - & - & - & - & - & - & - & - & - & - & - & - & - & - & - & \\
\hline $\begin{array}{l}\text { mt } \\
\text { Haplotyp }\end{array}$ & & - & - & - & - & - & - & - & - & - & - & - & - & - & - & - & - & - & - & \\
\hline
\end{tabular}

\begin{tabular}{|l|c|c|c|c|c|c|c|c|c|c|c|c|c|c|c|c|c|c|c|c|c|}
\hline M12 & \multicolumn{10}{|c|}{ E33 [Mandibula] } \\
\hline 33 & I & H & T & - & C & - & - & - & - & - & - & - & - & - & - & - & - & - & C & - & \\
\hline 51 & II & H & T & - & C & - & - & - & - & - & - & - & - & - & - & - & - & - & - & - & \\
\hline 55 & I & H & T & - & C & - & - & - & - & - & - & - & - & - & - & - & - & - & - & - & \\
\hline 55 & II & H & T & - & C & - & - & - & - & - & - & - & - & - & - & - & - & - & - & - & \\
\hline $\begin{array}{l}\text { mt } \\
\text { Haplotyp }\end{array}$ & & T & - & C & - & - & - & - & - & - & - & - & - & - & - & - & - & - & - & \\
\hline
\end{tabular}

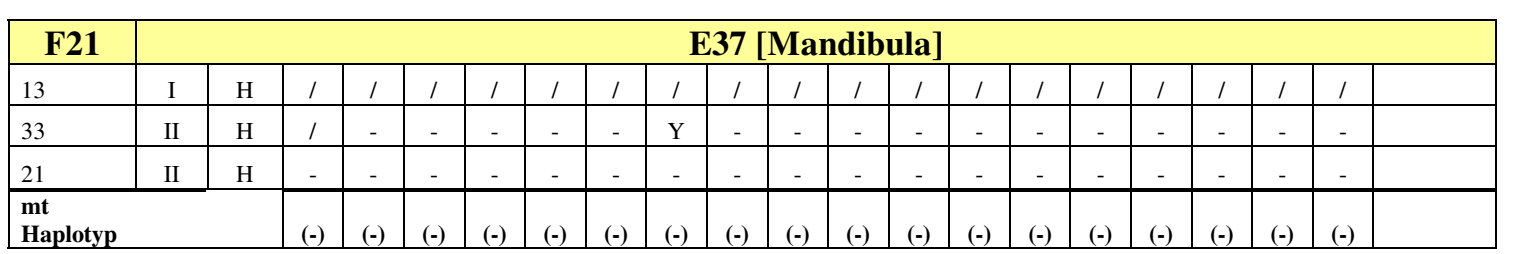

\begin{tabular}{|l|c|c|c|c|c|c|c|c|c|c|c|c|c|c|c|c|c|c|c|c|c|}
\hline & \multicolumn{10}{|c|}{ N969 [Mandibula] } \\
\hline 33 & II & H & - & - & - & - & - & - & - & - & - & - & - & - & - & - & - & - & C & - & \\
\hline 55 & II & H & - & - & - & - & - & - & - & - & - & - & - & - & - & - & - & - & C & - & \\
\hline 55 & I & H & $/$ & $/$ & $/$ & $/$ & $/$ & $/$ & $/$ & $/$ & $/$ & $/$ & $/$ & $/$ & $/$ & $/$ & $/$ & $/$ & $/$ & $/$ & \\
\hline 72 & III & H & - & - & - & - & - & - & - & - & - & - & - & - & - & - & - & - & C & - & \\
\hline $\begin{array}{l}\text { mt } \\
\text { Haplotyp }\end{array}$ & & - & - & - & - & - & - & - & - & - & - & - & - & - & - & - & - & C & - & \\
\hline
\end{tabular}

Legende: - = keine Abweichung zu CRS, / = Position nicht lesbar, $($ ) = unsicherer Sequenzpolymorphismus, $\mathrm{X}=$ Abschnitt nicht sequenziert; $\mathrm{H}=$ heavy chain, $\mathrm{L}=$ Light chain; bei mehr als einer Base an einer Position wurde der IUB-Code verwendet, z.B. Y. 
Fortsetzung Tabelle 33: Ergebnisse der Einzeltypisierung der HVR I-Analysen.

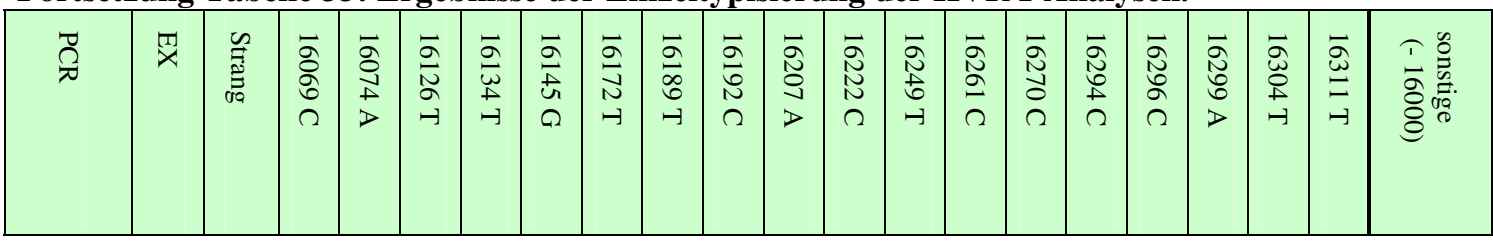

\begin{tabular}{|c|c|c|c|c|c|c|c|c|c|c|c|c|c|c|c|c|c|c|c|c|c|}
\hline \multirow{2}{*}{\multicolumn{2}{|c|}{\begin{tabular}{c|} 
F12 \\
Schultes 2000
\end{tabular}}} & & & & & & & & & & & & & & & & & & & & \\
\hline & & & & & & & & & & & & & & & & & & & & & \\
\hline 13 & I & $\mathrm{H}$ & I & I & 1 & 1 & 1 & 1 & 1 & $\underline{\Lambda}$ & $\underline{\Lambda}$ & $\underline{\Lambda}$ & l & - & 1 & 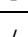 & 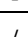 & - & - & 1 & \\
\hline 21 & I & $\mathrm{H}$ & - & - & - & - & - & - & - & - & - & - & - & - & - & - & - & $\mathrm{G}$ & - & - & \\
\hline 33 & I & $\mathrm{H}$ & - & - & - & - & - & - & - & - & - & - & - & - & - & - & - & G & - & - & \\
\hline $70 \mathrm{~A}$ & II & $\mathrm{H}$ & - & - & - & - & - & - & - & - & - & - & - & - & - & - & - & $\mathrm{G}$ & - & - & \\
\hline $70 \mathrm{~B}$ & II & $\mathrm{H}$ & - & - & - & - & - & - & - & - & - & - & - & - & - & - & - & G & - & - & \\
\hline $\begin{array}{l}\mathrm{mt} \\
\text { Haplotyp }\end{array}$ & & & - & - & - & - & - & - & - & - & - & - & - & - & - & - & - & G & - & - & \\
\hline
\end{tabular}

\begin{tabular}{|l|c|c|c|c|c|c|c|c|c|c|c|c|c|c|c|c|c|c|c|c|c|}
\hline F16 & \multicolumn{110}{|c|}{ R2 [Calvarium] } \\
\hline 13 & I & H & $/$ & $/$ & $/$ & $/$ & $/$ & $/$ & $/$ & $/$ & $/$ & $/$ & $/$ & $/$ & $/$ & $/$ & $/$ & $/$ & $/$ & $/$ & \\
\hline 33 & I & H & $/$ & $/$ & $/$ & $/$ & $/$ & $/$ & $/$ & $/$ & $/$ & $/$ & $/$ & $/$ & $/$ & $/$ & $/$ & $/$ & $/$ & $/$ & \\
\hline 51 & III & L & - & - & C & - & A & - & - & - & - & - & - & - & - & T & T & - & C & - & \\
\hline 55 & IVb & L & - & - & C & - & R & - & - & - & - & - & - & - & - & T & T & - & Y & - & \\
\hline 55 & IVa & H & - & - & C & - & R & - & - & - & - & - & - & - & - & T & T & - & C & - & \\
\hline 60 & III & H & - & - & C & - & A & - & - & - & - & - & - & - & - & T & T & - & C & - & \\
\hline $\begin{array}{l}\text { mt } \\
\text { Haplotyp }\end{array}$ & & - & - & C & - & A & - & - & - & - & - & - & - & - & T & T & - & C & - & \\
\hline
\end{tabular}

\begin{tabular}{|l|c|c|c|c|c|c|c|c|c|c|c|c|c|c|c|c|c|c|c|c|c|}
\hline M6 & \multicolumn{10}{|c|}{ [1Calvarium] } \\
\hline 13 & I & H & $/$ & $/$ & $/$ & $/$ & $/$ & $/$ & $/$ & $/$ & $/$ & $/$ & $/$ & $/$ & $/$ & $/$ & $/$ & $/$ & $/$ & $/$ & \\
\hline 21 & I & H & - & - & - & - & - & - & - & - & - & - & - & - & - & - & - & - & - & - & \\
\hline 68 & II & H & - & - & - & - & - & - & - & - & - & - & - & - & - & - & - & - & - & - & \\
\hline $\begin{array}{l}\text { mt } \\
\text { Haplotyp }\end{array}$ & & - & - & - & - & - & - & - & - & - & - & - & - & - & - & - & - & - & - & \\
\hline
\end{tabular}

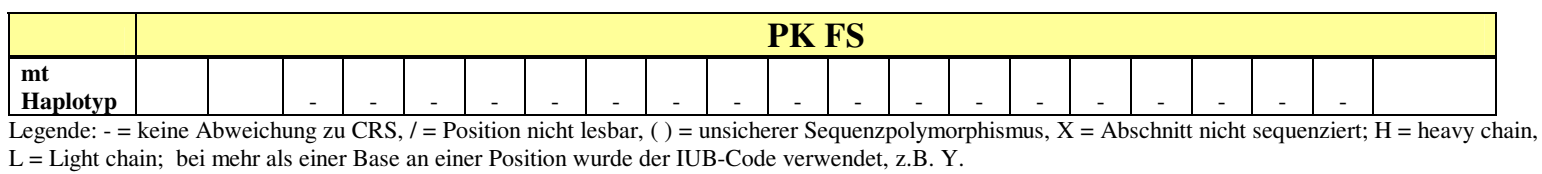


Tabelle 34: Ergebnisse der Einzeltypisierungen der HVR II-Analysen. Angegeben sind die Abweichungen zur CRS, welche in der Kopfzeile aufgezählt ist. Für die untersuchte Fundnummer ist das Skelettelement und wenn dies möglich war das Individuum angegeben.

\begin{tabular}{|c|c|c|c|c|c|c|c|c|c|c|c|c|c|c|c|c|c|}
\hline$\stackrel{\widetilde{O}}{\pi}$ & $\underset{x}{T}$ & 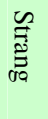 & $\begin{array}{l}\omega \\
\nu\end{array}$ & $\underset{>}{\infty}$ & 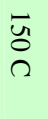 & $\begin{array}{l}\text { ज্ } \\
\stackrel{H}{H}\end{array}$ & $\begin{array}{l}\infty \\
w \\
a\end{array}$ & $\begin{array}{l}\overrightarrow{0} \\
u \\
\rightarrow\end{array}$ & $\underset{\sim}{\stackrel{N}{D}}$ & $\begin{array}{l}\mathbb{N} \\
\infty \\
\Omega\end{array}$ & $\begin{array}{l}\underset{\omega}{\omega} \\
-1\end{array}$ & $\begin{array}{l}\text { N } \\
\stackrel{N}{\Omega}\end{array}$ & $\begin{array}{l}\tilde{\omega} \\
>\end{array}$ & $\begin{array}{l}N \\
\mathscr{C} \\
r\end{array}$ & $\begin{array}{l}\tilde{e} \\
\text { ర } \\
?\end{array}$ & $\begin{array}{l}\tilde{\omega} \\
\tilde{u}\end{array}$ & 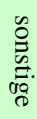 \\
\hline
\end{tabular}

\begin{tabular}{|l|c|c|c|c|c|c|c|c|c|c|c|c|c|c|c|c|c|}
\hline M4 & \multicolumn{10}{|c|}{ 4b [Mandibula] } \\
\hline 44 & II & L & - & - & - & - & - & - & - & - & - & - & G & - & - & $.1 \mathrm{C}$ & \\
\hline 67 & I & H & - & - & - & - & - & - & - & - & - & - & G & - & - & $.1 \mathrm{C}$ & \\
\hline mt Haplotyp & & - & - & - & - & - & - & - & - & - & - & G & - & - & $.1 \mathrm{C}$ & \\
\hline
\end{tabular}

\begin{tabular}{|l|c|c|c|c|c|c|c|c|c|c|c|c|c|c|c|c|l|}
\hline F1 & \multicolumn{10}{|c|}{38 [Mandibula] } \\
\hline 44 & I & H & $/$ & $/$ & - & C & - & - & - & - & - & - & G & - & - & $.1 \mathrm{C}$ & $156 \mathrm{~N} ; 156 \mathrm{IG}$ \\
\hline 63 & $\mathrm{I}$ & $\mathrm{H}$ & - & - & - & $\mathrm{C}$ & - & - & - & - & - & - & $\mathrm{G}$ & - & - & $.1 \mathrm{C}$ & $206.1 \mathrm{C} ; 257 \mathrm{IA}$ \\
\hline mt Haplotyp & & - & - & - & $\mathrm{C}$ & - & - & - & - & - & - & $\mathrm{G}$ & - & - & $.1 \mathrm{C}$ & \\
\hline
\end{tabular}

\begin{tabular}{|l|c|c|c|c|c|c|c|c|c|c|c|c|c|c|c|c|c|}
\hline & \multicolumn{10}{|c|}{ 46 [Maxilla] } \\
\hline 44 & I & H & - & - & - & - & - & - & - & - & - & - & G & - & - & $.1 \mathrm{C}$ & $156 \mathrm{~N} ; 156 \mathrm{IG}$ \\
\hline 63 & $\mathrm{II}$ & $\mathrm{H}$ & $/$ & $/$ & $/$ & $/$ & $/$ & $/$ & $/$ & $/$ & $/$ & $/$ & $/$ & $/$ & $/$ & $/$ & \\
\hline 67 & $\mathrm{I}$ & $\mathrm{H}$ & - & - & - & - & - & - & - & - & - & - & $\mathrm{G}$ & - & - & $.1 \mathrm{C}$ & \\
\hline \multicolumn{2}{l}{ mt Haplotyp } & & - & - & - & - & - & - & - & - & - & - & G & - & - & $.1 \mathrm{C}$ & \\
\hline
\end{tabular}

\begin{tabular}{|l|c|c|c|c|c|c|c|c|c|c|c|c|c|c|c|c|c|}
\hline \multicolumn{10}{|c|}{ M13 } & \multicolumn{10}{|c|}{58.3 [Femur li.] } \\
\hline \multicolumn{2}{|c|}{ Schultes 2000 } & & X & X & X & $/$ & $/$ & $/$ & $/$ & $/$ & $/$ & $/$ & $/$ & $/$ & $/$ & $/$ & \\
\hline 73 & Ref & H & G & - & - & - & - & - & - & - & - & - & G & - & - & $.1 \mathrm{C}$ & \\
\hline 73 & TP & H & $/$ & - & - & - & - & - & - & - & - & - & G & - & - & $.1 \mathrm{C}$ & \\
\hline \multicolumn{2}{|l}{ mt Haplotyp } & & (G) & - & - & - & - & - & - & - & - & - & G & - & - & $.1 \mathrm{C}$ & \\
\hline
\end{tabular}

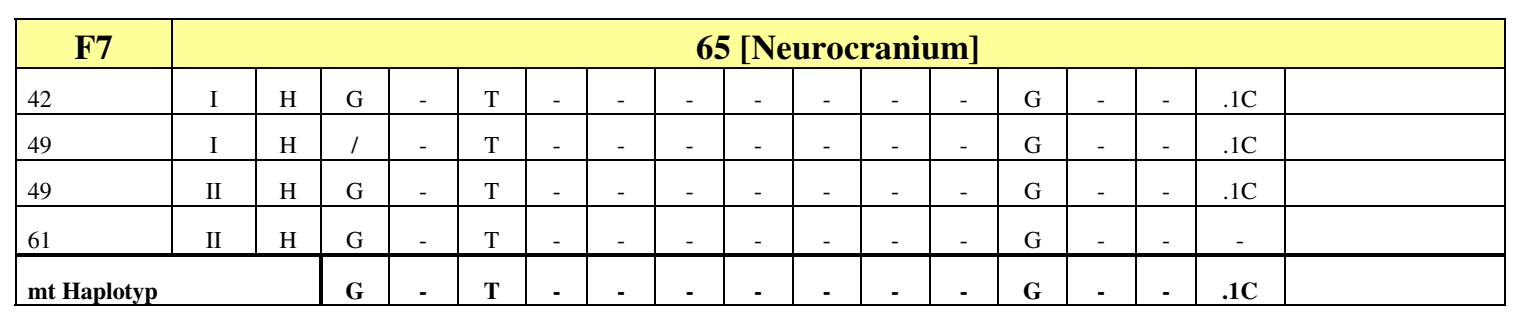

\begin{tabular}{|l|c|c|c|c|c|c|c|c|c|c|c|c|c|c|c|c|c|}
\hline & \multicolumn{11}{c|}{71 [Felsenbein] } \\
\hline 73 & II & H & - & - & - & - & - & - & - & - & - & - & G & - & $.2 \mathrm{C}$ & $.1 \mathrm{C}$ & \\
\hline mt Haplotyp & & 1 & $/$ & $/$ & $/$ & $/$ & $/$ & $/$ & $/$ & $/$ & $/$ & $/$ & $/$ & $/$ & $/$ & \\
\hline
\end{tabular}

\begin{tabular}{|c|c|c|c|c|c|c|c|c|c|c|c|c|c|c|c|c|c|}
\hline & \multicolumn{17}{|c|}{ 87a [Mandibula] } \\
\hline 24 & I & $\mathrm{L}$ & - & - & - & - & - & - & - & - & - & - & G & 1 & 1 & 1 & $253 \mathrm{~N}$ \\
\hline 24 & I & $\mathrm{H}$ & - & - & - & - & - & - & - & - & - & - & G & - & - & $.1 \mathrm{C}$ & \\
\hline 44 & II & $\mathrm{H}$ & - & - & - & - & - & - & - & - & - & - & G & - & - & $.1 \mathrm{C}$ & \\
\hline 63 & II & $\mathrm{H}$ & - & - & - & - & - & - & - & - & - & - & G & - & - & $.1 \mathrm{C}$ & \\
\hline & & & - & - & - & - & - & - & - & - & - & - & G & - & - & $.1 \mathrm{C}$ & \\
\hline
\end{tabular}

Legende: - = keine Abweichung zu CRS, / = Position nicht lesbar, $($ ) = unsicherer Sequenzpolymorphismus, $\mathrm{X}=$ Abschnitt nicht sequenziert; $\mathrm{H}=$ heavy chain, $\mathrm{L}=$ Light chain; bei mehr als einer Base an einer Position wurde der IUB-Code verwendet, z.B. Y. 
Fortsetzung Tabelle 34: Ergebnisse der Einzeltypisierungen der HVR II-Analysen.

\begin{tabular}{|c|c|c|c|c|c|c|c|c|c|c|c|c|c|c|c|c|c|}
\hline $\overrightarrow{0}$ & $\stackrel{\sqrt{x}}{x}$ & 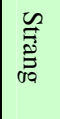 & $\begin{array}{l}\vec{\omega} \\
>\end{array}$ & $\underset{\sim}{\infty}$ & 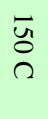 & $\begin{array}{l}\bar{N} \\
\stackrel{N}{H}\end{array}$ & $\begin{array}{l}\infty \\
w \\
u\end{array}$ & $\begin{array}{l}\overrightarrow{0} \\
u \\
\rightarrow\end{array}$ & $\begin{array}{l}\underset{N}{N} \\
>\end{array}$ & $\begin{array}{l}N \\
N \\
\infty \\
\Omega\end{array}$ & $\begin{array}{l}\underset{W}{W} \\
-1\end{array}$ & $\begin{array}{l}\stackrel{N}{N} \\
\Omega\end{array}$ & $\begin{array}{l}\tilde{\omega} \\
\mathbf{\omega} \\
\end{array}$ & 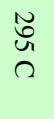 & 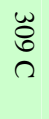 & $\begin{array}{l}\omega \\
\tilde{u} \\
\Omega\end{array}$ & 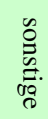 \\
\hline
\end{tabular}

\begin{tabular}{|l|c|c|c|c|c|c|c|c|c|c|c|c|c|c|c|c|c|}
\hline & \multicolumn{11}{c|}{ 87b [Mandibula] } \\
\hline 24 & I & L & - & - & - & C & - & - & - & - & - & - & $/$ & $/$ & $/$ & $/$ & \\
\hline 24 & I & L & - & - & - & Y & - & - & - & - & - & - & G & - & - & $/$ & \\
\hline mt Haplotyp & & & $/$ & $/$ & $/$ & $/$ & $/$ & $/$ & $/$ & $/$ & $/$ & $/$ & $/$ & $/$ & $/$ & $/$ & \\
\hline
\end{tabular}

\begin{tabular}{|l|c|c|c|c|c|c|c|c|c|c|c|c|c|c|c|c|c|}
\hline \multicolumn{1}{|c|}{ F1 } & \multicolumn{10}{c|}{ 152 [Neurocranium] } \\
\hline 42 & I & H & - & - & - & C & - & - & - & - & - & - & G & - & - & .1C & \\
\hline 49 & I & H & - & - & - & C & - & - & - & - & - & - & G & - & - & $.1 \mathrm{C}$ & \\
\hline 61 & II & H & - & - & - & C & - & - & - & - & - & - & G & & & $.1 \mathrm{C}$ & \\
\hline \multicolumn{2}{l|}{ mt Haplotyp } & & - & - & - & C & - & - & - & - & - & - & G & - & - & $.1 \mathrm{C}$ & \\
\hline
\end{tabular}

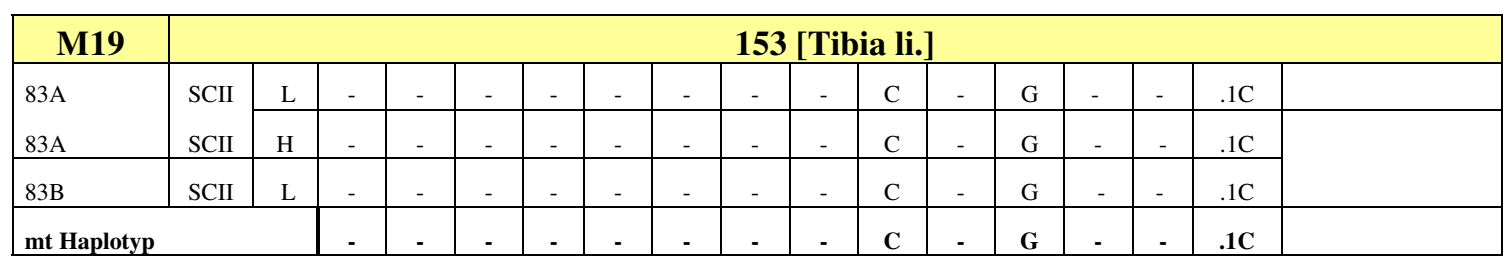

\begin{tabular}{|c|c|c|c|c|c|c|c|c|c|c|c|c|c|c|c|c|c|}
\hline M11 & \multicolumn{17}{|c|}{183 [Femur li.] } \\
\hline Schultes 2000 & & & $\mathrm{x}$ & $\mathrm{X}$ & $\mathrm{x}$ & 1 & - & - & - & - & - & - & G & - & - & $.1 \mathrm{C}$ & \\
\hline 73 & $\mathrm{~A}$ & $\mathrm{H}$ & 1 & - & $\mathrm{T}$ & - & - & - & - & - & - & - & G & - & - & $.1 \mathrm{C}$ & \\
\hline 73 & $\mathrm{~B}$ & $\mathrm{H}$ & G & - & $\mathrm{T}$ & - & - & - & - & - & - & - & $\mathrm{G}$ & - & - & $.1 \mathrm{C}$ & $213 \mathrm{~N}$ \\
\hline mt Haplotyp & & & (G) & - & $\mathbf{T}$ & - & - & - & - & - & - & - & G & - & - & $.1 \mathrm{C}$ & \\
\hline
\end{tabular}
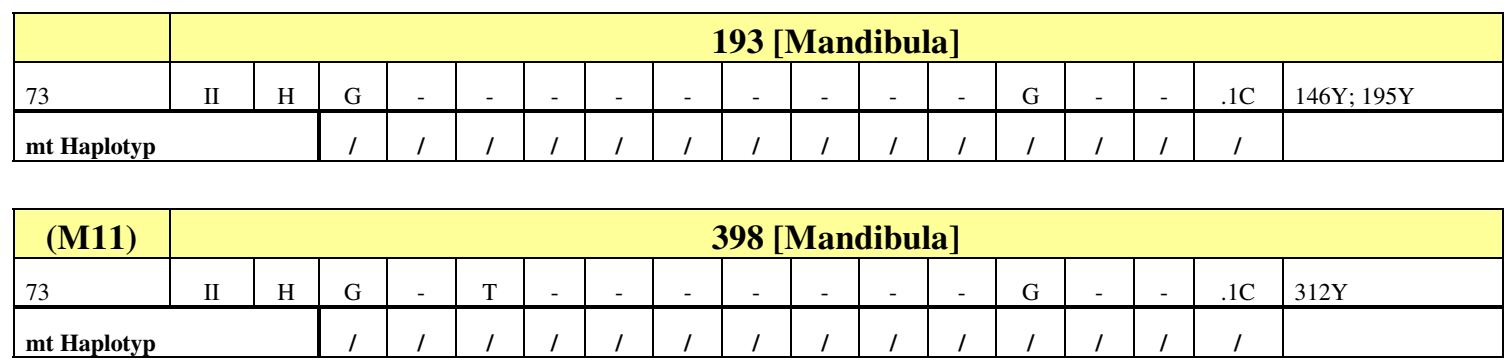

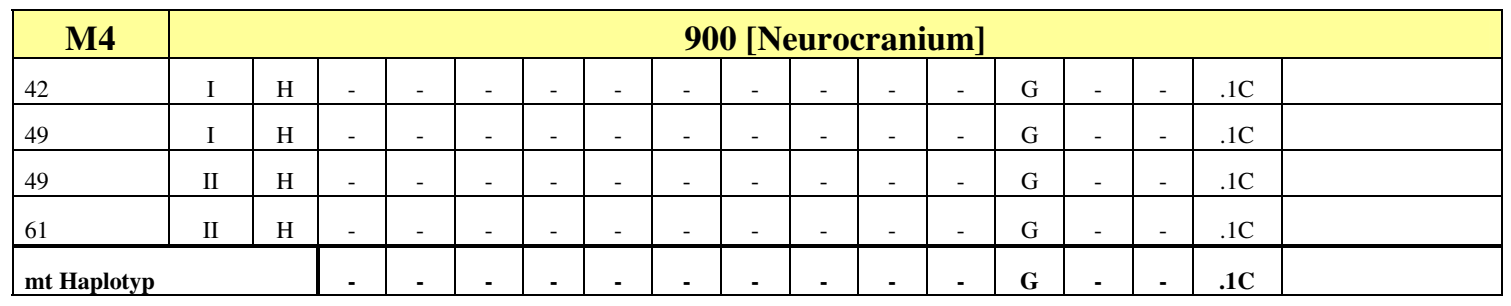

\begin{tabular}{|l|c|c|c|c|c|c|c|c|c|c|c|c|c|c|c|c|c|}
\hline \multicolumn{1}{|c|}{ M10 } & \multicolumn{10}{|c|}{902 [Femur li.] } \\
\hline Schultes 2000 & & X & X & X & $/$ & - & - & - & - & - & - & G & - & $.1 \mathrm{C}$ & $.1 \mathrm{C}$ & \\
\hline 73 & 1.9 & H & $/$ & $/$ & - & - & - & - & - & - & - & - & G & - & $/$ & $/$ & \\
\hline mt Haplotyp & & & X & X & X & $/$ & - & - & - & - & - & - & G & - & $.1 \mathrm{C}$ & .1C & \\
\hline
\end{tabular}

Legende: - = keine Abweichung zu CRS, / = Position nicht lesbar, $($ ) = unsicherer Sequenzpolymorphismus, $\mathrm{X}=$ Abschnitt nicht sequenziert; $\mathrm{H}=$ heavy chain, $\mathrm{L}=$ Light chain; bei mehr als einer Base an einer Position wurde der IUB-Code verwendet, z.B. Y. 
Fortsetzung Tabelle 34: Ergebnisse der Einzeltypisierungen der HVR II-Analysen.

\begin{tabular}{|c|c|c|c|c|c|c|c|c|c|c|c|c|c|c|c|c|c|}
\hline$\widetilde{\partial}$ & $\stackrel{\pi}{x}$ & 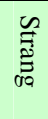 & $\begin{array}{l}\vec{\omega} \\
>\end{array}$ & $\begin{array}{l}\underset{\omega}{\omega} \\
>\end{array}$ & $\begin{array}{l}\vec{H} \\
0 \\
\Omega\end{array}$ & $\begin{array}{l}\overrightarrow{\breve{M}} \\
\stackrel{-1}{ }\end{array}$ & $\begin{array}{l}\vec{\infty} \\
\stackrel{a}{a}\end{array}$ & $\begin{array}{l}\overrightarrow{0} \\
u \\
\rightarrow\end{array}$ & $\begin{array}{l}\stackrel{N}{V} \\
>\end{array}$ & $\begin{array}{l}\mathbb{N} \\
\infty \\
\Omega\end{array}$ & $\begin{array}{l}\underset{W}{0} \\
-1\end{array}$ & $\begin{array}{l}\frac{N}{N} \\
\Omega \\
\Omega\end{array}$ & $\underset{\sim}{\tilde{\omega}}$ & $\begin{array}{l}\tilde{S} \\
u \\
\Omega\end{array}$ & $\begin{array}{l}\tilde{0} \\
0 \\
\Omega\end{array}$ & $\begin{array}{l}\omega \\
\tilde{\omega} \\
\Omega\end{array}$ & 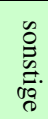 \\
\hline
\end{tabular}

\begin{tabular}{|c|c|c|c|c|c|c|c|c|c|c|c|c|c|c|c|c|c|}
\hline M5 & \multicolumn{17}{|c|}{908 [Calvarium] } \\
\hline 42 & I & $\mathrm{H}$ & - & - & - & - & - & - & - & - & - & - & G & - & - & $.1 \mathrm{C}$ & \\
\hline 49 & I & $\mathrm{H}$ & - & - & - & - & - & - & - & - & - & - & 1 & I & I & I & \\
\hline 49 & I & $\mathrm{H}$ & 1 & 1 & - & - & - & - & - & - & - & - & G & - & - & $.1 \mathrm{C}$ & $131 \mathrm{Y}$ \\
\hline 49 & II & $\mathrm{H}$ & - & - & - & - & - & - & - & - & - & - & G & - & - & $.1 \mathrm{C}$ & \\
\hline 49 & II & $\mathrm{H}$ & - & - & - & - & - & - & - & - & - & - & G & - & - & $.1 \mathrm{C}$ & \\
\hline 67 & II & $\mathrm{H}$ & - & - & - & - & - & - & - & - & - & - & G & - & - & $.1 \mathrm{C}$ & \\
\hline mt Haplot & & & - & - & - & - & - & - & - & - & - & - & G & - & - & $.1 \mathrm{C}$ & \\
\hline
\end{tabular}

\begin{tabular}{|l|c|c|c|c|c|c|c|c|c|c|c|c|c|c|c|c|c|}
\hline \multicolumn{10}{|c|}{ M7 } & \multicolumn{10}{c|}{910 [Calvarium] } \\
\hline 49 & II & H & - & - & - & - & - & - & - & - & - & - & G & - & $.2 \mathrm{C}$ & $.1 \mathrm{C}$ & \\
\hline 61 & II & H & - & - & - & - & - & - & - & - & - & - & G & - & $.2 \mathrm{C}$ & $.1 \mathrm{C}$ & \\
\hline 63 & IIIA & H & - & - & - & - & - & - & - & - & - & - & G & - & $.2 \mathrm{C}$ & $.1 \mathrm{C}$ & \\
\hline 63 & IIIB & H & $/$ & $/$ & $/$ & $/$ & $/$ & $/$ & $/$ & $/$ & $/$ & $/$ & $/$ & $/$ & $/$ & $/$ & \\
\hline 67 & IIIC & H & - & - & - & - & - & - & - & - & - & - & G & - & $.2 \mathrm{C}$ & $.1 \mathrm{C}$ & $306 \mathrm{Y}$ \\
\hline mt Haplotyp & & & - & - & - & - & - & - & - & - & - & - & G & - & $.2 \mathrm{C}$ & $.1 \mathrm{C}$ & \\
\hline
\end{tabular}

\begin{tabular}{|l|c|c|c|c|c|c|c|c|c|c|c|c|c|c|c|c|c|}
\hline M14 & \multicolumn{10}{|c|}{918 [Neurocranium] } \\
\hline 67 & III & H & - & - & - & - & - & - & - & - & - & - & G & - & - & $.1 \mathrm{C}$ & $63.1 \mathrm{C}$ \\
\hline 83 & III & H & - & - & - & - & - & - & - & - & - & - & G & - & - & $.1 \mathrm{C}$ & \\
\hline mt Haplotyp & & - & - & - & - & - & - & - & - & - & - & G & - & - & $.1 \mathrm{C}$ & \\
\hline
\end{tabular}

\begin{tabular}{|l|c|c|c|c|c|c|c|c|c|c|c|c|c|c|c|c|l|}
\hline \multicolumn{1}{|c|}{ F10 } & \multicolumn{10}{|c|}{ C46 [Calvarium] } \\
\hline 42 & I & H & G & - & - & - & - & - & - & - & - & - & G & - & $.1 \mathrm{C}$ & $.1 \mathrm{C}$ & $71 \mathrm{D}$ \\
\hline 49 & I & H & G & - & - & - & - & - & - & - & - & - & G & - & $.1 \mathrm{C}$ & $.1 \mathrm{C}$ & $71 \mathrm{D}$ \\
\hline 49 & II & H & G & - & - & - & - & - & - & - & - & - & G & - & $.1 \mathrm{C}$ & $.1 \mathrm{C}$ & $71 \mathrm{D}$ \\
\hline 61 & II & H & G & - & - & - & - & - & - & - & - & - & G & - & $.1 \mathrm{C}$ & $.1 \mathrm{C}$ & $71 \mathrm{D}$ \\
\hline mt Haplotyp & & & G & - & - & - & - & - & - & - & - & - & G & - & $.1 \mathrm{C}$ & $.1 \mathrm{C}$ & 71D \\
\hline
\end{tabular}

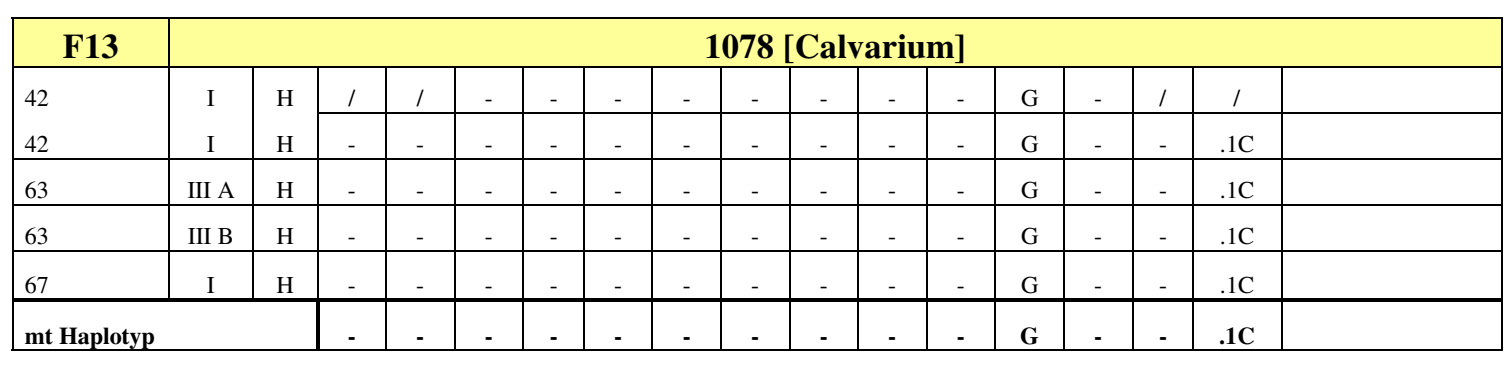

\begin{tabular}{|c|c|c|c|c|c|c|c|c|c|c|c|c|c|c|c|c|c|}
\hline M2 & \multicolumn{17}{|c|}{1102 [Femur li.] } \\
\hline Schultes 2000 & & & $\mathrm{X}$ & $\mathrm{X}$ & $\mathrm{X}$ & $\mathrm{C}$ & - & - & - & - & - & - & G & - & - & $.1 \mathrm{C}$ & \\
\hline 73 & MWZ & $\mathrm{H}$ & I & - & - & $\mathrm{C}$ & - & - & - & - & - & - & G & - & - & $.1 \mathrm{C}$ & $227 \mathrm{M}$ \\
\hline mt Haplotyp & & & $\mathbf{x}$ & $\mathbf{x}$ & $\mathbf{x}$ & C & - & - & - & - & - & - & G & - & - & $.1 \mathrm{C}$ & \\
\hline
\end{tabular}

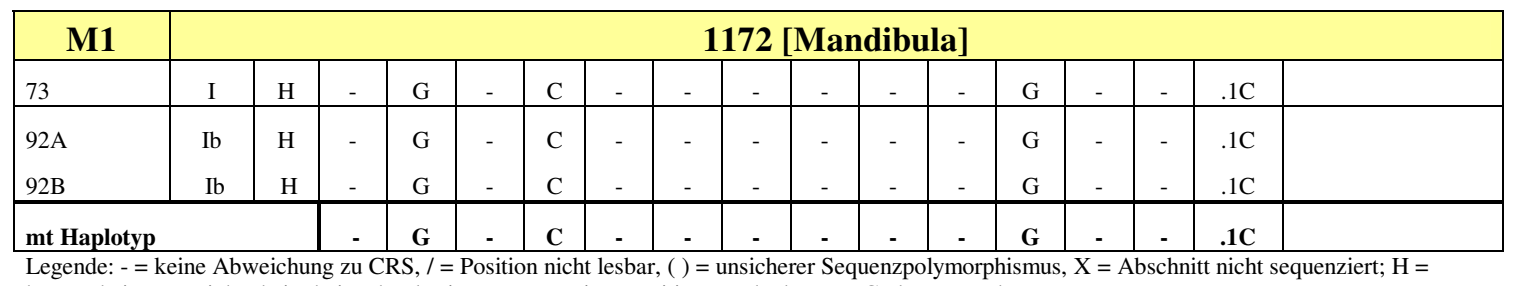

heavy chain, $\mathrm{L}=$ Light chain; bei mehr als einer Base an einer Position wurde der IUB-Code verwendet, z.B. Y. 
Anhang : Tabellen mt-Typisierungen

Fortsetzung Tabelle 34: Ergebnisse der Einzeltypisierungen der HVR II-Analysen.

\begin{tabular}{|c|c|c|c|c|c|c|c|c|c|c|c|c|c|c|c|c|c|}
\hline$\widetilde{\widetilde{D}}$ & $\sqrt{x}$ & 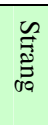 & $\begin{array}{l}\vec{\omega} \\
>\end{array}$ & $\underset{>}{\omega}$ & $\begin{array}{l}\vec{u} \\
\text { م}\end{array}$ & $\begin{array}{l}\vec{U} \\
\stackrel{N}{*}\end{array}$ & $\begin{array}{l}\vec{\infty} \\
u \\
a\end{array}$ & $\begin{array}{l}\overrightarrow{0} \\
u \\
\rightarrow\end{array}$ & $\begin{array}{l}\frac{N}{N} \\
D\end{array}$ & $\begin{array}{c}N \\
\infty \\
\infty \\
\Omega\end{array}$ & $\begin{array}{l}\underset{\omega}{\omega} \\
-1\end{array}$ & $\begin{array}{l}\frac{N}{N} \\
\text { n }\end{array}$ & $\begin{array}{l}\text { N } \\
\text { D }\end{array}$ & $\begin{array}{l}\text { U } \\
\text { U } \\
\Omega\end{array}$ & $\begin{array}{l}\text { w } \\
\text { O } \\
\text { r }\end{array}$ & $\begin{array}{l}\frac{\omega}{u} \\
\stackrel{r}{n}\end{array}$ & 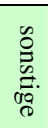 \\
\hline
\end{tabular}

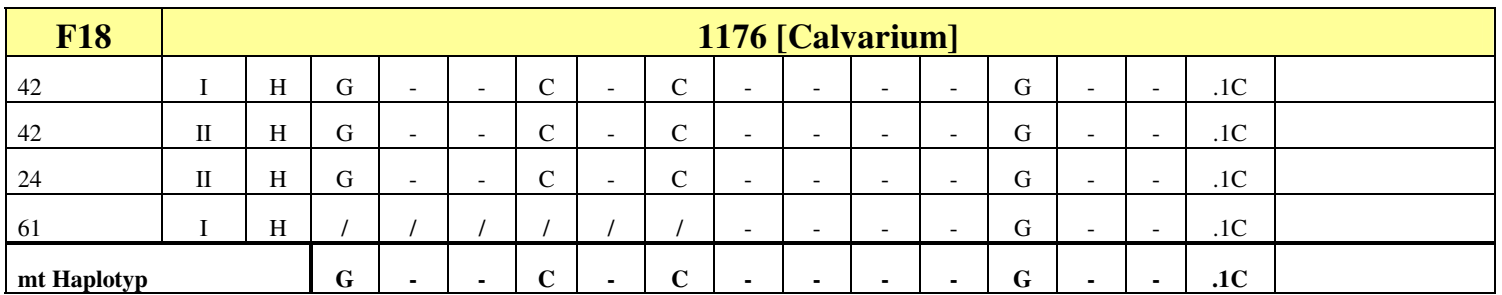

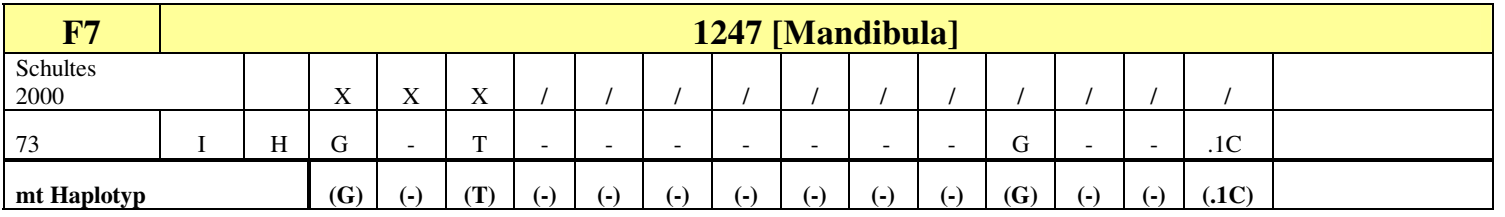

\begin{tabular}{|l|c|c|c|c|c|c|c|c|c|c|c|c|c|c|c|c|c|}
\hline M9 & \multicolumn{10}{c|}{1473 [Calvarium] } \\
\hline 42 & I & H & - & - & - & - & - & - & - & - & - & - & G & - & $.1 \mathrm{C}$ & $.1 \mathrm{C}$ & \\
\hline 63 & II & H & - & - & - & - & - & - & - & - & - & - & G & - & $.1 \mathrm{C}$ & $.1 \mathrm{C}$ & \\
\hline mt Haplotyp & & - & - & - & - & - & - & - & - & - & - & G & - & $.1 \mathrm{C}$ & $.1 \mathrm{C}$ & \\
\hline
\end{tabular}

\begin{tabular}{|c|c|c|c|c|c|c|c|c|c|c|c|c|c|c|c|c|c|}
\hline M3 & \multicolumn{17}{|c|}{1482 [Mandibula] } \\
\hline 24 & I & $\mathrm{H}$ & 1 & 1 & 1 & 1 & 1 & 1 & 1 & I & 1 & 1 & 1 & 1 & 1 & 1 & \\
\hline 42 & I & $\mathrm{H}$ & - & - & - & - & - & - & - & - & - & - & G & - & - & 1 & \\
\hline 42 & I & $\mathrm{H}$ & - & - & - & - & - & - & - & - & - & - & G & - & - & $.1 \mathrm{C}$ & \\
\hline 63 & III A & $\mathrm{H}$ & - & - & - & - & - & - & - & - & - & - & G & - & - & $.1 \mathrm{C}$ & \\
\hline 63 & III A & $\mathrm{L}$ & - & - & - & - & - & - & - & - & - & - & G & - & - & $.1 \mathrm{C}$ & \\
\hline 63 & III B & $\mathrm{H}$ & - & - & - & - & - & - & - & - & - & - & G & - & - & $.1 \mathrm{C}$ & \\
\hline 63 & III B & $\mathrm{L}$ & - & - & - & - & - & - & - & - & - & - & G & - & - & $.1 \mathrm{C}$ & \\
\hline mt Haplots & & & - & - & - & - & - & - & - & - & - & - & G & - & - & $.1 \mathrm{C}$ & \\
\hline
\end{tabular}

\begin{tabular}{|c|c|c|c|c|c|c|c|c|c|c|c|c|c|c|c|c|c|}
\hline M1 & \multicolumn{17}{|c|}{1485 [Calvarium] } \\
\hline 42 & I & $\mathrm{H}$ & - & G & - & $\mathrm{C}$ & - & - & - & 1 & 1 & 1 & 1 & 1 & 1 & 1 & \\
\hline 61 & II & $\mathrm{H}$ & $\mathrm{R}$ & $\mathrm{R}$ & - & $\mathrm{Y}$ & - & - & - & - & - & - & $\mathrm{G}$ & - & - & $.1 \mathrm{C}$ & $153 \mathrm{R}$ \\
\hline 61 & II & $\mathrm{H}$ & $\mathrm{R}$ & (R) & - & $\mathrm{Y}$ & - & - & - & - & - & - & G & - & - & $.1 \mathrm{C}$ & $153 \mathrm{R}$ \\
\hline 63 & I & $\mathrm{H}$ & 1 & 1 & - & $\mathrm{Y}$ & - & - & - & - & - & - & $\mathrm{G}$ & - & - & $.1 \mathrm{C}$ & $153 \mathrm{R}$ \\
\hline 67 & III & $\mathrm{H}$ & G & - & - & - & - & $\mathrm{Y}$ & - & - & - & - & G & - & 1 & 1 & 153G; 198Y \\
\hline 67 & III & $\mathrm{L}$ & $\mathrm{G}$ & - & - & - & - & C & - & - & - & - & $\mathrm{G}$ & - & $.1 \mathrm{C}$ & $.1 \mathrm{C}$ & $\begin{array}{l}\text { 74W; 153G; 154W; } \\
\text { 198T; 225A; }\end{array}$ \\
\hline mt Haplot & & & (G) & - & - & (C) & - & - & - & - & - & - & G & - & - & $.1 \mathrm{C}$ & $(153 G)$ \\
\hline
\end{tabular}

\begin{tabular}{|c|c|c|c|c|c|c|c|c|c|c|c|c|c|c|c|c|c|}
\hline F19 & \multicolumn{17}{|c|}{1585 [Calcaneus li.] } \\
\hline 73 & SKII & $\mathrm{H}$ & 1 & I & 1 & 1 & - & - & - & - & - & - & G & - & $.2 \mathrm{C}$ & $.1 \mathrm{C}$ & \\
\hline 73 & SKII & $\mathrm{H}$ & - & - & - & - & - & - & - & - & - & - & G & - & $.2 \mathrm{C}$ & $.1 \mathrm{C}$ & \\
\hline 83 & SKII & $\mathrm{L}$ & - & - & - & - & - & - & - & - & - & - & G & - & $.2 \mathrm{C}$ & $.1 \mathrm{C}$ & \\
\hline mt Haplot & & & . & - & - & - & - & - & - & - & - & . & G & - & $.2 \mathrm{C}$ & $.1 \mathrm{C}$ & \\
\hline
\end{tabular}

\begin{tabular}{|l|c|c|c|c|c|c|c|c|c|c|c|c|c|c|c|c|c|}
\hline \multicolumn{11}{|c|}{ 1745a [Mandibula] } \\
\hline 44 & II & L & G & - & T & - & - & - & - & - & - & - & G & - & - & $.1 \mathrm{C}$ & \\
\hline 63 & II & H & G & - & - & - & A & - & - & A & - & - & G & T & - & $.1 \mathrm{C}$ & \\
\hline mt Haplotyp & & $/$ & $/$ & $/$ & $/$ & $/$ & $/$ & $/$ & $/$ & $/$ & $/$ & $/$ & $/$ & $/$ & $/$ & \\
\hline
\end{tabular}

Legende: - = keine Abweichung zu CRS, / = Position nicht lesbar, ( ) = unsicherer Sequenzpolymorphismus, $\mathrm{X}=$ Abschnitt nicht sequenziert; $\mathrm{H}=$ heavy chain, $\mathrm{L}=\mathrm{Light}$ chain; bei mehr als einer Base an einer Position wurde der IUB-Code verwendet, $\mathrm{z}$.B. Y 
Fortsetzung Tabelle 34: Ergebnisse der Einzeltypisierungen der HVR II-Analysen.

\begin{tabular}{|c|c|c|c|c|c|c|c|c|c|c|c|c|c|c|c|c|c|}
\hline$\widetilde{\Omega}$ & $\underset{x}{x}$ & 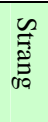 & $\begin{array}{l}\vec{\omega} \\
\nu\end{array}$ & $\begin{array}{l}\infty \\
\infty\end{array}$ & $\begin{array}{l}\bar{u} \\
0 \\
\Omega\end{array}$ & $\underset{\sim}{\vec{N}}$ & $\begin{array}{l}\vec{\infty} \\
u \\
a\end{array}$ & $\begin{array}{l}\vec{\sigma} \\
\stackrel{u}{-1}\end{array}$ & $\underset{D}{\stackrel{N}{v}}$ & $\begin{array}{l}N \\
\infty \\
\infty\end{array}$ & $\begin{array}{l}\underset{\omega}{0} \\
-1\end{array}$ & $\begin{array}{l}\stackrel{N}{N} \\
\stackrel{N}{\Omega}\end{array}$ & $\underset{\sim}{\tilde{\omega}}$ & $\begin{array}{l}N \\
\text { No } \\
r\end{array}$ & $\begin{array}{l}\text { Uి } \\
\text { O } \\
\text { ? }\end{array}$ & $\begin{array}{l}\frac{\omega}{\omega} \\
\Omega\end{array}$ & 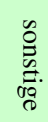 \\
\hline
\end{tabular}

\begin{tabular}{|l|c|c|c|c|c|c|c|c|c|c|c|c|c|c|c|c|c|}
\hline \multicolumn{10}{|c|}{ F3 } \\
\hline 67 & I & H & G & - & - & - & A & - & - & A & - & - & G & T & - & .1C & \\
\hline 83 & I & H & G & - & - & - & A & - & - & A & - & - & G & T & - & $.1 \mathrm{C}$ & \\
\hline 83 & I & L & G & - & - & - & A & - & - & A & - & - & G & T & - & $/$ & \\
\hline mt Haplotyp & & G & - & - & - & A & - & - & A & - & - & G & T & - & .1C & \\
\hline
\end{tabular}

\begin{tabular}{|l|c|c|c|c|c|c|c|c|c|c|c|c|c|c|c|c|c|c|}
\hline F3 & \multicolumn{10}{|c|}{ 1746II [Felsenbein li.] } \\
\hline 73 & II & H & G & - & - & - & A & - & - & A & - & - & G & T & - & .1 C & \\
\hline mt Haplotyp & & (G) & $(-)$ & $(-)$ & $(-)$ & (A) & $(-)$ & $(-)$ & (A) & $(-)$ & $(-)$ & (G) & (T) & (-) & (.1C) & \\
\hline
\end{tabular}

\begin{tabular}{|l|c|c|c|c|c|c|c|c|c|c|c|c|c|c|c|c|c|}
\hline M6 & \multicolumn{10}{|c|}{ 2111 [Mandibula] } \\
\hline 73 & I & H & - & - & - & C & - & - & - & - & - & - & G & - & - & $.1 \mathrm{C}$ & \\
\hline mt Haplotyp & & $(-)$ & $(-)$ & $(-)$ & (C) & $(-)$ & $(-)$ & $(-)$ & $(-)$ & $(-)$ & $(-)$ & (G) & $(-)$ & $(-)$ & $(.1 \mathrm{C})$ & \\
\hline
\end{tabular}

\begin{tabular}{|c|c|c|c|c|c|c|c|c|c|c|c|c|c|c|c|c|c|}
\hline F18 & \multicolumn{17}{|c|}{2133 [Mandibula] } \\
\hline 24 & II & $\mathrm{L}$ & G & - & - & $\mathrm{C}$ & - & $\mathrm{Y}$ & - & - & - & - & G & - & - & $.1 \mathrm{C}$ & 198Y; 275R \\
\hline 63 & II & $\mathrm{H}$ & G & - & - & $\mathrm{Y}$ & - & $\mathrm{Y}$ & - & - & - & - & G & - & - & $.1 \mathrm{C}$ & \\
\hline 63 & III & $\mathrm{H}$ & G & - & - & $\mathrm{C}$ & - & $\mathrm{C}$ & - & - & - & - & G & - & - & $.1 \mathrm{C}$ & \\
\hline 67 & III & $\mathrm{H}$ & $\mathrm{G}$ & - & - & $\mathrm{C}$ & - & $\mathrm{C}$ & - & - & - & - & G & - & - & $.1 \mathrm{C}$ & \\
\hline mt Haplot & & & G & - & - & C & - & C & - & - & - & . & G & - & - & $.1 \mathrm{C}$ & \\
\hline
\end{tabular}

\begin{tabular}{|c|c|c|c|c|c|c|c|c|c|c|c|c|c|c|c|c|c|}
\hline M15 & \multicolumn{17}{|c|}{2263 [Mandibula] } \\
\hline 24 & II & $\mathrm{L}$ & $\mathrm{G}$ & - & - & - & $\mathrm{A}$ & - & - & $\mathrm{A}$ & - & - & $\mathrm{G}$ & $\mathrm{T}$ & - & $.1 \mathrm{C}$ & $180 \mathrm{Y}$ \\
\hline 24 & II & $\mathrm{H}$ & $\mathrm{G}$ & - & - & - & $\mathrm{A}$ & - & - & $\mathrm{A}$ & - & - & G & $\mathrm{T}$ & - & $.1 \mathrm{C}$ & \\
\hline 63 & $\mathrm{I}$ & $\mathrm{H}$ & G & - & - & - & $\mathrm{A}$ & - & - & $\mathrm{A}$ & - & - & G & $\mathrm{T}$ & - & $.1 \mathrm{C}$ & \\
\hline 63 & II & $\mathrm{H}$ & $\mathrm{G}$ & - & - & - & M & - & - & $\mathrm{A}$ & - & - & G & $\mathrm{T}$ & - & $.1 \mathrm{C}$ & \\
\hline 67 & I & $\mathrm{H}$ & $\mathrm{G}$ & - & - & - & $\mathrm{A}$ & - & - & $\mathrm{A}$ & - & - & $\mathrm{G}$ & $\mathrm{T}$ & - & $.1 \mathrm{C}$ & \\
\hline mt Haploty & & & G & - & - & - & $\mathbf{A}$ & - & - & $\mathbf{A}$ & - & - & G & $\mathbf{T}$ & - & $.1 \mathrm{C}$ & \\
\hline
\end{tabular}

\begin{tabular}{|l|c|c|c|c|c|c|c|c|c|c|c|c|c|c|c|c|c|}
\hline F15 & \multicolumn{10}{c|}{ 2589 [Mandibula] } \\
\hline 24 & I & L & G & - & - & C & - & - & C & - & - & - & G & - & / & / & \\
\hline 63 & I & H & G & - & - & C & R & - & C & - & - & - & G & - & $.2 \mathrm{C}$ & $.1 \mathrm{C}$ & \\
\hline 63 & II & H & G & - & - & C & - & - & C & - & - & - & G & - & $.2 \mathrm{C}$ & $.1 \mathrm{C}$ & \\
\hline 67 & II & H & G & - & - & C & - & - & C & - & - & - & G & - & $.2 \mathrm{C}$ & $.1 \mathrm{C}$ & \\
\hline mt Haplotyp & & & G & & &
\end{tabular}

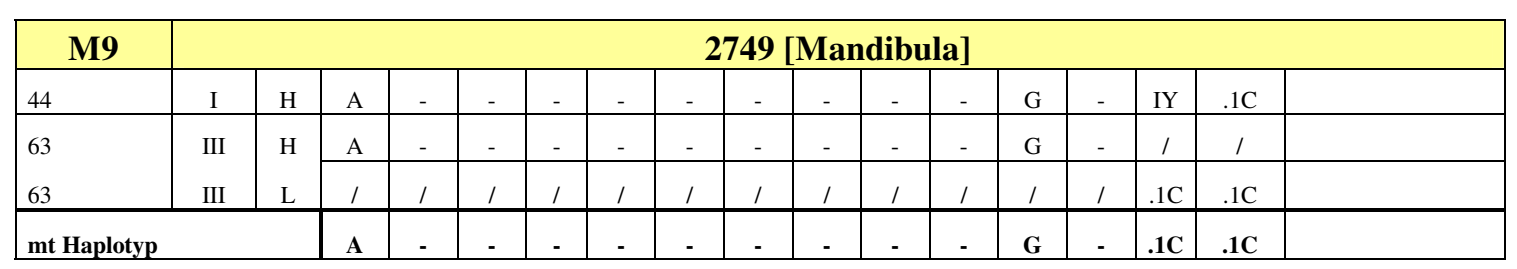

Legende: - = keine Abweichung zu CRS, / = Position nicht lesbar, $($ ) = unsicherer Sequenzpolymorphismus, $\mathrm{X}=\mathrm{Abschnitt} \mathrm{nicht} \mathrm{sequenziert;} \mathrm{H}=$ heavy chain, $\mathrm{L}=$ Light chain; bei mehr als einer Base an einer Position wurde der IUB-Code verwendet, z.B. Y 
Anhang : Tabellen mt-Typisierungen

Fortsetzung Tabelle 34: Ergebnisse der Einzeltypisierungen der HVR II-Analysen.

\begin{tabular}{|c|c|c|c|c|c|c|c|c|c|c|c|c|c|c|c|c|c|}
\hline$\widetilde{O}$ & $\stackrel{\pi}{x}$ & 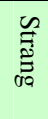 & $\begin{array}{l}\vec{\omega} \\
>\end{array}$ & $\begin{array}{l}\omega \\
\supset\end{array}$ & $\begin{array}{l}\vec{H} \\
0 \\
\Omega\end{array}$ & $\begin{array}{l}\overrightarrow{\breve{M}} \\
\stackrel{-1}{ }\end{array}$ & $\begin{array}{l}\vec{\infty} \\
\stackrel{a}{a}\end{array}$ & $\begin{array}{l}\overrightarrow{0} \\
u \\
\rightarrow\end{array}$ & $\underset{D}{\stackrel{N}{V}}$ & $\begin{array}{l}\mathbb{N} \\
\infty \\
0\end{array}$ & 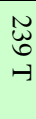 & $\begin{array}{l}\frac{N}{N} \\
\Omega \\
\Omega\end{array}$ & $\underset{\sim}{\tilde{\omega}}$ & $\begin{array}{l}\tilde{S} \\
u \\
\Omega\end{array}$ & $\begin{array}{l}\tilde{0} \\
0 \\
\Omega\end{array}$ & $\begin{array}{l}\omega \\
\tilde{\omega} \\
\Omega\end{array}$ & 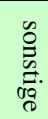 \\
\hline
\end{tabular}

\begin{tabular}{|c|c|c|c|c|c|c|c|c|c|c|c|c|c|c|c|c|c|}
\hline F20 & \multicolumn{17}{|c|}{3190 [Mandibula] } \\
\hline 42 & I & $\mathrm{H}$ & A & - & - & - & - & - & - & - & - & - & G & - & - & $.1 \mathrm{C}$ & $60 \mathrm{D} ; 71.1 \mathrm{G}$ \\
\hline 63 & II & $\mathrm{H}$ & A & - & - & - & - & - & - & - & - & - & G & - & - & $.1 \mathrm{C}$ & $76 \mathrm{~T}$ \\
\hline 67 & I & $\mathrm{H}$ & A & - & - & - & - & - & - & - & - & - & G & - & - & $.1 \mathrm{C}$ & \\
\hline mt Haplot & & & $\mathbf{A}$ & - & - & - & - & - & - & - & - & - & G & - & - & $.1 \mathrm{C}$ & \\
\hline
\end{tabular}

\begin{tabular}{|c|c|c|c|c|c|c|c|c|c|c|c|c|c|c|c|c|c|}
\hline M5 & \multicolumn{17}{|c|}{3380 [Mandibula] } \\
\hline 42 & I & $\mathrm{H}$ & 1 & - & - & - & - & - & - & - & - & - & G & - & - & $.1 \mathrm{C}$ & $305(\mathrm{~T})$ \\
\hline 63 & II & $\mathrm{H}$ & 1 & - & - & - & - & - & - & 1 & 1 & 1 & 1 & 1 & 1 & 1 & \\
\hline 63 & II & $\mathrm{L}$ & - & - & - & - & - & - & - & - & - & - & G & - & - & $.1 \mathrm{C}$ & \\
\hline mt Haplot & & & - & - & - & - & . & - & - & - & - & . & G & - & - & $.1 \mathrm{C}$ & \\
\hline
\end{tabular}

\begin{tabular}{|c|c|c|c|c|c|c|c|c|c|c|c|c|c|c|c|c|c|}
\hline F8 & \multicolumn{17}{|c|}{3631 [Calvarium] } \\
\hline 24 & I & $\mathrm{L}$ & 1 & 1 & 1 & 1 & 1 & 1 & 1 & 1 & I & 1 & 1 & 1 & 1 & 1 & \\
\hline 44 & II & $\mathrm{H}$ & G & - & - & - & A & - & - & A & - & - & G & $\mathrm{T}$ & - & $.1 \mathrm{C}$ & \\
\hline 61 & III & $\mathrm{H}$ & 1 & I & 1 & 1 & 1 & 1 & - & - & - & - & G & - & - & $.1 \mathrm{C}$ & \\
\hline 61 & III & $\mathrm{H}$ & G & - & $\mathrm{T}$ & - & - & - & - & - & - & - & G & - & - & $.1 \mathrm{C}$ & $111 \mathrm{~W}$ \\
\hline 61 & Z1:6 & $\mathrm{H}$ & G & - & $\mathrm{T}$ & - & - & - & - & - & - & - & G & - & - & $.1 \mathrm{C}$ & \\
\hline 63 & $\mathrm{Z1}: 6$ & $\mathrm{H}$ & G & - & $\mathrm{T}$ & - & - & - & - & - & - & - & G & - & - & $.1 \mathrm{C}$ & \\
\hline 63 & II & $\mathrm{H}$ & 1 & I & 1 & 1 & 1 & 1 & 1 & I & 1 & 1 & 1 & 1 & 1 & 1 & \\
\hline 63 & II & $\mathrm{L}$ & G & - & $\mathrm{T}$ & - & - & - & - & - & - & - & G & - & - & $.1 \mathrm{C}$ & $283.1 \mathrm{C}$ \\
\hline 67 & III & $\mathrm{H}$ & $\mathrm{G}$ & - & $\mathrm{T}$ & - & - & - & - & - & - & - & G & - & - & $.1 \mathrm{C}$ & \\
\hline mt Haplo & & & G & - & $\mathrm{T}$ & - & - & - & - & - & - & - & G & - & - & $.1 \mathrm{C}$ & \\
\hline
\end{tabular}

\begin{tabular}{|l|c|c|c|c|c|c|c|c|c|c|c|c|c|c|c|c|c|}
\hline M2 & \multicolumn{10}{c|}{ 3644 [Mandibula] } \\
\hline 24 & I & L & $/$ & - & - & C & - & - & - & - & - & - & G & - & - & .1C & \\
\hline 63 & I & H & - & - & - & (T) & - & - & - & - & - & - & G & - & - & $.1 \mathrm{C}$ & \\
\hline 67 & II & H & - & - & - & C & - & - & - & - & - & - & G & - & - & $.1 \mathrm{C}$ & \\
\hline \multicolumn{2}{l}{ mt Haplotyp } & & - & - & - & C & - & - & - & - & - & - & G & - & - & $.1 \mathrm{C}$ & \\
\hline
\end{tabular}

\begin{tabular}{|c|c|c|c|c|c|c|c|c|c|c|c|c|c|c|c|c|c|}
\hline F9 & \multicolumn{17}{|c|}{3705 [Calvarium] } \\
\hline 24 & I & $\mathrm{L}$ & G & - & $\mathrm{T}$ & - & - & - & - & - & - & - & G & - & - & 1 & $90 \mathrm{~K} ; 154(\mathrm{~K})$ \\
\hline 24 & II & $\mathrm{L}$ & G & - & $\mathrm{T}$ & - & - & - & - & - & - & - & G & - & - & $.1 \mathrm{C}$ & \\
\hline mt Haplo & & & G & - & $\mathbf{T}$ & - & - & - & - & - & - & - & G & - & - & (.1C) & \\
\hline
\end{tabular}

\begin{tabular}{|c|c|c|c|c|c|c|c|c|c|c|c|c|c|c|c|c|c|}
\hline F5 & \multicolumn{17}{|c|}{3706 [Calvarium] } \\
\hline 44 & I & $\mathrm{L}$ & G & - & - & - & - & - & - & - & - & - & G & - & - & $.1 \mathrm{C}$ & \\
\hline 61 & II & $\mathrm{H}$ & G & - & - & - & - & - & - & - & - & - & G & - & - & $.1 \mathrm{C}$ & \\
\hline 63 & III A & $\mathrm{H}$ & 1 & 1 & - & - & - & - & - & - & - & - & G & - & - & $.1 \mathrm{C}$ & \\
\hline 63 & III B & $\mathrm{H}$ & G & - & - & - & - & - & - & - & - & - & G & - & - & $.1 \mathrm{C}$ & \\
\hline mt Haplo & & & G & - & - & - & - & - & - & - & - & - & G & - & - & $.1 \mathrm{C}$ & \\
\hline
\end{tabular}

\begin{tabular}{|l|c|c|c|c|c|c|c|c|c|c|c|c|c|c|c|c|c|}
\hline \multicolumn{1}{|c|}{ F6 } & \multicolumn{10}{c|}{ 3709 [Mandibula] } \\
\hline 42 & I & H & G & - & - & - & - & - & - & - & - & - & G & - & - & $.1 \mathrm{C}$ & \\
\hline 24 & I & H & G & - & - & - & - & - & - & - & - & - & G & - & - & $.1 \mathrm{C}$ & \\
\hline \multicolumn{2}{|l}{ mt Haplotyp } & & G & - & - & - & - & - & - & - & - & - & G & - & - & $.1 \mathrm{C}$ & \\
\hline
\end{tabular}

Legende: - = keine Abweichung zu CRS, / = Position nicht lesbar, $($ ) = unsicherer Sequenzpolymorphismus, $\mathrm{X}=$ Abschnitt nicht sequenziert; $\mathrm{H}=$ heavy chain, $\mathrm{L}=$ Light chain; bei mehr als einer Base an einer Position wurde der IUB-Code verwendet, $\mathrm{z} . \mathrm{B}$. Y 
Fortsetzung Tabelle 34: Ergebnisse der Einzeltypisierungen der HVR II-Analysen.

\begin{tabular}{|c|c|c|c|c|c|c|c|c|c|c|c|c|c|c|c|c|c|}
\hline$\widetilde{\Omega}$ & $\stackrel{\mathbb{1}}{x}$ & 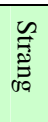 & $\begin{array}{l}\vec{\omega} \\
\nu\end{array}$ & $\begin{array}{l}\infty \\
\infty\end{array}$ & $\begin{array}{l}\vec{u} \\
0 \\
\Omega\end{array}$ & 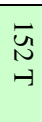 & $\begin{array}{l}\vec{\infty} \\
u \\
a\end{array}$ & $\begin{array}{l}\vec{\sigma} \\
\stackrel{u}{-1}\end{array}$ & $\frac{N}{\sim}$ & $\begin{array}{l}N \\
N \\
\infty \\
\Omega\end{array}$ & $\begin{array}{l}\underset{W}{\tilde{D}} \\
-1\end{array}$ & $\begin{array}{l}\frac{N}{N} \\
\stackrel{+}{N}\end{array}$ & 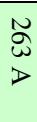 & 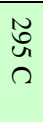 & $\begin{array}{l}\text { w } \\
\text { O } \\
\text { r }\end{array}$ & $\begin{array}{l}\tilde{\omega} \\
\tilde{u}\end{array}$ & 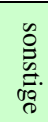 \\
\hline
\end{tabular}

\begin{tabular}{|c|c|c|c|c|c|c|c|c|c|c|c|c|c|c|c|c|c|}
\hline F11 & \multicolumn{17}{|c|}{3713 [Mandibula] } \\
\hline 44 & I & $\mathrm{L}$ & A & - & - & - & - & - & - & - & - & - & G & - & - & $.1 \mathrm{C}$ & 291 IT \\
\hline 44 & II & $\mathrm{L}$ & A & - & - & - & - & - & - & - & - & - & G & - & 1 & 1 & $\begin{array}{l}\text { 114N; 145N; 167Y; } \\
\text { 291IT }\end{array}$ \\
\hline 63 & I & $\mathrm{H}$ & 1 & 1 & 1 & 1 & 1 & 1 & 1 & 1 & 1 & 1 & 1 & 1 & 1 & 1 & \\
\hline 63 & I & $\mathrm{L}$ & G & - & - & $\mathrm{C}$ & - & $\mathrm{C}$ & - & - & - & - & G & - & - & $.1 \mathrm{C}$ & $74 \mathrm{~W}$ \\
\hline mt Haplot & & & 1 & 1 & I & 1 & 1 & 1 & 1 & 1 & 1 & 1 & 1 & 1 & I & I & \\
\hline
\end{tabular}

\begin{tabular}{|l|c|c|c|c|c|c|c|c|c|c|c|c|c|c|c|c|c|}
\hline F9 & \multicolumn{10}{|c|}{3746 [Mandibula] } \\
\hline 24 & I & L & G & G & T & - & - & - & - & - & - & - & G & - & - & $.1 \mathrm{C}$ & \\
\hline 61 & III & H & G & - & T & - & - & - & - & - & - & - & G & - & - & $.1 \mathrm{C}$ & \\
\hline mt Haplotyp & & G & - & T & - & - & - & - & - & - & - & G & - & - & $.1 \mathrm{C}$ & \\
\hline
\end{tabular}

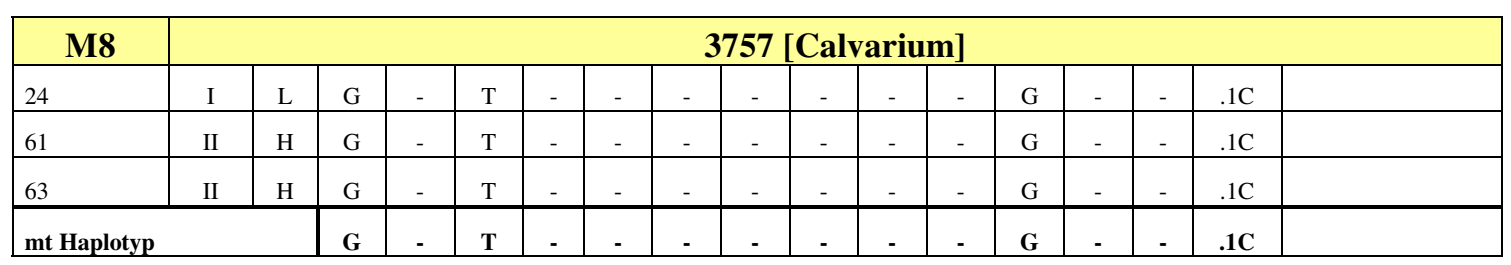

\begin{tabular}{|c|c|c|c|c|c|c|c|c|c|c|c|c|c|c|c|c|c|}
\hline M16 & \multicolumn{17}{|c|}{3886 [Felsenbein li.] } \\
\hline 67 & I & $\mathrm{H}$ & G & - & $\mathrm{T}$ & - & - & - & - & - & - & - & $\mathrm{G}$ & - & - & $.1 \mathrm{C}$ & \\
\hline 67 & II & $\mathrm{H}$ & G & - & $\mathrm{T}$ & - & - & - & - & - & - & - & G & - & - & $.1 \mathrm{C}$ & \\
\hline 73 & I & $\mathrm{H}$ & $\mathrm{G}$ & - & $\mathrm{T}$ & - & - & - & - & - & - & - & G & - & - & $.1 \mathrm{C}$ & \\
\hline 73 & II & $\mathrm{H}$ & $\mathrm{G}$ & - & $\mathrm{T}$ & - & - & - & - & - & - & - & $\mathrm{G}$ & - & - & $.1 \mathrm{C}$ & \\
\hline mt Haploty & & & G & - & $\mathbf{T}$ & - & - & - & - & - & - & - & G & - & - & $.1 \mathrm{C}$ & \\
\hline
\end{tabular}

\begin{tabular}{|c|c|c|c|c|c|c|c|c|c|c|c|c|c|c|c|c|c|}
\hline & \multicolumn{17}{|c|}{3889 [Mandibula] } \\
\hline 24 & II & $\mathrm{L}$ & G & - & $\mathrm{T}$ & - & A & - & - & A & - & - & 1 & 1 & 1 & 1 & $151 \mathrm{~T}$ \\
\hline 63 & I & $\mathrm{H}$ & $\mathrm{G}$ & - & - & - & $\mathrm{M}$ & - & - & A & - & - & G & $\mathrm{T}$ & - & $.1 \mathrm{C}$ & \\
\hline 67 & I & $\mathrm{H}$ & 1 & - & - & - & A & - & - & A & - & - & G & $\mathrm{T}$ & 1 & 1 & $85.1 \mathrm{C} ; 194 \mathrm{Y} ; 299 \mathrm{Y}$ \\
\hline & & & G & - & - & - & $\mathbf{A}$ & - & - & $\mathbf{A}$ & - & - & G & $\mathbf{T}$ & l & I & \\
\hline
\end{tabular}

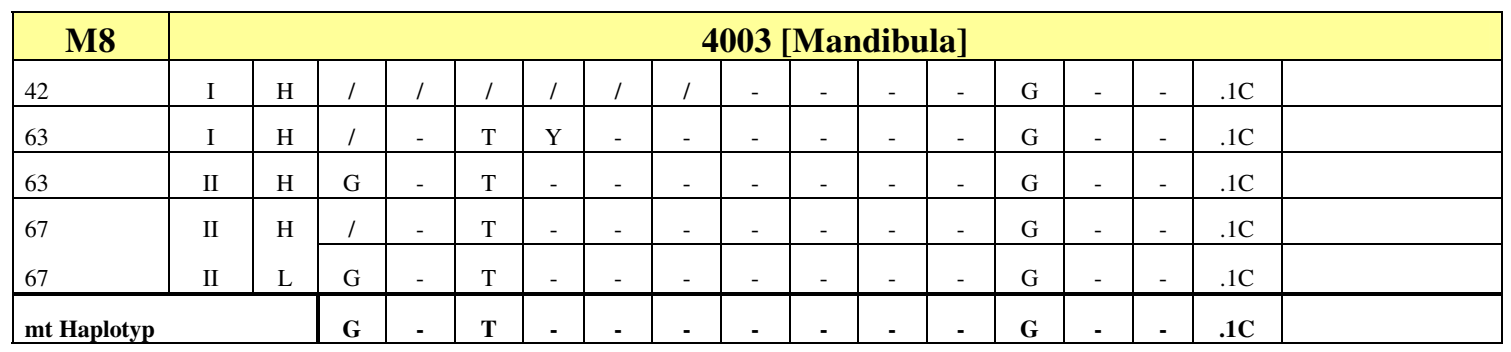

\begin{tabular}{|l|c|c|c|c|c|c|c|c|c|c|c|c|c|c|c|c|c|}
\hline F4 & \multicolumn{10}{|c|}{ 4078 [Mandibula] } \\
\hline 42 & I & H & $/$ & $/$ & $/$ & $/$ & - & - & - & - & - & - & G & - & - & $.1 \mathrm{C}$ & \\
\hline 63 & II & H & G & - & T & - & - & - & - & - & - & - & G & - & - & $.1 \mathrm{C}$ & \\
\hline mt Haplotyp & & (G) & - & (T) & - & - & - & - & - & - & - & G & - & - & .1C & \\
\hline
\end{tabular}

Legende: - = keine Abweichung zu CRS, / = Position nicht lesbar, $($ ) = unsicherer Sequenzpolymorphismus, $\mathrm{X}=$ Abschnitt nicht sequenziert; $\mathrm{H}=$ heavy chain, $\mathrm{L}=$ Light chain; bei mehr als einer Base an einer Position wurde der IUB-Code verwendet, $z . B$. Y 
Fortsetzung Tabelle 34: Ergebnisse der Einzeltypisierungen der HVR II-Analysen.

\begin{tabular}{|c|c|c|c|c|c|c|c|c|c|c|c|c|c|c|c|c|c|}
\hline$\widetilde{\widetilde{D}}$ & $\stackrel{\pi}{x}$ & 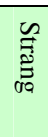 & $\begin{array}{l}\omega \\
\nu\end{array}$ & $\begin{array}{l}\varpi \\
>\end{array}$ & $\begin{array}{l}\vec{u} \\
\text { م }\end{array}$ & $\begin{array}{l}\bar{M} \\
\stackrel{N}{H}\end{array}$ & $\begin{array}{l}\vec{\infty} \\
\stackrel{a}{a}\end{array}$ & $\begin{array}{l}\overrightarrow{0} \\
\underset{-1}{1}\end{array}$ & $\begin{array}{l}\stackrel{N}{v} \\
>\end{array}$ & $\begin{array}{l}N \\
N \\
\infty \\
\Omega\end{array}$ & $\begin{array}{l}\underset{W}{\tilde{D}} \\
-1\end{array}$ & $\begin{array}{l}\frac{N}{N} \\
\text { n }\end{array}$ & $\begin{array}{l}\tilde{\omega} \\
>\end{array}$ & $\begin{array}{l}\tilde{U} \\
u \\
\Omega\end{array}$ & $\begin{array}{l}\text { U్ర } \\
\text { ? }\end{array}$ & $\underset{\tilde{u}}{\tilde{\omega}}$ & 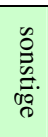 \\
\hline
\end{tabular}

\begin{tabular}{|c|c|c|c|c|c|c|c|c|c|c|c|c|c|c|c|c|c|}
\hline F14 & \multicolumn{17}{|c|}{4309 [Mandibula] } \\
\hline 24 & I & $\mathrm{L}$ & G & - & - & - & - & - & - & - & - & $\mathrm{T}$ & G & $\mathrm{T}$ & - & $.1 \mathrm{C}$ & \\
\hline 63 & I & $\mathrm{H}$ & G & - & - & - & - & - & - & - & - & $\mathrm{T}$ & G & $\mathrm{T}$ & - & $.1 \mathrm{C}$ & \\
\hline 63 & II & $\mathrm{H}$ & 1 & 1 & 1 & 1 & 1 & 1 & - & - & - & $\mathrm{T}$ & $\mathrm{G}$ & $\mathrm{T}$ & - & $.1 \mathrm{C}$ & \\
\hline 63 & II & $\mathrm{L}$ & $\mathrm{G}$ & - & - & - & - & - & - & - & - & $\mathrm{T}$ & 1 & 1 & 1 & 1 & \\
\hline 67 & II & $\mathrm{H}$ & G & - & - & - & - & - & - & - & - & $\mathrm{T}$ & $\mathrm{G}$ & $\mathrm{T}$ & - & $.1 \mathrm{C}$ & $287 \mathrm{~N} ; 288 \mathrm{~N}$ \\
\hline mt Haploty & & & G & - & - & - & - & - & - & - & - & $\mathbf{T}$ & G & $\mathbf{T}$ & - & $.1 \mathrm{C}$ & \\
\hline
\end{tabular}

\begin{tabular}{|c|c|c|c|c|c|c|c|c|c|c|c|c|c|c|c|c|c|}
\hline F4 & \multicolumn{17}{|c|}{5516 [Calvarium] } \\
\hline 24 & I & $\mathrm{L}$ & G & - & $\mathrm{T}$ & - & - & - & - & - & - & - & G & 1 & 1 & 1 & $81 \mathrm{~A}$ \\
\hline 44 & II & $\mathrm{H}$ & G & - & $\mathrm{T}$ & - & - & - & - & - & - & - & G & - & - & $.1 \mathrm{C}$ & \\
\hline 61 & I & $\mathrm{H}$ & G & - & $\mathrm{T}$ & - & - & - & - & - & - & - & $\mathrm{G}$ & - & - & $.1 \mathrm{C}$ & \\
\hline mt Haplo & & & G & - & $T$ & - & - & - & - & - & - & - & G & - & - & $.1 \mathrm{C}$ & \\
\hline
\end{tabular}

\begin{tabular}{|l|c|c|c|c|c|c|c|c|c|c|c|c|c|c|c|c|c|}
\hline F6 & \multicolumn{10}{c|}{ 5517 [Calvarium] } \\
\hline 24 & I & L & R & - & - & - & - & - & - & - & - & - & G & - & - & $.1 \mathrm{C}$ & \\
\hline 61 & II & H & G & - & - & - & - & - & - & - & - & - & G & - & - & $.1 \mathrm{C}$ & \\
\hline mt Haplotyp & & G & - & - & - & - & - & - & - & - & - & G & - & - & $.1 \mathrm{C}$ & \\
\hline
\end{tabular}

\begin{tabular}{|l|c|c|c|c|c|c|c|c|c|c|c|c|c|c|c|c|c|}
\hline M3 & \multicolumn{10}{|c|}{6525 [Calvarium] } \\
\hline 67 & I & H & - & - & - & - & - & - & - & - & - & - & G & - & $.1 \mathrm{C}$ & $.1 \mathrm{C}$ & \\
\hline 73 & II & H & - & - & - & - & - & - & - & - & - & - & G & - & $.1 \mathrm{C}$ & $.1 \mathrm{C}$ & \\
\hline 83 & II & H & - & - & - & - & - & - & - & - & - & - & G & - & $.1 \mathrm{C}$ & $.1 \mathrm{C}$ & \\
\hline \multicolumn{2}{l|}{ mt Haplotyp } & & - & - & - & - & - & - & - & - & - & - & G & - & $.1 \mathrm{C}$ & $.1 \mathrm{C}$ & \\
\hline
\end{tabular}

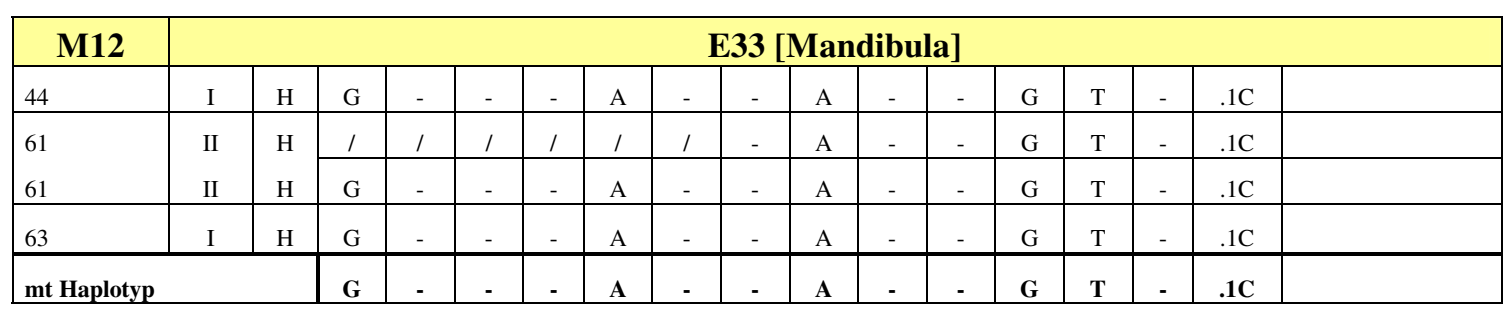

\begin{tabular}{|l|c|c|c|c|c|c|c|c|c|c|c|c|c|c|c|c|c|}
\hline F21 & \multicolumn{10}{c|}{ E37 [Mandibula] } \\
\hline 24 & I & H & - & - & - & - & - & - & - & - & - & - & G & - & - & .1C & \\
\hline 44 & I & L & - & - & - & - & - & - & - & - & - & - & G & - & - & .1C & 137M \\
\hline 63 & II & H & - & - & - & - & - & - & - & - & - & - & G & - & - & $.1 \mathrm{C}$ & \\
\hline 67 & II & H & - & - & - & - & - & - & - & - & - & - & G & - & - & $.1 \mathrm{C}$ & $317 \mathrm{~N}$ \\
\hline
\end{tabular}

Legende: - = keine Abweichung zu CRS, / = Position nicht lesbar, $(\mathrm{l})=$ unsicherer Sequenzpolymorphismus, $\mathrm{X}=\mathrm{Abschnitt}$ nicht sequenziert; $\mathrm{H}=$ heavy chain, $\mathrm{L}=$ Light chain; bei mehr als einer Base an einer Position wurde der IUB-Code verwendet, $\mathrm{z} . \mathrm{B}$. Y 
Fortsetzung Tabelle 34: Ergebnisse der Einzeltypisierungen der HVR II-Analysen.

\begin{tabular}{|c|c|c|c|c|c|c|c|c|c|c|c|c|c|c|c|c|c|}
\hline$\widetilde{\overparen{D}}$ & $\stackrel{\pi}{x}$ & 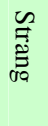 & $\begin{array}{l}\vec{\omega} \\
>\end{array}$ & $\underset{\nu}{\infty}$ & 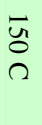 & $\begin{array}{l}\vec{心} \\
\stackrel{N}{-1}\end{array}$ & $\begin{array}{l}\vec{\infty} \\
u \\
\Omega\end{array}$ & $\begin{array}{l}\overrightarrow{0} \\
u \\
\rightarrow\end{array}$ & $\begin{array}{l}\stackrel{N}{\sim} \\
>\end{array}$ & $\begin{array}{l}N \\
N \\
\Omega \\
\Omega\end{array}$ & $\begin{array}{l}\underset{\omega}{\omega} \\
-1\end{array}$ & $\begin{array}{l}\text { N } \\
\stackrel{A}{N} \\
\Omega\end{array}$ & $\begin{array}{l}\tilde{\omega} \\
>\end{array}$ & $\begin{array}{l}\text { No } \\
u \\
r\end{array}$ & $\begin{array}{l}\tilde{\omega} \\
\text { ठ } \\
\text { ? }\end{array}$ & $\begin{array}{l}\tilde{\omega} \\
\tilde{u}\end{array}$ & 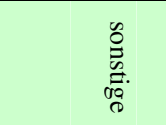 \\
\hline & \multicolumn{17}{|c|}{ N969 [Mandibula] } \\
\hline 44 & I & $\mathrm{H}$ & - & - & - & - & - & - & - & - & - & - & $\mathrm{G}$ & - & 1 & 1 & \\
\hline 44 & II & $\mathrm{H}$ & G & - & - & - & - & - & - & - & - & - & $\mathrm{G}$ & - & - & $.1 \mathrm{C}$ & $114 \mathrm{~N} ; 115 \mathrm{~N}$ \\
\hline 61 & II & $\mathrm{H}$ & - & - & - & - & - & - & - & - & - & - & $\mathrm{G}$ & - & 1 & 1 & \\
\hline 67 & I & \multirow{4}{*}{$\begin{array}{l}\mathrm{H} \\
\mathrm{L} \\
\mathrm{H} \\
\end{array}$} & 1 & 1 & - & - & - & - & - & - & - & - & $\mathrm{G}$ & - & - & $.1 \mathrm{C}$ & $205.1 \mathrm{~A} ; 207.1 \mathrm{~A}$ \\
\hline 67 & $\mathrm{I}$ & & G & - & - & - & - & - & - & - & - & - & G & - & - & $.1 \mathrm{C}$ & \\
\hline 73 & III & & $\mathrm{G}$ & - & - & $\mathrm{Y}$ & - & $\mathrm{Y}$ & - & - & - & - & $\mathrm{G}$ & - & - & $.1 \mathrm{C}$ & \\
\hline mt Haplc & & & G & - & - & - & - & - & - & - & - & - & G & - & - & $.1 \mathrm{C}$ & \\
\hline
\end{tabular}

\begin{tabular}{|c|c|c|c|c|c|c|c|c|c|c|c|c|c|c|c|c|c|}
\hline F12 & \multicolumn{17}{|c|}{ R1 [Calvarium] } \\
\hline Schultes 2000 & & & $\mathrm{x}$ & $\mathrm{x}$ & $\mathrm{x}$ & 1 & 1 & 1 & 1 & I & 1 & 1 & 1 & 1 & I & l & \\
\hline 24 & $\mathrm{I}$ & $\mathrm{L}$ & - & - & - & - & - & - & - & - & - & - & $\mathrm{G}$ & - & 1 & 1 & \\
\hline 24 & I & $\mathrm{L}$ & - & - & - & - & - & - & - & - & - & - & $\mathrm{G}$ & - & - & $.1 \mathrm{C}$ & \\
\hline 42 & I & $\mathrm{H}$ & 1 & 1 & 1 & 1 & 1 & - & - & - & - & - & G & - & - & $.1 \mathrm{C}$ & \\
\hline 73 & II & $\mathrm{H}$ & - & - & - & - & - & - & - & - & - & - & G & - & - & $.1 \mathrm{C}$ & \\
\hline 83 & II & $\mathrm{H}$ & - & - & - & - & - & - & - & - & - & - & G & - & - & $.1 \mathrm{C}$ & \\
\hline 83 & II & $\mathrm{L}$ & - & - & - & - & - & - & - & - & - & - & G & - & - & 1 & \\
\hline mt Haplotyp & & & . & - & - & - & - & - & - & - & - & - & G & - & - & $.1 \mathrm{C}$ & \\
\hline
\end{tabular}

\begin{tabular}{|c|c|c|c|c|c|c|c|c|c|c|c|c|c|c|c|c|c|}
\hline F16 & \multicolumn{17}{|c|}{ R2 [Calvarium] } \\
\hline 63 & III & $\mathrm{H}$ & G & - & - & - & - & $\mathrm{C}$ & - & - & - & - & G & - & $.2 \mathrm{C}$ & $.1 \mathrm{C}$ & \\
\hline 63 & IVa & $\mathrm{H}$ & G & - & - & - & - & - & - & - & - & - & G & - & $.1 \mathrm{C}$ & $.1 \mathrm{C}$ & \\
\hline 67 & III & $\mathrm{H}$ & G & - & - & - & - & $\mathrm{C}$ & - & - & - & - & G & - & $.2 \mathrm{C}$ & $.1 \mathrm{C}$ & $63.1 \mathrm{C}$ \\
\hline 67 & IVa & $\mathrm{H}$ & G & - & - & Y & - & $\mathrm{Y}$ & - & - & - & - & G & - & 1 & 1 & $63.1 \mathrm{C}$ \\
\hline mt Haplot & & & G & - & - & - & - & C & - & - & - & - & G & - & $.2 \mathrm{C}$ & $.1 \mathrm{C}$ & \\
\hline
\end{tabular}

\begin{tabular}{|l|c|c|c|c|c|c|c|c|c|c|c|c|c|c|c|c|c|}
\hline \multicolumn{1}{|c|}{ M6 } & \multicolumn{10}{c|}{ R3 [Calvarium] } \\
\hline 44 & II & H & $/$ & / & - & Y & - & - & - & - & - & - & G & - & - & $.1 \mathrm{C}$ & \\
\hline 24 & I & L & - & - & - & C & - & - & - & - & - & - & G & - & / & / & \\
\hline 24 & I & H & $/$ & - & - & C & - & - & - & - & - & - & G & - & - & $.1 \mathrm{C}$ & \\
\hline 44 & II & L & - & - & - & C & - & - & - & - & - & - & G & - & - & $.1 \mathrm{C}$ & \\
\hline mt Haplotyp & & - & - & - & C & - & - & - & - & - & - & G & - & - & $.1 \mathrm{C}$ & \\
\hline
\end{tabular}

\begin{tabular}{|l|l|l|l|l|l|l|l|l|l|l|l|l|l|l|l|l|}
\hline & \multicolumn{10}{c|}{ PK FS } \\
\hline mt Haplotyp & & - & - & - & - & - & - & - & - & - & - & G & - & - & $.1 \mathrm{C}$ & \\
\hline
\end{tabular}

Legende: - = keine Abweichung zu CRS, / = Position nicht lesbar, ( ) = unsicherer Sequenzpolymorphismus, $\mathrm{X}=$ Abschnitt nicht sequenziert; $\mathrm{H}=$ heavy chain, $\mathrm{L}=$ Light chain; bei mehr als einer Base an einer Position wurde der IUB-Code verwendet, $\mathrm{z} . \mathrm{B} . \mathrm{Y}$ 


\subsubsection{Y-chromosomale Typisierungsergebnisse}

Tabelle 35: Zusammenstellung der Gesamt-Y-Haplotypen der männlichen Individuen.

\begin{tabular}{|c|c|c|c|c|c|c|c|c|c|c|c|c|c|}
\hline No & $\begin{array}{l}\text { Fundnummer und } \\
\text { Skelettelement }\end{array}$ & $\begin{array}{c}\text { DYS } \\
391\end{array}$ & $\begin{array}{l}\text { DYS } \\
\text { 389I }\end{array}$ & $\begin{array}{c}\text { DYS } \\
439\end{array}$ & $\begin{array}{c}\text { DYS } \\
\text { 389II }\end{array}$ & $\begin{array}{c}\text { DYS } \\
438\end{array}$ & $\begin{array}{c}\text { DYS } \\
437\end{array}$ & $\begin{array}{c}\text { DYS } \\
19\end{array}$ & $\begin{array}{c}\text { DYS } \\
392\end{array}$ & $\begin{array}{c}\text { DYS } \\
393\end{array}$ & $\begin{array}{c}\text { DYS } \\
390\end{array}$ & $\begin{array}{c}\text { DYS } \\
385\end{array}$ & $\begin{array}{l}\text { Y- } \\
\text { Haplotyp }\end{array}$ \\
\hline \multirow[b]{4}{*}{ M1 } & 1076 [Femur li.] & 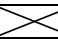 & 12 & & 28 & & & 16 & & & 25 & $3<$ & \multirow[b]{4}{*}{ Y1 } \\
\hline & 1172 [Mandibula] & 11 & 12 & 11 & 28 & 10 & 15 & 16 & 11 & 13 & - & $13-17$ & \\
\hline & 1485 [Calvarium] & 11 & 12 & 11 & 28 & 10 & - & 16 & 11 & 13 & 25 & $13-17$ & \\
\hline & Gesamtgenotyp & 11 & 12 & 11 & 28 & 10 & 15 & 16 & 11 & 13 & 25 & $13-17$ & \\
\hline \multirow[b]{3}{*}{ M2 } & 1102 [Femur li.] & - & 12 & - & 28 & - & - & 16 & - & - & 25 & - & \multirow[b]{3}{*}{ Y1 } \\
\hline & 3644 [Mandibula] & 11 & 12 & - & - & 10 & 15 & - & - & 13 & - & 13 & \\
\hline & Gesamtgenotyp & 11 & 12 & - & 28 & 10 & 15 & 16 & - & 13 & 25 & 13 & \\
\hline & & & & & & & & & & & & & \\
\hline \multirow[b]{4}{*}{ M3 } & 1482 (Mandibula) & 11 & 12 & 11 & 27 & 10 & 15 & 15 & 11 & 13 & 25 & $13-17$ & \multirow[b]{4}{*}{ Y2 } \\
\hline & 1911 (Femur li.) & $\sum$ & 12 & $\sum$ & (27) & $\infty$ & $>$ & (15) & $\sum$ & $>$ & $(25)$ & $3<$ & \\
\hline & 6525 (Calvarium) & 11 & 12 & 11 & 27 & 10 & 15 & - & - & 13 & - & - & \\
\hline & Gesamtgenotyp & 11 & 12 & 11 & 27 & 10 & 15 & 15 & 11 & 13 & 25 & $13-17$ & \\
\hline
\end{tabular}

\begin{tabular}{|l|l|l|l|l|l|l|l|l|l|l|l|l|l|}
\hline \multirow{2}{*}{ M4 } & $900[$ Neurocranium] & 11 & 12 & 11 & 28 & 10 & 15 & 16 & 11 & 13 & 24 & $13-17$ & \\
\cline { 2 - 12 } & Gesamtgenotyp & $\mathbf{1 1}$ & $\mathbf{1 2}$ & $\mathbf{1 1}$ & $\mathbf{2 8}$ & $\mathbf{1 0}$ & $\mathbf{1 5}$ & $\mathbf{1 6}$ & $\mathbf{1 1}$ & $\mathbf{1 3}$ & $\mathbf{2 4}$ & $\mathbf{1 3 - 1 7}$ & Y6 \\
\hline
\end{tabular}

\begin{tabular}{|l|l|l|l|l|l|l|l|l|l|l|l|l|l|}
\hline \multirow{3}{*}{ M5 } & $908[$ Calvarium] & 11 & 12 & - & 28 & 10 & 15 & 16 & 11 & 13 & 24 & $13-17$ & \\
\cline { 2 - 20 } & Gesamtgenotyp & $\mathbf{1 1}$ & $\mathbf{1 2}$ & - & $\mathbf{2 8}$ & $\mathbf{1 0}$ & $\mathbf{1 5}$ & $\mathbf{1 6}$ & $\mathbf{1 1}$ & $\mathbf{1 3}$ & $\mathbf{2 4}$ & $\mathbf{1 3}$ \\
\hline
\end{tabular}

\begin{tabular}{|c|l|c|c|c|c|c|c|c|c|c|c|c|c|}
\hline \multirow{5}{*}{ M6 } & 2030 [Femur li.] & - & 12 & - & 27 & - & - & 15 & - & - & 25 & - \\
\cline { 2 - 22 } & R3 [Calvarium] & 11 & 12 & 11 & - & 10 & - & 15 & - & 13 & - & $13-17$ \\
\cline { 2 - 10 } & Gesamtgenotyp & $\mathbf{1 1}$ & $\mathbf{1 2}$ & $\mathbf{1 1}$ & $\mathbf{2 7}$ & $\mathbf{1 0}$ & - & $\mathbf{1 5}$ & - & $\mathbf{1 3}$ & $\mathbf{2 5}$ & $\mathbf{1 3 - 1 7}$ \\
\hline
\end{tabular}

\begin{tabular}{|l|l|l|l|l|l|l|l|l|l|l|l|l|l|}
\hline \multirow{4}{*}{ M7 } & 3 [Felsenbein li.] & 11 & 12 & 11 & 28 & 10 & 15 & 16 & 11 & 13 & 25 & $13-17$ & \\
\cline { 2 - 24 } & 910 [Calvarium] & 11 & 12 & 11 & 28 & 10 & 15 & 16 & - & 13 & 25 & $13-17$ \\
\cline { 2 - 9 } & Gesamtgenotyp & $\mathbf{1 1}$ & $\mathbf{1 2}$ & $\mathbf{1 1}$ & $\mathbf{2 8}$ & $\mathbf{1 0}$ & $\mathbf{1 5}$ & $\mathbf{1 6}$ & $\mathbf{1 1}$ & $\mathbf{1 3}$ & $\mathbf{2 5}$ & $\mathbf{1 3 - 1 7}$ \\
\hline
\end{tabular}

\begin{tabular}{|l|l|l|l|l|l|l|l|l|l|l|l|l|l|}
\hline \multirow{3}{*}{ M8 } & $3757[$ Calvarium] & 11 & 12 & $(11)$ & 28 & 10 & - & 16 & 11 & 13 & 25 & $13-17$ & \\
\cline { 2 - 22 } & Gesamtgenotyp & $\mathbf{1 1}$ & $\mathbf{1 2}$ & $\mathbf{( 1 1})$ & $\mathbf{2 8}$ & $\mathbf{1 0}$ & - & $\mathbf{1 6}$ & $\mathbf{1 1}$ & $\mathbf{1 3}$ & $\mathbf{2 5}$ \\
\hline
\end{tabular}

\begin{tabular}{|c|c|c|c|c|c|c|c|c|c|c|c|c|c|}
\hline \multirow[b]{4}{*}{ M9 } & 1473 (Calvarium) & 11 & 13 & 12 & 29 & 12 & (15) & 14 & 13 & 13 & (23) & $11-14$ & \multirow[b]{4}{*}{ Y3 } \\
\hline & 1916 (Femur li.) & $2<$ & 13 & 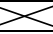 & 29 & $\geq$ & $2<$ & 14 & $\geq$ & $\geq<$ & 23 & $3<$ & \\
\hline & 2749 (Mandibula) & 11 & 13 & 12 & 29 & 12 & 15 & 14 & 13 & 13 & 23 & $11-14$ & \\
\hline & Gesamtgenotyp & 11 & 13 & 12 & 29 & 12 & 15 & 14 & 13 & 13 & 23 & $11-14$ & \\
\hline
\end{tabular}

\begin{tabular}{|l|l|l|l|l|l|l|l|l|l|l|l|l|l|}
\hline \multirow{2}{*}{ M10 } & 902 [Femur li.] & 11 & 13 & 11 & 30 & 11 & 14 & 15 & 11 & 13 & 25 & $11-(13)$ \\
\cline { 2 - 19 } & Gesamtgenotyp & $\mathbf{1 1}$ & $\mathbf{1 3}$ & $\mathbf{1 1}$ & $\mathbf{3 0}$ & $\mathbf{1 1}$ & $\mathbf{1 4}$ & $\mathbf{1 5}$ & $\mathbf{1 1}$ & $\mathbf{1 3}$ & $\mathbf{2 5}$ & $\mathbf{1 1}-(\mathbf{1 3})$ \\
\hline
\end{tabular}

\begin{tabular}{|c|l|l|l|l|l|l|l|l|l|l|l|l|l|}
\hline \multirow{3}{*}{ M11 } & 183 [Femur li.] & 11 & - & - & - & 11 & - & - & - & - & - & - \\
\cline { 2 - 16 } & Gesamtgenotyp & $\mathbf{1 1}$ & - & - & - & $\mathbf{1 1}$ & - & - & - & - & - & - \\
\hline
\end{tabular}

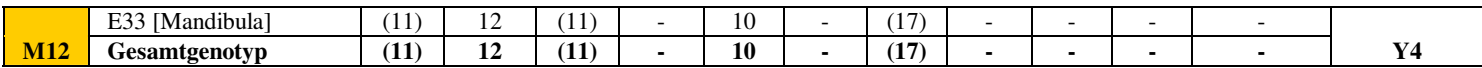

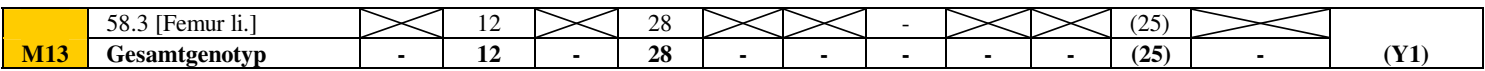

\begin{tabular}{|c|c|c|c|c|c|c|c|c|c|c|c|c|c|}
\hline \multirow[b]{3}{*}{ M14 } & 905 [Femur li.] & $>$ & (12) & $><$ & - & $>$ & $>$ & (15) & $>$ & $>$ & - & $3<$ & \\
\hline & (918 [Neurocranium]) & 11 & 12 & $(11)$ & - & - & - & - & - & - & - & - & \multirow[b]{2}{*}{ (Y2) } \\
\hline & Gesamtgenotyp & 11 & 12 & (11) & - & - & - & (15) & - & - & - & - & \\
\hline
\end{tabular}

\begin{tabular}{|l|l|l|l|l|l|l|l|l|l|l|l|l|l|}
\hline \multirow{2}{*}{ M15 } & $2263[$ Mandibula] & - & $(13)$ & - & - & - & - & - & - & - & - & - \\
\cline { 2 - 13 } & Gesamtgenotyp & - & $\mathbf{( 1 3 )}$ & - & - & - & - & - & - & - & - & - & nd. \\
\hline
\end{tabular}

\begin{tabular}{|l|l|l|l|l|l|l|l|l|l|l|l|l|l|}
\hline \multirow{3}{*}{ M16 } & 3886 [Felsenbein li.] & 11 & 12 & 11 & 28 & 10 & 15 & 16 & 11 & 13 & 25 & $13-17$ & \\
\cline { 2 - 22 } & Gesamtgenotyp & $\mathbf{1 1}$ & $\mathbf{1 2}$ & $\mathbf{1 1}$ & $\mathbf{2 8}$ & $\mathbf{1 0}$ & $\mathbf{1 5}$ & $\mathbf{1 6}$ & $\mathbf{1 1}$ & $\mathbf{1 3}$ & $\mathbf{2 5}$ & $\mathbf{1 3}$ \\
\hline
\end{tabular}

\begin{tabular}{|l|l|l|l|l|l|l|l|l|l|l|l|l|l|}
\hline \multirow{3}{*}{ M17 } & 57.2 [Femur li.] & - & - & - & - & - & - & - & - & - & - & - & \\
\cline { 2 - 13 } & Gesamtgenotyp & - & - & - & - & - & - & - & - & - & - & - & nd. \\
\hline
\end{tabular}

\begin{tabular}{c|l|l|l|l|l|l|l|l|l|l|l|l|l|}
\multirow{3}{*}{ M18 } & 901 [Femur li.] & - & - & - & - & - & - & - & - & - & - & - & \\
\cline { 2 - 11 } & Gesamtgenotyp & - & - & - & - & - & - & - & - & - & - & - & nd. \\
\hline
\end{tabular}

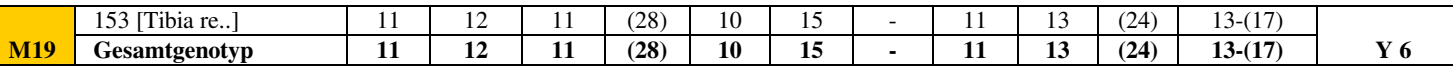

Legende: ( ) = unsicheres Allel, $\mathrm{X}=$ nicht untersucht; die Allelmuster der linken Femora entstammen im Wesentlichen den Typisierungen von Schultes (2000). 
Tabelle 36: Y-STR Einzeltypisierungen. Die Bestimmung des Y-Allelmusters wurde mit der YOktaplex und dem PowerPlex Y-System durchgeführt. Neben der Fundnummer ist das jeweilige Skelettelement angegeben und wenn möglich zu welchem Individuum es gehört.

\begin{tabular}{|c|c|c|c|c|c|c|c|c|c|c|c|c|}
\hline M7 & \multicolumn{10}{|c|}{3 [Felsenbein li.] } \\
\hline PCR & EX & DYS391 & DYS389 I & DYS 439 & DYS389 II & DYS 438 & DYS 437 & DYS19 & DYS392 & DYS393 & DYS390 & DYS385 \\
\hline 74 & I & 11 & 12 & 11 & 28 & 10 & 15 & 16 & 11 & 13 & 25 & $13-17$ \\
\hline 77 & I & 11 & 12 & 11 & 28 & 10 & 15 & 16 & 11 & 13 & 25 & $13-17$ \\
\hline Haplotyp & Y1 & 11 & 12 & 11 & 28 & 10 & 15 & 16 & 11 & 13 & 25 & $13-17$ \\
\hline
\end{tabular}

\begin{tabular}{|c|c|c|c|c|c|c|c|c|c|c|c|c|}
\hline M4 & \multicolumn{10}{|c|}{35 [Femur li.] } \\
\hline PCR & EX & DYS391 & DYS389 I & DYS 439 & DYS389 II & DYS 438 & DYS 437 & DYS19 & DYS392 & DYS393 & DYS390 & DYS385 \\
\hline \multicolumn{2}{|c|}{ Schultes 2000 } & & $?$ & - & $?$ & - & & $?$ & & & $?$ & ? \\
\hline 23 & TS00 & 11 & - & - & - & 10 & - & - & - & - & - & - \\
\hline 47 & I & - & - & - & - & - & - & - & - & - & - & - \\
\hline Haplotyp & - & - & - & - & - & - & - & - & - & - & - & - \\
\hline
\end{tabular}

\begin{tabular}{|c|c|c|c|c|c|c|c|c|c|c|c|c|}
\hline M17 & \multicolumn{10}{|c|}{57.2 [Femur li.] } \\
\hline PCR & EX & DYS391 & DYS389 I & DYS 439 & DYS389 II & DYS 438 & DYS 437 & DYS19 & DYS392 & DYS393 & DYS390 & DYS385 \\
\hline 23 & I & 11 & $12 /(13)$ & 11 & - & - & 15 & - & - & 13 & - & 13 \\
\hline 81 & II & - & - & - & - & $(9)$ & - & - & - & $(14)$ & - & 17 \\
\hline Haplotyp & - & - & - & - & - & - & - & - & - & - & - & - \\
\hline
\end{tabular}

\begin{tabular}{|c|c|c|c|c|c|c|c|c|c|c|c|c|}
\hline M19 & \multicolumn{10}{|c|}{153 [Tibia re.] } \\
\hline PCR & EX & DYS391 & DYS389 I & DYS 439 & DYS389 II & DYS 438 & DYS 437 & DYS19 & DYS392 & DYS393 & DYS390 & DYS385 \\
& & & & & & & & & & & & \\
\hline 81A & SCII & 11 & 12 & - & - & 10 & - & - & 11 & 13 & - & - \\
\hline 81B & SCII & 11 & $(12)$ & $(11)$ & - & 10 & 15 & - & - & 13 & - & 13 \\
\hline 83 A & SCII & 11 & 12 & - & - & 10 & - & - & - & - & - & - \\
\hline 83 B & SCII & 11 & - & - & - & 10 & - & 16 & - & 13 & - & 13 \\
\hline 83 C & SCII & 11 & 12 & 11 & 28 & 10 & - & - & 11 & 13 & - & 13 \\
\hline 87 A & SCI & 11 & 12 & 11 & - & 10 & 15 & - & 11 & 13 & 24 & $13-17$ \\
\hline 87 B & SCI & 11 & $12 / 13$ & - & $28 / 29$ & 10 & 15 & $(14)$ & 11 & 13 & 24 & 17 \\
\hline Haplotyp & Y6 & $\mathbf{1 1}$ & $\mathbf{1 2}$ & $\mathbf{1 1}$ & $\mathbf{( 2 8})$ & $\mathbf{1 0}$ & $\mathbf{1 5}$ & - & $\mathbf{1 1}$ & $\mathbf{1 3}$ & $\mathbf{( 2 4 )}$ & $\mathbf{1 3 - ( 1 7 )}$ \\
\hline
\end{tabular}

\begin{tabular}{|c|c|c|c|c|c|c|c|c|c|c|c|c|}
\hline M11 & \multicolumn{12}{|c|}{183 [Femur li.] } \\
\hline PCR & EX & DYS391 & DYS389 I & DYS 439 & DYS389 II & DYS 438 & $\begin{array}{c}\text { DYS } \\
437\end{array}$ & DYS19 & DYS392 & DYS393 & DYS390 & DYS385 \\
\hline Schultes & & $3<$ & - & $\sum<$ & - & 3 & $\sum<$ & - & $\sum<$ & $\sum<$ & - & $\sum<$ \\
\hline 23 & $\mathrm{~A}$ & 11 & - & - & - & 11 & 15 & 15 & - & - & - & - \\
\hline 47 & B & - & - & - & - & 11 & - & - & - & - & - & - \\
\hline 74 & $\mathrm{~A}$ & 11 & - & - & - & 11 & - & - & - & - & - & - \\
\hline 74 & $\mathrm{~B}$ & 11 & - & 11 & - & & - & - & - & 13 & - & - \\
\hline Haplotyp & - & 11 & - & - & - & 11 & - & - & - & - & - & - \\
\hline
\end{tabular}

\begin{tabular}{|c|c|c|c|c|c|c|c|c|c|c|c|c|}
\hline & \multicolumn{12}{|c|}{199 [Femur li.] } \\
\hline PCR & EX & DYS391 & DYS389 I & DYS 439 & DYS389 II & DYS 438 & $\begin{array}{c}\text { DYS } \\
437\end{array}$ & DYS19 & DYS392 & DYS393 & DYS390 & DYS385 \\
\hline Schultes 2 & 2000 & $3<$ & (14) & 3 & (30) & 3 & $>$ & (15) & $8<$ & 8 & (25) & $>$ \\
\hline 23 & $\mathrm{I}$ & - & - & - & - & - & (15) & - & - & - & 25 & - \\
\hline 27 & \begin{tabular}{|l|} 
IX \\
\end{tabular} & 11 & - & - & - & - & - & 13 & - & (15) & - & - \\
\hline 47 & \begin{tabular}{|l} 
DCH \\
$02 I X$
\end{tabular} & - & 13 & - & 29 & - & - & - & - & - & - & - \\
\hline Haplotyp & - & - & - & - & - & - & - & - & - & - & - & - \\
\hline
\end{tabular}

\begin{tabular}{|c|c|c|c|c|c|c|c|c|c|c|c|c|}
\hline M4 & \multicolumn{10}{|c|}{900 [Neurocranium] } \\
\hline PCR & EX & DYS391 & DYS389 I & DYS 439 & $\begin{array}{c}\text { DYS389 } \\
\text { II }\end{array}$ & DYS 438 & $\begin{array}{c}\text { DYS } \\
437\end{array}$ & DYS19 & DYS392 & DYS393 & DYS390 & DYS385 \\
\hline 38 & I & 11 & 12 & & 28 & & & 16 & 11 & 13 & 24 & $13-17$ \\
\hline 40 & I & $10 / 11$ & $(10) / 12$ & 11 & 28 & 10 & 15 & 16 & 11 & $12 / 13$ & 24 & $13-17$ \\
\hline 47 & II & 11 & 12 & 11 & 28 & 10 & 15 & - & 11 & 13 & 24 & 13 \\
\hline 57 & II & 11 & 12 & 11 & 28 & 10 & 15 & 16 & 11 & 13 & 24 & $13-17$ \\
\hline Haplotyp & Y6 & $\mathbf{1 1}$ & $\mathbf{1 2}$ & $\mathbf{1 1}$ & $\mathbf{2 8}$ & $\mathbf{1 0}$ & $\mathbf{1 5}$ & $\mathbf{1 6}$ & $\mathbf{1 1}$ & $\mathbf{1 3}$ & $\mathbf{2 4}$ & $\mathbf{1 3 - 1 7}$ \\
\hline
\end{tabular}

Legende: $\mathrm{X}=$ nicht untersucht, $($ ) = unsicheres Allel 


\section{Fortsetzung Tabellen 36: Y-STR Einzeltypisierungen.}

\begin{tabular}{|c|c|c|c|c|c|c|c|c|c|c|c|c|}
\hline M18 & \multicolumn{12}{|c|}{901 [Femur li.] } \\
\hline $\begin{array}{l}\text { PCR } \\
\end{array}$ & EX & DYS391 & DYS389 I & DYS 439 & DYS389 II & DYS 438 & DYS 437 & DYS19 & DYS392 & DYS393 & DYS390 & DYS385 \\
\hline 81 & $\begin{array}{l}\mathrm{aBZ} \\
\mathrm{ME} \\
\mathrm{X} \text { II }\end{array}$ & 11 & - & - & - & - & - & - & - & - & - & - \\
\hline Haplotyp & - & - & - & - & - & - & - & - & - & - & - & - \\
\hline
\end{tabular}

\begin{tabular}{|c|c|c|c|c|c|c|c|c|c|c|c|c|}
\hline M10 & \multicolumn{10}{|c|}{902 [Femur li.] } \\
\hline PCR & EX & DYS391 & DYS389 I & DYS 439 & DYS389 II & DYS 438 & DYS 437 & DYS19 & DYS392 & DYS393 & DYS390 & DYS385 \\
\hline \multicolumn{2}{|c|}{ Schultes 2000 } & & $(13)$ & & $(30)$ & & & $(15)$ & & & $(25)$ & ( \\
\hline 77 & SKrb & 11 & 13 & 11 & 30 & 11 & 14 & 15 & 11 & 13 & 25 & 11 \\
\hline 81 & SKrb & 11 & 13 & 11 & 30 & 11 & 14 & - & 11 & 13 & - & $11-13$ \\
\hline Haplotyp & Y5 & $\mathbf{1 1}$ & $\mathbf{1 3}$ & $\mathbf{1 1}$ & $\mathbf{3 0}$ & $\mathbf{1 1}$ & $\mathbf{1 4}$ & $\mathbf{1 5}$ & $\mathbf{1 1}$ & $\mathbf{1 3}$ & $\mathbf{2 5}$ & $\mathbf{1 1 - ( 1 3 )}$ \\
\hline
\end{tabular}

\begin{tabular}{|c|c|c|c|c|c|c|c|c|c|c|c|c|}
\hline M5 & \multicolumn{12}{|c|}{908 [Calvarium] } \\
\hline $\begin{array}{l}\text { PCR } \\
\end{array}$ & EX & DYS391 & DYS389 I & DYS 439 & DYS389 II & DYS 438 & DYS 437 & DYS19 & DYS392 & DYS393 & DYS390 & DYS385 \\
\hline 38 & I & 11 & (12) & 3 & 28 & $3<$ & 3 & 16 & 11 & (13) & 24 & $13-17$ \\
\hline 40 & $\mathrm{I}$ & 11 & 12 & - & 28 & 10 & - & 16 & - & - & - & 17 \\
\hline 47 & II & 11 & 12 & - & 28 & 10 & 15 & - & 11 & 13 & 24 & $13-17$ \\
\hline 57 & II & 11 & 12 & 11 & - & 10 & 15 & 16 & 11 & 13 & 24 & $13-17$ \\
\hline Haplotyp & Y6 & 11 & 12 & - & 28 & 10 & 15 & 16 & 11 & 13 & 24 & $13-17$ \\
\hline
\end{tabular}

\begin{tabular}{|c|c|c|c|c|c|c|c|c|c|c|c|c|}
\hline M7 & \multicolumn{12}{|c|}{910 [Calvarium] } \\
\hline PCR & EX & DYS391 & DYS389 I & DYS 439 & DYS389 II & DYS 438 & DYS 437 & DYS19 & DYS392 & DYS393 & DYS390 & DYS385 \\
\hline 38 & I & - & 12 & $3<$ & - & $><$ & $3<$ & - & - & 13 & - & $13-17$ \\
\hline 40 & $\mathrm{I}$ & - & 12 & - & - & - & - & - & - & - & - & - \\
\hline 47 & II & 11 & 12 & 11 & 28 & 10 & 15 & 16 & 11 & 13 & 25 & $13-17$ \\
\hline 57 & II & 11 & 12 & 11 & 28 & 10 & 15 & 16 & - & 13 & 25 & $13-17$ \\
\hline Haplotyp & $Y 1$ & 11 & 12 & 11 & 28 & 10 & 15 & 16 & - & 13 & 25 & $13-17$ \\
\hline
\end{tabular}

\begin{tabular}{|c|c|c|c|c|c|c|c|c|c|c|c|c|}
\hline (M14) & \multicolumn{12}{|c|}{918 [Neurocranium] } \\
\hline PCR & EX & DYS391 & DYS389 I & DYS 439 & DYS389 II & DYS 438 & DYS 437 & DYS19 & DYS392 & DYS393 & DYS390 & DYS385 \\
\hline 57 & II & 11 & 12 & - & - & 10 & 14 & - & - & - & - & - \\
\hline 66 & $\begin{array}{l}\text { AS } \\
\text { III }\end{array}$ & 11 & - & 11 & - & - & - & - & - & - & - & - \\
\hline 74 & III & - & 12 & - & - & - & - & - & - & 13 & - & - \\
\hline 77 & III & 11 & 12 & (11) & - & - & - & - & - & - & - & - \\
\hline Haplotyp & - & 11 & 12 & (11) & - & - & - & - & - & - & - & - \\
\hline
\end{tabular}

\begin{tabular}{|c|c|c|c|c|c|c|c|c|c|c|c|c|}
\hline M2 & \multicolumn{12}{|c|}{1102 [Femur li.] } \\
\hline PCR & EX & DYS391 & DYS389 I & DYS 439 & DYS389 II & DYS 438 & DYS 437 & DYS19 & DYS392 & DYS393 & DYS390 & DYS385 \\
\hline Schultes & 000 & $3<$ & 12 & $3<$ & 28 & $3<$ & $3<$ & 16 & $3<$ & $3<$ & 25 & $3<$ \\
\hline 74 & MWZ & (11) & (12) & - & (28) & 10 & 15 & 16 & - & 13 & - & - \\
\hline 77 & $\begin{array}{l}\text { MWZ } \\
\end{array}$ & 11 & - & 11 & - & - & - & 15 & 13 & - & - & - \\
\hline Haplotyp & $Y 1$ & - & 12 & - & 28 & - & - & 16 & - & - & 25 & - \\
\hline
\end{tabular}

\begin{tabular}{|c|c|c|c|c|c|c|c|c|c|c|c|c|}
\hline M1 & \multicolumn{10}{|c|}{1172 [Mandibula] } \\
\hline PCR & EX & DYS391 & DYS389 I & DYS 439 & DYS389 II & DYS 438 & DYS 437 & DYS19 & DYS392 & DYS393 & DYS390 & DYS385 \\
\hline 74 & I & 11 & 12 & 11 & 28 & 10 & 15 & 16 & 11 & 13 & - & $13-17$ \\
\hline 77 & I & 11 & 12 & 11 & 28 & 10 & 15 & 16 & 11 & 13 & 25 & $13-17$ \\
\hline Haplotyp & Y1 & $\mathbf{1 1}$ & $\mathbf{1 2}$ & $\mathbf{1 1}$ & $\mathbf{2 8}$ & $\mathbf{1 0}$ & $\mathbf{1 5}$ & $\mathbf{1 6}$ & $\mathbf{1 1}$ & $\mathbf{1 3}$ & - & $\mathbf{1 3 - 1 7}$ \\
\hline
\end{tabular}

\begin{tabular}{|c|c|c|c|c|c|c|c|c|c|c|c|c|}
\hline M9 & \multicolumn{10}{|c|}{1473 [Calvarium] } \\
\hline PCR & EX & DYS391 & DYS389 I & DYS 439 & DYS389 II & DYS 438 & DYS 437 & DYS19 & DYS392 & DYS393 & DYS390 & DYS385 \\
\hline 10 & I & - & 13 & & $(29)$ & & & & 14 & 13 & 13 & - \\
\hline 11 & I & - & - & & - & & & 14 & 13 & 13 & $(23)$ & $11-14$ \\
\hline 20 & II & 11 & 13 & 12 & 29 & 12 & 15 & 14 & - & 13 & 23 & 14 \\
\hline 43 & I & 11 & 13 & 12 & 29 & 12 & $(15)$ & 14 & - & 13 & - & 11 \\
\hline 47 & II & 11 & - & 12 & - & 12 & - & - & 13 & 13 & - & 14 \\
\hline Haplotyp & Y3 & $\mathbf{1 1}$ & $\mathbf{1 3}$ & $\mathbf{1 2}$ & $\mathbf{2 9}$ & $\mathbf{1 2}$ & $\mathbf{( 1 5})$ & $\mathbf{1 4}$ & $\mathbf{1 3}$ & $\mathbf{1 3}$ & $(\mathbf{2 3})$ & $\mathbf{1 1 - 1 4}$ \\
\hline
\end{tabular}

Legende: $\mathrm{X}=$ nicht untersucht, $($ ) = unsicheres Allel 


\section{Fortsetzung Tabellen 36: Y-STR Einzeltypisierungen.}

\begin{tabular}{|c|c|c|c|c|c|c|c|c|c|c|c|c|}
\hline M3 & \multicolumn{10}{|c|}{ 1482 [Mandibula] } \\
\hline PCR & EX & DYS391 & DYS389 I & DYS 439 & DYS389 II & DYS 438 & DYS 437 & DYS19 & DYS392 & DYS393 & DYS390 & DYS385 \\
\hline 20 & I & 11 & 12 & 11 & 27 & 10 & 15 & $(19)$ & 11 & 13 & 25 & 13 \\
\hline 27 & I & $(10) / 11$ & 12 & 11 & 27 & 10 & 15 & 15 & 11 & 13 & 25 & $13-17$ \\
\hline 47 & III & 11 & 12 & 11 & 27 & 10 & - & - & 11 & 13 & 25 & $13-17$ \\
\hline 57 & III & 11 & 12 & 11 & 27 & 10 & 15 & 15 & - & 13 & - & $13-17$ \\
\hline Haplotyp & Y2 & $\mathbf{1 1}$ & $\mathbf{1 2}$ & $\mathbf{1 1}$ & $\mathbf{2 7}$ & $\mathbf{1 0}$ & $\mathbf{1 5}$ & $\mathbf{1 5}$ & $\mathbf{1 1}$ & $\mathbf{1 3}$ & $\mathbf{2 5}$ & $\mathbf{1 3 - 1 7}$ \\
\hline
\end{tabular}

\begin{tabular}{|c|c|c|c|c|c|c|c|c|c|c|c|c|}
\hline M1 & \multicolumn{10}{|c|}{1485 [Calvarium] } \\
\hline PCR & EX & DYS391 & DYS389 I & DYS 439 & DYS389 II & DYS 438 & DYS 437 & DYS19 & DYS392 & DYS393 & DYS390 & DYS385 \\
\hline 10 & I & 11 & $(12) / 13$ & & - & & & 16 & 11 & 13 & 25 & $13-17$ \\
\hline 11 & I & 11 & $(12)$ & & - & & & - & 11 & 13 & - & $13-17$ \\
\hline 20 & I & 11 & 12 & 11 & 28 & 10 & - & 16 & - & 13 & 25 & $(13)-17$ \\
\hline 27 & I & 11 & 12 & 11 & 28 & 10 & 15 & - & 11 & 13 & 25 & 13 \\
\hline 43 & II & 11 & 12 & - & - & - & - & - & - & 13 & - & - \\
\hline 47 & III & 11 & 12 & 11 & - & 10 & 14 & - & 11 & 13 & 25 & 13 \\
\hline Haplotyp & Y1 & $\mathbf{1 1}$ & $\mathbf{1 2}$ & $\mathbf{1 1}$ & $\mathbf{2 8}$ & $\mathbf{1 0}$ & - & $\mathbf{1 6}$ & $\mathbf{1 1}$ & $\mathbf{1 3}$ & $\mathbf{2 5}$ & $\mathbf{1 3 - 1 7}$ \\
\hline
\end{tabular}

\begin{tabular}{|c|c|c|c|c|c|c|c|c|c|c|c|c|}
\hline M6 & \multicolumn{10}{|c|}{2030 [Femur li.] } \\
\hline PCR & EX & DYS391 & DYS389 I & DYS 439 & DYS389 II & DYS 438 & DYS 437 & DYS19 & DYS392 & DYS393 & DYS390 & DYS385 \\
\hline \multicolumn{2}{|c|}{ Schultes 2000 } & & 12 & & 27 & & & 15 & & & 25 & \\
\hline 77 & DS04 & - & - & - & - & - & - & - & - & - & - & - \\
\hline 77 & SKrb & 11 & - & 11 & - & - & 15 & - & 11 & $13 / 14$ & - & 13 \\
\hline Haplotyp & Y2 & - & $\mathbf{1 2}$ & - & $\mathbf{2 7}$ & - & - & $\mathbf{1 5}$ & - & - & $\mathbf{2 5}$ & - \\
\hline
\end{tabular}

\begin{tabular}{|c|c|c|c|c|c|c|c|c|c|c|c|c|}
\hline F18 & \multicolumn{12}{|c|}{2133 [Mandibula] } \\
\hline PCR & EX & DYS391 & DYS389 I & DYS 439 & DYS389 II & DYS 438 & DYS 437 & DYS19 & DYS392 & DYS393 & DYS390 & DYS385 \\
\hline 10 & I & - & - & $\sum$ & - & $\sum$ & 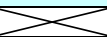 & - & - & 13 & $23 / 24$ & 11-(14) \\
\hline 11 & I & 11 & - & $3<$ & - & $\sum$ & $\sum$ & 14 & 13 & 13 & 24 & 11 \\
\hline 15 & I & $?$ & - & $\sum<$ & $?$ & $\sum$ & $\sum$ & $?$ & 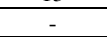 & 13 & $?$ & $?$ \\
\hline 16 & I & 10 & $13 /(14)$ & $\sum<$ & 29 & $\sum<$ & $\sum<$ & (14) & 13 & 13 & 23 & 11-14-(18) \\
\hline 20 & I & 11 & 13 & 11 & 30 & 11 & $14 / 15$ & - & $(11) / 13$ & 13 & 25 & 14-15-16 \\
\hline 27 & II & - & - & 12 & - & $8 /(12)$ & 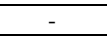 & 15 & - & $12 / 13$ & - & 12 \\
\hline 43 & II & 11 & 13 & $11 / 12$ & 31 & 12 & ((14)) & - & - & 13 & - & $11-16$ \\
\hline 47 & III & - & - & & - & - & - & - & - & - & - & - \\
\hline Haplotyp & - & 11 & 13 & - & - & - & - & - & 13 & 13 & - & - \\
\hline
\end{tabular}

Legende: Extrakte I und II höchstwahrscheinlich Kontamination (s.Kap. 5.1, S.77)

\begin{tabular}{|c|c|c|c|c|c|c|c|c|c|c|c|c|}
\hline M15 & \multicolumn{90}{|c|}{2263 [Mandibula] } \\
\hline PCR & EX & DYS391 & DYS389 I & DYS 439 & DYS389 II & DYS 438 & DYS 437 & DYS19 & DYS392 & DYS393 & DYS390 & DYS385 \\
\hline 15 & I & - & 13 & & & 29 & & & - & - & - & - \\
$(10)$ \\
\hline 16 & I & - & - & & - & - & - & - & - & - & - & - \\
\hline 38 & II & 11 & $(13)$ & - & - & - & - & - & - & $12 /(13)$ & - & - \\
\hline 40 & II & - & - & 13 & - & - & - & - & - & - & - & - \\
\hline Haplotyp & - & - & $(\mathbf{1 3})$ & - & - & - & - & - & - & - & - & - \\
\hline
\end{tabular}

\begin{tabular}{|c|c|c|c|c|c|c|c|c|c|c|c|c|}
\hline M9 & \multicolumn{10}{|c|}{ 2749 [Mandibula] } \\
\hline PCR & EX & DYS391 & DYS389 I & DYS 439 & DYS389 II & DYS 438 & DYS 437 & DYS19 & DYS392 & DYS393 & DYS390 & DYS385 \\
\hline 10 & I & (11) & - & & - & & & 14 & 12 & 13 & 23 & 14 \\
\hline 11 & I & 11 & 13 & & 29 & & & - & 13 & 13 & 23 & $11-14$ \\
\hline 20 & II & 11 & 13 & 12 & 29 & 12 & 15 & 14 & 13 & 13 & $23 /(25)$ & $11-14$ \\
\hline 43 & I & 11 & 13 & 12 & 29 & 12 & 15 & 14 & - & 13 & 23 & $11-14$ \\
\hline 47 & II & 11 & - & - & - & 12 & 15 & 14 & 13 & - & 23 & $11-14$ \\
\hline Haplotyp & Y3 & $\mathbf{1 1}$ & $\mathbf{1 3}$ & $\mathbf{1 2}$ & $\mathbf{2 9}$ & $\mathbf{1 2}$ & $\mathbf{1 5}$ & $\mathbf{1 4}$ & $\mathbf{1 3}$ & $\mathbf{1 3}$ & $\mathbf{2 3}$ & $\mathbf{1 1 - 1 4}$ \\
\hline
\end{tabular}

\begin{tabular}{|c|c|c|c|c|c|c|c|c|c|c|c|c|}
\hline M5 & \multicolumn{12}{|c|}{3380 [Mandibula] } \\
\hline $\begin{array}{l}\text { PCR } \\
\end{array}$ & EX & DYS391 & DYS389 I & DYS 439 & DYS389 II & DYS 438 & DYS 437 & DYS19 & DYS392 & DYS393 & DYS390 & DYS385 \\
\hline 38 & II & 11 & 12 & $\sum<$ & - & $\sum<$ & $\sum<$ & $15 / 16$ & 11 & 13 & - & 13 \\
\hline 40 & II & - & - & - & - & - & - & - & - & $(12) / 13$ & - & - \\
\hline 43 & I & 11 & - & - & - & - & - & - & - & 13 & - & - \\
\hline 47 & I & 11 & 12 & 11 & - & (10) & - & - & - & 13 & - & 13 \\
\hline Haplotyp & - & 11 & 12 & - & - & - & - & - & - & 13 & - & 13 \\
\hline
\end{tabular}

Legende: $\mathrm{X}=$ nicht untersucht, $($ ) = unsicheres Allel 
Fortsetzung Tabellen 36: Y-STR Einzeltypisierungen.

\begin{tabular}{|c|c|c|c|c|c|c|c|c|c|c|c|c|}
\hline M2 & \multicolumn{12}{|c|}{3644 [Mandibula] } \\
\hline PCR & EX & DYS391 & DYS389 I & DYS 439 & DYS389 II & DYS 438 & DYS 437 & DYS19 & DYS392 & DYS393 & DYS390 & DYS385 \\
\hline 23 & $\mathrm{I}$ & 11 & 12 & - & - & 10 & 15 & - & - & 13 & $(25)$ & $11-13$ \\
\hline 27 & $\mathrm{I}$ & 11 & 12 & 11 & - & 10 & 15 & (13) & (12) & 13 & - & 17 \\
\hline 38 & III & - & 12 & $3<$ & - & $3<$ & $3<$ & 16 & 11 & 13 & - & 13 \\
\hline 40 & III & 11 & 12 & - & 28 & (10) & - & $(15)$ & - & 13 & - & - \\
\hline Haplotyp & $Y 1$ & 11 & 12 & - & - & 10 & 15 & - & - & 13 & - & 13 \\
\hline
\end{tabular}

\begin{tabular}{|c|c|c|c|c|c|c|c|c|c|c|c|c|}
\hline M8 & \multicolumn{12}{|c|}{3757 [Calvarium] } \\
\hline PCR & EX & DYS391 & DYS389 I & DYS 439 & DYS389 II & DYS 438 & DYS 437 & DYS19 & DYS392 & DYS393 & DYS390 & DYS385 \\
\hline 10 & $\mathrm{I}$ & - & 14 & $3<$ & - & $3<$ & $><$ & - & 11 & 13 & 25 & - \\
\hline 11 & $\mathrm{I}$ & 11 & - & $3<$ & - & $3<$ & $><$ & - & 11 & 13 & - & $13-17$ \\
\hline 15 & I & 11 & 12 & $3<$ & 29 & $3<$ & $3<$ & 16 & 11 & 13 & 25 & $13-17$ \\
\hline 20 & II & 11 & 12 & 11 & 28 & 10 & - & - & 11 & 13 & - & $13-17$ \\
\hline 27 & $\mathrm{I}$ & 11 & 12 & - & - & 10 & - & 16 & 11 & 13 & - & $13-17$ \\
\hline 38 & II & 11 & $12 / 15$ & $3<$ & 28 & $3<$ & $3<$ & 16 & 11 & 13 & 25 & $13-17$ \\
\hline 40 & II & 11 & 12 & 11 & 28 & 10 & - & - & - & 13 & 25 & $13-17$ \\
\hline Haplotyp & $Y 1$ & 11 & 12 & (11) & 28 & 10 & - & 16 & 11 & 13 & 25 & $13-17$ \\
\hline
\end{tabular}

\begin{tabular}{|c|c|c|c|c|c|c|c|c|c|c|c|c|}
\hline M16 & \multicolumn{12}{|c|}{3886 [Felsenbein li.] } \\
\hline PCR & EX & DYS391 & DYS389 I & DYS 439 & DYS389 II & DYS 438 & DYS 437 & DYS19 & DYS392 & DYS393 & DYS390 & DYS385 \\
\hline $66 \mathrm{~A}$ & I & 11 & 12 & 11 & 28 & 10 & 15 & 16 & 11 & 13 & 25 & $13-17$ \\
\hline $66 \mathrm{~B}$ & I & 11 & 12 & 11 & 28 & 10 & 15 & 16 & 11 & 13 & 25 & $13-17$ \\
\hline $66 \mathrm{~A}$ & II & 11 & 12 & 11 & 28 & 10 & 15 & 16 & 11 & 13 & 25 & $13-17$ \\
\hline $66 \mathrm{~B}$ & II & 11 & 12 & 11 & 28 & 10 & 15 & 16 & 11 & 13 & 25 & $13-17$ \\
\hline Haplotyp & $Y 1$ & 11 & 12 & 11 & 28 & 10 & 15 & 16 & 11 & 13 & 25 & $13-17$ \\
\hline
\end{tabular}

\begin{tabular}{|c|c|c|c|c|c|c|c|c|c|c|c|c|}
\hline M3 & \multicolumn{12}{|c|}{6525 [Calvarium] } \\
\hline PCR & EX & DYS391 & DYS389 I & DYS 439 & DYS389 II & DYS 438 & DYS 437 & DYS19 & DYS392 & DYS393 & DYS390 & DYS385 \\
\hline 74 & I & (11) & 12 & 11 & 27 & 10 & 15 & - & - & 13 & - & - \\
\hline 74 & II & 11 & 12 & 11 & 27 & 10 & 15 & - & - & 13 & 25 & 17 \\
\hline 77 & IIb & 11 & 12 & 11 & - & 10 & 15 & 15 & 15 & - & 25 & 13 \\
\hline Haplotyp & $Y 2$ & 11 & 12 & 11 & 27 & 10 & 15 & - & - & 13 & - & - \\
\hline
\end{tabular}

\begin{tabular}{|c|c|c|c|c|c|c|c|c|c|c|c|c|}
\hline M12 & \multicolumn{12}{|c|}{ E33 [Mandibula] } \\
\hline PCR & EX & DYS391 & DYS389 I & DYS 439 & DYS389 II & DYS 438 & DYS 437 & DYS19 & DYS392 & DYS393 & DYS390 & DYS385 \\
\hline 40 & I & 11 & (12) & - & - & 10 & 14 & - & - & - & - & - \\
\hline 47 & II & 11 & 12 & 11 & - & 10 & - & 17 & $(11)$ & - & - & - \\
\hline 57 & II & - & 12 & 11 & 28 & 10 & 15 & 17 & - & - & - & $13-17$ \\
\hline Haplotyp & Y4 & (11) & 12 & (11) & - & 10 & - & (17) & - & - & - & - \\
\hline
\end{tabular}

\begin{tabular}{|c|c|c|c|c|c|c|c|c|c|c|c|c|}
\hline & \multicolumn{12}{|c|}{ N969 [Mandibula] } \\
\hline PCR & EX & DYS391 & DYS389 I & DYS 439 & DYS389 II & DYS 438 & DYS 437 & DYS19 & DYS392 & DYS393 & DYS390 & DYS385 \\
\hline 10 & I & - & - & $3<$ & - & 3 & 3 & - & - & 13 & - & - \\
\hline 11 & I & - & 13 & $S<$ & $29 / 31$ & 3 & 3 & - & $11 / 13$ & $13 / 14$ & $23 / 24$ & $11-15-16$ \\
\hline 38 & II & - & 13 & $3<$ & - & $3<$ & $3<$ & - & (13) & 13 & $((25))$ & - \\
\hline 40 & II & - & - & - & - & - & - & - & - & - & 24 & - \\
\hline Haplotyp & - & - & 13 & - & - & - & - & - & - & 13 & - & - \\
\hline
\end{tabular}

\begin{tabular}{|c|c|c|c|c|c|c|c|c|c|c|c|c|}
\hline M6 & \multicolumn{12}{|c|}{ R3 [Calvarium] } \\
\hline PCR & EX & DYS391 & DYS389 I & DYS 439 & DYS389 II & DYS 438 & DYS 437 & DYS19 & DYS392 & DYS393 & DYS390 & DYS385 \\
\hline 10 & $\mathrm{I}$ & - & - & $S<$ & - & $3<$ & $S<$ & - & - & 13 & - & - \\
\hline 11 & I & 11 & - & 3 & - & $>$ & 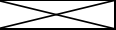 & - & (11) & 13 & - & 13 \\
\hline 15 & $\mathrm{I}$ & 11 & - & $3<$ & - & $S<$ & $\$<$ & 15 & - & 13 & - & $13-17$ \\
\hline 16 & I & - & $12 / 13$ & $><$ & - & $S<$ & $><$ & - & - & 13 & - & $13-17$ \\
\hline 20 & II & $(11)$ & $(12)$ & 11 & - & 10 & - & - & - & 13 & - & - \\
\hline 27 & $\mathrm{I}$ & 11 & - & 11 & - & 10 & 15 & 15 & - & - & 25 & $13-17$ \\
\hline Haplotyp & $Y 2$ & 11 & 12 & 11 & - & 10 & - & 15 & - & 13 & - & $13-17$ \\
\hline
\end{tabular}

\begin{tabular}{|c|c|c|c|c|c|c|c|c|c|c|c|c|}
\hline \multicolumn{13}{|c|}{$\mathrm{PK} F \mathrm{~F}$} \\
\hline & EX & DYS391 & DYS389 I & DYS 439 & DYS389 II & DYS 438 & DYS 437 & DYS19 & DYS392 & DYS393 & DYS390 & DYS385 \\
\hline Haplotyp & & 10 & 14 & 11 & 30 & 10 & 16 & 14 & 11 & 13 & 23 & $13-15$ \\
\hline
\end{tabular}

Legende: $\mathrm{X}=$ nicht untersucht, $(\mathrm{)}$ = unsicher es Allel 


\section{Danksagung}

$\mathrm{Zu}$ aller erst möchte ich allen Angehörigen des Anthropologischen Institutes für die immer freundliche und sehr erfolgreiche Zusammenarbeit danken. Zurückblickend war es stets eine sehr schöne Zeit.

Herrn Prof. Dr. Bernd Herrmann möchte ich für die Bereitstellung des Themas und des Arbeitsplatzes sowie für seine Hilfsbereitschaft und seine vielen fachbezogenen Ratschläge sehr herzlich danken.

Mein uneingeschränkter Dank gilt Frau Dr. Susanne Hummel für die umfangreiche Betreuung des Projektes, ihre Unterstützung bei der Ergebnisinterpretation, den zahlreichen konstruktiven Gesprächen und für die Weitergabe ihres großen Wissens im Bezug auf Analysen an degradierter DNA.

Ebenso möchte ich mich bei den langjährigen Mitarbeitern der Abteilung für Historische Anthropologie, insbesondere Ed George für die „Knochenarbeit“, Ulla Schulz für das Anfertigen der Histologiepräparate und der Unterstützung bei der Röntgenanalyse, Sibylle Hourticolon für die Fotodokumentation der Knochenelemente, Dr. Birgit Großkopf für die Hilfestellung bei der Zahnzementringanalyse und Gerlinde Tavakolian für die administrative Unterstützung des Projektes, recht herzlich bedanken.

Mein ganz besonderer Dank gilt Rebecca Schütt und Lars Fehren-Schmitz, die mir während meiner Arbeit immer sehr kollegial und zuverlässig geholfen haben. Ihr Zimmer bildete eine wichtige Anlaufstelle für Besprechungen aller Art. Nicht minder wertvoll war die Zusammenarbeit mit Jutta Pollmann.

Ein herzliches Dankeschön an die studentischen Hilfskräfte Judith Stauch und Sibylle Krause für die stets zuverlässigen und hervorragenden praktischen Arbeiten im Labor.

Ich bedanke mich bei Herrn Dr. Stefan Flindt für die unkomplizierte Bereitstellung des Probenmaterials, seinem großen Interesse an den molekulargenetischen Analysen sowie für die konstruktiven Gespräche über eine der wohl spannendsten archäologischen Fundstätten der Welt. 
Dipl.-Biol. Andreas Scholten möchte ich für die Durchsicht der Fliegenexuvien und der damit verbundenen kurzen Einführung in die forensische Entomologie danken. Steffi Croll, Sabine Gärtner, Susan Klingner und Denise Mußlick danke ich für die Mitarbeit am Verteilungsmuster der Knochen.

Ph.D. Charles H. Brenner danke ich für das screening der Individuen auf Verwandtschaftsbeziehungen.

Für die große Hilfe außerhalb des universitären Lebens möchte ich meinem Freundeskreis ganz speziell danken.

Mein herzlichster Dank geht an meine Familie für ihre grenzenlose Unterstützung, ihrem großen Vertrauen und dem einzigartigen Zusammenhalt. Meinen Eltern sei an dieser Stelle ganz besonders gedankt.

Meiner Frau Joana danke ich von Herzen ausnahmslos für alles. Sie ist mein Wolkenschieber und letztendlich der Sinn meines Lebens!

Die Arbeit wurde aus Mitteln des Niedersächsischen Ministerium für Wissenschaft und Kultur (MWK) Kapitel 0608 Titelgruppe 74 finanziert. 


\section{Lebenslauf}

Felix Schilz

geboren am 5.Juli 1975 in Kassel

Staatsangehörigkeit: deutsch

Familienstand: verheiratet

1982 - $1986 \quad$ Dorothea - Viehmann - Schule, Kassel

1986 - $1988 \quad$ Leimbornschule, Kassel

1988 - 1995 Wilhelmschule Gymnasium, Kassel

Abschluss: Allgemeine Hochschulreife

$1995-1996$

Wehrdienst in Sondershausen / Thüringen

$1996-1999$

Diplomstudiengang Biologie

an der Universität Gesamthochschule Kassel

1999 - $2003 \quad$ Hauptstudium der Biologie an der Georg-August-Universität Göttingen

14.04.1999

Biologie-Vordiplomsprüfung in den Fächern Botanik, Zoologie, Genetik und Mikrobiologie, Chemie und Physik

28.06.2002

Mündliche Prüfungen zum Diplom in den Fächern Zoologie, Anthropologie und Geographie

2002-2003

Diplomarbeit am Institut für Zoologie und Anthropologie, Abt.

Historische Anthropologie und Humanökologie der Universität Göttingen mit dem Titel:,,Design einer Multiplex-PCR zur Typisierung von 16 short tandem repeats in degradierter DNA aus forensischem und historischem Probenmaterial“"

23.06.2003

Absolvierung des Diploms in Biologie

2002-2004

Wiss. Hilfskraft am Johann Friedrich Blumenbach Institut für Zoologie und Anthropologie, Abteilung Historische Anthropologie der Georg-August-Universität Göttingen

seit 01.05.2004 Wissenschaftlicher Angestellter am Institut für Zoologie und Anthropologie, Abteilung Historische Anthropologie und Humanökologie der Georg-August-Universität Göttingen und Beginn des Promotionsvorhabens „Molekulargenetische Verwandtschaftsanalysen am prähistorischen Skelettkollektiv der Lichtensteinhöhle“ im Rahmen des MWK-Projektes „Die Lichtensteinhöhle bei Osterode - Menschenopferstätte oder Bestattungsplatz? Anthropologische Untersuchungen zur Biologie der Menschen aus der Höhle“ Kapitel 0608 Titelgruppe 74. 